The Measurement of Scientific, Technological and Innovation Activities

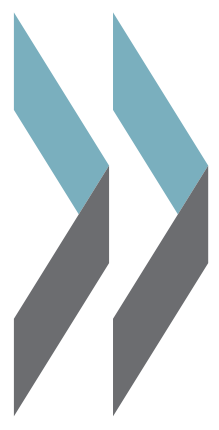

\title{
Frascati Manual 2015
}

GUIDELINES FOR COLLECTING AND REPORTING DATA ON RESEARCH AND EXPERIMENTAL DEVELOPMENT
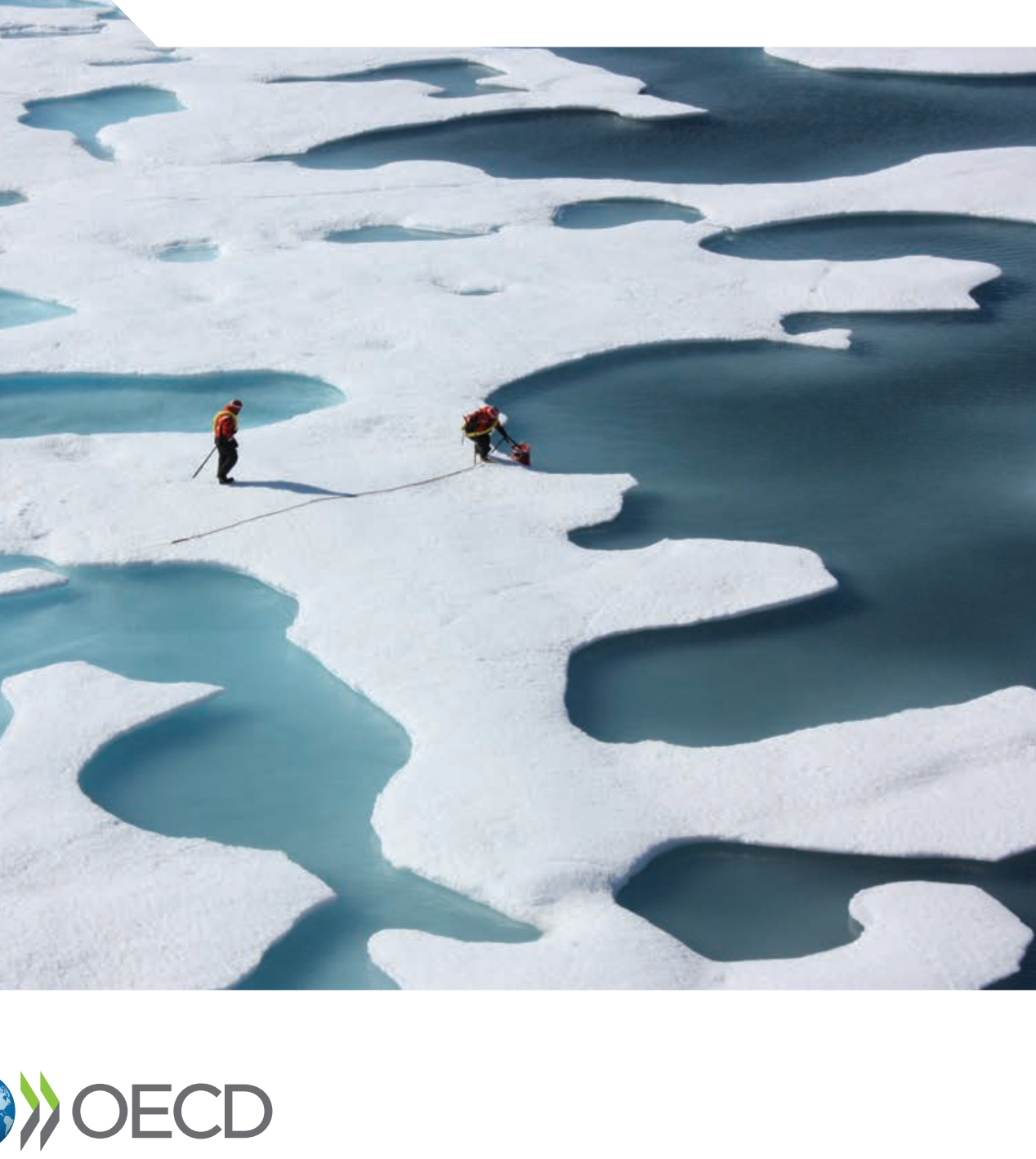



\title{
Frascati Manual 2015
}

\author{
GUIDELINES FOR COLLECTING \\ AND REPORTING DATA ON RESEARCH \\ AND EXPERIMENTAL DEVELOPMENT
}


This work is published on the responsibility of the Secretary-General of the OECD. The opinions expressed and arguments employed herein do not necessarily reflect the official views of the Organisation or the governments of its member countries.

This document and any map included herein are without prejudice to the status of or sovereignty over any territory, to the delimitation of international frontiers and boundaries and to the name of any territory, city or area.

\section{Please cite this publication as:}

OECD (2015), Frascati Manual 2015: Guidelines for Collecting and Reporting Data on Research and Experimental Development, The Measurement of Scientific, Technological and Innovation Activities, OECD Publishing, Paris.

DOI: http://dx.doi.org/10.1787/9789264239012-en

ISBN 978-92-6423880-0 (print)

ISBN 978-926423901-2 (PDF)

Series: The Measurement of Scientific, Technological and Innovation Activities

ISSN 2413-2756 (print)

ISSN 2413-2764 (online)

This manual has been endorsed by the OECD Committee for Scientific and Technological Policy (CSTP) and the OECD Committee for Statistics and Statistical Policy (CSSP).

Photo credits: Photo taken in July 2011 during the ICESCAPE "Impacts of Climate on EcoSystems and Chemistry of the Arctic Pacific Environment" mission. Image by NASA/Kathryn Hansen - Flickr, https://creativecommons.org/licenses/by/2.0/

Corrigenda to OECD publications may be found on line at: www.oecd.org/publishing/corrigenda.

(c) OECD 2015

You can copy, download or print OECD content for your own use, and you can include excerpts from OECD publications, databases and multimedia products in your own documents, presentations, blogs, websites and teaching materials, provided that suitable acknowledgment of the source and copyright owner is given. All requests for public or commercial use and translation rights should be submitted to rights@oecd.org. Requests for permission to photocopy portions of this material for public or commercial use shall be addressed directly to the Copyright Clearance Center (CCC) at info@copyright.com or the Centre français d'exploitation du droit de copie (CFC) at contact@cfcopies.com. 


\section{Foreword}

U

nderstanding how knowledge creation and dissemination contributes to economic growth and societal wellbeing requires a sound evidence base. Throughout history, the outcomes from research and development $(R \& D)$ have transformed people's lives and societies in multiple ways, as well as the natural environment we are part of. This realisation has created a sustained demand among policy analysts and decision makers for documenting the level and nature of both human and financial resources that different countries, regions, firms and institutions devote to such endeavour, as a first step towards learning how to direct them towards desired objectives. Supporting this evidence need through internationally comparable statistics and a common language is the main objective of this manual.

In June 1963, the OECD met with national experts on research and experimental development (R\&D) statistics at the Villa Falcioneri in Frascati, Italy. The result was the first official version of the Proposed Standard Practice for Surveys of Research and Development, which has come to be better known as the Frascati Manual. This publication is the seventh edition of a manual that was first written in a rather different economic and geopolitical context from today's. More than five decades later, its continued relevance is justified by even stronger interest in comparing the R\&D efforts made by different countries and identifying what key features underpin them. $R \& D$ is increasingly viewed as an input to innovation in the context of the overall efforts made in a knowledge-based global economy, but continues to play a crucial part and is a major focus of government policies because of its unique features. While demand for aggregate benchmarking is at the heart of this manual, this edition recognises the importance of enriching our macro picture of R\&D performance with a better understanding of the dynamics and linkages at the micro level. This emphasises the relevance of R\&D micro-data for purposes other than producing aggregate indicators, such as the analysis of its impacts across multiple actors.

Although the manual is basically a technical document, it is a cornerstone of OECD efforts to increase our understanding of the role played by science, technology and innovation when analysing national systems of research and innovation. Furthermore, by providing internationally accepted definitions of R\&D and classifications of its component activities, the manual contributes to intergovernmental discussions on good practices for science and technology policies. It is however beyond the scope of 
this manual to advise on the appropriateness of policy targets based on indicators and data described within this document.

This edition reflects probably one of the most substantial revisions of the original manual that have been carried out to date. It goes into a great level of detail to provide basic principles and practical suggestions on how to deal with the increasingly complex research and innovation landscape faced by today's economies and the defining features of different sectors. Among its many novelties, this manual pays specific attention to the relentless process of R\&D globalisation and the increasing variety of arrangements by which $R \& D$ is funded and performed within and across sectoral boundaries.

The Frascati Manual is not only a standard for R\&D data collection in OECD member countries. As a result of initiatives by the OECD, UNESCO, the European Union and various regional organisations, it has become a standard for R\&D measurement worldwide. It is also a recognised standard in other statistical domains, such as in education and trade statistics. Most notably, with the 2008 revision of the System of National Accounts, the Frascati Manual's definitions and data were adopted as the basis upon which to treat for the first time expenditures on $R \& D$ as a capital formation activity, i.e. investment.

The Frascati Manual is firmly based on experience gained from collecting $R \& D$ statistics in both OECD and non-member countries. It is a result of the collective work of national experts in NESTI, the OECD Working Party of National Experts on Science and Technology Indicators. This group, with support from the OECD Secretariat, has worked over now more than 50 years as an effective community of practitioners to implement measurement approaches for the concepts of science, technology and innovation. This effort has resulted in a series of methodological manuals known as the "Frascati Family", which in addition to this manual includes guidance documents on the measurement of innovation (the Oslo Manual), human resources devoted to science and technology, patents, and technological balance of payments, but most importantly, it has provided the basis for the main statistics and indicators on science and technology that are currently used.

Reflecting its intended use as a working tool, the Frascati Manual is also available as an online publication on the OECD web site http://oe.cd/frascati. The website provides additional material and links to information on how countries collect $R \& D$ data, databases and key indicators. This website is to be updated frequently to incorporate new resources and new guidelines on specific subjects that form part of the agenda of the NESTI group. Putting this revised manual into effective use, also a 
collective effort, will enable a new generation of $R \& D$ data, indicators and analyses that help meet policy needs and contribute to a better informed public debate on science, technology and innovation.

October 2015

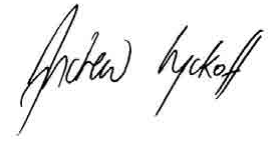

Andrew Wyckoff

Director for Science, Technology and Innovation, OECD

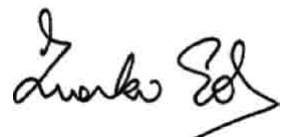

Ward Ziarko

Chair of NESTI initiating the sixth revision; Federal

Science Policy Office, Belgium

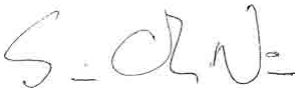

Svein Olav Nås

Chair of NESTI; The Research Council, Norway 


\section{Acknowledgements}

T

his publication is the outcome of a collective effort across all national delegates participating in the OECD Working Party of National Experts on Science and Technology Indicators (NESTI) and the Economic Analysis and Statistics (EAS) Division of the OECD Directorate for Science, Technology and Innovation (STI).

The present seventh edition came together thanks to the lead editing efforts of John Jankowski (National Science Foundation, United States) and Fred Gault (former NESTI Chair, UNU-MERIT, TUT-IERI and consultant to the Secretariat), on the basis of work conducted by national NESTI delegates and OECD experts organised as revision groups. Particular thanks are due to the members of the NESTI Bureau, namely Eveline von Gässler (Federal Ministry of Education and Germany), Tomohiro Ijichi (National Institute of Science and Technology Policy, Japan), John Jankowski (United States), Svein Olav Nås (The Research Council of Norway), Elisabeth Pastor (Federal Statistical Bureau, Switzerland), Giulio Perani (ISTAT, Italy and Eurostat) and Ward Ziarko (Federal Science Policy, Belgium). They invested considerable time and effort to help steer the revision process on behalf of the entire NESTI group and also contributed original material in the process.

Thanks are also due to Frank Foyn (Statistics Norway), Konstantin Fursov and Leonid Gokhberg (Higher School of Economics, Moscow, Russian Federation), Daniel Ker (Office for National Statistics, United Kingdom), Andreas Kladroba (Stifterverband, Germany), Francisco Moris (National Science Foundation, United States), Greg Peterson (Statistics Canada), Géraldine Seroussi (Ministry of Research and Higher Education, France) and Susanne Sundnes (Nordic Institute for Studies in Innovation, Research and Education, Norway) for the leading role played within the various revision groups set up to contribute content to this edition. Roberto de Pinho (Ministry of Science, Technology and Innovation, Brazil) helped set up the online collaborative space dedicated to the revision of the manual. Svein Olav Nås was Chair of the Working Party of National Experts on Science and Technology Indicators during this period, taking over the preparatory work steered by Ward Ziarko as previous Chair of NESTI. 
The revision work undertaken by NESTI was facilitated by the S\&T indicators unit in EAS led by Fernando Galindo-Rueda with support from Laudeline Auriol and Vladimir López-Bassols. The work was overseen by Alessandra Colecchia as Head of the EAS division. Andrew Wyckoff and Dirk Pilat provided guidance and comments. Valuable comments were also received from Nadim Ahmad, Silvia Appelt, Koen de Backer, Fabienne Fortanier, Dominique Guellec, Guillaume Kpodar, Fabien Verger, Bettina Wistrom. This work would not have been possible without the input of several other OECD colleagues, including IT, publications and communication support staff, as well as the assistance of Marion Barberis and Catherine Bignon in EAS.

The input from individual and institutional submissions to the online stakeholder consultation on this manual's revision, as well the CSTP and CSSP chairpersons and delegates and their national teams for the feedback provided up until declassification approval, is gratefully acknowledged. In particular, this edition greatly owes its final outcome to the United States' National Science Foundation/National Center for Science and Engineering Statistics which made a significant in-kind expert contribution to the preparatory and editing work required for this revision. Portugal's Directorate General for Education and Science Statistics kindly hosted a key revision workshop held in Lisbon in December 2014. The European Commission funded exploratory research on a number of topics feeding into the revision. Eurostat also made a significant in-kind expert contribution to the revision work and the UNESCO Institute for Statistics provided useful material and feedback of relevance to mainstreaming the guidance in this manual to facilitate its use by countries at different stages of development. 



\section{Table of contents}

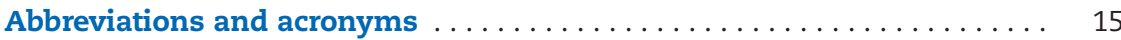

Chapter 1. Introduction to R\&D statistics and the Frascati Manual . . . . . 19

1.1. Objectives and background of the Frascati Manual. . . . . . . . 20

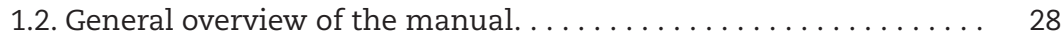

1.3. Implementing the recommendations in this manual $\ldots \ldots \ldots 38$

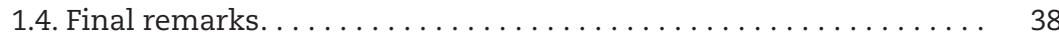

References. ................................ 39

Part I

Defining and measuring R\&D: General guidance

Chapter 2. Concepts and definitions for identifying R\&D . . . . . . 43

2.1. Introduction. . . . . . . . . . . . . . . . . . . 44

2.2. Definition of research and experimental development (R\&D) . . . 44

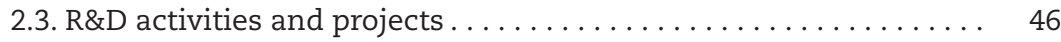

2.4. The five criteria for identifying $R \& D \ldots \ldots \ldots \ldots \ldots \ldots \ldots \ldots \ldots$

2.5. Distribution by type of R\&D. . . . . . . . . . . . 50

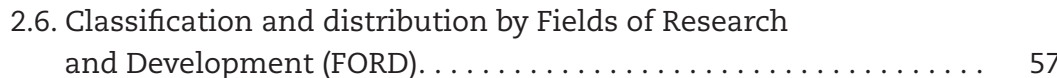

2.7. Examples of $R \& D$, boundaries and exclusions

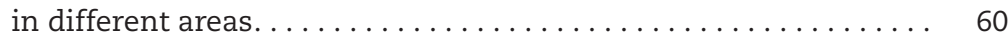

2.8. Activities to be excluded from $R \& D \ldots \ldots \ldots \ldots \ldots \ldots \ldots \ldots \ldots$

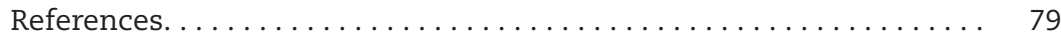

Chapter 3. Institutional sectors and classifications for R\&D statistics . . 81

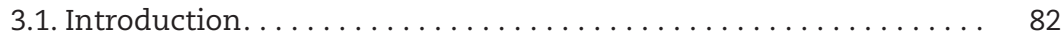

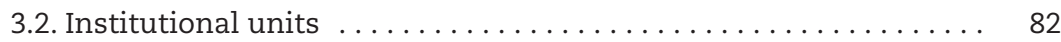

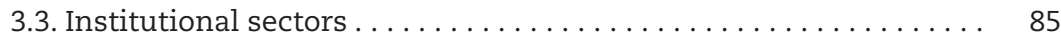

3.4. General classifications applicable to all institutional units . . . . . 92

3.5. Summary presentation of the Frascati main sectors,

their units and borderline cases $\ldots \ldots \ldots \ldots \ldots \ldots \ldots \ldots . \ldots \ldots$

References. . . . . . . . . . . . . . . . . . . . . . . . . . . . . 107 
Chapter 4. Measurement of R\&D expenditures: Performance

and sources of funds . . . . . . . . . . . . . . . 109

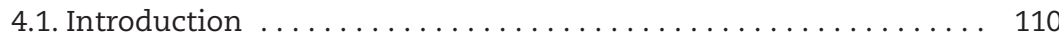

4.2. Intramural $R \& D$ expenditures (Performance of $R \& D$ ) $\ldots \ldots \ldots \ldots 112$

4.3. Funding of R\&D . . . . . . . . . . . . . . . . . 126

4.4. Reconciling differences in performer-based and funder-based approaches. . . . . . . . . . . . . . . . 141

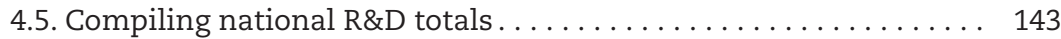

References ................................ 148

Chapter 5. Measurement of R\&D personnel: Persons employed and external contributors . . . . . . . . . . . . . . . 149

5.1. Introduction. . . . . . . . . . . . . . . . . . . . . . 150

5.2. Coverage and definition of R\&D personnel. . . . . . . . . 151

5.3. Recommended measurement units . . . . . . . . . . . 165

5.4. Recommended distribution of aggregate R\&D personnel totals . . 172

References.............................. 177

Chapter 6. Measuring R\&D: Methodologies and procedures . . . . . . . . 179

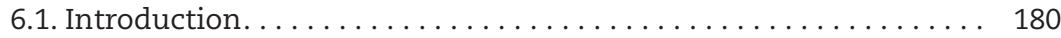

6.2. Units . . . . . . . . . . . . . . . . . . . . . . . . 181

6.3. Institutional sectors $\ldots \ldots \ldots \ldots \ldots \ldots \ldots \ldots \ldots \ldots \ldots \ldots \ldots \ldots \ldots \ldots \ldots \ldots$

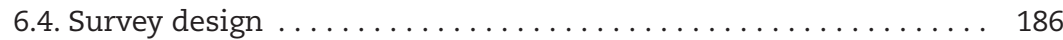

6.5. Collection. . . . . . . . . . . . . . . . . . . . . . . 190

6.6. Integration of data $\ldots \ldots \ldots \ldots \ldots \ldots \ldots \ldots \ldots \ldots \ldots \ldots \ldots$

6.7. Editing of collected data and imputation . . . . . . . . . . 191

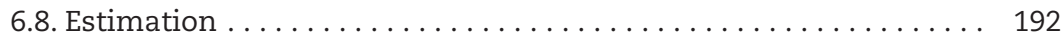

6.9. Output validation $\ldots \ldots \ldots \ldots \ldots \ldots \ldots \ldots \ldots \ldots \ldots \ldots \ldots$

6.10. Reporting to the OECD and other international organisations . . 193

6.11. Concluding remarks on data quality . . . . . . . . . . 194

References................................ 194

Part II

Measuring R\&D: Sector-specific guidance

Chapter 7. Business enterprise R\&D . . . . . . . . . . . . . . 199

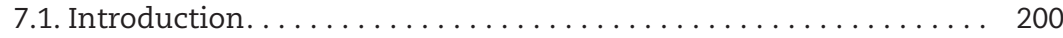

7.2. Coverage of the Business enterprise sector . . . . . . . . 200

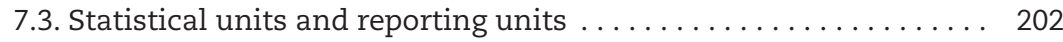

7.4. Institutional classifications for statistical units........... 203

7.5. Indicators of R\&D activity in business enterprises . . . . . . . 207

7.6. Functional distributions for Business enterprise

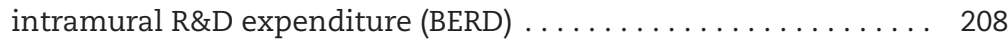


7.7. Functional distributions for extramural R\&D in the

Business enterprise sector. . . . . . . . . . . . . . . . . . . . . . . . . . . 219

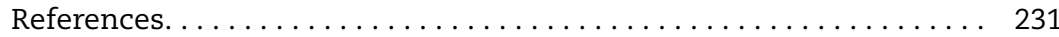

Chapter 8. Government R\&D....................... 233

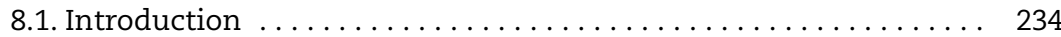

8.2. The scope of the Government sector for

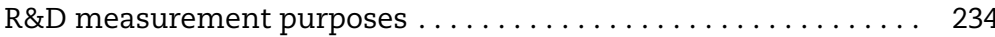

8.3. Identification of R\&D in the Government sector . . . . . . . . . 241

8.4. Measuring R\&D expenditures and personnel

in the Government sector . . . . . . . . . . . . . . . . . 243

8.5. Methods for compiling R\&D expenditure and personnel

in the Government sector . . . . . . . . . . . . . . . . . . 250

8.6. Measuring government funding of R\&D performance $\ldots \ldots \ldots 252$

References. . . . . . . . . . . . . . . . . . . . . . . . . . . . . . . . . . . . . 257

Chapter 9. Higher education R\&D . . . . . . . . . . . . . . . 259

9.1. Introduction. ........................... 260

9.2. Coverage of the Higher education sector . . . . . . . . . . . 260

9.3. Identification of R\&D in the Higher education sector . . . . . . . . 265

9.4. Measuring expenditures and personnel

in the Higher education sector . . . . . . . . . . . . . . . . . . . 269

9.5. Methods for compiling R\&D expenditure and personnel

in the Higher education sector . . . . . . . . . . . . . . . . 276

9.6. Links with education statistics. . . . . . . . . . . . . . . . . 284

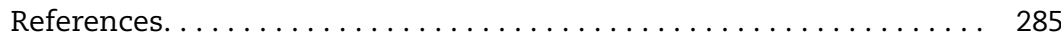

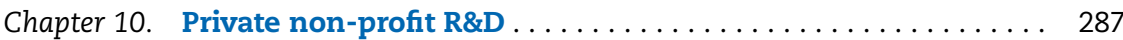

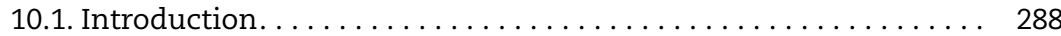

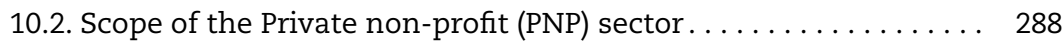

10.3. Recommended PNP institutional classifications . . . . . . . . . 291

10.4. Identification of R\&D in the PNP sector. . . . . . . . . . . 291

10.5. Measuring R\&D expenditures and personnel in the PNP sector . . . 292

10.6. Survey design and data collection in the PNP sector . . . . . . 295

References. . . . . . . . . . . . . . . . . . . . . . . . . . . . . . . . 296

Chapter 11. Measurement of R\&D globalisation . . . . . . . . . . . . . 297

11.1. Introduction. . . . . . . . . . . . . . . . . . . . . . . . 298

11.2. Measuring business R\&D globalisation ................ 299

11.3. International R\&D funding involving MNEs . . . . . . . . . 303

11.4 Developing, compiling and publishing MNE

R\&D aggregate statistics . . . . . . . . . . . . . . . . 305

11.5. Trade in $R \& D$ services. . . . . . . . . . . . . . . . . 308

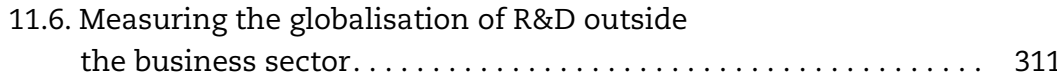

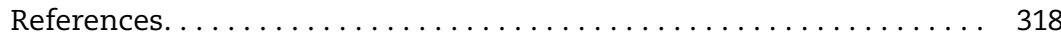




\section{Part III}

\section{Measuring government support for R\&D}

Chapter 12. Government budget allocations for R\&D. . . . . . . . . . 321

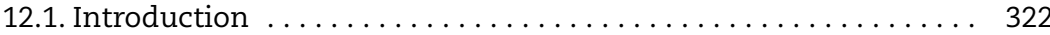

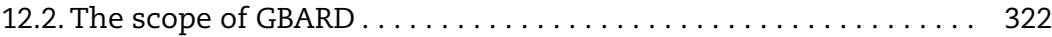

12.3. Sources of budgetary data for GBARD and estimation . . . . . 330

12.4. Distribution by socioeconomic objectives ............ 333

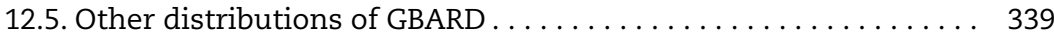

12.6. The use of GBARD data $\ldots \ldots \ldots \ldots \ldots \ldots \ldots \ldots \ldots \ldots \ldots \ldots \ldots$

References............................... 342

Chapter 13. Measurement of government tax relief for R\&D . . . . . . . . 343

13.1. Introduction. . . . . . . . . . . . . . . . . . . . . . . . . . 344

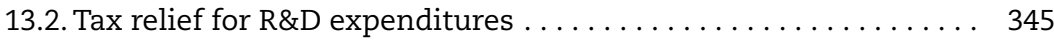

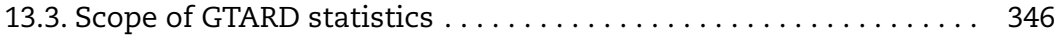

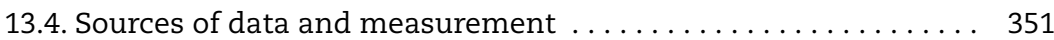

13.5. Priority breakdowns for GTARD statistics . . . . . . . . . 355

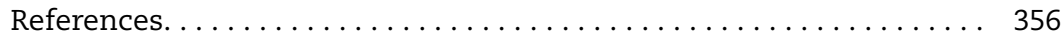

Annex 1 Brief history and origins of the present manual . . . . . . . . 357

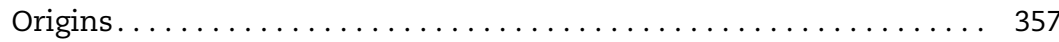

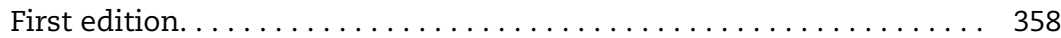

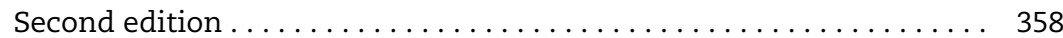

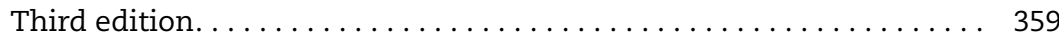

Fourth edition. . . . . . . . . . . . . . . . . . . . . . . 359

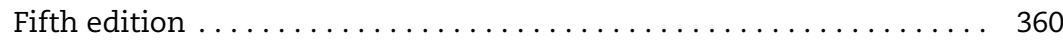

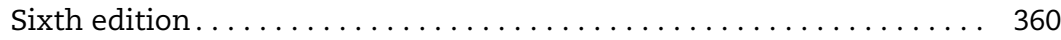

Key contributors to previous editions $\ldots \ldots \ldots \ldots \ldots \ldots \ldots \ldots \ldots \ldots \ldots$

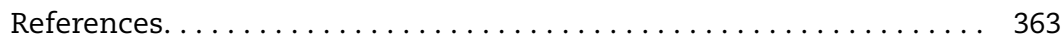

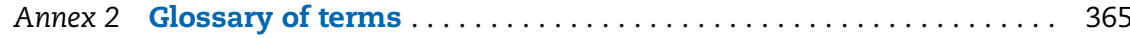

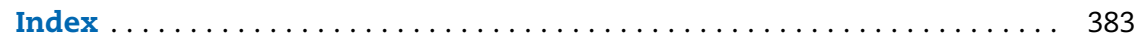

Tables

2.1. Examples of questions for identifying R\&D projects......... 49

2.2. Fields of R\&D classification . . . . . . . . . . . . . . . . . 59

2.3. Borderline between $R \& D$, innovation and other business activities $\ldots \ldots \ldots \ldots \ldots \ldots \ldots \ldots \ldots \ldots \ldots$

3.1. Approximate correspondence between Frascati

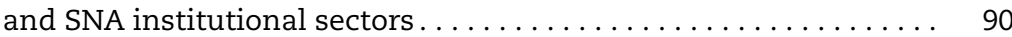

3.2. A simplified example of a potential frame structure tagging

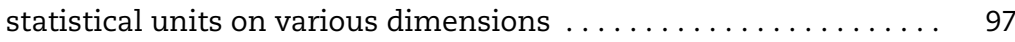

4.1. Summary of intramural R\&D expenditure categories. . . . . . . . . 122 
4.2. Intersection of performing and funding $R \& D \ldots \ldots \ldots \ldots \ldots \ldots$

4.3. Identifying which sources of funds should be collected on $R \& D$ performer surveys $\ldots \ldots \ldots \ldots \ldots \ldots \ldots \ldots \ldots \ldots \ldots \ldots$

4.4. Gross domestic expenditure on research and development (GERD).

4.5. Gross national expenditure on research and development (GNERD)

5.1. Personnel to be tracked as part of a statistical unit's intramural R\&D personnel . . . . . . . . . . . . . . . . . . . . . 154

5.2. Identification and reporting of $R \& D$ personnel and

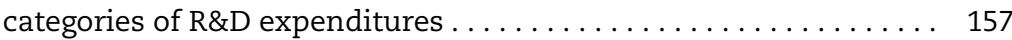

5.3. Consistency in $R \& D$ data collection . . . . . . . . . . . . . . 170

5.4.a. Total national R\&D personnel by sector and by employment status. . . . . . . . . . . . . . . . . . 175

5.4.b. Total researchers by sector and by employment status . . . . . . . 176

5.4.c. Total national employed R\&D personnel by sector and by R\&D function. . . . . . . . . . . . . . . . . . . . . 176

5.4.d. Total national employed researchers by sector and by age . . . . . . 176

5.4.e. Total national employed researchers by sector and by level of

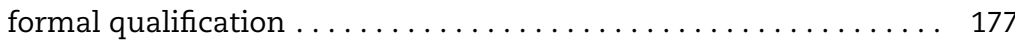

7.1. Identifying sources of funds for intramural R\&D in the Business enterprise sector . . . . . . . . . . . . . . . . . . . . . 209

7.2. Proposed activity-based classifications for the Business

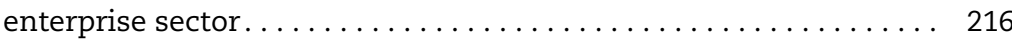

8.1. The components and boundaries of the Government sector

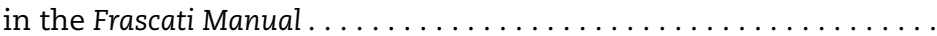

8.2. Source of funds to be collected in government $R \& D$ performer surveys $\ldots \ldots \ldots \ldots \ldots \ldots \ldots \ldots \ldots \ldots \ldots \ldots \ldots$

8.3. Flows of funds perspective for a government R\&D funding

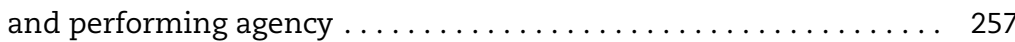

9.1. Profiles of higher education institutions. . . . . . . . . . . . . 265

9.2. Classification of activities of teachers and doctoral students at ISCED level 8 and master's students at ISCED level $7 \ldots \ldots \ldots 267$

10.1. Treatment of different types of non-profit institutions (NPIs) . . . . . 289

11.1. Scenarios for possibly reported versus actual MNE R\&D flows

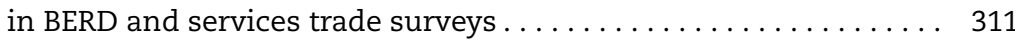

12.1. Classification of socioeconomic objectives for GBARD . . . . . . . 335

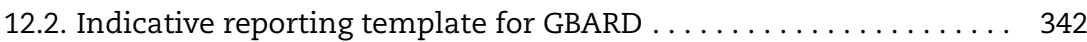

\section{Figures}

3.1. Decision tree for allocating institutional units to the main sectors in this manual. . . . . . . . . . . . . .

3.2. Stylised representation of domestic Frascati institutional sectors and their borderlines 
4.1. Funding flows from the perspective of an R\&D performer. . . . . . . 129

9.1. Framework for compiling statistics for the Higher education sector. . . . . . . . . . 277

11.1. Illustrative example of MNE member ownership relationships and corresponding terminology . . . . . . . . . 304

11.2. Aggregation of current costs and personnel for R\&D performed by MNEs and non-MNEs within a compiling country, and source of funds.

\section{Follow OECD Publications on:}

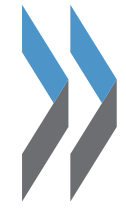

http://twitter.com/OECD_Pubs

http://www.facebook.com/OECDPublications

in. http://www.linkedin.com/groups/OECD-Publications-4645871

Ion http://www.youtube.com/oecdilibrary

Alerts http://www.oecd.org/oecddirect/ 


\section{Abbreviations and acronyms}

AMNE

BCA

$\mathrm{BE}$

BERD

BOP

CAA

CERN

COFOG

COPNI

CSSP

CSTP

DNA

EC

Eurostat

EU

FATS

FCA

FDI

FORD

FTE

GBARD

GDP

GERD
Activity of multinational enterprises

Branch campus abroad

Business enterprise (sector)

Business enterprise expenditure on R\&D

Balance of payments

Controlled affiliates abroad

European Organization for Nuclear Research

Classification of Functions of Government

Classification of the Purposes of Non-profit

Institutions Serving Households

OECD Committee for Statistics and Statistical

Policy

OECD Committee for Scientific and

Technological Policy

Deoxyribonucleic acid

European Commission

European Commission's Directorate General

for Statistics

European Union

Foreign affiliates statistics

Foreign-controlled affiliate

Foreign direct investment

Fields of Research and Development

Full-time equivalent

Government budget allocations for R\&D

Gross domestic product

Gross domestic expenditure on R\&D 


\begin{tabular}{|c|c|}
\hline GFS & Government finance statistics \\
\hline GNERD & Gross national expenditure on R\&D \\
\hline GOV & Government (sector) \\
\hline GOVERD & Government expenditure on R\&D \\
\hline GTARD & Government tax relief for R\&D \\
\hline GUF & General university funds \\
\hline HC & Headcount \\
\hline $\mathrm{HE}$ & Higher education (sector) \\
\hline HEI & Higher education institution \\
\hline HERD & Higher education expenditure on R\&D \\
\hline ICSU & International Council for Science \\
\hline ICT & Information and communication technology \\
\hline IEA & International Energy Agency \\
\hline ILO & International Labour Organisation \\
\hline IMF & International Monetary Fund \\
\hline IPP & Intellectual property product \\
\hline ISCED & $\begin{array}{l}\text { International Standard Classification of } \\
\text { Education }\end{array}$ \\
\hline ISCO & $\begin{array}{l}\text { International Standard Classification of } \\
\text { Occupations }\end{array}$ \\
\hline ISIC & $\begin{array}{l}\text { International Standard Industrial } \\
\text { Classification of All Economic Activities }\end{array}$ \\
\hline KAU & Kind of activity unit \\
\hline MNE & Multinational enterprise \\
\hline NABS & $\begin{array}{l}\text { Nomenclature for the Analysis and } \\
\text { Comparison of Scientific Programmes and } \\
\text { Budgets }\end{array}$ \\
\hline NESTI & $\begin{array}{l}\text { Working Party of National Experts on Science } \\
\text { and Technology Indicators }\end{array}$ \\
\hline NGO & Non-governmental organisation \\
\hline NPI & Non-profit institution \\
\hline NPISH & Non-profit institutions serving households \\
\hline O\&M & Operation and maintenance \\
\hline
\end{tabular}


OECD Organisation for Economic Co-operation and Development

PNP Private non-profit (sector)

PNPERD Private non-profit expenditure on R\&D

R\&D Research and experimental development

RD\&D Research, development and demonstration, as defined by the IEA

S\&T

Science and technology

SEO

Socio-economic objective

SME

Small and medium-size enterprise

SNA

System of National Accounts

STA

Scientific and technological activities

TRL

Technology readiness level

UIS

UNESCO Institute for Statistics

UN

United Nations

UNECE

United Nations Economic Commission for

Europe

UNESCO United Nations Educational, Scientific and Cultural Organization

UNWTO World Tourism Organization

VAT

Value-added tax

WTO

World Trade Organisation 



\section{Chapter 1}

\section{Introduction to R\&D statistics and the Frascati Manual}

The Frascati Manual has been an international standard for more than fifty years and it is now a world standard. The use of research and experimental development ( $R \& D)$ statistics, based on the guidance in the manual, has gained influence and the statistics are being used in a wide range of policy areas, and in many countries outside of the OECD. The manual provides the basis for a common language for talking about R\&D and its outcomes. In keeping with the extensive use of the manual, and the presence of its definitions in other international manuals and in country regulations, the definition of $R \& D$ and its components have been kept close to those in previous editions. More attention has been spent on identifying boundaries between what is and what is not R\&D and on meeting new demands on $R \& D$ statistics. An example is the decision to treat expenditure on R\&D as a capital investment in the System of National Accounts (SNA) and this has required greater attention to the flows of funds for $R \& D$. Tax incentives for R\&D performance are widespread and a chapter has been added to cover this. A new chapter has been added to address globalisation and its implications for $R \& D$ statistics. To remain current, extensive use is made of online annexes. This chapter introduces the manual. 


\subsection{Objectives and background of the Frascati Manual}

1.1 For more than 50 years, the OECD Frascati Manual has been the acknowledged worldwide standard for collecting and reporting internationally comparable statistics on the financial and human resources devoted to research and experimental development. The co-ordinated efforts among and beyond OECD countries to define and implement the recommendations in this manual have resulted in a valuable source of evidence for science, research and economic policy makers. The definitions provided herein have been adopted and adapted by many governments and serve as a common language for discussions across multiple domains, including those related to science and technology policy, economic development policy, and fiscal, tax and regulatory policy, as well as for the development of guidance on financial accounting, investment and trade statistics, among others.

1.2 Interest in measuring research and experimental development (which in this manual is used interchangeably, but precisely, with the term "R\&D") stems from its potential to make a significant contribution to economic growth and prosperity. The new knowledge resulting from R\&D can be used to meet national needs and global challenges and to improve overall societal well-being. Individuals, institutions, economic sectors and countries, both developed and developing, are affected in multiple ways by the outcomes of R\&D. Hence, the indicators collected in the framework of the Frascati Manual influence and inform discussions on such important debates.

1.3 From its initial origins, the Frascati Manual has been written by and for national experts who collect and issue national R\&D statistics and submit responses to R\&D surveys by the OECD, the EU, UNESCO and other international organisations. Although many examples are given, this manual remains a technical document that is intended as a reference work. In the same vein, the Frascati Manual has never been a binding document but instead a set of proposed guidelines discussed at length and agreed upon by consensus. Since the first guidelines were adopted in 1963 by the conference of national experts from OECD member countries in the Italian town of Frascati, this manual had been revised on five previous occasions, to reflect and address known measurement challenges, new user needs and best practices developed worldwide. The process of revision and dialogue with users reflects the capacity for the community of experts that produce this manual to engage in on-going learning.

1.4 Throughout its history, the Frascati Manual has provided the definitions of R\&D used in other manuals, and it has been complementary to other manuals 
that have appeared and now form part of a framework for science, technology and innovation statistics, known as the Frascati "family" of manuals, a body of guidelines in a state of constant and overlapping evolution.

\section{Main objectives of the revision}

1.5 This current version represents the outcome of the sixth revision of the Frascati Manual and incorporates major changes in terms of presentation, coverage and collection detail. Major changes, revisions and improvements are highlighted-in a chapter-by-chapter summary-in the second part of this introductory chapter. However, it is important to emphasise at the outset that the definition of R\&D presented in Chapter 2 of this manual, while clearer and more precise, is still consistent with the definition of $R \& D$ used in the previous edition of the Frascati Manual (OECD, 2002) and is intended to cover the same range of activities. Indeed, every effort was made to minimise the potential need for revisions in major statistical R\&D indicator time series. Nonetheless, revisions may be the necessary outcome in the practice of some individual countries, as the steps for convergence with established international guidance become clearer with the revised manual. It is also intended and expected that the clarifications contained in this manual will facilitate the assessment and interpretation by policy makers of official $R \& D$ statistics and of $R \& D$ figures obtained from complementary accounting, tax, trade and other sources.

1.6 Unlike the more recent revisions to this manual, the changes introduced in this edition appear, and to some degree are, extensive. A number of factors weighed on the decision to expand coverage and increase guidance on the hows, whats and whys of collecting R\&D statistics. Several of the more influential factors included the following:

- From its very beginning, this manual has been closely linked to the System of National Accounts (SNA). One major change in the 2008 revision of the SNA was the explicit adoption of Frascati R\&D definitions and data as the basis for recommending the treatment of $R \& D$ expenditures as capital formation, that is, as investment. This development placed the Frascati Manual firmly within the framework of national statistical accounting standards, but also called for a number of adaptations to facilitate the use of Frascati R\&D data by national statisticians. This revision thus considered the feasibility of implementing a number of recommendations laid out in the OECD Handbook on Deriving Capital Measures of Intellectual Property Products (OECD, 2009a). Classification relationships with and data needs for the SNA are introduced in detail in Chapter 3 and then highlighted and clarified throughout this manual.

- The widespread use of this manual for both statistical and policy-related purposes has resulted in repeated calls to clarify concepts, definitions and measurement practices. Quite often these requests reflect conflicting agendas and vested interests. This manual does not presume to take sides on such matters, but rather offers clear guidance on the preferred and recommended 
definitions and collection methods that should-or can be-universally applied. To that end, it has been necessary on the one hand to expand the manual's coverage to make R\&D statistics relevant for a wider range of policy decisions but on the other hand to provide for as few changes as possible so that there remains stability in the core historical series. Expanded coverage on R\&D tax relief in Chapter 13 treated outside of the historical measurement issues of business R\&D expenditures is one such example.

- The Frascati Manual is the de facto R\&D reference document across countries at different stages of economic development, with varying forms of economic structures and national research systems and with a wide spectrum of statistical infrastructures. In line with the expanding membership of the OECD itself and a major shift towards greater engagement with non-member countries, this manual attempts to provide guidance for identifying and collecting $R \& D$ data that is relevant for countries with very diverse economic and research characteristics. A conscious effort has been made to understand the idiosyncratic approaches used by some countries in apparent contradiction with Frascati guidance and to find a more appropriate formulation of the intentions behind the existing guidelines.To that end, this manual introduces individual sector-specific chapters (7 to 10), which allow for greater granularity in collection guidance than had previously been possible.

- There is mounting recognition of the importance of a variety of ongoing changes in the organisation of R\&D activities and the challenges these pose. These changes include R\&D's role in the globalisation of value chains; the adoption of new organisational arrangements that extend beyond the traditional boundaries of individual organisations, sectors or countries; and new approaches to providing financial support for $R \& D$, all of which are giving rise to new user needs as well as calls for data collection practices to be revised and extended. This manual recognises the importance of such developments and to the extent possible offers guidance on how to address these new statistical challenges. For example, there is extensive new material on measuring intramural versus extramural R\&D flows in Chapter 4 and internal versus external R\&D personnel in Chapter 5. An entirely new chapter (11) on R\&D globalisation considerations is introduced in this manual.

- The need to address emerging methodological challenges and opportunities is paramount. On the one hand, general guidance on such matters is of relevance to the collection of all types of economic statistics. On the other hand, the atypical characteristics of R\&D both from an activity perspective (a difficult-to-define, often nonexclusive, intangible service) and from a statistical perspective (a rare, highly skewed often non-continuous event) warrant special methodological guidance. There is furthermore the need to take into account new types of uses of R\&D data, including causal analysis of the relationship between inputs and outputs, using micro-data, subject to confidentiality constraints, matched with supplementary sources. An expanded Chapter 6 on statistical methodology as well as sector-specific 
guidance in the individual sector chapters addresses key issues, including difficulties experienced in maintaining response rates and reducing the burden on respondents; the use of administrative data sources; and demands for ensuring the international comparability and consistency over time of national R\&D indicators. Adherence to such guidance will enable countries to demonstrate compliance with best statistical practices and exploit the full potential of the resulting microdata.

- Finally, and of practical importance, there is the need to reflect changes in statistical classification systems and practices, such as the UN classifications of industry (ISIC), education (ISCED) and the 2008 SNA. Most statistical manuals have been revised since the 2002 edition of the Frascati Manual, which until this revision continued to refer to some outdated statistical practices and concepts. This manual's latest edition makes more active use of online annexes to keep track of possible future changes in such classifications.

1.7 The remainder of this Chapter 1 provides a summary of the coverage and contents of this manual in order to help in the use and interpretation of the data when its guidelines are followed. It also indicates why certain types of data are, or are not, collected, and the challenges of comparability this poses.

\section{The origins of the Frascati Manual}

1.8 For more than half a century, the Frascati Manual has provided the definition of research and experimental development (R\&D) that has been used to gather data on financial and human resources allocated to R\&D. One of the original intentions of the manual was to support the compilation of data, so that changes in resource allocations could be monitored over time and compared with those in other countries.

1.9 As R\&D statistics became standardised and were increasingly adopted by countries, international comparisons raised questions about their relative ranking based on R\&D performance. In time, this led governments to set targets as well as to policy initiatives to support R\&D and to advance strategic sectors or achieve strategic objectives. R\&D statistics became influential in science policy, and continue to be. They have also become influential in economic policy more generally, as it has been realised that knowledge, and new knowledge in particular, is a core contributor to economic growth and development. The manual provided the means with which to address a number of questions on the absolute and relative level of national R\&D efforts that mattered greatly at the time, and that still continue to be relevant to this date, although in a very different context.

1.10 The basic approach of the Frascati Manual in identifying resources for $R \& D$ is to study the activities of the R\&D performers. Part of understanding R\&D activities is determining the sources of funds for the performance of R\&D. Taken together, the institutions, the magnitude of their performance and the provision 
of funds, and changes in these over time, provide a picture of the R\&D system in a country and its relations to the rest of the world. Governments are significant funders of R\&D as well as being performers, and therefore this manual also provides guidance on collecting information on government budgets for R\&D funding.

1.11 The policy importance of R\&D statistics has placed a responsibility on those gathering the data to provide statistics that are both relevant to policy development and evaluation as well as accurate, timely and accessible. This manual has supported these objectives by providing the definitions needed and discussing the domains of applicability, and their boundaries, based on the best practices of the OECD member and partner countries and organisations that have contributed to the content of the manual and that continue to do so through each of the revisions. A more detailed history of the changes in each revision is found in Annex 1 and should be consulted in particular when dealing with long time series of R\&D data.

\section{Stable definitions to serve user needs}

1.12 Throughout extensive consultation for this revision, users have stressed the importance of a consistent approach to defining R\&D and preserving the historical R\&D data series. This manual's revision has taken into account the fact that, in many countries, legislation refers explicitly to this manual and definitions herein. While such uses are beyond the initial intention and core objectives of this manual, such uses have been taken into account as much as possible. As a result, the core definitions of $R \& D$ are unchanged to the extent possible. Apart from minor changes in language in order to become gender neutral and a clearer formulation on how to describe the intention to devise new applications, this stability has been achieved for the basic definition of R\&D. As a result, external references to the definition in national legislation and other classifications and statistical systems should not present a problem.

1.13 Although the basic definition of $R \& D$ is retained, there are slight modifications to the text of the definitions of its subcomponents - basic research, applied research and experimental development - with the last most affected. It was necessary in particular to clarify the distinction between R\&D and other types of innovation activities.

1.14 This manual introduces a set of five core criteria that explain what key features must be met for an activity to qualify as R\&D, and these are highlighted in this manual. The same criteria were effectively present in the previous edition, but did not appear in the same place to help interpret the R\&D definition. A number of countries have satisfactorily tested these criteria throughout the revision process in interviews with potential $R \& D$ performers.

1.15 An effort has also been made in this edition to better align the information on the human and financial resources devoted to $R \& D$, namely $R \& D$ personnel and R\&D expenditures. The definition of $R \& D$ personnel is slightly modified to clarify two issues: the treatment of doctoral and master's students, 
and the distinction between external personnel and persons employed by the statistical unit.

\section{Inputs and outputs of R\&D}

1.16 The defining feature of $R \& D$ in this manual is that it is carried out in order to generate new knowledge as an output, irrespective of its purpose, which could be the generation of economic benefit, addressing societal challenges or simply having the knowledge in itself. This intentionality is used in this manual to distinguish between experimental development and basic and applied research. In the same manner, it is of interest to identify and, if possible, to measure the different types of outputs from R\&D.

1.17 However, it is difficult to identify and measure R\&D outputs. This is due to a series of factors that affect both how knowledge is distributed and used in the economy and the complementary inputs necessary for results to occur. Any outputs and effects may take a long time to be realised and may occur at different places and for different actors than those carrying out the R\&D. Only very partial outputs can currently be directly identified and measured as part of collecting information on R\&D activities and funding. This manual provides a number of recommendations that can assist in that endeavour, in particular concerning R\&D micro data, the use of linked registers, and classifications that facilitate the analysis of knowledge flows.

\section{The Frascati family of manuals}

1.18 R\&D takes place throughout the economy, but it has certain characteristics that distinguish it from the larger family of scientific activities and from the economic activities of which it is a part. From the outset, it was intended that the OECD should establish a set of guidelines as a framework for the measurement of science, technology and innovation. Over time, additional manuals have been added to the framework, such as the OECD Patent Statistics Manual (OECD, 2009b), and the Oslo Manual (OECD/Eurostat, 2005), which provides guidelines for collecting and interpreting innovation data. There are others too.

1.19 Since the Frascati Manual is one of a family of manuals, the boundaries between the subject matter of the other manuals and that of the Frascati Manual need to be clear. Clarifying this is an objective of the current revision.

1.20 There is a division of labour between the different manuals and the production of the statistics that result from their implementation. To achieve and benefit from this, it is necessary to consider at which levels of aggregation, and for what samples or populations of observations, statistics from different sources can be combined and jointly analysed.

1.21 There is active work in the OECD to compare and test successful experiences at the country level before recommending their broad international adoption. This manual's revision has collected a wealth of evidence that is relevant to that objective. 


\section{New uses and users of R\&D statistics}

1.22 In the first edition, the main objective was that the Frascati Manual would lead to the adoption of standard practices by countries and to an improvement of R\&D statistics and their comparability. This is still an objective of this manual. However, half a century later the definition of R\&D is found in national legislation, and it also appears, sometimes with the text modified, in legislation and regulations pursuant to legislation related to tax or other types of financial support in some countries. The measurement of R\&D activities is now an integral part of official statistics and a key input to the policy process. The Frascati Manual is used for training statisticians and users of the data, in academic courses and in research into the science of science policy. The manual has acquired a relevance that goes beyond its initial role of providing guidance on proposed standard practices for surveys of R\&D.

\section{Frascati and the System of National Accounts}

1.23 As a statistical standard, the Frascati Manual has to align with other standards, the most relevant of which is the SNA. This manual provides the definitions of R\&D, but it uses, whenever possible, the SNA sectors. The exception is that this manual defines a separate higher education sector, whereas higher education institutions can appear in any of the SNA sectors. What makes the alignment of this manual and the SNA 2008 more important is the latter's recommendation for the first time to treat expenditures on $R \& D$ as leading to the creation of a capital asset, rather than as an expense. The SNA 2008 thus considers R\&D as a production and investment activity, a decision that changes how GDP is measured and how exercises in growth accounting interpret the contribution of R\&D to economic growth. In taking this decision, the SNA drew on the experience of the R\&D satellite accounts referred to in an annex to the previous edition of this manual and adopted the Frascati R\&D definition and its derived data as the basis upon which revised measures of capital investment and GDP can be constructed. This manual thus incorporates a number of recommendations made in the OECD Handbook on Deriving Capital Measures of Intellectual Property Products (OECD, 2009a), whose section on R\&D was developed jointly between the national accounting and R\&D statistics communities to guide national accountants in implementing the SNA decision.

1.24 As a result of a broader and more differentiated interest in $R \& D$ and the use of definitions and data, the reported figures for R\&D activity from different producers and for different purposes in some cases also differ in magnitude. It is extremely important to be aware of and understand such differences in order to avoid any misuse or misinterpretation of the data. There are two different approaches in the manual to collecting information, which yield different results: information collected from those performing R\&D (recommended), and information collected from those funding it (complementary). Similarly, there are differences between Frascati-based R\&D data and information reported in the SNA. National accountants draw on Frascati and other data sources and 
assumptions to derive SNA-consistent measures of output, capital investment and capital stocks. Specific differences arise in relation to the way software R\&D is reported as part of R\&D totals from a Frascati perspective, but is included in software totals in the SNA. These points are covered in Chapter 4 of this manual. A detailed and up-to-date overview of the relationship between the SNA and Frascati approaches is to be found as part of the online guidance in the annex to this manual, at http://oe.cd/frascati.

\section{Other international standards}

1.25 Another type of $R \& D$ data that is sometimes confused with Frascatibased $R \& D$ is accounting data, where $R \& D$ is one of the components that businesses include in their financial reports and sometimes itemise separately, based on a number of rules and strategies. The coverage is generally different, as is the definition in many cases. The two series are generally not comparable. This is detailed in Chapter 7.

1.26 Because of the need to situate $R \& D$ in a wider context, both conceptually, in terms of databases, and in order to match R\&D data with supplementary information, United Nations (UN) classifications are used as far as possible. These include the System of National Accounts, 2008 (EC et al., 2009), the International Standard Industrial Classification of All Economic Activities - ISIC (United Nations, 2008) and the International Standard Classification of Education - ISCED (UNESCO-UIS, 2012).

1.27 These external classifications are regularly updated. To deal with this, the current citations are given in the printed manual, but an updated set of references to classifications is maintained online as annex guidance to this manual.

\section{A truly global manual}

1.28 The performance of $R \& D$ and the use of $R \& D$ statistics in policy are not the exclusive province of the OECD countries or the developed countries. There are initiatives throughout the world to conduct R\&D surveys and to use the results in the policymaking process. As a result, this revision of the manual aims to be accessible to developed and developing countries as part of its role as a world standard. It also means that input to this revision has been sought and obtained from emerging and developing countries, as well as the institutions that support their efforts to develop R\&D measurement capabilities. The recommendations contained in a previous online annex on measuring R\&D in developing countries have now been mainstreamed and integrated into the core manual.

1.29 As a consequence of treating the manual as a global standard, the operational aspects of reporting data and indicators to the OECD are not covered in any detail. That is now left to the OECD and reporting countries to address. A description of the level of detail necessary to produce internationally comparable statistics is included in the manual. 


\subsection{General overview of the manual}

1.30 This section provides information on the coverage and contents of the different chapters of the manual as a guide to the reader. The full text should be consulted as the authoritative source.

\section{Outline}

1.31 Chapter 1 introduces the manual and the twelve subsequent chapters provide guidance on specific topics. A historical review of the Frascati Manual is provided in Annex 1. The five chapters (2-6) that follow contain general guidance on defining and measuring $R \& D$ in all sectors of $R \& D$ performance: concepts and definitions, institutional sectors, R\&D expenditures, R\&D personnel, and statistical methodologies and procedures. Then come five chapters (7-11) that address particular methodological and classification issues specific to each performing sector. The sectors are: Business enterprise, Government, Higher education and Private non-profit. The fifth sector, the Rest of the world (formerly referred to as Abroad) is discussed in Chapter 11 on R\&D globalisation, which addresses the performance and funding of R\&D in the Rest of the world. In addition, and for the first time, there is guidance on data collection on multinational enterprises (MNEs) and R\&D services trade. The sector chapters are followed by two chapters that approach the measurement of government support for R\&D from a funder perspective: government budget allocations for $R \& D$ and measurements of tax relief for $R \& D$. Some very detailed information and references to external classification systems that are being regularly updated are available online in annex guidance to this manual at http://oe.cd/frascati. A glossary of terms is also included in this manual and maintained online.

\section{Concepts and definitions for identifying R\&D (Chapter 2)}

1.32 R\&D comprise creative and systematic work undertaken in order to increase the stock of knowledge - including knowledge of humankind, culture and society - and to devise new applications of available knowledge.

1.33 A set of common features identifies $R \& D$ activities that aim to achieve either specific or general objectives, even if these are carried out by different performers. For an activity to be an R\&D activity, it must satisfy five core criteria. The activity must be:

- novel

- creative

- uncertain

- systematic

- transferable and/or reproducible. 
1.34 The definition of R\&D just given is consistent with the definition of R\&D used in the previous edition of the Frascati Manual (OECD, 2002) and covers the same range of activities.

1.35 The term R\&D covers three types of activity: basic research, applied research and experimental development. Basic research is experimental or theoretical work undertaken primarily to acquire new knowledge of the underlying foundation of phenomena and observable facts, without any particular application or use in view. Applied research is original investigation undertaken in order to acquire new knowledge. It is, however, directed primarily towards a specific, practical aim or objective. Experimental development is systematic work, drawing on knowledge gained from research and practical experience and producing additional knowledge, which is directed to producing new products or processes or to improving existing products or processes. This manual follows the SNA convention in which "product" refers to a good or a service. Further, throughout the manual, "process" refers to the transformation of inputs to outputs and to their delivery or to organisational structures or practices.

1.36 It is often helpful and relevant to classify R\&D according to the knowledge domain in which it is conducted, including the natural sciences, engineering and technology, the medical and health sciences, the agricultural and veterinary sciences, the social sciences, the humanities and the arts.

\section{Institutional sectors and classifications for R\&D statistics (Chapter 3)}

1.37 This chapter explains the institutional approach to R\&D statistics, in particular the collection and presentation of statistics based on the generic attributes of the institutional units. In this approach, the resources of an institutional unit that are dedicated to $R \& D$ are attributed to the sector in which the unit is classified. The classification of institutional units for R\&D purposes aims to ensure full consistency with the definition of R\&D and with the explicit needs of established R\&D statistics users, as well as with the classification criteria used by the System of National Accounts. The latter include residence criteria, the reference to the type of economic activity, and ownership and economic control.

1.38 Four main sectors (and the Rest of the word) are identified in this manual for the measurement of R\&D. The sectors are: Business enterprise, Government, Higher education and Private non-profit. The Higher education sector, institutions of which may be classified in the SNA as corporation, government unit or NPISH, according to the market and government control criteria that are applicable in each country, is kept as a separate sector for R\&D statistics.

1.39 A decision tree to assign institutional units to the different sectors is found in Figure 3.1 of Chapter 3. 


\section{Measurement of R\&D expenditures: Performance and sources of funds (Chapter 4)}

1.40 The amount of money spent on research and experimental development ( $R \& D$ expenditure) is of considerable interest to national and international policymakers. In particular, such statistics are used to measure who conducts and who funds R\&D and where it takes place, the level and purpose of such activities, and the interactions and collaborations between institutions and sectors. Intramural R\&D expenditures are all current expenditures (including labour and other costs) plus gross fixed capital expenditures (such as for land, buildings, machinery and equipment) for R\&D performed within a statistical unit during a specific reference period, whatever the source of funds.

1.41 A major change in the 2008 revision of the SNA was the explicit treatment of $R \& D$ as capital formation, that is, "investment". This change resulted in attendant demands for more detailed breakdowns of R\&D expenditures that are noted throughout this chapter, including guidance for collecting detailed data on the sources and flows of $R \& D$ funds and on the types of R\&D transactions. In particular, additional and more extensive information is needed to help measure R\&D sales and purchases than previously existed.

1.42 The basic concepts used to structure the collection of R\&D statistics for the purposes of this manual include the following (see Figure 4.1 in Chapter 4):

- expenditures on intramural R\&D are the amount of money spent on R\&D that is performed within a reporting unit; expenditures on (the funding of) extramural R\&D are the amount of money spent on $R \& D$ that is performed outside a reporting unit

- internal R\&D funds are the amount of money spent on R\&D that originate within the control of a reporting unit; external R\&D funds are the amount of money spent on R\&D that originates outside the control of a reporting unit

- exchange R\&D funds are funds that flow between statistical units with a compensatory return flow of R\&D; transfer R\&D funds are funds that flow between statistical units without a compensatory return flow of R\&D.

1.43 The main aggregate statistic used to describe a country's $R \& D$ activities is gross domestic expenditure on R\&D (GERD), which covers all expenditures for $R \& D$ performed in the national territory during a specific reference period. GERD is a primary indicator for international comparisons of R\&D activity.

\section{R\&D personnel: Persons employed and external contributors (Chapter 5)}

1.44 In broad terms, R\&D personnel include highly trained researchers, specialists with high levels of technical experience and training, and other supporting staff who contribute directly to carrying out R\&D projects and activities. Consistently with this manual's definition of $R \& D$, the scope of this concept encompasses all knowledge domains. 
1.45 R\&D personnel in a statistical unit include all persons engaged directly in $R \& D$, whether they are employed by the statistical unit or are external contributors fully integrated into the statistical unit's R\&D activities, as well as those providing direct services for the R\&D activities (such as R\&D managers, administrators, technicians and clerical staff).

1.46 Two main groups of individuals who potentially contribute to the R\&D activities can be identified in a statistical unit, with some differences according to the institutional sector it belongs to:

- Persons employed by the statistical unit who contribute to the unit's intramural R\&D activities (used interchangeably with the term "internal R\&D personnel" in this manual).

- External contributors to the unit's intramural R\&D activities (used interchangeably with the term "external R\&D personnel" in this manual). This group includes two subgroups: (i) persons who receive wages/salaries but not from the statistical unit performing the $R \& D$, and (ii) a number of special cases of persons external to a statistical unit who contribute to intramural R\&D.

1.47 Doctoral and master's students may be included in either group of $R \& D$ personnel if they meet the specific criteria identified in this chapter aimed at ensuring that only individuals with an appreciable contribution to the institution's R\&D are included.

$1.48 \mathrm{R} \& D$ personnel are identified according to their $R \& D$ function: Researchers, Technicians, and Other supporting staff.

1.49 The measurement of R\&D personnel (both persons employed and external R\&D personnel) involves three types of indicators:

- their number in headcounts (HC)

- their R\&D activities in full-time equivalent (FTE) or person-years

- their characteristics, including sex, R\&D function, age and formal qualification.

\section{Measuring R\&D: Methodologies and procedures (Chapter 6)}

1.50 A fundamental concern for R\&D statistics is to produce internationally comparable statistics. This is dependent not only on sound and consistent definitions, but also on the application of the definitions in practical data collection. Differences in methodological practices and in the application of definitions and recommendations are considered a major cause of the reduced comparability of R\&D data between countries. For this reason, a separate chapter on common methodological challenges across sectors is included in addition to sector-specific chapters.

1.51 Many considerations drive the methodology and procedures used to measure R\&D performance. R\&D activity tends to be concentrated in relatively few entities, particularly in the Business enterprise sector. While R\&D activity is highly concentrated, it occurs throughout the economy. Both the concentration and the breadth of occurrence have implications for guidelines on sampling 
strategy. In addition to these characteristics, the objectives of R\&D statistical programmes are multidimensional, including: aggregate indicators to support science policy; expenditures that provide input to a capital stock of R\&D in the SNA; and micro-level data to support - under restrictions with regard to data protection - unit-level analysis. These sometimes conflicting objectives influence sampling and processing strategies.

1.52 The data on R\&D may come from a variety of sources, including, but not necessarily limited to, direct measurement through surveys and administrative data sources. In some cases, estimates are required to supplement surveys and administrative data sources. Statistical offices decide on the sources of the data used based on their availability, quality, appropriateness and cost. This varies across countries.

\section{Business enterprise R\&D (Chapter 7)}

1.53 For most industrialised countries, the Business enterprise sector accounts for the largest share of R\&D expenditures and personnel. In analysing this sector and the units within it, it is important to take into account the multiple approaches used by companies to manage their R\&D activities. In particular, related businesses may jointly fund, generate, exchange and use R\&D knowledge in diverse and assorted ways. Complex business structures, particularly used by multinational enterprises (MNEs), are challenging for R\&D measurement. Also, for some businesses, R\&D is an occasional, rather than an on-going activity and therefore more difficult to identify and measure. From a methodological perspective, the collection of data from business enterprises also entails a number of practical challenges, ranging from the identification of firms that perform $R \& D$ to obtaining information on $R \& D$ as required in this manual, and including dealing with confidentiality and minimising the response burden.

1.54 The Business enterprise sector comprises:

- All resident corporations, including not only legally incorporated enterprises, regardless of the residence of their shareholders. It includes both private business enterprises (both publicly listed and traded, or not) and public business enterprises (i.e. government-controlled enterprises).

- The unincorporated branches of non-resident enterprises deemed to be resident and part of this sector because they are engaged in production on the economic territory on a long-term basis.

- All resident non-profit institutions (NPIs) that are market producers of goods or services or serve business.

1.55 This is a new stand-alone chapter in this current manual. The chapter highlights and gives recommendations on methodological challenges related to identifying the statistical and reporting units, sampling, and the classification of the activity according to several international standards. Measurement challenges in differentiating expenditures for intramural and extramural $R \& D$ are identified. 
1.56 The main aggregate statistic used to describe R\&D performance within the Business enterprise sector is BERD, Business enterprise Expenditure on R\&D. BERD represents the component of GERD (see Chapter 4) incurred by units belonging to this sector. It is the measure of intramural R\&D expenditures within the Business enterprise sector. There are a number of variables for which BERD might be usefully compiled, distributed and reported.

\section{Government R\&D (Chapter 8)}

1.57 This chapter focuses primarily on the measurement of $R \& D$ performance and personnel within the Government sector. It also attempts to provide a nexus between the performer and the complementary funder-based approaches to measuring the role of government as a funder of $R \& D$ throughout the entire economy. In addition, this chapter draws links with Chapter 12, on the measurement of government budget allocations for R\&D, and Chapter 13, on tax relief for R\&D. The Government sector comprises:

- all units of central/federal, regional/state and local/municipal government, including social security funds, except those units that fit the description of higher education institutions provided in Chapter 3 and further described in Chapter 9

- other government bodies: performing and/or funding agencies and all non-market NPIs that are controlled by government units, and that are not themselves part of the Higher education sector.

1.58 This is a new stand-alone chapter in this current manual. Extensive guidance is presented to address difficulties in separating R\&D from other related activities that arise when these activities are undertaken simultaneously within a Government unit.

1.59 The main aggregate statistic used to describe R\&D performance within the Government sector is GOVERD, Government Expenditure on R\&D. GOVERD represents the component of GERD (see Chapter 4) incurred by units belonging to this sector. It is the measure of intramural R\&D expenditures within the Government sector. Special guidance is provided on how to treat R\&D funding flows between and among units in this sector, including with intermediary funding agencies, to avoid the double counting of R\&D.

\section{Higher education R\&D (Chapter 9)}

1.60 This is a new stand-alone chapter in this current manual, replacing and extending what was previously an annex. The Higher education sector is unique to this edition of the manual and has no direct counterpart in the SNA. Institutions in the Higher education sector can be classified in any of the SNA sectors. The reason for the separate treatment of this sector is the policy relevance of information on its R\&D performing institutions. 
1.61 The Higher education sector comprises:

- all universities, colleges of technology and other institutions providing formal tertiary education programmes, whatever their source of finance or legal status

- all research institutes, centres, experimental stations and clinics that have their R\&D activities under the direct control of, or administered by, tertiary education institutions.

1.62 The Higher education sector is very heterogeneous, and countries' higher education systems and institutions are organised in many different ways. This is challenging for the compilation of R\&D statistics, and there are large variations between countries with regard to statistical methodology. This chapter gives general information on the methods used for calculating and estimating higher education R\&D expenditures and personnel. The different approaches are illustrated in Figure 9.1; the methodologies used include institutional surveys (full or partial), administrative data, and varying combinations of these data sources, often combined with R\&D coefficients from time-use surveys. There is a special focus on methods to estimate R\&D funded by a public block grant known as public general university funds (GUF), which many public higher education institutions receive to support all their activities.

1.63 For survey purposes, R\&D must be distinguished from a wide range of related activities with a scientific and technological basis. These other activities are very closely linked to R\&D both through the flows of information and in terms of the operations, institutions and personnel involved, but they should be excluded as much as possible when measuring R\&D. The Higher education sector has some sector-specific activities that are challenging with regard to the concept of R\&D. These are in particular related to education and training and specialised health care (e.g. university hospitals).

1.64 The main aggregate statistic used to describe R\&D performance within the Higher education sector is HERD, Higher education Expenditure on R\&D. HERD represents the component of GERD (see Chapter 4) incurred by units belonging to this sector. It is the measure of intramural R\&D expenditures within higher education.

\section{Private non-profit R\&D (Chapter 10)}

1.65 Private non-profit institutions (NPIs) have traditionally played a significant role in research and development both as performers and as funders, although generally at levels below those of other economic sectors. While this has been recognised in previous versions of this manual, which defined the Private non-profit sector (PNP), this is now the focus of a new stand-alone chapter. It outlines which NPIs should be considered for measurement in the PNP sector and gives guidelines on the measurement of their R\&D activities, taking into account both their specificities as well as emerging trends with respect to new forms of R\&D funding. 
1.66 The Private non-profit sector comprises:

- all non-profit institutions serving households (NPISH), as defined in the SNA 2008, except those classified as part of the Higher education sector

- for completeness of presentation, households and private individuals engaged or not engaged in market activities.

1.67 The main aggregate statistic used to describe R\&D performance within the this sector is PNPERD, Private Non-profit Expenditure on R\&D. PNPERD represents the component of GERD (see Chapter 4) incurred by units belonging to this sector. It is the measure of intramural $R \& D$ expenditures within the Private non-profit sector.

\section{Measurement of R\&D globalisation (Chapter 11)}

1.68 This manual explicitly recognises the concept of R\&D globalisation. Previous editions acknowledged the global aspects of R\&D primarily as a source of funds for domestic R\&D performance (as in the compilation of GERD) or as a destination for national sources of funds (as in the compilation of GNERD). Such sources previously were characterised as funds from/to "Abroad". Consistent with the SNA, the preferred terminology of the current Frascati Manual is "Rest of the world". The identification and measurement of non-domestic sources of and destinations for R\&D funds continues to be an important dimension of R\&D and is covered comprehensively. However, this current manual moves beyond flows of $R \& D$ funds and covers a more extensive list of measurement issues related to global R\&D (OECD, 2005; OECD, 2010). Guidance on this subject and links to other related statistical manuals are presented as a new stand-alone chapter.

1.69 In broad terms, globalisation refers to the international integration of financing, factor supply, R\&D, production, and the trade of goods and services. Globalisation in the for-profit sector is associated with international trade and foreign direct investment (FDI) primarily by business enterprises, although public and private non-profit institutions (including government and higher education institutions) also engage in international activities such as R\&D funding and collaboration.

1.70 R\&D globalisation is a subset of global activities that involve the funding, performance, transfer and use of R\&D. This chapter focuses on three measures of business R\&D globalisation, and a summary of measurement issues related to non-business sectors.

1.71 The three statistical measures of business R\&D globalisation covered are:

- cross-border R\&D funding flows

- current costs and personnel for R\&D performed by members of multinational enterprises (MNEs) within compiling countries and abroad

- international trade in R\&D services. 
1.72 Further guidance is provided on the measurement of R\&D globalisation phenomena of relevance to the non-business sectors, including the role of international organisations, government funding of $R \& D$ performed abroad, foreign campuses, and the international $R \& D$ activities of non-governmental organisations.

\section{Government budget allocations for R\&D (Chapter 12)}

1.73 There are different ways of measuring how much governments dedicate to funding $R \& D$ activities. The performer-based approach recommended by this manual is to survey the resident units that perform $R \& D$ (businesses, institutes, universities, etc.) in order to identify the amount spent on intramural $R \& D$ performance in the reference year. It is then possible to identify the portion of the intramural R\&D expenditure funded by government.

1.74 A complementary approach to measuring government funding of R\&D has been developed using data from budgets. This type of funder-based approach to reporting $R \& D$ involves identifying all the budget items that may support R\&D activities and measuring or estimating their R\&D content. Some advantages of this approach include presumably the ability to report significantly timelier government R\&D totals, since they are based on budgets, and to link the R\&D totals to policy considerations through classification by socioeconomic objectives.

1.75 The specifications of such budget-based data are described in this chapter and were first introduced in this manual's third edition. In more recent editions, budget-based data have been formally referred to as "government budget appropriations or outlays for R\&D" (GBAORD), a term that is replaced in this edition with government allocations for R\&D (GBARD).

1.76 The recommended distribution list is given in Table 12.1 and is based on the European Union classification adopted by Eurostat for the Nomenclature for the Analysis and Comparison of Scientific Programmes and Budgets (NABS).

\section{Measuring tax relief for R\&D (Chapter 13)}

1.77 Governments in several countries provide tax support for R\&D with the aim of promoting R\&D investment in the economy by granting preferential tax treatment of eligible R\&D expenditures, especially to business enterprises. Tax expenditures are complex objects of measurement; not all statistical systems separately capture all types of tax relief measures. However, because government policy objectives for R\&D tax relief are presumably achievable through either subsidies or other direct outlays, there is widespread acknowledgement that reporting such tax support in supplementary reports would facilitate transparency and more balanced international comparisons. 
1.78 In response to user and practitioner interest in addressing this gap in previous editions of this manual, this new chapter to the Frascati Manual provides some guidelines on the reporting of government support for $R \& D$ through tax incentives, with a view to assisting in the production of internationally comparable indicators of Government Tax Relief for R\&D (GTARD).

1.79 Although tax expenditures for R\&D have several elements in common with the government budget allocations for R\&D (GBARD) described in Chapter 12 , as in some instances they can be reported within the budget, this manual proposes that this category should be measured separately and in an integrated fashion, and only then subsequently integrated into the overall presentation of R\&D statistics, particularly for international comparisons.

\section{Annexes and complementary guidance}

1.80 The printed edition of this manual contains one annex that provides an overview of the history of the Frascati Manual and acknowledgements to the main contributors to the previous editions, who ensured the current standing of the manual. In addition, a glossary of terms is included in the printed edition listing the main terms used in this manual as well as their definitions. This glossary of terms is to be maintained and updated online.

1.81 Additional guidance is available through online only annex material at this manual's webpage http://oe.cd/frascati. Much of the guidance contained in the annexes available in previous editions has been superseded and/or incorporated in the printed edition of this manual, for example, guidelines on higher education, which now has its own chapter, and guidance on R\&D in developing countries, which has been mainstreamed into the manual. The guidance on the regionalisation of $R \& D$ statistics, $R \& D$ deflators and currency converters, methods for providing up-to-date estimates and projections on $R \& D, R \& D$ related to Health, Information and Communication Technology (ICT) and Biotechnology is still relevant, and users may wish to refer to the previous edition's annexes while these are pending, until revision by the OECD to incorporate more recent developments and methodologies.

1.82 The classifications referred to within this manual will be also be maintained online, with links to the relevant international standards. Information on the OECD classification by Fields of Research and Development and subsequent updates will also be managed on an online basis, notwithstanding the fact that the current classification is also available in the printed edition. The Frascati Manual webpage will be the space for the dissemination of briefing material and recommendations for specific R\&D-related measurement practices that are agreed in the future by the OECD community of national experts. As noted throughout, in preparing this manual's edition, the Working Party of National Experts on Science and Technology Indicators (NESTI) has accumulated a wealth of evidence on a number of topics that could provide the basis for future online annexes. 


\subsection{Implementing the recommendations in this manual}

1.83 This manual is intended to guide practical data collection and reporting efforts through a common vocabulary, agreed principles and practical conventions. These are aimed at ensuring the comparability of statistical outputs in order to support the build-up of a global statistical information infrastructure on $R \& D$ that has relevance for policy makers, academics, industry managers, journalists and the public at large.

1.84 It is however beyond the scope of this manual to cover every possible scenario or regulate which data are to be submitted to the OECD for the purpose of tabulation and dissemination. Additional tools used by NESTI, linked to but separate from this manual, support the implementation of its recommendations to meet user needs and serve the public. These include:

- the questionnaires for collecting aggregate data on R\&D from national authorities, as agreed between the OECD, other international organisations, and the countries asked to provide the data

- the quality assurance process, involving the OECD and the national experts providing the data

- the publication of R\&D databases and indicators, with the involvement of the relevant OECD committees

- the collection and publication of metadata specifying the main features of the sources and methods used by different countries

- the pursuit of co-ordinated analysis of R\&D micro-data in different countries, in order to address questions that cannot be readily assessed through standard indicators

- and, as a novelty arising from this edition, the development of an online community space in which practitioners can share questions and experiences, developing a cumulative and shared pool of precedents on how to treat specific situations.

1.85 The OECD works with other international organisations that play a key role in supporting capability development and $\mathrm{R} \& \mathrm{D}$ data dissemination, aiming to reduce reporting burdens on national organisations.

1.86 The adoption of a revised manual provides an opportunity for a number of countries to revisit some of their practices and bring them in line with globally accepted standards. This may require transitional arrangements as well as the appropriate communication of any potential changes in data series. The revision process has also been an opportunity to develop competencies within organisations and train new staff in charge of collecting and reporting R\&D data.

\subsection{Final remarks}

1.87 The intended purpose for the information collected under these Frascati Manual guidelines is to help decision makers, especially policy makers. As R\&D data have become more widely accessible and feature more prominently 
in public discussions, this information has also become an important component of the social and political dialogue about the use and impact of these resources. There is broad awareness that R\&D data, alone or in combination with other data, can provide only part of the basis for decision making. However, as long as governments, business leaders and the public recognise the special features of R\&D and confer upon it a special status, the measurement of the human and financial efforts dedicated to such endeavours will continue to play a major part in the statistical evidence required by societies worldwide. This manual's seventh edition seeks to support that goal.

\section{References}

EC, IMF, OECD, UN and the World Bank (2009), System of National Accounts, United Nations, New York. https://unstats.un.org/unsd/nationalaccount/docs/sna2008.pdf.

OECD (2010), Measuring Globalisation: OECD Economic Globalisation Indicators 2010, OECD Publishing, Paris. DOI: http://dx.doi.org/10.1787/9789264084360-en.

OECD (2009a), Handbook on Deriving Capital Measures of Intellectual Property Products, OECD Publishing, Paris. DOI: $h t t p: / / d x . d o i . o r g / 10.1787 / 9789264079205-e n$.

OECD (2009b), Patent Statistics Manual, OECD Publishing, Paris. DOI: http://dx.doi. org/10.1787/9789264056442-en.

OECD (2005), OECD Handbook on Economic Globalisation Indicators, OECD Publishing, Paris. DOI: http://dx.doi.org/10.1787/9789264108103-en.

OECD (2002), Frascati Manual: Proposed Standard Practice for Surveys on Research and Experimental Development, The Measurement of Scientific and Technological Activities, OECD Publishing, Paris. DOI: http://dx.doi.org/10.1787/9789264199040-en.

OECD/Eurostat (2005), Oslo Manual: Guidelines for Collecting and Interpreting Innovation Data, $3^{\text {rd }}$ edition, The Measurement of Scientific and Technological Activities, OECD Publishing, Paris. DOI: http://dx.doi.org/10.1787/9789264013100-en.

UNESCO-UIS (2012), International Standard Classification of Education (ISCED) 2011, UIS, Montreal. www.uis.unesco.org/Education/Documents/isced-2011-en.pdf.

United Nations (2008), International Standard Industrial Classification of All Economic Activities (ISIC), Rev. 4. https://unstats.un.org/unsd/cr/registry/isic-4.asp and http://unstats.un.org/ unsd/publication/seriesM/seriesm_4rev4e.pdf. 

PART I

\section{Defining and measuring R\&D: General guidance}





\section{Chapter 2}

\section{Concepts and definitions for identifying R\&D}

This chapter provides the definition of research and experimental development (R\&D) and of its components, basic research, applied research and experimental development. These definitions are essentially unchanged from those in previous editions of the manual. Where there are differences, they reflect changes in culture and the use of language. To provide guidance on what is and what is not an R\&D activity, five criteria are provided which require the activity to be novel, creative, uncertain in it outcome, systematic and transferable and/or reproducible. Since the last edition, the treatment of R\&D expenditure in the System of National Accounts (SNA) has changed from an expense to a capital investment. As a result, the language of this manual, and of the SNA, is closer and there are additional requirements for measurements of financial flows. While the manual has always applied to all scientific disciplines, there is more emphasis on the social sciences, humanities and the arts, in addition to the natural sciences and engineering. Measuring R\&D activities through surveys, administrative data, or interviews raises questions about boundaries and what is and what is not included and this chapter provides examples to help answer those questions. The manual is used to interpret R\&D data as part of policy development and evaluation, but the focus of this chapter is on definitions for measurement purposes. 


\subsection{Introduction}

2.1 The Frascati Manual has provided the definition of research and experimental development (R\&D) and of its components, basic research, applied research and experimental development, for more than half a century, and the definitions have stood the test of time. The definitions in this chapter do not differ in substance from those in previous editions. However, there is recognition of cultural change in the definition of $R \& D$ and of the use of language in the definition of experimental development.

2.2 Since the previous edition of this manual, the System of National Accounts (SNA) has changed the treatment of expenditure on R\&D from an expense to a capital investment leading to a capital stock of knowledge created as a result of R\&D. The SNA 2008 (EC et al., 2009) draws on this manual for the definition of R\&D. A consequence of becoming a more integral part of the SNA is the use of its language in this manual. Such usage will be noted when it occurs.

2.3 R\&D is found in the social sciences, humanities and the arts as well as in the natural sciences and engineering. This manual gives greater emphasis than past editions to the social sciences, humanities and the arts. This requires no changes in the definitions and conventions, but it does require greater attention to the boundaries that define what is and what is not R\&D. Also, countries using this manual are at different stages of economic development, and this chapter tries to accommodate the differing needs.

2.4 The chapter provides definitions of $R \& D$ and its components, together with a set of criteria for identifying R\&D. Examples of $R \& D$, boundaries and exclusions are provided to illustrate how the definitions are applied. This is a statistical manual, and its fundamental purpose is to provide guidance for the measurement of $R \& D$ activities using various means of data-gathering from surveys, interviews and administrative sources. The manual is also used for interpreting R\&D data as part of the development, implementation and evaluation of policy. However, users should note that the focus of this chapter is on definitions for measurement purposes.

\subsection{Definition of research and experimental development (R\&D)}

2.5 Research and experimental development (R\&D) comprise creative and systematic work undertaken in order to increase the stock of knowledge including knowledge of humankind, culture and society - and to devise new applications of available knowledge. 
2.6 A set of common features identifies R\&D activities, even if these are carried out by different performers. R\&D activities may be aimed at achieving either specific or general objectives. $R \& D$ is always aimed at new findings, based on original concepts (and their interpretation) or hypotheses. It is largely uncertain about its final outcome (or at least about the quantity of time and resources needed to achieve it), it is planned for and budgeted (even when carried out by individuals), and it is aimed at producing results that could be either freely transferred or traded in a marketplace. For an activity to be an R\&D activity, it must satisfy five core criteria.

2.7 The activity must be:

- novel

- creative

- uncertain

- systematic

- transferable and/or reproducible.

2.8 All five criteria are to be met, at least in principle, every time an $R \& D$ activity is undertaken whether on a continuous or occasional basis. The definition of R\&D just given is consistent with the definition of R\&D used in the previous editions of the Frascati Manual and covers the same range of activities.

2.9 The term R\&D covers three types of activity: basic research, applied research and experimental development. Basic research is experimental or theoretical work undertaken primarily to acquire new knowledge of the underlying foundations of phenomena and observable facts, without any particular application or use in view. Applied research is original investigation undertaken in order to acquire new knowledge. It is, however, directed primarily towards a specific, practical aim or objective. Experimental development is systematic work, drawing on knowledge gained from research and practical experience and producing additional knowledge, which is directed to producing new products or processes or to improving existing products or processes. These three types of R\&D are discussed further in Section 2.5.

2.10 This manual follows the System of National Accounts convention in which "product" refers to a good or a service (EC et al., 2009: para. 2.36). Throughout this manual, "process" refers to the transformation of inputs to outputs and their delivery or to organisational structures or practices.

2.11 The order in which the three types of R\&D activity appear is not meant to suggest that basic research leads to applied research and then to experimental development. There are many flows of information and knowledge in the R\&D system. Experimental development can inform basic research, and there is no reason why basic research cannot lead directly to new products or processes. 


\subsection{R\&D activities and projects}

2.12 An "R\&D activity" is the sum of actions deliberately undertaken by $R \& D$ performers in order to generate new knowledge. In most cases, R\&D activities can be grouped to form "R\&D projects". Each $R \& D$ project consists of a set of R\&D activities, is organised and managed for a specific purpose, and has its own objectives and expected outcomes, even at the lowest level of formal activity. The concept of an R\&D project, while useful for understanding how R\&D is done, is not likely to be applied in the same way in all the sectors used in this manual.

\subsection{The five criteria for identifying $R \& D$}

2.13 For an activity to be classified as an R\&D activity, five core criteria have to be jointly satisfied. A set of examples, which is by no means exhaustive, is used to illustrate how the five criteria can be effectively applied to identify R\&D activities as well as specific R\&D projects.

\section{To be aimed at new findings (novel)}

2.14 New knowledge is an expected objective of an R\&D project, but it has to be adapted to different contexts. For example, research projects in universities are expected to pursue entirely new advancements in knowledge, and the same can be said for projects designed and managed by research institutes.

2.15 In the Business enterprise sector (Frascati Manual sectors are defined in Chapter 3), the potential novelty of R\&D projects has to be assessed by comparison with the existing stock of knowledge in the industry. The R\&D activity within the project must result in findings that are new to the business and not already in use in the industry. Excluded from R\&D are activities undertaken to copy, imitate or reverse engineer as a means of gaining knowledge, as this knowledge is not novel.

2.16 Novelty could result from a project to reproduce an existing result that finds potential discrepancies. An experimental development project aimed at creating knowledge in support of the development of new concepts and ideas related to the design of new products or processes should be included in R\&D. As $R \& D$ is the formal creation of knowledge, including knowledge embodied in products and processes, the measurement focus is on the new knowledge, not on the new or significantly improved products or processes resulting from the application of the knowledge. An example of R\&D could be the integration of the "maintenance manual" of a very complex system (like a passenger aircraft) with additional material emerging from practical experience in ordinary maintenance and properly codified, so long as this was done as part of an R\&D project. Another example is systematic testing to provide documentation of the potential use of a chemical reaction that has already been adopted in production processes (an existing technology) in order to achieve a new molecule, which has been considered an improbable outcome by the scientific literature. 


\section{To be based on original, not obvious, concepts and hypotheses (creative)}

2.17 An R\&D project must have as an objective new concepts or ideas that improve on existing knowledge. This excludes from $R \& D$ any routine change to products or processes and, therefore, a human input is inherent to creativity in $R \& D$. As a result, an $R \& D$ project requires the contribution of a researcher (defined in Chapter 5). One area requiring care in assessment is the arts (Section 2.6): there is creativity, but the other criteria have to be confirmed for the activity to qualify as $R \& D$. While routine activity is excluded from $R \& D$, new methods developed to perform common tasks are included. As an example, data processing is not an R\&D activity unless it is part of a project to develop new methods for data processing. Vocational training is excluded from $R \& D$, but new methods to deliver training could be R\&D. A new method to fix a problem, developed as part of a project, could be R\&D if the outcome is original and the other criteria are met.

\section{To be uncertain about the final outcome (uncertain)}

2.18 R\&D involves uncertainty, which has multiple dimensions. At the outset of an R\&D project, the kind of outcome and the cost (including time allocation) cannot be precisely determined relative to the goals. In the case of basic research, which is aimed at extending the boundaries of formal knowledge, there is a broad recognition of the possibility of not achieving the intended results. For example, a research project may succeed in eliminating a number of competing hypotheses, but not all of them. For R\&D in general, there is uncertainty about the costs, or time, needed to achieve the expected results, as well as about whether its objectives can be achieved to any degree at all. For example, uncertainty is a key criterion when making a distinction between R\&D prototyping (models used to test technical concepts and technologies with a high risk of failure, in terms of applicability) and non-R\&D prototyping (preproduction units used to obtain technical or legal certifications).

\section{To be planned and budgeted (systematic)}

2.19 R\&D is a formal activity that is performed systematically. In this context "systematic" means that the R\&D is conducted in a planned way, with records kept of both the process followed and the outcome. To verify this, the purpose of the R\&D project and the sources of funding for the R\&D performed should be identified. The availability of such records is consistent with an R\&D project that is aimed at addressing specific needs and has its own human and financial resources. While the management and reporting structure just described is more likely to be found in large projects, it can also apply to smallscale activities where it would be sufficient to have one or more employees or consultants (providing that a researcher was included) charged with producing a specific solution to a practical problem. 


\section{To lead to results that could be possibly reproduced (transferable and/or reproducible)}

2.20 An R\&D project should result in the potential for the transfer of the new knowledge, ensuring its use and allowing other researchers to reproduce the results as part of their own $R \& D$ activities. This includes $R \& D$ that has negative results, in the case that an initial hypothesis fails to be confirmed or a product cannot be developed as originally intended. As the purpose of R\&D is to increase of the existing stock of knowledge, the results cannot remain tacit (i.e. remain solely in the minds of the researchers), as they, and the associated knowledge, would be at risk of being lost. The codification of knowledge and its dissemination is part of the usual practice in universities and research institutes, although there may be restrictions for knowledge arising through contract work or as part of a collaborative undertaking. In a business environment, the results will be protected by secrecy or other means of intellectual property protection, but it is expected that the process and the results will be recorded for use by other researchers in the business.

\section{Examples}

2.21 To understand the aim of a project, it is essential to identify its R\&D content and the institutional context in which $R \& D$ is performed. Some examples follow.

- In the field of medicine, a routine autopsy to determine the causes of death is the practice of medical care and is not $R \& D$; a special investigation of a particular mortality to establish the side effects of certain cancer treatments is R\&D (in fact, novelty and uncertainty about the final results of the study, as well as the transferability of the results for broader use, apply here).

- Similarly, routine tests such as blood and bacteriological tests carried out for medical checks are not R\&D, whereas a special programme of blood tests for patients taking a new drug is R\&D.

- Keeping daily records of temperatures or of atmospheric pressure is not $R \& D$, but a standard procedure. The investigation of new methods of measuring temperature is $R \& D$, as is the study and development of new models for weather prediction.

- $R \& D$ activities in the mechanical engineering industry often have a close connection with design. In small and medium-size enterprises (SMEs) in this industry, there is usually no special R\&D department, and R\&D performance is often included under the general heading "design and drawing". If calculations, designs, working drawings and operating instructions are needed for setting up and operating pilot plants or prototypes, they should be included in R\&D. If they are carried out for the preparation, execution and maintenance of production standardisation (e.g. jigs, machine tools) 
or to promote the sale of products (e.g. offers, leaflets, catalogues of spare parts), they should be excluded from R\&D. In this example, several R\&D features can be identified: novelty in exploring the potential of new devices - by running prototypes; uncertainty, as prototype testing could yield unexpected results; creativity - emerging in the design of new devices to be produced; transferability - by producing technical documentation to translate the results of testing in information to be used at the product development stage; and a systematic approach, as far as a detailed organisation of the project can be identified behind the afore-mentioned technical activities.

2.22 Table 2.1 provides some practical examples of how R\&D can be identified by using the five core criteria.

Table 2.1. Examples of questions for identifying R\&D projects

\begin{tabular}{|c|c|}
\hline Question & Comment \\
\hline $\begin{array}{l}\text { a. What are the objectives } \\
\text { of the project? }\end{array}$ & $\begin{array}{l}\text { The pursuit of original and challenging objectives through the creation of } \\
\text { "new knowledge" (such as seeking previously undiscovered phenomena, } \\
\text { structures or relationships) is a key criterion for R\&D. Any use of already } \\
\text { available knowledge (adaptation, customisation, etc.) which does not entail an } \\
\text { attempt to expand the state of the art should be excluded (Novelty). }\end{array}$ \\
\hline $\begin{array}{l}\text { b. What is new about this } \\
\text { project? }\end{array}$ & $\begin{array}{l}\text { In addition to the development of "new knowledge", an R\&D project should } \\
\text { have a creative approach, such as devising new applications of existing } \\
\text { scientific knowledge or new uses of available techniques or technologies } \\
\text { (Creativity). }\end{array}$ \\
\hline $\begin{array}{l}\text { c. What methods are being } \\
\text { used to carry out the } \\
\text { project? }\end{array}$ & $\begin{array}{l}\text { Methods used in scientific and technological research, as well as in } \\
\text { research in the social sciences, humanities and the arts, are accepted } \\
\text { provided that they address uncertainty about the project's final outcome. } \\
\text { The uncertainty could be about how much time and resources will be } \\
\text { needed to achieve the planned goal. The choice of method could be part of } \\
\text { the project's creativity and a means of dealing with uncertainty (Creativity } \\
\text { and uncertainty). }\end{array}$ \\
\hline $\begin{array}{l}\text { d. How generally applicable } \\
\text { are the findings or results } \\
\text { of the project? }\end{array}$ & $\begin{array}{l}\text { To be generally applicable, the findings of an R\&D project have to meet } \\
\text { the criterion of being transferable/reproducible, in addition to the other } \\
\text { four criteria. Transferring the results may for example be demonstrated by } \\
\text { publication in the scientific literature and the use of instruments of intellectual } \\
\text { property protection. }\end{array}$ \\
\hline $\begin{array}{l}\text { e. What types of staff are } \\
\text { working on the project? }\end{array}$ & $\begin{array}{l}\text { A range of skills is assumed to be required to undertake an R\&D project } \\
\text { (the } R \& D \text { personnel issue is discussed in Chapter } 5 \text { of this manual). } \\
\text { Research personnel in projects are classified as researchers, technicians } \\
\text { and other supporting staff, but only researchers, working as researchers, } \\
\text { are needed to identify an R\&D activity which, implicitly, satisfies all five } \\
\text { core criteria. }\end{array}$ \\
\hline $\begin{array}{l}\text { f. How should the research } \\
\text { projects of research } \\
\text { institutions be classified? }\end{array}$ & $\begin{array}{l}\text { In selected cases, an "institutional approach" can be used to distinguish } \\
\text { between } R \& D \text { and non-R\&D projects. For instance, most projects carried } \\
\text { out in research institutes or research universities can be qualified as R\&D } \\
\text { projects. Projects launched in other domains - like business enterprises or } \\
\text { institutions not totally devoted to R\&D - should be checked against the five } \\
\text { R\&D criteria (see institutions in Chapter } 3 \text { ). }\end{array}$ \\
\hline
\end{tabular}




\subsection{Distribution by type of R\&D}

2.23 A breakdown by type of $R \& D$ is recommended for use in all four of the sectors used in this manual and defined in Chapter 3: Business enterprise; Higher education; Government; and Private non-profit. For the purposes of international comparison, the breakdown could be based either on total R\&D expenditure or on current expenditures only (see Chapter 4). It may be applied at project level, but some R\&D projects may have to be further subdivided.

2.24 There are three types of R\&D:

- basic research

- applied research

- experimental development.

\section{Basic research}

\subsection{Basic research is experimental or theoretical work undertaken primarily to acquire new knowledge of the underlying foundations of phenomena and observable facts, without any particular application or use in view.}

2.26 Basic research analyses properties, structures and relationships with a view to formulating and testing hypotheses, theories or laws. The reference to no "particular application in view" in the definition of basic research is crucial, as the performer may not know about potential applications when doing the research or responding to survey questionnaires. The results of basic research are not generally sold but are usually published in scientific journals or circulated to interested colleagues. Occasionally, the publication of basic research may be restricted for reasons of national security.

2.27 In basic research, the researcher is expected to have some freedom to set goals. Such research is usually performed in the Higher education sector but also to some extent in the Government sector. Basic research can be oriented or directed towards some broad fields of general interest, with the explicit goal of a range of future applications. Business enterprises in the private sector may also undertake basic research even though there may be no specific commercial applications anticipated in the short term. Research on some kinds of energysaving technologies may be described as basic according to the above definition if it does not have a specific use in view. However, it does have a specific direction: improved energy savings. Such research in this manual is referred to as "oriented basic research".

2.28 Oriented basic research may be distinguished from "pure basic research" as follows:

- Pure basic research is carried out for the advancement of knowledge, without seeking economic or social benefits or making an active effort to apply the results to practical problems or to transfer the results to sectors responsible for their application. 
- Oriented basic research is carried out with the expectation that it will produce a broad base of knowledge likely to form the basis of the solution to recognised or expected current or future problems or possibilities.

\section{Applied research}

2.29 Applied research is original investigation undertaken in order to acquire new knowledge. It is, however, directed primarily towards a specific, practical aim or objective.

2.30 Applied research is undertaken either to determine possible uses for the findings of basic research or to determine new methods or ways of achieving specific and predetermined objectives. It involves considering the available knowledge and its extension in order to solve actual problems. In the Business enterprise sector, the distinction between basic and applied research is often marked by the creation of a new project to explore promising results of a basic research programme (moving from a long-term to a medium-short term perspective in the exploitation of the results of intramural [see Glossary] R\&D).

2.31 The results of applied research are intended primarily to be valid for possible applications to products, operations, methods or systems. Applied research gives operational form to ideas. The applications of the knowledge derived can be protected by intellectual property instruments, including secrecy.

\section{Experimental development}

2.32 Experimental development is systematic work, drawing on knowledge gained from research and practical experience and producing additional knowledge, which is directed to producing new products or processes or to improving existing products or processes.

2.33 The development of new products or processes qualifies as experimental development if it meets the criteria for identifying R\&D activity. An example is uncertainty about the resources needed to achieve the goal of the $R \& D$ project in which the development activity is taking place. In this manual the " $D$ " in R\&D refers to experimental development.

\section{Not "product development"}

2.34 The concept of experimental development should not be confused with "product development", which is the overall process - from the formulation of ideas and concepts to commercialisation - aimed at bringing a new product (good or service) to the market. Experimental development is just one possible stage in the product development process: that stage when generic knowledge is actually tested for the specific applications needed to bring such a process to a successful end. During the experimental development stage new knowledge is generated, and that stage comes to an end when the R\&D criteria (novel, uncertain, creative, systematic, and transferable 
and/or reproducible) no longer apply. As an example, in a process aimed at developing a new car, the option to adopt some technologies could be taken into consideration and tested for use in the car under development: this is the stage when experimental development is performed. It will lead to new results by dealing with new applications of some general knowledge; it will be uncertain, because testing could give rise to negative results; it will have to be creative, as the activity will focus on the adaptation of some technology to a new use; it will be formalised, by needing the commitment of a specialised workforce; and it will involve a codification, in order to translate the results of the tests into technical recommendations for the further stages of the product development process. However, there are cases of product development without R\&D that are discussed in the economics literature, especially in the case of SMEs.

\section{Not "pre-production development"}

2.35 The concept of experimental development should not be confused with "pre-production development", which is the term used to describe nonexperimental work on a defence or aerospace product or system before it goes into production. Similar cases apply in other industries. It is difficult to define precisely the cut-off point between experimental development and preproduction development; the distinction between these two categories requires "engineering judgement" as to when the element of novelty ceases and the work changes to routine development of an integrated system.

2.36 For example, once a fighter bomber has successfully passed through the stages of research, technology demonstration, project design and initial development to the flight-testing of a pre-production aircraft, up to ten additional airframes may be required in order to ensure full operational integration of the vehicle into air offence/defence systems. This would be a two-stage process. The first stage is development of the integrated air offence/defence system, which involves bringing together developed components and subsystems that have not previously been integrated in this context. It requires a large flight test programme for the aircraft, which is potentially very expensive and the main cost element prior to production. While much of the work commissioned during this stage is experimental development (R\&D), some does not have the element of novelty necessary for classification as R\&D and is instead pre-production development (non-R\&D). The second stage covers trials of the integrated air offence/defence system. Once the system is proven to work at stage one, the development project may move on to produce a trial production batch for operational trials (low-rate initial production). The full production order depends on their success. According to this manual, this work is not R\&D but pre-production development. However, problems may arise during the trials, and new experimental development may be needed to solve them. This work is described in this manual as "feedback R\&D" and should be included as R\&D. 


\section{How types of R\&D can be differentiated}

2.37 A key criterion guides the classification of R\&D activities by type: the expected use of the results. In addition, two questions can help identify the type of an R\&D project:

- how far ahead in time is the project likely to lead to results that can be applied

- how broad is the range of potential fields of application for the results of the $R \& D$ project (the more fundamental the research, the broader the potential field of application).

2.38 The relationship between basic research, applied research and experimental development has to be seen within a dynamic perspective. It is possible that applied research and experimental development could adapt fundamental knowledge arising from basic research directly for general application. However, the linearity of such a process is affected by the feedback that takes place when knowledge is used to solve a problem. This dynamic interaction between knowledge generation and the solution of problems links basic and applied research and experimental development.

2.39 With reference to the organisations where R\&D is performed, a clear-cut separation of the three types of R\&D rarely exists. All three types may sometimes be carried out in the same unit by essentially the same staff, but some research projects may genuinely straddle categories. For instance, the search for a new medical treatment for people affected by an epidemic disease may involve both basic and applied research. It is recommended to undertake an evaluation of the type of R\&D at the project level, by classifying the project's expected results according to the two "indicators" described above. Some examples are provided in the next paragraphs.

\section{Examples of how to differentiate types of R\&D in the natural sciences and engineering}

2.40 The following examples illustrate general differences between basic and applied research and experimental development in the natural sciences and engineering.

- The study of a given class of polymerisation reactions under various conditions is basic research. The attempt to optimise one of these reactions with respect to the production of polymers with given physical or mechanical properties (making it of particular utility) is applied research. Experimental development then consists of "scaling up" the process that has been optimised at the laboratory level and investigating and evaluating possible methods of producing the polymer as well as products to be made from it.

- The modelling of a crystal's absorption of electromagnetic radiation is basic research. The study of the absorption of electromagnetic radiation by this material under varying conditions (for instance, temperature, impurities, 
concentration, etc.) to obtain given properties of radiation detection (sensitivity, rapidity, etc.) is applied research. Testing a new device using this material in order to obtain a better detector of radiation than those already existing (in the spectral range considered) is experimental development.

- The development of a new method for the classification of immunoglobulin sequences is basic research. Investigations undertaken in an effort to distinguish between antibodies for various diseases is applied research. Experimental development then consists of devising a method for synthesising the antibody for a particular disease on the basis of knowledge of its structure and clinical tests of the effectiveness of the synthesised antibody on patients who have agreed to accept an experimental advanced treatment.

- A study about how the properties of carbon fibres could change according to their relative position and orientation within a structure is basic research. The conceptualisation of a method to allow for processing carbon fibres at industrial level with a degree of precision at the nano-scale could be the outcome of some applied research. Testing the use of new composite materials for different purposes is experimental development.

- Controlling material processes in the domain where quantum effects occur is an objective to be pursued through basic research. Developing materials and components for inorganic and organic light-emitting diodes for improved efficiency and cost reduction is applied research. Experimental development could be aimed at identifying applications for advanced diodes and incorporating them in consumer devices.

- Searching for alternative methods of computation, such as quantum computation and quantum information theory, is basic research. Investigation into the application of information processing in new fields or in new ways (e.g. developing a new programming language, new operating systems, program generators, etc.) and investigation into the application of information processing to develop tools such as geographical information and expert systems are applied research. Development of new applications software and substantial improvements to operating systems and application programmes are experimental development.

- The study of sources of all kinds (manuscripts, documents, monuments, works of art, buildings, etc.) in order to better comprehend historical phenomena (the political, social, cultural development of a country, the biography of an individual, etc.) is basic research. Comparative analysis of archaeological sites and/or monuments displaying similarities and other common characteristics (e.g. geographic, architectural, etc.) to understand interconnections of potential relevance to teaching material and museum displays is applied research. The development of new instruments and methods for studying artefacts and natural objects recovered through archaeological endeavours (e.g. for the age-dating of bones or botanic remains) is experimental development. 
- In agricultural sciences and forestry:

* Basic research: Researchers investigate genome changes and mutagenic factors in plants to understand their effects on the phenome. Researchers investigate the genetics of the species of plants in a forest in an attempt to understand natural controls for disease or pest resistance.

* Applied research: Researchers investigate wild potato genomes to locate the genes responsible for resistance to potato blight in an effort to improve the disease resistance in domestic/crop potatoes. Researchers plant experimental forests where they alter the spacing and alignment of the trees to reduce the spread of disease while ensuring the optimum arrangement for maximum yield.

* Experimental development: Researchers create a tool for gene editing by using knowledge of how enzymes edit DNA. Researchers use existing research on a specific plant species to create a plan for improving how a company plants its forests to achieve a specific goal.

- In nanotechnology:

* Basic research: Researchers study the electrical properties of graphene by using a scanning tunnelling microscope to investigate how electrons move in the material in response to voltage changes.

* Applied research: Researchers study microwaves and thermal coupling with nanoparticles to properly align and sort carbon nanotubes.

* Experimental development: Researchers use research in micromanufacturing to develop a portable and modular micro-factory system with components that are each a key part of an assembly line.

- In computer and information sciences:

* Basic research: Research on the properties of general algorithms for handling large amounts of real-time data.

* Applied research: Research to find ways to reduce the amount of spam by understanding the whole structure or business model of spam, what spammers do, and their motivations in spamming.

* Experimental development: A start-up company takes code developed by researchers and develops the business case for the resulting software product for improved on-line marketing.

\section{Examples of how to differentiate types of R\&D in the social sciences, humanities and the arts}

2.41 Another set of examples can be provided with reference to the social sciences, humanities and the arts where, as discussed above, the blurring of boundaries could affect the distinction between basic and applied research. Examples of experimental development in these domains can also be difficult to identify, because of the role played by other domains in the natural sciences and 
engineering. It should be noted that these examples must also meet the basic criteria identified in this chapter to be considered as R\&D.

- In economics and business:

- Basic research: A review of theories on the factors determining regional disparities in economic growth. Economists conducting abstract research in economic theory that focuses on whether a natural equilibrium exists in a market economy. The development of new risk theories.

* Applied research: The analysis of a specific regional case for the purpose of developing government policies. Economists investigating the properties of an auction mechanism that could be relevant to auctioning the telecommunications spectrum. The investigation of new types of insurance contracts to cover new market risks or new types of savings instruments.

Experimental development: The development of operational models, based upon statistical evidence, to design economic policy tools to allow a region to catch up in terms of growth. The development by a national telecommunications authority of a method for auctioning the telecommunications spectrum. The development of a new method to manage an investment fund is experimental development as long as there is sufficient evidence of novelty.

- In education:

Basic research: Analysis of the environmental determinants of learning ability. The investigation by researchers of the effect of different types of manipulatives on the way first graders learn mathematical strategy by changing manipulatives and then measuring what students have learned through standardised instruments

* Applied research: The comparative evaluation of national education programmes aimed at reducing the learning gap experienced by disadvantaged communities. The study by researchers of the implementation of a specific math curriculum to determine what teachers needed to know to implement the curriculum successfully.

* Experimental development: The development of tests for selecting which educational programme should be used for children with specific needs. The development and testing (in a classroom) of software and support tools, based on fieldwork, to improve mathematics cognition for student special education.

- In social and economic geography:

Basic research: Researchers seek to understand the fundamental dynamics of spatial interactions.

* Applied research: A research study analyses the spatial-temporal patterns in the transmission and diffusion of an infectious disease outbreak. 
- In history:

* Basic research: Historians study the history and human impact of glacial outburst floods in a country.

* Applied research: Historians examine past societies' responses to catastrophic natural events (e.g. floods, droughts, epidemics) in order to understand how contemporary society might better respond to global climate change.

* Experimental development: Using previous research findings, historians design a new museum exhibit on the adaptations of past human societies to environmental changes; this serves as a prototype for other museums and educational installations.

- In language/linguistics:

* Basic research: Linguists study how different languages interact as they come into contact with one another.

* Applied research: Speech therapists examine the governing neurology of languages and how humans acquire language skills.

* Experimental development: Linguists develop a tool for diagnosing autism in children based on their language acquisition, retention and use of signs.

- In music:

* Basic research: Researchers develop a transformational theory that provides a framework for understanding musical events not as a collection of objects that have particular relationships to each other but as a series of transformational operations applied to the basic material of the work.

* Applied research: Researchers use historical records and the techniques of experimental archaeology to recreate an ancient and long-disappeared musical instrument and to determine how it would have been constructed, how it was played and the types of sounds it would have produced.

* Experimental development: Music educators and theorists work to produce new pedagogical materials based on new discoveries in neuroscience that change our understanding of how humans process new sounds and information.

\subsection{Classification and distribution by Fields of Research and Development (FORD)}

2.42 For a number of reasons, survey practitioners and data users often find it helpful and relevant to classify R\&D-performing units and distribute their R\&D resources according to the knowledge domain in which they operate. This manual proposes the use of the OECD Fields of Research and Development (FORD) classification for such purposes. This classification, developed for R\&D 
measurement purposes, follows primarily a content approach. Where the content of the R\&D subject matter is closely related, subjects are grouped together to form the broad (one-digit) and narrower (two-digit) fields of the classification. While the classification can be applied to a broader range of science and technology (S\&T) and knowledge-based activities, its formulation by the OECD is focused on $\mathrm{R} \& \mathrm{D}$ as defined in this manual.

2.43 The aim is to distribute $R \& D$ efforts and classify the units that undertake such efforts. Two R\&D projects can be said to belong to the same field if their content is the same or sufficiently similar. The following criteria give rise to the FORD classification and can help inform the assessment of the degree of similarity of the subject matter content:

- The knowledge sources drawn upon for the R\&D activity carried out. The application of developments in some technology fields often gives rise to new scientific efforts, in the same way that scientific knowledge provides a basis for new technological developments.

- The objects of interest - the phenomena to be understood or the problems to be solved as part of R\&D.

- The methods, techniques and professional profiles of the scientists and other R\&D workers - different domains can be distinguished sometimes on the basis of the methodological approaches to the study of a given phenomenon or question.

- The areas of application. For example, in the FORD classification, the medical sciences and agricultural sciences are specifically defined by their applications to human health and agricultural activities.

2.44 This classification is closely related to and consistent with UNESCO's "Recommendation concerning the International Standardisation of Statistics on Science and Technology" (UNESCO, 1978), which provided the initial basis for the OECD classification of R\&D by the field of S\&T in previous versions of this manual. There is also a degree of relationship with the ISCED Fields of Education and Training (ISCED-F), which is aimed at the classification of study and training programmes and reflects to a large extent the way in which schools, departments, etc., organise their activities and award credentials to students who successfully complete these programmes. It is recognised that FORD and the ISCED-F have different purposes, and it is not feasible to ensure a direct correspondence between the two classifications (UNESCO-UIS, 2014, p. 17).

2.45 In light of ongoing changes in the way R\&D is conducted and the progressive emergence of new domains, the FORD classification will be subject to continuing revision after the publication of this manual's edition. For more upto-date versions, the reader should consult the online annexes to this manual where more detail can be found on this classification and its use. 
Table 2.2. Fields of R\&D classification

\begin{tabular}{|c|c|}
\hline Broad classification & Second-level classification \\
\hline 1. Natural sciences & $\begin{array}{l}\text { 1.1 Mathematics } \\
\text { 1.2 Computer and information sciences } \\
\text { 1.3 Physical sciences } \\
\text { 1.4 Chemical sciences } \\
\text { 1.5 Earth and related environmental sciences } \\
\text { 1.6 Biological sciences } \\
\text { 1.7 Other natural sciences }\end{array}$ \\
\hline 2. Engineering and technology & $\begin{array}{l}\text { 2.1 Civil engineering } \\
\text { 2.2 Electrical engineering, electronic engineering, } \\
\quad \text { information engineering } \\
\text { 2.3 Mechanical engineering } \\
\text { 2.4 Chemical engineering } \\
\text { 2.5 Materials engineering } \\
\text { 2.6 Medical engineering } \\
\text { 2.7 Environmental engineering } \\
\text { 2.8 Environmental biotechnology } \\
\text { 2.9 Industrial biotechnology } \\
\text { 2.10 Nano-technology } \\
\text { 2.11 Other engineering and technologies }\end{array}$ \\
\hline 3. Medical and health sciences & $\begin{array}{l}\text { 3.1 Basic medicine } \\
\text { 3.2 Clinical medicine } \\
\text { 3.3 Health sciences } \\
\text { 3.4 Medical biotechnology } \\
\text { 3.5 Other medical science }\end{array}$ \\
\hline 4. Agricultural and veterinary sciences & $\begin{array}{l}\text { 4.1 Agriculture, forestry, and fisheries } \\
\text { 4.2 Animal and dairy science } \\
\text { 4.3 Veterinary science } \\
\text { 4.4 Agricultural biotechnology } \\
\text { 4.5 Other agricultural sciences }\end{array}$ \\
\hline 5. Social sciences & $\begin{array}{l}\text { 5.1 Psychology and cognitive sciences } \\
\text { 5.2 Economics and business } \\
\text { 5.3 Education } \\
\text { 5.4 Sociology } \\
\text { 5.5 Law } \\
\text { 5.6 Political science } \\
\text { 5.7 Social and economic geography } \\
\text { 5.8 Media and communications } \\
\text { 5.9 Other social sciences }\end{array}$ \\
\hline 6. Humanities and the arts & $\begin{array}{l}\text { 6.1 History and archaeology } \\
6.2 \text { Languages and literature } \\
6.3 \text { Philosophy, ethics and religion } \\
6.4 \text { Arts (arts, history of arts, performing arts, music) } \\
6.5 \text { Other humanities }\end{array}$ \\
\hline
\end{tabular}




\subsection{Examples of R\&D, boundaries and exclusions in different areas}

\section{$R \& D$ and innovation activities and borderline cases}

2.46 Innovation is currently defined for measurement purposes in the third edition of the Oslo Manual (OECD/Eurostat, 2005) with a sole focus on the Business enterprise sector (see a definition for this sector in Chapter 3). In summary, it has to do with putting new or significantly improved products on the market or finding better ways (through new or significantly improved processes and methods) of getting products to the market. R\&D may or may not be part of the activity of innovation, but it is one among a number of innovation activities. These activities also include the acquisition of existing knowledge, machinery, equipment and other capital goods, training, marketing, design and software development. These innovation activities may be carried out in-house or procured from third parties.

2.47 Care must be taken to exclude activities that, although part of the innovation process, do not satisfy the criteria required to be classified as R\&D. For example, patent application and licensing activity, market research, manufacturing start-up, and tooling up and redesign for the manufacturing process are not in their own right $R \& D$ activities and cannot be assumed to be part of an R\&D project. Some activities, such as tooling up, process development, design and prototype construction, may contain an appreciable element of R\&D, making it difficult to identify precisely what should or should not be defined as R\&D. This is particularly true for defence and large-scale industries such as aerospace. Similar difficulties may arise in distinguishing public technology-based services such as the inspection and control of food and drugs from related $R \& D$.

\section{Examples of what is or is not $R \& D$ in innovation processes}

2.48 Table 2.3, and the examples that follow, provide more information on what should and what should not be counted as R\&D.

\section{Prototypes}

2.49 A prototype is an original model constructed to include all the technical and performance characteristics of the new product. For example, if a pump for corrosive liquids is being developed, several prototypes are needed for accelerated life tests with different chemicals. A feedback loop exists so that if the prototype tests are not successful, the results can be used for further development of the pump.

2.50 The design, construction and testing of prototypes normally falls within the scope of $R \& D$. This applies whether only one or several prototypes are made and whether they are made consecutively or simultaneously. However, when any necessary modifications to the prototype(s) have been made and testing has been satisfactorily completed, the end-point of R\&D has been 
reached. The construction of several copies of a prototype to meet a temporary commercial, military or medical need after successful testing of the original, even if undertaken by R\&D staff, is not part of R\&D. The virtualisation of prototyping could follow the same rules, and it will be included in R\&D as far as the testing activity is part of an R\&D project and is aimed at collecting evidence essential for achieving the objectives of the project.

\section{Table 2.3. Borderline between R\&D, innovation and other business activities}

\begin{tabular}{|c|c|c|}
\hline Item & Treatment & Remarks \\
\hline Prototypes & Include in R\&D & $\begin{array}{l}\text { As long as the primary objective is to make } \\
\text { further improvements. }\end{array}$ \\
\hline Pilot plant & Include in $R \& D$ & As long as the primary purpose is $R \& D$. \\
\hline Industrial design & Split & $\begin{array}{l}\text { Include design required during R\&D. Exclude } \\
\text { design for production process. }\end{array}$ \\
\hline $\begin{array}{l}\text { Industrial engineering and } \\
\text { tooling up }\end{array}$ & Split & $\begin{array}{l}\text { Include "feedback" R\&D and tooling up } \\
\text { industrial engineering in innovation processes. } \\
\text { Exclude for production processes. }\end{array}$ \\
\hline Trial production & Split & $\begin{array}{l}\text { Include if production implies full-scale } \\
\text { testing and subsequent further design and } \\
\text { engineering. Exclude all other associated } \\
\text { activities. }\end{array}$ \\
\hline Pre-production development & Exclude & \\
\hline $\begin{array}{l}\text { After-sales service and trouble- } \\
\text { shooting }\end{array}$ & Exclude & Except "feedback" R\&D (to be included). \\
\hline Patent and licence work & Exclude & $\begin{array}{l}\text { All administrative and legal work needed to } \\
\text { apply for patents and licences (delivering } \\
\text { documentation as an outcome of } R \& D \\
\text { projects is } R \& D \text { ). However, patent work } \\
\text { connected directly with } R \& D \text { projects is } R \& D \text {. }\end{array}$ \\
\hline Routine tests & Exclude & Even if undertaken by $R \& D$ personnel. \\
\hline Data collection & Exclude & Except when an integral part of R\&D. \\
\hline $\begin{array}{l}\text { Routine compliance with public } \\
\text { inspection control, enforcement } \\
\text { of standards, regulations }\end{array}$ & Exclude & \\
\hline
\end{tabular}

\section{Pilot plants}

2.51 The construction and operation of a pilot plant is a part of R\&D as long as the principal purposes are to obtain experience and to compile engineering and other data to be used in:

- evaluating hypotheses

- writing new product formulas

- establishing new finished product specifications

- designing special equipment and structures required by a new process

- preparing operating instructions or manuals on the process. 
2.52 If, as soon as this experimental phase is over, a pilot plant switches to operating as a normal commercial production unit, the activity can no longer be considered R\&D even though it may still be described as a pilot plant. As long as the primary purpose in operating a pilot plant is non-commercial, it makes no difference in principle if part or all of the output is sold. Such receipts should not be deducted from the cost of R\&D activity (Chapter 4).

\section{Large-scale projects}

2.53 Large-scale projects (in areas like defence, aerospace or big science) usually cover a spectrum of activity from experimental to pre-production development. Under these circumstances, the funding and/or performing organisation often cannot distinguish between $R \& D$ and other elements of expenditure. The distinction between $R \& D$ and non-R\&D expenditure is particularly important in countries where a large proportion of government $R \& D$ expenditure is directed to defence.

2.54 It is important to look closely at the nature of costly pilot plants or prototypes, such as the first of a new line of nuclear power stations or of icebreakers. They may be constructed almost entirely from existing materials and use existing technology, and they are often built for simultaneous use for R\&D and for providing the primary service concerned (power generation, ice breaking). The construction of such plants and prototypes should not be wholly credited to R\&D. Only the additional costs due to the experimental nature of these products should be attributed to R\&D.

\section{Trial production}

2.55 After a prototype has been satisfactorily tested and any necessary modifications made, the manufacturing start-up phase may begin. This is related to full-scale production; it may consist of product or process modification or retraining personnel in the new techniques or in the use of new machinery. Unless the manufacturing start-up phase implies further design and engineering $R \& D$, it should not be counted as $R \& D$, since the primary objective is no longer to make further improvements to the products but to start the production process. The first units of a trial production run for a mass production series should not be considered as R\&D prototypes even if they are loosely described as such.

2.56 For example, if a new product is to be assembled by automatic welding, the process of optimising the settings on the welding equipment in order to achieve maximum production speed and efficiency would not count as R\&D.

\section{Trouble-shooting}

2.57 Trouble-shooting occasionally shows the need for further R\&D, but more frequently it involves the detection of faults in equipment or processes and results in minor modifications of standard equipment and processes. It should not, therefore, be included in R\&D. 


\section{"Feedback" R\&D}

2.58 After a new product or process has been turned over to production units, there will still be technical problems to be solved, some of which may demand further R\&D. Such "feedback" R\&D should be included.

\section{Tooling up and industrial engineering}

2.59 In most cases, the tooling up and industrial engineering phases of any project are considered to be part of the production process, and not of R\&D. Three phases of tooling up can be identified:

- the first-time use of components (including the use of components resulting from R\&D efforts)

- the initial tooling of equipment for mass production

- installing equipment linked with the start of mass production.

2.60 If the tooling up process results in further R\&D work, such as improvements in the production of machinery and tools or changes to the production and quality control procedures or the development of new methods and standards, these activities are classified as R\&D. "Feedback" R\&D resulting from the tooling up phase should be defined as R\&D.

\section{Clinical trials}

2.61 Before new drugs, vaccines, devices or treatments can be introduced onto the market, they must be tested systematically on human volunteers to ensure that they are both safe and effective. These clinical trials are divided into four standard phases, three of which take place before permission to manufacture is granted. For the purposes of international comparison, by convention, clinical trial phases 1, 2 and 3 can be treated as R\&D. Phase 4 clinical trials, which continue testing the drug or treatment after approval and manufacture, should only be treated as R\&D if they bring about a further scientific or technological advance. Moreover, not all activities undertaken prior to permission to manufacture are considered to be $R \& D$, especially when there is a significant wait after the completion of phase 3 trials, during which activities related to marketing and process development may be started.

\section{$R \& D$ and design}

2.62 Design and R\&D activities are difficult to separate. Some design activities are an integral part of $R \& D$ projects, and $R \& D$ can be an input to new design efforts. There are similarities and linkages. However, not all design meets the functional novelty and uncertainty tests as captured in this chapter's five core R\&D criteria. Design plays a key role in the development and implementation of innovations. As an agreed definition of design for statistical purposes does not yet exist, design can be described as a potential multi-faceted innovation activity aimed at planning and designing procedures, technical specifications and other user and functional characteristics for 
new products and processes. Among these activities are initial preparations for the planning of new products or processes, and work on their design and implementation, including adjustments and further changes. This description emphasises the creative role of design within an innovation process, a feature potentially shared with the R\&D performed in the same context. Some designrelated activities may be considered $R \& D$ to the extent that they play a role in a product development process, which is aiming at something "new" (but not necessarily at new knowledge), is creative and original, can be formalised (performed by a dedicated team), and leads to a codified output to be passed on to the development team. The main difference with R\&D is that no uncertainty is likely to be found when skilled designers are asked to contribute to an innovation project. This leads to a view that design is not R\&D and that it has to be kept distinct from R\&D for any statistical purpose.

2.63 While an R\&D project involves uncertainty about whether an expected outcome will be delivered within an agreed time schedule, a design project's uncertainty will be directly influenced by the clarity and the feasibility of its original goals. As an example, designing a standard building does not involve major uncertainty about the final outcome; yet the more challenging the concept of the building, the adding of new features, for example, the higher the uncertainty about the time and costs needed to complete the project. R\&D activity, complementing the use of existing design tools, may be required to address the uncertainty.

\section{R\&D and artistic creation}

2.64 Design sometimes tends to be characterised by the use of artistic methods. This is another potential area of overlap. In order to address the discussion of R\&D and artistic creation, it can be useful to make a distinction between research for the arts, research on the arts and artistic expression.

\section{Research for the arts}

2.65 Research for the arts consists in developing goods and services to meet the expressive needs of artists and performers. There are enterprises in this line of business that devote a significant part of their resources to R\&D in this area. For instance, they engage in experimental development to produce new electronic musical instruments to suit the needs of a group of performers. Other types of R\&D organisations (mainly universities and technical institutes) also play a role in exploring new technologies for performance art (to improve audio/ video quality, for instance). The activity aimed at supporting the introduction of new organisational or marketing methods by art institutions (advertising, financial management, etc.) may qualify as R\&D, but caution should be exercised in making this decision. This area of R\&D performance is already covered by existing data collection. 


\section{Research on the arts (studies about the artistic expression)}

2.66 Basic or applied research contributes to most of the studies of the arts (musicology, art history, theatre studies, media studies, literature, etc.). Public research institutions could have a role in selected research domains (as some relevant research infrastructures - like libraries, archives, etc. - are often attached to arts institutions, such as museums, theatres, etc.). As far as preservation and restoration activities are concerned (if not to be included in the group above), it is recommended to identify the providers of such technical services as R\&D performers (employing researchers, publishing scientific works, etc.). This area of $\mathrm{R} \& \mathrm{D}$ performance is largely covered by existing data collection.

\section{Artistic expression versus research}

2.67 Artistic performance is normally excluded from R\&D. Artistic performances fail the novelty test of $R \& D$ as they are looking for a new expression, rather than for new knowledge. Also, the reproducibility criterion (how to transfer the additional knowledge potentially produced) is not met. As a consequence, arts colleges and university arts departments cannot be assumed to perform R\&D without additional supporting evidence. The existence of artists attending courses in such institutions is not relevant to the R\&D measurement. Higher education institutions have, nevertheless, to be evaluated on a caseby-case basis if they grant a doctoral degree to an artist as a result of artistic performances. The recommendation is to adopt an "institutional" approach and only to take account of artistic practice recognised as R\&D by higher education institutions as potential R\&D (to be further used by data collectors).

\section{R\&D and software development}

2.68 Information technology has a pervasive role in almost every innovation activity, and largely relies on R\&D activities but also influences the ability of enterprises and institutions to perform R\&D effectively. Software development is an innovation-related activity that is sometimes connected with R\&D and incorporates, under specific conditions, some $R \& D$. For a software development project to be classified as $R \& D$, its completion must be dependent on a scientific and/or technological advance, and the aim of the project must be the systematic resolution of a scientific and/or technological uncertainty.

2.69 In addition to the software that is part of an overall R\&D project (to record and monitor its different stages, for instance), the R\&D associated with software as an end product or software embedded in an end product could also be classified as $R \& D$ when the $R \& D$ criteria apply.

2.70 The nature of software development is such that it is difficult to identify its R\&D component, if any. Software development is an integral part of many projects that in themselves have no element of R\&D. The software development component of such projects, however, may be classified as R\&D if it leads to an advance in the area of computer software. Such advances are 
generally incremental rather than revolutionary. Therefore, an upgrade, addition or change to an existing program or system may be classified as R\&D if it embodies scientific and/or technological advances that result in an increase in the stock of knowledge. The use of software for a new application or purpose does not by itself constitute an advance.

2.71 The following examples illustrate the concept of R\&D in software and should be included in R\&D:

- the development of new operating systems or languages

- the design and implementation of new search engines based on original technologies

- the effort to resolve conflicts within hardware or software based on the process of re-engineering a system or a network

- the creation of new or more efficient algorithms based on new techniques

- the creation of new and original encryption or security techniques.

2.72 Software-related activities of a routine nature are not to be considered R\&D. Such activities include work on system-specific or programspecific advances that were publicly available prior to the commencement of the work. Technical problems that have been overcome in previous projects on the same operating systems and computer architecture are also excluded. Routine computer and software maintenance are not included in R\&D.

Examples of other software-related activities to be excluded from R\&D are:

- the development of business application software and information systems using known methods and existing software tools

- adding user functionality to existing application programs (including basic data entry functionalities)

- the creation of websites or software using existing tools

- the use of standard methods of encryption, security verification and data integrity testing

- the customisation of a product for a particular use, unless during this process knowledge is added that significantly improves the base program

- routine debugging of existing systems and programs, unless this is done prior to the end of the experimental development process.

2.73 In the systems software area, individual projects may not be considered as R\&D, but their aggregation into a larger project could generate some technological uncertainty, the resolution of which will need R\&D. Alternatively, a large project can be aimed at developing a commercial product by adopting available technologies and not include R\&D in its planning, but there may be some elements in the project that would need some additional R\&D activity to assure the smooth integration of different technologies. 
2.74 Starting in the 1993 SNA (EC et al., 1994), total expenditure on software (including R\&D for software development) was regarded as capital investment. In the 2008 SNA (EC et al., 2009), total expenditure on R\&D is regarded as capital investment. According to the Handbook on deriving capital measures of intellectual property products (OECD, 2009), which further developed the 2008 SNA guidance on intangibles, capitalised software R\&D remained in software investment. It is important to be able to identify explicitly R\&D expenditure devoted to software to better inform both R\&D and SNA statisticians and users of the overlap between software and R\&D. This is discussed further in Chapter 4.

\section{R\&D and education and training}

2.75 Educational and training institutions below the tertiary level focus their resources on teaching and, as a result, have a very low likelihood of being involved in $R \& D$ projects. On the other hand, in higher education institutions research and teaching are always very closely linked, as most academic staff undertake both, and many buildings, as well as much equipment, serve both purposes.

2.76 Because the results of research feed into teaching, and because the information and experience gained in teaching can often result in an input to research, it is difficult to define where the education and training activities of higher education staff and their students end and R\&D activities begin, and vice versa. R\&D's elements of novelty distinguish it from routine teaching and other work-related activities. The adoption of the key R\&D criteria can be supplemented, in this sector, by a consideration of the institutional role played by some actors:

- doctoral students and master's students meeting specific conditions (Chapters 5 and 9)

- supervisors of students (included in the university staff)

- providers of specialised health care in university hospitals.

2.77 Since the research activity performed by doctoral students should be included in the overall R\&D performed by the Higher Education sector, both they and the university staff acting as their instructors or supervisors should be included in R\&D personnel totals (see Chapter 5). Of course, the time spent by the university staff to undertake tasks that are not related to research should be excluded from the estimation of the actual R\&D performance. This applies to all scientific disciplines.

2.78 Similarly, in university hospitals where the training of medical students is an important activity in addition to the primary activity of health care, the activities of teaching, R\&D and advanced, as well as routine, medical care are frequently closely linked. Personnel and students providing specialised health care in university hospitals, when they can be safely assumed to be part of an overall R\&D effort, should be included in R\&D personnel. Any routine activity undertaken to provide health care in the same context should be excluded from $R \& D$. 


\section{R\&D in service activities}

2.79 The 2008 SNA defines services as the result of a production activity that changes the conditions of the consuming units, or facilitates the exchange of products or financial assets. Among the former, service providers can affect changes in the condition of the consumer's goods, in the physical and mental conditions of persons (e.g. through health or transportation, as well as through the provision of information, education, etc.). The SNA also defines a separate hybrid product category that has features of both goods and services, namely "Knowledge-capturing products". These concern the provision, storage, communication and dissemination of information, advice and entertainment in such a way that the consuming unit can access the knowledge repeatedly. The industries that produce these products are those concerned with the provision, storage, communication and dissemination of information, advice and entertainment in the broadest sense of those terms (EC et al., 2009).

2.80 The provision of services entails a high degree of proximity and interaction with customers. In addition, industries that specialise in the production of goods may be actively involved in the delivery of services. Firms in the service industries may in turn control several aspects of goods production, including for example the experimental development of new goods that are part of their service delivery.

2.81 Defining the boundaries of R\&D in service activities is therefore difficult, for two main reasons: first, it is difficult to identify projects involving $R \& D$ that is specific to a service and not embedded in a good or knowledgecapturing product; and, second, the line between $R \& D$ and other innovation activities is not always clear.

2.82 Among the many projects in services, those that constitute $R \& D$ result in new knowledge or the use of knowledge to devise new applications, in keeping with the definition of R\&D.

2.83 Identifying R\&D is more difficult in service activities than in goodsproducing industries because the $R \& D$ is not necessarily specialised in a field of research, although there may be specialisation reflecting the market served. R\&D covers several areas: technology-related $R \& D$, and $R \& D$ in the social sciences, humanities and arts, including R\&D relating to the knowledge of behaviour and organisations. This last notion is already included in the criterion "knowledge of humankind, culture and society", but it is particularly important in the case of service activities. Because these forms of R\&D may be combined in a project, it is important to define clearly the various forms of R\&D involved. If the analysis is confined to technology-related $R \& D$, for example, $R \& D$ may be understated. In many cases, R\&D findings in service industries may be part of service delivery activities. 
2.84 Also, in service companies, R\&D is not always organised as formally as in goods-producing companies (i.e. with a dedicated R\&D department, researchers or research engineers identified as such in the establishment's personnel list, etc.). The concept of R\&D in services is still less specific and sometimes goes unrecognised by the enterprises involved. As more experience becomes available on the collection of R\&D data in services, the criteria for identifying $R \& D$ and examples of service-related $R \& D$ may require further development.

\section{Criteria for identifying $R \& D$ in services}

2.85 In addition to the five core criteria, the following are indicators that may help to identify the presence of R\&D in service activities:

- links with public research laboratories

- the involvement of staff with doctoral degrees or doctoral students

- the publication of research findings in scientific journals, the organisation of scientific conferences or involvement in scientific reviews.

\section{Examples of R\&D in selected service activities}

2.86 The R\&D activities listed below may serve as examples of R\&D in service activities. The general and supplementary criteria for distinguishing $R \& D$ presented in Section 2.4 also have to be taken into account.

2.87 The general boundaries of $R \& D$ as defined above largely apply to service activities. The element of novelty is a basic criterion for distinguishing R\&D from related activities.

\section{Examples of R\&D in banking and insurance}

- mathematical research relating to financial risk analysis

- the development of risk models for credit policy

- the experimental development of new software for home banking

- the development of techniques for investigating consumer behaviour for the purpose of creating new types of accounts and banking services

- research to identity new risks or new characteristics of risk that need to be taken into consideration in insurance contracts

- research on social phenomena with an impact on new types of insurance (health, retirement, etc.), such as on insurance cover for non-smokers

- R\&D related to electronic banking and insurance, Internet-related services and e-commerce applications

- R\&D related to new or significantly improved financial services (new concepts for accounts, loans, insurance and saving instruments). 


\section{Examples of R\&D in some other service activities}

- analysis of the effects of economic and social change on consumption and leisure activities

- the development of new methods for measuring consumer expectations and preferences

- the development of new methods to deliver and measure social service outcomes that can be adapted in a variety of different socioeconomic or cultural settings

- the development of new survey methods and instruments

- the development of tracking and tracing procedures (logistics)

- research into new travel and holiday concepts.

\section{$R \& D$ and related scientific and technological activities}

2.88 Difficulties in separating R\&D from other scientific and technological activities (STA) arise when several activities are performed in the same institution. In data collection practices, criteria are usually applied on the basis of a direct knowledge of the performing institutions. As general guidelines:

- Institutions or units of institutions and firms whose principal activity is $R \& D$ often have secondary, non-R\&D activities (e.g. scientific and technical information, testing, quality control, analysis). Insofar as a secondary activity is undertaken primarily in the interests of $R \& D$, it should be included in $R \& D$; if the secondary activity is designed essentially to meet needs other than $R \& D$, it should be excluded.

- Institutions whose main purpose is an R\&D-related scientific activity often undertake some research in connection with this activity. Such research should be isolated and included when measuring R\&D.

2.89 In some sectors, the key criteria for distinguishing between R\&D and related scientific and technological activities are particularly difficult to apply. General-purpose data collection, testing and standardisation, big data projects, space exploration, and mineral exploration and evaluation are all areas involving large amounts of resources, and any variations in their treatment will have important effects on the international comparability of the resulting R\&D data. Large-scale projects also pose problems for the identification of their R\&D. As this edition is being finalised, UNESCO is updating its definitions of STA for statistical purposes (UNESCO, 1978; UNESCO, 1984), and the outcome of that process is expected to provide further guidance on the boundaries between $R \& D$ and other STA activities. Such guidance will be made available in due course as part of the online annex material to this manual.

\section{General-purpose data collection and documentation}

2.90 General-purpose data collection is undertaken generally by government agencies to record natural, biological or social phenomena that are of general public 
interest or that only the government has the resources to record. Examples are routine topographical mapping; routine geological, hydrological, oceanographic and meteorological surveying; and astronomical observations. Data collected solely or primarily as part of the $R \& D$ process are included in $R \& D$ (e.g. data collected by a detector that is part of an elementary particle scattering experiment at CERN). The same reasoning applies to the processing and interpretation of the data. The social sciences, in particular, are very dependent on an accurate record of facts relating to society in the form of censuses, sample surveys, etc. When these are specially collected or processed for the purpose of scientific research, the cost should be attributed to research and should cover the planning and systematising of the data. R\&D can also be identified when a specific project is aimed at developing totally new statistical methods (e.g. conceptual and methodological work in relation to the development of completely new or substantially modified surveys and statistical systems, work on sampling methodologies, small area statistical estimates and advanced data-capturing techniques) or data collection methodologies and techniques. However, data collected for other or general purposes, such as quarterly sampling of unemployment, should be excluded from R\&D even if exploited for research (unless the researcher had to pay for the right to use such data in the research). Market surveys should also be excluded.

2.91 The activities of a scientific and technical information service or of a research laboratory library that is maintained predominantly for the benefit of the research workers in the laboratory should be included in R\&D. The activities of a firm's documentation centre open to all the firm's staff should be excluded from $R \& D$ even if it shares the same premises as the business research unit (the need to avoid an over-evaluation of R\&D-related activities applies here). Similarly, the activities of central university libraries should be excluded from R\&D. These criteria, which will have to be applied also to electronic libraries and data repositories, apply only when it is necessary to deal with the activities of an institution or a department in their entirety. Where more detailed accounting methods are used, it may be possible to impute part of the costs of the excluded activities to R\&D overheads. Whereas the preparation of scientific and technical publications is, generally speaking, excluded, the preparation of the original report of research findings should be included in R\&D.

\section{Testing and standardisation}

2.92 Public bodies and consumer organisations often operate laboratories that are intended mainly to test products and verify that standards are met. In addition to standard testing and benchmarking activities - which are not R\&D the staff of these laboratories may also spend time devising new or substantially improved testing methods. Such activities should be included in R\&D.

\section{Big data projects}

2.93 The advent of new instruments and methods of data-intensive exploration is facilitating the process of data-intensive scientific discovery 
and data-driven innovation. These activities are R\&D if and only if they meet the five core criteria, in particular the general requirement that the activity or project should be undertaken in a systematic way - i.e. by clearly identifying the original knowledge gap and focusing specific resources on addressing it. An example is the "Human Genome Project", which attracted researchers and institutions from 18 countries to co-operate in a 13-year-long research effort to sequence and map out the human DNA code. Through digitisation, the R\&D codification criterion plays a major part in big data projects, as the usability of the data arising from "big data" science projects depends on its ability to convey knowledge about specific phenomena for which the data have been gathered. These data may or may not be made widely accessible or usable for research purposes. The concept of open science commonly refers to efforts to make the output of publicly funded research more widely accessible in digital format to the scientific community, the business sector or society more generally (OECD, 2015). In some cases, efforts to make research data openly accessible to the broad scientific community, including developing specific tools that facilitate the reproducibility of the research, will be an integral part of an R\&D project, provided that they are explicitly formulated as such within the R\&D project's objectives and are budgeted. In other cases, these should be treated as separate dissemination efforts and not counted as R\&D.

\section{Space exploration}

2.94 A difficulty with space exploration is that, in some respects, much space activity may now be considered routine; certainly, most costs are incurred for the purchase of goods and services that are not R\&D. It may be necessary to separate the activities associated with space exploration, including the development of vehicles, equipment, software and techniques, from those involved in the routine placing of orbiting satellites or the establishment of tracking and communication stations.

\section{Mineral exploration and evaluation}

2.95 Mineral exploration and evaluation is defined in the 2008 SNA as a category of activity leading to the creation of an intellectual property asset, separate from R\&D (EC et al., 2009; OECD, 2009). The activity of mineral exploration and evaluation adds to the knowledge of subsoil deposits in specific locations for the purpose of their economic exploitation. It includes the acquisition of exploration rights as well as topographical, geological, geochemical and geophysical studies, and trenching, sampling and evaluation activities.

2.96 This manual also makes a strict separation between $R \& D$ and mineral exploration. However, some links with R\&D can be found. For example, a number of geological tests undertaken in the context of $R \& D$ projects can provide initial evidence for exploration and mining companies to follow up with exploitationdriven exploration efforts, which are not $R \& D$. $R \& D$ may also be required to 
develop new test and drilling techniques that the mining industry can draw on for its exploration and routine activities. Mining and prospecting sometimes cause problems owing to a linguistic confusion between research for new or substantially improved resources (food, energy, etc.) and the search for existing reserves of natural resources, a confusion that blurs the distinction between $R \& D$ and surveying and prospecting. In theory, in order to establish accurate R\&D data, the following activities should be identified, measured and summed:

- the development of new surveying methods and techniques

- surveying undertaken as an integral part of a research project on geological phenomena

- research on geological phenomena, undertaken as a subsidiary part of surveying and prospecting programmes.

2.97 In practice, the last of these presents a number of problems. It is difficult to frame a precise definition that would be meaningful to respondents to national surveys. For this reason, only the following activities should be included in R\&D:

- the development of new or substantially improved methods and equipment for data acquisition and for the processing and study of the data collected and for the interpretation of these data

- surveying undertaken as an integral part of an R\&D project on geological phenomena, including data acquisition, processing and interpretation undertaken for primarily scientific purposes.

2.98 It follows that the surveying and prospecting activities of commercial companies will be almost entirely excluded from R\&D. For example, the sinking of exploratory wells to evaluate technological services is not R\&D.

\section{R\&D and the management of science and technology (S\&T) activities}

\section{Technology readiness levels}

2.99 The classification of large R\&D projects is discussed in Chapter 8, with an emphasis on the defence and aerospace industries. In some jurisdictions, classifications of the technology readiness level (TRL) are used in procurement and in the description of projects. As there are a number of such classifications, the recommendation is that, if there is one in use in the jurisdiction of interest, it can be assessed to determine whether it could make a contribution to improving the collection of R\&D statistics.

\section{Demonstration projects}

2.100 Two concepts of demonstration have already been adopted in R\&D statistics: "user demonstration", which takes place when a prototype is operated at or near full scale in a realistic environment to aid the formulation of policy or the promotion of its use, which is not R\&D; and "technical demonstration" 
(including the development of "demonstration projects" and "demonstration models") which, because it is an integral part of an R\&D project, is an R\&D activity.

2.101 With reference to its broad use in the management of large research projects, "technology demonstration" is seen as a step in the process of evaluating, ex-ante or ex-post, the implementation of new technologies. This meaning was originally adopted in the information and communication sector and has evolved to mean the activity carried out to show to potential investors and customers the expected potentiality of a technology under development. In this respect, the use of this concept is not recommended in association with the $R \& D$ concept, unless a clear role of a demonstration activity in an R\&D project can be identified.

\section{R\&D in the social sciences, humanities and the arts}

2.102 In the definition of R\&D in this manual, the phrase "knowledge of humankind, culture and society" includes the social sciences, humanities and the arts. Also for the social sciences, humanities and arts, the use of clear criteria to identify R\&D, such as having an appreciable element of novelty and dealing with uncertainty, is extremely helpful for defining the boundary between R\&D and related (routine) scientific activities as well as non-scientific investigations. The conceptual, methodological and empirical components of the project concerned have to be taken into consideration to identify an R\&D activity.

2.103 In the social sciences - e.g. sociology, economics or political sciencedata collection activities, e.g. statistical surveys on specific populations, can only be included in R\&D if they are undertaken as an integral part of a specific research project or for the benefit of a specific research project. Therefore, projects of a routine nature, in which social scientists bring established social science methodologies, principles and models to bear on a particular problem, cannot be classified as research. For example, a project using labour force survey data to identify long-term unemployment trends should exclude the data collection activity as an R\&D component (as those data are regularly collected by using an existing methodology). On the other hand, a casestudy on unemployment in a specific region, if applying original techniques in interviewing survey respondents could include such data collection in its R\&D effort. From a broader perspective, to the extent that the social sciences are using empirical data, the same guidelines have to be applied as for the natural sciences (although excluding the testing of their results on an experimental basis).

2.104 For the humanities, the same approach could be used as for the arts (studies on literature, music, visual arts, theatre, dance and other performing arts). Their historical or comparative nature can be pointed out as well as the relevant role played by universities or other specialised institutions in developing scientific guidelines to be followed by the scholars in the field. 
2.105 The broad range of sources used in history, archaeology, languages and legal studies and the different methods used by researchers are possible areas of $R \& D$. The adoption of the five core criteria for $R \& D$ should be recommended, mainly with reference to novelty, creativity and transferability and/or reproducibility.

2.106 In the fields of philosophy and religious studies, for instance, historical and comparative studies undertaken in line with current academic standards are included in R\&D. As a general rule cannot be given, beyond that of strictly applying the R\&D criteria, the use of the institutional approach is also recommended (i.e. potentially excluding research-related activities on philosophy and religion conducted outside recognised research institutions).

2.107 In conclusion, research in the humanities and the arts can be included in R\&D in so far as their own internal requirements for identifying the "scientific" nature of such research are met. Additional practical guidelines follow.

- Context of performance (institutional criterion). Research carried out within the framework of a university or an officially recognised research institution (including museums, libraries, etc.) can be included in R\&D.

- Adoption of recognised procedures. Research requires formalisation, and this applies to the humanities. Research activities could be identified and their results made available to the scientific community through their publication in scientific journals. In so far as these features can be identified and a scientific community is actively developing some rules to identify its own members, the same rules can be applied for identifying R\&D performance.

- Research in the humanities may deal with the systematic development of theories or interpretations of texts, events, material remains or any other available evidence. By convention, research activities carried out outside the fields of R\&D listed in Chapter 3 have to be excluded from R\&D.

\section{$R \& D$ and traditional knowledge}

2.108 A cross-cutting research domain with some overlap with the humanities and medicine is that dealing with "traditional knowledge". Traditional knowledge has been defined to be a largely tacit "cumulative body of knowledge, know-how, practices and representations maintained and developed by peoples with extended histories of interaction with the natural environment [...] a cultural complex that encompasses language, naming and classification systems, resource use practices, ritual, spirituality and worldview" (ICSU and UNESCO, 2002: 9). The issue of the relationship between traditional knowledge and $R \& D$ is particularly relevant in developing countries where the existence of a valuable stock of traditional knowledge can be a powerful incentive for domestic and foreign organisations to set up R\&D activities.

2.109 As a general rule, where activities associated with traditional knowledge form part of an R\&D project, the effort (financial and in terms of human resources) should be counted as R\&D. Otherwise they should be excluded. 
Examples of different types of activities involving traditional knowledge that should be counted as contributing to R\&D are as follows:

- An R\&D project may entail a scientific-based approach to establishing the content of traditional knowledge, in disciplines such as ethno-science (ethnobotany, ethno-pedology, ethno-forestry, ethno-veterinary medicine, and ethno-ecology) or cognitive anthropology. In this case, R\&D methods within established disciplines are used to study traditional knowledge.

- The application of scientific methods to identify the active ingredient of local health remedies and/or their effectiveness for certain medical conditions. In this case, R\&D methods are applied directly to traditional knowledge products with the purpose of expanding the stock of scientific knowledge.

- Activities undertaken by traditional knowledge practitioners to expand the stock of traditional knowledge, through the combined use of traditional and other, scientific methods. These activities must meet the standard criteria for being countable as $R \& D$ or must be carried out in universities.

2.110 Examples of traditional knowledge activities that would be excluded from R\&D include the following:

- the regular/continued use of traditional knowledge by practitioners, for example, in treating ailments or managing crops

- the routine development of products based on traditional knowledge

- the storage and communication of traditional knowledge in traditional ways (by the test of novelty)

- the traditional handing down of religious or cultural beliefs and practices.

\subsection{Activities to be excluded from R\&D}

2.111 For survey purposes, R\&D must be distinguished from a wide range of related activities with a scientific and technological basis. These other activities are very closely linked to $R \& D$ both through flows of information and in terms of operations, institutions and personnel, but as far as possible they should be excluded when measuring R\&D.

\section{Scientific and technical information services}

2.112 The specialised activities of:

- collecting

- coding

- recording

- classifying

- disseminating

- translating 
- analysing

- evaluating

by:

- scientific and technical personnel

- bibliographic services

- patent services

- scientific and technical information, extension and advisory services

- scientific conferences

are to be excluded, except when conducted solely or primarily for the purpose of $R \& D$ support (e.g. the preparation of the original report of $R \& D$ findings should be included in R\&D) or in the context of R\&D projects, as defined earlier in this section.

\section{Testing and standardisation}

2.113 This concerns the maintenance of national standards, the calibration of secondary standards and the routine testing and analysis of materials, components, products, processes, soils, atmosphere, etc. These activities are not R\&D.

\section{Feasibility studies}

2.114 The investigation of proposed engineering projects, using existing techniques to provide additional information before deciding on implementation, is not R\&D. In the social sciences, feasibility studies are investigations of the socio-economic characteristics and implications of specific situations (e.g. a study of the viability of a petrochemical complex in a certain region). However, feasibility studies on research projects are part of R\&D.

\section{Specialised health care}

2.115 This concerns the routine investigation and normal application of specialised medical knowledge. Usually this is not R\&D; there may, however, be an element of R\&D in what is usually called "specialised health care", when it is carried out, for example, in university hospitals.

\section{Policy-related studies}

2.116 In this context, "policy" refers not only to national policy but also to policy at regional and local levels, as well as the policy of business enterprises in the pursuit of their economic activity. Policy-related studies cover a range of activities, such as the analysis and assessment of the existing programmes, policies and operations of government departments and other institutions; the work of units concerned with the continuing analysis and monitoring of external 
phenomena (e.g. defence and security analysis); and the work of legislative commissions of inquiry concerned with general government or departmental policy or operations.

2.117 Any activity aimed at providing close support to policy actions, as well as to legislative activity, should be excluded from R\&D. This includes policy advice and relations with the media, legal advice, public relations or even technical support for the administrative activity (e.g. accounting).

2.118 It has to be pointed out that, on the other hand, research activities aimed at providing the decision makers with a thorough knowledge of social, economic or natural phenomena have to be included in R\&D. These R\&D activities are usually performed by skilled personnel - researchers - in small teams of experts and consultants and meet the standard academic criteria for scientific work (in addition to the R\&D criteria).

\section{Programmatic evaluations}

2.119 R\&D efforts may underpin the decision-making process within government and other institutions. While these efforts may be outsourced to external organisations, some institutions may have dedicated teams actively involved in carrying out analyses such as ex-ante and ex-post appraisals or evaluations, on an ad hoc or even formalised basis. These activities may in some cases meet the criteria for an R\&D project. However, this is not always the case, and not all intelligence or evidence-building efforts associated with policy or programmatic advice can be correctly described as R\&D. It is relevant to consider in some detail the expertise of those involved in the activity, how knowledge is codified within the organisation, and how quality standards are assured with regard to the research questions and the methodology applied. There is a significant risk that some types of socio-economic consultancy (internal or external) are inaccurately presented as R\&D.

2.120 Scientific advisors play an important role within government. However, the application of established decision-making criteria to policy making does not represent R\&D. Efforts aimed at developing improved methodologies for science-based decision making can be considered as R\&D.

\section{Purely R\&D-financing activities}

2.121 The raising, management and distribution of $R \& D$ grants to performers by ministries, research agencies, foundations or charities is not R\&D.

\section{Indirect supporting activities}

2.122 This covers a number of activities that are not R\&D but which provide support for $R \& D$. By convention, $R \& D$ personnel data cover $R \& D$ proper but exclude indirect supporting activities, whereas an allowance for these is included under overheads in the R\&D expenditure of performers. Typical examples are transportation, storage, cleaning, repair, maintenance and security 
activities. Administration and clerical activities undertaken not exclusively for $R \& D$, such as the activities of central finance and personnel departments, also come under this heading.

\section{References}

EC, IMF, OECD, UN and the World Bank (2009), System of National Accounts, United Nations, New York. https://unstats.un.org/unsd/nationalaccount/docs/sna2008.pdf.

EC, IMF, OECD, UN and the World Bank (1994), System of National Accounts, United Nations, New York. http://unstats.un.org/unsd/nationalaccount/docs/1993sna.pdf.

ICSU and UNESCO (2002), Science, traditional knowledge and sustainable development, ICSU Series on Science for Sustainable Development, No. 4, UNESCO, Paris. http://unesdoc. unesco.org/images/0015/001505/150501eo.pdf.

OECD (2015), Making Open Science a Reality, OECD Publishing, Paris.

OECD (2009), Handbook on Deriving Capital Measures of Intellectual Property Products, OECD Publishing, Paris. DOI: http://dx.doi.org/10.1787/9789264079205-en.

OECD/Eurostat (2005), Oslo Manual: Guidelines for Collecting and Interpreting Innovation Data, $3^{\text {rd }}$ edition, The Measurement of Scientific and Technological Activities, OECD Publishing, Paris. DOI: $h t t p: / / d x . d o i . o r g / 10.1787 / 9789264013100-e n$.

UNESCO (1984), Guide to Statistics on Science and Technology, Division of Science and Technology - Office of Statistics, ST/84/WS/19, UNESCO, Paris. www.uis.unesco.org/ Library/Documents/STSManual84_en.pdf.

UNESCO (1978), Recommendation concerning the International Standardization of Statistics on Science and Technology, UNESCO, Paris. http://portal.unesco.org/en/eu.php-URL_

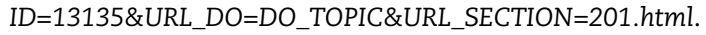

UNESCO-UIS (2014), ISCED Fields of Education and Training 2013 (ISCED-F 2013), UNESCO, Paris. www.uis.unesco.org/Education/Documents/isced-fields-of-education-training-2013.pdf. 



\section{Chapter 3}

\section{Institutional sectors and classifications for R\&D statistics}

This chapter considers institutions that perform or fund research and experimental development (R\&D) and identifies their shared characteristics. These characteristics are used to group institutions into sectors, which are then used for the presentation of statistics on $R \& D$. The chapter draws upon the approach of the System of National Accounts (SNA) to identify five sectors, Business enterprise, Higher education, Government, Private non-profit, and, for funding purposes only, the Rest of the World, (formerly referred to as Abroad). While four of the sectors can be related to those of the SNA, the Higher education sector, because of its policy relevance, is unique to this manual and is made up of institutions that can be in any of the SNA sectors. While there are chapters in the manual devoted to each sector, this chapter discusses the features of each sector and the boundaries that separate them. 


\subsection{Introduction}

3.1 The aim of this chapter is to explain the approach used in R\&D statistics to characterise and classify R\&D performing and funding institutions. Statistical units should be classified into sectors according to shared qualities or attributes. This chapter begins by describing what these units are, the purposes, including user needs, served by classification and the main criteria that are applied. The chapter then proceeds by introducing the institutional sectors that provide the basis for the common reporting of R\&D statistics and the boundaries that separate these sectors. This chapter is completed by the presentation of generally applicable classifications for institutional units and by a summary description of the main features for each sector.

3.2 A more detailed presentation of the definitions of units within the sectors and the classifications to be applied within them is the subject of chapters dedicated to each sector: Business enterprise (Chapter 7); Government (Chapter 8); Higher education (Chapter 9); Private non-profit (Chapter 10); and Rest of the world (Chapter 11 on R\&D globalisation).

3.3 This chapter draws upon the approach of the System of National Accounts (SNA) to institutional units and sectors in the SNA 2008 Manual (EC et al., 2009), especially Chapter 4 of that manual. Important terms are defined in the SNA 2008 Manual or in the Glossary. A summary overview is given in Box 3.2 of this chapter.

\subsection{Institutional units}

3.4 The definition of institutional units that are involved in the performing or funding of $R \& D$ activity is of fundamental importance to the collection, reporting and interpretation of R\&D statistics. Units are grouped to make up the sectors and subsectors of the Frascati Manual. They have to be characterised by a sufficient degree of internal cohesion and be distinctive and separately identifiable from other units.

3.5 An institutional unit is a national accounting concept and is defined as "an economic entity that is capable, in its own right, of owning assets, incurring liabilities, and engaging in economic activities and transactions with other entities" (EC et al., 2009: 61, para 4.2). This concept can be applied to the measurement of R\&D activities and R\&D-related flows. In the R\&D case, institutional units have to be capable of decision making in respect of the conduct of $R \& D$, from the allocation of financial resources for internal or external use, to the management of $R \& D$ projects. These are weaker requirements than those 
used to define an institutional unit in the National Accounts, but they serve for the purposes of this manual.

3.6 There are two main types of units that may qualify as institutional units, namely persons or groups of persons in the form of households, and legal or social entities. Legal entities are economic entities, the existence of which is recognised by law or society independently of the persons, or other entities, that may own or control them. Such units are responsible and accountable for the economic decisions or actions that they take, although their autonomy may be constrained to some extent by other institutional units; for example, shareholders (EC et al., 2009: 61, para 4.6). For reasons that have been explained in Chapter 2 on definitions and in Chapter 10, and which will be further discussed in this chapter, households are included as units in the framework for R\&D statistics, mainly for completeness.

\section{The institutional approach to R\&D statistics}

3.7 In principle, the statistical unit has to be uniform, within sectors, for all countries. In practice, however, this goal is never fully achieved, including because of international differences in terminology and regulations for the organisation and financial reporting of businesses and other types of units. In addition to this, the particular structure of the industries involved and the interaction with the reporting unit can lead to differences within and across countries and over time.

3.8 The institutional approach to R\&D statistics is aimed at the collection and presentation of statistics based on the generic attributes of the institutional units. In the institutional sector approach, a given unit's resources dedicated to R\&D are attributed to the sector into which it is classified, while flows relate to transactions between the statistical unit and third parties. In the functional distribution approach, a given unit's resources are distributed using information provided by the relevant reporting unit(s). Examples of functional distributions are the type of $R \& D$ (basic research, applied research and experimental development), the product field (or industry served), the field of R\&D (e.g. natural sciences, engineering and technology, social sciences and humanities and arts) and the socio-economic objective (e.g. economic development, health, environment, education). Institutional and functional approaches can often be combined, for example, when only large organisations are requested to break down their activities on a functional basis that may or may not match their own internal structure, while for burden reasons no such breakdown may be requested from smaller and simpler units, thus relying in such cases on the institutional classification. Functional distribution approaches can be used to address the potential mismatch between reporting units and intended statistical units when the reporting units encompass the statistical units of interest.

3.9 Whenever countries provide statistics for international comparisons, the statistical units should be specified as well as the use, alone or combined, of institutional and functional approaches. More detailed guidance is provided in Chapter 6 on methodology and in Chapters 7-10 which deal with specific sectors. 


\section{Statistical units}

3.10 A statistical unit is an entity about which information is sought and for which statistics are ultimately compiled; in other words, it is the institutional unit of interest for the intended purpose of collecting R\&D statistics. A statistical unit may be an observation unit for which information is received and statistics are compiled or an analytical unit, which is created by splitting or combining observation units with the help of estimations or imputations in order to supply more detailed and/or homogeneous data than would otherwise be possible (United Nations, 2007).

3.11 The need to delineate statistical units arises in the case of large and complex economic entities where the activities in which the entities engage fall into different classes, or the units of which they are composed are located in different geographical areas. There are various types or levels of statistical units according to their ownership, the control linkages, the homogeneity of economic activity, and their location, namely enterprise groups, enterprises, establishments and "kind-of-activity" units (KAUs), as described in Box 3.1. These concepts apply to statistical units in all sectors, and not only to what this manual defines as the Business enterprise sector. The choice of statistical unit and the methodology used are strongly influenced by the purposes of R\&D statistics as well as by the existence of records and the ability of respondents to provide the information of interest. In large and complex organisations, decisions concerning the strategic direction and financing of R\&D activities units tend to occur at a higher organisational level than does the day-to-day management of R\&D operations, possibly including decisions on the types of expenditures on $R \& D$ performance and the hiring of human resources to be devoted to R\&D. These decisions can cut across national borders, thus raising a challenge for the statistical activities of national authorities and agencies, whose responsibility is often limited to gathering information from resident units.

\section{Reporting units}

3.12 A reporting unit is the entity from which the required statistics are collected. It may consist of multiple reporting units in the institution where survey questionnaires are completed. In the case of administrative data, the reporting unit would correspond to the unit that is represented by the individual record. The choice of reporting units will vary from sector to sector and from country to country, depending on institutional structures, the legal framework for data collection, traditions, national priorities and survey resources. If the required statistics are obtained from a survey, the reporting unit is the respondent. In some countries, data may be collected from R\&D units; in others, it may be gathered at a more aggregate level. This manual can make no overarching recommendation concerning the reporting unit to be applied by each individual country. 


\section{Box 3.1. Types of statistical units}

An enterprise is the view (EC et al., 2009, para. 5.1) of any institutional unit - not necessarily within what this manual defines as the Business enterprise sector - as a producer of goods and services. The term enterprise may refer to a corporation, a quasi-corporation, a non-profit institution or an unincorporated enterprise. An enterprise is an economic transactor with autonomy in respect of financial and investment decision-making, as well as authority and responsibility for allocating resources for the production of goods and services. It may be engaged in one or more economic activities at one or more locations. An enterprise may be a sole legal unit.

A kind-of-activity unit (KAU) is an enterprise, or a part of an enterprise, that engages in only one kind of productive activity or in which the principal productive activity accounts for most of the value added. Each enterprise must, by definition, consist of one or more kind-of-activity units.

Enterprises often engage in productive activity at more than one location, and for some purposes it may be useful to partition them accordingly. Thus, a local unit is an enterprise, or a part of an enterprise, that engages in productive activity at or from a single location.

An establishment is an enterprise, or part of an enterprise, that is situated in a single location and in which only a single productive activity is carried out or in which the principal productive activity accounts for most of the value added. Establishments are sometimes referred to as local kind-of activity units (local KAUs).

An enterprise group is a set of enterprises controlled by the group head. The group head is a parent legal unit that is not controlled either directly or indirectly by any other legal unit. It can have more than one decisionmaking centre, especially for policies on production, sales and profits, or it may centralise certain aspects of financial management and taxation. It constitutes an economic entity that is empowered to make choices, particularly concerning the units which it comprises. The enterprise group as a unit is particularly useful for financial analyses and for studying company strategies; however, it can be too varied in nature and unstable to be adopted as a unit for statistical surveys and analysis.

Source: OECD, based on EC et al. (2009) and United Nations (2007).

\subsection{Institutional sectors}

\section{Main reasons for sectoring}

3.13 To facilitate the collection and production of internationally comparable statistics on R\&D personnel and R\&D expenditures and funding flows, which are described later in this manual, the statistical unit(s) should be classified into sectors according to shared qualities or attributes. The recommendation 
is to follow as closely as possible standard statistical classifications for these units while meeting the stated needs of established users of R\&D statistics. The classification to sectors of statistical units in the context of R\&D statistics can serve a range of purposes.

\section{R\&D data collection}

3.14 Sectoring plays an important role in organising data collections, for example, by indicating which survey instrument to apply to institutional units with a certain set of common features, for example, concerning the type and field of $R \& D$ carried out, the underlying accounting systems or the terminology used by these units to describe their R\&D activities. Sectoring also plays an important role in defining strata and in supporting data collection and estimation efforts. In particular:

- When measuring R\&D expenditure (Chapter 4) and personnel (Chapter 5), the sectoral approach offers a reliable approach for building up national aggregates.

- Sectoring offers a framework for analysing the flows of funds between R\&D-funding and R\&D-performing entities (Chapter 4). In this context, classifications should be relatively easy to interpret from the perspective of the survey respondents, for otherwise the flows from and to other units could be misreported.

\section{Interacting with and mapping to other statistical frameworks and data sources}

3.15 Insofar as units are tagged using standard classifications, it may be possible to relate $R \& D$ sources to other statistical sources. This may facilitate:

- the development of unit registers for R\&D collection efforts, by drawing on the sources available and on prior classification efforts undertaken in the context of other statistical frameworks

- the adaptation of R\&D statistics to and their subsequent use within other frameworks, such as the System of National Accounts (SNA), which draws on R\&D statistics to compile sectoral and national estimates of R\&D output and capital formation, feeding into major economic indicators

- an improved understanding of the role of R\&D in economic development and the formulation of related policy, by allowing for the linking of the data and the study of their relationships.

\section{Reporting R\&D statistics, on a national and international basis}

3.16 A standardised sectoring approach provides a basis for the stable and readily comparable public reporting of $\mathrm{R} \& D$ statistics, in particular to meet the needs of policy makers and other major users. For this reason, the recommendation is the use of a set of main institutional sectors for R\&D statistics. 
3.17 Aggregation into sectors also helps avoid the problem posed by the often confidential nature of R\&D data collected under statistical secrecy rules. Confidentiality rules and data quality issues place limits on the number of different, overlapping classifications that can be published by the statistical agencies compiling R\&D statistics. When unit-level data can be publicly released, sectoring provides a helpful organising and filtering tool for users seeking to retrieve specific information on individual actors.

3.18 It is acknowledged that a single classification scheme may not be sufficient on its own to accomplish each one of these multiple purposes or to meet the varied and increasing range of user interests in R\&D statistics. This manual proposes an institutional classification that attempts to strike a reasonable balance across all these, complemented by a range of optional crosscutting classifications to ensure that a wide range of user needs can be met.

\section{Criteria for the classification and choice of institutional sectors for $R \& D$ statistics}

3.19 For the general presentation of R\&D statistics, the domestic economy is made up of the entire set of institutional units resident in the economy; these are grouped into four mutually exclusive institutional sectors, namely, Business enterprise, Higher education, Government and Private non-profit, in addition to the Rest of the world sector, in order to capture, for completeness, the relationship with non-resident units. The underlying criterion for grouping institutional units into sectors is the homogeneity of the units in respect of economic objectives, principal functions and behaviour.

3.20 The classification of institutional units for R\&D purposes aims to ensure full consistency with the definition of R\&D and with the explicit needs of established R\&D statistics users, as well as with the classification criteria used by the System of National Accounts (SNA). The latter includes the completeness and residence criteria and the reference to the type of economic activity and ownership and economic control. Funding may also be a factor.

3.21 As defined in the SNA, the residence of each institutional unit is the economic territory with which it has the strongest connection, in other words, its centre of predominant economic interest. The economic territory includes the land area, airspace and territorial waters, including jurisdiction over fishing rights and rights to fuels or minerals. In a maritime territory, the economic territory includes islands that belong to the territory. The economic territory also includes territorial enclaves in the Rest of the world. These are clearly demarcated land areas (such as embassies, consulates, military bases and scientific stations) located in other territories and used by governments that own or rent them for diplomatic, military, scientific or other purposes with the formal agreement of the governments of the territories where the land areas are physically located (EC et al., 2009: 62, para. 4.11). The residence criterion helps demarcate the "Rest of the world" sector from the other institutional sectors. 
3.22 For R\&D statistics, an institutional unit has a centre of predominant economic interest in an economic territory when there exists, within the economic territory, a location, place of production or other premises on which or from which the unit engages and intends to continue engaging, either indefinitely or over a finite but long period of time, in $R \& D$ activities and/or transactions on a significant scale. The actual or intended location for one year or more is used as an operational definition. More relevant guidance on this criterion and related R\&D statistics is provided in Chapter 11 on R\&D globalisation.

\section{Box 3.2. The SNA institutional sector classification}

The Frascati Manual's sector classification is closely related to that recommended by the System of National Accounts (SNA). The SNA classifies all institutional units in the economy and groups them into five mutually exclusive institutional sectors. Sectors are groups of institutional units, and the whole of each institutional unit must be classified to one or other sector of the SNA: financial corporations and non-financial corporations; general government, non-profit institutions serving households (NPISH); and households. The SNA's recommended sequence for classification is to first separate households from legal institutional units, then focus next on the latter, which are primarily concerned with economic production. Further questions determine the sectoral allocation of all such units.

The first is whether the unit is a market or non-market producer, depending on whether the majority of the unit's production is offered at economically significant prices (EC et al., 2009, para. 22.28).

When non-market units are not controlled by government, these are defined as NPISH, while the rest are classified as general government. Nonprofit institutions (NPIs) are defined in EC et al. (2009), para. 4.8, and they can appear in any of the SNA sectors. Market units make up the corporation sector, which comprises private and public corporations, depending on whether they are controlled by government.

Source: EC et al. (2009).

3.23 The SNA institutional classification provides a basis for the recommended classification of the main sectors for R\&D statistics (i.e. the "Frascati sectors"). The relationship between the Frascati sectors and the SNA sectors is described in Table 3.1. There are two main differences.

3.24 First, since the first edition of this manual, the users of $R \& D$ statistics have repeatedly placed considerable emphasis on ensuring the consistent reporting of R\&D activity within higher education institutions and the units over which they exert control or administer. Implementing this requirement calls for an additional set of criteria that help identify institutional units for 
a separate Higher education sector, which in the SNA would be classified as either corporations, government units or NPISH, according to the market and government control criteria that are applicable in each country. The particular aspects of the Higher education sector for R\&D statistics are covered in detail in Chapter 9.

3.25 Second, and largely for economy of presentation, R\&D statistics combine into a single group households with non-profit institutions that are not allocated to the Higher education, Business enterprise or Government sectors, i.e. the units in the NPISH sector that are not part of this manual's Higher education sector. The resulting group could be called the "Other private and non-profit" sector, as an abbreviation to represent the residual group of households and other private and non-profit institutions and to complete the full representation of actors in the domestic economy. As the contribution of this residual group of households is small, the sector is referred to in the manual as the Private nonprofit sector (PNP).

3.26 This approach provides the basis for the national and international reporting of $R \& D$ data. This should be kept in focus, particularly for international reporting, while allowing for a number of more flexible, complementary approaches, as discussed below. Thus, five main sectors have been identified for the measurement of R\&D. They are summarily described below in Section 3.5 and discussed in more detail in the relevant methodology chapters:
- Business enterprise
Chapter 7
- Government
Chapter 8
- Higher education
Chapter 9
- Private non-profit
Chapter 10
- Rest of the world
Chapter 11.

\section{Implementing the institutional classification}

3.27 Classification can be a resource-intensive activity, particularly for agencies building comprehensive R\&D statistics systems for the first time. The classification activity needs to be continued over time, as units appear and disappear or need to be reclassified. For statistical agencies with access to official statistical registers, R\&D classification decisions can be made easier by supporting them in general with SNA classification decisions, introducing an additional filter check to help identify whether the unit corresponds to the Higher education sector as defined in Section 3.5. and which is discussed further in Chapter 9.

3.28 In some cases, the agency compiling R\&D statistics may need to reconsider and revise the generic classification available from standard registers if, for example, the classification reported in the register has not been kept upto-date with the most recent developments relevant to R\&D statistics, including 
changes in the profile of the statistical unit. Through its R\&D system monitoring and relationship building activities, the compiler of $R \& D$ statistics may be in a better position to observe and document those changes in the case of specific R\&D performing or funding units. These observations by R\&D statistics compilers can also be of further value to the compilers of general statistical registers.

Table 3.1. Approximate correspondence between Frascati and SNA institutional sectors

\begin{tabular}{|c|c|c|c|c|}
\hline \multirow{2}{*}{$\begin{array}{l}\text { SNA } \\
\text { institutional sectors }\end{array}$} & \multicolumn{4}{|c|}{ Frascati sectors } \\
\hline & $\begin{array}{l}\text { Higher education } \\
\qquad(\mathrm{HE})\end{array}$ & $\begin{array}{l}\text { Business enterprise } \\
\text { (BE) }\end{array}$ & $\begin{array}{l}\text { Government } \\
\text { (GOV) }\end{array}$ & $\begin{array}{l}\text { Private non-profit } \\
\text { (PNP) }\end{array}$ \\
\hline $\begin{array}{l}\text { Corporations } \\
\text { (financial and } \\
\text { non-financial) }\end{array}$ & $\begin{array}{l}\text { HE institutions in the } \\
\text { Corporations sector }\end{array}$ & $\begin{array}{l}\text { Same as SNA } \\
\text { Corporations sector, } \\
\text { including public } \\
\text { corporations, but not } \\
\text { HE institutions in the } \\
\text { Corporations sector }\end{array}$ & & \\
\hline General government & $\begin{array}{l}\text { HE institutions in the } \\
\text { General government } \\
\text { sector }\end{array}$ & & $\begin{array}{l}\text { Same as } \\
\text { SNA General } \\
\text { government sector, } \\
\text { except for the HE } \\
\text { institutions }\end{array}$ & \\
\hline NPISH & $\begin{array}{l}\text { HE institutions in the } \\
\text { NPISH sector }\end{array}$ & & & $\begin{array}{l}\text { Same as SNA NPISH } \\
\text { sector, except for the } \\
\text { HE institutions in the } \\
\text { NPISH sector }\end{array}$ \\
\hline Households & & $\begin{array}{l}\text { Enterprise-like } \\
\text { self-employed (most } \\
\text { likely captured as } \\
\text { quasi corporations) }\end{array}$ & & $\begin{array}{l}\text { For completeness: } \\
\text { Same as SNA } \\
\text { Households sector, } \\
\text { except for the } \\
\text { households "enterprise- } \\
\text { like self-employed" }\end{array}$ \\
\hline
\end{tabular}

3.29 For agencies without ready access to official registers, additional efforts are required to ensure a complete, up-to-date classification of statistical units that are potential R\&D performers in the economy. In the absence of datasharing arrangements, agencies in charge of compiling R\&D statistics may wish either to apply an SNA-like classification that is expanded by the application of the HE criterion or to adopt a sequential decision process that is more fully focused on R\&D statistics, as captured in Figure 3.1. 


\section{Figure 3.1. Decision tree for allocating institutional units to the main sectors in this manual}

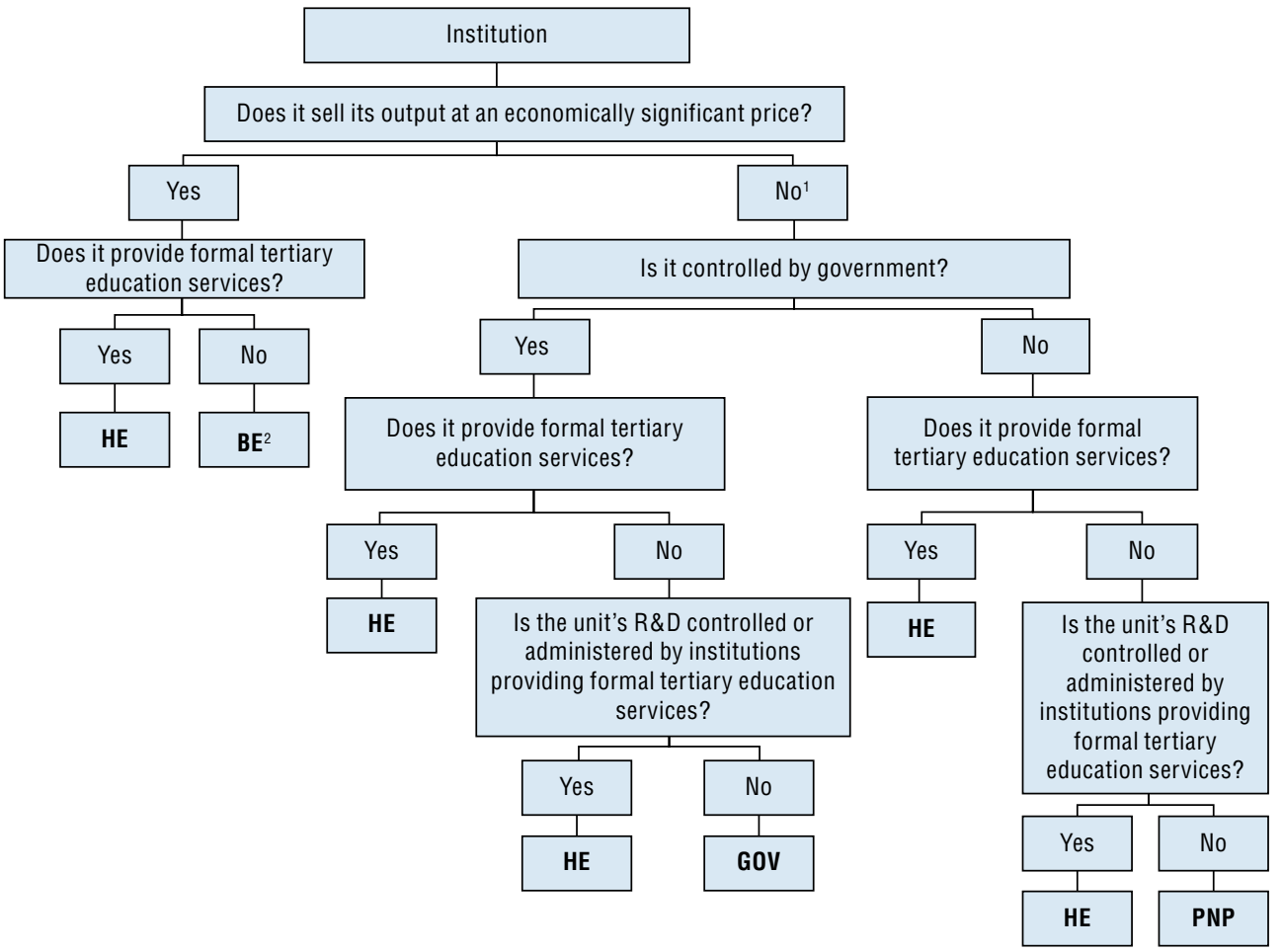

Key:

BE Business enterprise sector

HE Higher education sector

Gov Government sector

PNP Private non-profit sector

1. NPIs primarily serving businesses (e.g. trade associations, etc.) are classified in the Business enterprise sector, following the SNA convention of classifying those into the SNA Corporations sector.

2. This sector can be further subdivided into public and private Business enterprises, depending on whether the institution is controlled by government or not. This is analogous to the SNA treatment of public and private corporations.

3.30 In applying the above criteria to the classification of institutional units for R\&D statistics, a considerable number of borderline cases will be found. Further guidance on the main sectors and borderline cases is provided in Section 3.5 below, as well as in the chapters dedicated to each sector within this manual. Before considering this, Section 3.4 provides further guidelines on general classification principles and types of classifications of broad relevance that can be used to complement and to inform the Frascati institutional classification. 


\subsection{General classifications applicable to all institutional units Classification of units by main economic activity}

3.31 The economic activity is defined by the goods or services that are provided and is a feature of broad applicability to all units. All institutional units in an economy can be characterised by the goods or services they provide. A description of the R\&D activity on the basis of economic activity or industries (defined as consisting of a group of establishments engaged in the same, or similar, kinds of activity; United Nations, 2007) can be relevant for a range of uses. For example, economic activity, by reference to the provision of formal tertiary programmes (UNESCO-UIS, 2012), is a key defining attribute of the Higher education sector as defined in this manual. A further example is provided by units such as hospitals. Their focus on providing health services presents specific challenges that may require a special type of questionnaire to gather data on their R\&D activities. The classification by economic activity can help target suitable data-gathering instruments to specific types of units, regardless of the Frascati institutional sector to which they are classified.

3.32 The presentation of R\&D statistics can also be greatly assisted by assigning the units to an industry classification. As units with a common economic activity may be classified into different institutional sectors, the classification by economic activity can provide an additional source of insight into the structure and dynamics of R\&D across the entire economy, and not only the Business enterprise sector where the main economic activity classification is more systematically applied. For this reason, it is recommended that countries should tag institutional units in all sectors according to their principal economic activity even if they choose not to report these figures on a systematic basis.

3.33 An institutional unit may perform one or more economic activities. Units are classified according to their principal activity. In practice, the majority of production units perform activities of a mixed character. The International Standard Industrial Classification (ISIC) is the reference classification for economic activities (United Nations, 2008). Several countries and areas have their own adaptations of this classification to meet their individual needs, while attempting to keep a common core that allows for international comparability. The identification of a principal activity is necessary to allocate a unit to a particular category in the reference classification of economic activities. In order to determine the principal activity of a unit, the shares of value added (or other appropriate classification variable) by the different categories of activity that the unit undertakes have to be known. In practice, however, it is often impossible to obtain this information, so the activity classification has to be determined by using substitute criteria. Whenever possible and justifiable, the recommendation is that compilers of $R \& D$ statistics should avoid making separate classification decisions and use available information from statistical registers. 
3.34 A major focus of the economic activity classification of institutional units, in all institutional sectors, relates to the categories of R\&D services, health and education. Units involved in these activities can potentially be part of any Frascati institutional sector. The complete presentation of R\&D statistics on the basis of an economic activity may possibly reveal some potential differences for units engaged in education services with respect to the total reported for higher education, which can be due to a number of factors, including the distinction between primary and secondary activities. Even for units within the Higher education sector, it is relevant to note whether education is the unit's primary or secondary activity, and what is the role of $R \& D$ and possibly health services in the case of university hospitals.

\section{Classification of units according to public or private status}

3.35 The distinction between units controlled by government and those independent of it is relevant for the classification process and to identify what share of Business enterprise and Higher education sector R\&D should be reported as belonging in the public sector. The public or private status of an institutional unit should be determined by whether or not the unit is controlled by government.

3.36 The SNA defines the public sector as comprising general government and public corporations. Thus, a unit in the Business enterprise sector should be classified as being in the public sector on the basis of its being controlled by government. In contrast, a university that is commonly described as "public" but has its own board which can determine all facets of its organisational operations (including acquiring and disposing of assets and incurring liabilities), without approval by government officials, and which can cease its operations without the approval of government authorities, should be represented as private.

3.37 The borderline with public institutions can be difficult to establish, since both may receive significant amounts of government support, either directly or indirectly, and since even public institutions may have a significant degree of autonomy. The key, therefore, is whether the institution is clearly selfgoverning and not part of the government's administrative system. In some cases the definition of control is challenging, because the power to decide on the allocation and amount of funding can be a means of control. Therefore, in some instances it may be appropriate to use the major source of funding to decide whether the institution is controlled by government or not.

3.38 Although commonly reported as such, the simplified presentation of R\&D statistics should not attempt to identify the combination of the Higher education and Government sectors (Business enterprise and Private non-profit) with the category of "public sector" ("private sector"), since this fails to account, for example, for the fact that public enterprises are part of the Business enterprise sector and private and independent universities are part of the Higher education sector. Units tagged as private (or public) across all institutional sectors can be grouped together for the presentation of statistics that meet user requirements. 


\section{Classification of units by affiliation status to a broader group, domestic or foreign}

3.39 The sub-classification of units on the basis of independence or of affiliation to other units, in the same or a different sector, domestically or abroad, is of clear relevance to understanding the nature of the R\&D activity within the unit and to the production of R\&D statistics. Control relationships can dictate behaviour and decision making within the unit under analysis and underpin flows across the units that may be difficult to capture as transactions. Membership of a larger group of units can also enable access to a wider range of resources for the performance of $R \& D$ and influence the way that information on R\&D in the unit is managed, stored and shared. The systematic recording of this information and its selective use in the presentation of aggregated statistics is therefore relevant across all types of institutional units, particularly in the Business enterprise sector.

3.40 Specific attributes of institutional units that can be worth recording include:

- Whether the unit is controlled by a separate institutional unit, and/or whether the unit itself controls other institutional units.

- The sector to which the ultimate controlling unit belongs, in particular whether it is a resident unit or is based abroad. For example: is the unit controlled by a non-resident business enterprise or higher education institution?

3.41 As will be discussed in Chapter 4, these dimensions are relevant for informing the recommended breakdowns of R\&D by source of funds and by the recipients of $R \& D$ funds coming from the statistical unit.

\section{Classification of units into Corporations, General government and Non-profit sectors}

3.42 As indicated at the outset of this chapter, there are three types of institutional units with a legal status that can be the object of R\&D data collection, and these can differ from the institutional sector they are assigned to:

- Corporations comprise all entities that are capable of generating a profit or other financial gain for their owners, that are recognised by law as separate legal entities from their owners who enjoy limited liability, and that are set up for purposes of engaging in market production (EC et al., 2009: para. 4.38). The term covers cooperatives, limited liability partnerships and quasicorporations. For some practical purposes, this category can be extended to comprise households or individuals formally engaged in market production where the separation of liability is difficult to establish. Overall, this group should essentially match the units identified as business enterprises, details about which are provided in Chapter 7. 
- Government units are unique kinds of legal entities established by political processes that have legislative, judicial or executive authority over other institutional units within a given area (EC et al. 2009: para. 4.117). These units are of special relevance for the analysis of R\&D budgets and tax incentives, as covered in Chapters 12 and 13, respectively. More detailed analysis of government units and the Government sector is provided in Chapter 8.

- Non-profit institutions (NPIs) are legal or social entities, created for the purpose of producing goods and services, whose status does not permit them to be a source of income, profit or other financial gain for the units that establish, control or finance them (EC et al., 2009: para. 4.83). They can be engaged in market or non-market production. The interest in identifying the ensemble of NPIs in R\&D statistics stems from the rather residual nature of the Private non-profit sector in the main institutional classification, as covered in Chapter 10. This would be consistent with the SNA recommendations on a set of NPI satellite accounts. Not all NPIs are part of the Private non-profit sector; NPIs may be found in Higher education, Business enterprise and Government sectors, depending on the nature of the activities they undertake and whether or not they are controlled by government.

3.43 The institutional units are grouped into sectors in the SNA. The sectors used in this manual are defined in Section 3.5. In the SNA, the Corporations sector (EC et al., 2009: paras 4.94 and 4.98) is equivalent to the Business enterprise sector used in this manual, with the exception of the higher education units discussed in Section 3.5. The General government sector (EC et al., 2009: para. 127) is equivalent to the Government sector, with the exception of the higher education units discussed in Section 3.5. The Non-profit institutions serving households sector (NPISH) (EC et al., 2009: para. 4.166) is included in the Private non-Profit sector (PNP) with the exception of the higher education units discussed in Section 3.5. The PNP sector, for completeness, also includes the SNA Household sector, with the exception of the "enterprise-like self-employed", which are in the Business enterprise sector.

\section{Classification of units by field of R\&D}

3.44 The classification by field of R\&D (FORD) has been introduced in Chapter 2 to characterise the object of the R\&D activity, and it is presented in detail online in the annex guidance to this manual. Two R\&D projects can be said to belong to the same field if the main objects of their $R \& D$ are the same or sufficiently similar. The degree of similarity in subject matter content can be driven by (a) common knowledge sources drawn upon for the R\&D activity carried out; (b) common R\&D objects of interest and application areas - the phenomena to be understood or the problems to be solved; and the methods; (c) the techniques and professional identities of the scientists and other R\&D workers. 
3.45 Because of the great diversity of $R \& D$ domains covered within institutional units, the relevance of using this classification for grouping institutional units is limited to Frascati institutional sectors in which R\&D-performing units are fundamentally focused on the production of knowledge-based outputs, especially the Higher education sector, and to statistical units that are defined at a relatively disaggregated level. In those cases, the first level of the classification comprising six fields of R\&D should be used:

- natural sciences

- engineering and technology

- medical sciences

- agricultural sciences

- social sciences

- humanities and the arts.

3.46 Specific guidance on the use of this classification is provided separately for each sector, and principally from a functional distribution perspective. The more detailed classification is found online in annex guidance to this manual available at http://oe.cd/frascati.

\section{Classification of units by geography}

3.47 The location of R\&D-performing units is of great user interest but is challenging from the perspective of statistics collection, as statistical units defined on the basis of the R\&D decision making can span several locations, in different countries and in different regions within each country. A detailed geographical classification is most relevant for local units and establishments. For some types of enquiries, these may be the relevant statistical units, but it may not always be possible to secure data on their own R\&D activities, and therefore a geographical classification within a country may not always be possible. A priority for geographical demarcation should be the distinction between resident and non-resident units. Functional distribution approaches based on reporting units that cover more than a single site can also be used to attempt to regionalise $R \& D$ data. These methods are the subject of discussion in

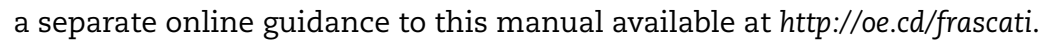

\section{Record-keeping practices for institutional classification}

3.48 Table 3.2 presents an illustrative example of how statistical agencies can compile comprehensive registers of units to tag them against a number of classifications and relevant descriptors. Similar systems can allow them to address specific national and international user needs on a regular or ad-hoc basis. 
Table 3.2. A simplified example of a potential frame structure tagging statistical units on various dimensions

\begin{tabular}{|c|c|c|c|c|c|c|c|}
\hline & $\begin{array}{c}\text { Frascati } \\
\text { institutional } \\
\text { sector }\end{array}$ & $\begin{array}{c}\text { SNA } \\
\text { institutional } \\
\text { sector }^{1}\end{array}$ & $\begin{array}{c}\text { Primary } \\
\text { economic } \\
\text { activity }^{1}\end{array}$ & $\begin{array}{c}\text { Secondary } \\
\text { economic } \\
\text { activity (if any) }\end{array}$ & $\begin{array}{l}\text { Private / } \\
\text { public } \\
\text { status }^{1}\end{array}$ & $\begin{array}{l}\text { Non-profit } \\
\text { institution } \\
(\mathrm{NPI}) ?^{1}\end{array}$ & $\begin{array}{l}\text { Links to } \\
\text { other units }\end{array}$ \\
\hline \multicolumn{8}{|l|}{ Unit A } \\
\hline \multicolumn{8}{|l|}{ Unit B } \\
\hline$\ldots$ & & & & & & & \\
\hline
\end{tabular}

1. Can be adopted from other statistical frameworks or sources as enabled by data-sharing agreements, or imputed by the agency compiling the R\&D statistics.

3.49 It is proposed that, in the interest of international comparability and quality assurance, countries disclose their classification decisions to the extent that provisions on statistical confidentiality allow them to do so. This is expected to strongly facilitate a better understanding of data differences and to promote convergence towards increased comparability.

\subsection{Summary presentation of the Frascati main sectors, their units and borderline cases}

3.50 The presentation of the Frascati sectors can be best summarised as four broad sectors comprising three that have a counterpart in the SNA institutional classification (Business enterprise, Government and Private non-profit) plus one sector defined on the basis of meeting user needs for units engaged in higher education, overlaid on the others. This is represented in Figure 3.2.

\section{Business enterprise sector}

\section{Main characteristics}

3.51 The Business enterprise sector comprises:

- All resident corporations, including not only legally incorporated enterprises, regardless of the residence of their shareholders. This group also includes all other types of quasi-corporations, i.e. units capable of generating a profit or other financial gain for their owners that are recognised by law as separate legal entities from their owners and set up for purposes of engaging in market production at prices that are economically significant.

- The unincorporated branches of non-resident enterprises that are deemed to be resident because they are engaged in production on the economic territory on a long-term basis.

- All resident NPIs that are market producers of goods or services or serve business. 


\section{Figure 3.2. Stylised representation of domestic Frascati institutional sectors} and their borderlines

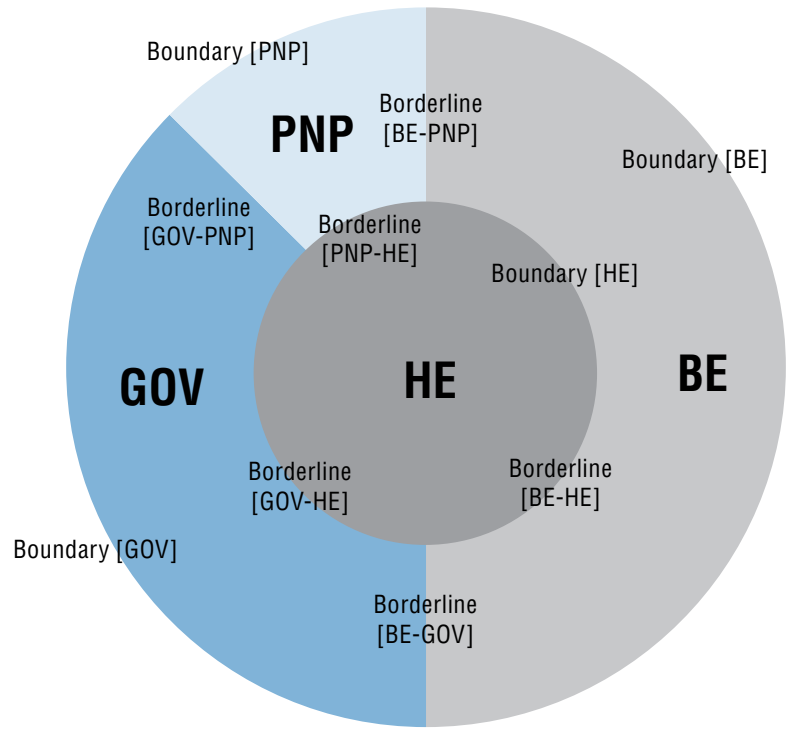

\footnotetext{
Key:

BE Business enterprise sector

HE Higher education sector

Gov Government sector

PNP Private non-profit sector
}

3.52 For these criteria to apply, the unit should not have been classified as part of the Higher education sector as a result of the criteria presented later in this section This sector comprises both private and public business enterprises.

\section{Statistical units in the Business enterprise sector}

3.53 Business enterprises organise their R\&D activities in order to better meet their objectives. Data requirements, specified in Chapters 4 and 5 generally and in Chapter 7 for this sector, determine the choice of the statistical unit(s) for business enterprises. Business enterprises can organise the funding and performance of $\mathrm{R} \& \mathrm{D}$ at various possible levels. Strategic decisions concerning the financing and direction of the R\&D efforts may be taken at the group level, regardless of national boundaries. Business enterprises engaged in R\&D may have activities spanning more than one country.

3.54 The statistical unit for the Business enterprise sector will generally be the enterprise, as defined in Box 3.1. When an enterprise is heterogeneous with regard to its economic activities and carries out significant amounts of R\&D for several kinds of activities, a more detailed reporting unit, e.g. on a kind-of-activity basis or on the establishment, may be preferable if the necessary information can be obtained. 


\section{Main borderline cases}

3.55 Most major borderline cases with other sectors are described later in this section. Some practical challenges may arise when deciding whether a business enterprise unit is resident or not, particularly when it concerns nonincorporated branches of foreign-controlled enterprises. Universities that sell their output at an economically significant price should be classified as part of the Higher education sector on the basis of their primary economic activity. Commercial firms owned by higher education institutions, for example as a result of agreements that give the university a major shareholding position in a spin-off company set up by staff and/or students, should be treated as business enterprises.

3.56 Some classification challenges may arise in the context of special entities created for a given purpose by a number of established institutional units. For example, many public units enter into arrangements with private entities or other public units to undertake a variety of activities jointly, including $R \& D$. As defined in the SNA, a joint venture involves the establishment of a corporation, partnership or other institutional unit in which each party legally has joint control over the activities of the unit. The units operate in the same way as other units except that a legal arrangement between the parties establishes joint control over the unit. As an institutional unit, the joint venture may enter into contracts in its own name and raise finance for its own purposes. If they are standalone units, R\&D joint ventures should also be classified on the basis of the units they predominantly serve, taking into account established SNA practice whenever possible.

3.57 Private-private or private-public partnerships are not necessarily institutional units, but in many cases, contracts between two institutions from different sectors. If these partnerships have the status of institutional units, the classification of such entities depends also on the institution with the greatest interest in the partnership. In some countries, R\&D partnerships have a legal status and should also be classified on the basis of the units they predominantly serve.

3.58 Practical difficulties may arise in establishing whether NPIs are or are not engaged in market production. Research institutes, clinics, hospitals, medical practitioners in private, fee-paying practices, etc., may be able to raise additional funds in the form of donations or own assets generating property income which allow them to charge below-average prices. Likewise, establishing whether an NPI has been set up for the purpose of serving business may be complicated by the existence of multiple stakeholders who are being served and their variability over time. In general, NPIs created and managed by associations of businesses whose activities they are designed to promote, such as chambers of commerce and agricultural, manufacturing and trade associations, financed by contributions or subscriptions from the businesses concerned, which provide 
core or project-based support for their $R \& D$, should be treated as part of the Business enterprise sector.

3.59 The many possible borderline cases relevant to the Business enterprise sector, as well as recommended sub-classifications, are discussed in Chapter 7.

\section{Government sector}

\section{Main characteristics}

3.60 The Government sector consists of the following groups of resident institutional units:

- all units of central (federal), regional (state) or local (municipal) government, including social security funds, except those units that provide higher education services or fit the description of higher education institutions provided in the previous subsection

- all non-market NPIs that are controlled by government units, which are not part of the Higher education sector.

3.61 The sector does not include public corporations, even when all the equity of such corporations is owned by government units. Public enterprises are included in the Business enterprise sector; the defining difference is that public corporations are market producers, while units classified in the Government sector are not.

\section{Statistical units in the Government sector}

3.62 This sector comprises government units and non-profit institutions controlled by government. Government units are unique kinds of legal entities established by political processes that have legislative, judicial or executive authority over other institutional units within a given area. These legal units or branches therein assume responsibility for the performance/provision of specific R\&D services for the use of government and the benefit of society and the economy, and also finance their direct provision or provision by third parties out of taxation or other incomes. Their engagement in R\&D may be principally as funders rather than performers of $R \& D$, but government units may have internal research departments and laboratories that perform some types of R\&D activities. Some agencies may be set up and given a separate legal identity to undertake research activities as a primary, secondary or ancillary activity. While the focus of enquiries will depend on whether the interest is in the performance of $R \& D$, the funding of $\mathrm{R} \& \mathrm{D}$, or both activities, the statistical unit will generally be the institutional unit. However, the data may be gathered at the department, ministry, local authority, agency or government institution, even if the reporting unit does not have all of the characteristics of an institutional unit (i.e. the ability to hold and control assets).

3.63 A substantial share of R\&D performance within government units is likely to be carried out by non-profit institutions such as foundations, museums, hospitals and institutes that are controlled by government; the statistical unit 
will generally be the enterprise, understood in the sense described in Box 3.1 earlier in this chapter.

\section{Main borderline cases}

3.64 Borderline cases between the Government and Higher education sectors are discussed later in this section. The borderline with the PNP sector is fundamentally driven by the extent to which government units control the operations of the relevant statistical unit. Control in this case is the ability to determine the non-market NPI's general policy or programme by having the right to appoint the NPI's management and/or otherwise ultimately direct its decisions. In some cases the definition of control is challenging, because the power to decide on the allocation and amount of funding can be a means of control. Therefore, it may be appropriate to use the major source of funding to decide whether the institution is government controlled or not.

3.65 For government-controlled units, the borderline with the Business enterprise sector is defined by the extent to which the unit operates on a market basis, i.e. whether its principal activity is the production of market goods or services, with the aim of selling most of its products at economically significant prices. A government research institute that may occasionally receive a considerable amount of revenue for the exploitation of some of its intellectual property should not be classified as a public Business enterprise if the majority of its R\&D activities are carried out with a non-commercial intent. On the other hand, an institute controlled by government whose operations for example rely on fees for providing R\&D services and access to research infrastructure that fully reflect the full economic cost of such services should be classified as a public Business enterprise.

3.66 The many possible borderline cases that affect units in the Government sector and recommended sub-classifications are discussed in Chapter 8 on government R\&D.

\section{Higher education sector}

\section{Main characteristics}

3.67 This sector does not have a direct counterpart in the SNA group of institutional sectors. Itis unique to this manual and is defined to reflect a policyrelevant category of $\mathrm{R} \& \mathrm{D}$-performing institutions. It comprises all universities, colleges of technology and other institutions providing formal tertiary education programmes, whatever their source of finance or legal status, and all research institutes, centres, experimental stations and clinics that have their R\&D activities under the direct control of, or administered by, tertiary education institutions. The term "formal" is defined in ISCED (UNESCO-UIS, 2012, para. 36) and is elaborated upon in Chapter 9. 
3.68 In this manual, the term "higher education" is used, in most cases, rather than the broader term, "tertiary education". In referring to the product of higher education institutions, the term "services" will be used, in preference to "programmes", which is common in education statistics and in ISCED.

3.69 Units in this sector may correspond to units classified by the SNA as either part of the Corporations, General government or NPISH sectors.

\section{Statistical units in the Higher education sector}

3.70 The recommendation of this manual is that the enterprise, or its institutional equivalent, be the statistical unit in order to meet the requirement for homogeneous units. However, data could be collected (reported) from the smallest homogeneous unit engaged at the top level of the field of the R\&D classification (FORD), or a combination of R\&D classifications at this level in the case of units working in interdisciplinary domains. Depending on the ability of the unit to report on personnel, expenditures and funding flows on a consistent basis, as well as on the specific terminology applied in each country, the reporting unit could be a department, a faculty, a centre or institute, or a college. The recommendation is that the reporting unit be determined by its capacity to provide homogeneous statistics.

\section{Main borderline cases}

3.71 The sector includes all units (establishments) the primary activity of which is to provide tertiary education services at ISCED level 5, 6, 7 or 8, regardless of their legal status (UNESCO-UIS, 2012: 83). These may be corporations, quasicorporations belonging to a government unit, market NPIs or NPIs controlled and mainly financed by government or by NPISHs (non-market NPIs). As noted above, the core is made up of universities and colleges of technology. It should be noted that not all tertiary institutions perform R\&D.

3.72 University hospitals and clinics are included in the HE sector when they provide tertiary education services (possibly as a secondary activity). In the case of other hospitals and clinics, these should be treated as part of the Higher education sector only when the entire R\&D activity is under the direct control of, or administered by, a higher education institution. The rationale for this is that in such a case the R\&D activity can be treated as part of the HE institution's own R\&D performance. Otherwise, the hospital unit should be classified as determined by standard criteria concerning its market focus and the extent to which it is controlled by government. The application of these guidelines may require working with statistical and reporting units below the level of the entire medical institution.

3.73 The Higher education sector comprises research centres and institutes where $R \& D$ is the primary activity and higher education is a significant core activity, for example, focused on the systematic training of doctoral students. The HE sector also comprises affiliated non-market centres and 
institutes for which there is no instructional component but the R\&D activities of which are controlled by the higher education institution(s). When neither of these conditions apply, the centre should then be allocated to the relevant sector, namely Business enterprise if it is operating on a market basis (regardless of government control), PNP if it is operating on a non-market basis and not controlled by government, or government if it is nonmarket and controlled by government. Location should not be used as a key criterion.

3.74 The many possible borderline cases that affect higher education units together with recommended sub-classifications for this sector are discussed in Chapter 9.

\section{Private non-profit sector}

\section{Main characteristics}

3.75 This sector comprises:

- all non-profit institutions serving households (NPISH), as defined in the SNA 2008, except those classified as part of the Higher education sector

- for completeness of presentation, households and private individuals engaged or not engaged in market activities, as explained in the section, Criteria for the classification of institutional sectors for $R \& D$ statistics, earlier in this chapter.

3.76 Examples of units within this sector may include independent professional and learned societies, and charitable organisations that are not controlled by units in the Government or the Business enterprise sector. These provide individual or collective services to households either without charge or at prices that are not economically significant. Such NPIs may be created by associations of persons to provide goods, or more often services, primarily for the benefit of the members themselves or for general philanthropic purposes. Their activities may be financed by regular membership subscriptions or dues or by donations in cash or in kind from the general public, corporations or government. A potentially much broader group of units in this sector, including households, is likely to be involved in the funding of $R \& D$ activities than in performance.

3.77 The statistical guidelines provided in this manual for the measurement of R\&D focus on the role played by institutional units as R\&D performers. This conforms with the definition of $R \& D$ in Chapter 2 and with the explanatory criteria provided to ensure that the definition can be operationalised in a robust way. For completeness, economy of presentation, and primarily for some specific purposes, such as capturing phenomena like philanthropic R\&D-funding activity by individuals, households complete the presentation of the economy and are pooled into the PNP sector.

- The roles played by individuals in $R \& D$ performance are fundamentally captured through the institutional units that they work for under a wide range of possible arrangements. Individual researchers may in some cases be the target of dedicated surveys, for example, surveys that aim to provide 
complementary information to improve the estimation processes that are based on data collected from institutional units (such as to identify the R\&D time use component when the information cannot be directly collected from the institutional units).

- Individuals or households may fit the institutional perspective in some instances, in particular when established as legal units or registered in other forms without the ability to separate their liabilities but still being formally organised. The difficulties both in ensuring that the criteria laid down in Chapter 2 are met and in capturing these micro-units are discussed in Chapter 6 and the dedicated sector chapters, in particular Chapter 7 for Business enterprises.

3.78 Individuals and the households they belong to make several other types of valuable contributions to R\&D knowledge, not only as funders (e.g. as philanthropists) or as subjects of research (e.g. as participants in clinical trials) but also as active creators of new knowledge (e.g. as compilers of scientific data and as inventors). There are several examples in the history of science of breakthroughs arising from individual efforts, and new types of individual engagement are being facilitated by networks that enable competitions and collaboration across informal groups of individuals as well as with formal institutional units. The coverage of individuals with regards to their engagement in research or broader innovation activity, for example as volunteers, is part of the general "research" agenda in the area of science, technology and innovation indicators. However, a general approach for implementation across countries cannot be recommended at this point. Any experimental efforts undertaken at the country level to measure R\&D undertaken by individuals should not be combined with the normal presentation of R\&D statistics.

\section{Statistical units in the Private non-profit sector}

3.79 This manual recommends that the statistical unit for the PNP sector should be defined at the enterprise level (as broadly defined in this chapter). Judgement must be exercised when dealing with complex institutions and the smallest homogeneous unit engaged in a single field of R\&D. An example is the case of PNP units working in specific interdisciplinary domains. When a major Private non-profit unit has significant $R \& D$ activity in more than one field of $R \& D$, and records are available, an attempt may be made to collect data for the statistical unit from smaller units and classify them to relevant fields of R\&D.

\section{Main borderline cases}

3.80 Borderline cases with Higher education and Government sectors have been discussed in the previous sub-sections. Those non-profit units offering higher education services or controlled by institutions of higher education should be classified as part of the Higher education sector. As indicated in this chapter, 
control should be the main criterion applied. But in some cases the definition of control is challenging, because the power to decide on the allocation and amount of funding can be a means of control. Therefore, it can be appropriate to use the major source of funding as a qualifying criterion to decide whether the institution is government-controlled or not.

3.81 In line with the SNA, non-profit institutions that are controlled by or primarily serve business enterprises, such as trade associations, industrycontrolled research institutes, etc., should be classified as part of the Business enterprise sector even if the institutions operate on the basis of subscriptions that barely cover their operating costs.

3.82 The market activities of unincorporated enterprises owned by households, i.e. self-employed consultants who undertake R\&D projects for another unit at an economically significant price, should be included in the Business enterprise sector whenever practicable and whenever it is possible to demonstrate, in the case of performance, the R\&D criteria established in Chapter 2.

3.83 As previously indicated, the activities of individuals to pursue in their own time their personal interests as researchers or inventors are currently beyond the scope of the institutional approach to R\&D statistics presented in this manual.

3.84 The appropriate treatment of individuals who may be part of a group of persons employed in a fully-fledged institutional unit, but not as employees, and who directly receive funds for their R\&D activities from third parties is discussed in Chapter 4 on R\&D expenditures and sources of funds and in Chapter 5 on R\&D personnel.

3.85 Also beyond the scope of this manual are the informal sector and any $R \& D$ activities that may be undertaken there, either by individuals or by "enterprises of informal employers" (EC et al., 2009: 475). As noted in the SNA 2008 Manual (EC et al., 2009: 474), dealing with the informal sector is an issue not just for developing countries, but for all economies, whatever their state of development.

3.86 The many possible borderline cases that affect institutions in the PNP sector and the treatment of households and individuals, as well as the recommended sub-classifications, are discussed in Chapter 10 on private nonprofit R\&D.

\section{Rest of the world}

\section{Main characteristics}

3.87 This sector is defined on the basis of the non-residence status of the relevant units. The Rest of the world sector consists of all non-resident institutional units that enter into transactions with resident units, or have other 
economic links with resident units. The concept of residence has been explained in Section 3.3. The Rest of the world includes:

- all institutions and individuals without a location, place of production or premises within the economic territory on which or from which the unit engages and intends to continue engaging, either indefinitely or over a finite but long period of time, in economic activities and transactions on a significant scale

- all international organisations and supranational authorities, defined below, including facilities and operations within the country's borders.

3.88 From the perspective of the agency compiling R\&D statistics, it is convenient to refer to non-resident units as resident abroad or in the Rest of the world. Whenever statistics are reported for institutional sectors, as well as for the total economy, it is recommended to report funding flows for R\&D with the Rest of the world, as indicated in Chapters 4 and 11. Transactions with the Rest of the world are recorded as if it is a de facto sector. The definition of this sector is also relevant for characterising R\&D performance in the domestic economy by resident units with affiliation relationships to the Rest of the world.

\section{Statistical units in the Rest of the world sector}

3.89 The description of statistical units in the Rest of the world sector is not relevant in this case, as no statistical data collection is recommended for national compilers of R\&D statistics.

\section{Main borderline cases}

3.90 Resident units may run operations outside the economic territory of a country, including the use of testing grounds, vehicles, ships, aircraft and space satellites operated by domestic entities. These are generally not institutional units separate from the domestic entity. In the SNA, all owners of land, buildings and immovable structures in the economic territory of a country, or units holding long leases on either, are deemed always to have a centre of economic interest in that country. All land and buildings are therefore treated as if owned by residents, and special units are created for that particular purpose.

3.91 When a unit maintains a site, branch, office or production site in another country in order to engage in R\&D over a long period of time (usually taken to be one year or more), the branch, office or site is considered a separate institutional unit resident in the country in which it is located. If an institution from country A maintains a long-standing presence for years in host country $B$, even if the teams rotate for a period of less than a year, R\&D statistics would treat this situation as there being a separate unit in country B. This separate unit would be within the scope of data collection for compilers in country B.

3.92 The concepts of economic territory and residence are designed to ensure that each institutional unit is a resident of a single economic territory. For this reason, it is recommended that national agencies compiling R\&D statistics 
coordinate their assessment of the residency of units at the boundaries of meeting the residence criterion with those of other countries potentially involved.

3.93 Some countries may be part of an institutional agreement that involves monetary flows from the member countries to the associated supranational authority (see Glossary for definition) and from the supranational authority to R\&D-performing units. The supranational authority itself may also engage in $R \& D$. For the individual countries, the supranational authorities are non-resident institutional units that are part of the rest of the world and may be classified in a specific subsector of the Rest of the world sector. In this manual, the terms "supranational authorities" and "supranational organisations" are used interchangeably.

3.94 According to the SNA, international organisations have as members either national states or other international organisations whose members are national states. They are established by formal political agreements between their members that have the status of international treaties; their existence is recognised by law in their member countries, and they are not subject to the laws or regulations of the country, or countries, in which they are located. For example, they cannot be compelled by national authorities to provide statistical information on their R\&D performance or funding activities. For the purposes of the SNA and also for R\&D statistics, international organisations are treated as units that are resident in the Rest of the world, regardless of the physical location of their premises or operations.

3.95 In order to attain a complete representation of R\&D activities on an area or even global basis, the relevant supranational and international statistical organisations should work to ensure full coverage of the units that lie beyond the scope of national statistical authorities and agencies. When by virtue of specific agreements, national compilers can collect data from these organisations, for example to better capture linkages with domestic units, the reporting of national figures should conform with the guidance in this manual to treat these units as part of the Rest of the world sector.

3.96 The types of units, their sub-classifications and boundary cases are discussed in Chapter 11 on R\&D globalisation.

\section{References}

EC, IMF, OECD, UN and the World Bank (2009), System of National Accounts, United Nations, New York. https://unstats.un.org/unsd/nationalaccount/docs/sna2008.pdf.

UNESCO-UIS (2012), International Standard Classification of Education (ISCED) 2011, UIS, Montreal. www.uis.unesco.org/Education/Documents/isced-2011-en.pdf.

United Nations (2008), International Standard Industrial Classification of All Economic Activities (ISIC), Rev. 4, United Nations, New York. https://unstats.un.org/unsd/cr/registry/isic-4. asp and http://unstats.un.org/unsd/publication/seriesM/seriesm_4rev4e.pdf.

United Nations (2007), Statistical Units, United Nations, New York. http://unstats.un.org/ unsd/isdts/docs/StatisticalUnits.pdf. 



\section{Chapter 4}

\section{Measurement of R\&D expenditures: Performance and sources of funds}

This chapter discusses the measurement of expenditure on the performance of research and experimental development $(R \& D)$, the sources of funds for the performance of $R \& D$ and expenditures for $R \& D$ performed in other statistical units. The measurement of gross domestic expenditure on R\&D (GERD), which covers all expenditures for R\&D performed in the economy during a specific reference period is the principal $R \& D$ indicator at country level. GERD, and the GERD/GDP ratio, are used for international comparisons. The chapter discusses the measurement of expenditures and flows in each of the four sectors of the manual where R\&D is performed, Business enterprise, Government, Higher education and Private nonprofit, and the flow of funds from the Rest of the world sector for the performance of $R \& D$ in the other four sectors. With the decision to treat the expenditure on the performance of $R \& D$ as a capital investment in the System of National Accounts (SNA), and the need for better statistics on the globalisation of $R \& D$, more information is needed and guidance is provided on what to collect. There is also discussion of the use of the statistics, of which the GERD/GDP ratio is an example, as is the estimation of the capital investment in R\&D in the SNA. There is also the need to be able to analyse data at the level of the individual statistical unit in order to have a better understanding of the dynamics of R\&D performance and funding. 


\subsection{Introduction}

\section{Why measure R\&D expenditures?}

4.1 The amount of money spent on research and experimental development ( $R \& D$ expenditure) is of considerable interest to national and international policy makers. In particular, statistics on R\&D expenditure are used to measure who conducts and who funds R\&D and where it takes place, the level and purpose of such activities, and interactions and collaborations between institutions and sectors. Expenditure statistics are used to inform the development of fiscal and financial incentives to stimulate R\&D activities, and to understand how R\&D contributes to economic growth, defence and societal well-being.

4.2 As detailed in Chapter 1, a major change in the 2008 revision of the System of National Accounts (SNA) was the explicit treatment of R\&D as capital formation, that is, "investment" (EC et al., 2009). This change resulted in attendant demands for more detailed breakdowns on $R \& D$ expenditures, which are noted throughout the chapter. This chapter also includes guidance for collecting detailed data on the sources and flows of R\&D funds and on types of $R \& D$ transactions. In particular, additional and more extensive information is needed to help measure R\&D sales and purchases.

4.3 Although the chapter focuses on the requirements necessary to produce internationally comparable statistics at different levels of aggregation, it is equally important to ensure that the data for individual statistical units can support analysis at the micro level. The guidelines presented here are therefore intended to address a multiplicity of statistical data needs and nuances.

\section{Data collection and compilation overview}

\section{Basic terms}

4.4 It may be helpful first to introduce the basic concepts used to structure the collection of R\&D statistics. For the purposes of this manual:

- Expenditures on intramural R\&D represent the amount of money spent on $R \& D$ that is performed within a reporting unit; expenditures on (the funding of) extramural $R \& D$ ) represent the amount of money spent on $R \& D$ that is performed outside a reporting unit.

- Internal R\&D funds are the amount of money spent on $R \& D$ that originates within the control of a reporting unit; external R\&D funds are the amount of money spent on $R \& D$ that originates outside the control of a reporting unit. 
- Exchange R\&D funds are funds that flow between statistical units with a compensatory return flow of $R \& D$; transfer $R \& D$ funds are funds that flow between statistical units without a compensatory return flow of R\&D.

4.5 These terms, their interrelationships and the measurement challenges are more precisely defined and discussed throughout the remainder of the chapter.

\section{Basic collection approach}

4.6 A statistical unit may have expenditures for performing R\&D and for funding $R \& D$. It might fund $R \& D$ but not perform $R \& D$ - as is sometimes the situation for businesses that occasionally need to purchase $R \& D$. Or it might perform R\&D but not fund R\&D - a somewhat uncommon occurrence, although this would be the case for a small business unit that has its R\&D funded totally by a government grant. Finally, a statistical unit might both perform R\&D and fund $R \& D$. Funding may be for $R \& D$ undertaken either within the reporting unit (intramural) or outside the reporting unit (extramural). The step-by-step approach for measuring these expenditures is as follows:

- Identify the amount of intramural expenditures on $R \& D$ performed within each statistical unit (see Section 4.2).

- Identify the sources of funds for these intramural $R \& D$ expenditures as reported by the performer (see Section 4.3).

- Identify the amount of funding for extramural R\&D provided by each statistical unit (see Section 4.3). Both R\&D-performing units and non-R\&D-performing units may provide funding for R\&D performed outside of the unit.

- Identify the amount of funding flows between statistical units that is made with and without a compensatory return flow of R\&D from the performer (see Section 4.3).

- Aggregate the data by sectors of performance and sources of funds to derive totals for the entire economy. Other classifications and distributions are then compiled within this framework (see Sections 4.3 and 4.5 ).

\section{Gross domestic expenditure on R\&D (GERD) - a country's principal $R \& D$ indicator}

4.7 GERD is total intramural expenditure on R\&D performed in the national territory during a specific reference period.

4.8 GERD is the main aggregate statistic used to describe a country's R\&D activities and covers all expenditures for R\&D performed in the economy. Thus, GERD includes domestically performed R\&D that is financed from abroad (i.e. from the "Rest of the world") but excludes funding for R\&D performed abroad. See Chapter 3, Section 3.3 on the concept of "residence" and Section 4.2 in this chapter for conventions related to reporting intramural $R \& D$ that takes place 
outside of the national territory. GERD is the primary indicator for international comparisons of R\&D activity.

4.9 A country may have statistical units that perform R\&D in each of the main sectors covered in this manual: Business enterprise, Government, Higher education and Private non-profit. Overall classification definitions are provided in Chapter 3, and specific definitions and characteristics of these four sectors are covered in Chapters 7, 8, 9 and 10, respectively. Intramural R\&D expenditure totals should be compiled for each of the main sectors. GERD is constructed by summing those sector totals to a national total. For each performing sector, the sources of funds from each sector should be compiled: Business enterprise sector, Government sector, Higher education sector, Private non-profit sector, and Rest of the world. Definitions and characteristics for Rest of the world are covered in Chapter 11. To the extent possible, and to reduce the possibility of double counting, GERD should be based on performer reports and not on information from the source of R\&D funds. The performer is in the best position to identify:

- how the funds were effectively used (e.g. whether an expenditure is for an R\&D or non-R\&D activity, the nature of the $R \& D$, the cost elements that comprise the $R \& D$, etc.)

- the year in which the R\&D activity actually took place

- the immediate source of the funds used for R\&D.

\subsection{Intramural R\&D expenditures (Performance of R\&D) Definition}

4.10 Intramural $R \& D$ expenditures are all current expenditures plus gross fixed capital expenditures for R\&D performed within a statistical unit during a specific reference period, whatever the source of funds.

4.11 Intramural $R \& D$ expenditure is synonymous with the performance of R\&D within a statistical unit. The aggregation of intramural R\&D for all units within a sector is synonymous with the performance of $R \& D$ within a sector of the economy; the summation of intramural $R \& D$ for all sectors is synonymous with the performance of R\&D for the entire economy (GERD).

4.12 Funding for, or expenditure on, extramural R\&D (that is, $R \& D$ performed outside the statistical unit) is not included in intramural R\&D performance totals. Such funding for R\&D received from others should be reported as a separate category in order to have full information on each unit's access to R\&D. Such funds would also be reported in the receiving units' R\&D intramural performance total, and therefore the exclusion of funding for extramural R\&D is to avoid double counting. It is not always easy to differentiate expenditures for intramural R\&D from extramural R\&D; several examples are provided in this chapter to help clarify these categorisation decisions. 
4.13 Expenditures for non-R\&D purchases made outside the statistical unit or sector but in support of intramural R\&D (e.g. purchase of supplies or of general services for the $R \& D$ activity) are included in intramural $R \& D$ totals.

4.14 Both current and capital expenditures are included in intramural R\&D totals, although separately reported.

\section{Current R\&D expenditures}

4.15 Current expenditures are composed of labour costs of R\&D personnel and other current costs used in R\&D. Services and items (including equipment) used and consumed within one year are current expenditures. Annual fees or rents for the use of fixed assets should be included in current expenditures.

\section{Labour costs of R\&D personnel}

4.16 Labour costs comprise compensation for employed R\&D personnel (called "internal R\&D personnel" in this manual), such as annual wages and salaries and all associated costs or fringe benefits, such as bonus payments, stock options and holiday pay, in addition to contributions to pension funds and other social security payments, payroll taxes, etc. It is important to include only labour costs for employed persons when they make a direct contribution to intramural $R \& D$, especially if such persons do not work full-time on R\&D activities. Just because a person is employed in an R\&D unit, for example, it cannot be assumed that all of their labour costs are for R\&D activities. See Chapter 5 for further guidance.

4.17 Labour costs are generally the largest component of current costs. Countries may find it useful to collect or otherwise estimate labour costs by type of R\&D personnel (for example, researchers, technicians and equivalent staff, other supporting staff). These additional breakdowns may be helpful in constructing cost indices for R\&D expenditures.

4.18 The labour costs of a statistical unit's employed persons who provide ancillary services and who are not included in the R\&D personnel data (such as security, canteen, cleaning and maintenance personnel; the staff of central computer departments and libraries; and the staff of central finance or personnel offices directly involved in supporting the R\&D effort) should not be included in labour costs, but should be included in other current costs.

4.19 The costs associated with engaging persons not employed in the statistical unit but who provide direct services that are an integral part of the statistical unit's R\&D projects or activities should not be included in labour costs. Costs for such personnel should be reported in other current costs (as defined below). The distinction between internal R\&D personnel in the statistical unit (labour costs) and self-employed persons working on R\&D in the same statistical unit (other current costs) may in some cases be blurred. Normally, the statistical unit pays self-employed persons for the total services specified in a contract, 
rather than paying them only wages and salaries. See Chapter 5 for further clarifications on R\&D personnel.

4.20 The calculation of wages and salaries for doctoral or master's students may sometimes seem problematic. As noted in Chapter 5, only those students who are employed by the statistical unit and who are engaged in the statistical unit's R\&D projects or activities (e.g. as researchers or research assistants) should be included in the totals. Sometimes they receive less money for their work than they would at "market value". Nonetheless, only actual salaries and associated labour costs for such students should be reported in the R\&D statistics. No inflated values should be derived.

4.21 Labour costs include actual or imputed contributions to pension funds and other social security payments for R\&D personnel. They need not be visible in the statistical unit's bookkeeping accounts; they may often involve transactions within or between sectors. Even when no transactions are involved, an attempt should be made to estimate these costs. To avoid double counting, labour costs do not include pension payments to former R\&D employees.

4.22 Labour costs of R\&D personnel should include employer payroll and related taxes, net of general subsidies/rebates on this workforce. However, some countries provide automatic incentives for hiring R\&D personnel that are implemented through various payroll tax instruments. To ensure that reported R\&D expenditures are not impacted by the choice of tax support instrument, it is recommended that any such $R \& D$ specific payroll incentives are not adjusted for when estimating labour costs.

$\rightarrow$ For example, if country A uses a hiring tax incentive offered through reduced payroll taxes (where a researcher costs "100" currency units comprising normal taxes less a "10" unit assumed wage tax subsidy), and country B uses an equivalent "10" unit hiring tax subsidy recovered separately through the corporate tax system, without this rule the measure of performed R\&D for the first year that the researcher was hired would incorrectly appear smaller in country A (90) than in country B (100). In both cases the labour costs should be recorded as 100 .

\section{Other current $R \& D$ costs}

4.23 These costs comprise non-capital purchases of materials, supplies, equipment and services to support R\&D performed by the statistical unit in the reference year. Examples are water and fuel (including gas and electricity); books, journals, reference materials, and subscriptions to libraries and scientific societies, etc.; imputed or actual costs of small prototypes or models made outside the statistical unit; and materials for laboratories (e.g. chemicals, animals, etc.). Other current costs include royalties or licences for the use of patents and other intellectual property rights, the lease of capital goods (machinery and equipment, etc.) and the rental of buildings to support R\&D performed by the statistical unit in the reference year. 
4.24 The distinction between purchasing R\&D (extramurally performed $R \& D$ not to be included as intramural $R \& D$ expenditure) and acquiring services to support intramural R\&D in the statistical unit may in some cases be blurred. See the text below on "Exclusion of acquired R\&D" for further guidance.

4.25 The category of other current R\&D costs includes costs for computer software that is used in the performance of R\&D for one year or less. It includes licences for or the acquisition of separately identifiable computer software, including program descriptions and supporting materials for both systems and applications software. The production costs (e.g. labour and materials) of internally produced software should be reported. Software from external vendors may be obtained through the outright purchase of rights or licences to use. Software used or licenced for more than one year should be reported under capital expenditures (see "Capitalised computer software" text below).

4.26 The costs associated with engaging persons who are not employed in the statistical unit but provide direct services that are integrated into the statistical unit's R\&D activities should be included in other current costs. Such persons include all on-site consultants and researchers from external organisations, research institutes, enterprises, etc., and the self-employed. Such persons also include technicians and other supporting staff employed by and hired through external statistical units, as long as they are contributing directly to the statistical unit's intramural R\&D performance. By convention for this manual, these R\&D personnel are termed "external R\&D personnel" to reflect that they are not receiving wages and salaries from the R\&D-performing statistical unit, as contrasted with the statistical unit's internal personnel who are receiving wages and salaries from the R\&D-performing statistical unit. Such costs should be separately identified in other current costs as "external R\&D personnel" costs. The distinction between purchasing R\&D (extramural R\&D) and acquiring consultancy services to support intramural $R \& D$ in the statistical unit (other current costs) may in some cases be blurred. See below, "Distinguishing between intramural and extramural costs related to labour", for classification guidance.

4.27 The distinction between acquiring external personnel services to support intramural R\&D in the statistical unit (other current costs, external personnel subcategory) and acquiring general services to support intramural R\&D in the statistical unit (other current costs, but not part of the external personnel subcategory) can in some cases be difficult to establish. How such current costs are reported will depend primarily on the details available from the statistical unit's internal R\&D financial accounts; regardless, the reporting of such $R \& D$ cost data should be consistent with how $R \& D$ personnel data are reported. See Chapter 5, Section 5.2, for their treatment in R\&D personnel data.

4.28 As noted in Chapter 5, the costs for doctoral and master's students who are engaged in the statistical unit's R\&D projects or activities but are 
not employed by the statistical unit should be included in the other current costs (external R\&D personnel) totals. These costs include research grants or scholarships that are tracked by or through the statistical unit.

4.29 Administrative and other overhead costs (e.g. office, information and telecommunications, utilities, insurance) should also be included in other current costs, prorated if necessary to exclude non-R\&D activities within the same statistical unit. Such prorated costs for indirect or ancillary services should be included here, whether carried out within the statistical unit or hired or purchased from outside suppliers. Examples include security; storage; the use, cleaning, repair and maintenance of buildings and equipment; computer services; and the printing of R\&D reports. Prorated costs should be included for staff of central computer departments and libraries and for staff of central finance or personnel offices. Interest charges should be excluded.

4.30 Statistical units that both perform intramural R\&D and fund extramural R\&D may include the administrative cost for preparing and monitoring extramural $R \& D$ contracts as part of R\&D other current costs, but not as labour costs. The raising, management and distribution of funds for $R \& D$ grants to performers by ministries, research agencies, foundations or charities should not be included as R\&D.

4.31 For the purpose of measuring R\&D for the SNA, expenditures for the purchases of materials and for the purchases of services should be separately identified. However, consideration should be given to data quality issues and to whether the response burden would be greatly increased.

\section{Allocated $R \& D$ costs within an enterprise group}

4.32 Consistent with international accounting standards, some enterprises that are part of an enterprise group (especially MNEs) record large R\&D payments to other members in the same group (especially foreign parents) as support for $R \& D$ within the enterprise group without actually receiving any $R \& D$ in return. Such "transfers" should be excluded from the intramural expenditure totals of the paying member and reported as funding for extramural R\&D. From the perspective of the R\&D-performing member that is the recipient of such group R\&D payments (e.g. foreign parent), if it gets allocations from its members without having to deliver R\&D in return, those funds are part of its intramural R\&D expenditures and should be categorised as external sources of funds. It is acknowledged, however, that based on practical considerations the bookkeeping accounts of the receiving unit of such inter-company allocations may not identify the funds as an external source of funds for intramural $R \& D$, but rather treat them as internal funds (similar to using retained earnings to fund its R\&D). See also Chapter 11 on R\&D globalisation. 


\section{Indirectly paid current costs}

4.33 R\&D activities may incur costs that are often not paid by the sector but borne by institutions classified in other sectors of the economy, usually the Government sector. Two examples are discussed below.

$\rightarrow$ Example 1. Rents for research facilities

4.34 In many countries, responsibility for "housing" public institutions (including universities) lies with a central agency that may not be an R\&D performer and therefore may not be surveyed. Or, if surveyed as part of the Government sector, its accounts may not reflect the functional breakdown between R\&D and other activities. This situation is particularly relevant for the Higher education sector.

4.35 In some cases, such facilities are available to institutions free of charge and are not accounted for in the institutions' books. In other cases, the institutions pay a rent to the owner of the facilities. To obtain a realistic cost of $R \& D$, all fees and rents associated with R\&D should in principle be included in expenditure data. Where the fee or rent is charged to a unit, this is easily done. If, however, there is no such charge, it may still be desirable to calculate an amount that represents the user cost of the facilities or the "market value". This may be included in other current costs. Care must be taken to avoid the double counting of costs between the suppliers and recipients of these services.

$\rightarrow$ Example 2. Operations and maintenance of research facilities

4.36 There are examples where the government owns and maintains special facilities that are used solely for R\&D activities. Such facilities are used both by government (including the agency that owns the facility and other government agencies) and non-government (generally business) performers for approved R\&D projects. When used by other government or non-government performers, user charges - which might include operation and maintenance (O\&M) costs - that are paid to the facilities owner are part of the current costs reported by the R\&D performer using the facilities. Such O\&M costs that are recovered in user charges should be excluded from reports from the government agency that owns the facilities in order to avoid the double counting of such expenditures.

4.37 However, if the facilities are in use only a couple of times per year, the owner may have ongoing and continual O\&M costs in order to keep the R\&D facilities ready for use. If the owner did not pay those costs, the R\&D facilities could not be used by the government owner or anyone else for an R\&D project. If such ongoing costs are not included in user charges (or in any other indirect charges) paid by government and non-government performers, then they may be included as intramural expenditure, in other current costs, by the government unit that owns the facility. 


\section{Depreciation and amortisation costs (excluded from intramural $R \& D$ totals)}

4.38 The depreciation costs of physical assets used in R\&D should not be included in the intramural R\&D expenditure totals. Similarly, the amortisation costs of intangible assets used in R\&D should not be included in the intramural R\&D expenditure totals. However, it is often the case that such costs of fixed capital used for R\&D are included in the reporting unit's internal R\&D financial accounts; they tend to be included under their other current cost category.

4.39 To avoid misreporting on R\&D surveys, it is recommended to collect combined depreciation/ amortisation costs as an item separate from the $R \& D$ cost categories, or at least to state clearly that these costs should be excluded from intramural R\&D expenditure totals.

\section{Principle of valuation for R\&D expenditure: Purchasers' prices}

4.40 R\&D expenditure totals should be collected and reported at purchasers' prices. Purchasers' prices are the amounts paid by the purchasers, excluding the deductible part of value-added taxes (VAT) and similar taxes. Purchasers' prices reflect the actual costs to the users. This means that the valuation of current and capital expenditures on goods and services for R\&D is the total price paid by the reporting unit including any taxes on products, which act to increase the price paid, and the price-reducing effect of any subsidies on the products purchased.

$\rightarrow$ For example, an enterprise buys "100 (currency units)" worth of materials to be used for R\&D. "60" are for material A taxed at $10 \%$ and " 40 " are for material $\mathrm{B}$ which is subsidised at $4 \%$. In addition, there is a fully deductible VAT tax of $15 \%$. In this case, the relevant measure of R\&D cost is 100 plus $(60 * 10 \%)$ minus $(40 * 4 \%)$, or $(100+6-1.6)=104.4$. The $15 \%$ reclaimable VAT does not contribute to the measure of $R \& D$ costs.

\section{Deductible value-added tax (excluded from intramural R\&D totals)}

4.41 Statistical offices should be careful to ensure that deductible taxes on products, such as some instances of VAT, are not included in the reported estimates. A market producer is able to recover the costs of any deductible VAT payable on their purchases by reducing the amount of their own VAT liability (to government) with respect to the VAT invoiced to its own customers. In line with the SNA and for purposes of international comparison, a net system of recording VAT should be followed. Under the net system, VAT is recorded as being payable by purchasers, not sellers, and only by those purchasers who are not able to deduct it.

4.42 For the Business enterprise sector, the separate recording of VAT payable on inputs is part of standard accounting procedures by firms and is deductible if offset against any VAT charged on output sold in the market. This rule should equally apply to firms whose turnover may be temporarily 
insufficient to recoup the paid VAT. Statistical units should be advised of these necessary adjustments in reporting their R\&D expenditure totals. In the case of the Government sector, VAT payable on inputs is often deductible and therefore separately identifiable.

4.43 More difficulties may arise in the Higher education and the Private non-profit sectors where VAT included in goods and services purchased as part of an R\&D project may not be deductible; it will therefore be regarded by the respondents as a legitimate part of their expenditures. Countries should make every effort to exclude deductible VAT from expenditure figures for these sectors. It is recommended that figures forwarded for international comparison should exclude deductible VAT.

\section{Capital R\&D expenditures}

4.44 Capital R\&D expenditures are the annual gross amount paid for the acquisition of fixed assets that are used repeatedly or continuously in the performance of R\&D for more than one year. They should be reported in full for the period when they took place, whether developed in-house or acquired, and should not be registered as an element of depreciation.

4.45 Such expenditures, which include purchases and other costs associated with the acquisition or formation of fixed assets, are termed "capital expenditures". In general, fixed assets consist of both tangible (also called physical) fixed assets (such as buildings and structures, transport equipment, other machinery and equipment, etc.) and intangible fixed assets (such as computer software and mineral exploration rights).

4.46 The measurement of capital expenditures for R\&D focuses on traceable transactions for capital used in R\&D rather than the economic cost of owning and using assets for R\&D. While the cost of using assets owned by third parties for intramural R\&D is to be reported as "other current R\&D costs", capital R\&D expenditures are a separate category to be reported on an "as acquired" basis. In order to avoid double counting capital costs, all depreciation and amortisation provisions for buildings, plant and equipment and other intangibles, whether real or imputed, should be excluded from the measurement of intramural R\&D expenditures (see earlier text on Depreciation and amortisation costs).

\section{Types of fixed assets used for $R \& D$}

4.47 The most relevant types of assets used for R\&D for which capital R\&D expenditures should be compiled are:

- land and buildings

- machinery and equipment

- capitalised computer software

- other intellectual property products. 


\section{Land and buildings}

4.48 This category includes land acquired for R\&D use (e.g. testing grounds, sites for laboratories and pilot plants) and buildings constructed or purchased for R\&D use, including major improvements, modifications and repairs. Since buildings are produced assets and land is a non-produced asset in National Accounts, R\&D expenditures for land and for buildings should be separately identified whenever possible.

4.49 When a new building is purchased or constructed for mixed use, the R\&D share of those capital expenditures is often difficult to quantify, and therefore the share element often is ignored in statistical compilations of $R \& D$ expenditure. See the text below on "Identifying the R\&D use of capital expenditures" for suggestions on how to estimate the R\&D content of capital expenditures.

4.50 The purchase of new research equipment often might be included in the cost of new buildings and not separately identifiable in the reporting unit's accounting records. This could result in an underestimation of the "machinery and equipment" component in total capital R\&D expenditures. Reporting units should be explicitly encouraged to separately identify and include such equipment purchases in the relevant fixed asset category.

\section{Machinery and equipment}

4.51 This category covers major (i.e. capitalised) machinery and equipment acquired for use in the performance of R\&D. For the purpose of measuring R\&D for National Accounts, expenditures on machinery and equipment should be identified by more detailed breakdowns, including "information and communications equipment" and "transportation equipment". However, consideration should be given to data-quality issues and to whether the response burden would be greatly increased.

\section{Capitalised computer software}

4.52 This category includes the costs of computer software that is used in the performance of R\&D for more than one year. It includes long-term licences or the acquisition of separately identifiable computer software, including program descriptions and supporting materials for both systems and applications software. The production costs (e.g. labour and materials) of internally produced software should be reported. Software from external vendors may be obtained through the outright purchase of rights or licences to use. Software used or licensed for one year or less should be reported under current expenditures (see earlier text on "Other current R\&D costs").

\section{Other intellectual property products}

4.53 This category includes the costs for purchased patents, long-term licences, or other intangible assets that are used in R\&D and which are in use for more than one year. Other intangibles that can be reported in a unit's internal 
financial accounts, such as marketing assets or goodwill, should not be included (see text on "Comparisons with capital investment reported in SNA").

\section{Conventions for distinguishing between current and capital items}

4.54 In measuring actual capital expenditure, small tools and instruments and minor repairs and improvements to existing buildings will normally be excluded: as in most accounting systems, these items are usually treated as current cost accounts. The boundary between "minor" and "major" items varies slightly across countries according to their taxation practices and across different businesses and institutions in the same country according to their accounting practices. These differences are rarely significant, and it is neither necessary nor practical to insist on any rigid standard. Thus, national conventions will govern allocations to current or to capital expenditures. Nevertheless, in those countries where expenditures on very expensive prototypes (e.g. aircraft) or equipment with a limited life (e.g. launching rockets) are considered current costs, such conventions should always be made explicit.

4.55 Although payments for current purchases of books, periodicals and annuals should be assigned to other current costs, expenditure for the purchase of complete libraries or large collections of books, periodicals, specimens, etc. should be included in the totals under expenditures on major equipment, especially if made when equipping a new institution.

\section{Identifying the R\&D use of capital expenditures}

4.56 Occasionally, the R\&D share of a fixed asset may be known at the time of acquisition. In this case, the appropriate portion of the expenditure for the acquisition of the asset should be attributed to R\&D capital expenditures. More often, when the R\&D share of the asset is not known and a fixed asset will be used for more than one activity and neither the R\&D nor any of the non-R\&D activities predominates (e.g. computers and associated facilities; laboratories used for R\&D, testing, and quality control), the costs should in principle be prorated between R\&D and other activities. This proportion could be based on the number of R\&D personnel using the facility, compared to total personnel, or on administrative calculations already made (e.g. the R\&D budget may be charged a certain portion of the capital cost, or a certain proportion of time or floor space may be assigned to R\&D).

4.57 Occasionally, a statistical unit (usually a government agency or large enterprise) may make major investments in large fixed assets that are considered to be "first of their kind" or offer previously unavailable capabilities. Because of their potential contribution to innovative activities, reporting units may be inclined to include all such construction costs as R\&D. For international comparability, however, only the costs that are specifically identified as capital to be used for R\&D should be included as intramural R\&D. Generally, such costs should not be reported as current R\&D expenditures, but should be reported as capital R\&D expenditures. 


\section{Sale of capital assets used for R\&D}

4.58 The sale or transfer of fixed assets originally acquired for R\&D creates a problem. Their disposal could be considered as a disinvestment in R\&D. However, no adjustment should be made to record capital expenditures, and the statistical unit's capital R\&D expenditures should not be reduced accordingly, either currently or retrospectively (for the years in which the capital costs were recorded). Current revisions can cause anomalies such as negative intramural R\&D expenditures. Retrospective revisions are difficult and confusing. Ideally, the purchase of the used R\&D capital equipment by another domestic R\&D performer should be excluded from measured $R \& D$ expenditures, in order to avoid double counting as R\&D at different points in time. In some cases, the assets sold may be used for other purposes or transferred to an R\&D performer abroad, in which case there would be no double counting of R\&D.

4.59 Table 4.1 provides a summary of the cost categories described above. Individual country circumstances will determine the level of the optional details that are collected.

Table 4.1. Summary of intramural R\&D expenditure categories

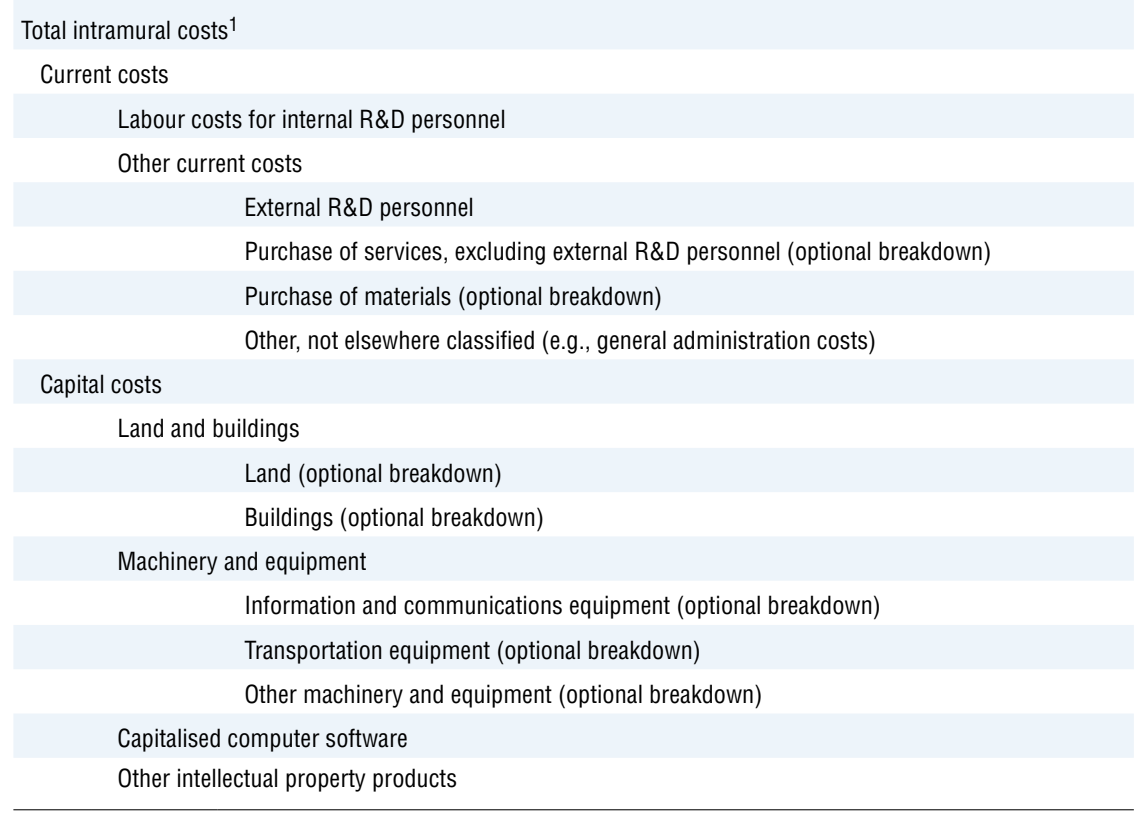

1. Depreciation should not be included in intramural expenditure totals, but should be reported separately. 


\section{Topics and challenges in compiling intramural R\&D totals}

\section{Exclusion of acquired R\&D}

4.60 The acquisition costs of R\&D from other units or sectors should not be included in the intramural R\&D expenditures of the reporting statistical unit or sector. For the acquisition of services closely related to intramural R\&D activities, it may be difficult conceptually to differentiate costs for intramural R\&D from costs for extramural R\&D. If these services are separate $R \& D$ projects specified in a contract, without detailed specifications given by the project manager of the funding unit, the expenditures can in most cases be regarded as funding for extramural R\&D. If they are certain tasks (not necessarily R\&D as such) necessary for the intramural $R \& D$ of the unit but contracted out, they can generally be regarded as intramural R\&D expenditure (other current costs).

4.61 It may be especially difficult for large enterprises to differentiate costs for intramural R\&D from those for extramural R\&D. Consistent with international accounting standards, their annual financial reports on R\&D expenses often will combine internal funds for both intramural R\&D and extramural R\&D as long as the R\&D performed is "for the benefit of" the reporting firm. Countries should provide explicit guidance to reporting units to minimise the possibility of any inconsistent differentiation of funds for intramural R\&D and extramural R\&D as recommended in this manual.

\section{Distinguishing between intramural and extramural costs related to labour}

4.62 If external personnel (self-employed or employed through other statistical units) are fully integrated into the $R \& D$ activities of the reporting statistical unit, and their work is managed by this performing unit, the costs for these personnel should be included in intramural R\&D as other current costs, preferably in a separate external R\&D personnel subcategory. It is recommended to separately identify the number and related full-time equivalents (FTEs) of these "non-employees", and not to include those totals with the number of employees in the performing unit (see Chapter 5). To avoid double counting, these totals should not be reported as R\&D costs and R\&D personnel by the delivering statistical unit where these external personnel are employed.

4.63 The costs for consultants who provide R\&D in fulfilment of a specific order (acquisition), but not as an integrated part of the reporting unit's R\&D projects, should be treated as funding of extramural R\&D by the reporting unit receiving the $R \& D$. The delivering statistical unit where these consultants are employed should report this activity as intramural R\&D expenditure.

4.64 A special case is personnel working remotely from abroad on a longterm basis. Their costs for such activity should usually be reported as funding for extramural R\&D (performed in the Rest of the world) in the reporting domestic unit. In the foreign unit, those costs should be reported as part of intramural 
R\&D expenditure. This manual cannot recommend a precise definition of what constitutes a "long-term" assignment, and it may be depend on the contractual or administrative arrangements with the hosting institution.

\section{Identifying intramural R\&D performed outside the national territory}

4.65 The concept of intramural R\&D expenditure is intended to measure the R\&D performed within the statistical units that are resident in the national territory of the compiling country. Some of the expenditures may, however, have occurred off-premise and even abroad. For example, intramural R\&D expenditures might include:

- costs for a floating ocean research vessel engaged in marine life studies

- costs for an MNE parent's engineering staff assigned on a short-term basis to work in its foreign affiliate where the domestic parent continues to pay staff salary and expenses

- costs for maintaining and utilising a permanent research presence in Antarctica

- costs for a higher education researcher to undertake field work in a location outside of the compiling country.

4.66 In classifying "intramural" R\&D that takes place outside of the national territory of the compiling country, priority should be given to the organisational structure of an activity rather than to the literal location of where the activity takes place. It is difficult to provide precise guidelines for such classification decisions, but at a minimum intramural R\&D that has occurred abroad should include only R\&D that is performed by a statistical unit to fulfil its own objectives and if the statistical unit has invested its own financial resources and $R \& D$ personnel in the activity. The R\&D must take place under the responsibility of the reporting unit, and the reporting unit must meet the economic residence criterion described in Chapter 3 (Institutional Sectors and Classification).

\section{Incomplete and inaccurate coverage of intramural $R \& D$}

4.67 All R\&D activity carried out in the statistical unit should be reported. However, there are many reasons why there may be under-coverage of a statistical unit's R\&D activity. Several of the more common reasons for under-coverage are:

- the R\&D occurs inside the statistical unit, but outside specific R\&D departments, such as pilot testing or initial production preparation, or during general technology development activities

- the R\&D is fully integrated in a development contract for a specified product (e.g. when a relatively small amount of R\&D is included in a very large defence procurement for fighter planes)

- the $\mathrm{R} \& \mathrm{D}$ is financed by customers (contract research), but not recognised as $R \& D$ in the financial accounts of the performing units (but rather possibly as the costs of sales of technical services). 
4.68 Finding effective solutions to these under-coverage problems can be challenging. One common solution used by statistical offices is active followup with respondents during data retrieval and data validation. A complicating factor for both respondents and statistical offices, however, is that the accounting systems of the statistical units may lack the detailed $R \& D$ expenditure information requested, or it is too burdensome for the respondents to dedicate the resources required to provide these detailed expenditures.

4.69 On the other hand, over-reporting of R\&D can also occur for different reasons. Statistical units may record in their financial accounts innovation expenditures that extend beyond an R\&D activity; for example, they may report all information technology costs or training costs for R\&D personnel as R\&D even if those costs are not actually related to R\&D.

4.70 There are multiple possible sources of misreporting of $R \& D$ within enterprise groups, and particularly within a multinational enterprise group (MNE). For example, intercompany transfers and company-specific cost allocation requirements complicate the collection of accurate $R \& D$ expenditure totals. (See Chapter 11 on Globalisation for additional guidance on measuring R\&D in MNEs.)

\section{Measuring capital expenditures as a service}

4.71 R\&D is a service activity and the outcome a service product. As previously detailed, $R \& D$ performance is derived by summing the $R \& D$ costs (intramural expenditures) of a statistical unit. Those expenditures represent the amount of money spent during a specific reference period on labour and other non-capital items plus the gross amount paid during that same reference period for the acquisition of fixed assets that are used repeatedly in the performance of R\&D. In the unusual situation where the only R\&D-related activity of the statistical unit during the reference period is to pay for a new building that will be used in their future R\&D activities, those capital expenditures effectively are being reported as a service activity (performance) in the current reference period. The use of the building for R\&D in future periods will not be recorded as part of the intramural R\&D in those future periods. Understanding these reporting conventions will assist in interpreting R\&D expenditure totals and in making comparisons with other sources on aggregate R\&D spending that are compiled differently, including R\&D reported in National Accounts and undertaken within MNEs (see Chapter 11 on Globalisation).

\section{Comparisons with capital investment reported in the SNA}

4.72 The accounting for capital R\&D expenditures in this manual differs from that in National Accounts. The 2008 edition of the SNA renamed the category of intangible fixed assets as "intellectual property products" and extended coverage of the produced asset boundary to include $R \& D$. As a result, $R \& D$ is considered as a capital asset in the SNA, which uses measures of R\&D production and investment based on adjustments to Frascati R\&D intramural data. By comparison, the notion 
of capital R\&D used in this manual refers to the annual gross amount paid for physical and intangible assets to be used for R\&D performance. This manual's R\&D performance totals are conceptually close to the SNA concept of gross output of $R \& D$, but these two measures differ, among other things, in the way in which the cost of capital used for R\&D is treated (OECD, 2009).

4.73 Whereas capital expenditures are included in intramural expenditure totals in this manual (and depreciation costs are excluded), National Accounts deal separately with capital investment expenditures (capital account for the respective assets) but incorporate measures of the current user cost of existing capital. The user cost of existing capital comprises depreciation for obsolescence and wear and tear, in addition to a measure of the opportunity cost of funding the capital asset. Similar adjustments are not made by statistical offices compiling $R \& D$ performance measures (intramural R\&D expenditures). More details on the linkages between the guidance for these two frameworks is to be found online in the annex guidance to this manual available at http://oe.cd/frascati.

\subsection{Funding of $R \& D$}

4.74 R\&D and the funds to cover the costs of R\&D involve significant flows between units, sectors and countries. In order to respond to the needs of policy makers, analysts and national accountants charged with capitalising R\&D, every effort should be made to trace the different flows of funds and the categories of funds for R\&D, from their original source to their ultimate destination.

4.75 From the perspective of performance, $R \& D$ is conducted by the statistical unit with funds either from the statistical unit's own sources (internal) or from sources outside of the statistical unit (external). These concepts are further clarified in Section 4.3 on the Internal and external sources of funds.

4.76 From the perspective of funding, R\&D funds pay for either the costs of $R \& D$ performance within the statistical unit (intramural) or the costs of $R \& D$ performance outside of the statistical unit (extramural).

4.77 There can be a flow of R\&D funds between statistical units either with (exchange) or without (transfer) compensatory return flows of R\&D from the performer. These concepts are further clarified in Section 4.3 on the Transfer and exchange categories of funds for R\&D.

4.78 R\&D activity often overlaps these discrete performer and funding categories, making it difficult at times to identify accurately the performers and sources of R\&D funds. For example, a government research laboratory might provide funds for $R \& D$ under a contract to an aerospace firm, and that firm might use part of those funds to purchase R\&D from another firm specialising in research services. The aerospace firm also might use some of its internal funds to purchase customised R\&D from the research services firm as an integral input into a separate intramural project. The identification of the funder(s) and the performer(s) is complex. A further complication is that all extramural R\&D for 
the funding unit is some other performing unit's intramural R\&D. It is important then to define clearly what each reporting category represents so as not to double or even triple count the R\&D expenditures, nor miss them entirely.

\section{Approaches to measuring flows of R\&D funds}

4.79 R\&D and R\&D funding flows may be measured in two ways. One approach is performer-based reporting of the sums that a statistical unit or sector has received from another statistical unit or sector for the performance of intramural $R \& D$ during a specific reference period. The funds received for $R \& D$ performed during earlier periods or for R\&D not yet started should be excluded from the sources of funds reported for the current reference period. The second approach is funder-based reporting of the sums that a statistical unit or sector reports having paid or committed itself to pay to another statistical unit or sector for the performance of $R \& D$ during a specific reference period.

4.80 Performer-based reporting is strongly recommended for the collection of $R \& D$ data. The performer is in the best position to know whether funds were actually used for R\&D, the amount and sources of funds used, and the year in which the R\&D activity took place. However, funder-based reporting may be helpful in obtaining R\&D information about the intentions of the units funding the R\&D.

4.81 Table 4.2 summarises the intersection of units performing R\&D and the sources of R\&D funds. The amounts reported in cell (i) plus cell (ii) represent total intramural R\&D expenditures and the sources of those funds (as reported by the performer). Cell (iii) represents the amount of money paid/transferred to other units for extramural $R \& D$ performance (as reported by the funder).

Table 4.2. Intersection of performing and funding R\&D

\begin{tabular}{lll}
\hline & R\&D performance within the unit & R\&D performance outside the unit \\
\hline Internal sources of funds & $\begin{array}{l}\text { (i) Intramural R\&D performed } \\
\text { with internal funds }\end{array}$ & $\begin{array}{l}\text { (iii) Funding extramural R\&D } \\
\text { performance using internal funds } \\
\text { External sources of funds }\end{array}$ \\
$\begin{array}{ll}\text { (ii) Intramural R\&D performed } \\
\text { with external funds }\end{array}$ & $\begin{array}{l}\text { (iv) Funding extramural R\&D } \\
\text { performance using external } \\
\text { funds }\end{array}$ \\
\hline
\end{tabular}

4.82 Cell (iv) represents the amount of money received by one recipient unit from a second "originating" unit that is subsequently paid/transferred (that is, subcontracted/sub-awarded) to a third sub-recipient unit for extramural R\&D performance. To avoid double counting, the sub-recipient unit should report the amount of (iv) as intramural R\&D externally funded by the "originating" unit. The initial recipient of external funds should in principle not include the amount in any of its R\&D totals. National statistical offices may need to include explicit questions in R\&D surveys to identify, and eliminate, such "pass-through" R\&D funds from reported totals. 


\section{Schematic presentation of R\&D and R\&D funding flows}

4.83 Figure 4.1 illustrates the various possible flows of $R \& D$ and funds used for R\&D from the perspective of a survey respondent that is an R\&D performer. These flows can be generalised to measure the R\&D performance of a statistical unit, sector or country. It should be explicitly noted that flows of funds used for R\&D are not identical to flows of R\&D. Transfer funds require no compensatory flow of R\&D.

4.84 From the perspective of a statistical unit performing $R \& D$, areas 1 and 2 of Figure 4.1 are surveyed. The key question being answered, after having first determined how much R\&D has been performed by the unit, is "where do the funds come from?" The sources of R\&D funds are divided into two main categories: internal sources (area 1 of the figure) and external sources (area 2 of the figure). External sources, or funds received from outside the statistical unit, should be classified by R\&D funding sector. See Section 4.3 (Source of funds, by institutional sector).

4.85 From the perspective of a statistical unit funding $R \& D$, areas 1 and 3 of Figure 4.1 are surveyed. The key question being answered is "where do the funds go?" The recipients of R\&D funds are classified into two main categories: own unit (area 1 of the figure) and external recipients (area 3 of the figure). External recipients, or extramural R\&D funding provided, should be classified by R\&Dperforming sector. See Sections 4.3 on "Measurement of funds for extramural R\&D" and "Sales and purchases of R\&D".

4.86 An interpretation of the graphed components follows:

$R \& D$ performed by the unit (total intramural $R \& D$ expenditures = performance):

(1) $=$ R\&D performed by the unit and funded by the unit (with internal funds)

(2) $=R \& D$ performed by the unit with funding from others (with external funds received)

(4) = exchanges (e.g. perform R\&D for sale)

(7) $=$ transfers (e.g. recipient of grants, grantee)

R\&D funding by the unit:

(1) = Funding by the unit for intramural R\&D performance (i.e. performed by the unit)

(3) = Funding by the unit for extramural R\&D performance (i.e. performed by other units)

(5) = exchanges (e.g. purchase of R\&D)

(6) = transfers (e.g. grants source, grantor) 
Figure 4.1. Funding flows from the perspective of an R\&D performer

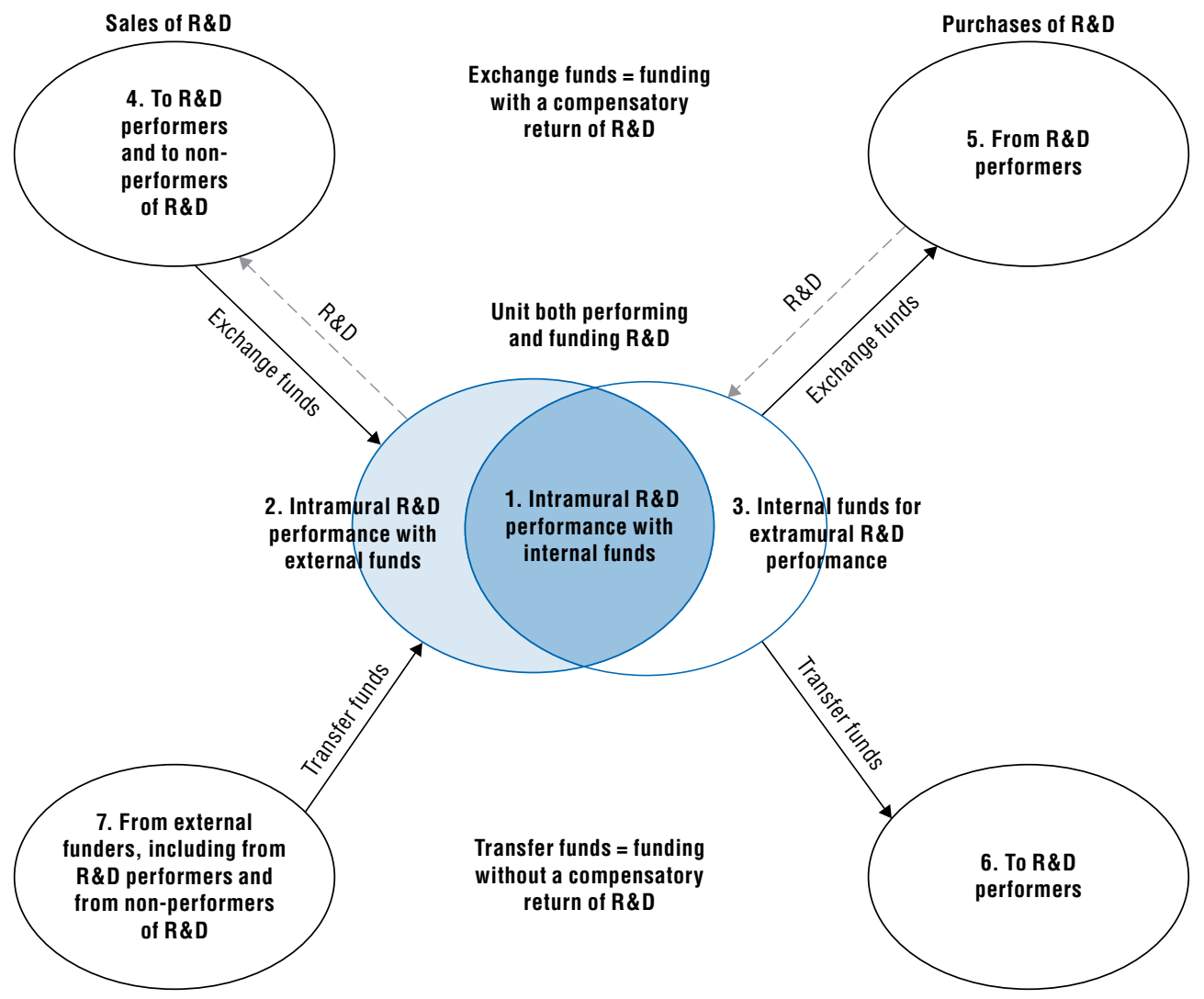

4.87 In order to avoid double counting (either in terms of R\&D performance or funding totals), it is important to determine that funding by the unit for $R \& D$ performance by others (extramural R\&D performance) includes only the unit's internal funds. External funds that the unit receives and are subsequently passed through or subcontracted to others should not be included as R\&D funding by the unit. This determination can be challenging.

4.88 For completeness, it is possible for an R\&D performer to provide R\&D to others without any compensatory flow of funds in return. For example, this occurs when an R\&D performer provides free use of its $R \& D$ to the open-source community.

\section{Internal and external sources of funds}

4.89 Funds to pay the costs of performing R\&D may come from inside the unit (internal) or outside the unit (external). 


\section{Internal funds}

4.90 What is defined as internal sources of funds to support R\&D depends on the sector of the reporting unit and, to some degree, on national considerations. Internal R\&D funds represent the amount of money spent on R\&D that originates within the control of and are used for $R \& D$ at the discretion of a reporting statistical unit. Internal $R \& D$ funds do not include $R \& D$ funds received from other statistical units explicitly for intramural R\&D. The term "internal funds" is preferred over "own funds" since the latter may have a broader interpretation among some respondents. For example, research grantees may inaccurately (in terms of conventions used in this manual) consider public funds as their "own funds" once they have been awarded the research grant.

4.91 In the Business enterprise sector, internal funds include for instance, the reserve or retained earnings (i.e. profits that have not been redistributed as dividends), sales of the unit's ordinary products (other than R\&D), raising capital in the form of equity, debt or other hybrid instruments (e.g. funds raised on financial markets, loans from banks, venture capital, etc.). Deductions from income tax liability arising as a result of government incentives for R\&D carried out in the past are also internal funds, as they need not be used to fund R\&D in the current reference period (see Section 4.3 on “Tax incentives encouraging R\&D”).

4.92 In the Higher education sector, internal funds include, for instance, receipts from student enrolment charges, income from endowments, and income from life-long learning and the provision of other services. The convention for international comparisons is that public general university funds (GUF), which is a type of government funding to higher education institutions, are not classified as internal funds (see Chapter 9).

4.93 As another example, a research institute may finance some of its work through receipts from royalties and profits from the sales of goods and services. Although these funds are received from other units and other sectors, they should not be considered as transactions for R\&D but as "retained receipts" and therefore internal sources of funds of the performing unit itself, since the purchasers of the institutes' goods and services did not intend to provide funds for R\&D.

4.94 Note that "intramural" is not synonymous with "internal". The dichotomy is made clear by noting that not all intramural performance is paid with internal funds (see Figure 4.1).

\section{External funds}

4.95 External R\&D funds refers to the amount of money spent on R\&D that originates outside the control of a reporting unit.

4.96 Funds received from other statistical units for the funding of $R \& D$ performed during earlier periods, or for the funding of $R \& D$ not yet started, should not be included for the current reference period reports. They should be reported for the period during which the $R \& D$ they relate to is performed. 
4.97 Funds from grants, gifts and philanthropy received explicitly for R\&D are external funds. Even though the receiving statistical unit may have considerable leeway on how and when such funds are used in specific intramural R\&D activities, the source of such funds is still external to the receiving unit. The amount should be reported for the period when expended on R\&D (which may cover multiple reporting periods) and not when the grant/gift/philanthropy was received. R\&D philanthropy from individual donors, particularly to address disease-specific research, is a rising phenomenon. As is detailed in Chapters 3 and 10, the Private non-profit sector, which includes individuals, should be reported as the external source of such funds. Gifts and philanthropy received with no requirement or expectation that any of the funds are necessarily to be used for $R \& D$ are classified as internal funds if used for $R \& D$, at the discretion of the receiving statistical unit.

4.98 The convention for international comparisons is that GUF should be reported as external government funds (see Chapter 9).

4.99 The convention for international comparisons is that R\&D funds received by a member of a business enterprise group from other members of the same business enterprise group should be reported as external funds (see Chapter 7, Section 7.7).

\section{Tax incentives for encouraging $R \& D$}

4.100 Some governments, principally at the central/federal level but also sometimes at the regional/local level, provide dedicated forms of tax relief with the aim of encouraging the funding or performance of $R \& D$, particularly in business enterprises. While such tax relief is a form of public financial support for $R \& D$, the quantification of such support should not be included in the reported government source of funds for R\&D performance totals. Guidance on the separate measurement of this type of support is provided in Chapter 13, while guidance on addressing the potential impact of $R \& D$ tax incentives on the reported labour costs of $R \& D$ personnel is provided in Section 4.2 of this chapter.

4.101 One major difficulty is that the forgone tax payments or potential direct transfers of funds to the enterprise or institution claiming support in a given period usually correspond to past R\&D activity. At the time when deciding on R\&D investments, the exact amount of any tax relief is generally not known precisely. Because of the practical difficulties in drawing an explicit link between tax support and R\&D performance, it is recommended that the cost of $R \& D$ performance that is "funded" on the expectation of future revenue or forgone tax, or claims realised in the current period against past performance, should be reported as internal funds.

4.102 Separately from intramural R\&D expenditure totals reported for the reference year, it may be useful to have information on both (i) the amount of future tax relief or future compensation that is expected from the R\&D tax incentive system and (ii) the amount of tax refund or forgone tax received in 
the survey reference period. Countries wishing to introduce questions on tax incentives in their R\&D surveys should ensure that these questions do not distort the reported levels of intramural R\&D and the breakdown of sources of funds that respondents are asked to report.

4.103 In countries where the provision of tax incentives is explicitly part of the government's budgetary policies to support R\&D and this obeys predictable patterns of funding for R\&D performance, surveys may include a separate item to identify the level of tax support received for reported R\&D performance in the reference period. For the purposes of internal national reporting, some countries might classify these amounts as government funds. However, the convention for international comparisons is to exclude these amounts from government funding totals and to report them as internal funds. If such tax benefits are reported as government funds, the amounts should be identified separately to ensure the international consistency of reporting and to avoid double counting with tax expenditure figures reported under the guidance set out in Chapter 13.

\section{Source of funds for R\&D}

4.104 Table 4.3 identifies the funding source details that should be collected - if relevant and if practical to do so - on R\&D surveys of institutions in each of the four main R\&D-performing sectors: Business enterprise, Government, Higher education and Private non-profit. In broad terms, there are five main sources for R\&D funding: Business enterprise, Government, Higher education, Private non-profit and the Rest of the world. Within each sector there are additional funding details that may be collected. The relative importance of various funding sources (and therefore the level of funding detail that is collected) will differ for each $R \& D$-performing sector and may vary depending on country-specific circumstances.

4.105 Internal funds used for intramural R\&D performance should be classified according to the sector of the statistical unit performing the R\&D.

4.106 GUF funds in support of intramural R\&D should be reported separately from other direct government funds for higher education R\&D performance (see Chapter 9, Section 9.4).

4.107 For the Government sector, it may be useful to design separately tailored surveys for R\&D performers in central/federal agencies and in provincial/ state agencies.

4.108 Funding from the "Rest of the world" includes the category "international organisations", which is defined to include supranational organisations. Different countries will identify different international organisations as relevant funding sources. For example, members of the European Union might include a funding category such as "European Union institutions and other bodies". 
Table 4.3. Identifying which sources of funds should be collected on R\&D performer surveys

\begin{tabular}{|c|c|c|c|c|}
\hline \multirow[b]{2}{*}{ Sources of funding } & \multicolumn{4}{|c|}{ Statistical unit performer being surveyed } \\
\hline & $\begin{array}{c}\text { Business } \\
\text { enterprise } \\
\text { sector }\end{array}$ & $\begin{array}{l}\text { Government } \\
\text { sector }\end{array}$ & $\begin{array}{c}\text { Higher } \\
\text { education } \\
\text { sector }\end{array}$ & $\begin{array}{l}\text { Private non- } \\
\text { profit sector }\end{array}$ \\
\hline Business enterprise sector & $x$ & $x$ & $x$ & $x$ \\
\hline Own enterprise (internal funds) & $x$ & - & - & - \\
\hline Other enterprises in the same group & $x$ & - & - & - \\
\hline $\begin{array}{l}\text { Other unaffiliated } \\
\text { enterprises }\end{array}$ & $x$ & - & - & - \\
\hline Government sector & $x$ & $x$ & $x$ & $x$ \\
\hline $\begin{array}{l}\text { Own agency/department/institution } \\
\text { (internal funds) }\end{array}$ & - & $x$ & - & - \\
\hline Central or federal (excludes GUF) & $X$ & $x$ & $x$ & $x$ \\
\hline Provincial or state (excludes GUF) & $x$ & $x$ & $x$ & $x$ \\
\hline Public general university funds (GUF) & - & - & $X$ & - \\
\hline Other government sector bodies & $x$ & $x$ & $x$ & $x$ \\
\hline Higher education sector & $X$ & $x$ & $X$ & $X$ \\
\hline $\begin{array}{l}\text { Own institution (internal } \\
\text { funds) }\end{array}$ & - & - & $x$ & - \\
\hline Other higher education institutions & - & - & $X$ & - \\
\hline Private non-profit sector & $X$ & $X$ & $X$ & $X$ \\
\hline $\begin{array}{l}\text { Own institution (internal } \\
\text { funds) }\end{array}$ & - & - & - & $x$ \\
\hline Other private non-profit institutions & - & - & - & $x$ \\
\hline Rest of the world & $X$ & $x$ & $X$ & $X$ \\
\hline Businesss enterprise & $x$ & $x$ & $x$ & - \\
\hline Enterprises in the same group & $x$ & - & - & - \\
\hline Other unaffiliated enterprises & $X$ & - & - & - \\
\hline Government sector & $x$ & $x$ & $\mathrm{X}$ & $x$ \\
\hline Higher education sector & $x$ & $x$ & $\mathrm{X}$ & $\mathrm{X}$ \\
\hline Foreign branch campuses & 一 & - & $X$ & - \\
\hline $\begin{array}{l}\text { Other higher education } \\
\text { institutions }\end{array}$ & - & - & $x$ & - \\
\hline Private non-profit sector & $x$ & $x$ & $\mathrm{X}$ & $\mathrm{x}$ \\
\hline $\begin{array}{l}\text { International } \\
\text { organisations }\end{array}$ & $x$ & $x$ & $\mathrm{X}$ & $x$ \\
\hline Total expenditures by performer & $x$ & $x$ & $X$ & $X$ \\
\hline
\end{tabular}

Note: $\mathrm{X}=\mathrm{R} \& \mathrm{D}$ funding from this source is to be collected and reported; - = not a relevant source of funding to collect from performers in this sector. 


\section{Transfer and exchange categories of funds for R\&D}

4.109 There can be a flow of R\&D funds between statistical units either with (exchange) or without (transfer) an actual or expected compensatory return flow of R\&D from the performer. To better satisfy policy-user requests and SNA statistical needs, it is recommended that countries report total intramural R\&D performance that is funded from external sources in these two categories. Separate categories could be collected for each source of external funds if considerations of the response burden and the data quality permit doing so.

4.110 On $R \& D$ performer surveys, there will be less misunderstanding or misinterpretation when using examples of transfers and exchanges (e.g. grants and contracts, respectively) than when using the terms "transfer" and "exchange".

\section{Transfer funds for R\&D}

4.111 R\&D transfer funds are funding flows from one statistical unit to another statistical unit to perform R\&D that does not require any good or service in return and where the funder is not entitled to any significant rights on the outcome of the R\&D it has funded. The unit that provides transfer funds for R\&D may impose some conditions on the performer, such as periodic reporting, compliance with the activity or project description set out in the terms of the agreement, or even public dissemination of research outcomes. Examples of transfer funds include grants, debt forgiveness, philanthropy, crowdfunding (unless this entails discounted prices for a new product), personal transfers such as gifts and GUF (by convention for international comparisons). To be included as $R \& D$ transfer funds, the funds should be intended by the originating source to be used for R\&D. Normally, the R\&D performer will retain most rights to the outcomes of the R\&D, which explains the transfer nature of this R\&D funding transaction.

4.112 There are examples of where institutions will transfer laboratory equipment or materials used for R\&D to institutions within and across sectors, located within and outside of the compiling country. A common example might involve a government or private non-profit institution providing such R\&D equipment in the context of international aid efforts. Such "in-kind" transfers do not entail monetary flows and therefore should not be included in intramural R\&D expenditure totals or in totals on extramural R\&D. However, for national reporting and analytical purposes, countries might find it worthwhile to separately identify and compile performer-reported totals on the "market value" of such in-kind donations; as noted, however, for international comparability they should not be included in reported R\&D totals.

\section{Exchange funds for R\&D}

4.113 R\&D exchange funds are funding flows from one statistical unit to another statistical unit in return for the performance of R\&D and the delivery of relevant R\&D outcomes. The unit funding the work incurs a delivery risk associated 
with the uncertainty of the project. Examples of exchange funds activities include R\&D purchases (sales from the perspective of the performer), R\&D outsourcing and contributions in the context of collaborative R\&D agreements.

4.114 The procurement of R\&D is one of the most common forms of the provision of $R \& D$ exchange funds. It includes funds paid to research services firms or other units performing R\&D under contract. From the perspective of the unit receiving the funds, they are part of the unit's intramural performance funded from external sources. It is possible that through a contract or procurement in some cases the unit funding the R\&D may forgo some of its rights to the outcomes of the research. For example, a government agency may give the performer exclusive rights on the resulting intellectual property on the condition that the government retains the right to use the R\&D outcomes for its own internal purposes. This case should also be considered as an instance of R\&D exchange funds, even if there may be an implicit transfer element.

4.115 A government agency funding an R\&D project through a procurement contract may wish to give away all rights on the outcome of the R\&D that has been contracted to a performer. Since such a decision is the funder's prerogative, the transaction that funds the $R \& D$ activity should still be considered as $R \& D$ exchange funds. There is a separate transfer of R\&D knowledge to society that is outside the scope of classifying intramural R\&D.

4.116 Tracking exchange fund flows may help meet the needs of policy analysts and economic researchers interested in R\&D outsourcing activities. Outsourcing refers to the total or partial movement of core or support business functions currently performed in-house to either non-affiliated external suppliers or affiliated enterprises located either domestically or abroad. International outsourcing is sometimes also termed "off-shoring".

4.117 In principle, the internal funds to support a unit's active participation in collaborative R\&D projects should be recorded as part of a unit's intramural performance. Each participant reports R\&D funding equal to the unit's contribution to the common project. If one unit has a dominant role in the project, the total R\&D can be reported as intramural for this unit, while the other participants report their funding (such as milestone payments and payments made under cost-sharing arrangements) as support for extramural R\&D paid to the dominant unit. However, if the consortium or partnership in charge of the collaborative project is a distinctive, separate legal entity, this will be a separate statistical unit and contributions made by all the partners should be considered as funding of extramural R\&D.

\section{Measurement of funds for extramural R\&D}

\section{Importance of measuring extramural $R \& D$}

4.118 To more fully understand the flows between R\&D performers and $R \& D$ funders, it is suggested that countries collect from all units with intramural $R \& D$ data on the amount of funds for extramural R\&D. To the extent practical, 
countries should also collect the breakdown between funds for exchange and funds for transfer and identify the recipient sectors of the funds. These data collections could be accomplished by including one or several funding type questions on surveys of R\&D performers. Those questions would address the information coverage represented by area 3 of Figure 4.1.

4.119 Summing individual statistical unit's intramural R\&D plus funding for extramural R\&D (areas 1 plus 2 plus 3 in Figure 4.1) allows a more complete picture of the unit's total R\&D activities. However, because of double counting, it is not meaningful to sum total intramural R\&D funds plus total extramural $R \& D$ funds for a sector or country. Extramural R\&D for one statistical unit is, in principle, intramural R\&D for another statistical unit.

\section{Measurement issues related to extramural R\&D}

4.120 As is the case for recipients of exchange and transfer funds, there will be less misunderstanding or misinterpretation by funders responding to survey questions when using more familiar terminology for these funding concepts.

- From the perspective of a unit that is purchasing $R \& D$, exchange funds are generally considered to be its "extramural R\&D expenditures".

- From the perspective of a unit that is granting R\&D, transfer funds are generally considered to be its "funding for extramural R\&D performance".

4.121 For the Business enterprise sector, most funds for extramural R\&D are expected to be exchange funds, that is, for the purchase and sale of $R \& D$. For the Government sector, the relative importance of one category over the other will likely be a function of the mission of the government unit/agency and the type of policy instruments at its disposal.

4.122 The borderline between funds for intramural and extramural R\&D is not always clear; hence, extramural R\&D funding may be incorrectly included in intramural R\&D reports. Surveys should specifically and clearly instruct respondents to exclude funding for extramural $R \& D$ performance from their reported intramural expenditures so as to avoid double counting.

4.123 The R\&D funder is likely to know whether the funds it is providing are for an exchange or for a transfer (no R\&D is expected in return). The R\&D funder also is likely to know to which unit or sector (extramural performer) the funds are being directly provided. They are unlikely to know details about the types of costs that the recipient spends those funds on (e.g. labour, materials) or the amount of those funds that may be subcontracted or sub-awarded to other units or sectors.

4.124 It should not be necessary to specify from which source purchased $R \& D$ (exchange $R \& D$ ) is funded, since normally this is funded from internal sources. However, the extensive - and increasing - use of sub-contracting, especially in the Business enterprise sector, is creating a number of challenges. If a business unit's external funds received from another business unit were 
originally public funds, the subcontractor may not know that the payment they receive originated in public funding sources. They may therefore report the funds coming from the contractor. Similarly, the contractor may not easily be able to specify whether internal or external funds were used to pay the subcontractor.

4.125 R\&D funding from external sources that is used to fund the purchase of $R \& D$ from another statistical unit should be excluded from intramural $\mathrm{R} \& \mathrm{D}$.

4.126 The purchase of R\&D should not be confused with the acquisition of licences or intellectual property resulting from previous R\&D work. The latter is not funding of R\&D.

4.127 Identifying flows of $R \& D$ and $R \& D$ funds among units in the same enterprise group is a particular challenge. Concerns for accuracy are compounded since the pricing of the R\&D may not reflect "market pricing", that is, the actual intramural costs. No specific guidance can be offered on how to correct for such misreporting except to emphasise that respondents should be encouraged to report actual costs.

\section{Measurement of funding extramural R\&D by non-R\&D performers}

4.128 An under-coverage problem arises when questions about funding flows to other units are included in surveys sent only to known or assumed $R \& D$ performers. The survey frames for R\&D performers often cover only the units active in R\&D. However, there are some units in each sector that fund extramural R\&D without carrying out R\&D themselves. Without undertaking a specific survey, these units are unlikely to be questioned, and the information on extramural funding collected from the R\&D performer survey will be incomplete.

4.129 Before drawing conclusions as to the importance of a sector as a funder of $R \& D$ and possibly sending surveys to such units, preliminary investigatory steps are recommended. It is advisable that national statistical offices first estimate, perhaps through targeted sampling, the number of statistical units in the sector that fund extramural $R \& D$ without being active themselves in performing R\&D. They also should estimate the relative size of such funding. If the number of units and the total funds are relatively low, the results obtained from adding funding questions to existing performer surveys (without changing the survey frame or sample) should be acceptable since the amount of "missed" funding from non-R\&D performers likely would be small. Otherwise, for a comprehensive estimate of funding for extramural $R \& D$, nonR\&D performers need to be sampled.

\section{Sales and purchases of $R \& D$}

4.130 The focus of this chapter is to provide guidance for the collection of statistics on $R \& D$ performance and on the sources of funds used to pay for the $R \& D$ performed. But as indicated earlier in this chapter (Measurement of funds 
for extramural R\&D), it also may be useful to collect supplementary information specifically on R\&D sales and purchases, particularly from statistical units within the Business enterprise sector.

4.131 This manual can make no specific recommendations on how best to define "R\&D sales" and "R\&D purchases" except to note that the former is revenue from the delivery of $R \& D$ to others and the latter is payment for the delivery of $R \& D$ from others. In collecting such statistics, it should be made very clear that the totals reported for the purchase and sales of R\&D may differ from their related intramural R\&D expenditures. For example, the intramural R\&D expenditure for R\&D sold includes labour and "other current costs". But when the performer sells the $R \& D$, the sales price likely includes the accounting cost of depreciation of fixed capital and some element of profit. The cost to the purchaser includes the whole price paid for the R\&D, including the elements covering depreciation costs, performer profit, delivery charges, etc.

4.132 Further, the reference period for when the R\&D is performed may differ from the period when the R\&D is actually purchased and sold. Even the apparent source of funds for the R\&D may differ between the two concepts. For example, a unit may perform $R \& D$ with internal funds, but subsequently - without the original intention to do so - sell the R\&D to a second unit. In terms of reported intramural $R \& D$ performance, the source of funds is the first unit. In terms of this specific extramural R\&D exchange, the second unit is the source of funds.

\section{Distribution by providers and recipients of extramural funds}

4.133 For the distribution of funding for exchange R\&D (and/or separately for the purchase and sale of $R \& D$ ), the following sector classification is recommended. This classification can also be used to account separately for R\&D transfer funds.

Domestic:

- Business enterprise sector:

* Enterprises in the same group

* Other unaffiliated enterprises

- Government sector

- Higher education sector

- Private non-profit sector

Rest of the world:

- Business enterprise sector:

* Enterprises in the same group

* Other unaffiliated enterprises

- Government sector

- Higher education sector 
* Foreign branch campuses

* Other higher education institutions

- Private non-profit sector

- International organisations.

4.134 The relative importance of various sectors as recipients of funds for extramural R\&D may vary depending on country circumstances. Furthermore, only business enterprises can report R\&D funds to (or make R\&D purchases from) enterprises in the same group; only higher education institutions can report R\&D funds to affiliated foreign campuses. See Chapter 9, Section 9.4 for a definition of these institutions.

\section{Problems in identifying for which sector funds are to be reported}

4.135 The concepts of "intramural" and "extramural" and "internal" and "external" may also be used at different aggregation levels other than those recommended by this manual for statistical units. For example, the content of what is "extramural performance" will differ from the perspective of enterprises, enterprise groups, institutional sectors or countries. In this chapter, the attributes of the institutional unit (and the sector of which it is a part) determine whether funds are to be treated as internal versus external sources and whether funding is for intramural versus extramural performance. As noted in Section 3.2, there are various possible types of statistical units, including enterprise groups, enterprises and establishments; the unit of interest for R\&D statistics is the enterprise. In this manual (see Section 6.2) the term "institutional unit" is preferred over "enterprise", with the latter being the term reserved for the Business enterprise sector.

4.136 It is sometimes unclear how to classify funds that flow from one unit to another, regardless of whether such units are in the same or different sectors. The recommended treatment and reporting of $R \& D$ funds is presented in the following sector-specific exemplars.

4.137 For the Business enterprise sector, the institutional unit of interest for such funds/funding classifications is the enterprise. Therefore, R\&D funds received by one member of a business enterprise group from other members of the same business enterprise groups should be reported as external funds for their intramural R\&D. For the member of a business enterprise group that provides (is the source of) those R\&D funds, they are to be reported as funds for extramural performance.

4.138 For the Government sector, the institutional unit of interest for such funds/funding classifications is the units that comprise the individual government subsectors (i.e. central/federal, regional/state, municipal/local). Therefore, R\&D funds received, for example, by a ministry $\mathrm{Y}$ of the central government from another central government ministry $\mathrm{X}$ should be reported as ministry Y's internal funds for intramural R\&D. For ministry $\mathrm{X}$ that provides 
(is the source of) those R\&D funds, they are not to be reported as either part of their internal funds or as funds for extramural performance. The rationale is that such transactions are among different parts of the same institutional unit of the central government, even if the statistical units are smaller entities such as ministries.

4.139 Transactions across different extra-budgetary units and other government-controlled non-profit institutions (NPIs) in the Government sector and between central or state governments should be reported as extramural funding, because these are separate institutions with their own accounts.

4.140 For example, R\&D funds received by agency $Z$ of a state government from a central government ministry $X$ should be reported as external funds for agency Z's intramural R\&D. For central government ministry X that provides (is the source of) those R\&D funds, they are to be reported as funds for extramural performance.

4.141 For the Higher education sector, the institutional unit of interest for such funds/funding classifications is the type of institution (e.g. universities, research institutes, university hospitals, etc.). Therefore, R\&D funds received, for example, by an economics department of university A from the engineering department of university A should be reported as the intramural R\&D of the economics department of university A and should not be reported as funds for extramural R\&D from the engineering department of university $A$. The source of the funds, for university A, is the originating source from which the engineering department received the funds.

\section{Problems in tracking flows of R\&D funds}

4.142 There are a number of potential difficulties in accurately collecting $R \& D$ funding flows, whether as a component of a unit's intramural R\&D or as part of their funding totals for extramural R\&D performance.

4.143 Problems may arise when funds pass through (flow within and across) several units before reaching the performer. This may occur when R\&D is sub-contracted, as may happen particularly in the Business enterprise sector. This also may occur when an R\&D grant has sub-awards and R\&D funds are passed through to other recipients, as may happen particularly in the Higher education sector. The performer should report costs only for R\&D projects actually conducted rather than as inputs into some other unit's R\&D, and indicate, to the extent possible, the original source of the funds for R\&D.

- For example, a large pharmaceuticals company (pharma) may engage the services of a biomedical contract research organisation (CRO) to undertake a phase 3 clinical trial for a new drug it has developed. The CRO provides funds to multiple hospitals for patient recruitment and testing in order to confirm the drug's effectiveness and monitor side effects. Although the hospital may provide technical reports on their clinical findings to the CRO, it is the CRO that measures the effectiveness of the drug and reports the results to the 
pharma company. In this example, the funds provided by pharma are funds for extramural R\&D paid to the CRO. All of the phase 3 costs are CRO's intramural R\&D paid with external (pharma) funds. The amount paid to the hospitals should be reported by the CRO as other current costs (not purchased R\&D). The hospitals should not report any of the payments for their part in the clinical trial as either intramural or extramural R\&D.

- Similar tracking/reporting issues occur with European Union (EU) funding, as the funds first go to the main contractor and are then distributed among the other participants (sub-contractors). In some countries, intermediary non-performing institutions play an important role in the funding of R\&D by distributing among performers grants that are received from several different sources but not "earmarked" for specific purposes. In such cases, while it is acceptable to regard these institutions as the source, it is nonetheless preferable to attempt to trace the funds to their original EU sources.

4.144 When the acquisition of R\&D is closely related to intramural R\&D performance, the borderline between funding for intramural and extramural performance is not always clear:

- Under-reporting may occur if an R\&D performer outsources part of an R\&D project. If the outsourcing activity is an $R \& D$ project in its own right, the funder may accurately report this as extramural R\&D. However, if the unit in charge of undertaking the outsourced project does not identify the project as $R \& D$, but as a service input into the funder's project, it will not report this as its own externally funded intramural R\&D.

- Conversely, over-reporting may occur if both the funder and performer report the funds and R\&D costs as their own intramural R\&D. If the R\&D outsourcing activity is a project in its own right, the intramural $R \& D$ should be attributed to the unit to which the work has been outsourced. If on the contrary, the outsourcing does not meet the intramural $R \& D$ performance criteria, it is the unit funding the work that should report the expenditures as other current intramural R\&D expenditures, as a purchase of related services for its own $\mathrm{R} \& \mathrm{D}$ activity or project.

\subsection{Reconciling differences in performer-based and funder-based approaches}

4.145 The estimated total of R\&D expenditure within a country based on performer reports will likely differ from the total based on reports from those funding R\&D owing to sampling difficulties and tracking/reporting differences.

4.146 Where estimates of GERD are obtained from sample surveys instead of surveys of the entire population, there is sampling error. Therefore performerbased and funder-based totals will likely differ. 
4.147 Where estimates of GERD are obtained from administrative records, there may be coverage differences between units included in performer-based reports and those included in funder-based reports. See Chapter 6, Section 6.3.

4.148 Financing may be provided by an intermediary, making it difficult for the performer to know the original source of funds. A related problem is measuring funding that goes outside of the funding sector but comes back to the sector as externally funded R\&D.

4.149 There may be instances where individuals directly receive funds from a third party (in the form of salaries or grants) to perform R\&D at host units, but the host units are unable to track (do not have access to information on) these flows of R\&D funds. This may apply for example in the case of government funding being provided to students or scholars to engage in R\&D performance at other institutions without those institutions having direct control over the funding so that the individuals might be allowed to move freely from one institution to another. Although countries should neither impute nor ask the statistical unit to impute for the cost of these individuals' R\&D performance at the level of the statistical unit, it may be possible to use aggregate funder data to address such triangular arrangement reporting gaps. For countries that collect and report statistics from funding institutions on the R\&D performance of individuals at a sector level, such data might allow for a more complete accounting of overall R\&D performance. If captured at all, these totals should be reported in "other current costs" but not as "other current costs-external R\&D personnel". Caution is advised to avoid double counting with the amounts reported by the host unit for its intramural R\&D performance.

4.150 The costs included in performer-based R\&D and funder-based R\&D may differ particularly in measuring exchange funds. In performer-based reporting, intramural R\&D expenditures include labour and "other current costs". But when the performer sells the R\&D, the sales price likely includes the accounting cost of depreciation of fixed capital and some element of profit. In funder-based reporting, the funder likely reports the whole price paid for the $R \& D$, including the elements covering depreciation costs and performer profit.

4.151 The accounting records of funders and performers may incorporate varying interpretations of whether the work being performed meets the definition of $R \& D$. For example, in the defence industry, funding of $R \& D$ within broad production and delivery contracts (such as those covering R\&D and trial production of aircraft) sometimes results in larger estimates of governmentfunded R\&D to business than what business defence contractors performing $R \& D$ track in their financial accounts as R\&D.

4.152 Contracts for research often extend over more than one year, with the result that there may be timing differences between funder and performer reports.

4.153 There also may be differences between performer-reported data and government budget (GBARD)data, which are essentially government funder data (although they record appropriations rather than expenditures). In this case, the 
lack of comparability may be due to the performance of a different amount of R\&D than was expected at the appropriations stage. Differences may also result from imprecision in the budget appropriations that do not allow for the separate identification of appropriations that are specifically targeted to R\&D. (For more information on GBARD methodology, see Chapter 12.)

4.154 It is also possible that respondents to funder and performer surveys may select different sectors when reporting the sector to which they provide extramural $R \& D$ funding and the sectors from which they receive external funds for intramural R\&D. For example, if a statistical unit receives funds from a non-profit institution controlled by the government, it is possible that it might (incorrectly from the perspective of this manual) report the source of such funds as the Private non-profit sector. An R\&D funder survey would classify the source as the Government sector (see Chapter 3).

4.155 To the extent possible, it is recommended that differences in R\&D expenditure totals between those estimated from $R \& D$ funders and those estimated from R\&D performers should be reported, and that causal factors for the differences, if known, should be identified. It should be recognised that such differences are not necessarily a result of inadequate or inaccurate measurement and that providing these data will aid analytical and statistical accuracy.

\subsection{Compiling national R\&D totals}

\section{Gross domestic expenditure on R\&D (GERD)}

4.156 High-level aggregations of R\&D performance, by performing sector and by funding source, are recommended for compiling internationally comparable GERD totals. GERD is constructed by summing the intramural R\&D expenditure totals for the four main sectors covered in this manual: Business enterprise, Government, Higher education and Private non-profit. For reporting GERD, all levels of government performance are often combined. For each performing sector, the main sources of funding should be compiled: Business enterprise, Government, Higher education, Private non-profit and Rest of the world.

4.157 This manual provides guidance on defining, measuring and reporting $R \& D$, including in this chapter the conventions and recommendations for compiling R\&D expenditure data. The recommended summation of performerreported intramural $R \& D$ expenditures represents a country's total R\&D effort. There are, however, other compilations of R\&D that may be confused with the GERD totals recommended here. Most notably, totals for R\&D are now notionally available from SNA accounts. As detailed in Chapter 1 and online in annex guidance to this manual available at http://oe.cd/frascati, SNA R\&D totals may differ substantially from GERD totals, one reason being the different treatments of software R\&D in the totals. Therefore for analytical purposes, it may be useful to identify the amount of software R\&D that is part of total GERD, or minimally the share of Business enterprise R\&D that is software R\&D. See Box 4.1. 


\section{Box 4.1. Software R\&D}

As noted in Chapter 1, a major change in the 2008 revision of the System of National Accounts (SNA) was to explicitly treat R\&D as capital formation, that is, "investment". For some countries, R\&D totals derived from SNA accumulations may differ substantially from GERD. One possible major source of differences between these R\&D totals stems from their treatment of software R\&D (i.e. R\&D devoted to software applications, including for both software products and software embedded in other products or projects, that are for both sale and own use). The 1993 SNA revision had previously treated software as capital formation; consequently, in implementing the 2008 SNA revision, estimates of R\&D investment have so far excluded software R\&D to avoid double counting. That is, software R\&D was already part of software investment in SNA terms.

For countries in which software $R \& D$ accounts for a relatively large share of total $R \& D$, the difference between $R \& D$ totals compiled using SNA conventions and those recommended in this manual may be substantial. Therefore it is recommended that $R \& D$ surveys (or at least surveys of the Business enterprise sector) include questions on the amount of software R\&D undertaken. Such totals may be extremely useful for understanding any apparent differences between R\&D collected according to the recommendations in this manual and SNA R\&D totals.

4.158 GERD is commonly presented as a matrix of R\&D performers by main sector arrayed against their sources of R\&D funding by sector. See Table 4.4.

4.159 For the purpose of this manual, international organisations, including supranational organisations such as European Union bodies (as defined in Chapter 3, Section 3.5), should be treated as units that are part of the "Rest of the world", regardless of the physical location of their offices or operations.

4.160 In the case of countries that collect and report statistics on the R\&D performance of international organisations located in their domestic territory, for international comparisons this should not be included in GERD, but should be reported separately from GERD.

4.161 It would be useful to compile separate totals for defence and civil GERD in order to map how trends in these areas affect the level and structure of total GERD. This is particularly true for countries with significant defence R\&D programmes. Similar breakdowns also are encouraged for other countries as a way to increase the international comparability of data on civil R\&D.

4.162 As an indicator of the R\&D intensity of a country's economy, both over time and in comparison with other countries, GERD is often presented as a ratio of GERD divided by gross domestic product (GDP). Hence, GERD-to-GDP ratios are useful means for normalising large differences in countries' aggregate R\&D totals that might partially reflect simply large differences in the size of countries' overall economies. 
Table 4.4. Gross domestic expenditure on research and development (GERD)

\begin{tabular}{|c|c|c|c|c|c|}
\hline \multirow{2}{*}{$\begin{array}{l}\text { Performing sector } \\
\text { Funding sector }\end{array}$} & \multicolumn{5}{|c|}{ Sector of performance } \\
\hline & $\begin{array}{c}\text { Business } \\
\text { enterprise sector }\end{array}$ & $\begin{array}{l}\text { Government } \\
\text { sector }\end{array}$ & $\begin{array}{l}\text { Higher education } \\
\text { sector }\end{array}$ & $\begin{array}{l}\text { Private non- } \\
\text { profit sector }\end{array}$ & TOTAL \\
\hline $\begin{array}{l}\text { Business enterprise } \\
\text { sector }\end{array}$ & & & & & $\begin{array}{l}\text { 1. Total domestic } \\
\text { performance financed } \\
\text { by the business } \\
\text { enterprise sector }\end{array}$ \\
\hline Government sector & & & & & $\begin{array}{l}\text { 2. Total domestic } \\
\text { performance financed } \\
\text { by the government } \\
\text { sector }\end{array}$ \\
\hline \multicolumn{6}{|l|}{$\begin{array}{l}\text { General university } \\
\text { funds (GUF) }\end{array}$} \\
\hline \multicolumn{6}{|l|}{ Other than GUF } \\
\hline Higher education sector & & & & & $\begin{array}{l}\text { 3. Total domestic } \\
\text { performance financed } \\
\text { by the higher education } \\
\text { sector }\end{array}$ \\
\hline $\begin{array}{l}\text { Private non-profit } \\
\text { sector }\end{array}$ & & & & & $\begin{array}{l}\text { 4. Total domestic } \\
\text { performance financed } \\
\text { by the private non- } \\
\text { profit sector }\end{array}$ \\
\hline Rest of the world & & & & & $\begin{array}{l}\text { 5. Total domestic } \\
\text { performance financed } \\
\text { by the rest of the world }\end{array}$ \\
\hline \multicolumn{6}{|l|}{$\begin{array}{l}\text { Business enterprise } \\
\text { sector }\end{array}$} \\
\hline \multicolumn{6}{|l|}{$\begin{array}{l}\text { Enterprises in the } \\
\text { same group }\end{array}$} \\
\hline \multicolumn{6}{|l|}{$\begin{array}{l}\text { Other unaffiliated } \\
\text { enterprises }\end{array}$} \\
\hline \multicolumn{6}{|l|}{ Government sector } \\
\hline \multicolumn{6}{|l|}{$\begin{array}{l}\text { Higher education } \\
\text { sector }\end{array}$} \\
\hline \multicolumn{6}{|l|}{$\begin{array}{l}\text { Private non-profit } \\
\text { sector }\end{array}$} \\
\hline \multirow[t]{2}{*}{$\begin{array}{l}\text { International } \\
\text { organisations }\end{array}$} & & & & & \\
\hline & $\begin{array}{l}\text { Total domestic } \\
\text { performance } \\
\text { by the business } \\
\text { enterprise } \\
\text { sector (BERD) }\end{array}$ & $\begin{array}{l}\text { Total domestic } \\
\text { performance by } \\
\text { the government } \\
\text { sector } \\
\text { (GOVERD) }\end{array}$ & $\begin{array}{l}\text { Total domestic } \\
\text { performance } \\
\text { by the higher } \\
\text { education } \\
\text { sector (HERD) }\end{array}$ & $\begin{array}{l}\text { Total domestic } \\
\text { performance by } \\
\text { the private non- } \\
\text { profit sector } \\
\text { (PNPRD) }\end{array}$ & GERD (sum of $1-5$ ) \\
\hline
\end{tabular}




\section{Regional distribution of R\&D}

4.163 Countries may find it useful to compile the separate totals for the distribution of GERD by region. The choice of regional distribution is determined according to national and international needs. Guidance for distributing R\&D by region is found in online annex guidance to this manual available at http://oe.cd/frascati.

4.164 Priority generally should be given to the organisational structure of an activity than to the literal location of where the activity takes place in classifying "intramural" R\&D that takes place outside of the physical location of the statistical unit. It is difficult to provide precise guidelines for such distribution decisions. At a minimum, intramural $R \& D$ that is performed outside the physical location of the statistical unit but is included in the location (e.g. regional) totals of the unit should include only R\&D that is performed by the unit to fulfil its own objectives and if the unit has invested its own financial resources and R\&D personnel in the activity.

$\rightarrow$ For example, a university researcher who is part of unit "A" located in region $\mathrm{X}$ within a country may occasionally perform short-term field work (as part of a unit "A" R\&D project) physically in region $Y$ within the same country. Unless there are countervailing reasons (for example, financing arrangements with a unit "B" located in the southern region), all of the intramural expenditure for that $R \& D$ may be reported as $R \& D$ for region $X$.

\section{Gross national expenditure on R\&D (GNERD)}

4.165 Other tabulations of R\&D performance and funding totals can provide supplementary information on $R \& D$ relationships and interactions between statistical units across different sectors and national boundaries. Gross national expenditure on R\&D (GNERD) comprises total expenditure on $R \& D$ financed by a country's institutions regardless of where the R\&D is performed. As such, it includes R\&D performed in the "Rest of the world" that is financed by national institutions or residents; it excludes R\&D performed within a country that is funded from institutions outside of the national territory (that is, from institutions that are part of the "Rest of the world"). GNERD is constructed by adding the domestically financed intramural expenditures of each performing sector plus the R\&D performed in the "Rest of the world" that is financed by domestic funding sectors (see Table 4.5). The inclusion of those latter totals presumes that national statistical offices have compiled data on their domestic institutions' financing of extramural $R \& D$ that is undertaken outside of the national territory (that is, performed in the "Rest of the world"). 


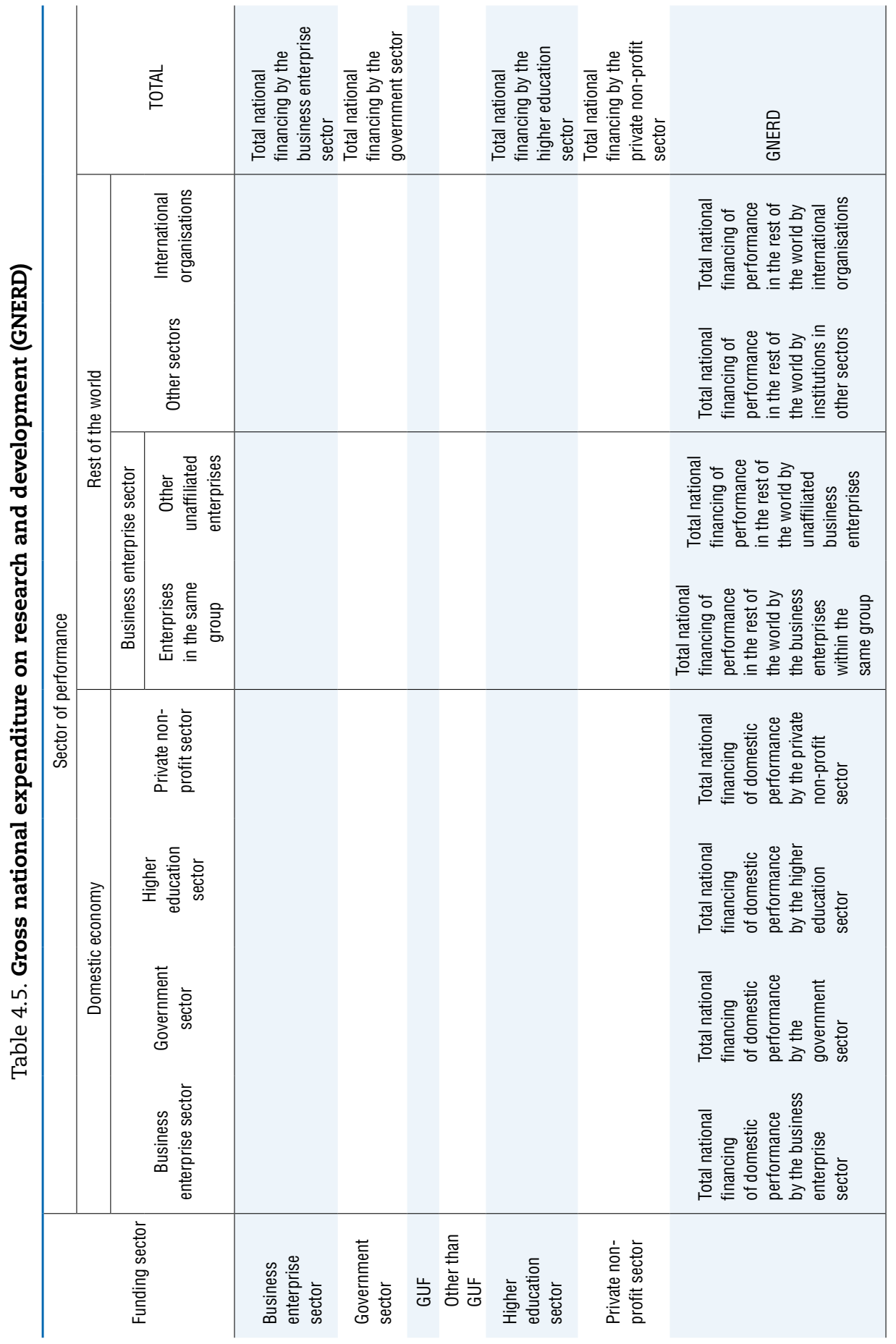




\section{References}

EC, IMF, OECD, UN and the World Bank (2009), System of National Accounts, United Nations, New York. https://unstats.un.org/unsd/nationalaccount/docs/sna2008.pdf.

OECD (2009), Handbook on Deriving Capital Measures of Intellectual Property Products, OECD Publishing, Paris. DOI: http://dx.doi.org/10.1787/9789264079205-en. 


\section{Chapter 5}

\section{Measurement of R\&D personnel: Persons employed and external contributors}

This chapter provides guidance on defining, identifying and measuring research and experimental development (R\&D) personnel, the people who perform $R \& D$, the highly trained scientists and engineers (researchers), technicians with high levels of technical experience and training, and supporting staff who contribute directly to carrying out $R \& D$ projects and activities in R\&D-performing statistical units. A distinction is made between internal $R \& D$ personnel, those employed by the statistical unit, and external R\&D personnel. The activities that characterise $R \& D$ personnel are listed. Definitions are provided for R\&D personnel, external R\&D personnel, researchers, technicians and equivalent staff, other supporting staff, fulltime equivalent (FTE) of R\&D personnel, and the headcount (HC) of R\&D personnel. The role of doctorate and master's students as R\&D personnel is discussed. Examples are provided to assist in making decisions about who are to be included as R\&D personnel and who not. The resulting statistics on the number, availability and demographic characteristics of human resources that contribute to $R \& D$ activities are used by researchers and by policy makers concerned with the sustainability of the R\&D enterprise. 


\subsection{Introduction}

5.1 Policy makers and scholars have a clear interest in and need for information on the size, availability and demographic characteristics of human resources that directly contribute to the $R \& D$ activities of institutions, economic sectors and nations as a whole. Those persons contributing to R\&D include highly trained researchers, technicians with high levels of technical experience and training, and other supporting staff who contribute directly to carrying out R\&D projects and activities in R\&D-performing statistical units. R\&D personnel may be directly employed either by the statistical unit (internal R\&D personnel) or by other units (external R\&D personnel) contributing directly to the intramural $R \& D$ of the statistical unit about which data is being reported. There are a number of specific circumstances in which $R \& D$ personnel are engaged in $R \& D$ activities but receive no compensation or remuneration for their contribution to the intramural R\&D of a statistical unit. This chapter provides guidance on defining, accurately identifying and measuring R\&D personnel. R\&D personnel data complement R\&D expenditure data (covered in Chapter 4 of this manual), which measure the total costs of performing R\&D, including the remuneration of R\&D personnel.

\section{Basic categorisation concepts}

5.2 In order to identify and distinguish R\&D personnel from the total personnel in a statistical unit performing $R \& D$, the following list of key R\&Drelated tasks can be used as a reference. R\&D personnel:

- perform scientific and technical work for an R\&D project (setting up and carrying out experiments or surveys, building prototypes, etc.)

- plan and manage R\&D projects

- prepare interim and final reports for R\&D projects

- provide internal services for R\&D projects (e.g. dedicated computing or library and documentation work)

- provide support for the administration of the financial and personnel aspects of R\&D projects.

5.3 Any individual undertaking one or more such tasks is contributing to the intramural R\&D activities of the statistical unit and is to be included in the R\&D personnel totals, irrespective of their function (formal role) or their employment status in the statistical unit. 
5.4 On the other hand, not all of the personnel contributing to or facilitating the performance of R\&D activities are to be included in the R\&D personnel totals. Only those individuals who make a direct contribution to R\&D activities (as described above) are included in the statistical measurement of R\&D personnel. R\&D personnel exclude individuals undertaking indirect support or ancillary activities in R\&D-performing units. Examples of indirect support and ancillary activities are:

- specific services to R\&D provided by central computer departments and libraries

- services by central finance and personnel departments dealing with R\&D projects and R\&D personnel

- the provision of services for security, cleaning, maintenance, canteens, etc., to R\&D-performing units.

5.5 While personnel providing such services are not included in the statistical unit's R\&D personnel totals, their related costs (including the remuneration of the personnel providing such services) should be included in the statistical unit's R\&D expenditures and be reported as "other current costs". It may be necessary to prorate such costs in order to exclude non-R\&D activities within the statistical unit (see Chapter 4, Section 4.2).

\subsection{Coverage and definition of R\&D personnel}

\section{Initial coverage: persons employed and external contributors}

5.6 R\&D personnel in a statistical unit include all persons engaged directly in R\&D, whether employed by the statistical unit or external contributors fully integrated into the statistical unit's R\&D activities, as well as those providing direct services for the R\&D activities (such as R\&D managers, administrators, technicians and clerical staff).

5.7 Persons providing indirect support and ancillary services, such as canteen, maintenance, administrative and security staff, should be excluded, even though their wages and salaries are included in "other current costs" when measuring R\&D expenditure.

5.8 R\&D units may be organised differently and may use different forms of engagement for their R\&D personnel. Therefore, when measuring human resources devoted to $R \& D$, all $R \& D$ personnel of the statistical unit should be counted.

5.9 Two main groups of individuals who potentially contribute to the R\&D activities can be identified in a statistical unit (with some differences according to the institutional sector it belongs to):

- Persons employed by the statistical unit who contribute to the unit's intramural R\&D activities (used interchangeably with the term "internal R\&D personnel" in this manual). 
- External contributors to the unit's intramural R\&D activities (used interchangeably with the term "external R\&D personnel" in this manual). This group includes two subgroups: (i) persons who receive wages/salaries but not from the statistical unit performing the R\&D and (ii) a number of special cases of persons external to a statistical unit who contribute to intramural R\&D.

5.10 R\&D personnel broadly include all individuals who are working in or for a statistical unit, whether full-time or part-time, and are contributing to the intramural R\&D. They can be either persons employed by the statistical unit or persons employed by other units contributing to the statistical unit's intramural R\&D activities. In this respect, both groups include independent and dependent workers. Table 4.1 provides a breakdown of the categories of personnel relevant for R\&D measurement. These categories are based on terms and concepts in the United Nations' International Recommendations for Industrial Statistics (United Nations, 2009).

5.11 The identification of the personnel (both internal and external) delivering services for intramural R\&D performance is essential for measurement purposes. As a practical consideration, an R\&D-performing unit can report on the characteristics of its R\&D personnel (sex, age, level of qualification, etc.; see Section 5.4) to statistical surveys only if it is involved in selecting the individuals who provide it with services for intramural $R \& D$. As a result, if a service provision contract includes the identification of the individuals who will deliver the service, such individuals (and their demographic characteristics) could be reported as external R\&D personnel by the unit receiving their services. Otherwise, it should be assumed that the service will be purchased from outside suppliers employing unidentified personnel. This distinction is relevant for the measurement of R\&D personnel (i.e. whether to include or exclude the persons providing a service as part of the statistical unit's R\&D personnel totals) but does not affect the measurement of R\&D expenditure since both activities are included in the same category of "other current costs" (although costs for individuals identified as external R\&D personnel should be reported as a specific sub-item, if possible). See further guidance on reporting $R \& D$ personnel and $R \& D$ expenditure in Section 5.2 of this chapter and Chapter 4, Section 4.2.

$\rightarrow$ For example, if a person is hired by a staffing agency to contribute on-site R\&D-related clerical work, but the clerk may be replaced by the staffing agency without the direct input/approval of the R\&D-performing statistical unit, that clerk is not R\&D personnel, but the clerk's costs (or actually the full costs paid to the staffing agency) would be included in "other current costs" (just not in the "external personnel" subcategory).

\section{Persons employed (internal personnel) contributing to a unit's intramural R\&D}

5.12 In most statistical units, intramural R\&D is performed primarily by persons employed by the statistical unit. "Persons employed" includes both employees (dependent workers) and some types of independent workers. 
Employees include all persons who work in or for the statistical unit, who have a contract of employment with the unit, and who receive compensation in cash or in kind at regular intervals of time. Employees engaged in activity ancillary to the main activity of the unit are also included, as well as the following groups: persons on short-term leave (sick leave, annual leave or vacation); persons on special paid leave (educational or training leave, maternity or parental leave); persons on strike; and part-time workers, seasonal workers and apprentices when on the payroll. Employees also include persons working physically outside the statistical unit's premises, when paid by and under the control of the unit (outworkers); for example, outside service engineers and repair and maintenance personnel are employees, i.e. dependent workers. If any of these persons contribute to the statistical unit's intramural R\&D, they are counted as internal R\&D personnel.

5.13 For statistical units in the Business enterprise sector, the definition of "persons employed" includes unpaid family workers and working proprietors (i.e. active business partners) as "independent workers". Silent or inactive partners whose principal activity is conducted outside of the statistical unit should be excluded.

5.14 By assumption, there are no independent workers among "persons employed" in the Government, Higher education and Private non-profit sectors (with the exception of households, to the extent that they are included, by convention, in the Private non-profit sector). In these sectors, almost all the "persons employed" are employees.

\section{External personnel contributing to a unit's intramural $R \& D$}

5.15 Statistical units performing R\&D increasingly rely on contributions by external personnel to improve the effectiveness of their internal R\&D staff or to bring in-house specific knowledge and skills not internally available. In such cases the external personnel are fully integrated into the intramural R\&D activities of the reporting statistical unit, and their work is managed by the reporting statistical unit. Such external R\&D personnel services should not be confused with a unit's extramural R\&D activities, that is, the acquisition of R\&D from external units in fulfilment of specific orders, but not as an integrated part of the reporting unit's intramural R\&D projects (see Chapter 4, Section 4.2 on "Other current R\&D costs" and on "Distinguishing between intramural and extramural costs related to labour"). Nor should such external R\&D personnel contributions be confused with the acquisition of services to support the intramural $R \& D$ performance delivered by external units without a specific agreement on who - one or more individuals - would deliver them.

5.16 "External R\&D personnel" includes persons who are not employed in the reporting statistical unit but who provide direct services that are an integral part of the statistical unit's R\&D projects or activities. That is, they contribute directly to the intramural R\&D of the reporting statistical unit. "External R\&D personnel" includes both self-employed professionals effectively acting as intramural R\&D consultants and persons fulfilling the provision of 
a scientific or technical service by their external employer(s) to the statistical unit reporting intramural R\&D. Leased employees are included in this category. Leased employment entails the provision for a fee of human resources for client businesses. Leased employees are on the payroll of an employment (or staffing) agency rather than the payroll of the statistical unit paying the fee. This provision of human resources is typically conducted on a short-term basis. (See specific exclusions in the notes to Table 5.1.)

\section{Table 5.1. Personnel to be tracked as part of a statistical unit's intramural $R \& D$ personnel}

\begin{tabular}{|c|c|c|c|c|}
\hline & \multicolumn{4}{|c|}{ Institutional sectors } \\
\hline & Business enterprise & Government & Higher education & Private non-profit \\
\hline \multicolumn{5}{|c|}{ Persons employed (internal personnel) contributing to a unit's intramural R\&D } \\
\hline Dependent & Employees $^{1}$ & Employees $^{1}$ & Employees $^{1}$ & Employees $^{1}$ \\
\hline Independent & $\begin{array}{l}\text { Working } \\
\text { proprietors }^{2} \\
\text { Unpaid family } \\
\text { workers }^{3}\end{array}$ & Not applicable & Not applicable & $\begin{array}{l}\text { Only applicable for } \\
\text { Households }\end{array}$ \\
\hline \multicolumn{5}{|c|}{ Special cases of external personnel contributing to a unit's intramural R\&D 4} \\
\hline $\begin{array}{l}\text { May be dependent } \\
\text { or independent }\end{array}$ & & $\begin{array}{l}\text { R\&D grant holders; } \\
\text { Doctoral/Master's } \\
\text { students }^{5}\end{array}$ & $\begin{array}{l}\text { Doctoral/Master's } \\
\text { students }^{5} \text {; R\&D grant } \\
\text { holders; Professors } \\
\text { emeritus }\end{array}$ & Volunteers ${ }^{6}$ \\
\hline
\end{tabular}

External personnel contributing to a unit's intramural R\&D

\begin{tabular}{|c|c|}
\hline & rsonnel contributing to a unit's intramural $\mathrm{f}$ \\
\hline \multirow[t]{2}{*}{ Dependent } & $\begin{array}{l}\text { Professionals and technical employees acting as intramural R\&D consultants in fulfilment of the } \\
\text { provision of a scientific or technical service by their employer(s) to the statistical unit reporting } \\
\text { intramural R\&D. }\end{array}$ \\
\hline & Leased employees ${ }^{7}$ are included in this category. \\
\hline Independent & Self-employed professionals acting as intramural R\&D consultants \\
\hline
\end{tabular}

1. The category "employees" is intended to include all persons engaged in the economic activity of the statistical unit other than working proprietors and unpaid family workers. It includes outworkers when they are paid by and are under the control of the same statistical unit. Employees engaged in activity ancillary to the main activity of the unit are also included, as well as the following groups: persons on short-term leave (sick leave, annual leave or vacation); persons on special paid leave (educational or training leave, maternity or parental leave); persons on strike; part-time workers, seasonal workers and apprentices when on the payroll.

2. Includes active business partners. Silent or inactive partners whose principal activity is conducted outside of the statistical unit should be excluded.

3. Family workers who receive pay for work performed should be classified as employees.

4. These categories may apply in more than one sector. Those where they are expected to have the largest impact are highlighted.

5. Students should be included only under the condition that they are formally engaged in R\&D of the host institution. 6. Volunteers who are contributing to the intramural R\&D activities of non-profit institutions should be clearly identified by the statistical unit reporting R\&D activities, in terms of qualification and tasks actually undertaken.

7. Leased employment entails the provision for a fee of human resources for client businesses. Leased employees are on the payroll of an employment agency rather than the payroll of the statistical unit paying the fee. This provision of human resources is typically conducted on a short-term basis. The following are excluded from leased employment: Purchased or managed services, such as janitorial, guard or landscape services; Professional or technical services purchased from another firm, such as software consulting, computer programming, engineering, and accounting services. Exclude temporary staffing obtained from a staffing service, contractors, subcontractors or independent contractors if such personnel are not contributing directly to the intramural R\&D of the statistical unit. 
5.17 For the purpose of this manual, a concise definition of external $R \& D$ personnel can be given with reference to the main characteristics of R\&D personnel not belonging to the group of "persons employed":

5.18 External R\&D personnel are independent (self-employed) or dependent (employee) workers fully integrated into a statistical unit's R\&D projects without formally being persons employed by the same R\&Dperforming statistical unit.

5.19 External R\&D personnel are usually professionals or technicians with a high degree of skill and specialisation in R\&D activities. Since the skills of external R\&D personnel are assumed, by definition, to be equivalent to those of similar employed internal R\&D personnel, it is possible that a statistical unit in any economic sector could perform intramural R\&D by engaging the services only of external R\&D personnel and not have any employed R\&D personnel.

5.20 Quite often external R\&D personnel are self-employed professionals and, as such, they should be classified as individual business enterprises. In some cases, they are employees of external organisations, research institutes or enterprises that market technical or scientific services that are delivered by skilled employees. In other cases, employment agencies do not sell a specific "R\&D service" to customers but offer the option of hiring skilled workers for a given period of time to meet a specific customer's need. Additionally, some individuals are employees of institutions - for instance, university professors or public researchers, in some countries - who are allowed by their employers to engage in market-based professional R\&D activities while still fulfilling their institutional job requirements. In such situations, it is not unusual for a single individual to have multiple affiliations, and therefore the same individual could be reported by two or more institutions.

5.21 In addition to self-employed persons and employees of other statistical units who are hired as external R\&D personnel, there are several other categories of individuals who perform tasks similar to such individuals and therefore should be included in external R\&D personnel totals.

5.22 In the Higher education sector, doctoral and master's students (see text below, "Treatment of doctoral and master's level students" for guidance on their inclusion) and individuals who are R\&D grant holders could be treated differently in accordance with their employment status. If a higher education institution gives them a status of employees (or, conversely, the institution's employees were enrolled as doctoral students),-i.e. they are on the payroll of the university-such persons should be included in R\&D personnel totals as "persons employed" (internal R\&D personnel) by the university (or by any other statistical unit in the Higher education sector). However, if they are not on the payroll of the university, such doctoral students and grant holders should be included in the R\&D personnel totals as external R\&D personnel when receiving compensation, whatever its source and funding channel, for the R\&D activity they undertake. It is also possible that doctoral students who do not receive 
funding are nonetheless included in R\&D personnel totals as external R\&D personnel. This guidance for students who do not receive funding holds also for master's level students, as long as they are enrolled in research master's degree programmes and the FTE research component can be reliably identified and separated from the tuition component.

5.23 A specific type of external R\&D personnel can be identified (almost exclusively) in the Higher education sector, namely that of a "professor emeritus". These individuals are retired professors who continue to research and collaborate in the academic activities of their former employer - usually a university - without receiving any compensation (although, they may receive some logistical support for their activities). To qualify as an external contributor to the higher education statistical unit's intramural $R \& D$, such individuals must have been on the payroll of a university before retiring and they must still be actively involved in research even though they are, quite often, no longer involved in teaching. Since their contribution to the intramural R\&D of an institution may not be negligible, it is therefore appropriate to include them in the external $R \& D$ personnel totals.

5.24 There is a final category of persons that potentially might be included (for measurement purposes) in external R\&D personnel: that of individuals contributing to intramural R\&D on a voluntary basis. Volunteers are unpaid workers providing a statistical unit with a defined and active R\&D contribution, under the responsibility of the R\&D-performing unit. This category could make a more significant difference to estimated totals in the case of the Private nonprofit sector. Volunteers can be included in the external R\&D personnel totals only under very strict criteria:

- They contribute to the R\&D intramural activities of (private non-profit) institutions.

- Their research skills are comparable to those of employees. For example, individuals who volunteer to participate as subjects in clinical trials, lend computer processing support to R\&D projects, etc., should not be included in the external R\&D personnel totals.

- Their R\&D activities are systematically planned according to both the needs of the volunteers and to those of the institution.

- Their contribution should be appreciable and an essential condition for enabling the institution to undertake an intramural R\&D activity or project.

\section{R\&D personnel and R\&D expenditure categories crosswalk}

5.25 The treatment of R\&D personnel and their related costs may differ according to their employment status (see Table 5.2) as explained below. As already noted there are two main groups of individuals that may be distinguished when reporting R\&D personnel and their costs-R\&D persons employed that 
comprise internal personnel and external R\&D personnel. The latter includes persons employed by others and several special cases of external personnel who are not employees.

\section{Table 5.2. Identification and reporting of R\&D personnel and categories of R\&D expenditures}

\begin{tabular}{|c|c|c|c|c|}
\hline Classification & $\begin{array}{c}\text { Persons' employment } \\
\text { status }\end{array}$ & Description & Institutional sector & $\begin{array}{l}\text { Reporting of R\&D } \\
\text { expenditures }\end{array}$ \\
\hline \multirow[b]{2}{*}{$\begin{array}{l}\text { Internal R\&D } \\
\text { personnel } \\
\text { contributing to a } \\
\text { unit's intramural } \\
\text { R\&D }\end{array}$} & $\begin{array}{l}\text { Person employed } \\
\text { (dependent) }\end{array}$ & Employees $^{1}$ & \multirow[b]{2}{*}{$\begin{array}{l}\text { Not relevant for } \\
\text { government and } \\
\text { higher education } \\
\text { sectors and for } \\
\text { most private non- } \\
\text { profit institutions }\end{array}$} & $\begin{array}{l}\text { Labour costs (payroll } \\
\text { data) }\end{array}$ \\
\hline & $\begin{array}{l}\text { Person employed } \\
\text { (independent) }\end{array}$ & $\begin{array}{l}\text { Working } \\
\text { proprietors, unpaid } \\
\text { family workers, etc }\end{array}$ & & $\begin{array}{l}\text { Usually not reported } \\
\text { because they do not } \\
\text { receive remuneration }\end{array}$ \\
\hline \multirow{2}{*}{$\begin{array}{l}\text { External R\&D } \\
\text { personnel: } \\
\text { employees }\end{array}$} & $\begin{array}{l}\text { Self-employed } \\
\text { consultants }\end{array}$ & $\begin{array}{l}\text { Contributors to the } \\
\text { intramural R\&D of } \\
\text { their customers on } \\
\text { a contractual basis }\end{array}$ & & $\begin{array}{l}\text { Other current } \\
\text { costs-external R\&D } \\
\text { personnel }\end{array}$ \\
\hline & $\begin{array}{l}\text { Employees of other } \\
\text { units hired as } R \& D \\
\text { consultants }\end{array}$ & $\begin{array}{l}\text { Contributors to the } \\
\text { intramural R\&D of } \\
\text { their employers' } \\
\text { customer on a } \\
\text { salary basis }\end{array}$ & & $\begin{array}{l}\text { Other current } \\
\text { costs-external R\&D } \\
\text { personnel }\end{array}$ \\
\hline \multirow{4}{*}{$\begin{array}{l}\text { External R\&D } \\
\text { personnel: special } \\
\text { cases }\end{array}$} & $\begin{array}{l}\text { Doctoral/Master's } \\
\text { students }\end{array}$ & & $\begin{array}{l}\text { To be found } \\
\text { primarily in } \\
\text { higher education } \\
\text { institutions but also } \\
\text { in other institutional } \\
\text { sectors }\end{array}$ & $\begin{array}{l}\text { Other current } \\
\text { costs-external R\&D } \\
\text { personnel (to the } \\
\text { extent students } \\
\text { receive R\&D grants } \\
\text { or external wages/ } \\
\text { salaries) }\end{array}$ \\
\hline & R\&D grant holders & & $\begin{array}{l}\text { To be found mainly } \\
\text { in higher education } \\
\text { institutions and in } \\
\text { government R\&D } \\
\text { institutions }\end{array}$ & $\begin{array}{l}\text { Other current } \\
\text { costs-external R\&D } \\
\text { personnel (to the } \\
\text { extent R\&D grants } \\
\text { would be reported) }\end{array}$ \\
\hline & Volunteers & & $\begin{array}{l}\text { To be paid special } \\
\text { attention within } \\
\text { private non-profit } \\
\text { institutions }\end{array}$ & $\begin{array}{l}\text { Usually not reported } \\
\text { because they do not } \\
\text { receive remuneration }\end{array}$ \\
\hline & $\begin{array}{l}\text { Professors emeritus } \\
\text { (similar to volunteers) }\end{array}$ & & $\begin{array}{l}\text { Specific case to } \\
\text { be found almost } \\
\text { exclusively in } \\
\text { higher education } \\
\text { institutions }\end{array}$ & $\begin{array}{l}\text { Usually not reported } \\
\text { because they do not } \\
\text { receive remuneration }\end{array}$ \\
\hline
\end{tabular}

1. Includes Doctoral/Master's students on the R\&D performing unit's payroll. It may be useful to obtain separate counts for students on payrolls of higher education institutions. 
Group 1. Internal $R \& D$ personnel (i.e. persons employed contributing to a unit's intramural R\&D), including:

- Employees (i.e. persons employed, dependent workers) working on R\&D are considered an integral part of the statistical unit and their salaries/wages should be included in the labour costs of the reported intramural R\&D expenditure. Doctoral/Master's students are included in the internal R\&D personnel totals if they are on the payroll of the statistical unit to which they contribute R\&D. (See text below, “Treatment of doctoral and master's level students" for further classification guidance.)

- Working proprietors and other persons employed as independent workers are usually not directly paid for their work.

Group 2 (i). External R\&D personnel who are not employed by the statistical unit reporting its R\&D but are employed by others and who provide direct services as an integral part of an R\&D project or activity of the reporting unit, under a specific contract, should not be included in the R\&D labour costs. Rather, their costs should be included with other current costs (preferably in a subcategory other current R\&D costs-external R\&D personnel) under the unit's intramural R\&D expenditure. They can be:

- Employees of other units hired as R\&D consultants, contributing to the intramural R\&D of the customers of their employers on a salary basis.

- Self-employed consultants, contributing to the intramural R\&D of their customers on a contractual basis. Self-employed consultants are also commonly referred to as "R\&D contractors".

Group 2 (ii). External personnel who are not employed by the unit but who undertake R\&D tasks similar to that provided by other internal R\&D personnel:

- Doctoral/Master's students are included in the external R\&D personnel totals if they receive compensation for their R\&D activity, other than through wages/salaries provided by the R\&D-performing statistical unit. If they are compensated through "R\&D grants" or external wages/salaries, these should be reported as "other current R\&D costs-external R\&D personnel". (See text below, "Treatment of doctoral and master's level students" for further classification guidance.)

- R\&D grant holders do not receive a salary. Monetary costs associated to their $R \& D$ grants can be reported, if available, in other current R\&D costs.

- Volunteers contributing to intramural R\&D are usually not directly paid for their work.

- Professors emeritus contributing to intramural $R \& D$ mainly in higher education institutions are usually not directly paid for their work.

As outlined above, total R\&D personnel are composed of two main groups of individuals: persons employed performing R\&D (i.e. internal R\&D personnel, a sub-group of the total persons formally employed by the statistical unit) and 
persons performing R\&D not employed by the statistical unit (i.e. external R\&D personnel). It is recommended that, as far as possible, data for these two groups should be separately identified, collected and reported in terms of both personnel and expenditure data. The need for consistency between R\&D personnel and expenditure data, as well as the need for accurate reporting on the composition of the R\&D workforce, provide the basis for this recommendation.

5.26 When collecting data from units that provide (lease) R\&D personnel to other R\&D-performing units, it is important that these R\&D personnel service providers not include such external R\&D personnel and their related R\&D costs as part of their own intramural R\&D. To do so would result in double counting. Since it may be the case that R\&D personnel service providers also perform intramural R\&D (either for own use or for sale), such units may have difficulty differentiating between personnel and expenditures for intramural R\&D and for external R\&D activities.

\section{Treatment of doctoral and master's level students}

5.27 Master's and doctoral students can be identified according to the level of their studies. They have completed university education at bachelor's level (ISCED level 6) and are studying at the master's (ISCED level 7) or doctoral level (ISCED level 8), respectively. (See Section 5.4, "R\&D personnel and researchers by formal qualification", for definitions of ISCED categories.)

5.28 Doctoral students attend "tertiary programmes which lead to the award of an advanced research qualification [and which] are therefore devoted to advanced study and original research and are not based on course work only." Such students are usually required to submit a thesis or dissertation of publishable quality that is the product of original research and represents a significant contribution to knowledge. As a result, doctoral students at the ISCED level 8 who are engaged as researchers should be included in R\&D personnel and expenditure measures of higher education institutions. The difficulty of identifying the borderline between the R\&D and education and training activities of doctoral students (and of their teachers/mentors) is discussed in general terms in Chapter 9, Section 9.2.

5.29 In principle, all doctoral students contribute to the R\&D activities of the university in which they are enrolled. Furthermore, universities are often entitled to a number of rights on the outcome of research on the basis of the supervision time and access to facilities. However, there may be no formal obligation for them to spend their time contributing to the intramural R\&D performed by the university or even if there is, such obligations may not be enforced. By convention, a distinction is made between doctoral students receiving compensation or other types of financial support from the university (or from any other source) for their R\&D activity and doctoral students without any compensation or financial support. In some cases, such compensation are salaries-the doctoral students are on the university's 
payroll; in other cases, they simply receive a grant, usually a research grant or one with a research component. For practical reasons, it cannot be assumed that students without salaries/grants substantially contribute to their universities' R\&D. Students receiving salaries or grants are more likely to do so. Only the latter should be included in the overall R\&D personnel counts (internal or external depending on their funding arrangements); while the former may be included as external R\&D personnel depending on particular circumstances, as explained below.

5.30 Master's students may in some cases be counted as researchers. This applies, in particular, to students following an ISCED level 7 research master's programmes, i.e. those leading to the award of research qualifications that are designed explicitly to train participants in conducting original research but are below the level of a doctoral degree. However, it is important to include in R\&D personnel totals only master's students receiving some form of payment for their R\&D activity or for which a significant FTE research component can be reliably identified and separated from the tuition component totals.

5.31 To facilitate international comparability, the following heuristic guidance on the classification and treatment of students engaged in $R \& D$ is recommended. Students are initially identified as students engaged in $R \& D$, as described above.

- Case 1: Doctoral/master's students are paid-either through salaries or grants-by the R\&D-performing unit to do research. They are internal R\&D personnel and their costs are included with labour costs. They are not separately counted as students.

- Case 2: Doctoral students receive external or no funding to do research in the R\&D-performing unit. They are external R\&D personnel and their costs (when they are funded) are included with "other current costs-external R\&D personnel". Their costs can be tracked and reported by the performing unit, or they can be estimated at a sector level by the triangular approach (see Chapter 4, Section 4.4); steps should be taken to avoid the possibility of double counting. This guidance also extends to master's students to the extent they are receiving funding that is explicitly for R\&D or for which a significant FTE research component can be reliably identified and separated from the tuition component. To the extent possible, it is recommended to obtain counts of doctoral/master's students, particularly for the Higher education sector. For some countries, it also may be useful to separately count doctoral students and master's students.

- Case 3: Doctoral students conduct only independent research, whether funded or not. They are not covered in R\&D personnel counts but their funding may be counted with "other current costs" if they receive an external grant (that can be estimated at a sector level by the triangular approach; see Chapter 4, Section 4.4). This guidance also extends to master's students to the extent they are receiving funding that is explicitly for R\&D. 


\section{R\&D personnel by function}

5.32 Following the identification of the individuals who potentially might contribute to the intramural $R \& D$ of a statistical unit, criteria are needed to identify the actual R\&D personnel, i.e. those having effectively performed R\&D in the reporting statistical unit during a specific reference period:

- For external R\&D personnel contributing to a statistical unit's activities, there is no difference between potential and actual R\&D performance, since such personnel are identified on the basis of specific evidence that they contribute to an intramural R\&D activity.

- For "persons employed" by the statistical unit, including working proprietors, paid employees and other persons, one needs to consider the tasks undertaken by each individual in the R\&D performance of the statistical unit in order to identify those having delivered a "direct" contribution to intramural $\mathrm{R} \& \mathrm{D}$ in the reference year. By convention, any kind or level (intensity) of direct contribution to $R \& D$ is sufficient to be classified as "R\&D persons employed". Nevertheless, it is recommended to include in R\&D personnel totals only those persons employed who have made an appreciable contribution to the intramural $R \& D$ as a percentage of their working time (with reference to a work year). See text on "Full-time equivalent (FTE) of R\&D personnel" for general guidance on what might constitute an "appreciable" contribution.

5.33 Both groups of R\&D personnel will need to be classified according to their R\&D function: researchers, technicians and other supporting staff. This classification is often misinterpreted because of the common use of the terminology in a number of different contexts. In this respect, it is stressed that in this manual this classification of $R \& D$ personnel refers to the actual function (in terms of tasks) of the individuals contributing to the intramural R\&D activities of the statistical unit. From a practical perspective, it is acknowledged that reporting units (and even statistical offices compiling R\&D data) may sometimes rely on existing and easily accessible criteria for categorising R\&D personnel. Hence, it may be useful to summarise criteria that should not be the sole basis for classifying R\&D personnel as "researchers", "technicians" or "other supporting staff", although these criteria may help in identifying the appropriate classification category.

- It is not based on job positions. Although some employees have job contracts as "researchers", it does not necessarily mean that they undertake the tasks of "researchers" in all of their employer's R\&D activities. In some cases, a "researcher" could perform the tasks of a "technician" in a specific R\&D project. The latter should be reported in R\&D statistics. Conversely, individuals with a formal position of "technician" could be asked to perform tasks similar to that of "researchers" for a specific project: again, it is the latter (i.e. the tasks actually performed by the individual) that should define what is reported on R\&D surveys. 
- It is not based on formal qualifications or level of education. While persons who hold a doctorate degree will most likely be involved in R\&D projects as "researchers", it should not be assumed that the R\&D tasks undertaken by all individuals will always be consistent with their qualifications. For example, a technician with several years of work-related experience, but only a secondary education degree, might undertake tasks similar to that performed by a "researcher" in a given context.

- It is not based on seniority at work. It is not uncommon for young "researchers" to manage complex R\&D projects and for colleagues (or consultants) with more experience to have functionally different roles (technical or administrative support, for instance).

- It is not based on employment relationships with the R\&D-performing unit. Although most intramural R\&D activities are managed by employees (or by working proprietors in small enterprises), it is also possible for external R\&D personnel to perform the same R\&D tasks as "persons employed". As a consequence, a statistical unit can perform intramural R\&D relying only on the R\&D activity undertaken by external R\&D personnel.

5.34 At times it may be necessary for analytical purposes to link the R\&D personnel categories defined below to other labour force and employment data using international standard classifications such as the International Standard Classification of Occupations (ISCO) (UN-ILO, 2012) and the International Standard Classification of Education (ISCED) 2011 (UNESCO-UIS, 2012). See the text below for the classification of R\&D personnel and researchers by formal qualification. In terms of identifying the main occupations in which R\&D workers are found, ISCO-08 is the relevant reference document: researchers are classified in ISCO08 Major Group 2, "Professionals", and in "Research and Development Managers" (ISCO-08, 1223); technicians and equivalent staff are classified in ISCO-08 Major Group 3, "Technicians and associate professionals"; and other R\&D supporting staff are essentially found in ISCO-08 Major Groups 4, "Clerks"; 6, "Skilled agricultural and fishery workers"; and 8, "Plant and machine operators, and assemblers". By convention, R\&D personnel working in defence are classified in ISCO-08 Major Group 0, "Armed forces occupations".

\section{Researchers}

5.35 Researchers are professionals engaged in the conception or creation of new knowledge. They conduct research and improve or develop concepts, theories, models, techniques instrumentation, software or operational methods.

5.36 Researchers may be involved fully or partially in different types of activities (e.g. basic or applied research, experimental development, operating research equipment, project management, etc.) in any sector of the economy. Researchers identify options for new R\&D activities, and plan for and manage them by using high-level skills and knowledge developed through formal education and training or from practical experience in performing research. 
Researchers play an essential role in the conduct of an R\&D project or activity. R\&D projects generally are led by researchers (as contrasted with other R\&D personnel who might serve as the lead on component parts of a project. Accordingly, every statistical unit performing R\&D has at least one person who is a researcher; the researcher can be part of the unit's internal or its external R\&D personnel, but need not be engaged full-time on R\&D activities.

5.37 The tasks implemented by researchers in the framework of specific R\&D projects or general R\&D activities typically include:

- conducting research, experiments, tests and analyses

- developing concepts, theories, models, techniques, instrumentation, software and operational methods

- gathering, processing, evaluating, analysing, and interpreting research data

- evaluating the results of investigations and experiments and positing conclusions using different techniques and models

- applying principles, techniques and processes to develop or improve practical applications

- advising on designing, planning and organising the testing, construction, installation and maintenance of structures, machines, systems and their components

- providing advice and support to governments, organisations and businesses on the application of research results

- planning, directing and coordinating the R\&D activities of institutions that provide related services to other organisations

- preparing scientific papers and reports.

5.38 Managers and administrators engaged in the planning and management of the scientific and technical aspects of a researcher's work are also classified as "researchers". Their position in the unit is usually equal or superior to that of persons directly employed as researchers; they are sometimes part-time researchers.

5.39 For practical reasons, doctoral students engaged in R\&D should be counted as "researchers". They typically hold basic university degrees (ISCED level 7) and perform research while working towards their doctoral thesis (ISCED level 8). When they cannot be identified separately, they may be included either with technicians or with researchers; however, such practices may cause inconsistencies in the researcher series.

\section{Technicians and equivalent staff}

5.40 Technicians and equivalent staff are persons whose main tasks require technical knowledge and experience in one or more fields of engineering, the physical and life sciences, or the social sciences, humanities and the arts. They participate in R\&D by performing scientific and technical tasks involving 
the application of concepts and operational methods and the use of research equipment, normally under the supervision of researchers.

5.41 In most cases technicians and equivalent staff do not run R\&D projects independently of researchers. They essentially are implementing directions, on the basis of their experience and qualifications, which are given by researchers who are responsible for managing the $R \& D$ projects.

5.42 Nonetheless, technicians and equivalent staff tend to have a high level of autonomy in accomplishing their tasks since they are usually highly skilled workers. Tasks implemented by technicians and equivalent staff typically include:

- carrying out bibliographic searches and selecting relevant material from archives and libraries

- preparing computer programs

- carrying out experiments, tests and analyses

- providing technical assistance and support in $R \& D$, or testing prototypes

- operating, maintaining and repairing research equipment

- preparing materials and equipment for experiments, tests and analyses

- recording measurements, making calculations and preparing charts and graphs

- collecting information using accepted scientific methods

- assisting in analysing data, keeping records and preparing reports

- carrying out statistical surveys and interviews.

\section{Other supporting staff}

5.43 Other supporting staff includes skilled and unskilled craftsmen, and administrative, secretarial and clerical staff participating in R\&D projects or directly associated with such projects.

5.44 Other supporting staff includes any number of differentjobs and skills. In principle, any activity contributing directly to the performance of intramural $R \& D$ that is not undertaken by researchers or technicians is undertaken by the supporting staff. Consequently, it is nearly impossible to provide an exhaustive list or description of the activities potentially carried out by $R \& D$ supporting staff; these activities range from administrative and secretarial work to the provision or the management of materials and devices needed to run an R\&D project. These R\&D personnel typically perform supporting functions connected to R\&D such as planning, information and financial support, legal and patent services, and assistance in assembling, adjusting, maintaining and repairing scientific equipment and instruments. Managers and administrators dealing mainly with financial and personnel matters and general administration, insofar as their activities are a direct service to $R \& D$, are included as "other supporting staff". 
5.45 Importantly, only "direct support services" are included in R\&D personnel statistics. For example, if the budget of a large R\&D project is managed by an employed accountant working only for a specific research team, then a "direct" service provision can be identified: the accountant should be reported in the "other supporting staff" R\&D personnel function and the related compensation costs should be reported in the "labour costs" of the R\&Dperforming statistical unit. On the other hand, if the "general accounting branch" of a large enterprise has the responsibility for managing the budgets of several intramural $\mathrm{R} \& \mathrm{D}$ projects carried out by different teams, then those activities represent an "indirect" administrative service: no R\&D personnel are reported and the administrative costs generated by the R\&D activities will be reported, for the purposes of R\&D surveys, in "other current costs".

\subsection{Recommended measurement units}

5.46 The measurement of R\&D personnel (both internal R\&D personnel and external R\&D personnel) involves three exercises:

1. measuring their number in headcounts (HC)

2. measuring their R\&D activities in full-time equivalent (FTE) or person-years

3. measuring their characteristics.

5.47 The value of collecting both HC and FTE statistics is based on the observation that R\&D may be the primary function of some individuals (e.g. researchers in an R\&D laboratory) but a secondary function of others (e.g. members of a design and testing establishment). It may also be a significant part-time activity (e.g. university professors, doctoral/master's students, consultants and other external experts) and not necessarily involve R\&D personnel on a full-time basis. Including only individuals whose primary function is $R \& D$ would result in an underestimation of the efforts devoted to $R \& D$; however, including everyone spending any time at all on $R \& D$ in the R\&D personnel totals would lead to an overestimation. The number of persons engaged in R\&D must, therefore, be expressed both in HCs and FTEs: the two statistics provide users with complementary information.

5.48 To ensure compatibility between the two data series (FTEs and HCs), an integrated approach to measuring R\&D personnel is proposed on the basis of the following principles:

- FTE is considered the main R\&D personnel statistic for international comparisons.

- The use of HCs is mostly recommended in terms of exploring, usually in percentage terms, the characteristics of R\&D personnel.

- Direct collection of R\&D personnel data is the recommended methodology to be used for the production of both FTE and HC data series. 
- There should be consistency between FTE and HC data regardless of whether the FTE and HC data are collected in a single statistical exercise or result from a coordinated effort of data collection from different statistical and/or administrative sources.

- When no direct data collection is possible, an estimation process can be undertaken in order to derive FTE and HC indicators from administrative data.

- Either ex-ante or ex-post, R\&D personnel data must be consistent with R\&D expenditure data, principally with the categories of "labour costs" and "other current costs-external R\&D personnel".

\section{Full-time equivalents (FTEs) of R\&D personnel}

5.49 The Full-time equivalent (FTE) of R\&D personnel is defined as the ratio of working hours actually spent on R\&D during a specific reference period (usually a calendar year) divided by the total number of hours conventionally worked in the same period by an individual or by a group.

5.50 National statistical offices compiling R\&D data should pay specific attention to the quantification of total working time, which is the basis for the calculation of full-time equivalent R\&D personnel. Even though the evaluation of total working time and of working time devoted to R\&D is not necessarily straightforward (particularly not for external R\&D personnel), by convention it is noted that no one person can account for more than one FTE in a single year and hence cannot perform more than one FTE on R\&D on an annual basis.

5.51 In practice, however, it may not always be easy to apply this principle. Some researchers, for example, may have activities in several R\&D units. This is a common situation for academics who also are external R\&D consultants to business enterprises. In such cases, it may be necessary to reduce the FTE of a single individual to one, if such information on multiple $R \& D$ contributions to multiple statistical units is available. The same principle should be adopted in those cases when the total R\&D FTEs are estimated on the basis of administrative data.

5.52 In order to be included in the R\&D personnel totals, an individual should make an appreciable contribution to the R\&D performed. Therefore, for both internal personnel and external personnel, it is recommended to express FTEs in decimals and to check for the significance of the contribution to a unit's R\&D performance by individuals spending less than $\mathbf{0 . 1}$ FTE on R\&D on an annual basis (i.e. 10 per cent of the total working time, which is about 20 working days per year).

5.53 It should be noted that when very small contributions to $R \& D$, in terms of working time, are included in the R\&D personnel totals (a few days per year of R\&D activity, for instance), it could be difficult - both at the unit level and at an aggregate level - to report appropriately about the characteristics of the 
R\&D personnel (their R\&D function, for example), as noted in Section 5.2 and further detailed in Section 5.4 below.

5.54 Total R\&D personnel in FTE terms includes the R\&D performance, on an annual basis, by all individuals - internal R\&D personnel and external R\&D personnel, including volunteers - who contributed to the intramural R\&D of a statistical unit, an institutional sector or a country.

5.55 Total employed $R \& D$ personnel in FTE terms includes the $R \& D$ performance, on an annual basis, by all internal personnel who contributed to the intramural R\&D of a statistical unit, an institutional sector or a country.

5.56 Reporting units should be explicitly advised to include the relevant $\mathrm{R} \& \mathrm{D}$ contribution (in terms of working time) of full-time and part-time individuals, including permanent and temporary personnel, in their FTE totals. See this Section on "Estimation of FTE indicators" for examples on how reporting units might calculate the FTE R\&D contributions of various R\&D personnel if they do not keep detailed records of the R\&D activities of their staff.

5.57 Even though it is recommended that the FTE of all individuals contributing to intramural R\&D in the reference period be individually calculated in order to estimate the total FTE R\&D personnel, some statistical units responding to $R \& D$ surveys may choose to produce their estimates based on the "average number" of individuals contributing to the intramural R\&D during the reference period. In this case, it is strongly recommended to check for consistency between the reported total FTE R\&D personnel and the reported total HC R\&D personnel. By convention, any measure of R\&D personnel expressed in FTE terms should be equal to or less than the same measure expressed in HC terms, at any level of aggregation.

\section{Headcount (HC) of R\&D personnel}

5.58 The headcount (HC) of R\&D personnel is defined as the total number of individuals contributing to intramural R\&D, at the level of a statistical unit or at an aggregate level, during a specific reference period (usually a calendar year). Various options are available for reporting headcount numbers:

- number of persons engaged in R\&D at a given date (e.g. end of period)

- average number of persons engaged in R\&D during the (calendar) year

- total number of persons engaged in R\&D during the (calendar) year.

These three options may result in different numbers, and the last option is prone to double counting. The preferred approach for measuring headcount data for R\&D personnel should be as of a given date (first option). Preferably, the point in time should be the same for all reporting units within all sectors of the reporting country. The choice of the point in time should take into account potential seasonality and other factors that may skew totals during the year and is left to each country to decide, as this seasonality may be highly country-specific. 
Insofar as possible, the date used should be similar to that used for collecting other statistical headcount series (e.g. employment, education) with which the R\&D series are likely to be compared.

5.59 Consistency between HC and FTE totals is a priority when producing R\&D personnel data. As a result, all individuals included in the FTE totals should also be included in the HC totals, i.e. everyone who contributed to intramural $R \& D$ in the reference period should be reported consistently both in HC and in FTE terms. Similarly, individuals engaged in R\&D who are not included in FTE totals (i.e. individuals spending less than 0.1 FTE on R\&D on an annual basis) also should not be included in R\&D personnel HC totals. It should be noted that the inclusion of all individuals who might make very small contributions to R\&D activities could greatly exaggerate reported R\&D personnel totals, making international comparisons problematic and making reporting on R\&D personnel characteristics difficult (see Section 5.4).

5.60 When reporting headcount aggregate numbers of, it is likely that individuals who contribute to the $R \& D$ of two or more statistical units (either business enterprises or other institutions) will be double-counted. The indicator may be interpreted as a sum of jobs. Working in terms of FTE totals provides a more accurate estimate of the human resource input to $R \& D$.

5.61 When there is incomplete information available on the characteristics of external R\&D personnel, rather than not reporting them in HC totals, it is recommended to collect as much information as possible on them and report them in a line separate from persons employed. Ideally, some basic R\&D personnel indicators - both FTE and HC - should be collected by their type of employment as detailed in Section 5.2: such as persons employed (whose remuneration is reported in the "labour costs"); paid external R\&D personnel (whose remuneration is reported under a specific sub-category of "other current costs-external R\&D personnel"); and all others (who are contributing to intramural R\&D activity without any compensation). To summarise, the recommendations for producing HC statistics by means of direct data collection (surveys) are as follows:

- Identify total R\&D personnel including internal personnel engaged in $R \& D$ and all external $R \& D$ personnel contributing to intramural activities. (Regarding the total number of internal personnel, it is recommended to use, as a reference, up-to-date administrative registers and, for the business sector, official business registers when available.)

- Compile and report the data on internal R\&D personnel separately from the data on external R\&D personnel (both compensated and unpaid personnel). Separate totals should be compiled for students working in $R \& D$ who are part of the external R\&D personnel totals.

- Produce separate HC time series for the two groups of the R\&D personnel. A number of basic features of this group of workers should be available to the statistical unit since they include internal personnel working in the unit and 
involved in R\&D, as well as external R\&D personnel who have contributed "on site", or at least in close geographical proximity, to the unit's R\&D activities. If this is not possible, compile such data at least for the internal R\&D personnel who have contributed to intramural R\&D in the reference period.

\section{Coordinated data collection of FTE and HC data}

5.62 The step-by-step survey process for collecting HC and FTE totals is summarised in Box 5.1.

\section{Box 5.1. Data collection and reporting process}

1. Total persons employed in the statistical unit that performed intramural $\mathrm{R} \& \mathrm{D}$ in the reference year (usually available from business registers). All of them are "potentially" R\&D contributors $\left(\mathrm{N}_{\mathrm{t}}\right)$.

2. Persons employed in the statistical unit (HC) who actually contributed to intramural $\mathrm{R} \& \mathrm{D}$ in the reference year $\left(\mathrm{HC}_{\text {int }}\right)$.

3. Persons employed in the statistical unit (FTE) who actually contributed to intramural R\&D in the reference year, weighted for the share of the working time devoted to R\&D; $100 \%=1\left(\mathrm{FTE}_{\text {int }}\right)$.

4. External R\&D personnel (including unpaid personnel) (HC) who actually contributed to intramural $\mathrm{R} \& \mathrm{D}$ in the reference year $\left(\mathrm{HC}_{\mathrm{ext}}\right)$.

5. External R\&D personnel (including unpaid personnel) (FTE) who actually contributed to intramural R\&D in the reference year, weighted for the share of the working time devoted to R\&D, 100\% =1 $\left(\mathrm{FTE}_{\text {ext }}\right)$.

Total R\&D personnel $(\mathrm{HC})=\mathrm{HC}_{\text {int }}+\mathrm{HC}_{\text {ext }}$

Total R\&D personnel $(\mathrm{FTE})=\mathrm{FTE}_{\text {int }}+\mathrm{FTE}_{\text {ext }}$

Employed R\&D personnel/Total persons employed ratio $=\mathrm{FTE}_{\text {int }} / \mathrm{N}_{\mathrm{t}}$

5.63 It is highly recommended that R\&D surveys collect on a single form all available data on both R\&D-related expenditures and R\&D personnel (HCs), including their level of engagement in R\&D (represented by FTEs) directly from R\&D-performing units. This approach minimises the costs of data collection and provides the highest degree of consistency between the different R\&D indicators. Such expenditure-personnel consistency checks should be part of the datacapture process. By convention, FTE counts should be less than or equal to HC counts.

5.64 The basic relationships between R\&D expenditure and HC and FTE R\&D personnel totals are summarised in Table 5.3. 
Table 5.3. Consistency in R\&D data collection

\begin{tabular}{|c|c|c|c|c|}
\hline R\&D expenditure & & FTE R\&D personnel totals & & $\begin{array}{l}\text { HC R\&D } \\
\text { personnel totals }\end{array}$ \\
\hline Labour costs & $\leftrightarrow$ & $\begin{array}{l}\text { Internal R\&D personnel } \\
\text { (persons employed) }\end{array}$ & $\leq$ & $\begin{array}{l}\text { Internal R\&D } \\
\text { personnel } \\
\text { (persons } \\
\text { employed) }\end{array}$ \\
\hline $\begin{array}{l}\text { Other current costs- } \\
\text { external R\&D personnel }\end{array}$ & $\leftrightarrow$ & External R\&D personnel & $\leq$ & $\begin{array}{l}\text { External R\&D } \\
\text { personnel }\end{array}$ \\
\hline Not applicable & & Unpaid R\&D personnel & $\leq$ & $\begin{array}{l}\text { Unpaid R\&D } \\
\text { personnel }\end{array}$ \\
\hline
\end{tabular}

\section{Estimating FTE and HC indicators of R\&D personnel Estimation of FTE indicators}

5.65 Under some circumstances, it may not be possible to carry out direct data collection of FTE and HC personnel. Thus, in order to make R\&D personnel data available, it may be necessary to estimate these indicators on the basis of information available from sources other than direct surveys. In such circumstances it is strongly recommended that national statistical offices check for consistency between reported R\&D expenditure and estimated R\&D personnel totals.

5.66 The FTEs of R\&D personnel should be estimated at the level of the reporting unit. This is done using information available at the level of the institution (e.g. from administrative data) or sometimes at the level of individuals (e.g. time-use surveys). Time-use surveys can be a useful source of data in the absence of other robust data sources and are commonly used for deriving FTEs of R\&D personnel in the higher education sector. See Chapter 9 for more details regarding Higher education time-use surveys.

5.67 The first step for estimating FTE R\&D personnel is to collect detailed information (from administrative sources if survey data are not available) on the actual or contractual (normative/statutory) involvement of R\&D personnel in intramural R\&D. This approach could be straightforward when estimating public research institutions (or universities) totals since working roles and employment statuses in those sectors are often formally defined.

5.68 Data for full-time R\&D personnel and part-time R\&D personnel should be separately identified and reported, for both "R\&D persons employed" and "external R\&D personnel". A full-time person therefore will be identified with reference to their employment status, the type of contract (full-time or part-time worker) and the level of their engagement in R\&D.

5.69 Accordingly, one FTE of R\&D personnel is equivalent to one individual working full-time on R\&D. It is measured by combining two variables: actual involvement in R\&D activities and formal engagement on the basis of normative/ 
statutory working hours. When information on one of these two variables is not available, the calculation could be based on only one of the two criteria.

5.70 Also when estimating FTE data, there are a number of challenges:

- identifying the time spent on R\&D by an individual worker or by a group of $R \& D$ contributors versus the time spent on other activities

- taking into account the different employment patterns of the relevant $R \& D$ personnel, i.e. working full-time, part-time or on a temporary basis

- selecting the appropriate data sources and methods to compile FTE totals.

5.71 The process of estimation can be summarised in the following formula:

$$
\mathrm{FTE}=\mathrm{ftRD}+(\mathrm{ntuRD} / \mathrm{stu})
$$

Where:

ftRD: number of full-time R\&D personnel;

ntuRD: number of working hours spent on R\&D by other categories of personnel; stu: number of normative/statutory working hours of full-time personnel for a given sector/country.

5.72 For personnel not working full time on $R \& D$, different circumstances can be identified:

- persons employed working part-time on $R \& D$, as a result of either a reduced work schedule or a limited involvement in R\&D activities

- persons employed (or external R\&D personnel) working on a temporary basis during the reference period for which the FTE is calculated (e.g. a calendar year).

5.73 The following examples indicate how the formula could be used in the calculation of FTE totals:

- a full-time employee spending $100 \%$ of time on R\&D during a year $=1 \mathrm{FTE}$

- a full-time employee spending $30 \%$ of time on R\&D during a year $=0.3 \mathrm{FTE}$

- a full-time R\&D person spending $100 \%$ of time on R\&D employed at an R\&D institution only for six months $=0.5 \mathrm{FTE}$

- a full-time employee spending $40 \%$ of time on R\&D during half of the year (the person is only active for 6 months per year) $=0.2 \mathrm{FTE}$

- a part-time employee (working $40 \%$ of a full-time year) engaged only in R\&D (spending $100 \%$ of time on R\&D) during a year $=0.4 \mathrm{FTE}$

- a part-time employee (working $40 \%$ of a full-time year) spending $60 \%$ of time on $R \& D$ during half of the year (person is only active for 6 months per year) $=0.12 \mathrm{FTE}$.

\section{Estimation of HC indicators}

5.74 In compiling information on the size and composition of R\&D personnel in HC terms, it is recommended to use, as much as possible, the data available from administrative and personnel registers (including payroll data, if relevant), as well as data from business registers when available. To the extent national statistical offices 
are unable to produce consistent HC indicators for all groups of R\&D personnel (internal R\&D personnel, paid external R\&D personnel, and unpaid/volunteer external R\&D personnel), it is recommended that national statistical offices focus on identifying and estimating HC indicators for internal R\&D personnel (i.e. R\&D persons employed by the statistical unit performing the intramural R\&D).

\subsection{Recommended distribution of aggregate R\&D personnel totals HC and FTE R\&D personnel characteristics}

5.75 To address the needs of data users, aggregate HC and FTE totals should be distributed, to the extent practical, across a number of different variables: notably by sex, function, employment status, age and formal qualification, but also by seniority level, geographic origin and personnel flows.

\section{R\&D personnel by sex}

5.76 In line with the Beijing Declaration following the 1995 World Conference on Women (United Nations, 1995), every effort should be made to produce genderdisaggregated data for statistics on R\&D personnel. This applies to both FTE and HC totals and should be based on reliable information about the individuals belonging to both groups of R\&D personnel: internal R\&D personnel and external R\&D personnel.

\section{R\&D personnel by R\&D function}

5.77 A key variable of interest is the distribution of R\&D personnel by R\&D function (researchers, technicians and equivalent staff, and other supporting staff). Even when the direct collection of personnel data is problematic, the identification of "who is doing what" in intramural R\&D projects helps verify the accuracy of the R\&D performance being reported by statistical units. Further, the collection and reporting of R\&D personnel totals by function highlight the contribution by researchers to the overall R\&D effort within a statistical unit, a sector of the economy or the entire economy. This breakdown is recommended for both FTE and HC measures of internal R\&D personnel and of external R\&D personnel.

\section{R\&D personnel by employment status}

5.78 It is recommended that every individual included in R\&D personnel totals be identified as an internal R\&D personnel (i.e. "R\&D person employed" whose remuneration is reported in the "labour costs"), as paid/compensated "external R\&D personnel" (whose remuneration is reported under a specific sub-item of "other current costs"), or as "external R\&D personnel" volunteers or volunteer equivalents (who are contributing to intramural R\&D activity without any compensation). This breakdown is recommended for both FTE and HC measures of R\&D personnel. 
To the extent practical, it could also by useful to collect the breakdown between permanent employment and temporary employment. Some indicators, e.g. the average annual salary of a FTE researcher, could be made available only for R\&D persons employed (whose data can be assumed to be already available in their employers' records).

\section{$R \& D$ personnel by age}

5.79 To report R\&D personnel and specifically "researchers" by age, a breakdown into six categories is recommended. These categories are in line with the United Nations Provisional Guidelines on Standard International Age Classifications (United Nations, 1982):

- under 25 years

- 25-34 years

- 35-44 years

- 45-54 years

- 55-64 years

- 65 years and more.

5.80 Age data are often unavailable for external R\&D personnel since age generally is not (or cannot be) an influential factor for hiring an individual to contribute to a statistical unit's intramural R\&D. However, since there is considerable interest in age data, priority should be given to collecting this information for HCs of internal R\&D personnel and of external R\&D personnel only if the available information is reliable.

\section{$R \& D$ personnel and researchers by formal qualification}

5.81 In terms of classifying R\&D personnel and specifically "researchers" by formal qualification, the International Standard Classification of Education (ISCED) 2011 (UNESCO-UIS, 2012) is the relevant reference document. Five classes are recommended for the purpose of R\&D statistics: separately, ISCED levels 5, 6, 7 and 8, and ISCED levels 1-4 combined. A breakdown into these five classes should allow for full comparability with other economic and social statistics.

5.82 The ISCED levels are defined exclusively by level of education, regardless of the field in which personnel are qualified.

- Holders of university degrees at doctoral or equivalent level (ISCED level 8). This category includes holders of degrees earned at universities proper and also at specialised institutes with university status.

- Holders of university degrees at master's or equivalent level (ISCED level 7). This category includes holders of degrees earned at universities proper and also at equivalent tertiary educational institutions. 
- Holders of university degrees at bachelor's or equivalent level (ISCED level 6). This category includes holders of degrees earned at universities proper and also at equivalent tertiary educational institutions.

- Holders of other tertiary level diplomas (ISCED level 5). Subject matter is typically specialised, presented at a level requiring the equivalent of full secondary level education to master it. It provides a practically oriented/occupation-specific education and may also provide a pathway to other programmes at a tertiary level.

- Holders of post-secondary non-tertiary diplomas (ISCED level 4). This class includes holders of degrees providing students who completed ISCED level 3 with the non-tertiary qualifications required for progression to tertiary education or for employment when their ISCED level 3 qualification does not grant such access.

- Holders of diplomas of upper secondary education (ISCED level 3). This class includes not only all ISCED level 3 diplomas obtained in the secondary school system but also equivalent level 3 vocational diplomas obtained from other types of educational establishments.

- Other qualifications. These include holders of diplomas below ISCED level 3 or with education not falling under any of the other six classes.

5.83 However, it is recognised that it is difficult to collect reliable information on the level of education of internal personnel (and even more so for external personnel) and that employers do not necessarily keep updated records of the level of education attainment of their employees. In this respect, for the breakdown of R\&D personnel and researchers by formal qualification priority should be given to collecting this information for HCs of internal R\&D personnel.

\section{R\&D personnel by seniority level}

5.84 Data on "seniority levels" can improve knowledge on R\&D management practices and provide invaluable insight on researchers' careers. For this variable, priority should be given to collecting this information for HCs of internal R\&D personnel in the Government (see Chapter 8) and Higher education sectors (see Chapter 9).

\section{R\&D personnel by geographic origin}

5.85 Data users are also interested in the geographic origin of $R \& D$ personnel, mainly to monitor the international mobility of researchers and of R\&D personnel in general. Different criteria can used to identify national origin: nationality, citizenship or country of birth. Other criteria may also be of interest, such as country of previous residence, previous occupation or country of study at the highest level. All have advantages and disadvantages and provide different types of information. The combination of two or more of these criteria will provide considerably more analytical information. On the other hand, it is difficult to identify reliable sources of information when collecting such data from employers. Priority should be given to collecting this information for HCs of internal R\&D personnel. 


\section{R\&D personnel flows}

5.86 Finally, indicators on the flows of R\&D personnel (newly recruited vs. leaving/retiring personnel), to complement available information that mainly focuses on the stock of R\&D personnel, are frequently requested by users. Such information assists employers, analysts and policymakers to anticipate needs and possible shortages of R\&D personnel. These indicators are of particular interest at the sector level, and therefore priority should be given to collecting this information only for HCs of internal R\&D personnel.

\section{Recommended tables on HC and FTE R\&D personnel and researchers}

5.87 To the extent practical, countries should separately collect information on the demographic characteristics of internal R\&D personnel (R\&D persons employed) and external R\&D personnel. Such collections will over time allow for a more complete recording of all persons engaged in R\&D and further enhance international comparisons. However, it is also recognised that such collections may be difficult if not impossible for some countries and that international comparisons may be misleading if countries report different aggregates of R\&D personnel totals. Therefore it is recommended that priority be given to reporting national aggregates on internal R\&D personnel and specifically "researchers" for the following demographic variables. For presentation purposes, and to differentiate these totals from those that include external $R \& D$ personnel, such aggregates are referred to as "national employed R\&D personnel totals". For comparison, aggregated totals of internal R\&D personnel plus external R\&D personnel are referred to as "national R\&D personnel totals".

5.88 Below are exemplars of recommended tables that should be produced for R\&D personnel totals.

Table 5.4.a. Total national R\&D personnel by sector and by employment status (FTE and HC by sex)

\begin{tabular}{|c|c|c|c|c|c|}
\hline & \multicolumn{5}{|c|}{ Sector } \\
\hline & $\begin{array}{l}\text { Business } \\
\text { enterprise }\end{array}$ & Government & $\begin{array}{l}\text { Higher } \\
\text { education }\end{array}$ & $\begin{array}{l}\text { Private non- } \\
\text { profit }\end{array}$ & Total \\
\hline $\begin{array}{l}\text { a) Internal R\&D personnel (i.e. } \\
\text { employed R\&D personnel) }\end{array}$ & & & & & \\
\hline $\begin{array}{l}\text { b) External R\&D personnel (R\&D } \\
\text { personnel whose costs are reported } \\
\text { as "other current costs-external R\&D } \\
\text { personnel") }\end{array}$ & & & & & \\
\hline $\begin{array}{l}\text { c) Unpaid external R\&D personnel } \\
\text { (including volunteers and professors } \\
\text { emeritus) }\end{array}$ & & & & & \\
\hline Total & & & & & \\
\hline
\end{tabular}


Table 5.4.b. Total researchers by sector and by employment status (FTE and HC by sex)

\begin{tabular}{|c|c|c|c|c|c|}
\hline & \multicolumn{5}{|c|}{ Sector } \\
\hline & $\begin{array}{l}\text { Business } \\
\text { enterprise }\end{array}$ & Government & $\begin{array}{l}\text { Higher } \\
\text { education }\end{array}$ & $\begin{array}{c}\text { Private } \\
\text { non-profit }\end{array}$ & Total \\
\hline $\begin{array}{l}\text { a) Internal researchers } \\
\text { (i.e. employed researchers) }\end{array}$ & & & & & \\
\hline $\begin{array}{l}\text { b) External researchers (researchers } \\
\text { whose costs are reported as "other } \\
\text { current costs - external R\&D } \\
\text { personnel") }\end{array}$ & & & & & \\
\hline $\begin{array}{l}\text { c) Unpaid external researchers } \\
\text { (including volunteers and } \\
\text { professors emeritus) }\end{array}$ & & & & & \\
\hline Total & & & & & \\
\hline
\end{tabular}

Table 5.4.c. Total national employed R\&D personnel by sector and by R\&D function

(FTE and HC by sex)

\begin{tabular}{|c|c|c|c|c|c|}
\hline & \multicolumn{5}{|c|}{ Sector } \\
\hline & $\begin{array}{l}\text { Business } \\
\text { enterprise }\end{array}$ & Government & Higher education & Private non-profit & Total \\
\hline \multicolumn{6}{|l|}{ Researchers } \\
\hline \multicolumn{6}{|l|}{ Technicians and equivalent staff } \\
\hline \multicolumn{6}{|l|}{ Other supporting staff } \\
\hline Total & & & & & \\
\hline
\end{tabular}

Table 5.4.d. Total national employed researchers by sector and by age

(HC by sex)

\begin{tabular}{|c|c|c|c|c|c|}
\hline & \multicolumn{5}{|c|}{ Sector } \\
\hline & $\begin{array}{l}\text { Business } \\
\text { enterprise }\end{array}$ & Government & Higher education & Private non-profit & Total \\
\hline \multicolumn{6}{|l|}{ Under 25 years } \\
\hline \multicolumn{6}{|l|}{$25-34$ years } \\
\hline \multicolumn{6}{|l|}{$35-44$ years } \\
\hline \multicolumn{6}{|l|}{$45-54$ years } \\
\hline \multicolumn{6}{|l|}{$55-64$ years } \\
\hline \multicolumn{6}{|l|}{65 years and more } \\
\hline Total & & & & & \\
\hline
\end{tabular}




\section{Table 5.4.e. Total national employed researchers by sector and by level of formal qualification}

(HC by sex)

\begin{tabular}{|c|c|c|c|c|c|}
\hline \multirow[b]{2}{*}{ Holders of } & \multicolumn{5}{|c|}{ Sector } \\
\hline & $\begin{array}{l}\text { Business } \\
\text { enterprise }\end{array}$ & Government & Higher education & Private non-profit & Total \\
\hline \multicolumn{6}{|l|}{ Tertiary degrees } \\
\hline \multicolumn{6}{|l|}{ Doctoral or equivalent (ISCED 8) } \\
\hline \multicolumn{6}{|l|}{ Master's or equivalent (ISCED 7) } \\
\hline \multicolumn{6}{|l|}{ Bachelor's or equivalent (ISCED 6) } \\
\hline \multicolumn{6}{|l|}{ Other tertiary level diplomas (ISCED 5) } \\
\hline \multicolumn{6}{|l|}{$\begin{array}{l}\text { Other degrees } \\
\text { (ISCED } 1 \text { to 4) }\end{array}$} \\
\hline Total & & & & & \\
\hline
\end{tabular}

\section{References}

International Labour Organization (2012), International Standard Classification of Occupations (ISCO), ILO, Geneva. www.ilo.org/public/english/bureau/stat/isco/isco08/index.htm.

UNESCO-UIS (2012), International Standard Classification of Education (ISCED) 2011, UIS, Montreal. www.uis.unesco.org/Education/Documents/isced-2011-en.pdf.

United Nations (2009), International Recommendations for Industrial Statistics 2008, Statistical Papers, Series M, No. 90, United Nations, New York. http://unstats.un.org/unsd/ publication/seriesM/seriesm_90e.pdf.

United Nations (1995), Beijing Declaration following the 1995 World Conference on Women, United Nations, New York. www.un.org/womenwatch/daw/beijing/platform/declar.htm.

United Nations (1982), Provisional Guidelines on Standard International Age Classifications, Statistical Papers, Series M, No.74, United Nations, New York. http://unstats.un.org/ unsd/pubs/gesgrid.asp?id=134. 



\section{Chapter 6}

\section{Measuring R\&D: Methodologies and procedures}

This chapter discusses how to measure research and experimental development (R\&D) activity, noting that is highly concentrated, specially in the Business enterprise sector, but it is also widely spread across the economy. These characteristics give rise to measurement challenges as do the disparate uses of $R \& D$ statistics. These include the use of aggregate statistics for policy analysis, policy evaluation and target setting, the use of $R \& D$ expenditures as input to a capital stock of $R \& D$ in the System of National Accounts (SNA), and unit level analysis of R\&D activity. Measurement, whether through surveys, the use of administrative data, or combinations of the two, requires a statistical infrastructure including registers of institutions, methodological support, means of linking data sets to enhance analytical capacity, and quality assurance standards. All of these are discussed, but, recognising that countries have quite different infrastructures and measurement challenges no specific formal recommendations are made. Sources are provided to support the development of statistical measurement. 


\subsection{Introduction}

6.1 Many considerations drive the methodology and procedures used to measure R\&D performance. R\&D activity tends to be concentrated in relatively few entities, particularly in the Business enterprise sector. While R\&D activity is highly concentrated, it occurs throughout the economy and the identity of performers changes over time. Both the concentration and breadth of its occurrence have implications for guidelines on sampling strategy. In addition to these characteristics, the objectives of R\&D statistical programmes are multidimensional, including: aggregate indicators to support science policy; expenditures providing input to a capital stock of R\&D in the System of National Accounts; and micro-level data to support - under restrictions with regard to data protection - unit-level analysis where the units may include business enterprises, government, higher education and private non-profit institutions. These sometimes conflicting objectives influence the sampling and processing strategies.

6.2 The measurement of the performance of $R \& D$ is governed by the statistical infrastructure available, including registers of survey units, experienced statisticians, and the extent to which there is legislation that authorises compulsory surveys and enables the linkage of survey data to other data sources to support policy-relevant analysis. This chapter presents methodologies and procedures that draw upon statistical infrastructures and provides guidance on measurement, data quality and the transfer of data to international organisations. This manual does not make recommendations about specific methods for surveys or data analysis, as the variety of national circumstances is too great to permit the preparation of standard rules of approach to respondents, or of standard questionnaires or sampling techniques.

6.3 Data on R\&D may come from a variety of sources, including, but not necessarily limited to, direct measurement through surveys and administrative data sources. Administrative data may include both financial data from revenue agencies as well as other types of administrative sources, such as company records. Use of administrative data is discussed in Section 6.4. In some cases, estimates are required to supplement surveys and administrative data sources. An example of this would be the modelling (or indirect estimation) of R\&D expenditures in the Higher education sector. Statistical offices decide on the sources of data used based on their availability, quality, appropriateness and cost. This varies across countries.

6.4 The direct collection of data has a distinct advantage in that the concepts and definitions used can align completely with those contained in this manual. 
However it comes at a cost, both directly in terms of data collection, and indirectly through the cost incurred by respondents in completing survey questionnaires.

6.5 For the purpose of this chapter, "R\&D surveys" may refer to data collected directly through a statistical survey, through administrative data sources, or through a combination of the two.

\subsection{Units}

6.6 The target population, for R\&D surveys, is the set of institutional units that are R\&D performers (or funders). This population can be classified to the institutional sectors that perform or fund $\mathrm{R} \& \mathrm{D}$. These are the Business enterprise, Government, Higher education and Private non-profit sectors. This manual focuses on collecting data from $R \& D$ performers; there is also a need for data on the funding of R\&D that addresses the requirements of the System of National Accounts (SNA), as well as a need to distinguish exchange and transfer funding (discussed in Chapter 4). The target population of performers may not be sufficient to support statistics on funders. Similarly, a target population of funders may not support statistics on performers.

6.7 It is recommended that the sampling unit for R\&D surveys should be the institutional unit.

\section{Institutional unit}

6.8 The institutional unit is a national accounting concept and is defined as "an economic entity that is capable, in its own right, of owning assets, incurring liability, and engaging in economic activities and transactions with other entities" (Chapter 3 and EC et al., 2009: 61, para. 4.2).

\section{Statistical unit}

6.9 A statistical unit is an entity about which information is sought and for which statistics are ultimately compiled. A survey frame will be composed of statistical units. The statistical units selected as part of the sample may have a weight (i.e. the inverse of the probability of selection) that will be applied to develop estimates of the population from which the sample is drawn.

6.10 A statistical unit may have a number of attributes. These could include:

- Frascati Manual (FM) sector (i.e. Business enterprise, Government, Higher education, Private non-profit)

- SNA sector (i.e. Corporations, General government, NPI)

- a principal (used interchangeably with 'main' in this manual) economic activity (the principal economic activity allows the unit to be classified using, for example, the International Standard Industrial Classification of All Economic Activities, Revision 4 (United Nations, 2008)

- geography

- size (e.g. number of employees, turnover, etc.). 
6.11 Various possible types of statistical units are discussed in Chapter 3, including enterprise groups, enterprises and establishments. While this nomenclature is developed for the Business enterprise sector, it can be applied to other institutional sectors.

6.12 In this chapter the preferred term is the "institutional unit", with "enterprise" being used interchangeably with "institutional unit" only in the Business enterprise sector.

\section{Reporting unit}

6.13 In this manual, the reporting unit is the entity from which data are reported. Within a given statistical unit, there may be different units at which level the desired data are available and can be reported. For example, data on the geographic distribution of R\&D activity by an enterprise may be available from reporting units at the establishment level. Data on fields of R\&D (FORD) for a higher education institution may be available at the level of individual departments. In the case of administrative data, the reporting unit corresponds to the unit that is represented by the individual record. A single collection point may be the conduit for gathering data for multiple reporting units.

\section{Relationship between units}

6.14 In general, reporting units will correspond to individual institutional units or groups of them. There are exceptions, particularly in cases where it is easier for respondents to report on a different basis. This may take place for a group of institutional units in the case of international transactions and at the level of individual government ministries and university departments (in the cases where these units do not fulfil all of the conditions of being institutional units).

6.15 Related institutional units may be brought together into a group of institutional units (enterprise group in the Business enterprise sector). This level should be able to produce consolidated income statements and balance sheets for the entire group of institutional units.

6.16 In the case of simple structures, a single legal entity may correspond to a single institutional unit. In more complex structures, there may be many-toone or many-to-many relationships between legal entities and enterprises.

6.17 How these complex structures are addressed will differ from country to country, and no attempt is made here to prescribe specific approaches.

\subsection{Institutional sectors}

\section{Business enterprise}

6.18 The Business enterprise sector is defined in Chapter 3, Section 3.5. Business performers of $\mathrm{R} \& \mathrm{D}$ have two distinguishing characteristics. First, they may form a rare subset of the total Business enterprise sector population. 
Second, they may not perform R\&D continuously. This creates challenges in the development and maintenance of survey frames (Chapter 7).

6.19 Some business enterprises may perform R\&D occasionally, while others may perform it continuously. It is important that both types of enterprises be included in the survey frame. It is recommended that, at a minimum, all business enterprises likely to be performing R\&D either continuously or occasionally be included in R\&D survey frames (Chapter 7, Section 7.3).

6.20 The sampling unit for the Business enterprise sector will generally be the institutional unit or enterprise. The desired attributes of the sampling unit include: principal (main) economic activity, size, geography and ownership, and control. The reporting unit will be dependent on the entity that is best able to report. This may involve combinations of enterprises or establishments (Chapter 3, Box 3.1).

6.21 The sample may be drawn from a co-ordinated frame that contains information on both SNA sectors and Frascati sectors, as discussed in Chapter 3. The use of such a frame assists in ensuring that the SNA sectoring of R\&D units is done on a consistent basis while also allowing units to be selected from Frascati sectors. In the Business enterprise sector, an example would be a university providing formal education programmes that sold its output at an economically significant price. It would be classified to the Higher education sector for Frascati purposes, and the corporations sector for SNA purposes. If linked to a business register, it would also assist in the integration of R\&D survey data with other types of data to support micro-level analysis.

6.22 There are different ways of developing a frame of business units. Where current and historical information or administrative data are available, R\&D performing and funding units should be identified on the survey frame. If these indicators are not available, alternate means of identifying these units could be the first stage of a two-stage sample design for R\&D surveys. Another method of assessing the coverage is to conduct a precontact on units that are likely to be performing or funding R\&D (i.e. targeted industries). More information for countries starting $R \& D$ surveys is found in UNESCO-UIS (2014).

6.23 Other sources of data could be used to improve survey coverage. These external sources should be assessed to ensure that they are of an adequate level of quality to determine if they could be used to supplement the survey frame. If so, they should be used to flag business enterprises that are performing or funding R\&D.

\subsection{It is recommended to:}

- include in R\&D surveys of the Business enterprise sector all firms known or very likely to perform (or fund) $R \& D$

- identify R\&D performers not known / uncertain to perform R\&D by surveying a sample of all other firms. 
6.25 The survey frame should include all business enterprises performing (or funding) R\&D. There may be budget or respondent burden constraints on sampling and stratification that should be documented as part of data quality reporting.

\section{Government}

6.26 The Government sector is defined in Chapter 3, Section 3.5.

6.27 While this manual's recommended statistical unit is the enterprise equivalent, in this case the Government sector, for practical purposes, the sampling unit will generally be the department, ministry or agency, even if the unit does not have all of the characteristics of an institutional unit (i.e. the ability to hold and control assets). This choice of sampling unit does not mean that financial flows between government departments are extramural (see Glossary and Chapter 4, Section 4.3 on identifying fund flows between sectors). The desired attributes of the sampling unit for the Government sector include: principal (main) economic activity, geographic location and level of government. The reporting unit will be dependent on the entity that is best able to report. This may include the whole of government in the case of sub-national or municipal governments.

6.28 There may be several ways of updating lists of R\&D performing and funding units such as legislation, budget and related funding actions, as well as registers, directories of R\&D performing units, research associations, bibliometric sources, and requests for updates from administrative bodies.

6.29 If available, the survey frame could be linked to a central business register. This would assist in the integration of data from various sources. It would also reduce the risk of double counting.

6.30 Particular attention should be paid to the use of administrative data in the identification of R\&D performing and funding institutions.

6.31 It is especially difficult to identify R\&D activities at the local (municipal) government level owing to the large number of units, the small number of likely $R \& D$ performers and the difficulties in the interpretation of the concept of $R \& D$. Lists of R\&D performers usually do not include these units. If local governments undertake a significant amount of R\&D activity, then consideration could be given to including R\&D performers in large local governments. Given the nature of many sub-national forms of government, it may not be core to the government department or agency mission to conduct $R \& D$, but to address a specific problem as identified by the legislature or the department. Therefore, some R\&D activities may be occasional. A more detailed discussion of the Government sector is found in Chapter 8.

\section{Higher education}

6.32 The Higher education sector is defined in Chapter 3, Section 3.5. The surveys and estimation procedures should cover all universities, colleges 
of technology and other institutions providing formal tertiary education programmes, whatever their source of finance or legal status, and research institutes, centres, experimental stations and clinics that have their $R \& D$ activities under the direct control of, or are administered by, tertiary education institutions.

6.33 This sector does not have a direct counterpart in the SNA group of institutional sectors. There is guidance on the cross-classification of the Higher education sector with SNA sectors in Table 3.1 in Chapter 3. Higher education sector institutions are found in all SNA sectors and are treated separately because of the high degree of policy relevance of R\&D performed within this group of institutions.

6.34 The sampling unit for the Higher education sector is the higher education institution (corresponds to the institutional unit). The desired attributes include geographic location and economic sector. The reporting unit may be individual faculties or departments. It will be the level in the institution that is best able to report expenditures and funding flows. Attention should be paid to hospitals that perform R\&D and may be part of the Higher education sector.

6.35 Surveys of the Business enterprise, Higher education, Government and Private non-profit sectors should ensure that research hospitals are included in the survey frame and that they are correctly assigned to a sector (Chapter 3 ).

6.36 In some jurisdictions, there may need to be a distinction between the research hospitals that conduct $R \& D$ and the charitable foundations associated with these hospitals that fund R\&D. Where university hospitals are financially integrated with higher education institutions, they may be treated together as a single sampling unit. If they are separate units with separate accounts and administrations, they may be treated as two separate sampling units.

6.37 Care should be taken to ensure coherent treatment of R\&D units under joint management by two or more entities, by persons receiving salaries from different entities, and by persons employed by other institutions. This applies to units in all sectors, but it is more of an issue with R\&D units in hospitals.

6.38 Chapter 9 provides more guidance on measuring $R \& D$ activity in the Higher education sector.

\section{Private non-profit}

6.39 The sector is defined in Chapter 3, Section 3.5. The additional sources for identifying possible survey respondents are mainly the same as for the Government sector. Frame information may be less comprehensive and could be completed by information from tax authorities, researchers or research administrations. This sector may be more relevant for gathering data on R\&D funding.

6.40 In general, the sampling unit for the Private non-profit sector will be the institutional unit. The desired attributes of the sampling unit are: principal (main) economic activity, size, geographic location and control. The reporting 
unit will be dependent on the entity that is best able to report. This may include combinations of units. Chapter 10 provides more guidance on measuring R\&D activity in the Private non-profit sector.

\subsection{Survey design}

\section{Sampling plan}

6.41 Compared to other activities, R\&D activity is a rare event and relatively concentrated in a small number of institutional units. For these populations where large units account for a significant proportion of the overall estimate, a separate sampling stratum should be created. This is sometimes referred to as a "take all" stratum, where these large units are sampled with certainty. Such units will have sampling weights of one. Smaller units may be selected with a probability of selection smaller than one. The sampling plan in this section is not prescriptive, as the Business enterprise and Private non-profit sectors are quite different from the Government sector or the Higher education sector. The survey design and the sampling plan must take account of the national context and practices.

6.42 To stratify the sample, it is important to choose the size variable that best represents the population. The previous year's data, or some other proxy for R\&D, may be preferable to other size variables (e.g. turnover, overall budget appropriation or persons employed) if there is little correlation between these variables and R\&D expenditures or funding. For units that are continuous performers of $R \& D$, the previous year's data are preferable.

6.43 In determining the optimal sample size for stratified samples, it is important to account for the desired level of precision in the estimates. The sample size should also be adjusted to reflect the expected non-response rate, the expected rates of misclassification of units, and other deficiencies in the survey frame used for sampling.

6.44 A stratified sample may contain "take all" and "must take" strata where units are selected with a probability of $100 \%$. Units selected with certainty are expected to be the most important R\&D performers or funders. A "must take" stratum is used for complex respondents that may have more than one industry classification, location or jurisdiction. A stratified sample may also contain a "take-some" stratum with a probability of less than one. A probability sample is preferred for these strata, as it allows for the calculation of sample error, as a quality measure, and helps to reduce the risk of bias.

6.45 If sufficient auxiliary data exist to identify a unit in an existing register as an R\&D performer, then a frame can be constructed by identifying those known performers. If auxiliary information is not sufficient or is lacking, it may be necessary to use a two-phase sample design. In this case, a large sample is selected in the first phase to identify statistical entities that are involved in $R \& D$, then a sub-sample is selected from the first phase sample. 
6.46 Given the sectoral breakdown of $R \& D$ activity, it is possible that multiple frames are used. In this case, it is important that the frame membership for each unit is managed. If combining multiple frames, institutional units should be included only once in the combined frame. If R\&D institutional units could be flagged on a centralised business register, it may reduce the possibility of the duplication and possible double counting of R\&D activity.

\section{Design of data collection methodology}

6.47 Direct data collection can occur by various modes, including by a paper questionnaire, by telephone, or by web-based collection, provided there are sufficient security measures in place to protect sensitive data, or by interview in countries where computers, telephones and postal services are not widely available. Data may also be collected from administrative sources.

6.48 In the case of direct data collection, consideration should be given to the cost and the response burden associated with the survey.

6.49 Regardless of the mode used, the survey questionnaire should include the minimum number of core questions to provide the required data on $R \& D$. The questionnaire should be as short as possible (without sacrificing the collection of needed core data), logically structured and clear, and should make reference to definitions and instructions. Consideration should be given to the use of electronic questionnaires that can embed this information in the questions. Electronic questionnaires may contain edits that will help the respondent to report complete and coherent data. Data editing is a means to detect and correct reporting errors (logical inconsistencies) in the data. For example, the insertion of a letter into a numeric field should be identified by an editing process, and the questionnaire is then said to have "failed the edit".

6.50 The data collection methodology should consider the person filling out the questionnaire. The respondent can be the R\&D manager or, more likely, is in the accounting or finance unit of the R\&D unit. Each has its advantages and disadvantages. The R\&D manager can better identify the R\&D activity and better understand the concepts contained within this manual. However, the financial officer may be better placed to report detailed financial information. A human resources officer may be best placed to respond to R\&D personnel questions, if these are included in R\&D surveys. Reporting responsibility may involve all of these areas.

6.51 The collection strategy must therefore consider the possibility that the questionnaire may have to "travel" through an organisation in order to provide a complete response. Nevertheless, it is preferable to identify a single point of contact for the enterprise or institution. If not already known, a pre-collection interview may be required to identify the person best suited to coordinate the completion of the questionnaire. This is especially important in the case of complex institutional units. 
6.52 In addition to collecting spending and personnel data for the reporting period that has just ended ( $t$ ), compilers of $R \& D$ statistics are recommended to collect budgeted expenditure data for the following year, the year in which the collection is taking place $(t+1)$. Compilers may also collect information on expenditures budgeted for the year following the collection $(t+2)$. However, care should be exercised in the interpretation of these budget results, as they represent only the expected behaviour of businesses, and there may be significant revisions between expected and actual data. The recommendation for the collections of budget expenditure data for the year following the year of the data collections, and not data on personnel, is based on experience of unreliable results for personnel. For expenditures, the collection of data on budgeted spending is preferable to estimating expenditures based on past $R \& D$ performance, or concurrent measures of economic performance, such as sales.

\section{Administrative data and survey design}

6.53 If the concepts, definitions and coverage used by administrative data sources are sufficiently close to those contained in this manual, then the administrative data sources may be used as a primary source of information. If there are discrepancies between the concepts used by the administrative data source and this manual, then the administrative dataset may still be used as an auxiliary source of information to assist in the imputation of missing or inconsistent information. Imputation is a procedure for entering a value for a specific data item where the response is missing or unusable. The uses of administrative data will vary across countries based on their availability and quality.

6.54 The presence of administrative data will also influence the design of the data collection. For example, if there is a register of applicants for R\&D tax credits, the resulting administrative data could be used to estimate the R\&D performance for performers of small amounts of $R \& D$, reducing the burden on these units. This is not an option for countries without R\&D tax programmes.

6.55 There are a number of ways in which administrative data may be used in the compilation of estimates. If the concepts contained within the administrative programme are sufficiently similar to those contained within this manual, then the administrative dataset may be used for direct data replacement. This data replacement could occur both in the case of planned data replacement as well as in the case of a partial or complete non-response by the respondent. Apart from data replacement, administrative data may be used for sampling frame maintenance. These data may also be useful in data validation (i.e. by examining whether or not the survey trends align with the trends found in the administrative data). If there is sufficient correlation between a variable in the administrative dataset and one found in the survey data, then the administrative data may be used as an auxiliary variable in a calibration estimator. A description of various uses can be found in Australian Bureau of Statistics (2005). 
6.56 There are a number of considerations that should be made in assessing the utility of administrative data. The coverage of the administrative data should match the population of R\&D funders and performers. The timeliness of the administrative data should be considered, including through an assessment of how long the revenue/regulatory authority takes to complete its work on the input data. The definitions and concepts of the administrative data should be the same as those found in this manual. The quality of the administrative data should be compared to the standards and expectations of a survey. If, for instance, there is a high edit failure rate, the quality of the administrative data may be insufficient. If the programme that generates the administrative data is subject to frequent changes, then the relationship between the concepts in the administrative data and the concepts contained in this manual may not be consistent over time. This may limit the usefulness of the administrative data source. The stability of the administrative data source over time is important. There needs to be adequate legal or regulatory authority to access the data for statistical purposes. Finally, the administrative data should be sufficiently documented so as to permit their use.

\section{Questionnaire design considerations}

6.57 Questionnaires, either paper or electronic, have a significant impact on respondent behaviour, respondent relations and data quality. Questionnaires should strive to minimise response burden and make it as easy as possible for the respondent to reply. A well-designed questionnaire should help to reduce the amount of edit and imputation performed, thus easing post-collection processing.

6.58 As much as possible, the words and concepts contained in the questionnaires should mean the same thing for survey-taking organisations and respondents. It should not be incumbent on survey respondents to interpret the data requirements of the survey, but rather questions should be posed in such a manner that they are understood well by the respondent, even if post-collection transformation of these variables is required to align them with the concepts contained within this manual. For this reason, it is appropriate to have different questions for businesses and for public sector institutions, if they have different accounting standards and terminology.

6.59 In order to aid respondents, instructions should be short, clear and easy to find. Definitions for the concepts should be made easily available. Inclusions and exclusions should be clearly explained within the survey instruments. Electronic questionnaires should embed a limited amount of consistency and range edits to aid the respondent in accurately completing the questionnaire. Whatever the mode, the wording and the routing options that govern the skipping of questions through the survey questionnaire should be the same.

6.60 In order to ensure that questionnaires are well understood by respondents, it is recommended that they be tested before collection. These tests could include qualitative tests (i.e. focus groups or cognitive testing) or 
pilot surveys. In the case of electronic collection, it is important that the final collection application is tested on a variety of users and operating systems to ensure that the content is well understood and that the application is functional. Methods for testing questionnaires can be found in Couper et al. (2004).

6.61 R\&D surveys are usually designed as stand-alone collection instruments. If R\&D surveys are combined with other collection instruments, care should be taken to ensure that the coverage of the combined instrument remains inclusive and representative of all R\&D activity and that there is no reduction in data quality. While there are examples of R\&D surveys combined with innovation surveys and there is discussion of combining them with capital expenditure surveys, stand-alone R\&D surveys are recommended.

\subsection{Collection}

6.62 The burden imposed upon the respondent should be minimised. Of particular importance to respondents in the Business enterprise sector is maintaining the confidentiality of data, where $R \& D$ expenditures represent important strategic decisions.

6.63 In the process of collecting data, there may be the generation of paradata or information related to the survey process. Examples of paradata may include whether or not the unit is in the sample; a response follow-up history; and the mode of collection. The use of paradata after a survey cycle may assist in improving the survey instrument in future iterations.

6.64 A data collection process should strive to minimise the burden and cost and maximise timeliness, the response rate and accuracy. Web collection is emerging as the preferred mode type. However, it is important that multiple modes of collection be made available, especially in countries where electronic or postal collections are not likely to work. Collection strategies should be flexible enough to allow for a change in the mode of collection (i.e. collection of information by telephone where a respondent has not replied to a request to complete the questionnaire on-line or on paper). If multiple modes are used to collect survey data, a post-collection study on possible mode effect biases might be suggested.

6.65 A pre-contact may be a useful exercise to confirm frame information before collection. This pre-contact may include: contact information on the respondent (including e-mail addresses); an industrial or activity classification of the institutional unit; and confirmation that it is involved in R\&D activity.

6.66 For large, complex organisations, consideration should be given to special reporting relationships if this helps respondents to complete the questionnaire. This may include: identification of a single point of contact for collection; customisation of the reporting unit; and modification of the collection instrument to make it easier for respondents to relate their own financial and human resource management systems to the survey questions. It is anticipated that this type of treatment would be focused on institutional units that make significant contributions to the overall estimate. 
6.67 Given the complexity involved in the measurement of R\&D expenditure, consideration should be given to the development of interviewer manuals and training so as to enable interviewers to answer respondents' questions. Some of these tools may be shared directly with the respondent, particularly in the case of electronic collection. These tools may include: explanatory notes; hypothetical examples and documentation on the treatment of different cases.

6.68 Once data are received, a preliminary set of edits should be conducted, and a follow-up should be performed with respondents where these edits fail. In the case of electronic questionnaires, these edits may be embedded in the questionnaire itself, reducing the need for interviewer follow-up.

6.69 Response rates should be monitored throughout the collection. In situations where the response rates are low, as a quality assurance measure a sub-sample of non-responding units may be contacted after collection to determine whether there is any non-response bias in the estimates (i.e. the respondents are more or less likely to be R\&D performers). This information could be collected directly (i.e. a telephone follow-up) or indirectly, through the use of administrative data.

6.70 Also, at the end of the survey process, paradata may be used to assess the effectiveness and cost efficiency of the collection operation. This type of analysis may be used to streamline and improve survey operations.

\subsection{Integration of data}

6.71 If datasets are integrated (i.e. in the case of firm-level analysis), then it is important that there is a linking key that allows for the datasets to be combined. These linking keys are typically found on a central business register. If this type of activity is undertaken, then the linkage rates between the datasets should be monitored as a quality measure. If the non-linkage rates are unacceptably high, this may indicate the inability to use this linked dataset.

\subsection{Editing of collected data and imputation}

6.72 The collected data is edited to identify possible errors and either to validate a record or variable or to correct for errors and inconsistencies. It is important that edits do not generate bias in the aggregate estimates. It is possible to over-edit a record if the editing has a negligible impact on the final survey estimate and care should be taken to avoid this in the editing strategy.

6.73 Edits should be automated and reproducible. An automated process allows for increased accuracy and scope. Care must be taken in the development of automated systems not to over-edit the data. In examining and correcting for edit failures, consideration should be given to the use of selective editing where the focus of follow-up is the units that contribute most to the estimate of a particular domain. Edit failure rates should be tracked, as they provide information on how to improve the questionnaire or other aspects of collection. Tracking should include manual edits when they occur. 
6.74 Imputation is used to assign valid values for missing or inconsistent data. Imputation typically occurs after collection (including follow-up with respondents) and an initial manual review of questionnaires. Imputation can be used to handle both a complete questionnaire non-response (i.e. unit non-response) as well as non-response for a particular variable (i.e. item nonresponse). After imputation is completed, the micro-data file should contain only complete and internally consistent data. Imputation processes should be automated, objective and reproducible.

6.75 A number of imputation methods are available to replace missing or inconsistent information. Deterministic imputation methods include:

- logical imputation

- mean imputation

- ratio imputation

- nearest neighbour imputation.

6.76 Other methods are available, and their use will depend on the practice of the institution doing the collection.

6.77 If there is a sufficient relationship between the available administrative data and missing or inconsistent survey data, then the administrative data may be used as a direct replacement.

6.78 Given the variability of $R \& D$ as an investment activity, it is preferable to use imputation methodologies that make use of data available from the respondent (either directly or through the use of auxiliary data) over the use of information from other responding units (e.g. nearest neighbour imputation).

6.79 Metadata should be retained to identify the variables and records that have been imputed, as well as the methods used for imputation. Imputation rates are an important indicator of data quality, and domains that have a high weighted imputation rate should be treated with caution. To support this decision, the sampling variance due to imputation is required.

\subsection{Estimation}

6.80 All units in the sample will have a design weight based upon the units' probability of selection into the sample. The design weight is equal to the inverse of the probability of selection. For a two-stage sample, this is equal to the product of the weights for each stage.

6.81 Design weights may be adjusted to reflect the actual number of units responding. This strategy should be used only if it is believed that nonrespondents and respondents share similar characteristics. Methods of estimation are discussed in Lundström and Särndal (2005).

6.82 If there is an administrative dataset available that contains auxiliary data that are highly correlated with a questionnaire variable (e.g. total $R \& D$ expenditures), the design weight may be adjusted by calibrating the weights. 
In a calibration estimator, the weights are adjusted to achieve known control totals. Specific methods available include: regression and ratio and raking-ratio estimators.

6.83 The use of a calibration estimator may be preferred, as it will allow for increased precision in the estimates. It may also improve the coherence between different data sources.

6.84 The precision of the estimate should be measured through the estimation of the standard error.

\subsection{Output validation}

6.85 There are a number of steps that should be conducted to validate and certify estimates coming from R\&D surveys.

6.86 It is important that the reporting units in the sample remain representative of the population of $R \& D$ performers. Checking for the population coverage can be assessed by examining response rates. Using response rates weighted by the value of $R \& D$ expenditures can provide feedback on the proportion of the estimate accounted for by actual data.

6.87 In order to assure continuity of the estimates, data from R\&D surveys should be compared to previous cycles, and explanations should be available for differences.

6.88 Data should be compared with other comparable data sources. If there are discrepancies, these should be explored, leading to improvements in the estimate or to an explanation of differences.

6.89 The final estimates should be validated against expectations and domain intelligence. Again, discrepancies should be explored, leading to improvements in the estimate or to an explanation of differences.

\subsection{Reporting to the OECD and other international organisations}

6.90 National authorities carry out R\&D surveys to obtain data relevant to national concerns in the framework of national institutional arrangements. Differences may exist between national practices and the international norms laid down in this or other manuals. Nevertheless, every effort to reduce the impact of such differences should be made when reporting these data to the OECD or to other international organisations by making adjustments or estimates, even if this means that the R\&D data in international sources will differ from those in national documents. If national authorities are unable to make such adjustments on their own responsibility, they might help the relevant organisations to make informed estimates. Where such adjustments cannot be made, full technical notes should be submitted. Discrepancies are generally of two kinds:

- explicit differences in approach between national R\&D surveys and that recommended in this manual 
- "implicit" differences between national economic or educational classifications used in the country's surveys and the international classifications recommended in this manual.

6.91 It is important to identify and report both kinds of differences and any break in series. When changes in any aspect of the survey process (e.g. sample design and unit classification, data collection methods, survey instrument design, question construction or definitions) result in known breaks in the historical data series, such breaks should be openly identified and conveyed to data users. Whenever it is possible to provide a measure of the likely impact of the break (e.g. percent of reported totals) or to chain link current and future estimates with past estimates, this should be done.

6.92 National authorities should provide indicators of data quality for the published aggregates. These may be based upon standard errors as well as response rates. They may be provided globally as well as for individual domains of estimation. Coverage statements should include how the survey population was constructed, maintained and assessed. Variable imputation rates should be provided. These rates assist in determining data quality and question construction. Some concepts may be unfamiliar or difficult for respondents, and the questionnaire design needs to be reviewed to account for these weaknesses regularly. Cell level suppression due to confidentiality may be useful to anonymise a population too rare or too concentrated to support the detail requested. Timeliness should be considered, as should revision rates.

\subsection{Concluding remarks on data quality}

6.93 This chapter has provided a range of approaches to measuring R\&D in the main institutional sectors of this manual and to producing results of reproducible quality, using commonly accepted data quality measures. Practitioners can find discussions of data quality in Snijkers et al. (2013), Lyberg et al. (1997) and also www.oecd.org/std/qualityframeworkforoecdstatisticalactivities.htm and http://unstats. un.org/unsd/dnss/QualityNQAF/nqaf.aspx. The range of approaches is intended to offer both options for data collection to countries with limited statistical infrastructure and points for discussion for those with a highly developed statistical system. In all cases, statistical methods and supporting technologies and practices change over time, and users of this manual are encouraged to monitor, and use, best practices for their statistical environment.

\section{References}

Australian Bureau of Statistics (2005), “The Experience of ABS with Reducing Respondent Burden Through the Use of Administrative Data and Through the Use of Smarter Statistical Methodology", UNECE Conference of European Statisticians $35^{\text {th }}$ Plenary Session CES/2005/18. 
Couper, M.P., Judith T. Lessler, E.A. Martin, J. Martin, J.M. Rothgeb and E. Singer (2004), Methods for Testing and Evaluating Survey Questionnaires, John Wiley and Sons, Hoboken, NJ.

EC, IMF, OECD, UN and the World Bank (2009), System of National Accounts, UN, New York. https://unstats.un.org/unsd/nationalaccount/docs/sna2008.pdf.

Lundström, S. and C.-E. Särndal (2005), Estimation in Surveys with Nonresponse, John Wiley and Sons, Hoboken, NJ.

Lyberg, L., P. Biemer, M. Collins, E. de Leeuw, C. Dippo, N. Schwarz and D. Trewin (eds.) (1997), Survey Measurement and Process Quality, John Wiley and Sons, Hoboken, NJ.

Snijkers, G., G. Haraldsen, J. Jones, D. Willimack (2013), Designing and Conducting Business Surveys, John Wiley and Sons, Hoboken, NJ.

UNESCO-UIS (2014), "Guide to conducting an R\&D survey: For countries starting to measure research and development", Technical Report 11, UIS, Montreal. www.uis. unesco.org/ScienceTechnology/Documents/TP11-guide-to-conducting-RD-surveys.pdf.

United Nations (2008), International Standard Industrial Classification of All Economic Activities (ISIC), Rev. 4, United Nations, New York. https://unstats.un.org/unsd/cr/registry/isic-4.asp and http://unstats.un.org/unsd/publication/seriesM/seriesm_4rev4e.pdf. 

PART II

\section{Measuring R\&D: Sector-specific guidance}





\section{Chapter 7}

\section{Business enterprise R\&D}

This chapter provides guidance on the measurement of research and experimental development ( $R \& D)$ performed in the Business enterprise sector, the sources of funding, breakdowns of the statistics by main economic activity, employment size of the business enterprise and geography. The indicators of $R \& D$ activity for the sector include $R \& D$ expenditure, $R \& D$ personnel, sources of $R \& D$ funds, the distribution of the $R \& D$ by basic research, applied research and experimental development. There is a discussion of breaking down the statistics by the industry orientation (the product field or the industry served) and why this should be considered. Distributions by fields of R\&D (FORD), by socioeconomic objectives, geographic location and by specific technology areas are discussed. The chapter ends with a review of survey design, data collection and estimation in the sector. The resulting statistics support policy discussion related to dominant and emerging industries, concentration of $R \& D$ in regions, industries and enterprises, and the industry served by $R \& D$ performed by enterprises in the sector. 


\subsection{Introduction}

7.1 For most industrialised countries, the Business enterprise sector accounts for the largest share of R\&D expenditures and personnel. In analysing this sector and the units within it, it is important to take into account the multiple approaches used by companies to manage their R\&D activities. In particular, related businesses may jointly fund, generate, exchange and use R\&D knowledge in diverse and assorted ways. Complex business structures, particularly used by multinational enterprises (MNEs), are challenging for R\&D measurement. Also, for some businesses, R\&D is an occasional, rather than an on-going activity and therefore more difficult to identify and measure. From a policy perspective, collecting information from businesses on the role of government as a provider of financial support for R\&D and on interactions with the public science and research base is particularly relevant. From a methodological perspective, the collection of data from business enterprises also entails a number of practical challenges, ranging from identifying R\&D performing firms to obtaining information on $R \& D$ as required in this manual through to dealing with confidentiality and the minimisation of response burden.

\subsection{Coverage of the Business enterprise sector}

7.2 As detailed in Chapter 3, the Business enterprise sector comprises:

- All resident corporations, including not only legally incorporated enterprises, regardless of the residence of their shareholders. This group includes all other types of quasi-corporations, i.e. units capable of generating a profit or other financial gain for their owners, recognised by law as separate legal entities from their owners, and set up for the purpose of engaging in market production at prices that are economically significant. They include both financial and non-financial corporations.

- The unincorporated branches of non-resident enterprises deemed to be resident and part of this sector because they are engaged in production on the economic territory on a long-term basis.

- All resident non-profit institutions (NPIs) that are market producers of goods or services or serve business. The former NPI category comprise independent research institutes, clinics and other institutions whose main activity is the production of goods and services for sale at prices designed to recover their full economic costs. The latter category of NPIs serving business comprises entities controlled by business associations and financed by contributions and subscriptions. 
- Specifically excluded are units that belong to the Higher education sector as described in Chapter 3, Section 3.5, and in Chapter 9. However, commercial firms owned by higher education institutions, for example as a result of agreements that give the university a major shareholding position in a spin-off company set up by staff and/or students, should be treated as business enterprises.

7.3 The Business enterprise sector includes both private enterprises (either publicly listed and traded, or not) and government-controlled enterprises (see Chapter 3, Section 3.5), which in this manual are termed "public enterprises". (The terms "private enterprises" and "public enterprises" are used interchangeably with the term "private business enterprises" and "public business enterprises", respectively.) For public enterprises, the borderline between the Business enterprise and Government sectors is defined by the extent to which the unit operates on a market basis, i.e. whether its principal activity is the production of goods or services for market at economically significant prises. A government research institute that may occasionally receive a considerable amount of revenue from the sale or licensing of its intellectual property should not be considered a public enterprise if the majority of its R\&D activities are carried out with a non-commercial intent. On the other hand, a government-controlled institute whose operations rely on fees for providing R\&D services and access to research infrastructure that fully reflect the economic cost of such services should be classified as a public enterprise. The concept of "public" sector is wider than that of "government".

7.4 In line with the SNA, Non-profit institutions controlled by or primarily serving business enterprises, such as trade associations, industry-controlled research institutes, etc., should be classified as part of the Business enterprise sector even if the institutions operate on the basis of subscriptions that barely cover their operating costs and draw significantly on government grants that allow them to break even. In general, NPIs that are created and managed by associations of businesses whose activities they are designed to promote, such as chambers of commerce and agricultural, manufacturing or trade associations, and that are financed by contributions or subscriptions from the businesses concerned which provide core or project-based support for their $R \& D$, should be treated as part of the Business enterprise sector.

7.5 The market activities of unincorporated enterprises owned by households (i.e. some types of partnerships and even self-employed consultants or contractors undertaking R\&D projects for another unit at an economically significant price) are included in the Business enterprise sector whenever practicable.

7.6 As indicated in Chapter 3, the activities of individuals who pursue in their own time and at their own expense their personal interests as researchers or inventors are currently beyond the scope of the institutional approach to R\&D statistics presented in this manual.

7.7 As defined in the SNA, a joint venture involves the establishment of a corporation, partnership or other institutional unit in which each party legally 
has joint control over the activities of the unit. The units operate in the same way as other units except that a legal arrangement between the parties establishes joint control over the unit. Joint ventures should also be classified on the basis of the units they predominantly serve, whenever possible taking into account established SNA practice.

7.8 When a separate institutional unit is created to manage a joint venture, it should have the same industrial classification as the institutional unit that has the greatest interest in this partnership. In some instances, R\&D partnerships may have a formal, independent status, and in which case should also be classified on the basis of the units they predominantly serve.

\subsection{Statistical units and reporting units}

7.9 Business enterprises organise their R\&D funding and performance activities at various possible levels in order to better meet their own objectives. Strategic decisions concerning the financing and direction of the R\&D efforts may be taken at the enterprise group level, regardless of national boundaries, while the day-to-day management of $R \& D$ operations, possibly including decisions on the type of expenditures on R\&D performance and on the hiring of human resources to be devoted to $R \& D$, may occur at lower levels in the organisation. The activities of MNEs engaged in R\&D may occur in more than one country, making those responsible for decision-making hard to identify and survey. These factors may impact the classifications identified with a statistical unit and influence the choice of reporting unit (both defined in Chapter 6).

\section{Statistical unit}

7.10 The statistical unit for the Business enterprise sector will generally be the enterprise, defined in Chapter 6.

7.11 As a general requirement, all the statistical units included in an R\&D survey population should be properly identified on the basis of a number of descriptive variables, which are usually available from statistical business registers. Identification variables (or tags as described in Chapter 3) should include: an identification code, a location variable (geography), a variable on the kind of economic activity undertaken and a size variable. Additional information on the economic or legal organisation of a statistical unit, as well as on its ownership, could be extremely helpful and make the survey process more effective and efficient.

\section{Reporting unit}

7.12 The choice of reporting units in the Business enterprise sector will vary from country to country, depending on institutional structures, the legal framework for data collection, traditions, national priorities, survey resources and ad hoc agreements with the business enterprises. When an enterprise is heterogeneous with regard to its economic activities and carries out significant 
amounts of $R \& D$ for several kinds of activities, it may be advisable that data are collected from (reported by) more detailed statistical units, e.g. on a kindof-activity basis or even an establishment basis when regional location is an important. This manual can make no overarching recommendation concerning the choice of reporting unit to be queried by each individual country. Rather, national statistical offices should ensure the additivity of the R\&D performance and personnel data and the appropriate handling of funding flow data, regardless of the collection approach taken. The selection of an appropriate reporting unit should be made in line with the general guidance provided in Chapter 6 for the identification of statistical and reporting units and with the recommendation to avoid collecting data from a reporting unit that is not required to keep formal accounting records.

7.13 Because there may be information that companies may have readily available only at higher levels of aggregation, national statistical offices may have to engage with these units to ensure that business enterprise R\&D statistics conform to the principles of national statistics, separating their activities by jurisdiction and distinctive lines of business. Profiling business groups is an important activity that should be undertaken, whenever possible, in a coordinated fashion with those agencies and officials responsible for business registers. In some cases, for synergy or comprehensiveness, the compilers of R\&D statistics may decide it is appropriate to sample all enterprises within the consolidated set of enterprises that are resident in the country.

7.14 The enterprise group level may play a prominent role as a reporting unit because questionnaires may be filled or responses approved by a central administrative office. In the case of holding companies, a number of different approaches may be used, for example, asking them to report the activities for the enterprises they hold in the industries of the actual activity, or forwarding the questionnaire to the actual R\&D-performing company at the holding company's request.

\subsection{Institutional classifications for statistical units}

\section{Identification codes}

7.15 An identification code is a unique number assigned to a statistical unit included in a survey's target population. The availability of identification codes is extremely relevant for R\&D statisticians, who are usually dealing with potential R\&D performers identified on the basis of a range of different statistical and administrative sources. Identification codes should avoid the duplication of units in the population as well as the partial overlap between units (to the extent that statistical units should refer to different organisational levels: establishments, enterprises, groups). A code is essential for an effective sampling process and, if applicable, for collecting administrative data (when the same codes are used also for administrative purposes). From the perspective of users of R\&D statistics, identification codes allow for matching micro-data from different 
sources, including R\&D surveys, other business surveys or administrative data collections, and they facilitate longitudinal analyses when the structure of a unit changes over time. When statistical business registers already have available identification codes, it is preferable to use such codes when compiling R\&D data.

\section{Classification according to main economic activity}

7.16 A business enterprise may operate in one or more economic activities. Enterprises, as institutional (statistical) units, are classified according to their principal activity. In practice, the majority of production units perform activities of a mixed character. The International Standard Industrial Classification (ISIC) (United Nations, 2008a) is the relevant reference document for the international classification of economic activities or industries. Enterprises might be engaged in any economic activity, including agriculture, mining, manufacturing and services.

7.17 Countries that use national (or regional) industrial classification systems rather than ISIC should use concordance tables to convert their industrially classified data to ISIC for international reporting and comparison purposes. The preferred reporting of the main economic activity of a single statistical unit should allow for detail at the ISIC "class" level (4 digits) and therefore "group" level (3 digits). Nevertheless, it should not be made available at a level higher than that of a "division" (2 digits). The adoption of industrial classifications that differ from ISIC - such as NAICS in North America or NACE in Europe - has no impact on the production of R\&D statistics as long as they are consistent with ISIC in the definition of industries (usually, direct correspondence is assured at the 1 and 2 digits level and indirect correspondence at the 3 and 4 digits level).

7.18 No industry should be excluded from the reporting of R\&D activities. All economic activities included in the ISIC Classification potentially could perform $R \& D$, although with varying levels of probability. Therefore every unit belonging to every industry could be assigned a level of probability for being an R\&D performer. In this respect, appropriate methodologies will have to be developed and implemented to deal with industries whose enterprises have, on average, a low probability of being identified as R\&D performers (such as agriculture or household services). In such cases, a preliminary screening is recommended before including enterprises from such industries in regular R\&D surveys.

7.19 The identification of a principal activity is necessary to classify a statistical unit into a main economic activity category. In order to determine the principal activity of a unit, the shares of its value added for its different economic activities (if more than one) must be known. In practice, however, unless this is obtained from a central register, it is often difficult to obtain such detailed information, so the activity classification has to be determined by using substitute criteria. Whenever possible, national statistical offices that compile R\&D data should avoid making separate classification decisions and should use 
available information from business registers or other administrative sources of comparable quality. This information is essential in sampling surveys to properly draw a representative sample of enterprises.

7.20 Practical challenges arise in the context of large enterprises with multiple economic activities and complex structures. Such large enterprises can also account for a very large share of R\&D. The relevance of industry classifications in measuring R\&D totals is further clarified below in Section 7.6. National statistical offices should strive to find the appropriate equilibrium between maintaining a minimum degree of homogeneity with regards to the economic activity of the business enterprise and taking into account the extent to which the business enterprise can provide the requested information on its activities.

\section{Classification according to public or private status and by affiliation status}

7.21 Following the recommendations given in Chapter 3, Section 3.4, the following classification of business enterprises is recommended:

- private domestically controlled business enterprises (not controlled by government or by non-resident institutional units).

- public business enterprises (subject to control by government units).

- parents or members of a domestic or foreign group.

- foreign-controlled business enterprises (controlled by non-resident institutional units). The interest in this category is further explained in Chapter 11 on R\&D globalisation.

7.22 R\&D data compilers may also wish to apply classifications that reflect the legal status of different enterprises (e.g. publicly listed, non-incorporate enterprises, etc.) in order to meet specific user needs within their own countries.

\section{Classification according to size of the business enterprise}

7.23 Units may be classified according to size on the basis of employment, revenues or other economic and financial attributes. Employment is often a less ambiguous measure and therefore preferable, but even in this case some countries may prefer to use the number of persons employed (recommended in this manual), while others may opt for the number of employees, the difference between them being determined by the number of owner-managers and unpaid personnel.

7.24 Classification by size is relevant for stratification, sampling, types of survey form targeting, and presentation of statistical results. In some countries, statistical regulations limit the surveying of very small enterprises. Since R\&D performance tends to be a highly concentrated activity, the under-coverage of smaller performers may not have substantial impacts on reported aggregate totals but could significantly distort other types of R\&D-based statistics and 
analysis. For this reason, all possible means should be used to ensure the most comprehensive possible coverage.

7.25 The size of the enterprise is an identification variable essential for sample design and data estimation, as well as for the proper management of data collection activities. A definition of size based on the average number of persons employed is recommended because of its simplicity, general applicability, usefulness and international comparability. A size variable can be used to intentionally exclude units from the target population (e.g. enterprises below a given size threshold, if applicable) or to adapt the data collection methods to the size and organisation of the targeted units.

7.26 It is recommended that all the units belonging to the Business enterprise sector, irrespective of their main economic activity and of their size, be considered potential $R \& D$ performers. In countries where small or micro enterprises are excluded from regular R\&D surveys in compliance with statistical regulations or because of practical and technical constraints, some effort should be made to identify to overall contribution of these small or micro enterprises to the business R\&D total.

7.27 The following size groups (based on the number of persons employed) are proposed for classifying business enterprises:

1-4

5-9

10-19

20-49

50-99

100-249

250-499

500-999

$1000-4999$

5000 and above

For practical reasons, given the ubiquity of zero employment businesses in registers and the impossibility for them to perform R\&D, it is recommended that they should be excluded from the scope of R\&D surveys.

7.28 These categories have been chosen for a variety of reasons, in particular for consistency with the size classification usually adopted for microenterprises (including enterprises with less than 5, 10 or 20 persons employed, depending on country-specific practices) or for small and medium-sized enterprises (including enterprises with less than 250 or 500 persons employed, depending on country-specific practices). Thus, these ten categories are not proposed for joint use, but rather to provide a classification structure on which country-specific practices could be based. Nonetheless, it is recommended that 
all countries maintain groups with breaks at 9, 49 and 249 persons employed so that internationally comparable statistics can be available for small, mediumsized and large enterprises. For large economies, it is recommended that a break at 999 persons employed also be maintained.

\section{Classification according to geographic location}

7.29 Another key classification variable is the unit's geographic location. While the residency is usually defined in terms of "country of residency", the location can be available at different levels of detail: States or regions (according to the administrative organisation at country level), local areas (towns or municipalities) or addresses. When dealing with reporting units that differ from statistical units - or multiple reporting units for a single enterprise - care should be used to identify the specific location relevant for a data compilation.

\subsection{Indicators of R\&D activity in business enterprises}

7.30 The R\&D activity undertaken by the units belonging to the Business enterprise sector is measured in terms of expenditures both for R\&D and for R\&D personnel. These two sets of indicators are often available according to the recommendations given in Chapter 4 and Chapter 5, respectively, and business R\&D expenditure may be functionally distributed according to guidance described in Section 7.6.

\section{R\&D expenditure}

7.31 In order to ensure coherence between $R \& D$ and non-R\&D information available from respondents, national statistical offices compiling R\&D data should review accounting relationships, when practical to do so. For instance: R\&D labour costs should be lower than total labour costs (or even equal under the condition that all the persons employed would be involved full time in R\&D). R\&D capital expenditure similarly should be included in, and therefore be no larger than, the overall capital expenditure of the enterprise. Total $R \& D$ costs should generally not exceed the value added generated by the enterprise in a reference year. For enterprises that undertake continuous $R \& D, R \& D$ might possibly be a stable fraction of value added over a multi-year period. Monitoring these relationships should help reduce the misreporting of R\&D data and thereby improve overall data quality.

\section{$R \& D$ personnel}

7.32 There is a similar need for consistency on the personnel totals for the reporting enterprises and the collected $R \& D$ data. The measurement of the R\&D workforce in business enterprises, as well as the involvement of external personnel in intramural R\&D activities (see Chapter 5), can be challenging. It is suggested that the reporting unit check first for R\&D activity carried out in the reference period by the persons employed by the enterprise. Full coverage of their 
contribution to R\&D - both in terms of time (full-time equivalent) and labour costs - is facilitated if the unit directly utilises their payroll data so that part-time workers and trainees are included. If such data are available from their business register or administrative sources, national statistical offices should check for coherence of personnel totals: for example, total internal R\&D personnel should not be larger than total personnel.

7.33 A further step is to identify all external contributors to intramural R\&D, which could include a broad range of profiles/positions: self-employed consultants, contractors' employees acting as intramural consultants, leased personnel, etc. A significant effort is requested of respondents in order to identify personnel who contribute an appreciable effort (in terms of time - see Chapter 5, Section 5.3) to the unit's intramural R\&D.

7.34 The distribution of the R\&D personnel by function (researchers, technicians and equivalent staff, or other supporting staff) is discussed extensively in Chapter 5, with the recommendations presented there being totally relevant to the Business enterprise sector. Both FTE and headcount data are to be collected, as are additional demographic distributions of those totals for characteristics such as sex, age, level of qualification, etc. (see Section 5.4). The functional distribution of the R\&D personnel should be based on a direct observation of the role actually played by the individuals involved in intramural $R \& D$, independently of their formal role in the enterprise. As a common practice, no direct relationship can be assumed between the formal (contractual) skill level (even described in terms of occupation) of a person employed and the type of their contribution to intramural R\&D. It is commonly observed, for instance, that persons who participate as "researchers" in the intramural R\&D activities of an enterprise have a formal job position of either "technicians" or "managers", rather than "researchers".

\subsection{Functional distributions for Business enterprise intramural R\&D expenditure (BERD)}

7.35 The main aggregate statistic used to describe R\&D performance within the Business enterprise sector is BERD, Business enterprise Expenditure on R\&D. BERD represents the component of Gross domestic expenditure on R\&D (GERD) (see Chapter 4) incurred by units belonging to the Business enterprise sector. It is the measure of expenditures on intramural $R \& D$ within the Business enterprise sector during a specific reference period. There are a number of variables for which BERD might be usefully compiled, distributed and reported. Some distributions have widespread international applicability and interest; others will have countryspecific relevance for analytical and policy-making purposes. Below is a list of the recommended distributions that national statistical offices should compile in order to best address international comparability needs. Most all of the recommended functional distributions are possible only by separately identifying the activity within individual statistical units and then accumulating unit-distributed details 
for the sector as a whole (e.g. R\&D by source of funds). Other reported distributions of BERD will derive naturally from accumulating the total R\&D of statistical units based on their initial institutional classification criteria (e.g. R\&D by main economic activity and size of enterprise). Surveys and other data collection efforts should be undertaken with these recommendations in mind.

\section{Distribution of BERD by sources of R\&D funds}

7.36 As described in Chapter 4, Section 4.3, it is recommended that five major sources are considered when collecting and reporting on the source of funds for BERD, according to the sector where the funds originate: Business enterprise (which includes both internal funds and external funds received from other enterprises), Government, Higher education, Private non-profit and Rest of the world (Table 7.1).

\section{Table 7.1. Identifying sources of funds for intramural R\&D in the Business enterprise sector}

\begin{tabular}{l} 
Sources of funding \\
\hline Business enterprise sector \\
Own enterprise (internal funds) \\
Other enterprises in the same group \\
Other unaffiliated enterprises \\
Government sector ${ }^{1}$ \\
Central or federal \\
Provincial or state \\
Other government sector bodies \\
Higher education sector \\
Private non-profit sector \\
Rest of the world \\
Business enterprise \\
Private non-profit sector \\
International organisations (including supranational) \\
Government sector \\
Higher education sector
\end{tabular}

1. It is recommended to separately identify $R \& D$ exchange funds from R\&D transfer funds.

\section{Funds from the Business enterprise sector}

7.37 This manual does not recommend a specific approach for collecting data on BERD sources of funds. Some countries may estimate total intramural R\&D and then determine the individual sources of funds. In such cases, internal business funds might be measured as a residual, after having accounted for all 
external sources contributing to the intramural R\&D effort. Other countries may ask respondents to separately report intramural R\&D paid for with internal funds and intramural R\&D paid for by others in order to accommodate data extraction from financial accounts. This latter approach might facilitate reporting from businesses that keep their internally funded intramural R\&D physically and financially separate from contracted intramural R\&D (e.g. for defence-related activities because of security considerations).

7.38 In the Business enterprise sector, internal funds include the reserve or retained earnings (i.e. profits that have not been redistributed as dividends), sales of the unit's ordinary products (other than R\&D), capital raised in the form of equity, debt or other hybrid instruments (e.g. funds raised on financial markets, loans from banks, venture capital, etc.). Deductions from income tax liability arising as a result of government incentives for $R \& D$ that has been carried out in the past are also internal funds, as they need not be used to fund R\&D in the current reference period. Given the high relevance of this category, individual countries may choose to enquire about these specific internal sources of funds to identify, for instance, the impact of specific R\&D policies, but no specific breakdown for those funds is recommended in this manual.

7.39 Under some circumstances, an enterprise might need to apply for loans/borrowing to fund its R\&D. In broad terms, a loan is a debt provided by one unit (institution or household) to another unit with an interest rate. Thus, when an R\&D performing enterprise, as a borrower, receives a given amount of money from a lender to fund its R\&D activities, the enterprise is committing itself to pay back to the lender at a later time an equal amount of money plus remuneration for the service as interest on the debt. Loan amounts are to be included as part of internal funds since, in fact, the external source anticipates that the loaned funds will be paid back. The cost of borrowing money is not included as R\&D. The same reasoning applies when guarantees to access loans are provided by external units or when interest is totally or partially covered by other sources of funds (as is sometimes the case for government-subsidised R\&D loans). Such support is to be included as part of internal funds.

7.40 It is recommended to separately identify funds received both from other domestic unaffiliated enterprises and from affiliated enterprises that are part of the same domestic group. Both categories of enterprises are considered external sources of funds. For most international reporting on BERD, the Business enterprise sector source of funds is the sum of business enterprise internal funds plus funds from domestic unaffiliated enterprises plus funds from affiliated enterprises that are part of the same domestic group. See also Section 7.7 on reporting extramural $\mathrm{R} \& \mathrm{D}$.

7.41 In the case of both affiliated and unaffiliated enterprises located abroad, these should be separately requested and are to be presented as part of the Rest of the world. 


\section{Funds from the Government sector}

7.42 In the case of funding for intramural R\&D received from government, it is important to ensure that respondents separately identify funds received without an expectation of compensatory R\&D (e.g. funds received through grants) from funds received in exchange for $R \& D$, typically in the form of procurement contracts from government institutions. Some enterprises may find it difficult to differentiate between R\&D procured by public enterprises and that procured by government units. It may also be difficult in practice to separate exchange funds and transfer funds, depending on the allocation of risk and rights on the uncertain outcome of the business R\&D being funded by government. The ultimate intention is to distinguish between the two categories introduced in Chapter 4, Section 4.3. For example, it is not unusual that a business enterprise uses the term "contract" in the context of grant agreements, but every effort should be made to categorise such funds accurately.

7.43 Some countries may wish to collect information on the level of government that is providing the funds for $R \& D$, and possibly even the specific institutions or schemes. Considering the most widespread practices, a distinction between central/federal funds and regional/state funds is usually adopted (often jointly with the split between transfer funds, like grants, and exchange funds, like procurement contracts' revenues).

7.44 For reporting purposes and to the extent practical, the original source of funding should be identified, even when an intermediary public or private institution is responsible for the actual transfer of funds. In many cases the beneficiary enterprise can report only about the intermediary institution, i.e. the most proximate source of funding.

7.45 Some governments provide dedicated forms of tax relief with the aim of encouraging the funding or performance of R\&D. Guidance on the separate measurement of this type of support is provided in Chapter 12. As explained in Chapter 4 (Section 4.3.), this manual recommends that the cost of R\&D performance that is "funded" on the expectation of future revenue or forgone tax, or claims realised in the current period against past performance, should be reported as internal funds, and not as sources of government support.

\section{Funds from the Rest of the world}

7.46 In collecting data on funding from abroad, it is often relevant to identify the sector from which the funding originates, as in the case of domestic funding sources. As previously indicated, it is particularly important to identify funding from affiliated business enterprises located abroad separately from other non-affiliated non-resident firms. Different countries will identify different international and supranational funding organisations and agencies as relevant funding sources. For member countries of the European Union, one such funding source might be "EU institutions and other bodies". 


\section{Distribution of BERD by type of R\&D}

7.47 As for all other sectors, it is recommended that data are collected from business enterprises on the breakdown of $R \& D$ expenditures by type of $\mathrm{R} \& \mathrm{D}$, as defined in Chapter 2 and clarified below.

- Basic research. Business enterprises can and do undertake "pure" basic research. However, they undoubtedly engage more in research with a view to preparing for the next generation of technologies even though they do not have in mind a specific immediate commercial application or use. Such research is basic according to the definition, as it does not have a specific use in mind, but an undefined number of future potential applications. Such research is commonly referred to as "oriented basic research". Since it is assumed that only a small share of business R\&D is likely to be basic research, it is recommended that national statistical offices carefully check whether respondents reporting relatively substantial amounts of intramural expenditure on basic research correctly interpreted the meaning of basic research as defined in this manual.

- Applied research. This activity aims at solving a specific problem or meeting a specific commercial objective. The distinction between basic and applied research is often marked by the creation of a new project to explore promising results of a basic research programme (often moving from a long-term to a medium- or short-term perspective). Also, enterprises often need to support their "product development" activities with additional knowledge stemming from applied research activities, the results from which in turn can often have a potentially broad range of applications.

- Experimental development. Commonly the largest component of Business enterprise $R \& D$, experimental development is intended to result in a plan or design for a new or substantially improved product or process, whether intended for sale or own use. Based on past research or practical experience, it includes concept formulation, design and the testing of product alternatives, and can include construction of prototypes and the operation of pilot plants (see Chapter 2, Section 2.7). It does not include routine testing, troubleshooting or periodic alterations to existing products, production lines, processes, or on-going operations. The first units of a trial production run for a mass production series should not be considered as R\&D prototypes. Such activities do not explicitly meet the criteria of novelty and uncertainty. To be counted as experimental development, activities must require the knowledge/expertise of a "researcher". Further, data compilers should help respondents differentiate "experimental development" from more expansive product development (which includes commercialisation) and from pre-production development, a term often used in large-scale government defence or aerospace projects, which includes non-experimental work on products or systems such as final design engineering, tooling and industrial engineering, and user demonstrations and even sometimes low-rate initial production activities. The boundaries often may not be totally clear. 


\section{Distribution of BERD by industry orientation versus economic activity classification}

\section{$R \& D$ by main economic activity of the business enterprises}

7.48 As noted earlier, institutional classification variables can be used to distribute BERD. For example, indicators of $R \& D$ expenditures and $R \& D$ personnel are regularly produced with reference to a broad range of industries. A classification variable by ISIC (United Nations, 2008a) activity should be available for all the enterprises included in the target population of an R\&D survey (see Section 7.4). The aggregation of individual enterprises' intramural R\&D will allow for reporting the level of R\&D performed by all units belonging to a specific industry. An advantage of this type of unit-based indicator is that it can be readily matched to other industry-based economic statistics defined on the basis of the main activity, provided that the criteria for defining business enterprises as statistical units and assigning them to industries are mutually consistent.

7.49 The main economic activity of an enterprise is usually defined with reference to the economic activity that accounts for most of its economic outputs. This classification of enterprises is also relevant for R\&D measurement. For example, R\&D resources in business enterprises classified into the ISIC Rev.4 Division 72 should be reported as such. R\&D content-based approaches correspond to the functional distribution by $R \& D$ product field or industry served presented below.

7.50 This manual acknowledges that in some countries a functional distribution of $R \& D$ by industry orientation is seen as most relevant for business $R \& D$ reporting, and full consistency with a classification of $R \& D$ performing units in terms of main economic activity is not assured. Different priorities should be compared in order to define national strategies of R\&D reporting and dissemination, but it is also stressed that countries should be encouraged to adopt the international standard classifications of economic activities for the R\&D domain as well.

\section{$R \& D$ by industry orientation (product field or industry served)}

7.51 The industry orientation of the $R \& D$ carried out by units in the Business enterprise sector cannot be gauged by simply taking into account their main economic activity. There are two main reasons:

- First, business enterprises can be active in exploring multiple current or possible future product lines at the same time. A company may be developing a new product to prepare entry onto a new market, which may fall outside its current specialisation portfolio. Furthermore, variations in national practices in the classification of business enterprises may lead to differences in the granularity of the detail with which data on the main activity is collected. For a number of purposes, the aggregate picture may be distorted by not taking into account the internal functional distribution of R\&D (which may not 
match with the composition of value added or turnover in terms of the goods and services produced).

- Second, the implicit assumption that the main economic activity of $R \& D$ is entirely performed internally and is used for a business's own activities is, for many businesses, not appropriate. Some enterprises may specialise in providing R\&D services to other enterprises that use the R\&D to support their economic activity; others may perform $R \& D$ with their internal resources on a speculative basis and choose not to use the R\&D themselves but rather to let others commercialise the R\&D in return for the payment of royalties and licence fees, or sell the R\&D-resulting intellectual property outright. Such actions may weaken the link between the main economic activity and R\&D performance and its industry orientation.

7.52 On a more practical basis, the classification by main economic activity may simply not reflect the main area of a business enterprise's R\&D activity. As an example, an enterprise classified to wholesale trade could still be engaged in the sale of goods that it manufactures, and its R\&D activities could be focussed entirely on improving its manufacturing production processes. General classification practices are also likely to evolve in the future as specific guidelines on how to treat different types of factory-less goods producers are implemented by national statistical offices (UNECE, 2014). These guidelines place considerable emphasis on the role of intellectual property products (IPPs), including R\&D-based assets.

7.53 One approach for minimising potential measurement distortions caused by these different models for funding, performing and using R\&D is to ask performers about the actual industry orientation of the R\&D carried out. In principle, this should be more informative for some types of comparisons with production statistics on the basis that the knowledge input and the related economic activity that uses the knowledge can be matched.

7.54 There are different concepts that are potentially relevant to the notion of the industry orientation of R\&D as well as different ways in which R\&D surveys can seek to elicit this information. The industry orientation can be identified in terms of either:

- the output or product (good or service) that is expected to embed the outcome of the R\&D, regardless of which industry produces it, or

- the industry likely to be making use of the expected R\&D results (either as codified R\&D, such as patents, or embedded in new goods and services).

7.55 Both approaches are intimately related, and from a respondent's perspective not easy to differentiate. Furthermore, R\&D may be for a product that is a subcomponent of a more complex system, or for a process that will be commercialised or incorporated into the production of other goods and services. R\&D may be for internal use by a given industry, or ultimately for use by the industries with which it is vertically integrated. 
7.56 In light of these challenges, pragmatic solutions should be applied. One major limitation is that respondents may not be fully aware of the most likely "industry served" by its future goods and services when R\&D is performed, especially in the case of basic and applied research. The use of goods and services embedding R\&D results may evolve over time in line with business conditions and opportunities. Reported breakdowns may be based on heuristics informed by the experience of previous R\&D efforts and internal records, including business cases for R\&D projects. For non-oriented basic research or research with multiple known applications, a breakdown based on the lines of business pursued by the enterprise might be considered by respondents.

7.57 Regarding the choice of a classification system, standard international industry and product classifications are potential candidates. The ISIC classification is not designed to measure product data at any detailed level. For this purpose, a separate UN classification exists, the Central Product Classification (United Nations, 2008b). Although each category in the CPC is accompanied by a reference to the ISIC industry in which the goods or services are mainly produced (criterion of industry origin), this does not imply that all units producing these goods or services are classified there. The classification of products is based on the intrinsic characteristics of the goods or the nature of the services rendered, which results in a classification structure that is different from that used for ISIC. In the case of $R \& D$, the use of established product or commodity-based classifications presents several challenges, since the classifications include items such as licences for the use of knowledge products. Those categories may mainly reflect the business model for undertaking and exploiting the outcomes of the $R \& D$ rather than its content. For this reason, the use of the CPC cannot be widely recommended, although countries may wish to use specific CPC categories on an ad hoc basis to meet specific user needs.

7.58 Even though no specific recommendation can be made (in order to allow for the adoption of the methods most suitable for individual country circumstances), for the purposes of distributing business R\&D by industry orientation, a simplified industry list (based on ISIC or an equivalent classification) may be used, with a choice between focusing either on the industry served or on the product field. This manual acknowledges that, due to a number of practical constraints, some countries may use hybrid approaches (Table 7.2) but this should be avoided whenever possible.

7.59 In the ISIC 2008 classification (ISIC Rev4), "Division 72, Scientific research and development" includes the activities of two types of research and development as defined in this manual: natural sciences and engineering; and social sciences and the humanities. (ISIC 72, and this manual, excludes market research - see Class 7320, ISIC Rev4.) ISIC 72 captures units primarily involved in the provision of R\&D services to affiliated companies or third parties. Some of these units may provide undifferentiated services to industry; in some cases these may be companies involved in developing new products or in providing 


\section{Table 7.2. Proposed activity-based classifications for the Business enterprise sector}

\begin{tabular}{|c|c|c|c|c|}
\hline Classification & $\begin{array}{l}\text { Classification } \\
\text { basis }\end{array}$ & $\begin{array}{l}\text { Criterion and } \\
\text { classification }\end{array}$ & $\begin{array}{l}\text { Implementation of the } \\
\text { classification criterion }\end{array}$ & $\begin{array}{l}\text { Other features and potential } \\
\text { limitations }\end{array}$ \\
\hline $\begin{array}{l}\text { Main economic } \\
\text { activity } \\
\text { (Recommended } \\
\text { for all units in } \\
\text { all institutional } \\
\text { sectors) }\end{array}$ & $\begin{array}{l}\text { Institutional: } \\
\text { All the R\&D } \\
\text { expenditures } \\
\text { or personnel } \\
\text { reported by } \\
\text { the statistical } \\
\text { unit are } \\
\text { allocated to } \\
\text { the industry } \\
\text { corresponding } \\
\text { to the unit's } \\
\text { classification. }\end{array}$ & $\begin{array}{l}\text { Main activity of } \\
\text { the statistical } \\
\text { unit, as by ISIC or } \\
\text { national/regional } \\
\text { implementation } \\
\text { of this industry } \\
\text { classification. }\end{array}$ & $\begin{array}{l}\text { Turnover, gross } \\
\text { value added or } \\
\text { other sufficiently } \\
\text { close criteria. R\&D } \\
\text { compilers can rely on } \\
\text { classifications used } \\
\text { for other business } \\
\text { statistics, as available in } \\
\text { registers. In that case, } \\
\text { no further questions are } \\
\text { required. }\end{array}$ & $\begin{array}{l}\text { In most cases this enables } \\
\text { improved consistency } \\
\text { with (business) economic } \\
\text { statistics on production and } \\
\text { employment. } \\
\text { The classification may } \\
\text { over-allocate R\&D units and } \\
\text { resources to specific service } \\
\text { industries (chiefly, wholesale) } \\
\text { in enterprises active in multiple } \\
\text { economic activities and where } \\
\text { the composition of turnover } \\
\text { or value added (or other } \\
\text { classification criteria) does not } \\
\text { match the distribution of R\&D } \\
\text { activity within the enterprise. }\end{array}$ \\
\hline $\begin{array}{l}\text { Industry } \\
\text { orientation } \\
\text { (industry served / } \\
\text { product field) } \\
\text { (Recommended } \\
\text { for business } \\
\text { enterprises, in } \\
\text { addition to the } \\
\text { main economic } \\
\text { activity approach) }\end{array}$ & $\begin{array}{l}\text { Functional } \\
\text { distribution: } \\
\text { The statistical } \\
\text { unit distributes } \\
\text { its R\&D } \\
\text { resources } \\
\text { across } \\
\text { different lines } \\
\text { of business for } \\
\text { which the R\&D } \\
\text { is relevant. }\end{array}$ & $\begin{array}{l}\text { Based on the } \\
\text { industrial } \\
\text { orientation of } \\
\text { the R\&D, which } \\
\text { can be based } \\
\text { on the notion of } \\
\text { industry served } \\
\text { or type of product } \\
\text { embedding the } \\
\text { outcomes of the } \\
\text { R\&D (eventually } \\
\text { reclassified in ISIC } \\
\text { terms). }\end{array}$ & $\begin{array}{l}\text { Necessarily } \\
\text { implemented through } \\
\text { dedicated survey } \\
\text { question(s). } \\
\text { There are different } \\
\text { possible ways to } \\
\text { formulate the question } \\
\text { so that it captures the } \\
\text { intended concept. }\end{array}$ & $\begin{array}{l}\text { High policy and user relevance } \\
\text { on the economic activities } \\
\text { potentially benefiting from } \\
\text { the R\&D. } \\
\text { Implies some additional } \\
\text { reporting burden for } \\
\text { enterprises. Some of them } \\
\text { may have limited awareness } \\
\text { about final use of their R\&D, } \\
\text { especially for basic and } \\
\text { applied research. }\end{array}$ \\
\hline $\begin{array}{l}\text { Hybrid } \\
\text { approaches } \\
\text { (Not } \\
\text { recommended, } \\
\text { except when no } \\
\text { alternative is } \\
\text { available) }\end{array}$ & $\begin{array}{l}\text { Functional } \\
\text { combined with } \\
\text { institutional. } \\
\text { For some } \\
\text { firms, } \\
\text { their R\&D } \\
\text { resources are } \\
\text { apportioned } \\
\text { on a functional } \\
\text { basis, while } \\
\text { for others their } \\
\text { entire R\&D is } \\
\text { allocated to a } \\
\text { given sector. }\end{array}$ & $\begin{array}{l}\text { A functional } \\
\text { distribution } \\
\text { approach is } \\
\text { applied to the one } \\
\text { group of firms, } \\
\text { while for the } \\
\text { other, the main } \\
\text { activity criterion is } \\
\text { applied. }\end{array}$ & $\begin{array}{l}\text { Different approaches: } \\
\text { - Simple extension } \\
\text { of main activity } \\
\text { classification, } \\
\text { applying distributional } \\
\text { classification to R\&D } \\
\text { sector only. } \\
\text { - Functional distribution } \\
\text { constrained to large } \\
\text { firms, small firms } \\
\text { not asked product } \\
\text { distribution question to } \\
\text { avoid burden. } \\
\text { - Use of functional } \\
\text { distribution as an } \\
\text { alternative to main } \\
\text { economic activity. }\end{array}$ & $\begin{array}{l}\text { The approach is justified only } \\
\text { when reliable information } \\
\text { on the main economic } \\
\text { activity of R\&D units is not } \\
\text { available (for instance, from } \\
\text { business registers) or burden } \\
\text { considerations prevent asking } \\
\text { about industry orientation. The } \\
\text { results are more difficult to } \\
\text { compare internationally, due to } \\
\text { different combination criteria. }\end{array}$ \\
\hline
\end{tabular}


their customers with new technological or organisational knowledge. In general it is recommended that in an industry orientation distribution, $R \& D$ performed by enterprises whose main economic activity is ISIC 72 be attributed to the relevant industries served (usually the ISIC industries most of its customers belong to). The same applies to companies that specialise in the leasing of intellectual property (Group 774, ISIC Rev4).

7.60 It is recommended that all business enterprises be classified by main economic activity, and it is strongly suggested that their intramural R\&D expenditures be distributed on an industry orientation basis, regardless of their size and activity. In principle, capital R\&D expenditure should be excluded from a classification by product field or industry served, thus only the current $R \& D$ expenditure is expected to be distributed according to these criteria. The reasoning is that only a unit's current R\&D performance could be linked to some expected results and to the potential users of those results. In practical terms, enterprises may find it easier to report on their total R\&D expenditure. In order to assure consistency between the set of data provided by different countries, it is recommended to clearly report in the R\&D metadata which approach was used to collect and distribute this data. Whenever possible, for those countries reporting for all BERD, it would be useful to indicate the amount by which it may differ from the distribution that would apply to current R\&D expenditures only, based on the proportion of capital expenditure out of total R\&D within a given industry.

\section{Combining main activity and industry orientation information}

7.61 For some analytical purposes, it can be relevant to provide crosstabulations of industry orientation breakdowns by the main activity of R\&D performers. These tabulations could provide the basis for constructing ad hoc R\&D supply-use matrices that show the relationship between the performers of $R \& D$ and the likely R\&D uses. Such matrices might be used for R\&D impact analyses. If practical, countries are encouraged to produce these analytical compilations, which also might be used to help assess the quality of the data provided by respondents.

\section{Distribution of BERD by fields of R\&D}

7.62 The distribution of BERD on the basis of fields of R\&D (FORD) is a common practice in only a small number of countries. While a breakdown for most of the activities already identified as "basic" or "applied" research should be possible in FORD terms, the distribution of experimental development across FORD categories can be problematic for businesses. In many countries, businesses seldom maintain their records for R\&D projects and activities by such 
categories, and it is arguable that experimental development by businesses is likely to involve interdisciplinary technology areas and a combination of multiple fields that are not easily and individually identified. Because of such difficulties, this manual cannot specifically recommend such a breakdown of BERD across FORD fields. If however countries do choose to report a FORD distribution, it is recommended that they adopt the FORD categories identified in Chapter 3, Section 3.4; more detailed classification is found online in annex guidance to this

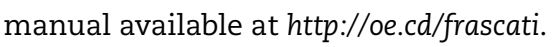

\section{Distribution of BERD by socioeconomic objective}

7.63 Few countries currently attempt to distribute their BERD across socioeconomic objective categories. Although it is possible that much R\&D could be classified on an ad hoc basis to categories representing societal goals, business are unlikely to view their R\&D allocations in such terms. Therefore, this manual makes no explicit recommendation to provide such a breakdown. On the other hand, in countries where specific policies are aimed at influencing the functional orientation of business sector R\&D (such as for health, the environment, energy or defence), it could be relevant to collect information on the contribution of business R\&D to the achievement of specific objectives of social or political relevance. Given that such collections likely would reflect very country-specific circumstances, caution is recommended in comparing the resulting data at an international level.

\section{Distribution of BERD by geographic location}

7.64 Countries may find it useful to compile the separate totals for distribution of BERD by location/region. When a unit's BERD is classified entirely into its main location or centre of operations, this may fail to represent where the $R \& D$ is actually performed. It is not uncommon for a business enterprise to have activities at multiple locations. As described in Section 7.4, each statistical unit should have a geographic location classification variable. This variable may or may not be relevant for identifying where an enterprise's R\&D takes place. An enterprise may have a dedicated R\&D department/division at a site outside of the geographic location of its production facilities that determined its classification variable. Further, an enterprise could perform R\&D (including occasional R\&D) at multiple locations (establishments) spread across multiple geographic locations. The choice of geographic distribution is determined according to national and international needs. Guidance for distributing R\&D by region is found in online annex guidance to this manual available at http://oe.cd/frascati.

\section{Distribution of BERD by specific technology areas}

7.65 Further guidance for collecting and compiling business R\&D data beyond the specific recommendations identified in this chapter is found in online

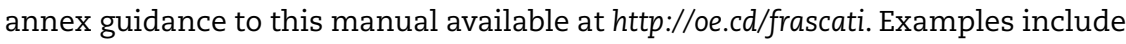


questions on $R \& D$ enabling and general purpose technologies. User interest in these questions includes the processes for generating new technologies as well as their diffusion and application patterns.

7.66 Most of the OECD statistical work on the measurement of technologies is based on methodologies, procedures and classifications developed for the measurement of ICT- and biotechnology-related phenomena. The relationship between ICT and R\&D statistics has been addressed by developing ICT indicators based on the classification of R\&D by main activity and product field. More recent efforts have been pursued in the area of nanotechnology, applying the general model of biotechnology, and there is broad interest in capturing, across a range of industries and research fields, the impact of software R\&D (see Box 4.1 in Chapter 4 for suggested guidance on collecting software R\&D). Several countries include questions on these technology areas in their business R\&D surveys, although methodologies differ, for example, to the extent that they allow the same $R \& D$ resource to be attributed to different technologies, since these might easily overlap (e.g. bio-nano R\&D activities).

7.67 Since 2005, the OECD has adopted specific guidelines on the production of biotechnology R\&D statistics (OECD, 2005) and, more recently, a statistical project has been launched to collect data on nanotechnology R\&D at international level. Several countries have already adapted their R\&D surveys to collect this kind of information from business enterprises and a statistical Compendium is regularly published by the OECD.

7.68 Data users have shown strong interest in technology application areas (e.g. health, energy, agro-bio, green- or low-carbon-related R\&D). These categories generally are related to specific socio-economic objectives, but often cut across several objectives. Moreover, there is interest in much greater granularity than is usually possible for surveys to collect in a consistent fashion. While it is important for R\&D national statistical offices to consider how best to provide information on efforts undertaken by business enterprises that are relevant to societal challenges, no general guidelines or recommendations can be provided at this point. Definitions and strategies for collecting R\&D data on specific technology areas should be developed through extensive consultation between statisticians, policy makers, data users and subject-matter experts.

\subsection{Functional distributions for extramural R\&D in the Business enterprise sector}

7.69 Business enterprises may also provide funds to others for the performance of extramural R\&D; further, business enterprises may both purchase R\&D from others and sell R\&D to others. These circumstances affecting statistical units in all economic sectors are covered in detail in Chapter 4 (notably Section 4.3 on Measurement of funds for extramural R\&D and on Sales and Purchases of $R \& D)$. Because the enterprise is the unit of interest for $R \& D$ statistics, $R \& D$ funds from one member " $A$ " of an enterprise group to another member " $B$ " of the same 
group should be reported as the by member "A" of the extramural performance of member " $B$ ". In line with the recommendations given in Chapter 4 , the following abbreviated distribution is recommended for business enterprises funding R\&D performed extramurally and for tracking the purchases and sales of R\&D:

Domestic:

- Business enterprise sector:

* Enterprises in the same group

* Other unaffiliated enterprises

- Government sector

- Higher education sector

- Private non-profit sector.

Rest of the world:

- Business enterprise sector:

* Enterprises in the same group

* Other unaffiliated enterprises

- Government sector

- Higher education sector

- Private non-profit sector

- International organisations.

\section{Survey design: framing the R\&D population}

7.70 The identification of the reference (target) population is the first step of every statistical activity. For business R\&D data collections, the target population is all businesses performing $R \& D$ (or funding $R \& D$ as is described in Chapter 4, Section 4.3 related to the measurement of funds for extramural R\&D) and located in a given territory (usually, a country). As recommended in Chapter 6.3, R\&D surveys of the Business enterprise sector should identify and include in their populations all businesses located in a given territory known or very likely to perform (or fund) $R \& D$ with reference to a single period of time. In turn, this population of businesses known or likely to perform R\&D is considered a sub-population of the universe of active businesses, any of which could potentially perform R\&D. Consequently, it is also recommended to survey a sample of all other firms in order to identify R\&D performers about which it is not known a priori whether they actually perform or are highly likely to perform R\&D. Realistically, in many countries most micro-businesses - which often comprise the majority of the Business enterprise population - are very unlikely to perform (or fund) R\&D. Therefore, on a practical level, such micro-businesses are often treated (for statistical purposes) as being outside the 
scope of "potential" R\&D performers. A common practice by national statistical offices is to use a single "business register", which includes all active businesses in a given year, for all of its all business surveys.

\section{Business registers}

7.71 Business registers are major tools for compiling R\&D statistics, but may not be sufficient to identify the relevant population to be surveyed about R\&D. Although they provide essential information on key characteristics of enterprises potentially included in an $R \& D$ survey sample (e.g. size, industry, ownership, age, etc.), business registers often do not include information on their actual R\&D or likelihood for R\&D performance. As a result, a common practice is to survey the total population of enterprises (or a subset of them, possibly identified in terms of size and industry) only for exploratory purposes, i.e. to single out, or screen for, those enterprises with $R \& D$ potential. In collecting $R \& D$ data, it is recommended to target only enterprises with some evidence of at least likely R\&D potential, in order to reduce the data collection costs and burden on respondents.

7.72 Since $R \& D$ performance in the Business enterprise sector is a rare event (i.e. a small percentage of business enterprises is usually involved in R\&D), every effort should be made to identify and monitor enterprises with high R\&D potential. In this respect, simple random sampling may not be the most reliable way of determining R\&D - companies that appear to be similar in terms of what they offer to the market may in fact have very different R\&D strategies, and random sampling may not yield sufficiently reliable estimates.

7.73 On the other hand, many countries have neither a comprehensive and up-to-date business register nor a directory of companies that perform R\&D. And even when a business register does exist, it is important - before launching a survey - to ascertain that it has been properly updated, that it includes only active companies, and that it excludes ghost or shelf companies. Without a complete business register (or similar business enterprise lists), it will not be possible to produce reliable census or sample estimates, or even undertake an accurate R\&D screening survey.

7.74 Assuming that sufficiently complete information on the total population of active enterprises is available (either from a business register or from other sources), it is rather straightforward to carry out a purposive survey that deliberately sets out to identify $R \& D$ performers and then elicit the required data from them directly. This entails surveying all firms known to or highly likely to perform R\&D. In order to carry out the purposive survey, an ad-hoc business register (or directory) of firms that perform R\&D should be developed. Eliciting and compiling this information is time-consuming and represents an important investment in future surveys. 


\section{Compiling directories of potential R\&D performers}

7.75 When no prior directory of R\&D performers in the Business enterprise sector exists, a significant amount of work may have to be done before launching an R\&D survey to create a list or inventory of businesses that are highly likely to be R\&D performers. The following may be useful sources of information on firm behaviour that might help identify such businesses:

- Chamber of Commerce/Industries, trade associations, professional associations, associations of R\&D performing firms. A good starting point is to seek out these various associations and ask their information offices what they know about the R\&D activities of associated firms (and if they are allowed to disclose information on individual firms). Associations of performers might be able to share directories of associates and related information.

- Publicly traded company listings, such as national stock exchanges. Working through the businesses listed on the main stock exchange is a necessary task.

- Company annual reports, trade journals, directories of R\&D laboratories. A base list of R\&D performing firms can be created by reviewing R\&D expenditures that are included in financial reports or regular accounting systems. These sources should also be reviewed for specific information related to R\&D activities, particularly the construction of prototypes, establishing pilot plants, etc.

- Registers of publicly funded research grants/contracts for R\&D. In more sophisticated environments, ministries dealing with science and technology or research - usually the most relevant national research grant funders - may have a list of business beneficiaries of research or innovation grants. Lists of contributors to international research programs are also easily accessible.

- Lists of enterprises claiming tax relief for R\&D activities and projects. Close cooperation between business survey managers and the government departments responsible for R\&D tax incentives, import facilitation, export promotion and price controls may also help identify R\&D performers.

- Lists of enterprises reporting $R \& D$ activities in previous $R \& D$ surveys, in innovation surveys or other structural business surveys.

- Lists of enterprises having filed for a patent application during the past several years. This is an indicator, again, of possible R\&D activity.

- Registers of approved clinical trials or similar administrative registers.

7.76 A survey frame of businesses with R\&D can be developed through consultation of these sources and direct interaction with known R\&D performers. Efforts to identify actual R\&D performers should focus first on large firms in industries that usually exhibit a high level of R\&D intensity. When attempting to identify R\&D performers among several hundred large firms, a sequential process may be implemented, prioritising areas of most likely R\&D performance 
and then focusing on the connections of the identified performers with other enterprises to which they are related through supply chains, competitors, etc. Unless published information confirms the existence of $R \& D$, direct interaction is needed with firms to verify the existence of R\&D activities. One approach would be to conduct a two-stage survey to first identify R\&D performers using a very short questionnaire, possibly embedded in other business surveys, and then to target those firms reporting $R \& D$ activities with a more extensive questionnaire.

\section{Survey strategies}

7.77 Countries use a broad range of practices in conducting business R\&D surveys. In all cases, however, the identification of the population of known and highly likely business enterprise R\&D performers is an essential first step in the data collection process. Unlike the situation for other sectors where directories of higher education or government institutions are available and fully known, business enterprise $R \& D$ surveys are largely dependent on the quality of the available frame and on its reliability for preventing under- or over-coverage of R\&D activities.

7.78 Assuming the existence of a highly reliable frame, national statistical offices may conduct either a census or a sample survey. In order to take into account the high concentration of R\&D activities (in terms both of expenditure and personnel) in a relatively small group of size classes and industries, a census is usually recommended for this cohort of business enterprises, since they may have a higher probability of having undertaken R\&D activities in the reference year. Very large, known R\&D performers are included in this "take all" survey group.

7.79 In turn, those enterprises with a lower probability of having been engaged in $R \& D$ in the reference year could be surveyed either by census or by sample. This approach is based on the assumption that all potential R\&D performers are actually included in the frame and that the probability of finding additional performers outside the frame is negligible, or might include only small or micro-enterprises.

7.80 If a reliable survey frame (directory of potential $R \& D$ performing businesses) does not exist, a different approach is needed. In this case, it is possible that a non-negligible number of R\&D units could still be unidentified or that a few large R\&D performers may not yet be included in the frame. Under such conditions, a survey of large, known R\&D performers (preferably, by census) should be complemented by a sample survey of a sub-population of the overall business register (or similar register) where most of the missing units could be assumed to be included with a given degree of probability (mostly on the basis of a cross-classification by size and industry). Also in this case, a two-stage survey (screening for R\&D performance plus data collection) may be recommended in order to reduce the data collection costs and statistical burdens on enterprises. 
7.81 Setting a minimum size threshold is irrelevant when a survey of business R\&D is based on a reliable frame where individual enterprises are included if they meet country-identified indicators of likely R\&D activity. On the other hand, when drawing a sample from an overall business register with the aim of identifying new potential R\&D performers, it is recommended that microenterprises be excluded from the sample unless there are sufficient resources to undertake a thorough review and screening for potential R\&D performers. This recommendation is based on the need to avoid the risk of inflating the number of performers that would possibly result from the high number of microenterprises in the overall population. This recommendation should also result in lower survey costs and a lower overall response burden.

\section{Questionnaire design}

7.82 Questionnaires are tools designed to collect data. They should be understandable, easy to use, effective and flexible. Business survey questionnaires, which are usually self-administered, are answered by a wide range of individuals working for many diverse types of enterprises. In this respect, questionnaires need to be adaptable to very different needs and conditions of use.

7.83 Electronic questionnaires offer the capability of pre-processing the delivered data - which is made possible by implementing filtering questions allowing respondents to skip irrelevant modules, and embedded edit checks. They allow for an effective interaction with respondents by preventing errors and inconsistencies in data provision. It may be necessary to adopt multi-mode data collection strategies when a relatively large number of enterprises cannot be assumed to have easy access to the Internet or access at an acceptable cost. The need for a questionnaire to be easily managed by different contacts inside a company (who have different expertise and knowledge about the enterprise's R\&D expenditures, contracts and personnel) should be taken into consideration.

7.84 Several countries have implemented "combined surveys", mainly by merging business R\&D surveys and business innovation surveys, as described in the Oslo Manual (OECD/Eurostat, 2005). This approach is accepted by this manual but not recommended, as it may affect the international comparability of $R \& D$ results: by asking questions about both $R \& D$ and innovation in a single questionnaire, respondents may find it difficult to differentiate between $R \& D$ and any number of other innovation-related activities (see Chapter 2). For countries that choose to undertake a combined innovation-R\&D survey, it is recommended to: (a) deliver to respondents two questionnaires or, at least, a questionnaire with two distinct sections, making clear that the two statistical concepts are not complementary but rather overlapping; (b) reduce as much as possible the size of the combined questionnaire to make it more understandable; (c) report in a systematic way information on the data collection approach adopted (mostly when comparing the R\&D results with those from other countries not using combined surveys); and (d) use a single business register as the statistical 
frame for both the innovation and the business R\&D survey (according to the procedures described above). These steps will also help ensure consistency with the Oslo Manual (OECD/Eurostat, 2005) guidance and recommendations.

\section{Data collection practices}

7.85 A high response rate is the goal of any statistical survey, and this is of particular importance for $R \& D$ surveys since business $R \& D$ is a rare activity (i.e. relatively few enterprises in the total Business enterprise sector are R\&D performers, and they are therefore hard to find). This point is stressed both for censuses (since it is extremely difficult to make assumptions about the actual R\&D performance of non-respondents) and sample surveys, as a low rate of response could lead to significant measurement biases (in addition to an increase in the sampling error). Ideally, every effort should be taken to minimise the rate of non-response. To maintain data quality standards, statistical offices should identify minimally acceptable response rates below which population estimates cannot be made; when response rates fall below an acceptable level, follow-up non-response bias analyses should be conducted. This manual cannot recommend specific non-response tolerances. Obviously, a compulsory survey is likely to obtain higher response rates than is a voluntary survey.

7.86 In practical terms, however, the unweighted average rate of response may not be the best indicator to measure the rate of coverage of the R\&D phenomenon achieved by a business survey. In fact, the high heterogeneity which can be systematically observed among business R\&D performers suggests that, for most countries, a full coverage of a small group of large R\&D performers would account for a very high percentage of the total business R\&D expenditure (as well as of the R\&D personnel, although to a lesser extent).

7.87 As a consequence, specific strategies to pursue the twin objectives of increasing the overall rate of response and of assuring a nearly full coverage of the leading R\&D performers should be implemented. This reinforces the need for exploiting all available sources of information to support the data collection activity. The availability of data on R\&D tax credits is a case in point since this information could be useful for identifying the key performers to be specifically targeted during the data collection effort.

7.88 A range of other activities, in addition to the improvement of the frame, should be implemented to improve the quality of the R\&D data collection effort. Respondents should be aware, at all times, that they are participating in a statistical survey: they should be informed of the subject of the survey and its nature, who is responsible for it and whether they have the right to choose the way to transmit the requested data (or even if they have chance to be excluded from the survey). In broader terms, the data collection team should be constantly available to answer the respondents' questions and to provide technical support and advice. This is currently a standard in most official statistical agencies, and it should be implemented by every institution that aims to produce internationally comparable business R\&D data. 
7.89 To evaluate the success of survey implementation and of relevant population coverage, statistical offices are encouraged to calculate response rates (RR), weighted response rates (WRR) and coverage rates (CR). These are each measures of quality and offer different perspectives, depending on what aspect is of interest. For populations that are relatively homogeneous with respect to the variables measured, there probably is very little difference in the three measures. But since R\&D activity is skewed and highly concentrated in the Business enterprise sector, all three measures are relevant (see Box 7.1).

\section{Box 7.1. Importance of multiple measures of collection quality}

There are multiple ways of measuring coverage and response rates. In collecting intramural $\mathrm{R} \& \mathrm{D}$ for the Business enterprise sector, several measures of survey quality may be appropriate.

For example, if there were a population of 1000 units within an ISIC sector that have R\&D measures of

1000000 for 1 unit; 1000 for 1 unit; and 1 each for the remaining 998 units, and the statistical office drew a sample of 10 units, including the purposive selection of the units with 1000000 and 1000 and a random sample of 8 units each with 1.

Below are four scenarios for data collection for which each reports a response rate (RR) of $70 \%$ (i.e. 7 of the 10 sample units respond to the survey). However, the measures take on a different light depending on which units respond (assuming 7 of 10 units respond) in the four scenarios presented below:

\begin{tabular}{cccc}
\hline \multicolumn{4}{c}{ Unit measure and number responded } \\
\hline Scenario & 1000000 & 1000 & 1 \\
1 & 0 & 0 & 7 \\
2 & 0 & 1 & 6 \\
3 & 1 & 0 & 6 \\
4 & 1 & 1 & 5 \\
\hline
\end{tabular}

\begin{tabular}{ccc}
\hline \multicolumn{3}{c}{ Measures of response } \\
\hline RR & WRR & CR \\
$70.0 \%$ & $87.3 \%$ & $0.0 \%$ \\
$70.0 \%$ & $75.0 \%$ & $0.1 \%$ \\
$70.0 \%$ & $75.0 \%$ & $99.8 \%$ \\
$70.0 \%$ & $62.6 \%$ & $99.9 \%$ \\
\hline
\end{tabular}

In this imaginary example, scenario 3 would seem to do relatively best across in terms of population count - weighted response rates (WRR) even though the unit known to have the second largest R\&D expenditure in the sector did not respond. In term of the overall coverage rate (CR), scenario 4 indicates best coverage of the sector's total BERD.

\section{Weighting and estimation}

7.90 The final step in processing business R\&D data collections is the production of statistical results on the level of the R\&D activity undertaken by the enterprises in the compiling country (in terms of R\&D expenditure and R\&D personnel). For business R\&D surveys, the estimation process is highly dependent on the procedures used for the identification of the reference population. A few specific cases, and related issues, are discussed here. 
7.91 As a preliminary statement, this manual recommends against the use of extraneous coefficients (such as applying past sector-wide R\&D/sales ratios to firms' total sales) as a means of estimating sector-wide business R\&D totals. Whereas under some specific conditions coefficients might be helpful for estimating the $R \& D$ activities of institutions in other economic sectors (primarily for the Higher education sector; see Chapter 9), this is not the situation for the Business enterprise sector. Enterprises are constantly facing the choice on whether - and to what extent - to be involved in R\&D activities. Intramural R\&D is expensive and risky and, at any time, an enterprise could choose to abandon its internal R\&D projects and switch to purchasing external $R \& D$ services or to acquiring knowledge codified in intellectual property. The high heterogeneity of business strategies, including R\&D-related ones, across industries and size classes is the basic reason that this manual does not recommend the use of coefficients in the production of business R\&D statistics.

7.92 Before initiating estimation procedures, the survey data should be accurately edited and validated. Outliers should be found and corrected. In order to correct for the non-response of large R\&D performing enterprises, imputation - based on auxiliary information (e.g. company reports) and historical responses - is preferred over the re-weighting of other respondents' data.

7.93 Additional guidance concerns grossing up the results of an R\&D survey of an undifferentiated population of enterprises (e.g. a sample drawn from a business register). Since the sub-population of enterprises that are likely R\&D performers is, in statistical terms, a rare population, before grossing up the results of a survey it is recommended that preliminary screening for non-eligible units first be undertaken. Alternatively, statistical methods should be used to minimise the possibility of introducing bias by over-estimating total business R\&D activity (see Chapter 6).

\section{Quality control related to business R\&D responses}

\section{Cautionary note related to financial accounting records}

7.94 As noted above, company annual reports are usually a good source to help identify likely business R\&D performers. These published totals also may help assess the quality of reported survey totals and address item nonresponse issues (see Chapter 6). At the same time, this manual explicitly cautions that figures on R\&D activities published according to national and international financial accounting standards and guidance may differ from R\&D compiled according to the recommendations presented in this manual. Some R\&D costs may be capitalised in companies' balance sheets and others may be posted as expenses (including depreciation, see Chapter 4) in their income-costs statements. For public reporting purposes, some companies include "technical services" performed by R\&D personnel with intramural R\&D (see Chapter 5 on personnel job titles). 
7.95 Even when the definition of $R \& D$ is precisely the same as that recommended in Chapter 2, the composition of the accounting-based totals may differ from R\&D totals compiled in accordance with this manual. For example, if the R\&D is not "material" to the enterprise's total costs, those costs may not be explicitly identified. Also, the R\&D paid for by others may not be accounted for separately from internally funded intramural R\&D; indeed, R\&D performed under contract may not be counted or perceived as R\&D in financial records (Chapter 4). Especially in reports for large enterprises, the costs for intramural R\&D may not be differentiated from those for extramural R\&D. Consistent with most accounting standards, their annual financial reports on R\&D expenses may combine internal funds for both intramural R\&D and extramural R\&D as long as the R\&D performed is "for the benefit of" the reporting enterprise. Especially for MNEs, published R\&D totals may include R\&D expenses for the global group (see Chapter 12) rather than for the individual members.

\section{Differentiating intramural from extramural $R \& D$}

7.96 There are a number of potential difficulties in accurately collecting $R \& D$ funding flows, whether as a component of a unit's intramural R\&D or as part of their funding totals for extramural $R \& D$ performance.

7.97 Problems may arise when funds pass through (flow within and across) several units before reaching the performer. This may occur when $\mathrm{R} \& \mathrm{D}$ is sub-contracted, as may happen particularly in the Business enterprise sector. The performer should report only costs for R\&D projects actually conducted rather than as input to some other unit's R\&D, and indicate, to the extent possible, the original source of the funds for R\&D. See Chapter 4.3 for further guidance on differentiating funds for intramural R\&D from those for extramural R\&D.

\section{Potential under- and over-reporting of business R\&D activity}

7.98 The process to produce business R\&D statistics, especially taking into account different country-specific practices, can be quite complex. Even when detailed quality reporting is available, questions remain concerning the potential under- or over-reporting of business R\&D activity. On the basis of the country experiences, some best practices - in addition to the formal recommendations of this manual - can be suggested to reduce the risk of error in measuring business R\&D. Two issues are particularly relevant in this respect: (i) identification of a proper reference population for business R\&D surveys (avoiding under- or over-coverage in terms of performers) and (ii) identification of the actual R\&D activities carried out by survey respondents (avoiding under- or over-coverage in terms of R\&D performance).

7.99 The under-coverage of R\&D units results from insufficient knowledge of the Business enterprise sector. Usually, under-coverage of large enterprises can be excluded by definition since they are a small part of the Business enterprise 
sector and easily identified. On the other hand, under-coverage is a relevant issue for the population of small-sized performers. Given that any screening of the business population by means of statistical surveys is at best an approximation, a systematic exploitation of administrative data sources (public R\&D funding, $R \& D$ tax incentives, participation in public R\&D projects, patent filing, etc.) is recommended to help identify a high percentage of potential R\&D performers among small and micro-enterprises. Even so, it is highly likely that some R\&D performing enterprises will still be missed, and a potential (minimised) under-coverage of small performers must be accepted when interpreting R\&D data. The impact of such under-coverage in terms of total R\&D expenditure or personnel, however, is considered negligible in most countries.

7.100 Under-estimating the R\&D performance of business enterprises has been always a concern. The adoption of some methodological recommendations given in this chapter can help to minimise this risk (for instance, by identifying the right contact within a surveyed enterprise). A few data collection best practices can help to encourage respondents:

- to consider all of the R\&D activity undertaken inside the statistical unit, even that performed outside specific R\&D departments, such as activity focussed on pilot testing, preparations for production, general technological development

- to include "non-obvious" R\&D that is fully integrated into (usually large) development contracts for specified products/systems (knowledge embedded in products)

- to include R\&D activities funded by customers on a project-specific basis.

7.101 The over-coverage of R\&D performing businesses results mostly from misinterpreting the information collected from other business surveys or from administrative databases. All such sources, which are essential for identifying the reference population of R\&D surveys, have to be used carefully: it is unlikely that many reference sources have adopted the exact same concepts of R\&D as defined in this manual. Lists of enterprises applying for $R \& D$ tax credits is a case in point, since the concept of "R\&D activity" used by tax authorities may include both the internal performance of $R \& D$ and the funding of $R \& D$ undertaken by other units. Statistical surveys therefore need to provide respondents with clear definitions of R\&D (and check for the accuracy of answers) to minimise the risk of respondents' misinterpretation of what are R\&D activities.

7.102 Over-estimating R\&D performance by business enterprises can result from a variety of different factors:

- insufficient knowledge about the activities to be reported

- objective difficulty in discriminating R\&D activities from other innovation- or technology-related activities

- the acquisition of R\&D from other units that is included in the intramural performance totals (with an additional risks of double reporting). 
7.103 It is difficult to overstate the risk of over-reporting since surveyed enterprises are often reluctant to adapt their own understanding of R\&D phenomena (which are often influenced by accounting, fiscal and regulatory reporting requirements) to the definitions given in this manual for statistical purposes. Best practices to deal with the above-mentioned issues include an accurate checking of data collected from respondents (ideally, identifying any deviation from the expected behaviour of an enterprise as a result of its size and its main economic activity) and an appropriate treatment of outliers.

\section{Quality control of business R\&D totals}

7.104 As noted in Chapter 6, the use of quality reporting standards for R\&D statistics is highly recommended. In this respect, business $R \& D$ is not different from R\&D performed in other sectors. Nevertheless, the methodological heterogeneity observed in business R\&D surveys carried out by individual countries suggests the need for common criteria for survey/data quality reporting.

7.105 Beyond the quality reporting recommendations given by the OECD (2011) or those provided, for instance, by the United Nations (2012), some practical recommendations are given below for improving the understanding and international comparability of business R\&D statistics. These reporting recommendations focus on indicators of the level of accuracy of the business R\&D data estimates and on their coherence with other business statistics.

7.106 Since the incidence of $R \& D$ performance is rare and the population of actual R\&D performers is highly skewed, an accurate and up-to-date frame is one of the most important factors in determining whether a business R\&D survey will be successful and provide high-quality results. The quality of compiled business $R \& D$ statistics depends in large part on the identification of the population of known and highly likely R\&D performers, which is usually largely approximated. This uncertainty in the number of potential businesses who actually perform R\&D or are estimated to do so, in a statistical sense, is, in turn, the main reason why statistics on the number of performers or the rate of performers in the total population of enterprises is not usually produced.

7.107 When BERD data are released, detailed reporting on the methodology used for the data production should also be made available. More specifically, it is recommended that the dissemination of business $R \& D$ statistics at the national level include the publication of metadata: e.g. the number of units included in the reference population (potential R\&D performers), possibly identified by their main economic activity; the number of units surveyed by the census and the rate of response; and the number of units sampled and the rate of response.

7.108 A key feature of business R\&D statistics is their potential for integration with other business statistics, especially if the sampling and classification criteria for R\&D surveys are the same as for the collection of other business economic variables. As a partial indicator of the level of coherence of the 
estimates on $R \& D$ expenditure and personnel with other statistical indicators, a few ratios could be made available to users as metadata in parallel with the publication of the national data: the ratio of R\&D expenditure to value added by main economic activity; the ratio of total R\&D personnel (FTE) to total persons employed by main economic activity (for all sectors).

\section{References}

OECD (2011), Quality Framework and Guidelines for OECD Statistical Activities, Version 2011/1, OECD Publishing, Paris. www.oecd.org/statistics/qualityframework.

OECD (2005). A framework for biotechnology statistics. OECD Publishing, Paris. www.oecd.org/ sti/sci-tech/34935605.pdf.

OECD/Eurostat (2005), Oslo Manual: Guidelines for Collecting and Interpreting Innovation Data, $3^{\text {rd }}$ edition, The Measurement of Scientific and Technological Activities, OECD Publishing, Paris. DOI: http://dx.doi.org/10.1787/9789264013100-en.

UNECE (2014), Guide to measuring global production, United Nations Economic Commission for Europe, Geneva. www.unece.org/fileadmin/DAM/stats/documents/ece/ces/bur/2014/ Guide_to_Measuring_Global_Production_-_CES.pdf.

United Nations (2012), National Quality Assurance Frameworks, United Nations, New York. http://unstats.un.org/unsd/dnss/QualityNQAF/nqaf.aspx.

United Nations (2008a), International Standard Industrial Classification of All Economic Activities (ISIC), Rev. 4, United Nations, New York. https://unstats.un.org/unsd/cr/registry/ isic-4.asp and http://unstats.un.org/unsd/publication/seriesM/seriesm_4reu4e.pdf.

United Nations (2008b), Central Product Classification (CPC Ver. 2), United Nations, New York. http://unstats.un.org/unsd/cr/registry/cpc-2.asp. 



\section{Chapter 8}

\section{Government R\&D}

This chapter provides guidance on the measurement of financial and human resources for research and experimental development (R\&D) performed in the Government sector. It also deals with the Government sector as a funder of $R \& D$ and links to work in Chapter 12 on government budget allocations for R\&D (GBARD) and Chapter 13 on government tax relief for $R \& D$ (GTARD). The chapter draws upon the System of National Accounts (SNA) for the description of the Government sector which not only includes governments, but non-profit institutions controlled by government. It describes approches for measuring government intramural $R \& D$ expenditure (GOVERD), the functional distribution of $R \& D$ by types of costs follows the recommendations in Chapter 4, but raises specific cases for attention. Distribution of GOVERD by source of funds, by type of $R \& D$, field of $R \& D$, technology area, socioeconomic objectives, functions of government and geographic location are discussed. Guidance is provided on the measurement of R\&D personnel in the Government sector. Finally there is an overview of issues arising in the measurement of government funding of $R \& D$ from the perspective of the funder. 


\subsection{Introduction}

8.1 Interest in measuring the role of the Government sector in R\&D has been a constant feature of this manual since its first edition in 1963. Governments play a significant role both as performers and funders of R\&D activities, both domestically and in the Rest of the world. This chapter focuses primarily on the measurement of R\&D performance and personnel within the Government sector, in line with this manual's recommended approach to measuring the resources dedicated to R\&D. However, it also attempts to provide a nexus between the recommended performer-based approach and the complementary funder-based approach to measuring government's role as a funder of $R \& D$ throughout the entire economy. As countries have evolved in their use of R\&D policy instruments over time, national statistical offices that compile R\&D data have had to consider how best to reflect such practices within this statistical framework. This chapter provides basic guidance on this, in addition to drawing links with Chapters 12 and 13, which are respectively dedicated to the measurement of government budget allocations for R\&D (GBARD) and government tax relief for R\&D (GTARD).

\subsection{The scope of the Government sector for R\&D measurement purposes}

\section{Definition and scope of the Government sector}

8.2 For broad statistical purposes, the System of National Accounts (SNA) notes that the principal functions of government are to assume responsibility for the provision of goods and services to the community or to individual households and to finance their provision out of taxation or other incomes, to redistribute income and wealth by means of transfers, and to engage in nonmarket production.

8.3 As defined in the SNA (EC et al., 2009: para. 4.117) and reflected in this manual (Chapter 3, Section 3.4), government units are unique kinds of legal entities established by political processes that have legislative, judicial or executive authority over other institutional units within a given area. Consistent with the SNA, however, the Government sector is a broader entity that comprises not only these "core" government units, but also the non-profit institutions (NPIs) it controls. As explained in Chapter 3, the definition of the Government sector used in this manual - and in reporting R\&D statistics - differs from that of the SNA ("General government"), because the former does not include higher education institutions that meet the SNA attributes of government institutions. With that sole exception, the definitions are intended to fully match. 
8.4 Consistent with the SNA, government-controlled enterprises (termed "public enterprises" or interchangeably, "public business enterprises" in this manual) are excluded from the Government sector; rather, public enterprises are included in the Business enterprise sector (see Chapter 7 and the guidance below on the boundary between units that are part of the Government and Business enterprise sectors).

8.5 The Government sector thus comprises all units of central (federal), regional (state) and municipal (local) government, including social security funds, except those units that fit the description of higher education institutions provided in Chapter 3 and further described in Chapter 9, as well as all nonmarket non-profit institutions that are controlled by government units, and that are not themselves part of the Higher education sector.

8.6 Central (or federal) government is generally composed of a central group of departments or ministries that make up a single institutional unit this unit is often referred to as the national government and the unit covered by the main budget account - plus, in many countries, other institutional units. The departments may be responsible for considerable amounts of R\&D expenditure (for intramural or extramural $R \& D$ ) within the framework of the government's overall budget, but often they are not separate institutional units capable of owning assets, incurring liabilities, engaging in transactions, etc., independently of central government as a whole. Their revenues as well as expenses and expenditures are normally regulated and controlled by a Ministry of Finance or its functional equivalent by means of a general budget approved by the legislature.

8.7 In addition to government departments and ministries, the Government sector also comprises other government bodies such as agencies that have a separate legal identity and substantial autonomy, including discretion over the volume and composition of their expenses and outlays, and that also possibly have direct sources of revenue. These are separate government units and are often referred to as extra-budgetary units because they have separate budgets, and any transfers from the main budget account are supplemented by their own sources of revenue, such as earmarked taxes or fees for services. They may have been established to carry out specific functions, including possibly R\&D funding, R\&D performance or both. In some countries, these specialised agencies, centres and institutes may account for a large proportion of R\&D performance within government and possibly the whole economy. These institutions are also part of the Government sector.

8.8 Included in "other government bodies" are non-profit institutions (NPIs) that are non-market producers and are controlled by a government unit, regardless of whether their legal status describes them as established independently of government. A number of R\&D-performing institutions such as research centres, museums, etc., may fit under this category. As recognised in Chapter 3, economic control over these entities can be difficult to establish; 
it entails considerable nuances that may result in international differences in practical implementation. In many cases, governments may be able to exert control by means of funding decisions, but this should not be the sole criterion used in establishing whether such an institution is effectively controlled by government. It is possible for an NPI to be majority-funded by government, but the latter may not have the power to direct its research activities.

8.9 The regional (or state) government subsector consists of regional or state governments that are separate institutional units, in addition to agencies and non-market NPIs that are controlled by regional (state) governments. This subsector exercises some of the functions of government at a level below that of central/federal government and above that of the governmental institutional units existing at a local level. They are institutional units whose fiscal, legislative and executive authority extends only over the individual "states" into which the country as a whole may be divided. Such "states" may be described by different terms in different countries, i.e. by reference to terms such as "regions" or "provinces".

8.10 The local (or municipal) government subsector consists of local (or municipal) governments that are separate institutional units, in addition to agencies and non-market NPIs that are controlled by local governments. In principle, local (or municipal) government units are institutional units whose fiscal, legislative and executive authority extends over the smallest geographical areas distinguished for administrative and political purposes. The scope of their authority is generally much less than that of central (or federal) government or regional (or state) governments.

\section{Identification and boundaries of Government sector units}

8.11 Units in the Government sector can be involved in a range of different economic activities, including public administration, health and social work, defence, education (except those in the Higher education sector), as well as several other public services, which may include institutions such as public museums, archives, historical sites, botanical and zoological gardens, natural reserves, or even institutions specialised in providing research and development services for use by government itself or other sectors.

8.12 Three main attributes help identify whether any given unit should be classified into the Government sector: whether it sells its output at economically significant prices, whether government units control the institution, and whether it is appropriate to consider this unit as part of the Higher education sector, given the special rules that apply in this manual for identifying that sector. The implementation of these criteria is summarised in Table 8.1.

8.13 Core government units can adopt a wide range of legal designations whose terminology and application vary across jurisdictions. This may include ministries or departments with ministerial-like oversight, agencies, nondepartmental public bodies and institutions with special charters. These terms are provided for illustrative purposes. 


\section{Table 8.1. The components and boundaries of the Government sector in the Frascati Manual}

[The components of the Government sector identified in bold]

\begin{tabular}{|c|c|c|c|c|}
\hline \multirow{4}{*}{$\begin{array}{l}\text { Level of } \\
\text { government }\end{array}$} & \multicolumn{4}{|c|}{ The public sector } \\
\hline & \multirow{3}{*}{ Government units } & \multicolumn{3}{|c|}{ Institutions controlled by government units } \\
\hline & & \multicolumn{2}{|c|}{ Non-market non-profit institutions (NPIs) } & \multirow{2}{*}{ Market producers } \\
\hline & & $\begin{array}{c}\text { Not in higher } \\
\text { education }\end{array}$ & Higher education & \\
\hline $\begin{array}{l}\text { Central/federal } \\
\text { Regional/state } \\
\text { Municipal/local }\end{array}$ & $\begin{array}{l}\text { Ministries, } \\
\text { departments, } \\
\text { agencies... } \\
\text { Regional/state } \\
\text { departments, } \\
\text { ministries, agencies... } \\
\text { Local authorities, ... }\end{array}$ & $\begin{array}{l}\text { Non-market NPIs }{ }^{1} \\
\text { controlled by } \\
\text { government (e.g. } \\
\text { some research } \\
\text { institutes, centres, } \\
\text { museums...) }\end{array}$ & $\begin{array}{l}\text { Non-market higher } \\
\text { education institutions } \\
\text { (HEls) }^{2} \text { controlled by } \\
\text { government }\end{array}$ & $\begin{array}{l}\text { Public business } \\
\text { enterprises (including } \\
\text { NPIs serving them) and } \\
\text { public HEls that are } \\
\text { market producers }^{3}\end{array}$ \\
\hline $\begin{array}{l}\text { Observations on } \\
\text { classification }\end{array}$ & $\begin{array}{l}\text { Core government } \\
\text { units, at various } \\
\text { jurisdictional levels, } \\
\text { primarily dedicated to } \\
\text { public administration } \\
\text { activities, in the } \\
\text { executive, legislative } \\
\text { and judiciary. Can } \\
\text { also comprise extra- } \\
\text { budgetary units. }\end{array}$ & $\begin{array}{l}\text { Part of FM } \\
\text { Government sector } \\
\text { and SNA General } \\
\text { government, and } \\
\text { therefore part of } \\
\text { public sector }\end{array}$ & $\begin{array}{l}\text { Not part of FM } \\
\text { Government sector, } \\
\text { but part of public } \\
\text { sector and SNA } \\
\text { General Government. } \\
\text { Part of FM Higher } \\
\text { education sector. }\end{array}$ & $\begin{array}{l}\text { Not part of FM } \\
\text { Government sector } \\
\text { or SNA General } \\
\text { Government sector. } \\
\text { Part of FM Business } \\
\text { enterprise sector or } \\
\text { Higher education sector } \\
\text { and also part of public } \\
\text { sector }\end{array}$ \\
\hline
\end{tabular}

Notes: FM = Frascati Manual; NPISH $=$ Non-profit institutions serving households; SNA = System of National Accounts.

1. This group does not contain all non-market NPIs, only those controlled by government. Its counterpart outside the public sector comprises all private non-profit institutions including NPISHs and market NPIs classified in the Business Enterprise sector (SNA corporations sector).

2.This group does not contain all higher education institutions, only those controlled by government. Its counterpart outside the public sector comprises all private non-market higher education institutions. 3. The counterpart to these market producers outside the public sector comprises all private business enterprises as well as private market-based higher education institutions.

\section{The boundary between units in the Government and in the Private non-profit sectors}

8.14 Control is the key criterion in determining whether an NPI is clearly self-governing or is part of the government's administrative system. Establishing whether a given institute, museum, research centre, etc., is controlled by government can be challenging, especially if it is not possible to draw on authoritative classifications embedded in statistical registers. With the exception of overlaps with Higher education, which is not separately identified as an institutional sector in the SNA, the SNA classifications are a fortiori appropriate criteria for allocating units to the Government sector. Broad guidance on how to apply the control criteria is provided in Chapter 3 and Chapter 10. 
8.15 In general, the predominance of government funding over other sources is not sufficient for defining control by government, but it can be a major factor to take into consideration, in combination with other information about the nature of such funding (e.g. competitively awarded or not, board membership, golden shares, etc.) when deciding whether government has decision-making authority (i.e. control) for the R\&D performing unit (see Box 8.1).

\section{Box 8.1. Government control of non-profit institutions (NPIs)}

Control of an NPI is defined as the ability to determine the general policy or programme of the NPI. To determine whether an NPI is controlled by the government, the following five indicators of control are typically used:

1. the ability to dictate the appointment of officers or management boards

2. the ability to dictate other provisions, allowing the government to determine significant aspects of the general policy or programme of the NPI, such as the right to remove key personnel or veto proposed appointments, require prior approval of budgets or financial arrangements by the government, or prevent the NPI from changing its constitution or dissolving itself

3. the presence of contractual agreements, giving rights to impose conditions such as those cited above

4. the degree and type of financing by government, to the extent that this may prevent the NPI from determining its own policy or programme

5. the existence of risk exposure, if a government openly allows itself to be exposed to all, or a large proportion of, the financial risks associated with an NPI's activities.

Source: IMF (2014), Government Finance Statistics Manual. www.imf.org/external/np/sta/gfsm.

8.16 National academies of science exist within several countries, and they may exhibit different roles and responsibilities. In some cases, they may encompass scientific research institutes, but in many other cases their role can be related more to the dissemination of knowledge and the general promotion of scientific research. The status of these organisations can change over time, especially in transition economies where they may change from being part of the Government sector to becoming part of the Private non-profit sector or possibly the Business enterprise sector, which encompasses both public and private business enterprises.

\section{The boundary between units in the Government and in the Business enterprise sectors}

8.17 As noted earlier and in Table 8.1, it is important not to confuse the concept of "Government sector" with that of "public sector". Indicators for the total public sector can be produced by aggregating the Government sector 
and the government-controlled components of the Business enterprise and Higher education sectors. Corporations and other types of business enterprises that are controlled by governments fall outside the scope of the definition of the Government sector. As indicated in Chapters 3 and 7 and in line with standard SNA guidance, the dividing line between these public [business] enterprises and units in the Government sector is that the former primarily aim to sell most of their output at economically significant prices (see Glossary), including a profit margin for their activities.

8.18 There may be R\&D-performing institutions like research centres, museums or academies of science that generate some significant commercial revenue, for example, from the licensing of intellectual property arising from past R\&D or by providing research and consultancy services on market terms. Whenever possible, it is important that classification decisions are not driven by unusual circumstances, perhaps one-time occurrence such as, for example, when extraordinary commercial revenues are realised as a result of the disposal of an asset.

\section{The boundary between units in the Government and in the Higher education sectors}

8.19 There are a number of challenges in differentiating Government from Higher education sector activities. Chapter 3 and Chapter 9 deal with these boundary issues in some detail. There can be extensive personnel and institutional overlaps and linkages between higher education institutions as defined in this manual and units within the General government sector, as defined by the SNA.

8.20 In many countries, government units may have the ability to direct and control the activities of several if not all higher education institutions. This form of control does not make higher education institutions part of the Government sector as defined in this manual, but still qualifies them as part of the public sector.

8.21 Government units may be staffed by research personnel with affiliations to other institutions, in particular higher education institutions. At times it can be difficult to differentiate their government-related activities from those for their higher education employers. The double affiliation of individuals to a higher education institution should not drive the reclassification of the government unit unless there are other institutional control mechanisms that warrant the classification of the government unit as a higher education institution.

8.22 One area of potential difficulty is the treatment of government hospitals and related health institutions with some type of formal connection to higher education institutions, where the formal provision of tertiary education programmes and other major control linkages criteria would guide the classification of such government institutions to the Higher education sector. 
However, it is possible for a university hospital (described as such on the basis of its history and connections to a higher education institution, e.g. allowing it to support/host the training of medical students) to be classified under the Government sector. This will be the case if the hospital happens to be controlled and principally funded by government authorities, operates on a non-profit basis, and has sufficient independence from the higher education institution with respect to the $R \& D$ activities it engages in.

\section{Other special cases}

8.23 Government units may enter into partnerships with other organisations in government or other sectors to set up entities that are involved in $R \& D$ performance. These entities, if they attain the status of institutional units, are subject to the same general classification principles outlined in Chapter 3.

\section{Possible classifications of Government sector units \\ Classification by main economic activity}

8.24 The cross-cutting relevance of this institutional classification for distributing R\&D performance (as well as personnel) has been noted in Chapter 3. This also applies to the Government sector in light of the various possible economic activities, especially services, provided by government institutions. It is recommended that all government units including NPIs controlled by government be classified into their main economic activity as identified by the 2-digit Division ISIC Rev4 categories (United Nations, 2008), the detailed classification for which is found online in annex guidance to this

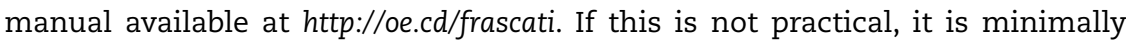
recommended to identify those units that are part of ISIC Division 72: Scientific research and development, with a view to identifying government research organisations. It is also recommended that government-controlled hospitals and clinics (which usually are classified in Division 86; Human health activities) be separately identified, for reasons clarified above.

\section{Classification of functions of government}

8.25 The Classification of Functions of Government (COFOG) is a generic classification of the functions, or socioeconomic objectives, that general government units aim to achieve through various kinds of expenditure. COFOG was produced by the OECD and published alongside three other classifications (United Nations, 2000). COFOG provides a classification system for government entities and financial outlays by functions of general interest (see the online annex to this manual available at http://oe.cd/frascati for COFOG categories). The levelone headings in COFOG have significant similarities with the classifications of socioeconomic objectives used for R\&D (see Section 8.4 on Distribution of GOVERD by socioeconomic objective and Chapter 12, Section 12.5). The use of COFOG headings for government institutions in the context of R\&D statistics cannot be 
recommended by this manual, because the categories are not optimised for the purpose of describing R\&D expenditures, although a tentative correspondence table may be useful should COFOG become more widely adopted in mainstream national statistical systems.

\subsection{Identification of R\&D in the Government sector}

8.26 The identification of what is R\&D should follow the principles laid down in Chapter 2.The core units in central/federal, regional/state and municipal/ local government may themselves perform R\&D. Examples may include special research units within ministries of variable size but also larger bodies such as the armed forces.

8.27 Difficulties in separating R\&D from other related activities arise when these are undertaken simultaneously within an organisation. Not all government units performing R\&D will be fully dedicated to such endeavours, but may often conduct $R \& D$ as a means to further the primary objectives of the unit. Government units can be engaged in activities such as health provision, general-purpose data collection for monitoring natural or social systems, or the development of largescale infrastructures, whose delivery may benefit from internal or external R\&D performance. The intellectual and physical assets arising from the core activities of government units may also be used as main inputs for R\&D projects that may be carried out within such organisations. Consistency in how these activities are dealt with in the collection of R\&D statistics can have important effects on the international comparability of the resulting R\&D data.

\section{Related Science \& Technology (S\&T) activities}

8.28 In addition to the pursuit of basic or applied research and experimental development, common R\&D-related roles for units in the Government sector include the provision of technology services such as technical testing and standardisation, technology transfer (e.g. physical transfer of technology, prototypes and processes and/or "know-how"), the development of new instrumentation, the preservation, storage and access to knowledge and scientific collections through libraries, databases and repositories, and the provision of major scientific infrastructure and facilities (e.g. nuclear reactors, satellites, large telescopes, oceanographic vessels etc.). These should not be included in R\&D.

\section{System development and demonstration}

8.29 Occasionally, government units may make major investments in large fixed assets that are considered to be "first of their kind" or to offer previously unavailable capabilities. Because of their potential contribution to innovative activities, they may be inclined to include all such construction costs as R\&D. For international comparability, however, only the costs that are specifically identified as capital to be used for R\&D should be included 
as intramural R\&D. Generally, such costs should not be reported as current $R \& D$ expenditures, but should be reported as capital $R \& D$ expenditures (see Chapter 4).

8.30 Some countries use technology readiness-level (TRL) classifications in the description and management of projects in defence, aerospace and other sectors requiring systems engineering. Different TRL models have been developed to help assess the maturity of the technological elements of such programmes, but remain largely untested in other domains. Given the level of government involvement in the areas where TRL models are used, they can be referred to in the description of government intramural R\&D as well as in procurement contracts specifying the performance of R\&D by a third party. In line with Chapter 2, it is recommended that if such models are used, they should be assessed to determine whether they can contribute in any way to improving the collection of statistics on government $R \& D$ performance or government funding of R\&D (Section 8.6).

8.31 Because of the multiplicity of TRL classification systems and their generic description, it is not possible to provide a concrete and generally applicable mapping of TRLs - or more specifically, the work conducted in order to bring the programme to a higher readiness level - to the types of R\&D (basic, research, applied research and experimental development) as defined in this manual. TRL to R\&D mapping may be most difficult in relation to the various stages that involve the demonstration of projects/systems in diverse, more realistic, use environments, resulting in new specification requirements for the projects/systems. Chapter 2 indicates that when a prototype performance is assessed by actual operational usage, this assessment is unlikely to represent R\&D. Efforts to address major flaws identified through operations or new requirements may, however, represent $R \& D$ as long as the criteria formulated in Chapter 2 are met.

\section{Policy-related studies}

8.32 R\&D efforts may underpin the decision-making process within government units. While R\&D may be outsourced to external organisations, government units may have dedicated teams actively involved in carrying out analyses such as ex-ante and ex-post appraisals or evaluations. These activities may in some cases meet the criteria for an R\&D project. However, this is not always the case, and not all evidence-building efforts associated with policy advice can be accurately described as R\&D. It is relevant to consider in some detail what is the expertise of those involved in the activity, how knowledge is codified within the organisation, and how quality standards are assured in terms of the research questions and the methodology applied. There is a significant risk that some types of socio-economic consultancy (internal or external) may be inaccurately reported as $R \& D$. 
8.33 The role of scientific advisors within government is an important one. However, the application of established decision criteria to policy making does not represent R\&D. Efforts aimed at developing improved methodologies for science-based decision making can be considered R\&D.

\section{Health care and R\&D in "public" hospitals}

8.34 As previously noted, in many countries a substantial fraction of hospitals and other healthcare institutions are controlled by government and do not meet the criteria for classification as part of the Higher education sector. As a result, health-related $R \& D$ can be an important component of the R\&D performed within government. The combination of healthcare, research and training activities can make it difficult to identify the R\&D share of such institutions' activities. R\&D can take place in partnership with higher education institutions, government or private non-profit institutions or business enterprises, for example in the context of clinical trials. Relevant guidance is provided in Chapters 2, 4 and 9.

\section{$R \& D$ financing and its administration}

8.35 As noted in Chapter 4, the raising, management and distribution of funds for R\&D grants to performers by ministries, research or funding agencies, and other government units should not be included as R\&D. In the case of government units that both perform intramural $R \& D$ and fund extramural $R \& D$, the administrative cost for preparing and monitoring extramural R\&D contracts may be counted as part of intramural R\&D expenditure.

\subsection{Measuring R\&D expenditures and personnel in the Government sector}

\section{Government intramural R\&D expenditure (GOVERD)}

8.36 The main aggregate statistic used to describe R\&D performance within the Government sector is GOVERD, Government Expenditure on R\&D. GOVERD represents the component of Gross domestic expenditure on R\&D (GERD) (see Chapter 4) incurred by units belonging to the Government sector. It is the measure of expenditures on intramural R\&D within the Government sector during a specific reference period.

8.37 Government units often host significant components of R\&D projects carried out under the responsibility of non-government institutions. For example, a government facility may allow the use of its equipment for testing by a range of business enterprises as part of their R\&D projects to develop new products. In such a case, regardless of the fact that some of that performance has occurred on government premises, this may not be sufficient to describe the government unit as an R\&D performer. The government is providing a service to the business enterprise, which is the unit performing the $R \& D$. The government unit may nonetheless be an $R \& D$ performer if it undertakes its own projects in the facility. 


\section{Functional distributions of GOVERD Distribution of GOVERD by type of costs}

8.38 The rules that apply to the distribution of GOVERD by type of costs are detailed in Chapter 4 (Table 4.1). These recommendations include a breakdown between the labour costs of $R \& D$ personnel and other current costs (current expenditures) and capital expenditures (by asset type), with separately itemised capital depreciation costs for capital assets owned. Because of the specificity of individual government units within a country, this information should, if possible, be directly requested from respondents and not imputed from other units.

8.39 Within this general guidance, there are some particular cases that deserve particular attention:

- Labour costs include actual or imputed contributions to pension funds and other social security payments for R\&D personnel. They need not be visible in the statistical unit's bookkeeping accounts; they may often involve transactions to other parts of the Government sector, such as social security funds. Even when no transactions are involved, an attempt should be made to estimate these costs from the perspective of the reporting unit.

- Value-added tax (VAT) for materials and services may not be reclaimable for units in the Government sector, in which case, it needs to be counted as part of other current costs.

8.40 The quantification of $R \& D$ expenditures incurred in the context of facilities used for R\&D is potentially one of the most challenging aspects of $R \& D$ measurement in the Government sector. The examples discussed in Chapter 4 indicate the need to capture the economic cost of facilities that are used without paying an actual fee, as well as to avoid possible double counting of asset acquisition or construction costs and the costs to the recipients who use the facilities.

8.41 There are examples where the government owns and maintains special facilities that are used by researchers employed by the facility and visitors from other agencies and business enterprises for approved R\&D projects. When used by other government or non-government performers, user charges - which might include operation and maintenance (O\&M) costs - that are paid to the facilities owner are part of the current costs reported by the R\&D performer using the facilities. Such O\&M costs that are recovered in user charges should be excluded from reports from the government agency that owns the facilities in order to avoid the double counting of such expenditures. Because the use of the facilities may be infrequent or the charge too small to cover the costs of keeping R\&D facilities operational, then an appropriately justified component of O\&M costs may be attributed as intramural expenditure, in other current costs, by the government unit that owns the facility. 


\section{Distribution of GOVERD by source of funds}

8.42 Traditionally, it had been largely assumed that funding from non-government sources was of limited relevance in the case of R\&D performance within the Government sector, given the dominant role of internal budgetary sources. However, in current circumstances the absence of such information could be quite misleading. The widespread use of private-public partnerships and mixed arrangements, the search for alternative funding sources within extra-budgetary government units and NPIs controlled by government, and the existence of international agreements between countries and supranational organisations call for a detailed collection of information on the origin of funds used for R\&D in government, from both domestic sources and the Rest of the world.

8.43 The sources of funding for government institutions and their $R \& D$ activities can be based on earmarked revenues (e.g. when defined as a percentage of total government revenues or when identified with specific taxes or social security contributions), transfers from the budget, general sales of goods and/or services or user charges, sales of financial and nonfinancial assets, borrowing, or general donor funds (IMF, 2014). Extra-budgetary sources refer to general government transactions, often with separate banking and institutional arrangements that are not included in the annual central government-level budget law and the budgets of subnational levels of government.

8.44 The reporting structure presented in Table 8.2 is recommended for the collection of information on the source of funds. The breakdown between exchange and transfer-based funds is more relevant for extra-budgetary government units as well as for NPIs controlled by government, which may rely to a larger extent on non-budgetary sources of funds and are more likely to undertake R\&D as a service to other organisations or firms and receive financial compensation in return.

\section{Distribution of GOVERD by type of R\&D}

8.45 As for all other sectors, it is recommended that data are collected from government units on the breakdown of $R \& D$ expenditures by type of $R \& D$, basic research, applied research and experimental development, as defined in Chapter 2.

\section{Distribution of GOVERD by field of $R \& D$}

8.46 It is recommended whenever possible to distribute R\&D performance within government units by the top level field of research and development (FORD). 


\section{Table 8.2. Source of funds to be collected in government R\&D performer surveys}

\begin{tabular}{lccc}
\hline $\begin{array}{l}\text { Source of funds for R\&D performed within } \\
\text { a government institution }\end{array}$ & $\begin{array}{c}\text { Funds for R\&D } \\
\text { in exchange }\end{array}$ & $\begin{array}{c}\text { Funds for } \\
\text { R\&D as a } \\
\text { transfer }\end{array}$ & $\begin{array}{c}\text { Total funds for } \\
\text { R\&D intramural } \\
\text { performance }\end{array}$ \\
\hline Government sector & x & $\checkmark$ \\
- Own agency/institution (internal funds) & x & $\checkmark$ \\
- Other central or federal & x & $\checkmark$ \\
- Other regional or state or local & $\times$ & $\checkmark$ & $\checkmark$ \\
Business enterprise sector & $\checkmark$ & $\checkmark$ & $\checkmark$ \\
Higher education sector & $\checkmark$ & $\checkmark$ & $\checkmark$ \\
Private non-profit sector & $\checkmark$ & $\checkmark$ & $\checkmark$ \\
Rest of the world & $\checkmark$ & $\checkmark$ & $\checkmark$ \\
- Government sector & $\checkmark$ & $\checkmark$ & $\checkmark$ \\
- International organisations (including & & & $\checkmark$ \\
supranational organisations) & $\checkmark$ & $\checkmark$ & $\checkmark$ \\
- Business enterprise sector & & $\checkmark$ & $\checkmark$ \\
- Higher education sector & $\checkmark$ & $\checkmark$ & \\
- Private non-profit sector & $\checkmark$ & & $\checkmark$ \\
All sources & $\checkmark$ & & $\checkmark$ \\
\hline
\end{tabular}

Notes: Adapted from Table 4.1 in this manual.

$\mathrm{x}=$ not applicable; no need to collect.

1. Breakdown exchange/transfer more relevant for extra-budgetary government units and NPIs controlled by government.

8.47 At least in th e case of government institutions classified in ISIC Rev. 4 Division 72, scientific research and development, it can be helpful to classify these according to the main FORD, using its top level headings. The detailed FORD classification can be found online in annex guidance to this manual available at http://oe.cd/frascati. Given the existence of multidisciplinary centres in government, it may be useful to indicate a secondary field of research or use an additional, multidisciplinary category.

\section{Distribution of GOVERD by technology area}

8.48 Countries may find it useful to report GOVERD by technology area. Biotechnology, Nanotechnology and Information Communication Technologies (ICT) are among the most important.

\section{Distribution of GOVERD by socioeconomic objective}

8.49 Performer-based reporting of GOVERD by socioeconomic objective is in principle possible for institutions in the Government sector. This approach should not be confused with the analysis of government budget allocations for R\&D (GBARD) by socioeconomic objective (see Chapter 12 for extensive details about such distributions). 
8.50 The recommended distribution list is based on the categories in the Nomenclature for the Analysis and Comparison of Scientific Programmes and Budgets (NABS) (Eurostat, 2008) and other national adaptations with a direct correspondence to it. This list is the same as that suggested for government $R \& D$ funding, with the exception of research financed from general university funds, which is not appropriate in this instance. R\&D should be distributed by reporting units according to the primary project objectives and aggregating over their research portfolio.

8.51 In the case of the Government sector and following the guidance in Chapter 4, it is particularly important to compile separate totals for defence and civil GOVERD and to document any potential under-coverage of defence-related R\&D. This is especially relevant for countries with significant defence R\&D programmes, part of which may be carried within government units. Furthermore, information on these defence R\&D projects may be highly sensitive and classified in a way that makes R\&D expenditures not distinguishable from non-R\&D-based programmes. As noted in Chapter 4, it is important to ensure the international comparability at least of data on civil R\&D. It is also important that the ancillary metadata on the GOVERD clearly documents the margins of uncertainty concerning unmeasured R\&D within government.

\section{Distribution of GOVERD by functions of government}

8.52 Some countries may find it useful to distribute GOVERD to COFOG categories (see Section 8.2 on institutional classifications). However, for reasons described previously, the use of COFOG categories in the context of R\&D statistics is not recommended by this manual.

\section{Distribution of GOVERD by geographic location}

8.53 Countries may find it useful to compile separate totals for the distribution of GOVERD by location/region. The choice of geographic distribution is determined according to national and international needs, with further details found online in annex guidance to this manual available at http://oe.cd/frascati.

\section{GOVERD versus government funding of extramural R\&D performance}

8.54 Section 8.6 will consider in more detail the reporting of funding by government units for extramural $R \& D$. This subsection is principally concerned with the boundaries between intramural R\&D and extramurally performed R\&D for the Government sector. Among R\&D performers in this sector, some of the expenditures may have been incurred for activities carried out off-premises and even possibly abroad, for example in outer space, in Antarctica, in the government institution's diplomatic or consular representations abroad, or on a short-term basis, e.g. as field work, in some other country. When such R\&D takes place under the responsibility of the government institution under observation, 
this corresponds to its intramural R\&D. Payments for services to other parties that contribute to the R\&D effort also correspond to its own intramural R\&D.

8.55 Costs for consultants that provide R\&D in fulfilment of a specific order (acquisition), but not as an integrated part of the government unit's R\&D projects, should be treated as funding of extramural R\&D by the statistical unit receiving the R\&D. The delivering statistical unit, where these consultants are employed, should report this activity as intramural R\&D expenditure. The breakdown of expenditures for extramural $R \& D$ expenditures should be as indicated in Chapter 4 .

8.56 In classifying whether funds provided by one government entity to another government entity should be treated as funds for intramural versus extramural performance, the level of government (i.e. central/federal, regional/ state, local/municipal; see Table 8.1) is the institutional unit of interest and provides the determining criterion. For example, $R \& D$ funds received by a ministry $\mathrm{Y}$ of the central government from another central government ministry $\mathrm{X}$ should be reported as ministry Y's internal funds for intramural R\&D. For ministry X that provides (is the source of) those R\&D funds, they are not to be reported as either part of their internal funds or as funds for extramural performance. At a sector aggregation, these funds are simply internal central government funds for central government's intramural $R \& D$ performance. The rationale is that such transactions are among different parts of the same institutional unit of the central government, even if the statistical units are smaller entities such as ministries.

8.57 Attention should be given to avoid the possibility of double counting R\&D funds provided by "intermediary" agencies that receive funds from ministries and agencies and then re-allocate and pass through funds to other performing institutions. In the previous example, if the funds provided by ministry $X$ to ministry $Y$ are passed on by the intermediary ministry $Y$ to an $R \& D$ performer outside of the Government sector, the government institution is not the performer - i.e. there is no GOVERD), and the funds are reported as government funds for extramural non-government performance, originating from ministry $\mathrm{X}$, if such detail is collected (see Section 8.5 and Table 8.3).

8.58 Transactions across entities within central and regional governments or different extra-budgetary units and other government-controlled NPIs in the Government sector should be reported as extramural funding when these are separate institutions with their own accounts. For example, R\&D funds received by agency $\mathrm{Z}$ of a regional government from a central government ministry $\mathrm{X}$ should be reported as external (government) funds for agency Z's intramural $R \& D$. For central government ministry $X$ that provides (is the source of those $R \& D$ funds, they are to be reported as funds for extramural performance by regional government. 


\section{R\&D personnel in the Government sector}

8.59 The R\&D personnel categories to be reported for the Government sector are the same as those of the other R\&D performing sectors and are defined in Chapter 5 of this manual. The distributions recommended above for expenditures should be applied whenever possible to R\&D personnel.

8.60 Individuals in government institutions solely dedicated to the administration and assessment of R\&D funding proposals, e.g. in the context of awarding grants or procurement contracts, should not be considered as $R \& D$ personnel. Their activities are not $R \& D$. However, as noted in Chapter 4, government institutions that combine $R \& D$ funding and performance roles may include the costs of their personnel working on the substantive, financial or administrative aspects of R\&D contracts in "other current costs"; but such personnel should not be classified as R\&D personnel.

8.61 Given the likely presence of external R\&D personnel in government $\mathrm{R} \& \mathrm{D}$ facilities, it is recommended in line with Chapter 5 to report these individuals in the appropriate category, separately from internal $R \& D$ personnel. This also applies to trainees such as doctoral and master's students, if they are actually performing $R \& D$ under the criteria set out in Chapters 2 and 5 .

8.62 In general, within government research organisations, the categories proposed in Chapter 5 can be easily reported, although this may not be the case within some core government units. Whenever possible, a classification of researchers by seniority grade similar to that proposed in Chapter 9 may be useful for the purpose of documenting the organisation of $R \& D$ within government institutions. The categories include typical positions for each group (EC, 2013: 87):

- Category A: The single highest grade/post at which research is normally conducted.

* Example: "director of research".

- Category B: Researchers working in positions not as senior as top position (A) but more senior than newly qualified doctoral graduates (ISCED level 8).

* Example: "senior researcher" or "principal investigator".

- Category C: The first grade/post into which a newly qualified doctoral graduate would normally be recruited.

* Examples: "researcher", "investigator" or "post-doctoral fellow".

- Category D: Either doctoral students at the ISCED level 8 who are engaged as researchers, or researchers working in posts that do not normally require a doctorate degree.

* Examples: "Ph.D. students” or “junior researchers” (without a Ph.D.). 


\subsection{Methods for compiling R\&D expenditure and personnel in the Government sector}

\section{The statistical and reporting units in the Government sector}

8.63 Government units that should be covered by surveys include:

- $R \& D$ institutes, laboratories and centres

- R\&D operations of general administrations of central/federal, regional/state or municipal/local government, statistical, meteorological, geological and other public services, museums and hospitals

- R\&D operations at all levels of government (where appropriate: central/federal, regional/state, and municipal/local).

8.64 The statistical unit will generally be the department, ministry or agency, even if the unit does not have all of the characteristics of an institutional unit (e.g. individual ministries often lack the ability to hold and control assets separately from the ensemble of the central/federal [or regional/state] government). The desired attributes of the sampling unit for the Government sector include: branch of activity, geographic location and level of government. The reporting unit will be dependent on the entity that is best capable of reporting. This may include the whole of government in the case of regional/ state or municipal/local governments.

8.65 If available, the survey frame should be linked to a central statistical register. This would assist in the integration of data from various sources and simplify classification decisions. It would also reduce the risk of double counting units if approached from different perspectives.

8.66 Particular attention should be paid to the use of administrative data in the identification of R\&D performing and funding institutions. In some countries, these would include institutions that could identify R\&D expenditures as a second-level COFOG.

8.67 It is especially difficult to identify R\&D activities at the local (and in some countries, the regional/state) government level owing to the large number of units, the small number of likely R\&D performers and difficulties in the interpretation of the concept of $R \& D$. If local governments undertake a significant amount of R\&D activity, it is advised to make the effort to include R\&D performers in large local governments. Given the nature of many regional/ state forms of government, they may perform R\&D occasionally: it may not be core to the governments' department or agency mission to conduct R\&D per se, but they need to address a specific problem identified by the legislature or the department. Therefore, some R\&D activities may be temporary.

\section{Survey data collection}

8.68 It is standard practice to carry out a census of government units and organisations that are known or presumed to be performing R\&D. For reasons related to the practical burden, typically these will only account for a relatively 
small list of all known government units. Registers/directories of government departments, research institutes and statutory bodies, including a review of available legislation and budgetary actions, can help identify the possible R\&D performers in the Government sector. Other sources of information could be academic or professional and stem from learned societies; research associations; lists of science and technology (S\&T) service institutions; registers or databases of scientists and engineers; and databases of scientific publications, patents and other intellectual property documents, as well as requests for updates from administrative bodies.

8.69 Officials in charge of the compilation of R\&D data should not understate the potential challenges of collecting this data from government institutions. A lack of underlying information in the format requested and limited buy-in can significantly affect the comprehensiveness and quality of the data collected. In the case of research institutes where the personnel have civil servant status, it is advisable that arrangements be made in advance, ensuring the buy-in of the senior civil servant in charge of the reporting institution. In general, it is recommended that an appropriate "outreach" programme be used to support data collection, involving the provision of respondent training packages, investigative studies to provide $\mathrm{R} \& \mathrm{D}$ terminology familiar to subnational government staff, and direct feedback on the results of the data collected.

8.70 Some institutions in the Government sector may report that all staff perform research and that their R\&D personnel FTE is equal to or close to 100 percent (UNESCO-UIS, 2014). Although activities that are not R\&D should be excluded, this may be difficult to apply in practice. Because government institutions differ in their orientation and institutional cultures, this manual advises against applying general "rules of thumb" whereby a fixed percentage of professionals in these institutions are deemed to be researchers. A systematic count will be expected from respondents. Where government institutions primarily engaged in S\&T services undertake research in connection with this activity, such research activities should be clearly identified and systematically captured in the R\&D survey.

\section{Estimation of R\&D expenditure and personnel}

8.71 The estimation of $R \& D$ expenditures and personnel in the Government sector should pose a priori less of a challenge than for other sectors where complete enumeration is not the norm. However, given the scope for nonresponse and the limitations on the type of information that can be requested from government institutions, a number of strategies may need to be used.

8.72 In some cases, government information systems aimed at improving co-ordination and ensuring greater transparency may provide an adequate basis for collecting information on research work funded or performed by central government. Such systems may integrate all research and development projects funded or performed by a substantial part of government and allow the production of statistics on R\&D performance by government units. In some 
other cases, budgetary information may need to be used to address data gaps and quality-assure the consistency between surveys and totals.

8.73 The use of coefficients to estimate the structure of $R \& D$ expenditures or personnel within organisations is in general discouraged, because of the large heterogeneity between R\&D performing units.

8.74 Whenever possible and where the quality of the collected data permits doing so, it is recommended to publish selected disaggregated data at the level of individually-named government institutions, as this may serve several other user needs.

\subsection{Measuring government funding of $R \& D$ performance}

8.75 As noted in Chapter 4, there are two main approaches available for measuring the cost of the resources that governments dedicate to fund R\&D. One approach is performer-based reporting of the sums that a statistical unit or sector has received from government units for the performance of intramural $R \& D$ during a specific reference period. The second approach is funder-based reporting of the sums government units report having paid or committed themselves to pay to other statistical units or sectors for the performance of R\&D during a specific reference period. The funder-based approach relies on the reporting made by government funding units, including for R\&D performed within government, as well as funds for R\&D to be performed outside government.

\section{Performer-based approach (recommended)}

8.76 The recommended approach for compiling figures of R\&D funding by government is the performer-based approach, which is based on combining the funding levels reported by units in all sectors, including government. For a particular country, the aggregate total represents the total domestic R\&D performance financed by the Government sector. This indicator, Government-financed GERD (GOV-financed GERD), should not be confused with GOVERD, which represents the Government sector's overall intramural $R \& D$ performance. The overlap between these two totals is the share of $R \& D$ performed within government that is internally funded by government out of its own resources.

8.77 The measurement of government funding of GERD relies on the robust measurement of sources of funds in all sectors. Most of the main challenges have been discussed at some length in Chapter 4 and the relevant sector chapters.

8.78 It is highly recommended that surveys of R\&D performers in all nongovernment sectors provide a breakdown of funds received from government according to whether the funds are provided in exchange for $R \& D$ or as a transfer. This information is of particular relevance for policy makers and for building a better understanding of the policy instruments used to support R\&D. This information is also of relevance to the production of capital investment series in national accounts. 
8.79 The implementation of the performer reporting approach, however, can present some difficulties when dealing with specific forms of government financial support for R\&D. For example:

- The use of dedicated forms of tax relief with the aim of encouraging the funding or performance of R\&D has been addressed in Chapter 4 and is the focus of dedicated guidance in Chapter 13. With some specific exceptions, most modes of tax support for R\&D cannot be easily aligned formally and in practice to this manual's concept of R\&D performance. For this reason, the capture of this form of support is primarily undertaken from a source perspective and, in international comparisons, generally excluded from analyses of statistics on government-financed GERD.

- Loans for R\&D provided by government, as well as other financial investments aimed at providing financial resources for R\&D in other sectors, should be treated as internal performer funds (Chapter 4). Financial investments represent an exchange of financial assets (e.g. cash in return for future repayments at an agreed interest, or a claim on an institution's profits). While it is possible that such an investment may not be repaid or that the interest charged implies a subsidy, it is deemed impractical to ask performers to estimate and reveal its implicit value.

- Free or sponsored use of government facilities for R\&D. For practical reasons, it is impossible to secure reliable estimates from R\&D performers of the economic value of the services secured or its equivalent implicit subsidy. In some cases and as previously noted, the cost of services that is not charged to users may be allocated to the R\&D performance of the service provider for a better aggregate representation of the full R\&D effort.

\section{Funder-based approach (complementary)}

8.80 While this manual highlights the importance of ensuring a common and consistent approach based on the reporting of R\&D by performers (through surveys and other, justifiable, auxiliary methods), it also acknowledges a range of complementary practices intended to improve the quality, timeliness and relevance of $R \& D$ statistics. The reference to such practices is based on the experience within a number of countries that have already been developing source-based statistics on how much R\&D is funded by government, for performance within and outside government.

8.81 In many cases, data on the funding of extramural R\&D by government units can be used to address reporting gaps from performers, and thereby improve the quality of R\&D performance statistics. This may apply for example in the case of funding being provided for individuals, for example, students or scholars, to engage in R\&D performance at other units, without these units having direct control over the funding (see Section 4.4). This arrangement may be intended to allow individuals to move freely from one organisation to another. Data from government funding sources may thus allow a more complete representation of 
the overall R\&D performance. It is however necessary that the host organisations have a formal record of the presence and contribution made by such individuals, for otherwise it may be impossible to demonstrate compliance with the criteria for R\&D outlined in Chapter 2.

8.82 Another example of the application of funder-based statistics is the use of budgetary funding measures to help estimate general funding for universities, with the assistance of coefficients on the use of those general resources (see Chapter 9).

\section{Government budget allocations for $R \& D$ (recommended)}

8.83 This manual provides guidance on the collection of data on government budget allocations for R\&D (GBARD) in Chapter 12. The main rationale for this budget-based approach is the greater timeliness of the data (including budget plans) and the ability to provide a first-order approximation to the distribution of government R\&D funding levels by socioeconomic objective.

\section{Statistical enquiries on government funding of $R \& D$ (optional)}

8.84 As previously noted, it is recommended that surveys of government units include questions on the funding by these units of $R \& D$ performed extramurally. In general, these surveys cannot be used to construct aggregates of government funding unless their coverage is expanded to cover not only R\&D performing units in the Government sector but also other units that only undertake $\mathrm{R} \& \mathrm{D}$ funding roles.

8.85 The potential relevance of these data further derives from the additional information elements that can be collected through specifically targeted questions on the funding of both intramural and extramurally performed R\&D, which standard budgetary information cannot provide in sufficient detail. A number of examples can be provided, indicating potential areas of development within countries for which it is not possible at present to provide common guidelines.

\section{More detailed information on individual government sources of R\&D funds}

8.86 One possible advantage of government funder-based surveys is that they may allow a more detailed accounting of which government institutions provide funds for R\&D performed by units in each of the economic sectors. While surveys of R\&D performers in the Business enterprise, Higher education and Private non-profit sectors ask for data on total government funds for $\mathrm{R} \& \mathrm{D}$, it may be particularly burdensome to ask respondents to identify the individual government units that are the source of such funds. Surveys of individually identified government $R \& D$ funders asking for $R \& D$ funding totals provided to extramural R\&D performers, by sector, do not have this limitation. 


\section{Funding by government of R\&D performed abroad}

8.87 Indicators of R\&D funding by government for performers abroad and in international organisations (all part of the "Rest of the world") cannot be obtained from surveys of domestic performers. Similarly, information on government contributions to programmes and institutions developed in partnership with other countries' governments or supranational organisations can be of significant policy relevance to the extent that it may enable the monitoring of international collaboration on R\&D and the extent to which bilateral or multilateral agreements are actually supported by government funding.

\section{Funder-based information on modes of funding}

8.88 Information could be collected indicating the extent to which funds are provided as a transfer (as in a standard type of grant or contribution agreement) or in exchange for R\&D services (as in many forms of government R\&D procurement) (see Chapter 4). For a number of reasons, the perspective provided by funders may differ substantially from that of performers, who may possibly report external funding as internal and therefore understate the true extent of funding from government.

8.89 Information could be collected on a number of other policy-relevant dimensions of modes of funding, such as the extent to which the funding is allocated on a competitive basis (versus other criteria) or is allocated on a programmatic or project basis instead of as institutional allocations. Under an institutional mode of funding, the organisations receiving funding have full discretion over the type of $R \& D$ projects and activities that they can undertake, whereas funding provided on a project or programmatic basis leaves more limited room for decision. Public general university funds (GUF) for R\&D are a particular case of institutional $R \& D$ funding, aimed at higher education institutions, to which this manual assigns special status (see Chapters 4, 9 and 12). It is important to note that when block funding recipients can decide on whether the funds are to be used for R\&D or other purposes, it is unlikely that what funders report as funding allocated on R\&D-based criteria - for example, on past scientific publication performance - will necessarily coincide with what performers report as being used for R\&D.

\section{Challenges of statistical enquiries on R\&D funding by government}

8.90 The comprehensive collection of data on R\&D funding by government units entails a number of practical challenges to take into account:

- The availability of additional data requires additional efforts to "reconcile" differences between budget-based data and reports on government sources of funds from all domestic performing sectors. If information is collected on the sectoral affiliation of the likely performers, this may give rise to a different performance-funder matrix from that derived from performer-based 
surveys. This entails a non-negligible risk of confusion among data users if not appropriately described and explained.

- The approach also requires extending the coverage of government $R \& D$ surveys to non-R\&D performing government units, which may have some resource and burden implications. The burden placed on government agencies will depend on the extent to which the information is already available, at least internally for other administrative purposes, and whether these align with the intended statistical concepts.

- In order to implement a funder-based approach, there is a need to address the potential double counting of R\&D funds provided by "intermediary" agencies that receive funds from ministries and agencies and then re-allocate and pass through funds to other performing institutions. This also requires developing clear criteria on how these funds are distributed across functional categories. For example, the funds provided by a ministry to a major funding council may align with the "general advancement of knowledge" objective, while the agency's own funding of $R \& D$ at the project or programme level may register funding on a more granular basis.

8.91 Table 8.3 provides a schematic representation of the various situations that a government agency engaged in both R\&D funding and performance may find itself in if confronted by a questionnaire on R\&D performance and funding activities with third parties. This table shows that for computing aggregate estimates of R\&D funding by the Government sector, it would be necessary to either focus on funds ultimately provided to R\&D performers or focus on the first-time allocation of funds. In general, respondents can be asked to include the amounts transferred to other agencies to support research and development, but in that case the receiving agencies should not report funds transferred to them. Similarly, a subdivision of an agency that transfers funds to another subdivision within that agency could report such outlays as its own. To ensure that no undue distortion of funds for intramural R\&D performance takes place, the agency transferring the funds should make a special effort, within practical limits, to determine whether the ultimate performer is intramural or extramural, and report accordingly. The transfer of funds to another government agency should not be the sole basis for reporting that the R\&D performance is intramural.

8.92 Discrepancies with either budget-based data or data on expenditures for R\&D performance may arise, depending on whether government units are asked to report their outlays on a cash or accrual basis. Cash or related payments may be made in a different period with respect to the year in which the use of funds by the agency was approved, and this may also in turn be different from the point at which the commitment is made to pay a given performer, and also the time at which R\&D performance is deemed to be accrued. 


\section{Table 8.3. Flows of funds perspective for a government R\&D funding and performing agency}

\begin{tabular}{|c|c|c|c|}
\hline $\begin{array}{l}\text { Funds available to } \\
\text { agency }\end{array}$ & Agency's use of funds & Possible ultimate use of funds & $\begin{array}{l}\text { Intra / extramural R\&D } \\
\text { performance }\end{array}$ \\
\hline \multirow{4}{*}{$\begin{array}{l}\text { Internal or other } \\
\text { government } \\
\text { sources, } \\
\text { including budget, } \\
\text { and funds } \\
\text { retained from } \\
\text { previous years }\end{array}$} & \multirow{2}{*}{ Funds retained } & Intramural $R \& D$ within the government agency & Intramural \\
\hline & & Spending decision deferred & Not applicable \\
\hline & \multirow[t]{2}{*}{ Funds passed through } & $\begin{array}{l}\text { Agency delegates R\&D funds allocation decision } \\
\text { to another agency }\end{array}$ & $\begin{array}{l}\text { Potential for double } \\
\text { counting }\end{array}$ \\
\hline & & $\begin{array}{l}\text { Funds allocated to performers through grants, } \\
R \& D \text { procurement, subcontracted } R \& D \text {, etc. }\end{array}$ & $\begin{array}{l}\text { Extramural } \\
\text { Potential for double } \\
\text { counting }\end{array}$ \\
\hline \multirow{4}{*}{$\begin{array}{l}\text { Other external } \\
\text { sources }\end{array}$} & \multirow{2}{*}{ Funds retained } & Intramural $R \& D$ within the government agency & Intramural \\
\hline & & Spending decision deferred & Not applicable \\
\hline & \multirow{2}{*}{ Funds passed through } & $\begin{array}{l}\text { Agency delegates R\&D funds allocation decision } \\
\text { to another agency }\end{array}$ & $\begin{array}{l}\text { Potential for double } \\
\text { counting }\end{array}$ \\
\hline & & $\begin{array}{l}\text { Funds allocated to performers through grants, } \\
R \& D \text { procurement, subcontracted R\&D, etc. }\end{array}$ & $\begin{array}{l}\text { Extramural } \\
\text { Potential for double } \\
\text { counting }\end{array}$ \\
\hline
\end{tabular}

8.93 A number of countries already collect R\&D performance and funding within the entire Government sector in a systematic fashion. Countries that wish to experiment with this approach are encouraged to do so. However, further work is needed in order to bring convergence towards a standard for conducting comprehensive surveys of $R \& D$ funding by governments.

\section{References}

EC, IMF, OECD, UN and the World Bank (2009), System of National Accounts, United Nations, New York. https://unstats.un.org/unsd/nationalaccount/docs/sna2008.pdf.

EC (2013), She Figures 2012: Statistics and Indicators - Gender in Research and Innovation, European Commission, Brussels. http://ec.europa.eu/research/science-society/document_ library/pdf_06/she-figures-2012_en.pdf.

Eurostat (2008), Nomenclature for the Analysis and comparison of Scientific programmes and Budgets (NASB), www.oecd.org/science/inno/43299905.pdf.

International Monetary Fund (2014), Government Finance Statistics Manual, IMF, Washington, D.C. www.imf.org/external/np/sta/gfsm/.

UNESCO Institute for Statistics (2014), Guide to Conducting an R\&D Survey: For countries starting to measure research and experimental development. www.uis.unesco.org/ ScienceTechnology/Documents/TP11-guide-to-conducting-RD-surveys.pdf.

United Nations (2008), International Standard Industrial Classification of all Economic Activities (ISIC) Revision 4. Department of Economic and Social Affairs, Statistics Division, Statistical papers, Series M, No 4, Rev. 4. United Nations, New York. http://unstats. un.org/unsd/class/default.asp.

United Nations (2000), Classification of expenditure according to purpose: Classification of the functions of government, United Nations, New York. http://unstats.un.org/unsd/class/ default.asp. 



\section{Chapter 9}

\section{Higher education R\&D}

The Higher education sector, because of its policy relevance, is unique to the manual and has no counterpart in the System of National Accounts (SNA). This chapter defines the Higher education sector and in doing this, draws upon existing definitions of tertiary education programmes, and of formal education. As the objective of the definition is to capture all research and experimental development (R\&D) activity in the sector, the definition includes all research institutes, centres, experimental stations and clinics that have their R\&D activities under the direct control of, or administered by, tertiary education institutions. The Higher education sector differs across countries so the first task is to identify the institutions belonging to the sector and then to collect and report the R\&D statistics in such a way as to support international comparison. The chapter provides guidance on identifying institutions in the sector and on measuring R\&D expenditures, flows between institutions within and external to the sector and the human resources committed to $R \& D$ in the sector. 


\subsection{Introduction}

9.1 The Higher education sector is unique to this manual and has no counterpart in the System of National Accounts (SNA) (EC et al., 2009). Institutions belonging to the Higher education sector can also be classified to any of the SNA sectors, depending on their characteristics. The reason for defining this sector is the policy relevance of information on its R\&D performing institutions.

9.2 Education statistics are well established and are guided by the International Standard Classification of Education (ISCED) as well as by the manual on concepts, definitions and classifications for the UNESCO, OECD, Eurostat data collection on formal education (UOE, 2014). The UOE Manual uses the same definition of R\&D as does this manual.

9.3 In education statistics, education programmes are classified according to ISCED, and tertiary education is defined as ISCED levels 5, 6, 7 and 8. In this manual, institutions that satisfy the definition of the Higher education sector are classified to that sector. These are two quite different processes, and it will become clear that, in this manual, tertiary education and higher education are not the same.

9.4 As the definition of the sector given in Section 9.2 shows, the institutions in the Higher education sector of this manual are not only those that provided formal tertiary education programmes, but there are also research institutes, centres, experimental stations and clinics that may or may not provide education programmes, but which satisfy a condition defined in Chapter 3 and explained further in the next section.

9.5 As the Higher education sector differs across countries, the first task is to identify the institutions belonging to the sector and then to collect and report the R\&D statistics in such a way as to support international comparison. This is particularly important for statistics on the performance of R\&D in the Higher education sector. How this is done is the subject of this chapter.

\subsection{Coverage of the Higher education sector}

9.6 This sector is composed of:

- all universities, colleges of technology and other institutions providing formal tertiary education programmes, whatever their source of finance or legal status

- all research institutes, centres, experimental stations and clinics that have their R\&D activities under the direct control of, or administered by, tertiary education institutions. 
9.7 To be more specific, the sector includes all units (institutions) whose primary activity is to provide formal tertiary education programmes, ISCED levels 5, 6, 7, or 8, regardless of their legal status (UNESCO-UIS, 2012: 83). Formal education is defined in ISCED (UNESCO-UIS 2012, paras. 36-42), and it is part of the definition of the Higher education sector to include education programmes that are recognised by the relevant national education or equivalent authorities and to exclude programmes that are not. This manual uses the term "education services" rather than "education programmes", but the two terms are considered to be equivalent. As noted in the definition, this sector's coverage is extended in this manual to take into account the performance of R\&D by providers of tertiary programmes in other non-market institutions, such as certain types of research institutes and clinics where all R\&D activity takes place under the direct control of the tertiary education institution(s) and can thus be considered, for practical purposes, to be part of their intramural R\&D.

9.8 The above definition specifies the coverage of the sector (see also Chapter 3, Section 3.5). The decision tree in Figure 3.1 of Chapter 3 indicates the sectors used in this manual to which the institutions in the Higher education sector would be assigned if the sector did not exist. As the Business enterprise, Government and Private non-profit sectors are close to SNA sectors, Figure 3.1 is also indicative of how institutions in the Higher education sector would be assigned to the corresponding SNA sectors.

9.9 A major distinction recommended for institutions in the Higher education sector is whether they are classified as public or private. Within the latter, it is also important for SNA bridging purposes to be able to distinguish whether the higher education institution belongs to the SNA corporate, general government or NPISH (non-profit institutions serving households) sector. This is discussed further in Section 9.2 below on Public and private institutions and international comparisons.

9.10 As indicated in Chapter 3 (Section 3.4) and Chapter 8, the classification between public and private is made according to whether a government entity has ultimate control over the institution. Ultimate control, as defined in those chapters, is decided with reference to which institution has the power to determine the general policies and activities of the institution and to appoint the officers managing the institution. Since many institutions are under the operational control of a governing body, the constitution of that body will also have a bearing on the classification.

9.11 The core of the sector in all countries is made up of universities and colleges of technology. Where the treatment varies, it is with respect to other tertiary education institutions and above all to several types of institutions linked to universities and colleges. Three categories are considered below:

- tertiary education institutions

- university hospitals and clinics

- "borderline" research institutions. 


\section{Tertiary education institutions}

9.12 The sector includes all establishments for which the primary activity is to provide formal tertiary education, regardless of their legal status. These may be corporations or quasi-corporations, either private or belonging to a government unit, market NPIs (non-profit institutions) or NPIs controlled and mainly financed by government or by NPISHs (non-profit institutions serving households). As noted above, the core is made up of universities and colleges of technology. Not all tertiary institutions perform R\&D, and there may be some institutions at the upper secondary or post-secondary non-tertiary level (ISCED 3 or 4 ) that perform R\&D. Depending on the governance and funding of these institutions, they may be included in the Higher education sector, but these inclusions should be made clear when the data are reported. Some countries have institutions of tertiary education with a vocational focus. Their purpose is teaching, and they do not perform R\&D. They may be excluded from surveys of the sector.

\section{University hospitals and clinics}

9.13 Although not formally defined, the concept of a university hospital is normally applied to hospitals that are affiliated to a university, although many other types of linkages and arrangements are often referred to as university hospitals. By combining health, education and research activities, and being subject to different forms of governance arrangements, their classification can pose a number of conceptual and practical challenges.

9.14 Inclusion of most types of university hospitals and clinics in the Higher education sector is justified both because they are tertiary education institutions in their own right (teaching hospitals) and/or because they are research units "associated with" higher education institutions (e.g. advanced medical care in clinics at universities).

9.15 R\&D in university hospitals and clinics can be funded from many sources: from the university's general "block grant", i.e. public general university funds (GUF); the hospital's own internal funds (e.g. revenue from patients for treatment or general government block grants related to health provision); direct government funds for R\&D (e.g. from a medical research council); as well as private funds, such as philanthropists or business support for clinical trials.

9.16 Where all or nearly all activities in a hospital/medical institution have a teaching/training component, the entire institution should be included as part of the Higher education sector. If, on the other hand, only a few of the clinics/ departments within a hospital/medical institution have a higher education component, only these teaching/training clinics/departments should be classified in the Higher education sector. All other non-teaching/training clinics/ departments should, as a general rule, be included in the appropriate sector (Business enterprise, Government or Private non-profit sector). The relevant 
SNA institutional classification should also be captured whenever possible for bridging purposes. Care must be taken to avoid the double counting of R\&D activities between the sectors concerned.

9.17 It can be challenging to distinguish between universities and university hospitals and clinics. However, it is recommended to split the two groups of institutions when reporting R\&D expenditure and personnel. In line with the recommendation made in Chapter 3 to tag institutions by economic activity (United Nations, 2008), the tagging of health institutions within the higher education system can assist with the production of statistics for university hospitals and clinics.

\section{Borderline research institutions}

9.18 There are institutions that are at the borderlines between the Higher education and other institutional sectors. These present specific classification challenges, which may be addressed in different ways. The decision tree in Chapter 3 provides guidance. Generally, the provision of higher education is considered a decisive criterion for their classification in the Higher education sector. Funding, administration, control and location, as well as the integration in university budgets are also used to support classification. For those countries holding complete institutional registers, the use of the ISIC class (United Nations, 2008 ) is also of practical use.

9.19 Some examples of borderline institutions commonly encountered are given below.

\section{Institutions involved in higher education funding}

9.20 A number of institutions having an important role in funding, such as higher education councils or similar institutions, may be included in the sector when they also provide formal tertiary education services or are controlled or administered by and serve universities.

\section{"Mission or subject-oriented" research institutes}

9.21 Universities are major centres of research, and when countries have wished to expand their R\&D in specific fields, universities have frequently been considered appropriate locations for new institutes and units. Many such units are principally government-financed and may be mission-oriented research units; others are financed by Private non-profit sector funds and by the Business enterprise sector. Examples can be units established to meet national priorities regarding environment, life sciences, medicine or science and engineering; often they have a time-limited horizon. When they are set up to be managed by universities or university departments, these can be considered as belonging to the Higher education sector. Whatever the choice, it is important to report on the institutions that are included in the sector. 


\section{Institutions linked to universities}

9.22 A higher education institution may have "links" with other research institutes that are not directly concerned with teaching or that have other non-R\&D functions, such as consulting, for example through the mobility of personnel between the higher education institution and the research institute concerned, or the sharing of facilities between institutes classified in different sectors. These institutes may be classified according to other criteria, such as control and finance or services rendered.

9.23 In some countries, borderline institutions may have a private legal status and carry out contract research for other sectors, or they may be government-financed research institutions. It is difficult to decide, in such cases, whether the links between the units are strong enough to justify including the "external" unit in the Higher education sector.

\section{Institutes with researchers affiliated to universities}

9.24 There are institutes that are generally funded and controlled by governments, such as academies of sciences or national research councils, and that also employ researchers affiliated with universities. Generally, these are classified in the Government sector, especially when they are independent of the university and not integrated in university budgets. It may happen however that they are considered part of the Higher education sector when these institutes and their researchers are involved in teaching activities.

\section{Other cases}

9.25 "Research, science or technology parks" located at or near universities and colleges host a range of entities that are goods and services producers and R\&D performers. For such groupings, it is recommended not to use physical location and use of common resources as criteria for classifying these units in the Higher education sector. Units that are controlled and hosted in these parks and mainly financed by government should be included in the Government sector; those controlled and mainly financed by the Private non-profit sector should be included in the Private non-profit sector; while enterprises and other units serving enterprises should be classified in the Business enterprise sector.

9.26 Units controlled or administered by tertiary teaching units (including teaching hospitals), as defined above, that are not primarily market producers should be included in the Higher education sector. If they are primarily market producers, they should be included in the Business enterprise sector despite any links with higher education units (Chapter 3, Fig. 3.1).

9.27 In line with Chapter 3 guidance, institutions that are non-market producers and are affiliated with or have all their R\&D activity controlled by higher education institutions should be considered as belonging to the Higher education sector, while spin-offs involving university personnel that are market producers are to be classified with the Business enterprise sector. 


\section{Public and private institutions and international comparisons}

9.28 As recommended in Chapter 3, classifying institutions as public or private provides information of policy relevance and facilitates the comparison with SNA sectors and subsectors. This is therefore recommended in the case of Higher education institutions.

9.29 In addition to the breakdown between public and private institutions, it is useful, for the purpose of international comparisons, to know the breakdown between universities proper, university hospitals and other tertiary education institutions.

9.30 All statistical units in this sector should therefore be classified by the most appropriate profile, as presented in Table 9.1. Where there is difficulty in making the assignment, this should be reported along with its implications.

Table 9.1. Profiles of higher education institutions

Type of institution
$\begin{array}{r}\text { A. Tertiary level education institutions } \\ \text { A.1. Education institutions } \\ \text { - Universities } \\ \text { - Other tertiary level education institutions } \\ \text { A.2. University research institutes or centres } \\ \text { A.3. University hospitals and clinics } \\ \text { B. Research organisations the R\&D of which is controlled by } \\ \text { higher education institutions }\end{array}$

9.31 Reporting R\&D expenditure and personnel in the Higher education sector, by type of institution according to the categories in the above table, is therefore encouraged.

\subsection{Identification of R\&D in the Higher education sector}

9.32 For survey purposes, R\&D must be distinguished from a wide range of related activities with a scientific and technological basis. These other activities can be very closely linked to R\&D both through flows of information and funding and in terms of operations, institutions and personnel, but as far as possible, they should be excluded when measuring R\&D. In the Higher education sector there are some challenging sector-specific activities with regard to the concept of R\&D. These are in particular related to education and training and specialised health care (university hospitals).

\section{Borderline between R\&D and education and training}

9.33 In institutions of higher education, research and teaching are always very closely linked, as most academic staff does both, and many buildings, as well as much equipment, serve both purposes. 
9.34 As a main rule, in line with guidance in Chapter 2, all education and training of personnel in the natural sciences, engineering, medicine, agriculture, the social sciences and the humanities and the arts in universities and special institutions of higher education should be excluded from R\&D. However, research by students at the doctoral level carried out at universities should be counted, whenever possible, as a part of R\&D personnel and expenditures. In some cases, students following a research master's programme (ISCED 7, Section 9.4.) and their associated R\&D expenditures may also be counted in some appropriate form (personnel cost/other current costs; internal or external R\&D personnel) under the guidance provided in Chapters 4 and 5 .

9.35 Because the results of research feed into teaching, and because information and experience gained in teaching can often result in an input to research, it is difficult to define where the education and training activities of higher education staff and their students end and where R\&D activities begin, and vice versa. Fulfilment of the five criteria in the R\&D definition distinguishes R\&D from routine teaching and other work-related activities. Deciding whether or not to consider as R\&D those scientific activities that are the by-products of educational or training activities presents a problem.

9.36 The following cases are considered:

- doctoral students at ISCED level 8, master's students at ISCED level 7 and their activities

- supervision of students by university staff

- personal education of academic staff (own reading).

\section{Doctoral students at ISCED level 8 and master's students at ISCED level 7}

9.37 It is particularly difficult to establish the boundaries between education and training activities and R\&D for doctoral students. Both the activities of doctoral students and of their teachers and supervisors need to be taken into consideration.

9.38 Parts of the curricula for studies at ISCED level 8 are highly structured, involving, for instance, study schemes, set courses and compulsory laboratory work. Here, the teacher transmits knowledge and provides training in research methods. Students who fall under this heading typically attend compulsory courses, study the literature on the subject and learn research methodology. These activities do not fulfil the criterion of novelty specified in the definition of R\&D.

9.39 In addition, in order to obtain a final qualification at ISCED level 8 (ISCED level 7 for research masters students), students are also expected to prove their competence by undertaking relatively independent study, usually containing the elements of novelty required for R\&D projects and presenting their results. These activities should, therefore, be classified as $R \& D$, as should any supervision by the teacher. In addition to $R \& D$ performed within the framework 
of postgraduate education courses, it is possible for both teachers and students to be engaged in other R\&D projects.

9.40 Furthermore, students at this level are often attached to, or directly employed by, the establishment in which they study and have contracts or similar engagements that oblige them to teach at lower levels or to perform other activities, such as specialised medical care, while allowing them to continue their studies and to do research.

9.41 Some borderlines between R\&D and education at ISCED level 8 and level 7 are illustrated in Table 9.2. The more practical problems of applying these concepts are dealt with in Chapter 5 (R\&D Personnel), in particular, Section 5.2 on the treatment of doctoral and master's level students.

\section{Table 9.2. Classification of activities of teachers and doctoral students at ISCED level 8 and master's students at ISCED level 7}

\begin{tabular}{|c|c|c|c|}
\hline & Education and Training at levels 7-8 & $R \& D$ & Other activities \\
\hline \multirow{2}{*}{$\begin{array}{l}\text { Non-student } \\
\text { teaching } \\
\text { personnel }\end{array}$} & Teaching students at levels 7-8 & $\begin{array}{l}\text { Supervision of R\&D projects required } \\
\text { for student qualification at levels } 7-8\end{array}$ & $\begin{array}{l}\text { Teaching at levels } \\
\text { lower than level } 7\end{array}$ \\
\hline & $\begin{array}{l}\text { Training students at levels } 7-8 \text { in R\&D } \\
\text { methodology, laboratory work, etc. }\end{array}$ & $\begin{array}{l}\text { Supervision of other R\&D projects and } \\
\text { performance of own } R \& D \text { projects }\end{array}$ & Other activities \\
\hline \multirow[t]{2}{*}{$\begin{array}{l}\text { Doctoral } \\
\text { students and } \\
\text { masters students } \\
\text { at ISCED level } 7\end{array}$} & $\begin{array}{l}\text { Following course work for formal } \\
\text { qualification }\end{array}$ & $\begin{array}{l}\text { Performing and writing up } \\
\text { independent studies (R\&D projects) } \\
\text { required for attaining formal } \\
\text { qualification }\end{array}$ & $\begin{array}{l}\text { Teaching at lower } \\
\text { levels }\end{array}$ \\
\hline & & Any other R\&D activities & Other activities \\
\hline
\end{tabular}

Supervision of students by university staff

9.42 Closely allied to the problem of identifying the R\&D element of doctoral students' work is that of extracting the R\&D component of the time spent by academic supervisors on supervising these students and their research projects. The same applies to the shorter term master's students at ISCED level 7.

9.43 Such supervision activities should be included in R\&D only if they are equivalent to the direction and management of a specific R\&D project containing a sufficient element of novelty and having as its objective the production of new knowledge. In such cases, both the academic staff member's supervision and the student's work should be included as R\&D. If the supervision deals merely with the teaching of R\&D methods and the reading and correction of theses and dissertations or the work of undergraduate students, it should be excluded from R\&D.

\section{Personal education of academic staff (own reading)}

9.44 This activity covers time spent on activities such as continued professional learning ("own reading"), research-related training (for example on equipment), and attendance at conferences and seminars. 
9.45 In distinguishing R\&D from related activities, the question of whether "own reading" should be included as part of R\&D activities is often raised. It is certainly part of the general professional development of research staff and, in the long term, the knowledge and experience gained are incorporated into the researcher's thinking about, if not into the actual implementation of, R\&D. Own reading, in fact, constitutes a cumulative process, and when the information gained from this activity is translated into research activity, it should be measured as R\&D.

9.46 However, only personal education (including "own reading") carried out specifically for a research project should be considered as an R\&D activity. In general, attendance at conferences cannot be considered $R \& D$, but the presenting of the researcher's own research may be counted as R\&D.

\section{Specialised health care}

9.47 In university hospitals where the training of medical students is an important activity in addition to the primary activity of health care, the activities of teaching, R\&D and medical care (both advanced and routine) are frequently closely linked. "Specialised health care" is an activity that is normally to be excluded from R\&D. However, there may be an element of $R \& D$ in specialised health care, when carried out, for example, in university hospitals. It is difficult for university doctors and their assistants to evaluate the part of their overall activities that is exclusively R\&D. If, however, time and money spent on routine medical care are included in the $R \& D$ statistics, $R \& D$ resources in the medical sciences will be overestimated. Usually, such specialised health care is not considered $R \& D$, and all medical care not directly linked to a specific $R \& D$ project should be excluded from the R\&D statistics.

9.48 However, a particular project may be R\&D if undertaken for one reason, but not if carried out for another, as shown in the following example: In the field of medicine, a routine autopsy on the causes of death is the practice of medical care and is not R\&D; a special investigation of a particular mortality to establish the side effects of certain cancer treatments is R\&D. Similarly, routine tests such as blood and bacteriological tests carried out for doctors are not $R \& D$, whereas a special programme of blood tests in connection with the introduction of a new drug is R\&D.

9.49 University hospitals may also be involved in clinical trials. Further guidelines on identifying R\&D in clinical trials are given in Chapter 2.

\section{$R \& D$ in the social sciences, humanities and the arts}

9.50 A large share of R\&D in the social sciences and humanities is being conducted in the Higher education sector. Guidelines on the boundaries and exclusions related to R\&D in the social sciences and the humanities are given in Chapter 2.

9.51 Much of the research on, for and in the arts is also conducted in the Higher education sector. Chapter 2 provides guidelines on what should be considered as R\&D in the field of the arts. 


\subsection{Measuring expenditures and personnel in the higher education sector}

9.52 This section is aimed at giving guidelines on the main variables and breakdowns to be collected, with special emphasis on the specificities encountered in the Higher education sector. Section 9.5 will complete the overall picture by describing the methods commonly used (e.g. direct surveys, administrative data and R\&D coefficients) for collecting and estimating these variables and breakdowns.

9.53 The main aggregate statistic used to describe R\&D performance within the Higher education sector is HERD, Higher education Expenditure on R\&D. HERD represents the component of Gross domestic expenditure on R\&D (GERD) (see Chapter 4) incurred by units belonging to the Higher education sector. It is the measure of intramural R\&D expenditures in the Higher education sector during a specific reference period.

\section{Higher education expenditure on intramural R\&D (HERD) by type of costs}

9.54 In line with Chapter 4 of this manual, HERD should be broken down by current and capital expenditures, which in turn consist of labour and other current costs, on the one hand, and on the other hand, expenditures on fixed assets used for R\&D, such as machinery/equipment and land/buildings.

9.55 If no data are directly available for each of these R\&D components for a certain unit, an estimate must be made on the basis of the information on total expenditure.

9.56 Labour costs (i.e. salaries and all associated costs) represent a significant portion of the total R\&D expenditure in the Higher education sector. In principle, $R \& D$ labour costs should be linked to the time spent on $R \& D$, the full-time equivalent (FTE) measure. Information on total labour costs is usually available or calculated on the basis of one or several of the following data sources:

- point on the salary scale for each researcher, technician or other member of the staff, and the scale itself

- labour costs by category of personnel

- labour costs by category of personnel, field of R\&D, and possibly department.

9.57 Labour costs include the actual or imputed contributions to pension funds and other social security payments for R\&D personnel. They need not be visible in the statistical unit's bookkeeping accounts. Even when no transactions are involved, an attempt should be made to estimate these costs. To avoid double counting, labour costs do not include pension payments to former R\&D employees.

9.58 Information on other current costs is usually available by department or equivalent and often concerns resources at the disposal of these units for the purchase of items such as documents, minor equipment, subscriptions to scientific journals, travelling costs, etc. The reporting units are usually asked to 
estimate the R\&D share of these costs on the basis of "intended use". The part that is not available by department (overhead costs such as water, electricity, rent, maintenance, general administration, etc.) has to be distributed among the institutional units concerned. If "intended use" is not feasible as a criterion, the same distribution coefficients as for labour costs may be used. (See Section 9.5 below for a discussion on "R\&D coefficients".) The shares of $R \& D$ may also be determined on the basis of conventions or the value judgement of the reporting units.

9.59 The imputation of real estate and facility management costs of higher education institutions differs across countries. This is due to the fact that educational or research buildings and lands can be either owned, used free of charge or rented by the institutions. Likewise, energy costs can be imputed following different methods. As a result, international comparisons of current and capital expenditures will be affected by the country-specific treatment of these costs. For reasons of international comparability and to obtain realistic costs, it may be desirable to include a notional amount that represents an actual payment. This might serve as an estimated "market value", to be included in other current costs.

9.60 Information on total capital expenditure on machinery and equipment is usually available at the level of the institution. In many surveys, the shares accounted for by $R \& D$ activities are estimated by the institutes according to the "intended use" of the equipment. R\&D coefficients (see Section 9.5) are of less use for estimating the shares of R\&D in machinery and equipment than for estimating various types of current expenditure. The share of R\&D in investments in machinery and equipment may also be based on conventions or on value judgements, as for certain types of other current costs discussed above.

9.61 Information on total capital expenditure on land and buildings is usually available only at the level of the institute or the university. R\&D coefficients are seldom used to estimate the shares of R\&D in these investments. Here again, the R\&D data are often estimated on the basis of the intended use of the facilities.

\section{HERD by source of funds}

\section{General}

9.62 As noted in Chapter 4, funds for R\&D performed in the Higher education sector come from different sources.

- The main source in many countries is traditionally a proportion of the publicly funded block grant known as public general university funds (GUF) that public higher education institutions receive to support all activities. The different activities of the staff in higher education institutions - teaching, $R \& D$, administration, health care, etc. - are in general not specifically identified for separate payment from these grants, which, in a general way, cover the payment of a wide range of work-related activities. 
- In addition, $R \& D$ funds are received in the form of grants or contracts from other sources such as ministries, departments and other public institutions, including research councils, as well as from private non-profit institutions, industry and the Rest of the world.

- Some universities may also have internal funds (such as income from endowments, income from student fees, etc.) that they ultimately dedicate to pay for R\&D performance.

9.63 In this manual, GUF is defined as the R\&D funding share coming from the general grant that universities receive from the central government (federal) ministry of education or the corresponding regional (state) or local (municipal) authorities in support of their overall research/teaching activities.

9.64 Time-use studies and other methods used to identify the R\&D share of universities' total activities usually concern only GUF. External funds are often for R\&D but may be used for other purposes as well. For each project funded by external sources, therefore, the survey respondent often has to evaluate whether or not it funds research, if the information is not available from central administration registers.

9.65 Some external funds (especially funds from foundations and research councils) are not always fully included in the central accounting records of the universities. Some research contracts may in fact go directly to a university institute or to individual professors. To obtain as broad coverage as possible, in some cases data on institutes' external funds have to be taken from funders' accounts (although this manual recommends the principle of performer-based reporting as the preferred approach) or should, at least, be double-checked against those accounts. Funder-based data usually give only expenditures, and the problem of acquiring the corresponding R\&D personnel data is therefore a difficult one.

9.66 Accounting procedures will therefore largely determine how well the sources of R\&D funds can be separately defined and identified. Producers of R\&D statistics are dependent on the detail available in such accounts. A further complication in identifying the sources of $R \& D$ funds is the fact that outside organisations do not always pay the "full market cost", however defined, of the R\&D carried out for them in institutions of higher education.

9.67 All countries commonly encounter problems in the accurate coverage of R\&D funding sources, but the main area of lack of international comparability concerns distinguishing between GUF and other sources of public R\&D income.

\section{Separation of general university funds from other funding sources}

9.68 Some of the problems of identifying what part of these grants is attributable to R\&D have already been discussed above. This identification process is an intrinsic part of the methodology employed in each country. Inconsistencies arise because different countries classify the R\&D component of GUF differently. 
9.69 A separate category, GUF, has been defined for the Higher education sector so as to take account of the special funding mechanisms for $R \& D$, as compared to other sectors. Most countries are of the view that, as R\&D forms an intrinsic part of the activities of higher education institutions, any funds allocated to a tertiary education institution have an inbuilt and automatic R\&D component. On this interpretation, such funds are classified as GUF.

9.70 In adding up national totals, these data are usually included in subtotals of government funding on the grounds that government is the original source and foresees that a significant portion of the general funds provided will be devoted to R\&D.

9.71 However, it is the prerogative of universities to decide how much money to dedicate to R\&D out of their general resource pool, which contains both public general university funds and own sources. On this basis, some countries argue that the sums concerned could be first credited to higher education as a source of funds. Some countries use this convention when reporting data at the national level.

9.72 By convention, the R\&D content of these public general university funds should be credited to government as a source of funds, and this is the approach recommended for international comparisons. In any case, GUF should be separately reported, as indicated in Chapter 4. Social security, pension provisions and other relevant costs (real or imputed) should be taken into account and be credited to GUF. For clarity, government-financed GERD is divided into two sub-categories: direct government funds and GUF. For the calculation of GUF, see Section 9.5 below.

\section{Other internal funds}

9.73 Income from endowments, shareholdings and property, plus surplus from the sale of non-R\&D services such as fees and tuition from individual students, subscriptions to journals and the sale of serum or agricultural produce, should be considered as internal funds. Although national accounting practices will dictate how easily all this can be identified, such R\&D income ("retained receipts") can, notably in the case of private universities, be a considerable source of income and should be classified as internal funds.

\section{External funds}

9.74 In addition to GUF, units in the Government, Business enterprise and Private non-profit sectors provide money for higher education R\&D in the form of earmarked research contracts or research grants. Such funding may also be received from the Rest of the world. These sources of research funds are more readily identified and do not, in general, pose major problems for the producers of statistics, who can readily classify them as direct sources of funds. 


\section{Recommendations}

9.75 To enhance the international comparability of higher education R\&D statistics, it is preferable to disaggregate the sources of funds as much as possible; this largely depends on the availability of information from central accounting records in institutions of higher education.

9.76 A problem for international comparability occurs when data for GUF are not separately reported and are classified by different countries either with the Higher education sector's internal funds or with the Government sector.

9.77 Whenever such type of funding exists, GUF should be reported separately within the category of funds from the Government sector, and not as funds from Higher education.

\section{Expenditures on extramural R\&D}

9.78 The increasing complexity of how R\&D activities are organised is challenging for the Higher education sector as well as for the other sectors. In large cooperative $R \& D$-projects, universities may receive a grant from government or other organisations and pass through part of the grant to other partners in the project. Therefore it is also desirable to collect the amount of $R \& D$ funds passed through (via subcontracts and sub-grants) to extramural R\&D performers in the Higher education sector so as to avoid double counting (see Chapter 4, Section 4.3). As noted in Chapter 4, flows of funds provided to other departments in the same Higher education institutions should not be considered extramural $R \& D$, as the different departments are part of the same statistical unit.

\section{R\&D linkages with the Rest of the world}

9.79 The Higher education sector participates in R\&D globalisation activities as defined in Chapter 11 on R\&D Globalisation. This section provides details on four international aspects of the Higher education sector: R\&D funding to/from the Rest of the world; foreign-owned branch campuses; branch campuses abroad; and foreign students. R\&D statistics related to these activities may be useful to understand: the globalisation of scientific research in certain fields of R\&D; for analysis or policy making in or about emerging markets (especially regarding foreign-owned campuses); and for educational policy or research purposes.

9.80 Higher education institutions should provide information on all types of R\&D funding to or from organisations located outside the compiling country.

9.81 The scope covers all of a reporting country's domestic educational activity (i.e. within its own territory), regardless of the ownership or sponsorship of the institutions concerned and the education delivery mechanism. Higher education institutions have established branches or campuses outside their borders. To the extent that foreign-owned branch campuses inside the compiling country and branch campuses abroad (i.e. in the Rest of the world) 
owned by domestic education institutions perform R\&D, HERD surveys may include supplementary information about these campuses (see Section 9.3 of this chapter for information on the boundaries between R\&D and education/ teaching).

9.82 For the purpose of this manual, a foreign-owned branch campus (FBC) is defined as a tertiary education institution that is inside the compiling country; that is owned, at least in part, by an entity located (or resident) outside the compiling country (termed a "foreign education provider"); that operates in the name of the foreign education provider; that engages in at least some face-to-face teaching; and that provides access to an entire academic programme leading to a credential awarded by the foreign education provider. As part of the identifying information (for possible R\&D tabulations, as feasible), HERD surveys may inquire whether or not a respondent that falls within the scope of the survey is a foreignowned branch campus.

9.83 For the purpose of this manual, a branch campus abroad (BCA) is defined as a tertiary education institution that is owned, at least in part, by a local higher education institution (i.e. resident inside the compiling country) but is located in the Rest of the world (resident outside the compiling country); that operates in the name of the local higher education institution; that engages in at least some face-to-face teaching; and that provides access to an entire academic programme leading to a credential awarded by the local higher education institution. HERD surveys may ask information about a) the country location of foreign branch campuses (called host countries); b) whether or not these foreign branch campuses performed R\&D in their host countries (binary or yes/no question); and c) the amount of R\&D performance in the currency of the compiling country. If an institution has several such campuses in a given country, R\&D information may be consolidated at the host country level for reporting purposes, if such consolidation facilitates responses. The details by field of R\&D may be at higher levels of aggregation for these campuses.

9.84 R\&D performed by FBCs is part of the domestic HERD performance totals of the compiling country. However, R\&D performed in BCAs cannot be included in the domestic HERD performance totals of the compiling country, and instead could be separately identified and tabulated as R\&D performed in the Rest of the world by tertiary education institutions outside the compiling country's education institutions.

9.85 Apart from the desirable separate identification of these campuses using the definitions above, R\&D expenditures and human resources statistics for these units should be collected following the guidance elsewhere in this chapter.

9.86 Since BCAs are outside the compiling country, collecting or editing information may be particularly difficult. Getting information on the latter is thus considered a secondary priority, but encouraged. For example, information on outward global activities by the Higher education sector, such as R\&D-performing foreign campuses, may be of special interest for respondent institutions. 
9.87 Another aspect of the globalisation of tertiary education institutions is the extent of foreign student enrolment. Foreign students (sometimes called international students) are defined as non-citizens of the country in which they study (see Section 4.6.1 of Volume 1, UOE Manual). Research carried out at universities by all students at both the doctoral level and the ISCED 7 master's level should be counted in R\&D expenditures, regardless of the students' citizenship status or sponsors' nationality.

\section{Categories of R\&D personnel}

9.88 The R\&D personnel categories to be reported for the Higher education sector do not differ from those of the other R\&D performing sectors and are defined in Chapter 5 of this manual. In particular, the reference classification for reporting R\&D personnel by educational level is the International Standard Classification of Education (ISCED 2011).

9.89 The notion of "R\&D personnel" and even sometimes of "researcher" may however not be commonly used and understood in tertiary level institutions and may need to be approximated with academic titles. It may also be useful to report data on researchers by academic grade for shedding light on seniority in research / academic careers.

9.90 Where possible, it is proposed to use the following classification of seniority grades for reporting data on researchers in the Higher education sector (EC, 2013) where academic titles apply. The categories include typical positions for each group:

- Category A: The single highest grade/post at which research is normally conducted.

* Example: "Full professor".

- Category B: Researchers working in positions not as senior as top position (A) but more senior than newly qualified doctoral graduates (ISCED level 8).

* Examples: "Associate professor" or "senior researcher".

- Category C: The first grade/post into which a newly qualified doctoral graduate would normally be recruited.

* Examples: "Assistant professor" or "post-doctoral fellow".

- Category D: Either doctoral students at the ISCED level 8 who are engaged as researchers, or researchers working in posts that do not normally require a doctorate degree.

* Examples: "PhD students" or "junior researchers" (without a PhD).

9.91 Master's students may be counted as researchers (see Chapter 5) if they are following a research master's programme at ISCED-2011 level 7, i.e. in "programmes leading to the award of research qualifications that are designed explicitly to train participants in conducting original research but are below the level of a doctoral degree". The definition states that "these programmes will 
often meet many of the same criteria as an ISCED level 8 programme, although they tend to be of shorter duration (cumulative duration of five to six years from the start of tertiary education), typically lack the level of independence required of students seeking an advanced research qualification, and prepare for entry into ISCED level 8 programmes". Those master's students counted as researchers will normally fall under category D above.

9.92 However, it is important that only master's students receiving payment, directly or indirectly, for their R\&D activity are included in R\&D personnel (see Chapter 5, Section 5.2).

\subsection{Methods for compiling R\&D expenditure and personnel in the Higher education sector}

9.93 This section gives general information on the methods used for calculating and estimating R\&D expenditures and R\&D personnel in the Higher education sector. Different approaches are illustrated in the framework for compiling HERD statistics (Figure 9.1). There is a special focus on methods to estimate $R \& D$, in particular GUF, which may constitute an essential funding component in the Higher education sector. Normally these funds include an important part of the R\&D funding, but the R\&D share of GUF is often unknown to the universities themselves.

\section{General methodology}

9.94 The Higher education sector is a very heterogeneous sector, and countries' higher education systems and institutions are organised in many different ways. This is challenging for the compilation of R\&D statistics, and there are large variations between countries with regard to statistical methodology. In practice this means that different methods may be used for compiling good quality R\&D statistics.

9.95 The framework for compiling HERD statistics provides options for statisticians to consider when choosing the method most suitable for their institution for producing R\&D statistics for the Higher education sector, in accordance with the available resources in the statistical organisation (use of a survey or not), the quality and availability of administrative data for the higher education institutions and the availability of data at the preferred type of statistical unit, institute or department. Time-use surveys are important elements of the Higher education sector R\&D statistics in many countries, and may be combined with an institutional R\&D survey (full or partial) or with administrative data alone, or with a combination of survey and administrative data.

9.96 The different methods for obtaining data are illustrated in the framework in Figure 9.1. An important prerequisite for using administrative data is their quality in terms of data availability, reliability and timeliness (see below). 
Methodologies range from institutional surveys (full or partial) to administrative data and the different combinations of these data sources, often combined with R\&D coefficients from time-use surveys.

\section{Figure 9.1 Framework for compiling statistics for the Higher education sector}

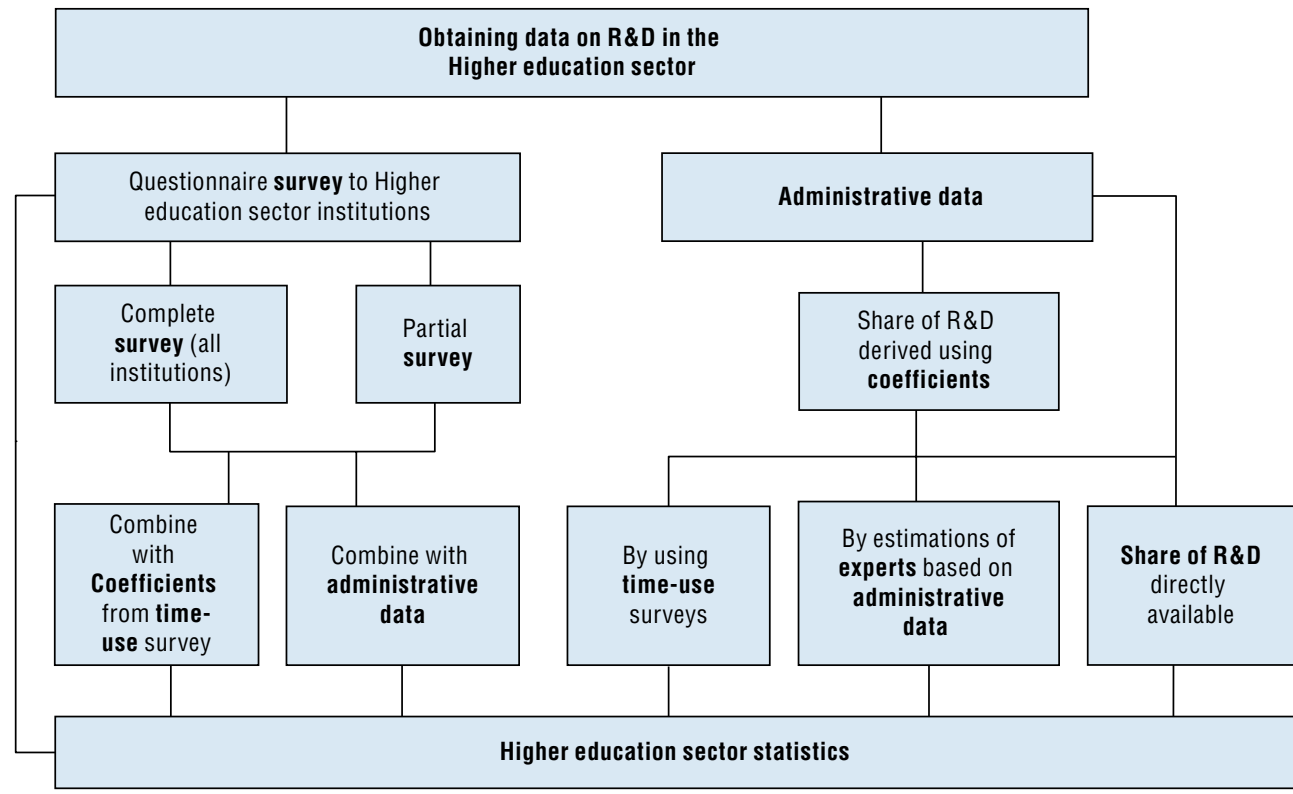

\section{The statistical unit}

9.97 While institutional units are more or less clearly defined in the Higher education sector (see Section 9.3 and Chapter 3, Section 3.2.), it is more challenging to define statistical units, i.e. the entities for which information is sought. There is no unique rule that can be given here, as educational systems differ widely across countries.

9.98 Whenever possible, statistical units in the Higher education sector are classified into six major fields of research and development (FORD), as follows:

- natural sciences

- engineering and technology

- medical and health sciences

- agricultural and veterinary sciences

- social sciences

- humanities and arts. 
9.99 The major R\&D fields, together with sub-fields, are presented in Chapter 2.

9.100 While the major fields are clearly defined, the level of disaggregation within each component is left to each country's discretion. In the Higher education sector, where detailed administrative information is available, a detailed FORD classification can be used as an institutional classification.

9.101 Since higher education institutions are often involved in more than one of the six major fields of $R \& D$, this type of information may be available at more disaggregated levels of reporting units such as departments, research institutes, "centres", faculties, hospitals or colleges.

9.102 In some countries ministries for education can provide the information on higher education institutions. This can also be done by regional authorities. Surveys often ask the institutions themselves. In many cases it will be necessary to break down to the level of university departments. It is crucial to find the right reporting units for extracting the R\&D data from overall figures.

\section{Survey data}

9.103 Regular, systematic and harmonised special surveys are the preferred mechanism for collecting data on R\&D. However, when satisfactory administrative records are available and the statistical surveys are considered too burdensome, it may be appropriate to use other approaches. This applies in particular to the Higher education sector.

9.104 Information on R\&D in the Higher education sector may be obtained from two different main sources: surveys (the survey-based method) and administrative data. Often a combination of the two methods is used. There are many advantages to the survey-based method, for example for identifying the content of $R \& D$ and for allocating the $R \& D$ activity to the field of $R \& D$, the type of $R \& D$, etc.

9.105 To enhance and ensure international comparability, this section gives some methodological guidelines for conducting R\&D surveys. As R\&D survey methodologies and procedures are well established in many countries, the guidelines are quite general so as to be as widely applicable as possible. These methodologies supplement those discussed in Chapter 6.

\section{Scope of R\&D surveys}

9.106 In theory, R\&D surveys should identify and measure the total financial and personnel resources devoted to all R\&D activities within all R\&D performing units in the Higher education sector. R\&D surveys are mainly addressed to R\&D performing units, which may also fund R\&D performed in other units. 


\section{Identifying the target population and survey respondents}

9.107 R\&D data compilers may not always be able to undertake an exhaustive and reliable survey of all possible R\&D performers within this sector. Generally, there are many constraints on the extent of surveys. For example, the number of respondents may have to be restricted to keep costs down; an R\&D survey may have to be taken in conjunction with another survey with acceptable, but not ideal, respondents; and surveys of some groups may require the participation of other agencies with different data needs and hence different questions for respondents. It is therefore not possible to make detailed recommendations on survey methods that would be equally relevant to all countries, as the size and structure of national R\&D capacities vary widely.

9.108 The surveys and estimation procedures in the Higher education sector should cover all universities and corresponding institutions, especially those awarding degrees at the doctorate level. Other institutions in the sector known or assumed to perform R\&D should also be included (see Section 9.2). If possible, it is often preferable to rely on subunits, such as departments or institutes of the university, as reporting units.

\section{University hospitals and clinics}

9.109 Hospitals/healthcare institutions are a special category. Some countries may find it satisfactory to include hospitals and healthcare institutions in regular R\&D surveys, using the standard questionnaire for the sector concerned. Additional guidance on the boundaries between research and healthcare activities and on the treatment of clinical trials may be supplied within the questionnaires, consistent with the definitions and criteria provided in Chapter 2.

9.110 Where university hospitals are administratively and financially integrated very closely with teaching establishments, they may be treated together for the purposes of R\&D surveys/data compilation. If they are separate units with separate accounts and administrations, they may receive a specific questionnaire if more appropriate, or a standard R\&D questionnaire. For university hospitals (or parts thereof) that are not integrated with teaching establishments, a specific survey may be useful. If this is not possible, the standard R\&D questionnaire may be used.

9.111 Whatever survey approach is used, care should be taken to ensure the coherent treatment of $R \& D$ in units/projects under joint management by two or more entities, by persons receiving two salaries from different entities, and by persons working at hospitals but employed by other institutions.

9.112 The survey questionnaire must include a minimum number of basic questions on the R\&D activity in order to produce harmonised and comparable statistics for transmission to international organisations. Owing to 
the response burden, the questionnaire should be logically structured and as simple and short as possible, with clear definitions and instructions. Generally, the longer the questionnaire is, the lower the response rates. Most countries use electronic questionnaires, available online (see Chapter 6 for more details on survey methodology).

\section{Administrative data}

9.113 Administrative data are a common source for R\&D statistics in the Higher education sector (see the previous framework discussion and Figure 9.1). Examples of administrative data are accounting data from higher education institutions, registers of employed personnel, data from R\&D funding organisations, etc.

9.114 Although the majority of countries base their $R \& D$ statistics on a survey - full or partial - some countries base their R\&D statistics for the Higher education sector solely on administrative data. Many countries also use a mix of the two methods. In general, the use of registers and administrative data for statistical purposes will be less resource-intensive than a survey and will ease the burden on respondents. Increasing the availability and quality of administrative data with a view to extending their use and streamlining the production of R\&D statistics should therefore be considered an important goal.

9.115 However, theclearadvantages of surveys should notbeunderestimated, particularly in terms of identifying the $R \& D$ content in different activities, the distribution of $R \& D$ by fields of $R \& D$ or the type of $R \& D$, etc. A combination of survey and administrative data is commonly used as the approach for collecting R\&D statistics in the Higher education sector, in combination with time-use surveys or other procedures for the estimation of the R\&D component.

9.116 There are a number of ways in which administrative data may be used in the compilation of R\&D statistics in the Higher education sector. If the concepts, definitions and coverage used by administrative data sources are sufficiently close to those contained in this manual, then the administrative data sources can be used as a primary source of information. More often, administrative data may be used in combination with R\&D coefficients derived from time-use surveys (see Section 9.5.5.) in order to estimate the R\&D content. Administrative data may also be used for the imputation of missing or inconsistent survey data and for control after data editing (see Chapter 6).

9.117 In many cases, data are derived from multiple administrative sources. The role of central administrations varies from country to country and from level to level - nationally at the ministry of education, regionally, locally or within the higher education institute itself. Regardless of the administrative level, such sources usually have a vast quantity of information as a result of activities carried out at that level. The administrative information held by central administrations in their files varies according to the function of 
the particular administration. Ministries of education may have very broad overall information, while the finance officers of higher education institutions may have income and expenditure information associated with individual researchers and other staff. However, it may not be completely certain whether this information conforms to the definitions in this manual, which limits the possibilities for using it directly (although it could still be useful for deriving estimation coefficients - see below).

9.118 To identify the R\&D in individual disciplines/fields of $R \& D$ may require information at the level of the researcher or institute/department at large institutions that carry out research in many disciplines. Information at the level of the institution is sufficient if its R\&D is confined to a single field of R\&D.

\section{Estimation procedures}

9.119 Surveys and the use of administrative data (if they are compiled using the same definitions and guidance recommended in this manual) are the preferred means for collecting information on the Higher education sector. However, they are not always suited to the resources, the legal framework or the needs of individual countries. If for some reason it is not possible to conduct a full survey or to use administrative data to calculate expenditure and personnel for the Higher education sector, estimation procedures are an alternative choice, in combination with survey data and/or administrative data.

\section{$R \& D$ coefficients}

\section{Purpose of coefficients}

9.120 R\&D coefficients are a tool for calculating / estimating the shares of personnel and expenditure totals attributable to R\&D performance. They are used especially for distributing total resources among research, teaching and other activities (including administration). They can be used to estimate total HERD or parts of it, such as GUF, or for estimating only R\&D personnel totals.

\section{Concepts}

9.121 Coefficients may be derived in different ways as an alternative to more costly large-scale surveys, or as a supplement to surveys. The methods depend on the specific situations in countries; therefore there is no single best way for developing coefficients. Alternative methods are described below:

- use of administrative (register) data directly: relevant in a few countries, but not practical in most countries

- estimations of experts based on administrative data

- calculations on the basis of time-use surveys (see below for guidelines).

9.122 Reporting metadata on calculation methods used for coefficients should be considered for the purpose of quality control. 


\section{Methods}

- R\&D coefficients are used directly at an appropriate level (individual, institute, department, university) to estimate the share of R\&D in total labour costs; if necessary, adjustments should be made to include the costs of various associated social security or retirement schemes.

- R\&D coefficients can be expected to vary according to the teaching or research discipline, the occupational category of the personnel directly involved in $R \& D$, and the type of institution in which the activity is performed. At the greatest level of detail, coefficients can be applied to the financial and personnel data of individual institutions.

\section{Coefficients are typically applied in stages}

- R\&D coefficients applied to different categories of staff, if possible by discipline and institution, yield full-time equivalent (FTE) personnel estimates.

- These personnel estimates, converted to coefficients themselves, may be applied to financial data to provide R\&D expenditure estimates.

9.123 In the absence of direct survey data, R\&D coefficients offer the only way to estimate the share of R\&D in labour costs. They play a significant role in estimating shares of R\&D in other current costs, but are of minor importance in calculating shares of machinery and equipment or of land and buildings used for R\&D.

9.124 When reporting data for international comparisons, R\&D compilers are encouraged to indicate to which sets of expenditure and personnel data coefficients are applied to calculate $R \& D$ data, together with the actual coefficients used. These metadata could be collected every couple of years in parallel to the regular data collection and made available online.

\section{Time-use surveys}

9.125 If the necessary coefficients cannot be derived from other surveys or administrative data, time-use surveys are the recommended method to derive the necessary information for estimating the R\&D component of FTEs and expenditures. To reduce the variation stemming from the various possible methods of conducting time-use surveys, guidelines for designing more uniform time-use surveys are proposed below on an optional basis.

\section{Census or sample}

9.126 Due to very different national situations (e.g. legal framework, size of country), a census cannot be recommended for all countries. When using a sample, it should be representative of the categories of employees considered in a typical academic year, and stratified by FORD.

\section{Reporting unit}

9.127 The preferred reporting unit for a time-use survey should be the individual researcher, not the university administration. 


\section{Categories of employees considered}

9.128 The time-use surveys should consider at a minimum employed researchers (i.e. internal personnel; see Chapter 5) engaged in R\&D activity in the higher education institutions, and possibly other R\&D personnel, e.g. other researchers under contract (external R\&D personnel), technicians and other supporting staff.

\section{Type of activities}

9.129 The proportion of time dedicated to R\&D performance should be the focus of the survey. There should be a uniform and understandable list of activities asked for in the time-use survey, with three key activities:

1. $R \& D$

- $\mathrm{R} \& \mathrm{D}$

- Administration of R\&D

2. Teaching

- Teaching

- Administration of teaching

3. Other work: All other work

9.130 Due to their specific needs, most countries collect more detailed information on a more comprehensive list of activities. It is recommended to allow for these activities to be categorised, or rolled-up, under one of the three key activities listed above.

\section{Period of time}

9.131 The reference period used in time-use questionnaires may differ widely across countries (i.e. whole year versus 1-2 typical weeks versus a survey on a rolling basis). If a comprehensive survey is not possible, it should be ensured that the estimates account for the various types of activities during the year and that they cover the whole year. All typical periods within one year should be covered. One possible approach is to consider a typical week during the lecture period and another typical week in the lecture-free period. Due to different systems in the organisation of higher education, the reference period should be individually chosen by each country.

\section{Frequency of time-use surveys}

9.132 It is desirable for the surveys to be regular; however, the feasibility of this will depend on the country's size, its legal framework and the resources it has available to carry out a survey. It is nevertheless proposed that the interval between two surveys should, if possible, not exceed five years.

\section{Procedure in the intermediate years}

9.133 If the period between surveys is longer than two years, a concept for now-casting the potential changes in coefficients, based for example on changes in the structure of university staff, could be envisaged. 


\section{Contractual working hours}

9.134 As an introductory question to the time-use survey, it is recommended to collect information on the number of contractual working hours during the reference week (or weeks) and then report the relative distribution of the different activities as percentages. (See Chapter 5 for the definition of working hours.)

\section{Calculation of GUF}

9.135 Data on general university funds are often available from university records. An increasing number of countries collect GUF data through R\&D surveys. In some instances, it is the total amount of the "block grant" that is collected through the survey, and the R\&D share (i.e. GUF used for R\&D) is subsequently estimated using coefficients derived from time-use surveys.

9.136 In countries where there is no HERD survey, data are compiled using a combination of different sources and applying coefficients that in most cases are derived from time-use surveys. In some cases, GUF is calculated by subtracting other sources of funding from HERD.

9.137 The main way time-use surveys and other methods to identify the R\&D share of universities' total activities are used is for the calculation of GUF, which account for the majority of higher education R\&D expenditure in many countries (see Section 9.4). The institutions' block grants from government cover all the basic activities: teaching, $R \& D$, supervision, administration, rent and other overhead expenditures. As the R\&D share of this funding is most often unknown to the universities themselves, the use of R\&D coefficients is the most convenient method to calculate the R\&D content of the activity. Different methods are used for this purpose.

\subsection{Links with education statistics}

9.138 Data on R\&D expenditure in the Higher education sector are also collected in the framework of the UNESCO/OECD/Eurostat (UOE) data collection on education statistics. A joint UOE methodological manual (UOE, 2014), developed by education statisticians, outlines the concepts, definitions and classifications to be used for data reporting at the international level. The guidelines given in the UOE manual for reporting R\&D data are based on the Frascati Manual. Education and R\&D statisticians have collaborated for decades with a view to moving towards common guidelines in both manuals. This will continue. While it seems unavoidable that some data discrepancies remain due to the different nature of both data collections, experience has shown that coordination between data providers on both sides has a positive effect on the reduction of these discrepancies. 


\section{References}

EC, IMF, OECD, UN and the World Bank (2009), System of National Accounts, United Nations, New York. https://unstats.un.org/unsd/nationalaccount/docs/sna2008.pdf.

EC (2013), She Figures 2012: Statistics and Indicators - Gender in Research and Innovation, European Commission, Brussels. http://ec.europa.eu/research/science-society/document_ library/pdf_06/she-figures-2012_en.pdf.

UNESCO-UIS (2012), International Standard Classification of Education (ISCED) 2011, UIS, Montreal. www.uis.unesco.org/Education/Documents/isced-2011-en.pdf.

United Nations (2008), International Standard Industrial Classification of All Economic Activities (ISIC), Rev. 4, United Nations, New York. https://unstats.un.org/unsd/cr/registry/isic-4.asp and http://unstats.un.org/unsd/publication/seriesM/seriesm_4rev4e.pdf.

UOE (2014), UOE data collection on formal education: Manual on concepts, definitions and classifications, Version of5September2014,UIS,Montreal,OECDPublishing,Paris,Eurostat, Luxembourg. https://circabc.europa.eu/sd/a/38b873d6-4694-459f-ae56-d5025f3d7cf3/ UOE2014manual.pdf. 



\section{Chapter 10}

\section{Private non-profit R\&D}

Institutional units within the Private non-profit sector historically have played a significant role in R\&D activities in many countries. Non-profit institutions (NPIs) can be identified and classified in all sectors; they can be either market producers or non-market producers; and they include both performers and funders of R\&D. This chapter outlines which NPIs should be considered for measurement in the PNP sector, and it gives guidelines on the measurement of their R\&D activities, taking into account their particular characteristics as well as emerging trends with respect to new forms of $R \& D$ funding. The sector is residual, in that NPIs not classified to business enterprise, government or higher education are classified to the Private non-profit sector. The sector also includes, for completeness, households and private individuals engaged or not in market activities. The chapter provides guidance on the institutional classifications by main economic activity, the measurement of $R \& D$ expenditures and personnel in the sector and there is a discussion of survey design and data collection in the sector. There is also a brief discussion, new to the manual, of the role of philanthropists and of crowdfunding and the implications for measurement. 


\subsection{Introduction}

10.1 Institutional units within the Private non-profit (PNP) sector historically have played a significant role in R\&D activities in many countries. Their importance has been recognised in previous versions of this manual. As is described in Chapter 3, non-profit institutions (NPIs) can be identified and classified in all sectors; they can be either market producers or non-market producers; and they include both performers and funders of R\&D. This chapter outlines which NPIs should be considered for measurement in the PNP sector, and it gives guidelines on the measurement of their $R \& D$ activities, taking into account their particular characteristics as well as emerging trends with respect to new forms of R\&D funding.

\subsection{Scope of the Private non-profit (PNP) sector Definition of the PNP sector for R\&D measurement purposes}

10.2 This sector comprises:

- all non-profit institutions serving households (NPISH), as defined in the SNA 2008, except those classified as part of the Higher education sector

- for completeness of presentation, households and private individuals engaged or not engaged in market activities.

10.3 Examples of units within this sector may include independent professional and learned societies, and charitable organisations that are not controlled by units in the Government or the Business enterprise sectors. Such NPIs provide individual or collective services to households either without charge or at prices that are not economically significant. In practice, institutions in this sector may be called foundations, associations, consortia, joint ventures, charities, non-governmental organisations (NGOs), etc. Institutions, individuals and households should however be attributed to the relevant sectors according to the guidelines in this manual, regardless of their generic names.

\section{Residual nature of the sector}

10.4 The PNP sector as defined above is residual by nature. In accordance with the sector definitions given elsewhere in this manual (see Chapter 6 and Chapter 9), private non-profit units offering higher education services or 
controlled by institutions of higher education should be classified as part of the Higher education sector. In the same way, private non-profit units owned or controlled by government should be classified as part of the Government sector if they are not market producers. Non-profit units controlled by or primarily serving business enterprises should be classified as part of the Business enterprise sector. Finally, the market activities of unincorporated enterprises owned by households, i.e. self-employed consultants undertaking $R \& D$ projects for another unit at an economically significant price, should be included in the Business enterprise sector. This framework is illustrated in Table 10.1 .

10.5 It should be noted that in some cases the definition of control is challenging, because the power to decide on the allocation and amount of funding can be a major means of control. Therefore, it can be appropriate to use the major source of funding as an additional criterion to decide whether the institution is government controlled or not. (See Chapter 8, Box 8.1, for further guidance on the concept of control.)

Table 10.1. Treatment of different types of non-profit institutions (NPIs)

\begin{tabular}{|c|c|c|c|c|}
\hline $\begin{array}{l}\text { SNA criterion - main } \\
\text { economic purpose }\end{array}$ & $\begin{array}{l}\text { Additional SNA criterion } \\
\text { - control / sector served }\end{array}$ & SNA treatment & Specific instances & FM treatment \\
\hline \multirow[t]{3}{*}{ Market production } & $\begin{array}{l}\text { Independent NPIs, but } \\
\text { primarily engaged in } \\
\text { market production }\end{array}$ & Corporations & (Some) private universities & $\begin{array}{l}\text { Higher education } \\
\text { sector }\end{array}$ \\
\hline & & & (Some) private hospitals & $\begin{array}{l}\text { Business } \\
\text { enterprise } \\
\text { sector, except } \\
\text { for university } \\
\text { hospitals }\end{array}$ \\
\hline & $\begin{array}{l}\text { NPIs serving enterprises } \\
\text { (domestic or non- } \\
\text { resident) }\end{array}$ & Corporations & $\begin{array}{l}\text { Industry-funded research } \\
\text { institutes }\end{array}$ & $\begin{array}{l}\text { Business } \\
\text { enterprise sector }\end{array}$ \\
\hline \multirow[t]{5}{*}{$\begin{array}{l}\text { Non-market } \\
\text { production }\end{array}$} & $\begin{array}{l}\text { Controlled by } \\
\text { government }\end{array}$ & $\begin{array}{l}\text { General } \\
\text { government }\end{array}$ & $\begin{array}{l}\text { R\&D foundations controlled } \\
\text { by government }\end{array}$ & $\begin{array}{l}\text { Government } \\
\text { sector }\end{array}$ \\
\hline & & $\begin{array}{l}\text { General } \\
\text { government }\end{array}$ & $\begin{array}{l}\text { Universities controlled by } \\
\text { government }\end{array}$ & $\begin{array}{l}\text { Higher education } \\
\text { sector }\end{array}$ \\
\hline & $\begin{array}{l}\text { Not controlled by } \\
\text { government }\end{array}$ & $\begin{array}{l}\text { Non-profit } \\
\text { institutions } \\
\text { serving } \\
\text { households } \\
\text { (NPISH) }\end{array}$ & $\begin{array}{l}\text { Independent research } \\
\text { charities, learned societies, } \\
\text { etc. (may receive very } \\
\text { significant government } \\
\text { grants but government } \\
\text { cannot dictate major } \\
\text { decisions) }\end{array}$ & $\begin{array}{l}\text { Private non-profit } \\
\text { sector }\end{array}$ \\
\hline & & & $\begin{array}{l}\text { Also resident NPIs controlled } \\
\text { by non-resident PNPs }\end{array}$ & \\
\hline & & & $\begin{array}{l}\text { Independent universities with } \\
\text { charitable status }\end{array}$ & $\begin{array}{l}\text { Higher education } \\
\text { sector }\end{array}$ \\
\hline
\end{tabular}


10.6 Private non-profit institutions that do not have a separate and distinguishable identity from their owners, such as most types of unincorporated associations, consortia, or membership organisations consisting of business enterprises, research institutions, universities, associations, etc., are not institutional units as defined in this manual. For this reason, the R\&D activities of these unincorporated non-profit institutions should be attributed to each member according to their contribution. In other words, any unit in any sector that contributes to the R\&D activities in unincorporated non-profit institutions should not have its activity counted as extramural $R \& D$, but as their own intramural R\&D.

10.7 The R\&D activities of incorporated private non-profit institutes that consist of members belonging to two or more sectors should be attributed in accordance with the guidelines given in Chapter 3 .

10.8 The treatment of individuals deserves particular attention. First, individuals who are employees and are employed by institutions, including self-employed persons, are not included in this sector. Second, the activities of individuals who pursue their personal interests as researchers or inventors on their own time are currently beyond the scope of the institutional approach to R\&D statistics presented in this manual. Finally, the appropriate treatment of individuals who may be part of a group of persons employed in an institutional unit, but not as employees, and who directly receive funds for their R\&D activities from third parties is discussed in Chapter 5.

\section{Borderline with other sectors}

10.9 Where there are strong linkages between private non-profit units and government, it may not always be clear into which sector a particular non-profit unit should be classified. Many foundations or charities that are originally or primarily funded by individual donors also receive important shares of their funding from the government. These units are usually classified with the PNP sector. The demarcation with the Government sector should be based on the degree of control that the private non-profit units can exert over how they operate (see Chapter 3 and Chapter 8).

10.10 It should be noted that some incorporated joint ventures or consortia between business enterprises and higher education institutions may be classified in the PNP sector. Depending on their legal status, some publicprivate partnerships may be also included in the PNP sector.

10.11 There exist many private non-profit institutions whose membership and/or activities span across international boundaries. The residence criteria that apply for business enterprises equally apply for these institutions. To be considered resident, the institutions must have a centre of economic interest in the relevant economy. Further guidance is available in Chapter 11; see, for example, Section 11.6 on Special case of international organisations. 


\subsection{Recommended PNP institutional classifications}

\section{Classification by main economic activity}

10.12 It is recommended that statistical units performing R\&D within this sector are classified by main economic activity according to ISIC or an equivalent national classification (United Nations, 2008).

10.13 For some countries it may be useful to classify institutions in the PNP sector by the intended purpose of their activity. Originally developed as an elaboration of ISIC for NPIs, one such classification reference is the Classification of the Purposes of Non-profit Institutions Serving Households (COPNI) (United Nations, 2000). However, the use of COPNI as classification criteria for the PNP sector is not specifically recommended by this manual. Further information on these classifications can be found online in annex guidance to this manual

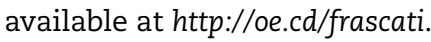

\section{Possible classification tags}

10.14 In line with Chapter 3 and with a view to meeting the requirements of the SNA, it is suggested that statistical units performing R\&D in this sector be tagged as either non-profit institutions serving households (NPISHs) or households, the latter of which are not surveyed according to the recommendations in this manual.

10.15 Further tagging of NPIs belonging to the other sectors using statistical registers would allow presentation of total performance as per general non-profit accounts. This would require adding-up:

- R\&D by PNPs (e.g. R\&D by NPIs in the PNP sector as defined in this manual)

- R\&D by NPIs serving corporations and by other NPIs engaged in market production counted as part of the Business enterprise sector (see Chapter 7)

- R\&D by NPIs controlled by government (see Chapter 8 )

- R\&D by NPIs in the Higher education sector (see Chapter 9).

\subsection{Identification of R\&D in the PNP sector}

10.16 R\&D in the PNP sector may be conducted in a broad range of fields. Depending on the nature of the PNP unit, in terms both of its membership and of its purpose, it may be more or less difficult to distinguish R\&D from the other activities conducted in the unit. For example, a non-negligible number of units in this sector, such as research foundations, are comprised of members that are themselves research organisations. Identifying the R\&D activities of these units will be more straightforward than in cases where the PNP institution has a broader goal than just research or science.

10.17 Many foundations or charitable organisations are active in the domains of health, environment, education or social and development aid, 
among others. In a number of instances, these organisations conduct some form of research or study preliminary to their actions. The challenge will be to determine whether the type of research carried out meets the criteria set in Chapter 2 and can therefore be considered R\&D. In other cases, the action itself may involve an R\&D element that will need to be clearly identified.

10.18 R\&D efforts may underpin the decision-making process within NPIs. While this may be outsourced to external organisations, some units in the PNP sector may have dedicated teams that are actively involved in carrying out analyses such as ex-ante and ex-post appraisals or evaluations, on ad hoc or even formalised bases. These activities may in some cases meet the criteria for an R\&D activity. However, this is not always the case, and not all evidencebuilding efforts associated with programmatic evaluations and assessments can be accurately described as R\&D. It is relevant to consider in some detail what is the expertise of those involved in the activity, how knowledge is codified within the organisation and how quality standards are assured in terms of the research questions and the methodology applied. There is a significant risk that some types of socio-economic consultancy (internal or external) are inaccurately represented as $R \& D$.

10.19 In the domain of health, it may be necessary to distinguish R\&D from health care actions (see Chapter 9 on the Higher education sector, Section 9.3) and from clinical trial phases that are considered to be R\&D (see Chapter 2, Section 2.7 on definitions).

10.20 Chapter 2 gives useful complementary information on the boundaries between R\&D and education or other science and technology activities and also provides examples of R\&D activities in the social sciences and humanities, and in service activities.

\subsection{Measuring R\&D expenditures and personnel in the PNP sector}

\section{Private non-profit intramural R\&D expenditure (PNPERD)}

10.21 The main aggregate statistic used to describe R\&D performance within the PNP sector is PNPERD, Private Non-Profit Expenditure on R\&D. PNPERD represents the component of Gross domestic expenditure on R\&D (GERD) (see Chapter 4) incurred by units belonging to the Private non-profit sector. It is the measure of intramural R\&D expenditures within the Private non-profit sector during a specific reference period. As a general rule, intramural R\&D expenditures in the PNP sector should be measured according to the recommendations explained in Chapter 4, Section 4.2.

10.22 Some NPIs play a dual funding-performance role in R\&D activities. In those cases, the institution's intramural expenditures for conducting R\&D activities should be differentiated from the expenditures for conducting R\&D activities by other extramural units, i.e. PNP funds for extramural R\&D. However, such NPI funds 
that are received by other NPIs for the performance of intramural R\&D should be reported by the receiving NPIs as external funds from these other NPIs.

10.23 Some institutions in this sector may also play an intermediary role in the funding flows between the ultimate funders and the actual performers. As explained in Chapter 4, external funds that the unit receives and subsequently passes through to others should not be included as R\&D funding by the unit.

\section{Functional distributions for PNPERD}

\section{Distribution of PNPERD, by sources of funds}

10.24 Priority should be given to reporting R\&D expenditure by the source of funds according to the guidance given in Chapter 4 of this manual.

10.25 Some philanthropists and research charities based on donations from the public also provide funds to support R\&D activities. These are usually dedicated to specific areas or topics and mainly conducted in universities and research institutes as well as in hospitals. More recently, crowd-funding, which calls on individuals and households to support R\&D as well as other activities, has emerged as a new private funding source.

10.26 Data on R\&D funding from institutions, individuals and households in the PNP sector should be collected from performers in all sectors, including the PNP sector, and measured despite the sector's residual nature and often its small size.

10.27 Individuals and households can be included as funding sources for $R \& D$ (while they are excluded from the scope of measurement as R\&D performers). With a view to having the sources of funds correspond to the breakdowns of the SNA, it may be possible to make a distinction between institutes, which are part of NPISH on the one hand, and individuals and households on the other hand.

10.28 As explained in Chapter 4, only the funds that are provided explicitly for the purpose of conducting R\&D in the statistical units should be counted as external funds. The funds that are provided for a general purpose to the R\&D performing institutes or which are grants, subsidies, gifts or philanthropy that a statistical unit can use at its discretion should be counted as internal funds only if used for R\&D.

\section{Other recommended PNPERD distributions}

10.29 It is recommended to distribute the intramural R\&D expenditure of the Private non-profit sector by type of R\&D costs, as is detailed in Chapter 4 (Table 4.1). These recommendations include a breakdown between labour costs of R\&D personnel and other current costs (current expenditures) and capital expenditures (by asset type).

10.30 It is recommended to distribute PNPERD by type of R\&D (see Chapter 2) and by field of research and development (FORD). At least the top level of FORD should be collected. 
10.31 Consideration may be given to distributing PNPERD data by socioeconomic objective, based on the Nomenclature for the Analysis and Comparison of Scientific Programmes and Budgets (NABS) (Eurostat, 2008) categories and other national adaptations with a direct correspondence to it.

10.32 It may be noted that, although not actively recommended by this manual, COPNI classification categories (see section 10.3) may also be used to distribute PNPRD.

\section{PNP funds for extramural R\&D}

10.33 As explained in Chapter 4, Section 4.3, it is suggested that the funds for extramural R\&D should be measured in surveys of R\&D performers in the PNP sector, distinguishing between affiliated and non-affiliated recipients. In collecting these data, it is likely that PNP reporting units include not only funds provided for R\&D performance in other PNP institutions but also individuals and households, who are by definition part of the PNP sector, but who would not be captured within R\&D institutional surveys. Data collectors should attempt to provide the relevant guidance to ensure that only funding for extramural activities that meet the R\&D definition criteria are included.

\section{R\&D personnel in the PNP sector}

10.34 The number of R\&D personnel, and in particular researchers, should be measured according to the recommendations provided in Chapter 5 . These totals should include both internal and external R\&D personnel in the same way as is recommended for the other sectors. In particular, R\&D performance in the Private non-profit sector may be carried out by external self-employed professionals who are acting as intramural R\&D consultants but belong to the Business enterprise sector.

10.35 It should be noted that independent workers may be found among internal R\&D personnel (also termed "R\&D persons employed") in the Private non-profit sector, which by convention includes households (see Chapter 5).

10.36 For measurement purposes, it is recognised that the Private nonprofit sector often may include individuals contributing to intramural R\&D on a largely unpaid basis. As detailed in Chapter 5, volunteers are unpaid workers providing a statistical unit with a defined R\&D contribution. Volunteers can be included in the external $R \& D$ personnel totals only under very strict criteria:

- they contribute to the R\&D intramural activities of private non-profit institutions

- their research skills are comparable to those of employees

- their R\&D activities are systematically planned according to the needs both of the volunteers themselves and of the institution. 
10.37 Their contribution should be appreciable and an essential condition for enabling the institution to undertake an intramural R\&D activity or project. Separate reporting of the number of volunteers contributing to R\&D in the PNP sector would be of particular interest (see Chapter 5 for further guidance).

10.38 Doctoral students and R\&D grant holders may occasionally contribute to $R \& D$ activities in this sector.

10.39 The costs of these specific categories of personnel will in many cases fall under "other current costs" or will not be reported at all.

\subsection{Survey design and data collection in the PNP sector}

\section{Survey design}

\section{Identification of statistical units: Practice and challenges}

10.40 As mentioned in Chapter 6, frame information may be less comprehensive for this sector. The list of possible statistical and reporting units should be maintained and updated through the usual sources, such as business registers, directories of $R \& D$ institutions, associations, as well as the results from previous surveys. Countries may include questions on R\&D performance in more general surveys to NPIs in order to identify the possible R\&D performing statistical units.

10.41 Only the institutions that meet the conditions of R\&D performance explained in this manual should be identified as possible statistical units for the R\&D measurement. In accordance with the institutional approach used for R\&D measurement, individuals and households should be excluded from the frame population.

10.42 More so than is the case for other types of institutions, control over NPIs may change over time, for example with government control becoming more prominent. When this happens, care should be taken to ensure that the necessary reallocation of institutions to the other sectors is made according to the definitions in Chapter 3.

\section{Implications of individuals as R\&D funders}

10.43 Some forms of $R \& D$ funding by individuals present radically new approaches or make renewed use of channels that were very significant several decades ago. For example, wealthy philanthropists can play a major role in funding research institutes or promoting research initiatives related to several possible domains. They may do this as individuals or through charitable or mixed institutions such as foundations or trusts. This manual recommends that the measurement of such flows is primarily adopted from the perspective of the performers. Funding flows should be captured on a gross basis, regardless of the potential extent of tax benefits to donors. 
10.44 Crowdfunding, which is being enabled by new online technologies, has also become an emerging and potentially promising source of R\&D funds. Crowdfunding is generally described as the practice of funding a project or venture by raising monetary contributions from a large number of people, typically via the internet. Individuals respond to crowdfunding for R\&D purposes. One example is the field of health and medical research, where they may have a direct interest as patients.

10.45 R\&D-related crowdfunding constitutes a new funding model with which individuals do not necessarily receive equity but other types of benefits such as naming rights for new discoveries, acknowledgements in journal articles, visits to field sites, tax deductions, etc.

10.46 Those phenomena may cause an under-estimation of domestic R\&D totals if the recipients of such funds are not captured through surveys or related methods. Data collected from funders and crowdfunding platforms may help assist in improving registers of R\&D performers.

\section{Funder-based approach (complementary)}

10.47 As previously noted, institutions in the PNP sector may both perform and fund R\&D. Therefore it is recommended that such performers also be asked about their funds for extramural R\&D. However, in some countries there are many institutions in the PNP sector (e.g. foundations and charitable organisations) that do not have intramural R\&D but do provide often large amounts of funds for extramural R\&D (usually in the form of grants or gifts - i.e. transfer funds) generally to higher education or other non-profit institutions (either within or outside the PNP sector). While this manual recommends collecting data from $R \& D$ performers rather than R\&D funders, the funder-based approach is also acknowledged as a complementary practice. Such an approach should be chosen only as a second-best option, and the sample primarily should be focused on institutions in this sector, as opposed to individuals and households.

\section{References}

Eurostat (2008), Nomenclature for the Analysis and comparison of Scientific programmes and Budget (NASB). www.oecd.org/science/inno/43299905.pdf.

United Nations (2008), International Standard Industrial Classification of All Economic Activities (ISIC), Rev. 4, United Nations, New York. https://unstats.un.org/unsd/cr/registry/isic-4.asp and http://unstats.un.org/unsd/publication/seriesM/seriesm_4rev4e.pdf.

United Nations (2000), Classification of the Purposes of Non-Profit Institutions Serving Households (COPNI), United Nations, New York. http://unstats.un.org/UNSD/cr/registry/ regcst. $a s p ? \mathrm{Cl}=6 \& \mathrm{Lg}=1$. 


\section{Chapter 11}

\section{Measurement of R\&D globalisation}

This chapter goes beyond previous discussions of 'Abroad', now referred to as the Rest of the world, which treated the sector primarily as a source of funds for domestic research and experimental development (R\&D) performance (as in GERD), or as a destination for national sources of funds (as in GNERD). The chapter provides a definition of the Rest of the world consistent with the approach of the System of National Accounts (SNA). Globalisation in this chapter refers to the international integration of financing, factor supply, $R \& D$, production and the trade in goods and services. In the Business enterprise sector, globalisation is associated with international trade and foreign direct investment (FDI), whereas public or private non-profit institutions (including government and higher education units) also engage in international activities such as R\&D funding and collaboration. R\&D globalisation is a subset of global activities involving the funding, performance, transfer and use of $R \& D$. The chapter deals with indicators of R\&D globalisation for both business and non-business sectors. 


\subsection{Introduction}

11.1 This manual explicitly recognises the concept of R\&D globalisation. Prior editions of this manual have acknowledged the global aspects of R\&D primarily as a source of funds for domestic R\&D performance (as in the compilation of GERD) or as a destination for national sources of funds (as in the compilation of GNERD). Such sources previously were characterised as funds from/to "Abroad". Consistent with the SNA, the preferred terminology of the current manual is the "Rest of the world". The Rest of the world is defined on the basis of the non-residence status of the relevant units. The Rest of the world consists of all non-resident institutional units that enter into transactions with resident units, or have other economic links with resident units. The identification and measurement of non-domestic sources of and destinations for $R \& D$ funds continues to be an important dimension of $R \& D$ and is covered comprehensively in Chapters 3 and 4, and in the individual sector chapters. However, this current manual moves beyond flows of R\&D funds and covers a more extensive list of measurement issues related to global R\&D.

11.2 In broad terms, globalisation refers to the international integration of financing, factor supply, R\&D, production, and the trade of goods and services. Globalisation in the Business enterprise sector is associated with international trade and foreign direct investment (FDI), whereas public or private non-profit institutions (including government and higher education units) also engage in international activities such as R\&D funding and collaboration. In this manual the terms globalisation and internationalisation are used interchangeably. It may be noted that financial flows of FDI and operations that arise from FDI are separate indicators of globalisation (IMF, 2009, Chapter 6). Financial flows indicators of FDI are currently outside the scope of this manual. For details see the Handbook on Economic Globalisation Indicators (OECD, 2005, Chapter 2) and the OECD Benchmark Definition of FDI (OECD, 2009a).

11.3 R\&D globalisation is a subset of global activities involving the funding, performance, transfer and use of R\&D. This chapter first focuses on three measures of business R\&D globalisation, followed by a summary of measurement issues related to non-business sectors. 


\subsection{Measuring business R\&D globalisation}

\section{Statistical framework for measuring business R\&D globalisation}

11.4 Three types of statistical measures of business R\&D globalisation are covered here:

- cross border R\&D funding flows (see Section 11.3)

- current costs and personnel for R\&D performed by members of multinational enterprises (MNEs) within the compiling countries and abroad (see Section 11.4)

- international trade in R\&D services (see Section 11.5).

11.5 The first of these measures is an extension of traditional R\&D statistics recommended to be collected from resident business enterprises to/from the Rest of the world (see Chapter 7, Section 7.6). Both MNEs and non-MNEs may have such activities, although this chapter focuses on MNE reporting. The second of these three measures concerns only the activities of MNEs. The third measure is constructed in the context of service trade statistics, based on the receipts from and payments to non-resident units in exchange for R\&D.

11.6 Most measurement recommended in this manual is limited to characterising $R \& D$ performed within the reference year. In particular, cross-border $R \& D$ funding flows are associated with the intramural R\&D of a specific reference period, as are measures of R\&D performance and funding by MNE status. On the other hand, international trade in R\&D services may capture transactions involving the rights to outcomes of $R \& D$ that may have been performed in prior years. As such, trade in R\&D services is a function of cumulative R\&D expenditures (in the compiling country for exports and in trading partner countries for imports), and not only of current year R\&D funding or production. The latter are measured at market prices, consistent with balance of payments (BOP) concepts and collected in existing services trade surveys, as discussed later in this chapter. Therefore, each measure serves different purposes and represents partial but complementary aspects of complex, underlying arrangements for the performance of R\&D across different global locations. For example, trade in R\&D services is used for adjusting domestic stocks of R\&D for capitalisation purposes as discussed later in this chapter, consistent with guidance in the OECD Handbook on Deriving Capital Measures of Intellectual Property Products (OECD, 2009b). Another major difference between measures of cross-border R\&D funding flows and trade in R\&D services is that cross-border R\&D funding includes transfers (such as grants, see below) and all sectors; the statistics for trade in R\&D services typically do not include R\&D grants, and coverage outside the business sector, for practical reasons, may be limited.

11.7 Statistical measures of $R \& D$ globalisation related to the $R \& D$ performed or funded by MNEs are anchored not only in national statistics on $R \& D$, but also in wider international economic statistics on global production, direct investment, employment, financing and trade. The multiplicity of reference sources presents particular challenges to statistical offices, survey respondents, 
and users of R\&D and related globalisation statistics. Yet given the complexity of R\&D globalisation issues, no single reference is likely to cover all relevant measurement concepts. Therefore the guidance in this chapter attempts to use terminology consistent both with the terms defined elsewhere in this manual and with the globalisation statistical manuals specifically referenced in this chapter (which in the future may be described in detail online in annex guidance to this manual available at http://oe.cd/frascati).

11.8 More generally, globalisation has two major implications for the activity and measurement of $R \& D$. First, $R \& D$ is part of complex global value chains that involve dispersed suppliers and fragmented production processes of goods and services. Secondly, R\&D itself increasingly involves organisations and personnel that are dispersed across different countries, reflecting broadening globalisation trends. Given this complexity, no single survey instrument is likely to cover all R\&D globalisation data needs. This situation presents opportunities for collaboration on data development and/or collection among $R \& D$ surveys and other surveys, in particular, BERD, FDI/MNE, and the services trade surveys discussed herein. Thus, this chapter summarises $R \& D$ material in various globalisation manuals and relates this information to Frascati concepts.

11.9 Although the focus of this chapter is on the cross-border ownership linkages and financial aspects of global R\&D activities (e.g. expenditure, costs, funding flows), the globalisation of R\&D is also reflected in the mobility of R\&D personnel. Therefore identifying and tracking the flow of R\&D personnel within and across MNEs is encouraged. However, the ability of R\&D surveys to gather information on the human resource aspects of R\&D globalisation is somewhat limited compared with surveys of individual researchers or highly educated individuals.

\section{Relevant multinational enterprise (MNE) definitions}

11.10 The accurate collection and compilation of business R\&D globalisation statistics depend on a consistent understanding and application of the necessary business globalisation terminology. Relying on extensive material available from existing globalisation and related manuals, the key terms are defined below. See Box 11.1 for a summary of the various reference manuals that provide the statistical framework and underlying terminology adopted in this chapter.

11.11 Foreign direct investment (FDI) reflects the objective of obtaining a lasting interest by an enterprise resident in one economy (an MNE parent or "direct investor") in an enterprise resident in another economy (a foreign affiliate or "direct investment enterprise"). For official statistical purposes, a lasting interest is deemed to exist by direct or indirect ownership of $10 \%$ or more of the ordinary shares or voting power of an incorporated enterprise, or the equivalent of an unincorporated enterprise. The $10 \%$ voting power criterion also establishes the existence of a direct investment relationship between an affiliate and its MNE parent.

11.12 For the purposes of this manual, the statistical focus is on R\&D and related activities involving majority-owned or controlled affiliates. Majority ownership or control refers to ownership of more than $50 \%$ of the ordinary 
shares or voting power of an incorporated enterprise or the equivalent of an unincorporated enterprise. Examples of majority-owned or controlled affiliates include subsidiaries (incorporated enterprises) and branches (unincorporated enterprises).

11.13 From the perspective of the compiling country, where the MNE parent is resident, this MNE parent company is measured as the fully consolidated enterprise group within that compiling country and includes all units resident in the compiling country that are majority-owned by the company (for a summary of consolidation issues involving MNE members, see OECD, 2005). This excludes its majority-owned affiliates located abroad.

11.14 From the perspective of the compiling country, an MNE refers to a parent company resident in the country and its majority-owned affiliates located abroad, labelled controlled affiliates abroad (CAA). Thus, CAAs are the majorityowned affiliates located abroad of a parent company resident in the compiling country. MNEs are also referred to as global enterprise groups (EC, 2010).

\section{Box 11.1. International statistical manuals related to business R\&D globalisation}

System of National Accounts 2008 (EC et al., 2009). The SNA provides guidance on measures of economic activity within an economic territory in an integrated system of accounts. It also covers economic flows between a compiling country and the rest of the world. The definition of R\&D in the 2008 SNA (SNA 10.103) is essentially consistent with the 2002 Frascati Manual. However, the SNA also contemplates the measurement of economic transactions on R\&D-based assets (also called R\&D), which may have been developed in previous years.

Handbook on Economic Globalisation Indicators (OECD, 2005). This manual describes a framework for statistics and derived indicators on globalisation including FDI financial flows and stocks (positions) and the activity or operations of MNEs.

Benchmark Definition of FDI (OECD, 2009a). This manual describes in detail definitions of FDI and related flows consistent with the 6th edition of the Balance of Payments Manual. It also covers statistics on the activity of MNEs (AMNE).

Balance of Payments and International Investment Position Manual, $6^{\text {th }}$ edition (IMF, 2009). This manual covers accounting and statistical standards to compile the balance of payments (BOP) between residents and non-residents during a specific time period, along with the external balance sheet, accumulated assets and liabilities (or positions) as a result of transactions with the external sector. It is the source for definitions on international transactions, economic territory, residence and related definitions. Its definition of " $R \& D$ " in $R \& D$ services includes but goes beyond the Frascati definition by including testing services that give rise to patents. 


\section{Box 11.1. International statistical manuals related to business R\&D globalisation (cont.)}

Manual on Statistics of International Trade in Services 2010 (UN et al., 2011). This manual covers statistics on the international supply of services, including R\&D services in two major forms: conventional cross-border trade in services and the supply of services locally by foreign-owned subsidiaries. The latter are covered in foreign affiliates (FATS) statistics (EC, 2012). Its definition of "R\&D" in R\&D services includes but goes beyond the Frascati definition by including testing services that give rise to patents, but its subcategories are formulated in order to facilitate comparisons. A compiler's guide for this manual was published in 2014 (UN et al., 2014).

Handbook on Deriving Capital Measures of Intellectual Property Products (OECD, 2009b). This handbook describes statistical procedures to develop market-value measures of R\&D and other Intellectual Property Products (IPP) for purposes of incorporating these assets in national and international economic accounts, in line with SNA 2008. It describes domestic R\&D output for measurement purposes in terms of three components consistent with both the SNA and Frascati: own-account R\&D (R\&D conducted and used internally regardless of funding source); custom $R \& D$ ( $R \& D$ conducted for, and funded by, another unit); and speculative or non-customised R\&D. It describes different forms of recording the international transfer, use or sale of R\&D and other IPPs: sale or licensing agreements, transfers (provision without a fee, especially within MNEs), and changes in value of company assets or investment income that include (but not separately identified) R\&D flows. This manual also describes how the domestic supply of R\&D is obtained by adjusting domestic R\&D output by adding imports and subtracting exports using statistics on trade in R\&D services. This allows for the calculation of capital formation (investment) in R\&D and the estimation of capital stocks of R\&D.

The Impact of Globalisation on National Accounts (UNECE/Eurostat/OECD, 2011). This guide focuses on the difficulties brought by MNE activity for the measurement of national production and trade, including R\&D. The guide further develops statistical guidance for internationally comparable measures of IPP production and trade in its Chapter 7. The manual also discuss measurement issues such as transfer prices and the implications for national and international statistics.

Guide to Measuring Global Production (UNECE/OECD, 2015). This manual extends guidance from the previous two manuals by focusing on global value chains, supply chains, and arrangements for the production of goods and services, including R\&D inputs. 
11.15 From the perspective of the compiling country, foreign-controlled affiliates (FCA) are the fully consolidated enterprise group within the compiling country that are majority-owned members of foreign MNEs (thus majority-owned by their foreign parent companies. The activities of FCAs are a consequence of inward FDI, whereas the activities of CAAs relate to outward FDI. For a summary of consolidation issues involving FCAs, see OECD (2005).

11.16 Fellow enterprises abroad are identified from the point of view of a foreign-controlled affiliate resident in the compiling economy. The term refers to enterprises located outside the compiling country that are under the control or influence of the same foreign parent company as the foreign-controlled affiliate. For the purposes of this manual, fellow enterprises abroad are of interest as sources or destinations of R\&D funds involving foreign-controlled affiliates.

11.17 For inward investment, the immediate parent company of an FCA is the first foreign investor outside the compiling country that exercises control over the foreign affiliate. The investor of ultimate control of an FCA (also called the "ultimate controlling institutional unit") is the head of a chain of companies or affiliates that controls all the enterprises in the chain without itself being controlled by any other company.

11.18 Non-MNEs refer to companies located in the compiling country that are not members of any MNE (domestic or foreign) and thus do not engage in any form of FDI (OECD, 2005, Box 3.3). Non-MNEs may engage in other forms of global activities such as international R\&D funding, collaboration, contracting and trade.

11.19 Figure 11.1 presents an illustrative example of MNE concepts and terms defined from the perspective of "Compiling country 1" (so that countries 2 and 3 constitute the "Rest of the world"). Arrows run from parent to affiliate and show majority ownership in direct investment relationships. Section 11.2 addresses R\&D funding flows among MNE members and others, and Section 11.3 provides guidance on compiling cross-tabulations of current costs for R\&D performance and R\&D funding sources for MNEs and non-MNEs.

\subsection{International R\&D funding involving MNEs}

\section{Rest of the world}

11.20 International or cross-border R\&D funding involves non-resident units as sources or destinations of funds. As detailed in Chapter 3, Section 3.3, the Rest of the world is defined on the basis of the non-residence status of the relevant units; transactions with the Rest of the world are recorded as if it is a de facto sector. This sector consists of all non-resident institutional units that 
Figure 11.1. Illustrative example of MNE member ownership relationships and corresponding terminology

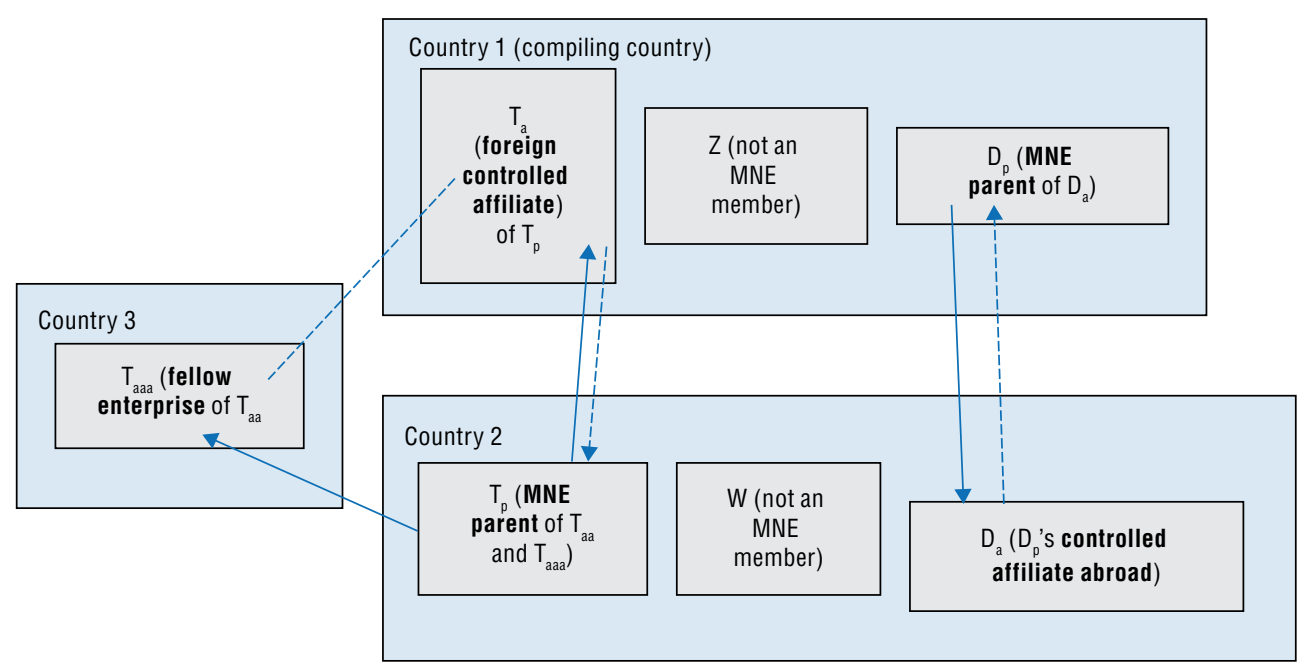

Note: $\mathrm{D}_{\mathrm{p}}$ is the parent company of $\mathrm{D}_{\mathrm{a}}$. $\mathrm{T}_{\mathrm{p}}$ is the parent company of $\mathrm{T}_{\mathrm{aa}}$ and $\mathrm{T}_{\text {aaa }}$.

$\longrightarrow$ Parent to affiliate link

Affiliate to parent link

Fellow affiliation link

enter into transactions with resident units, or have other economic links with resident units. For regular BERD reporting purposes (Section 7.6), the sources of R\&D funds from the Rest of the world are:

Rest of the world

Business enterprise sector

Enterprises in the same group

Other unaffiliated enterprises

Government sector

Higher education sector

Private non-profit sector

International organisations

\section{MNE international R\&D funding flows}

11.21 This section discusses MNEs in the context of cross-border funding flows, the first of the three types of statistical measures of business R\&D globalisation identified in Section 11.1. It supplements guidance on identifying BERD sources of funds from the Rest of the world.

11.22 Business units abroad can be sources or recipients of R\&D funding. MNE members (as defined in this chapter and illustrated in Figure 11.1) typically are involved in cross-border funding flows within their global operations and 
with other companies and organisations. These flows reflect different global arrangements to acquire or provide R\&D. An important distinction is affiliated vs. unaffiliated source of funds within business enterprises. Affiliated units include MNE parent companies and fellow enterprises abroad (if foreign-owned) and controlled affiliates abroad (if an MNE parent). To obtain finer granularity in non-resident sources of R\&D funds, R\&D surveys of MNEs could ask for the following funding source details within the Rest of the world (see Figure 11.2).

- Affiliated units (enterprises within the same group)

* controlled affiliates abroad (CAA)

* foreign parents (if respondent is foreign-owned)

* fellow enterprises abroad (if respondent is foreign-owned).

- Unaffiliated units - other enterprises abroad (any company that is not part of the MNE group of the respondent).

11.23 Building on the definitions presented in Chapter 4, a transfer of cash or in-kind is a transaction where the provider receives nothing in return (i.e. the flow of money is not requited with a compensatory flow of goods or services). Cross-border or international transfers are transfer transactions between a resident and a non-resident. R\&D funding to/from the Rest of the world should separately identify transfers from exchanges. This information may facilitate distinguishing between cross-border $R \& D$ funding flows and trade in $R \& D$ services that typically excludes transfers. Further, intra-MNE flows that are closer to transfers than to exchanges may not be recorded in services trade surveys but may appear in R\&D funding items in R\&D surveys, as described below.

\subsection{Developing, compiling and publishing MNE R\&D aggregate statistics}

\section{General approach for compiling MNE R\&D aggregate statistics}

11.24 This section discusses the collection of current costs for R\&D performed by members of MNEs within compiling countries and abroad, the second of the three types of statistical measures of business R\&D globalisation identified in Section 11.1. Information on R\&D performance by MNEs, apart from funding sources, is important for understanding the production of new knowledge. For example, measures of current costs for R\&D performance are directly related to R\&D employment. In turn, cross-tabulations of business R\&D performance/funding statistics for MNEs and non-MNEs (based on the categories summarised in Figure 11.2) provide a more complete picture of global arrangements for the production of new knowledge compared with the exclusive focus on cross-border R\&D funding flows. The focus on current R\&D costs of MNEs is to facilitate comparisons with MNEs' non-R\&D operations statistics such as output, sales/turnover, value added, employment, number of enterprises, and trade in goods and services. Of course, it could be possible to separately identify the capital R\&D costs of MNEs. 


\section{Figure 11.2. Aggregation of current costs ${ }^{1}$ and personnel for R\&D performed by MNEs and non-MNEs within a compiling country, and source of funds}

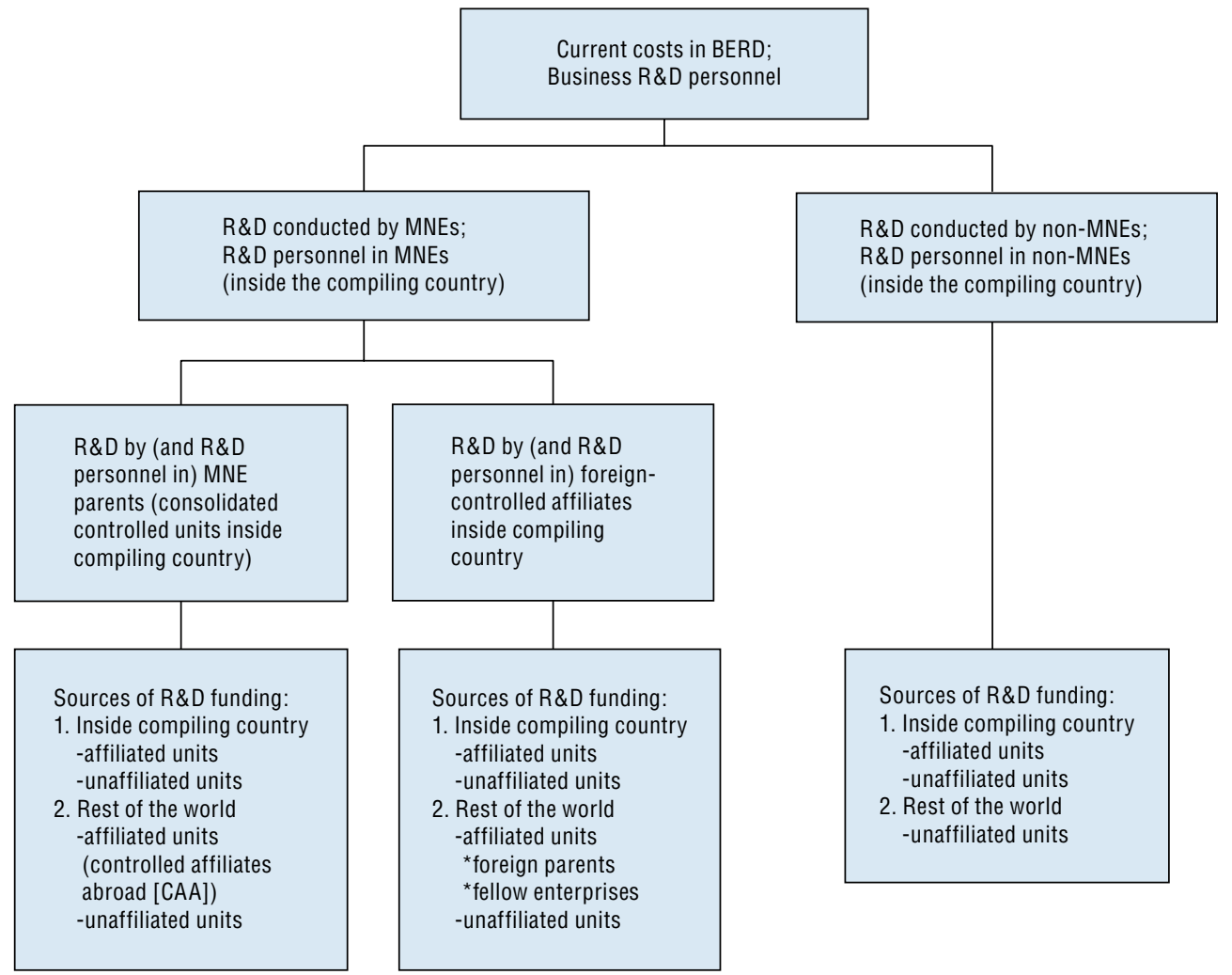

1. The focus on current $R \& D$ costs is to facilitate comparison with MNEs' non-R\&D operations statistics. It could be possible to separately identify the capital R\&D costs of MNEs.

11.25 At the same time, the collection of statistics on activities abroad presents practical challenges to respondents and national statistical agencies, because the data collection authority of a compiling country typically does not extend beyond its national borders; data on affiliates abroad usually must be collected through surveys targeting or including MNE parents. To the extent that surveys of FDI or MNEs include the activities of affiliates abroad, R\&D may be included in these surveys, consistent with the definitions and guidance of this chapter and elsewhere in this manual.

11.26 BERD surveys may also include the R\&D activities of controlled affiliates abroad along with other information that is typically outside the scope of FDI/MNE surveys (e.g. type of R\&D) with questions directed to MNE parent companies that reside in the compiling economy. 
11.27 To the extent that a country collects R\&D expenditures and related statistics (such as human resources) for MNE members defined in this chapter, priority should be given to MNE members within the compiling country, namely:

- fully consolidated parent companies of MNEs that own CAAs

- foreign-controlled affiliates (FCA) that are members of foreign MNEs.

11.28 To the extent possible, statistics may also be tabulated for the following categories, which are part of the de facto Rest of the world sector:

- controlled affiliates abroad (CAA) owned by resident MNE parents

- consolidated MNE controlled by residents of the compiling country, that is, resident MNE parents plus their CAAs.

\section{MNE R\&D statistics, by country and other characteristics}

11.29 Foreign MNEs may own affiliates in a given country through ownership chains that extend across multiple countries. R\&D and other activity statistics (e.g. employment) related to inward investment may be classified by the country of immediate control or by the country of ultimate control. The immediate investing country is the country of residence of the immediate parent company. The ultimate investing country is where the investor of ultimate control resides.

11.30 For activity statistics related to outward investment, CAAs can be classified by the country in which the operations actually take place (immediate host country).

11.31 This manual recommends that MNE R\&D statistics be collected and tabulated by the country of ultimate control (inward investment) and the country of location of controlled affiliates abroad (outward investment), to the extent possible, especially if other MNE statistics (employment, sales, trade, etc.) are published by the compiling country on this basis. Indeed, consistency between enhanced R\&D and non-R\&D globalisation statistics increases the analytical value and policy relevance of these statistics, in light of evolving complex organisational arrangements and transactions.

11.32 The industry classification (and related distributions) for inward and outward MNE statistics should follow the guidance in Chapter 7. The industry classification of CAAs should be based, as a first priority, on their own main economic activity in their location abroad and not that of their parent company in the home (compiling) country. To the extent that compiling countries have access to data on parent companies, a second priority on CAAs is to tabulate data by the main economic activity industry of the parent company, particularly for key variables such as current costs for $R \& D$ performance, employment and $R \& D$ employment.

11.33 MNE R\&D statistics are examples of statistics on activities of multinational enterprises (AMNE), including MNE parents and affiliates that may be collected in dedicated R\&D surveys or as part of other surveys on international activity such as FDI surveys. MNE R\&D may also be published in 
national statistics as part of foreign affiliate statistics (FATS), which differ from AMNE statistics by not covering MNE parents. The R\&D activities of FCAs in the compiling economy are part of inward FATS; the R\&D activities of CAAs are part of outward FATS.

\subsection{Trade in R\&D services}

11.34 This section discusses the collection of data on trade in R\&D services, the third of the three types of statistical measures of business R\&D globalisation identified in Section 11.1. In the SNA and international trade statistics, "R\&D services" cover services associated with basic and applied research and experimental development, including activities in the physical and social sciences and the humanities. "R\&D services" can be provided by any company, and thus these services are not limited to companies classified in ISIC Rev. 4 division 72 or an equivalent national classification. In standard product classifications, following the capitalisation of $R \& D$, a distinction is made between R\&D originals and other R\&D services. While the latter have a direct correspondence with $R \& D$ performance, the former correspond to assets that have been generated from past R\&D performance. The sale and acquisition of those "finished" assets count as part of trade in R\&D services in trade statistics, while it is outside the scope of the funding flows captured in this manual.

11.35 Within trade statistics, the general category of R\&D services may also include testing and other non-R\&D technical activities that result in patents, thus reflecting a wider scope than the R\&D definition in this manual. However, the cited manuals account for this difference by explicitly recommending the separate collection of services related to "work undertaken on a systematic basis to increase the stock of knowledge" from "other" services within "R\&D services". Details on R\&D services in economic accounts and services trade statistics, as well as the concordance between Balance of payments classification codes and the Classification of Product Codes for R\&D and selected related technical services in the future may be found in

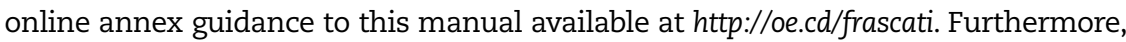
in light of the updated globalisation manuals discussed here, Technology Balance of Payments guidance may be updated in the future.

\section{$R \& D$ services trade surveys}

11.36 Surveys on international trade in services collect data on cross-border transactions in R\&D services from companies located in the compiling economy (regardless of ownership or industrial classification), among other intellectual property transactions and business services. International transactions refer to transactions between residents and non-residents. See the Glossary for a definition of "transactions". These surveys also collect data on sales/purchases and licences involving proprietary rights arising from R\&D (e.g. sale of patents and royalties and licence fees), which are part of "R\&D services". In turn, trade 
in services is a component of the current account in the Balance of Payments, a summary measure of economic transactions between resident and nonresidents in a given time period.

\section{Valuation of $R \& D$ services trade versus recording of $R \& D$ funding}

11.37 Market price is used as the basis for the valuation of international transactions in services trade surveys. Transactions are recorded on an accrual basis, when services are provided or received, irrespective of when cash is received or paid. At the same time, $R \& D$ funded by others outside the company as defined in this manual - and as reported by the funder of the R\&D, but not the performer of the R\&D - is presumed to include mark-ups and other items beyond R\&D costs. However, all R\&D expenditures are collected on a cash basis and, more generally, valuation issues are outside the scope of the Frascati Manual.

11.38 The previous discussion suggests that R\&D funding measures are not a suitable substitute for services trade statistics for national accounts and balance of payment purposes. At the same time, R\&D surveys with detailed funding and grants information can complement information from services trade surveys.

\section{Cross-border R\&D transfers in the balance of payments}

11.39 In the balance of payments, current transfers such as R\&D cash grants are recorded in the secondary income account of the current account. Capital transfers consist of either the transfer of ownership of a good or asset, other than cash, or the provision of a service, without receiving anything in return of economic value. As a produced asset (following the recognition of R\&D as investment or capital formation in the 2008 SNA), in-kind transfers of R\&D are recorded as R\&D services trade. Intra-MNE transfers of in-kind R\&D are difficult to quantify though they are within the scope of both services trade surveys and BERD surveys. Note that this balance of payments treatment of in-kind R\&D transfers differs from "in-kind" R\&D transfers that might be captured on R\&D surveys. As noted in Chapter 4, Section 4, Transfer funds for R\&D, since in-kind transfers do not entail monetary flows, they are not included in intramural R\&D expenditure totals or in totals on extramural R\&D.

\section{Cross-border R\&D transfers, across sectors}

11.40 R\&D cash grants and other transfers can occur across institutional sectors (from government or business units to higher education or non-profit sectors). But cross-sector international transactions are typically not covered in services trade surveys. Thus BERD and other R\&D surveys are an important source of R\&D transfers, both within the compiling economy and internationally. For example, cash transfers for R\&D involving the Rest of the world are part of total R\&D funding in R\&D surveys (see Chapter 4). 


\section{Cross-border R\&D transfers, among unaffiliated companies}

11.41 R\&D transfers (cash or in-kind) among unaffiliated companies are likely to be infrequent between developed economies, but may occur as part of technical assistance across countries, along with R\&D transfers involving governments and non-profit institutions. Statistics on grants from R\&D surveys along with other sources such as administrative data can be useful to differentiate R\&D and non-R\&D components of international technical assistance involving private and public sector units.

\section{Intra-group services and transfer prices}

11.42 When R\&D is transferred within MNEs across borders, it is difficult to obtain market-equivalent measures to assess internal transfer prices that may be distorted due to accounting and organisational complexities, or to tax minimisation strategies (OECD, 2014). Within MNEs, the provision of goods and services that are unrecorded or below market prices does not represent a "transfer" as defined above, unless there is nothing in return to the sender within the survey reference period. Instead, misreported exchanges constitute unreported dividends or investment that should be imputed. Alternatively, cross-border transfer of R\&D and other intra-firm services may be part, though not separately identified, of other accounting entries such as retained earnings, dividend payments or cost redistributions/allocations. For detailed guidance on intra-group R\&D services, see UNECE/OECD (2015) (para 3.2, 3.3, 4.3, and 4.4). Although there is consensus on the conceptual need for statistical adjustments for "transfer prices" issues (misreported or unreported exchanges), there is little agreement on practical guidance for such adjustments. UNECE/OECD (2015) (para 3.42, 4.23, 4.45) suggests to "stay close to statistical observation".

11.43 For both intra-MNE R\&D services trade and intra-MNE R\&D funding of exchanges, some reported data may be based on accounting charges or cost allocations formulas with little resemblance to the actual flows of R\&D, whereas free or unreported transfers may also result in response error (see possible scenarios in Table 11.1). Another difficulty is that international R\&D transactions within MNEs often are difficult to separate from related activities and the transfers of blueprints, prototypes and other intellectual property (see the related discussion in IMF 2014, para 12.126, 12.131, 12.134). Complex global production arrangements involving, for example, factoryless goods manufacturing and special purpose entities, further complicate the recording of intangibles production and trade within and across companies (OECD, 2014, Chapters 3-5 and 11). Respondent recordkeeping studies, survey and statistical methodology research, and MNE accounting research, along with cross-survey collaboration practices, discussed below, are necessary to further develop measures of crossborder MNE flows of R\&D, R\&D grants and related intangibles flows. 


\section{Table 11.1. Scenarios for possibly reported versus actual MNE R\&D flows in BERD and services trade surveys}

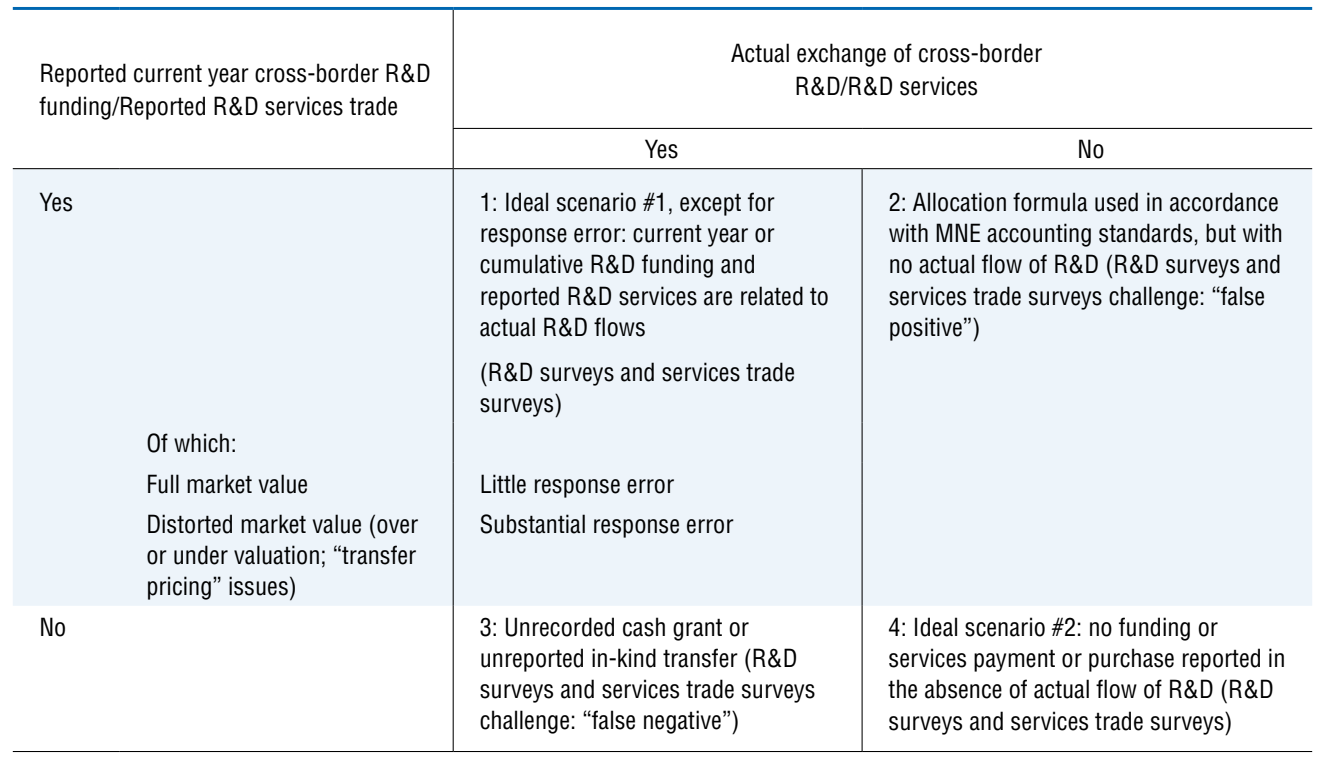

\subsection{Measuring the globalisation of R\&D outside the business sector}

11.44 While it is widely recognised that institutions other than business enterprises play an important role as performers and funders in the globalisation of $R \& D$, there is relatively less guidance on how to measure the international R\&D flows of such institutions. To a large extent, several of the R\&D globalisation measurement concepts and practices outlined for business enterprises can also be applied to units in the Government, Higher education and Private nonprofit sectors (or collectively termed here, the non-business sectors). These concepts include flows of funds for R\&D as well as ownership and control-based linkages. However, it is necessary to take into account some specific features that characterise the international R\&D linkages of institutions in the non-business sectors (hereafter collectively termed "non-business units").

\section{Fundamental concepts for measuring non-business global R\&D activities}

\section{Rest of the world sources of funds for intramural R\&D}

11.45 Non-business units can engage in R\&D funding and performance activities with the Rest of the world (non-resident units). The Rest of the world consists of all non-resident institutional units that enter into transactions with resident units or have other economic links with resident units. It also includes 
all international organisations and supranational organisations, defined further below, including facilities and operations within the country's borders. Several borderline cases are presented in Chapter 3.

11.46 As noted in Chapter 4, the analysis of the sources of funds for R\&D performed by domestic units should seek to identify funding from units located in the Rest of the World for the following categories:

- Business enterprise sector

- Government sector

- Higher education sector

- Private non-profit sector

- International organisations, including those with a physical presence in the compiling country.

11.47 Although these sources are all potentially relevant to each individual performing sector, the use of these categories in surveys should be tailored to the sector of affiliation of the reporting unit. In particular, surveys may potentially inquire about the type of funding received and the extent to which it corresponds to transfer payments (i.e. not requiring a compensatory R\&D) or an exchange of funds for R\&D or future claims on the outcome of the R\&D, using the terminology introduced in Chapter 4.

\section{Institution affiliations, by type of foreign control linkages}

11.48 Most types of non-business units can be linked across countries by various forms of ownership and control ties. As noted in the previous sections on business enterprises, this is an important element of R\&D globalisation, since R\&D conducted by affiliated units implies both a financial effort on the part of the entire "group" as well as a potential knowledge benefit. For example, as universities or independent research organisations expand globally, it is important to take into account the extent to which the R\&D performance in these institutions shares the features of economic globalisation described earlier in this chapter. For example, an organisation comprising a number of research institutes may open institutes abroad, drawing on sources of funds that are specific to the locations in which it sets up, such as local research grants and contracts. This manual currently offers no specific recommendation on identifying and reporting such relationships, except to note that affiliation linkages can shed light on the nature and purpose of the funds received by non-business R\&D performers.

\section{$R \& D$ personnel and globalisation in the non-business sectors}

11.49 The globalisation of R\&D not only relates to flows of funds and cross-border ownership linkages but is also reflected in the mobility of R\&D personnel. As is the case with the business sector, the ability of non-business 
sector $R \& D$ surveys to gather information on the human resource aspects of $R \& D$ globalisation is somewhat limited.

11.50 In some cases, it is possible that the human resource records of nonbusiness institutions contain information about the nationality, country of birth or country of previous employment of their R\&D personnel, especially researchers (see Chapter 5, Section 5.4). The collection of these data through institutional surveys is not necessarily recommended, although it may be illustrative of some types of R\&D international flows.

11.51 When information on the controlled status of institutions is available, breakdowns of standard human resource R\&D indicators can be provided, distinguishing those active in foreign-controlled and independent non-business institutions.

\section{Government sector}

11.52 Government units can receive R\&D funds from abroad, and they can fund extramural R\&D activities abroad. These funding activities abroad (with nonresident units) should be collected according to the following categories of the Rest of the world, as defined in Chapter 8:

- Business enterprises sector

- Government sector

- Higher education sector

- Private non-profit sector

- International organisations.

11.53 It is also recommended to break down the global performance and funding of $R \& D$ by the Government sector into the two categories of funds: exchange funds (specifically termed public procurements for Government sector funding) and transfer funds. While government intramural R\&D performance outside of its national territory is not very frequent, government R\&D funding to the Rest of the world may be significant. For example:

- As a funder, the government can use public procurements abroad (exchange funds) to encourage the development of a technology or an R\&D sector.

- The government is also the main funder of international R\&D organisations. With "national contributions" (transfers), the government may fund intergovernmental R\&D institutions and intergovernmental R\&D programmes/ projects. However, only contributions to international $R \& D$ programmes or organisations solely or mainly concerned with R\&D should be included. General standing contributions to the general budget (such as those to the UN, the OECD, the EU, etc.) should be excluded unless a defined component is specifically earmarked for R\&D activities (see Chapters 8 and 12). 


\section{Higher education sector}

11.54 Higher education units can receive R\&D funds from the Rest of the world, and they can fund R\&D activities in the Rest of the world. These funding activities with non-resident units should be collected according to the following categories of the Rest of the world:

- Business enterprises sector

- Government sector

- Higher education sector

* Branch campuses abroad

* Other universities

- Private non-profit sector

- International organisations.

11.55 In particular, many institutions in the Higher education sector have established branches or campuses outside their borders. To the extent that foreign-owned branch campuses inside the compiling country and branch campuses abroad owned by local educational institutions perform R\&D, HERD surveys may include supplementary information about these campuses.

- For the purpose of this manual, a foreign-owned branch campus (FBC) is defined as a tertiary educational institution, inside the compiling country, that is owned, at least in part, by an entity located (or resident) outside the compiling country (termed a "foreign education provider"); that operates in the name of the foreign education provider; that engages in at least some face-to-face teaching; and that provides access to an entire academic programme leading to a credential awarded by the foreign education provider.

- For the purpose of this manual, a branch campus abroad (BCA) is defined as a tertiary educational institution that is owned, at least in part, by a local higher education institution (i.e. resident inside the compiling country) but is located in the Rest of the world (resident outside the compiling country); that operates in the name of the local higher education institution; that engages in at least some face-to-face teaching; and that provides access to an entire academic programme leading to a credential awarded by the local higher education institution.

11.56 R\&D performed by foreign-owned branch campuses is part of the domestic HERD performance totals of the compiling country. However, R\&D performed in BCAs cannot be included in the domestic HERD performance totals of the compiling country, and instead could be separately identified and tabulated as R\&D performed in the Rest of the world by tertiary educational institutions outside the compiling country educational institutions (see Chapter 9, Section 9.4) for further guidance for collecting FBC and BCA totals). 


\section{Private non-profit sector}

11.57 As with units in other sectors, R\&D performing institutions in the Private non-profit sector may have multiple global activities with both affiliated vs non-affiliated units. An institution may receive funds to perform R\&D in the form of grants or contracts from other, unaffiliated non-profit institutions located outside of the national territory, or (depending on its affiliation structure) may receive funds from another affiliate or the parent organisation in order to support its activities in the country where it is located. Thus, private non-profit institutions can receive $R \& D$ funds from the Rest of the world, and they can fund R\&D activities in the Rest of the world. Such relationships can be extremely complex in terms both of identification and statistical measurement. Relevant categories for the Rest of the world are:

- Business enterprises sector

- Government sector

- Higher education sector

- Private non-profit sector

* Affiliated institutions (International non-governmental organisations, INGO)

* Other non-affiliated institutions

- International organisations, including supranational organisations.

11.58 Some PNP institutions may have a global presence, as is the case of many non-governmental organisations. These are not international organisations in the sense of the SNA and this manual (see Chapter 3 and the section on International organisations below).

\section{Special case of international organisations}

11.59 According to the SNA, international organisations have as members either national states or other international organisations whose members are national states. International organisations include supranational organisations, as defined in Chapter 3. They are established by formal political agreements between their members that have the status of international treaties; their existence is recognised by law in their member countries, and they are not subject to the laws or regulations of the country, or countries, in which they are located. One potential implication of this particular status is that, for example, they cannot be compelled by national authorities to provide statistical information on their R\&D performance or funding activities. From the perspective of the compiling country, they are part of the Rest of the world sector.

11.60 Because of the importance of international organisations to global $R \& D$ performance in several domains, and in order to attain a more complete representation of $R \& D$ activities worldwide, the relevant international and supranational statistical organisations should collaborate to ensure full coverage of these $R \& D$ performing units that lie beyond the scope of national 
statistical offices. In the future, these totals could be presented in comparative international statistics as part of a separate country-level category. This could also help improve the coherence between R\&D statistics and other indicators, such as scientific publications, which are typically attributed on the basis of the country in which the authors' affiliations are based.

11.61 When national statistical offices are able to collect data from the international organisations operating in their national territory, the reporting of national figures should conform to the guidance in this manual to treat these units as part of the Rest of the World sector. In order to establish whether a given institutional unit has the status of an international organisation, attention should be paid to its foundational charter and to the relevant agreements that govern its functioning, including exemptions from the jurisdiction of local law on a number of aspects as a result of the engagement of sovereign states in the organisation's membership.

11.62 One area of potential confusion stems from the potential similarity between international organisations, which are defined in this and other statistical manuals to refer to intergovernmental organisations, and other international bodies comprising non-governmental organisations (NGOs), which do not meet the criteria to be treated as non-resident units.

11.63 NGOs are voluntary self-governing bodies or organisations established to pursue the essentially non-profit-making objectives of their founders or members (Council of Europe, 2007). They do not include political parties. NGOs encompass bodies or organisations established both by individual persons (natural or legal) and by groups of such persons. They can be either membership-based or non-membership-based. NGOs can be either informal bodies or organisations or bodies that have a legal personality. NGOs can be national or international in their composition and sphere of operation. NGOs should not distribute any profits that might arise from their activities to their members or founders but can use them for the pursuit of their objectives.

11.64 For example, a global NGO that is an international association of universities involved in research in a particular field operating and using research facilities may undertake very similar activities in similar locations to those carried out by an existing international organisation that has governments as its members. From the perspective of the compiling country hosting the R\&D performing facilities, the local centre owned by the international association (i.e. the global NGO) should be counted as part of the domestic economy and its intramural R\&D performance included in GERD, while the intergovernmental organisation should be treated as part of the Rest of the world.

11.65 Some countries may be part of an institutional agreement that involves financial flows from the member countries to the associated international organisation and the reverse, for example, to R\&D performing units. The international organisation may itself also engage in R\&D. For the individual countries, the international organisations are non-resident institutional units 
that are part of the Rest of the world and may be classified in a specific subsector of the Rest of the world.

11.66 There may be other research infrastructures and organisations with rather similar operational activities to those of international organisations, even within the same country. For example, while a not-for-profit scientific research and measurement facility may have been set up by an organisation whose members are sovereign member states, there may be another similar facility carrying out equivalent functions but under the control of an international consortium of universities or other private and non-profit organisations. The former should be considered as an international organisation in the intergovernmental sense, while the latter should be treated as part of the Private non-profit sector (controlled by abroad). This latter non-governmental institution would contribute to the GERD of the domestic economy, while the former would not. Similar criteria would apply to the human resources engaged in R\&D by these organisations.

\section{R\&D performer issues - domestic or Rest of the world}

11.67 International affiliation linkages need not be constrained to operate within the same sector. For example, a domestic private research centre with a non-profit or even business status may be owned by a foreign university, or vice versa. In regular survey practice, it may be overly burdensome to attempt to introduce all possible permutations of non-resident institutional sources of funds with affiliation linkages.

11.68 Chapter 4 clarifies that the concept of intramural R\&D and its allocation to a domestic sector or to Rest of the world is not based solely on where R\&D performance takes place, but also concerns under whose institutional authority the research is carried out. For example, if a local university researcher spends part of his/her time at the facility owned by an international organisation while working for her university, and is accountable as an employee to this university, the costs corresponding to this researcher's salary should be counted as the intramural performance of the domestic university. If the international organisation behind the facility funds some of the work, or the individual can claim a double affiliation, the attribution can be more complicated, and there is a possible risk of double counting that should be carefully managed.

11.69 Also as noted in Chapter 4, intramural R\&D expenditure is intended to measure the R\&D performed within the statistical units resident in the national territory of the compiling country. Some of the expenditures may, however, have occurred abroad. For example, intramural R\&D expenditures might include:

- costs for maintaining and utilising a permanent government research presence in Antarctica

- costs for a higher education researcher to undertake field work in a location outside of the compiling country or within an international organisation located within its own country. 
11.70 Priority should be given more to the organisational structure of an activity than to the literal location of where the activity takes place in classifying "intramural" R\&D that takes place outside of the national territory of the compiling country. It is difficult to provide precise guidelines for such classification decisions, but at a minimum intramural $R \& D$ that has occurred in the Rest of the world should include only R\&D that is performed by a statistical unit to fulfil its own objectives and only if the statistical unit has invested its own financial resources and $R \& D$ personnel to the activity. The R\&D must take place under the responsibility of the reporting unit, and the reporting unit must meet the economic residence criterion described in Chapter 3.

\section{References}

Council of Europe (2007), Recommendation CM/Rec (2007) 14 of the Committee of Ministers to member states on the legal status of non-governmental organisations in Europe, Council of Europe, Strasbourg. https://wcd.coe.int/ViewDoc.jsp?id=1194609.

EC, IMF, OECD, UN and the World Bank (2009), System of National Accounts, United Nations, New York. https://unstats.un.org/unsd/nationalaccount/docs/sna2008.pdf.

EC (2012), Foreign Affiliates Statistics (FATS) Recommendations Manual, Eurostat, Luxembourg.

EC (2010), Business Registers Recommendations Manual, Eurostat, Luxembourg.

IMF (2014), Balance of Payments and International Investment Position Compilation Guide, IMF, Washington, D.C.

IMF (2009), Balance of Payments and International Investment Position Manual, Sixth Edition, IMF, Washington, D.C.

OECD (2014), Guidance on Transfer Pricing Aspects of Intangibles, OECD/G20 Base Erosion and Profit Shifting Project, OECD Publishing, Paris. DOI: http://dx.doi.org/10.1787/ 9789264219212-en.

OECD (2009a), Benchmark Definition of Foreign Direct Investment, 4th Edition (BD4), OECD Publishing, Paris. DOI: http://dx.doi.org/10.1787/9789264045743-en.

OECD (2009b), Handbook on Deriving Capital Measures of Intellectual Property Products, OECD Publishing, Paris. DOI: $h t t p: / / d x . d o i . o r g / 10.1787 / 9789264079205-e n$.

OECD (2005), Measuring globalisation: OECD Handbook on Economic Globalisation Indicators, OECD Publishing, Paris. DOI: http://dx.doi.org/10.1787/9789264108103-en.

UNECE/Eurostat/OECD (2011), The Impact of Globalisation on National Accounts, UNECE, Geneva.

UNECE/OECD (2015), Guide to Measuring Global Production, UNECA, Geneva.

UN, Eurostat, IMF, OECD, UNCTAD, UNWTO and WTO (2014), The Compilers Guide for MSITS 2010, United Nations, New York. http://unstats.un.org/unsd/trade/publications/ MSITS2010_Compilers\%20Guide_Unedited\%20White\%20Cover\%20Version\%20-\%2012\%20 February\%202015.pdf.

UN, Eurostat, IMF, OECD, UNCTAD, UNWTO and WTO (2011), Manual on Statistics of International Trade in Services 2010 (MSITS), United Nations, New York. 
PART III

\section{Measuring government support for $R \& D$}





\section{Chapter 12}

\section{Government budget allocations for R\&D}

This chapter presents an approach for measuring government funding of R\&D using data from government budgets. This type of funder-based approach for reporting $R \& D$ involves identifying all the budget items that may support R\&D activities and measuring or estimating their $R \& D$ content. Advantages of this approach include the ability both to report significantly more timely government $R \& D$ funding totals since they are based on budgets and to link these totals to policy considerations through classification by socioeconomic objectives.

The definitions discussed in this chapter are, as far as possible, compatible with the international methodologies and guidelines contained in the IMF's Government Finance Statistics Manual (GFS) of 2014 and the 2008 System of National Accounts, as well as the methodologies developed by Eurostat such as the Nomenclature for the Analysis and Comparison of Scientific Programmes and Budgets (NABS). 


\subsection{Introduction}

12.1 There are different ways of measuring how much governments spend on $R \& D$. The performer-based approach recommended in Chapter 4 is to survey the resident units that perform R\&D (businesses, institutes, universities, etc.) in order to identify the amount spent on intramural R\&D performance in a reference year. It is then possible to identify the portion of the intramural R\&D expenditure funded by government (Chapter 4, Table 4.4). These totals provide an accurate measure of government funding for intramural R\&D performed in the economy as a fraction of gross domestic expenditure on R\&D (GERD). The disadvantages are that it takes time for this information to become available and that R\&D performers are not necessarily able to link the government funding they receive to policy objectives.

12.2 A complementary approach for measuring government funding of R\&D has been developed using data from budgets. This type of funder-based approach for reporting R\&D involves identifying all the budget items that may support R\&D activities and measuring or estimating their R\&D content. Advantages of this approach include presumably the ability both to report significantly timelier government R\&D totals since they are based on budgets and to link the R\&D totals to policy considerations through classification by socioeconomic objectives (Section 12.4 below).

12.3 The specifications of such budget-based data are described in this chapter and were first introduced in this manual's third edition. In more recent editions, budget-based data have been formally referred to as "government budget appropriations or outlays for R\&D" (GBAORD), a term that is replaced in this edition with the simpler term of Government budget allocations for R\&D (GBARD).

12.4 The definitions discussed in this chapter are, as far as possible, compatible with the international methodologies and guidelines contained in the IMF's Government Finance Statistics Manual (GFS) of 2014 and the 2008 System of National Accounts, as well as the methodologies developed by Eurostat such as the Nomenclature for the Analysis and Comparison of Scientific Programmes and Budgets (NABS).

\subsection{The scope of GBARD}

\section{Relevant government units within the scope of GBARD}

12.5 As specified in Chapter 3 (Section 3.5) and elaborated upon in Chapter 8, the Government sector comprises the central (federal) government, 
regional (state) government and local (municipal) government subsectors. The focus of GBARD statistics is on the R\&D expenditure operations conducted by the government at all these levels and financed through the budget under standard budgetary approval procedures. To minimise the potential reporting burden and ensure timeliness, local government budget funds may not be included if their contribution is not deemed to be significant or if the data cannot be collected.

12.6 As noted in the System of National Accounts and the IMF Government Finance Statistics Manual, the budgetary central (federal) government is often a single unit of the central government that encompasses the fundamental activities of the national executive, legislative and judiciary powers. This component of general government is usually covered by the main (or general) budget. The budgetary central government's revenue and expense are normally regulated and controlled by a ministry of finance, or its functional equivalent, by means of a budget approved by the legislature (IMF, 2014: para. 2.81).

12.7 At a given level of government, ministries, departments, agencies, boards, commissions, judicial authorities, legislative bodies and other entities that make up a government rarely have the authority to own assets, incur liabilities or engage in transactions in their own right. In general, all entities the operations of which are funded as a result of appropriations made in accordance with a budget controlled by the legislature are not separate institutional units and are treated as a single statistical unit.

12.8 General government entities with individual budgets not fully covered by the general budget are considered extra-budgetary (see Chapter 8) and are included for the purpose of GBARD measurement. The budgetary arrangements for these entities vary widely across countries, and various terms are used to describe them, but they are often referred to as "extra-budgetary funds" or “decentralised agencies” (IMF, 2014).

12.9 GBARD encompass all spending allocations met from sources of government revenue foreseen within the budget, such as taxation. Spending allocations by extra-budgetary government entities are within the scope only to the extent that their funds are allocated through the budgetary process. Likewise, R\&D funding by public (business) enterprises is outside the scope of GBARD statistics, as it is based on funds raised within the market and outside the budgetary process. Only in the exceptional case of budgetary provisions for R\&D to be carried out or distributed from public enterprises should this be counted as part of GBARD. This manual does not define what spending concepts should be used, since they vary across countries. Some countries will report on outlays, others on budget authorisations, and still others on budget obligations. It is important that whatever concept is used, it is consistently used in the compilation of GBARD totals. 


\section{Definition and identification of R\&D in GBARD}

12.10 The definition of R\&D is given in Chapter 2. As already noted, the SNA 2008 and GFS 2014 - the core statistical frameworks for government and public sectors statistics - use the definitions in the previous edition of this manual, which are essentially the same as those in Chapter 2 of this edition.

12.11 Basic research, applied research and experimental development are all included but are not identified separately for the purposes of GBARD compilation. Likewise, the analysis for budgetary data on R\&D covers natural sciences and engineering and social sciences, humanities and the arts.

12.12 As far as possible, all guidelines and conventions listed in Chapter 2 for distinguishing R\&D from non-R\&D activities should be applied. Particular care should be taken to check the R\&D content of budget items that are officially described as "science and technology activities", "development contracts" or the "purchase of prototypes", as discussed in Chapters 2, 4 and 7, as well as other science, technology and innovation expenditures, which some countries may identify as, or combine with, R\&D expenditures in their presentation of general budget data.

12.13 Compilers of GBARD statistics may need to develop a set of coefficients according to discipline, institution, other criteria or a mixture of these in order to determine the proportion of $R \& D$ in non-exclusive budget items, including for a range of institutions that also perform activities other than R\&D. As far as possible, these coefficients should be consistent with what is reported by these institutions as R\&D in performer-based surveys. The information on coefficients should be made available to users as openly as possible in order to facilitate review and updates.

12.14 Government budgets for R\&D may include a provision for the costs of administering $R \& D$ programmes and projects, including for example the formulation of calls, competitive procurement processes and grant solicitations, as well as the monitoring and evaluation of programmes. In principle, GBARD should cover only the funding of R\&D performance. It is, however, acknowledged that such delivery costs can be an integral part of the process required to ensure that the funds are used for R\&D and for meeting the government's objectives, and these can also be difficult to separate, particularly in the budgetary stages. This is one potential source of divergence between performer-based and governmentbased estimates of R\&D support by government (see Section 4.4 in Chapter 4). For this reason, when information is available, it would be helpful to use it to report on the potential magnitude of R\&D administration funds.

\section{Types of R\&D expenditures covered by GBARD data Types of costs}

12.15 GBARD includes in principle both funding for current costs and capital expenditures. A major difference with finance statistics is that government expenses will include a depreciation-based component, while the presentation 
of the budget may report capital expenditures separately. The recommendations made in Chapter 4 concerning the treatment of capital expenditures that are intended to avoid double counting also apply in the context of GBARD statistics. Another factor to take into account is that funders and performers may have different perspectives on what constitutes capital expenditure.

\section{Types of fund recipients}

12.16 GBARD covers not only government-financed R\&D that is performed in government entities but also government-financed $R \& D$ in the three other sectors comprising the domestic economy (Business enterprise, Higher education and Private non-profit) as well as in the Rest of the world (including international organisations). GBARD should therefore not be confused with Government intramural R\&D expenditures (GOVERD). As noted in Chapters 4 and 8, not all GOVERD is necessarily financed by government.

12.17 Budget allocations may be made for institutions that are not necessarily performers of R\&D. A large component of government R\&D budgets may be assigned to institutions such as agencies or organisations that have the specific responsibility of allocating R\&D funds to performers or other intermediary agencies in line with their stated responsibilities. The level of detail available in the general budget of a central, regional or local government will therefore not necessarily allow GBARD data compilers to identify the ultimate use of the funds. In contrast, the budget statements of these intermediary agencies, within or outside government, may comprise additional detail, including possibly the identity of the final beneficiaries of financial support for R\&D. Such beneficiaries may also subcontract some of the R\&D activities.

12.18 A number of departments and agencies can play a role in distributing and allocating budgetary funds to other public or private organisations. It is not envisaged that GBARD is used to report for subsets of government, but due care should be exercised for example to:

- remove central (federal) government allocations to regional (state) or local (municipal) budgets in compiling GBARD estimates at the state level, if those have already been taken into account at the level of central government

- avoid the risk of double counting or undercounting when constructing GBARD statistics based on separate reports from central government agencies and departments.

\section{Government funding of R\&D in the Rest of the World}

12.19 Government R\&D budgets may include the provision of R\&D funding to non-resident institutions. In the case of GBARD funds for R\&D in the Rest of the world, only contributions to international R\&D programmes or organisations solely or mainly concerned with R\&D should be included. General standing contributions to the general budget (such as those to international organisations or the European Union) should be excluded unless a defined component is 
specifically designated for R\&D activities. The complementary guidance in the

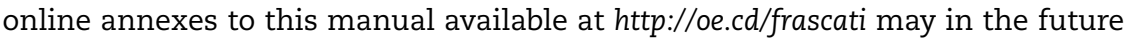
provide an illustrative list of such international organisations with particularly high levels of R\&D intensity. This subject is covered in more detail in Chapter 11 on $R \& D$ globalisation.

\section{Types of R\&D support mechanisms and their treatment in GBARD statistics}

\section{Government funds for government intramural R\&D}

12.20 The concept of government support for R\&D performed within the Government sector has been covered in Chapter 8. From the perspective of GBARD statistics, the main challenge arises in the case of budgetary approvals for R\&D performed by government institutions but expected to be financed from other sources. In some countries, these may be included in the government budget, on the grounds that the agency concerned needs government permission to spend them (gross approach). In others, they may be excluded (net approach). When dealing with these government funds, a distinction should be made between:

a) Contracts or grants from other sectors for the performance of $R \& D$ by government institutions. These do not represent government budget allocations for R\&D.

b) Other government funds, such as receipts from general levies that have a status comparable to tax or other budget-based government financing. These do fall within the scope of government budget allocations for R\&D.

12.21 Budgeted amounts for which corresponding revenue is expected from non-budgetary sources should be excluded from GBARD according to the net principle. For example, if the general budget shows that a government R\&D institute has a total gross budget of 10 million (including 3 million for externally financed contract research), only 7 million should be counted as net budgetary appropriations for the institute, since the 3 million is in the budget of the funder of the contract research.

\section{Provision of infrastructure and services for R\&D performed by third parties}

12.22 Some examples of government units providing such services have been discussed in Chapter 8 , in particular with regard to whether this represents performance of $R \& D$ within government. The services provided by the government facilities may be partly subsidised through government budgetary funding, according to the difference between the economic cost of the service provided by government units and any fees or prices paid by the user that is carrying out the $R \& D$, in line with the net principle. The cost of the service may comprise both the operating cost and the opportunity cost of the resources used by the infrastructure assets. In some cases, fees may also extend to cover for the 
depreciation and financing costs of the infrastructure. For GBARD statistics, it is recommended that:

- The budgetary funding for acquiring or building the $R \& D$ equipment by government should be counted as GBARD, and separately itemised if possible. Most budget documents separate current and capital investments. Capital investments of this type can be lumpy, particularly if the assets are to be used over a long period of time and may distort comparisons if the capital investments are not taken into account when comparisons are made.

- The infrastructure's operating and maintenance costs, net of usage fees, etc., should be counted as GBARD on an ongoing basis, as long as this cost is recognised in the budget.

- The infrastructure's depreciation and financing costs should be excluded, if possible, to avoid double counting. For some purposes, it could be of value to report those separately.

12.23 The same principles can be applied when the infrastructure is developed and/or operated by a third party, to the extent that it is possible to identify the R\&D component and confirm the budgetary intention.

\section{Payments for R\&D services}

12.24 Paying for R\&D services provided by third parties may result in the government securing economic and legal rights, not necessarily exclusive, on the outcomes of the R\&D. This corresponds to the procurement of R\&D services, typically described as contracts for $R \& D$ services, or $R \& D$ procurement. $R \& D$ procurement represents an exchange rather than a transfer, as is defined in Chapter 4. R\&D procurement may be subject to specific rules and carried out on a commercial or pre-commercial basis. Both forms should be considered as part of GBARD as long as it is part of the budget.

12.25 Payments made under R\&D contracts may include a profit and/or subsidy component. The full value of the payments should be counted as GBARD, even though this will accentuate the difference with performer-based estimates, which should in principle exclude the profit component. Payments for goods and services that incorporate or anticipate $R \& D$ activities should not be considered as GBARD unless the R\&D component can be identified and isolated in the budget and payments are made specifically for the delivery of the R\&D component.

\section{R\&D grants}

12.26 Governments can provide funding for R\&D by firms or other types of organisations without requiring any significant rights on the outputs/outcomes of the project or without specifying a product or service as a requirement for the funds provided. These transactions are transfer payments, and are often described as R\&D subsidies or grants. A formal agreement is likely to underpin such grant agreements, which may also foresee milestones and deliverables as 
conditions for the payment to be made or, if the conditions are not met, for it to be returned. Grants are part of GBARD as long as these are in the budget. Grants can be provided to cover operating and capital costs. Governments may also provide grants for units in other sectors to deliver services or access to infrastructure or to transfer capital assets for R\&D performers to use.

12.27 Public general university funds (GUF) represent a particular type of government transfer mechanism for R\&D. GUF (see Chapters 4 and 9) represent an exception to the direct support rule applied in R\&D statistics, as higher education institutions (HEIs) have a significant degree of discretion on the use of block grant funding received from governments. On the other hand, these block grants (most often) take place in the context of transactions between governments and HEIs that are partly controlled by the governments, and hence it may be legitimate to consider them as direct funding. In some countries, government may provide block or institutional funding similar to GUF. Funds are sometimes provided to institutions in sectors other than Higher education for general purposes, which recipients can but are not obliged to use for R\&D purposes. The only type of general block or institutional funding captured by GBARD is GUF for those countries where these funds apply.

12.28 On a practical basis, budget documents do not provide, by themselves, the degree of detail and information required to identify the R\&D component of GUF where this type of funding applies. Survey information may be required to provide an accurate estimate of GUF to report in GBARD, which in turn can significantly reduce the timeliness of GBARD data. As noted in Section 12.3 below, such delays should be avoided.

\section{Financial investments supporting $R \& D$}

12.29 Governments can provide debt or equity financing for units to carry out R\&D activities. This type of support entails the exchange of money for financial assets in the form of claims on future, potentially uncertain cashflows. Governments may also underwrite some of the risk incurred by third parties providing the financing, and may or may not ask for a fee in full or partial compensation.

12.30 While the guidance in Chapter 4 for performer-based reporting is to treat these financial investments as internal resources for the performer, GBARD statistics have to account for the fact that governments tend to record the budgetary implications of these transactions, depending in particular on whether the accounting principles are resource-based or cash-based. Estimates of grantequivalent costs, accounting for risk, are often used in the budget to account for the resource requirements, but these can require complicated calculations and significant assumptions that need to be revised over time (see Chapter 13).

12.31 For the purposes of R\&D statistics and GBARD statistics in particular, it can be challenging to find a basic reporting principle that is internally consistent, supported by available data sources and sufficiently internationally comparable. 
In the case of a loan for $R \& D$, and given the risk, the government may not be able to, or wish to, claim back the full amount. When there is an expectation that this might happen, the implementation of the net approach calls for capturing the expected value of the transfer. When this element is economically significant and it is accounted for in the budget, it should be included in GBARD as incurred. Loans and other potentially repayable advances should be covered in GBARD only on an expected net basis, on the basis of the transfer component.

12.32 Debt forgiveness is recorded in government statistics as a capital transfer received by the debtor from the creditor at the time specified in the agreement that the debt forgiveness takes effect. In the case of R\&D-related loans, these should be recorded separately from GBARD, as the ex-post forgiveness transfer does not represent actual funding of R\&D. Similarly, repayments should not be counted as negative budgetary funds.

12.33 Equity investments for $R \& D$ projects, including the provision of equity for new joint ventures with industry, should not be counted within GBARD in application of the expected net principle that government receives in return a financial asset in the form of ownership right over future profits. For practical purposes, countries may wish to report the value of such equity and loan investments separately.

\section{Guarantees for R\&D loans}

12.34 For practical reasons, loan guarantees are unlikely to be counted because it may not be possible to identify the R\&D component of the investment guaranteed by government. In the case of loan guarantees directly attributable to the financing of R\&D projects, most governments are likely to record the contingent liabilities outside the balance sheet and to differ in their accounting of their budgetary costs, potentially making provisions for the exposure. Whenever significant, the resource provision for a loan guarantee or other contingent funding, net of fees paid by the parties to the loan, should count as direct funding and included in GBARD, provided that the budget process recognises this as expenditure. As per earlier guidance on forgiveness, in the cases that the government had to release the funds to cover the guarantee, this payment should not be counted as GBARD.

\section{Tax relief for $R \& D$ expenditures}

12.35 Many governments allow a more advantageous tax treatment of R\&D incurred by business enterprises and, in some cases, other units. Current or future tax revenues may be forgone and, in some circumstances, money gets directly transferred from government to these units when their tax liability is insufficient to offset the entitlement for relief. The provision of tax relief for R\&D expenses incurred by enterprises is a form of $R \& D$ subsidy that is implemented through the tax system and intended to reduce the economic cost of R\&D investments (see Chapter 13 for a thorough description of such R\&D tax relief possibilities). 
12.36 The cost of providing tax relief for R\&D expenditures may be part of the budget or feature within budget sections describing non-discretionary expenditures and adjustments to revenues, but this is not always the case. Some governments may have a dedicated amount in the budget for this activity, with actual payments being adjusted ex post to fit within the available budget, or they may provide tax relief to all units that demonstrate their eligibility, working on an on-demand basis. For the purposes of this manual, and as explained in Chapter 13 , tax revenues forgone by government and amounts actually paid to firms are both considered to be tax subsidies. That information may not always be available in budget documents.

12.37 Due to these potential gaps, for international reporting purposes it is recommended that GBARD statistics exclude all forms of tax relief, including amounts payable to enterprises. When national authorities deem that this type of support is an integral part of their budget, this should be appropriately itemised so that users do not make the error of adding separately derived estimates of tax relief for $R \& D$, compiled under the guidance provided in Chapter 13, with GBARD estimates that contain some specific forms of budgetary support for tax relief. An illustrative reporting schedule is provided in Table 12.2 below.

\section{Other indirect support}

12.38 There are several other mechanisms for governments to support indirectly the performance and funding of R\&D in an economy. Because of the lack of proven methodologies to assign a monetary value to this type of support, particularly in an internationally comparable way, these should be excluded from GBARD estimates.

\subsection{Sources of budgetary data for GBARD and estimation}

\subsubsection{Funding and performer-based reporting}

12.39 As noted in Section 12.1 and in Chapters 4 and 9, R\&D expenditures financed by government can be reported either by the government authorities providing the financial resources (funding) or by the institutional unit actually performing the R\&D. In general, and for consistency with total GERD estimates, this manual recommends the second approach. However, in order to meet its stated aim of collecting timely data on funding that can be classified by socioeconomic objective, GBARD data should be collected from the funder rather than the performers.

\subsubsection{Sources of budgetary data}

12.40 In analysing government expenditure, one can distinguish the day that a budget is voted upon by the legislature, the day that the ministry of finance authorises a department to pay out specified funds, the day that a particular commitment is entered into by the departments, the day that deliveries take place, and finally the day that payment orders are issued and cheques are 
paid. Although guidance is suggested below, this manual does not prescribe what spending concepts must be used since these vary across countries. It is most important that whichever concept is used, it is used consistently in the compilation of GBARD totals.

\section{Common patterns}

12.41 Although details of the budgetary procedure vary from country to country, seven broad stages can be identified:

1. Forecasts (estimates of funding before beginning of budget discussion).

2. Budget forecasts (preliminary figures as requested by ministries, especially for inter- ministerial discussions).

3. Budget proposals (figures presented to the parliament for the coming year).

4. Initial budget appropriations (figures as voted by the legislature for the coming year, including changes introduced in the parliamentary debate). In this context, an appropriation is defined as the act of setting aside money or other resources for a specific purpose, as authorised by the legislature to be spent on a particular programme or line item.

5. Final budget appropriations (figures as voted by the parliament for the coming year, including additional votes during the year).

6. Obligations (money actually committed during the year).

7. Expenditures, as accrued in the accounts or as effectively paid in cash/money.

12.42 Stages 1-4 describe the government's intentions. The data for budgetary year $t$ should be available as soon as possible towards the end of year $t-1$. It is suggested that the preliminary GBARD data should be based on the first budget agreed between the government and the parliament, or stage 4 . Some countries might even base their preliminary figures on stage 3. The reporting of data on intentions may be too broad to support the identification of $R \& D$ content and detailed objectives. This may require some form of estimation or the use of explicit assumptions that the growth of R\&D budgets will match that of the identifiable budget categories. This can give rise to significant revisions in later years.

12.43 During the budgetary year, supplementary budgets may be voted, including increases, cuts and reallocations of R\&D funding. These are reflected in stage 5. Data should be available as soon as possible after the end of the budgetary year. It is suggested that the final GBARD data should be based on the final budget appropriations. Some countries may have to base their final figures on stages 6 or 7 . These figures may be available on a cash or accruals basis. The cash basis recognises a transaction when the cash is received or when cash is paid out. The accruals basis recognises a transaction when the activity (decision) generating revenue or consuming resources takes place, regardless of when the associated cash is received or paid. Appropriations may be left unexpended. There can also be an unappropriated balance for the cash reserves that have not 
been allocated to any purpose. This manual suggests that the reporting of GBARD not be based on figures in stages 6 or 7 .

\section{Appropriations carried forward}

12.44 In some countries it is common budgetary practice to carry forward large sums from one year to the next, sometimes including them in sums voted in successive years. Multi-annual projects budgeted in only one year or over several should be allocated to the GBARD of the year(s) in which they are budgeted, not in the years of performance. Multi-annual programmes that are authorised at some stage but budgeted over several years should be allocated to the years in which they are budgeted, not the year of authorisation.

\section{Sources of data on obligations and outlays beyond the budget process}

12.45 It is common practice for a number of countries to use extended surveys of government units, including agencies and ministries, to measure not only R\&D performance but also funding. Potential reasons for this extended effort include the ability to gather more detailed information than that contained in general budget documents, allowing, for example, the identification of the R\&D content of budget items, their nature and other policy-relevant information.

12.46 In addition to the resource implications of additional data collection, there can be a substantial loss in timeliness when requiring the adoption of measures to avoid the potential double counting of funds. This applies when resources flow from ministries to intermediary agencies which transfer funds in turn to other agencies and/or performers. From an international perspective, there is a significant risk that the variable adoption of more in-depth inquiries to complete budgetary data may result in difficult-to-compare data, in particular between countries that capture only R\&D reflected in high-level budgetary items, versus countries that undertake a more exhaustive search of expenditure items within budgetary items.

12.47 As noted in Chapter 8, the use of such surveys when providing a more complete and accurate representation is not discouraged, although the diversity of practice in countries precludes guidelines in this manual. If this practice is used, it should be well documented, and not interfere with the purposes of presenting timely and internationally comparable GBARD data.

12.48 A number of GBARD components may not be available on a sufficiently timely basis to meet the standard required for preliminary figures (e.g. publication of estimates for year $t$ in year t-1). For example:

- Estimates at the subnational level of government may not be readily available. Additional efforts are required for data at the level of regional (state) or possibly local (municipal) government budgets, delaying the full final compilation.

- Incorporating GUF (see Chapters 4 and 9) into GBARD may require estimates derived from survey-based data in the Higher education sector. 
Applying up-to-date coefficients to general budget items may require agencylevel data on how funds have been actually used.

12.49 In general, and in the interest of timeliness, it is recommended that when no alternatives are available, preliminary estimates may, for example, result from extrapolating the level of GBARD from its last available estimate using the known rate of growth of a significant component, e.g. the growth rate of central/federal budgets for R\&D. This practice should be validated by continued re-assessment of how well the leading indicator has tracked the growth rate of the GBARD series. Users of statistics should be prepared to deal with potential data revisions, as is common in other statistical domains. Although this is not required, it can be helpful and highly policy-relevant for preliminary, forwardlooking estimates to include a breakdown of GBARD by socioeconomic objective.

\subsection{Distribution by socioeconomic objectives}

\section{Criteria for distribution}

\section{Purpose or content}

12.50 It is possible to distribute GBARD according to the general knowledge content of the R\&D programme or project, according to the purpose (i.e. objective) of the R\&D programme or project, using a suitable classification of socioeconomic objectives (SEO). However, it is not necessarily easy to identify the content of the $R \& D$ and then correctly interpret how it relates to the purpose of the project. The difference between the various concepts can be illustrated by the following example:

$\rightarrow$ A research project to develop fuel cells to provide power in remote, hostile locations for the military, which is entirely financed by the Ministry of Defence: the R\&D content may draw upon engineering and technology domains and is related to "energy" generation objectives, but the primary objective is "defence".

12.51 In the case of GBARD, the primary objective is more fundamental from the viewpoint of documenting government policy objectives for $R \& D$. It is also the case that information on the primary objective is least likely to be secured from the performers, making a case for the adoption of this criterion based on budgetary data. Therefore, it is recommended that the primary objective approach is used, in principle, for the collection and distribution of budget data.

12.52 Though some government-supported R\&D programmes have only one objective, others may have several that feed into each other or that are pursued in parallel. For example, a government may commit money to an aircraft project primarily for military reasons but also to encourage export sales by the aerospace industry and even to assist spin-offs to civil aviation. Multiple objectives can be recorded in a country's information system. However, in reporting to international organisations, R\&D should be classified according to its primary objective. 


\section{Identifying primary objectives}

12.53 The allocation of R\&D budgets to socioeconomic objectives should be at the level that most accurately reflects the funder's objective(s). The actual reporting level chosen will depend on practical possibilities. The whole appropriation may be to an R\&D performing or R\&D funding unit. In some cases, information on the programme or project level may be obtained.

\section{The distribution of GBARD}

12.54 The recommended distribution list is given in Table 12.1 and explained below. It is based on the European Union classification adopted by Eurostat for the Nomenclature for the Analysis and Comparison of Scientific Programmes and Budgets (NABS) at the one-digit level. The NABS nomenclature was originally established in 1969 and most recently revised in 2007 (Eurostat, 2008). While not all countries use the NABS, the correspondence between the NABS list and this manual's should be used for reporting to the OECD, even if countries use their own classifications for the purposes of producing their national GBARD or equivalent compilations.

12.55 In principle, subject to information being available, all budget items can be assigned to a secondary socioeconomic objective in order to provide a more complete picture. Such an approach can provide a useful source of information for conducting sensitivity analysis and cross-country and longitudinal comparisons for specific objectives. A potential risk of reporting secondary objectives is that comparisons between funds allocated to objectives may fail to duly account for this multiplicity.

\section{Description of socioeconomic objectives (SEO)}

\section{Exploration and exploitation of the Earth}

12.56 This SEO covers funds for R\&D with objectives related to the exploration of the Earth's crust and mantle, seas, oceans and atmosphere, as well as for R\&D on their exploitation. It also includes climatic and meteorological research, polar exploration and hydrology. It does not include R\&D related to soil improvement (SEO 4), land use or fishing (SEO 8), or pollution (SEO 2).

\section{Environment}

12.57 This SEO covers R\&D aimed at improving the control of pollution, including the identification and analysis of the sources of pollution and their causes, and all pollutants, including their dispersal in the environment and the effects on humans, species (fauna, flora, micro-organisms) and the biosphere. The development of monitoring facilities for the measurement of all kinds of pollution is included, as is R\&D for the elimination and prevention of all forms of pollution in all types of environment. 


\section{Table 12.1. Classification of socioeconomic objectives for GBARD}

Based on NABS 2007

\begin{tabular}{|c|c|c|}
\hline $\begin{array}{l}\text { Chapter } \\
\text { number }\end{array}$ & NABS categories for socioeconomic objectives of R\&D & Recommended subcategories \\
\hline 1 & \multicolumn{2}{|l|}{ Exploration and exploitation of the earth } \\
\hline 2 & \multicolumn{2}{|l|}{ Environment } \\
\hline 3 & \multicolumn{2}{|l|}{ Exploration and exploitation of space } \\
\hline 4 & \multicolumn{2}{|l|}{ Transport, telecommunication and other infrastructures } \\
\hline 5 & \multicolumn{2}{|l|}{ Energy } \\
\hline 6 & \multicolumn{2}{|l|}{ Industrial production and technology } \\
\hline 7 & \multicolumn{2}{|l|}{ Health } \\
\hline 8 & \multicolumn{2}{|l|}{ Agriculture } \\
\hline 9 & \multicolumn{2}{|l|}{ Education } \\
\hline 10 & \multicolumn{2}{|l|}{ Culture, recreation, religion and mass media } \\
\hline 11 & \multicolumn{2}{|l|}{ Political and social systems, structures and processes } \\
\hline \multirow[t]{6}{*}{12} & \multirow{6}{*}{$\begin{array}{l}\text { General advancement of knowledge: R\&D financed from } \\
\text { general university funds (GUF) }\end{array}$} & 12.1 R\&D related to Natural Sciences \\
\hline & & 12.2 R\&D related to Engineering Sciences \\
\hline & & 12.3 R\&D related to Medical Sciences \\
\hline & & 12.4 R\&D related to Agricultural Sciences \\
\hline & & 12.5 R\&D related to Social Sciences \\
\hline & & 12.6 R\&D related to Humanities ${ }^{1}$ \\
\hline \multirow[t]{6}{*}{13} & \multirow{6}{*}{$\begin{array}{l}\text { General advancement of knowledge: R\&D financed from } \\
\text { other sources than GUF }\end{array}$} & 13.1 R\&D related to Natural Sciences \\
\hline & & 13.2 R\&D related to Engineering Sciences \\
\hline & & 13.3 R\&D related to Medical Sciences \\
\hline & & 13.4 R\&D related to Agricultural Sciences \\
\hline & & 13.5 R\&D related to Social Sciences \\
\hline & & 13.6 R\&D related to Humanities ${ }^{1}$ \\
\hline 14 & \multicolumn{2}{|l|}{ Defence } \\
\hline
\end{tabular}

Note: Recommended classification subject to potential revision and update.

1. The Arts are to be included.

Source: Eurostat. Accessed from http://oe.cd/seo.

\section{Exploration and exploitation of space}

12.58 This SEO covers all civil space R\&D relating to the scientific exploration of space, space laboratories, space travel and launch systems. Corresponding R\&D in defence is classified in SEO 13. Although civil space R\&D is not in general concerned with particular objectives, it frequently has a specific goal, such as the advancement of knowledge (e.g. astronomy) or relates to particular applications (e.g. telecommunications satellites or earth observation). The category is nonetheless maintained to facilitate reporting by countries with major space programmes. This chapter does not include corresponding R\&D for defence purposes. 


\section{Transport, telecommunication and other infrastructures}

12.59 This SEO covers R\&D aimed at infrastructure and land development, including the construction of buildings. More generally, this SEO covers all R\&D relating to the general planning of land use. This includes $R \& D$ into protection against harmful effects in town and country planning but not research into other types of pollution (SEO 2). This SEO also includes R\&D related to transport systems; telecommunication systems; general planning of land use; the construction and planning of buildings; civil engineering; and water supply.

\section{Energy}

12.60 This SEO covers R\&D aimed at improving the production, storage, transportation, distribution and rational use of all forms of energy. It also includes $R \& D$ on processes designed to increase the efficiency of energy production and distribution, and the study of energy conservation. It does not include R\&D related to prospecting (SEO 1) or R\&D into vehicle and engine propulsion (SEO 6). See also Box 12.1 for further clarification on the composition of "energy R\&D" as defined by this manual.

\section{Box 12.1. Differences between energy GBARD and IEA RD\&D data}

The series of data collected and issued by the OECD Directorate for Science, Technology and Innovation, as well as by other international and national organisations for GBARD on this objective, which compile them under the guidelines in this manual, should not be confused with the special series collected and issued by the International Energy Agency (IEA) of the OECD, which covers energy research, development and demonstration expenditures, or "RD\&D", a somewhat broader concept.

The IEA concept of Energy RD\&D differs from the Frascati concept of R\&D, in that: (i) it focuses on energy-related programmes; (ii) it includes all kinds of "demonstration projects"; and (iii) it includes state-owned companies. The IEA has decided to include demonstration projects when collecting R\&D budget data because quite often this is an important part of the development of new technologies. The project's outcome may be uncertain, and there is an element of risk that is often too large for the private sector to assume alone (IEA, 2011).

Demonstration is defined by the IEA as the design, construction and operation of a prototype of a technology at or near commercial scale with the purpose of providing technical, economic and environmental information to industrialists, financiers, regulators and policy makers. Information on funding for demonstration is collected alongside R\&D and separately itemised.

The subject matter scope of IEA's RD\&D data is also broader than SEO 5, because it comprises all programmes that focus on: (i) sourcing energy; (ii) transporting energy; (iii) using energy; and (iv) enhancing energy efficiency. 


\section{Box 12.1. Differences between energy GBARD and IEA RD\&D data (cont.)}

This includes all RD\&D programmes that concern one of the following seven main branches of energy-related developments, as collected by the IEA, which are: (i) energy efficiency; (ii) fossil fuels (oil, gas and coal); (iii) renewables; (iv) nuclear fission and fusion; (v) hydrogen and fuel cells; (vi) other power and storage techniques; and (vii) other cross-cutting technologies or research. Source: International Energy Agency (2011). Accessed from www.iea.org/stats/RDD\%20Manual.pdf.

\section{Industrial production and technology}

12.61 This SEO covers $R \& D$ aimed at the improvement of industrial production and technology, including R\&D on industrial products and their manufacturing processes, except where they form an integral part of the pursuit of other objectives (e.g. defence, space, energy, agriculture).

\section{Health}

12.62 This SEO covers R\&D aimed at protecting, promoting and restoring human health broadly interpreted to include health aspects of nutrition and food hygiene. It ranges from preventive medicine, including all aspects of medical and surgical treatment, both for individuals and groups, and the provision of hospital and home care, to social medicine and paediatric and geriatric research.

\section{Agriculture}

12.63 This SEO covers all R\&D aimed at the promotion of agriculture, forestry, fisheries and foodstuff production, or furthering knowledge on chemical fertilisers, biocides, biological pest control and the mechanisation of agriculture, as well as concerning the impact of agricultural and forestry activities on the environment. This also covers R\&D aimed at improving food productivity and technology. It does not include R\&D on the reduction of pollution (SEO 2); on the development of rural areas; on the construction and planning of buildings; on the improvement of rural rest and recreation amenities and agricultural water supply (SEO 4); on energy measures (SEO 5); or on the food industry (SEO 8).

\section{Education}

12.64 This SEO includes $R \& D$ aimed at supporting general or special education, including training, pedagogy, didactics, and targeted methods for specially gifted persons or those with learning disabilities. This objective applies to all levels of education, from pre- and primary school through to tertiary education, as well as to subsidiary services to education. 


\section{Culture, recreation, religion and mass media}

12.65 This SEO includes R\&D aimed at improving the understanding of social phenomena related to cultural activities, religion and leisure activities so as to define their impact on life in society, as well as to racial and cultural integration and on socio-cultural changes in these areas. The concept of "culture" covers the sociology of science, religion, art, sport and leisure, and also comprises inter alia R\&D on the media, the mastery of language and social integration, libraries, archives and external cultural policy.

12.66 This SEO also includes R\&D related to: recreational and sporting services; cultural services; broadcasting and publishing services; and religious and other community services.

\section{Political and social systems, structures and processes}

12.67 This SEO includes R\&D aimed at improving the understanding of and supporting the political structure of society; public administration issues and economic policy; regional studies and multi-level governance; social change, social processes and social conflicts; the development of social security and social assistance systems; and the social aspects of the organisation of work. This objective also includes R\&D related to gender-related social studies, including discrimination and familiar problems; the development of methods of combating poverty at local, national and international level; the protection of specific population categories on the social level (immigrants, delinquents, "drop outs", etc.), on the sociological level, i.e. with regard to their way of life (young people, adults, retired people, disabled people, etc.) and on the economic level (consumers, farmers, fishermen, miners, the unemployed, etc.); and methods of providing social assistance when sudden changes (natural, technological or social) occur in society.

12.68 This SEO does not include R\&D related to industrial health, the health control of communities from the organisational and socio-medical point of view, pollution at the place of work, the prevention of industrial accidents and the medical aspects of the causes of industrial accidents (SEO 7).

\section{General advancement of knowledge: $R \& D$ financed from general university funds}

12.69 When reporting GBARD by "purpose", this SEO should include, by convention, all R\&D financed from general purpose grants from ministries of education, although in some countries many of these programmes may be relevant to other objectives. This convention has been adopted because of the problem of obtaining suitable data and thus of comparability. In order to prevent this category from becoming a large, uninformative item, a supplementary breakdown by top level fields of research and development (FORD) is recommended. 


\section{General advancement of knowledge: R\&D financed from sources other than GUF}

12.70 This SEO covers all those budget allocations that are earmarked for R\&D but which cannot be attributed to an objective and are financed by sources other than GUF. A supplementary breakdown by top level FORD is also recommended in this case.

\section{Defence}

12.71 This SEO covers R\&D for military purposes. It may also include basic research and nuclear and space research when financed by ministries of defence. Civil research financed by ministries of defence, for example in the fields of meteorology, telecommunications and health, should be classified in the relevant SEOs.

\subsection{Other distributions of GBARD}

\section{Classification of Functions of Government}

12.72 The Classification of Functions of Government (COFOG) has been introduced in Chapter 8. COFOG provides a classification of government outlays by functions (see the online annexe to this manual available at $h t t p: / / o e . c d / f r a s c a t i$ for COFOG categories). The level one headings have significant similarities with the NABS classification used for R\&D. The use of the COFOG classification for GBARD estimates has not been recommended because the categories are not optimised for the purpose of describing R\&D expenditures nor aligned with the definitions of $R \& D$ in this manual, and its implementation worldwide is still fairly limited. A tentative correspondence table for GBARD may be useful in the near future. Whenever possible, it is recommended that statistical agencies document the differences observed between government expenditure estimates based on the COFOG and those from GBARD estimates so that users can be appropriately informed.

\section{Modes of R\&D funding}

12.73 Other breakdowns of GBARD and its predecessor have been proposed in recent years in response to policy interests in understanding the nature of government direct support for R\&D. For example:

- GBARD by destination of funds, by institutional sector, including the Rest of the world for which no information can be collected by national surveys of domestic R\&D performers.

- GBARD by mode of funding, depending on whether the funding is allocated on a project, programmatic or institutional basis. A number of users are also interested in the breakdown of government funding according to the use of competitive criteria (which may apply at both the project and institutional levels). 
- GBARD by type of policy instrument, such as procurement contracts and grants in addition to funding of intramural R\&D.

- GBARD by level and type of government organisation.

- Furthermore, the European Commission collects data on "National public funding to transnationally coordinated R\&D", including:

* national contributions to transnational public R\&D performers

* national contributions to Europe-wide transnational public R\&D programmes

* national contributions to bilateral or multilateral public R\&D programmes established between EU Member State governments.

12.74 The experience of recent experimental data collections has indicated that a limited number of countries are currently in a position to provide a majority of these indicators on the basis of budget data. This means that further detailed information has to be collected from ministries, agencies and administrative records. Notwithstanding its potential usefulness, the manual cannot therefore recommend pursuing the collection of such information through the GBARD framework. Countries with an interest in this type of data may see their needs best served by using surveys of government entities, extending the scope of these beyond known R\&D performers in the government sector, as discussed in Chapter 8.

\subsection{The use of GBARD data}

12.75 The production of GBARD data should be aimed principally at pursuing its two main objectives: providing timely information on governmental R\&D budgets, and providing a consistent picture of how this funding is distributed, based on the socioeconomic objective.

\section{Main differences between GBARD and GERD data}

12.76 Users of the GBARD often discover and have difficulty in understanding differences between the sums reported as total GBARD (funder-based approach) and government-financed GERD (performer-based approach). The variations in the sums reported spring from differences in the specifications of the data.

\section{General differences}

12.77 Although in principle both series should be established on the basis of the same definition and scope of R\&D, covering R\&D in all fields of knowledge and comprising both current and capital expenditures, they differ in a number of respects.

- Government-financed GERD and GERD objectives data are based on reports by R\&D performers, whereas GBARD is based on reports by funders and is based principally on budgetary data. Performers may have a different and more 
accurate idea of the R\&D content of the project or activities concerned, but may also understate the full extent of government support.

- The performer's appreciation of the objectives of the project concerned may differ significantly from that of the funder, notably for R\&D funded from block grants such as GUF, which should be distributed by objective in the GERD approach for countries that report such a distribution.

- It is also possible for the measure of GUF to differ between that derived from R\&D performance estimates (within HERD) and that provided from within GBARD. Consider the following example: a central government may provide universities with a block grant worth 100 currency units, out of which 30 is allocated on the basis of scientific and R\&D excellence-related criteria, while the rest is determined on the basis of student numbers and teaching costs. Upon receipt of such block grants, universities may be free to allocate the total 100 across research, teaching or other legitimate purposes. One year they may ultimately choose to dedicate 40 to $R \& D$, another year 20. The GBARD measure of GUF may in some cases be reported as 30, while the HERD-based measure of GUF would be 40 (or 20). The GBARD measure of GUF should in no case be reported as 100 , as this would clearly overstate the amount of budget support intended and provided for R\&D.

- Budget-based measures are also likely to include a component of funding for profits and overheads that are excluded from the measure of R\&D performance.

- GERD-based series cover only R\&D performed by resident units, whereas GBARD also includes payments to foreign performers, including international organisations. Differences may also occur because of difference in the reference periods applied (calendar or fiscal years), or because appropriations may never be realised, or because there is a difference in the time when appropriations are made and when R\&D is performed.

- Estimates of government-financed GERD should include R\&D financed by central (federal), regional (state) and local (municipal) government, whereas GBARD excludes local (municipal) government, and not all countries report, or can report, data at the regional (state) level.

\section{GBARD reporting and indicators}

12.78 Table 12.2 presents an indicative template for the reporting of GBARD data. The template highlights the importance of timeliness for total GBARD and foresees the possibility of using estimates based on the relevant budget categories. The possibility that the availability of delayed GUF figures may impact on timeliness points to the advanced reporting of GBARD excluding GUF, which may be used as an indicator for overall GBARD growth. 
Table 12.2. Indicative reporting template for GBARD

\begin{tabular}{|c|c|c|c|c|c|c|c|}
\hline \multirow{2}{*}{ Main categories } & \multirow{2}{*}{\multicolumn{2}{|c|}{ Subdivision }} & \multicolumn{5}{|c|}{ Year } \\
\hline & & & $t-\ldots$ & $t-2$ & $t-1$ & $\mathrm{t}$ & $t+1$ \\
\hline \multicolumn{3}{|l|}{ Total GBARD } & $\checkmark$ & $\checkmark$ & $\checkmark$ & $\checkmark p$ & $\checkmark e$ \\
\hline \multirow[t]{8}{*}{ GBARD-excluding GUF } & & & $\checkmark$ & $\checkmark$ & $\checkmark$ & $\checkmark p$ & $\checkmark e$ \\
\hline & SE01 & & $\checkmark$ & $\checkmark$ & $\checkmark$ & $\checkmark p / e$ & \\
\hline & SEO2 & & $\checkmark$ & $\checkmark$ & $\checkmark$ & $\checkmark \mathrm{p} / \mathrm{e}$ & \\
\hline & .. & & $\checkmark$ & $\checkmark$ & $\checkmark$ & $\checkmark \mathrm{p} / \mathrm{e}$ & \\
\hline & SE011 & & $\checkmark$ & $\checkmark$ & $\checkmark$ & $\checkmark \mathrm{p} / \mathrm{e}$ & \\
\hline & SE013 & Total & $\checkmark$ & $\checkmark$ & $\checkmark$ & $\checkmark \mathrm{p} / \mathrm{e}$ & \\
\hline & & Breakdown by top level FORD & & & & & \\
\hline & SE014 & & $\checkmark$ & $\checkmark$ & $\checkmark$ & $\checkmark \mathrm{p} / \mathrm{e}$ & \\
\hline \multirow[t]{2}{*}{ GUF GBARD } & SE012 & Total & $\checkmark$ & $\checkmark$ & $\checkmark$ & $\checkmark \mathrm{p} / \mathrm{e}$ & \\
\hline & & Breakdown by top level FORD & & & & & \\
\hline \multicolumn{8}{|l|}{$\begin{array}{l}\text { Optional breakdowns and } \\
\text { relevant memo items }\end{array}$} \\
\hline \multirow[t]{2}{*}{ Capital } & \multirow{2}{*}{\multicolumn{2}{|c|}{$\begin{array}{l}\text { Capital } R \& D \text { funds } \\
R \& D \text { depreciation funds }\end{array}$}} & $\checkmark$ & $\checkmark$ & $\checkmark$ & $\checkmark$ & $\checkmark$ \\
\hline & & & & & & & \\
\hline \multirow[t]{2}{*}{ Level of government } & \multirow{2}{*}{\multicolumn{2}{|c|}{$\begin{array}{l}\text { Central/federal government } \\
\text { Regional/state government }\end{array}$}} & & & & & \\
\hline & & & & & & & \\
\hline \multirow{2}{*}{$\begin{array}{l}\text { Budget funds allocated } \\
\text { through tax relief }\end{array}$} & \multirow{2}{*}{\multicolumn{2}{|c|}{$\begin{array}{l}\text { Not separated from GBARD total } \\
\text { Separated from GBARD total }\end{array}$}} & $\checkmark$ & $\checkmark$ & $\checkmark$ & $\checkmark$ & \\
\hline & & & & & & & \\
\hline \multicolumn{3}{|l|}{ Modes of funding } & & & & & \\
\hline
\end{tabular}

Note: $\mathrm{p}=$ preliminary; $\mathrm{e}=$ estimate, $\checkmark$ Indicates priority information.

12.79 The schema also points to the breakdown of SEO12 and SEO13 by fields of $R \& D$, the itemisation of capital-related components, the level of government, as well as the potential tax relief included in GBARD estimates or excluded but reported in budgets. The latter should allow a better integration of the budget data and avoid double counting with estimates of tax relief for R\&D as compiled following the guidelines in Chapter 13 and a more complete representation of government financial support for R\&D.

\section{References}

EC, IMF, OECD, UN and the World Bank (2009), System of National Accounts, United Nations, New York. https://unstats.un.org/unsd/nationalaccount/docs/sna2008.pdf.

Eurostat (2008), Nomenclature for the Analysis and Comparison of Scientific Programmes and Budgets (NABS), Comparison between NABS 2007 and NABS 1992, Eurostat, Luxembourg. www.oecd.org/science/inno/43299905.pdf.

International Energy Agency (2011), IEA Guide to Reporting Energy RD\&D Budget/ Expenditure Statistics, IEA/OECD Publishing, Paris. www.iea.org/stats/RDD\%20Manual.pdf.

International Monetary Fund (2014), Government Finance Statistics (GFS) Manual, Pre-publication Draft, IMF, Washington, DC. www.imf.org/external/np/sta/gfsm/. 


\section{Chapter 13}

\section{Measurement of government tax relief for $R \& D$}

Governments in several countries provide tax support for $R \& D$ with the aim of promoting $R \& D$ investment in the economy by granting preferential tax treatment of eligible $R \& D$ expenditures, especially to business enterprises. Tax expenditures are complex objects of measurement, and not all statistical systems separately capture all types of tax relief measures. Reporting such tax support in supplementary reports would facilitate transparency and more balanced international comparisons. In response to user and practitioner interest in addressing this gap in previous editions of this manual, this chapter provides guidelines on reporting government support for R\&D through tax incentives, with a view to assisting in the production of internationally comparable indicators of Government Tax Relief for R\&D expenditures. These guidelines are based on the experience accumulated from a series of exploratory data collections carried out by OECD. Because of the novelty of the guidelines introduced in this chapter, further measurement improvements may be introduced after the publication of this manual. 


\subsection{Introduction}

13.1 Governments in several countries provide tax support for $R \& D$ with the aim of promoting R\&D investment in the economy by granting preferential tax treatment of eligible R\&D expenditures, especially to business enterprises. Such support is provided at the national and in some cases subnational level. Tax expenditures are complex objects of measurement, and not all statistical systems separately capture all types of tax relief measures. However, because government policy objectives for R\&D tax relief are presumably also achievable through either subsidies or other direct outlays, there is widespread acknowledgement that reporting such tax support in supplementary reports would facilitate transparency and more balanced international comparisons.

13.2 In response to user and practitioner interest in addressing this gap in previous editions of this manual, this chapter provides guidelines on reporting government support for R\&D through tax incentives, with a view to assisting in the production of internationally comparable indicators of Government Tax Relief for R\&D expenditures (GTARD). These guidelines are based on the experience accumulated from a series of exploratory data collections carried out by the OECD since 2007 as well as on previous efforts in the 1990s. They also aim to align as closely as possible to standard OECD definitions (OECD, 2010) and general statistical conventions (EC et al., 2009; IMF, 2014).

13.3 Although tax expenditures for $R \& D$ have several elements in common with the government budget allocations for R\&D (GBARD) described in Chapter 12, this manual proposes that GTARD should be measured separately and only then integrated into the overall presentation of R\&D statistics, particularly for international comparisons. The GTARD indicator can be suitably combined with GBARD to produce an indicator of overall government financial support for $R \& D$ that is robust to changes over time in the relative importance assigned to direct versus tax-based support. While these estimates may be less accurate and less internationally comparable than are performer-based statistics, since they are derived from the budget and other government sources, they can be significantly more timely and informative about a government's intentions and actual financial efforts.

13.4 Because of the novelty of the guidelines introduced in this chapter, further measurement improvements may be introduced after the publication of this manual. Data producers and users are encouraged to consult the annex 
guidance provided online to this manual available at http://oe.cd/frascati for any possible updates that are not reflected in the printed edition.

\subsection{Tax relief for $R \& D$ expenditures}

\section{Tax relief and tax expenditures}

13.5 Tax relief measures are incentives that reduce the amount of tax owed by institutional units such as business enterprises or other eligible organisations subject to different types of taxes (IMF, 2014; EC et al., 2009). The extent to which units can reduce their tax liability may be related to the amount of eligible R\&D expenditures incurred in the reference period. This type of relief is defined in this manual as tax relief for R\&D expenditures and the level of financial resources (in terms of forgone revenue and added expenditure) dedicated to this as tax expenditures for $R \& D$.

13.6 In general, tax relief can take the form of a tax allowance, an exemption, a deduction or a credit. Tax allowances, exemptions and deductions are subtracted from the tax base before the tax liability is computed - they reduce the taxable amount before assessing the tax. For example, in the case of an R\&D special tax allowance, a monetary unit of spending on R\&D expenditures can be deducted from taxable profits by a factor in excess of one. Using a simplistic formulation based on a corporation income tax for presentation purposes:

After-tax profit

$$
\begin{aligned}
= & (1-\text { tax rate }) * \text { (revenues }- \text { other deductible expenses } \\
& - \text { tax allowance factor } * \text { eligible R\&D expenditures })
\end{aligned}
$$

13.7 A tax credit is an amount subtracted directly from the tax liability due from the beneficiary unit after the liability has been computed (IMF, 2014, § 5.29). This can be represented, in a very simplified form, as follows:

After-tax profit

$$
\begin{aligned}
= & (1-\text { tax rate })^{*}(\text { revenues }- \text { all deductible expenses }) \\
& + \text { tax credit rate }{ }^{*} \text { eligible } \mathrm{R} \& \mathrm{D} \text { expenditures }
\end{aligned}
$$

13.8 Tax credits can be payable or non-payable. Under a payable tax credit system,, when the tax credit exceeds the tax liability, this excess amount may be paid in full or in part to the beneficiary. The payable credits may be awarded to beneficiaries regardless of their tax-paying status. In contrast, tax credits that are non-payable (sometimes called "wastable") are limited at most to the amount of the tax liability of the taxpayer. When the credit is non-payable, the taxpayer may be allowed to carry-over the unclaimed amount into the future.

13.9 Allowances, exemptions and deductions can also exceed the taxable base of the taxpayer. In that case, authorities may approve provisions for the said excess to be converted into a payable or refundable credit, or to be carried-over (back or forward) under normal or special conditions. A similar treatment may apply to unused, non-payable credits. 


\section{Specific challenges for measuring the cost of government tax relief for $R \& D$}

13.10 Measuring the cost of tax relief is more challenging than just measuring financial flows, such as in the context of R\&D grants or procurements, since the objective is to quantify how much revenue government ceases to gain and dedicate to other activities. The measurement of this concept requires a counterfactual based on how much the government would have raised in the absence of the relief. In practice, this is done by reference to a "normal" or baseline tax structure. The main measurement challenge is the formulation of a consistent approach for estimating the value of the concessions or exemptions beyond a "normal" tax structure that reduce government revenue collections or increase expenditures as a result of R\&D expenditures.

13.11 As a general principle for GTARD expenditure statistics, the "normal" tax structure is defined to comprise allowances and deductions that are applicable to otherwise identical, non-R\&D expenditures, as well as tax credits provided for comparable activities that do not qualify as R\&D. This applies regardless of whether other statistical frameworks compute these as adjustments to the tax payable/paid by the relevant units or as expenditures incurred by government. This approach ensures comparability across countries and an equal treatment of forgone revenues and tax refunds with the specific intent of rewarding $R \& D$ activities. The implementation of these criteria is discussed in Section 13.5 in this chapter.

\section{The link with R\&D}

13.12 For the purposes of measuring GTARD, there has to be a well-defined link with policy intentions to grant preferential tax treatment to a range of R\&D expenditures. For example, an employment tax subsidy that can benefit employers of $R \& D$ personnel on par with employers of other non-R\&D employees should not be imputed in part to GTARD, as the intention of the tax provisions is not the specific subsidy of R\&D activities.

13.13 To be counted as part of GTARD, tax relief provisions should be undertaken as part of an integrated R\&D policy, with sources appropriately documented and included in inter-ministerial discussions and reports to the legislature in the area of science and research.

\subsection{Scope of GTARD statistics}

\section{$R \& D$ definition and boundaries}

\section{$R \& D$ expenditures versus $R \& D$-based income}

13.14 GTARD is focused on tax relief that is explicitly provided for the reporting of eligible R\&D expenditures. The tax expenditures associated, for example, with the advantageous treatment of income arising from past R\&D activities, such as "patent boxes" or related instruments, are outside the scope of GTARD statistics. 


\section{R\&D definitions}

13.15 As far as possible, all guidelines, definitions and conventions identified in Chapter 2 are applicable to the collection of data on tax relief for $R \& D$. The basic definition of $R \& D$ is as given in Chapter 2. The analysis covers R\&D in all fields of R\&D (FORD) and makes no distinction between natural sciences and engineering (NSE) and all other fields, although not all countries may necessarily extend tax relief to all domains.

13.16 Definitions of R\&D or other types of expenditures eligible for tax relief may differ across jurisdictions and with respect to this manual's definition and explanatory guidance. Definitions of R\&D for R\&D tax purposes are under continuous evolution and reinterpretation by national tax authorities, a feature that may also have an impact on the records kept by R\&D performers. Particular care should be taken to check the actual R\&D content of the tax relief provided by governments for innovation-related areas, particularly those relating to other innovation expenditures and expenditures on intellectual property rights or their commercialisation, which may not be an integral part of R\&D projects. This manual recommends against the use of coefficients unless the tax records provide a sufficiently informative breakdown between R\&D and other costs.

\section{Sectoral scope}

13.17 GTARD is concerned with tax relief provided by the government sector for $R \& D$ expenditures incurred by tax-paying units, for R\&D performed within them (or possibly outside i.e. bought-in) across all institutional sectors covered within this manual.

13.18 The Business enterprise sector is usually the main intended direct recipient of tax relief for R\&D. Provisions may allow relief for R\&D expenditures subcontracted to third parties, in other domestic sectors or abroad. These are all within the scope of GTARD.

13.19 Tax relief for R\&D can also in principle be granted to higher education institutions, private non-profit institutions, individuals and possibly government organisations. The scope of GTARD can reach beyond business enterprises by using tax vehicles that apply directly to these groups. With the exception of individuals, these should be included from GTARD statistics.

13.20 In the case of forms of relief that are targeted directly towards individuals, without going through the institutions that they work for, their exclusion is recommended because it is very difficult to validate and assess the true extent of R\&D content, which most likely will be related to the individual's occupation, rather than to $R \& D$ activity. This approach ensures greater consistency with the institutional approach to R\&D statistics in this manual. Specific examples will be discussed in the following section.

13.21 While R\&D tax incentives typically attempt to incentivise the performance of R\&D within the domestic economy, authorities can in principle allow provisions that provide tax relief for non-resident taxpayers' R\&D 
and/or allow taxpayers to declare R\&D expenditures subcontracted to affiliated or non-affiliated units abroad. As in the case of GBARD, these are within the scope of GTARD.

13.22 Tax exemptions for international organisations exclusively dedicated to performing $R \& D$ in the national territory should not be counted as part of GTARD, on the grounds that these are unlikely to be systematically monitored.

\section{Relief for intramural R\&D expenditures and extramural R\&D}

13.23 Adopting a funder approach (as identified in Chapter 4 and Chapter 8), GTARD statistics cover not only tax relief provided for intramural R\&D within the beneficiary organisations, but also relief provided for expenses for outsourced $R \& D$ services and contributions to $R \& D$ carried out in other organisations.

13.24 If a firm carries out R\&D for another company, it should not be assumed that tax provisions prevent both the buyer and seller of R\&D services to claim relief for the same unit of R\&D expenditure. This may not always be the case. While the measurement of R\&D intramural expenditure helps avoid double counting, the data should reflect the actual tax relief provided to both taxpayers. Whenever possible, double counting should be identified.

\section{Types of R\&D costs}

13.25 All types of R\&D costs, including current and capital expenditures, are within the scope of GTARD. This applies to R\&D that is expensed by firms as well as $R \& D$ expenditures that a firm capitalises in its balance sheet. Also included is tax relief for the amortisation costs of assets used for R\&D activities.

\section{Types of tax instruments}

13.26 Governments can provide tax relief for R\&D expenditures through a number of tax instruments. The OECD classification of taxes (OECD, 2013) is structured according to the base on which the tax is levied and the type of taxpayer.

\section{Corporate taxes on income, profits and capital gains}

13.27 Taxes on the profits of corporations and quasi-corporations are by and large the main vehicle for implementing R\&D tax incentives. Tax relief for business enterprises that reduces the cost of after-tax R\&D performance or funding by the beneficiary by linking the relief provided in the corporation tax bill to the level of eligible R\&D is within the scope of GTARD statistics.

13.28 Tax relief for capital gains on R\&D-based assets, for example on the revalorisation of patents, etc., should be excluded from GTARD statistics, because this type of relief is not aimed at directly reducing the cost of R\&D expenditures but at enhancing the potential, uncertain benefits from such investments. Special tax regimes for intellectual property revenues, sometimes described as 
patent or innovation "boxes", as well as similar types of incentives that fit in this category are therefore excluded.

\section{Taxes on income, profits and capital gains of individuals}

13.29 The basic distinction between taxes on corporations and taxes on individuals is that corporation taxes are levied on the corporation as an entity, not on the individuals who own it, and without regard to the personal circumstances of these individuals. In principle, tax relief for R\&D provided to individuals is outside the scope of GTARD, because this manual focuses on R\&D carried out by institutional units and excludes R\&D carried out in an individual capacity. Only tax relief provided to individuals as self-employed, unincorporated firms or R\&D contractors can potentially qualify for inclusion. Relief on the income taxes paid by $R \& D$ professionals as individuals may be reported separately but should not be combined with GTARD.

\section{Social security contributions}

13.30 Compulsory social security contributions are compulsory payments that confer an entitlement to receive a (contingent) future social benefit. Being compulsory payments to general government, they clearly resemble taxes and are sometimes treated as such. These can apply to employees or employers:

- Employers, on a payroll or income basis. These are within the scope of GTARD.

- Employees, on a payroll or income basis. This category should be excluded for the same reasons as tax relief to individuals is excluded. It is possible however that the employer is tasked with withholding employee contributions and that relief is applied on withheld amounts. In that case, it would be necessary to identify whether the employer is the real beneficiary, in which case it should be reported as part of GTARD statistics. Some countries may have rules in place that are intended to ensure that relief on withheld amounts does not reduce the employee's entitlement to benefits arising from the social security contributions.

\section{Taxes on payroll and workforce}

13.31 Included here are taxes paid by employers, employees or the selfemployed either as a proportion of payroll or as a fixed amount per person, and which do not confer an entitlement to social benefits. The same distinction between employers and employees applies for the purpose of compiling GTARD statistics.

\section{Taxes on property}

13.32 Included here are recurrent and non-recurrent taxes on the use, ownership or transfer of property. Only relief on taxes on the use of property for R\&D is within the scope of GTARD. For the time being, relief on tax related to transactions on assets arising from R\&D is excluded. 


\section{Taxes on goods and services}

13.33 Included here are excise, sales and value-added taxes for R\&D services. In practice, all OECD countries with value-added taxes normally allow the immediate deduction of taxes on purchases by all but the final consumer and impose taxes at all stages. Relief on these amounts should be excluded in principle from GTARD on the basis that these taxes can be deducted by all R\&D beneficiaries, unless the relief measure provides a material, quantifiable additional benefit to the enterprise or relevant institution.

\section{Sub-sectors of government}

\section{Central (or federal) government}

13.34 The central (or federal) government sub-sector includes all governmental departments, offices, establishments and other bodies that are agencies or instruments of the central authority whose competence extends over the whole territory, with the exception of the administration of social security funds. Central (or federal) government therefore has the authority to impose taxes on all resident and non-resident units engaged in economic activities within the country. $R \& D$ tax relief provided at this level of government should always be reported.

\section{Regional (or state) government}

13.35 This sub-sector consists of intermediate units of government exercising a competence at a level below that of central (or federal) government. It includes all such units operating independently of central/federal government in a part of a country's territory that encompasses a number of smaller localities. In unitary countries, regional governments may be considered to have a separate existence where they have substantial autonomy to raise a significant proportion of their revenues from sources within their control and their officers are independent of external administrative control in the actual operation of the unit's activities. R\&D tax relief provided at this level of government should be reported when its contribution is significant.

\section{Local (or municipal) government}

13.36 This sub-sector includes all other units of government exercising an independent competence in part of the territory of a country, with the exception of the administration of social security funds. It encompasses various urban and/or rural jurisdictions (e.g. local authorities, municipalities, cities, boroughs, districts). For practical reasons, it is unlikely that R\&D tax relief provided at the level of local/municipal government can be captured in a sufficiently precise and timely manner. Unless there is evidence that a significant level of tax support is provided, this category should be excluded. 


\subsection{Sources of data and measurement}

\section{Estimation method}

13.37 Given the need to establish a benchmark to identify the amount of relief provided for R\&D expenditures, tax expenditures need to be estimated based on the data available by applying a number of conventions and assumptions. According to OECD (2010), there are three mechanisms for estimating the value of tax expenditures associated with relief measures.

- Initial revenue loss: the amount by which tax revenue is reduced as a consequence of the introduction of tax expenditure, based upon the assumption of unchanged behaviour and unchanged revenues from other taxes.

- Final revenue loss: the amount by which tax revenue is reduced as a consequence of the introduction of a tax expenditure, taking into account the change in behaviour and the effects on revenues from other taxes as a consequence of its introduction.

- Outlay equivalence: the direct expenditure that would be required in pre-tax terms to achieve the same after-tax effect on taxpayers' incomes as the tax expenditure if the direct expenditure is accorded the tax treatment appropriate to that type of subsidy or transfer in the hands of the recipient.

13.38 The three methods can yield significantly different estimates of tax expenditure. The main difference between the first two methods is whether or not behavioural effects are taken into account, while the third method takes into account the additional administrative costs of running a programme delivering direct support. The simplest approach (initial revenue loss) is used in most OECD countries to estimate tax expenditures, as it does not require complex assumptions on behavioural responses to the hypothetical removal of the tax incentive. A number of budget documents are based on the initial revenue loss method and modified or complemented with behaviour-based estimates for planned future changes in provisions. Such estimates are often based on assumptions about the impact on the eligible amount of R\&D claimed by taxpayers.

13.39 For practical purposes, the initial revenue loss is recommended as the method to be applied.

\section{Formulation of a common benchmark for international reporting}

13.40 Formulating a common benchmark is a crucial element in producing internationally comparable GTARD statistics that reflect in a robust fashion the financial effort made by governments in providing a preferential treatment for R\&D expenditures. This is also one of the most difficult tasks. It is helpful to distinguish current and capital expenditures.

13.41 In the case of current R\&D expenditures, it is recommended to exclude from GTARD estimates the tax revenues that are forgone as a result of 
provisions that allow firms to treat current $R \& D$ expenditures as an expense and deduct them from profits. Such provisions that treat current R\&D expenditures like other types of business expenses are the norm across all countries, not least because of the difficulty of enforcing different approaches. For the sole purposes of this manual, the focus is on the cost of provisions that imply a more favourable treatment of $R \& D$. This approach is proposed in order to ensure comparability with countries not reporting dedicated R\&D tax relief but allowing the deductibility of current R\&D expenses. In the absence of enhanced incentives, companies have the ability to report the current expenditure components of $R \& D$ as the deductible costs of sales, without necessarily identifying the $R \& D$ nature of the activity.

13.42 This guidance does not preclude that for internal purposes countries may sometimes wish to describe these "normal" expensing provisions as enhanced incentives for $R \& D$ by stating that the relevant comparison is with other capital, not current, investments.

13.43 For capital $R \& D$ expenditures, the derivation of a benchmark is considerably more problematic, as the baseline treatment for assets varies more significantly across countries. For practical reasons, it is recommended that countries report estimates against the benchmark of identical capital assets within their own country.

\section{Recording type of tax relief and dealing with carryover}

13.44 In the recording of tax relief from the perspective of the (usually Business enterprise) recipient, important points in time are the period in which the liability arises and the period in which the R\&D eligible for relief takes place, the moment the tax liability is definitively assessed, the day it becomes due for payment without penalty, and the day the tax is actually paid or refunds are made.

13.45 In principle, the recording of tax relief for R\&D should occur when the R\&D generating the basis for claiming relief has taken place; in practice, this may be possible only when the claim is recognised by government regardless of the time when it is paid in cash by government or used to decrease the amount of taxes to be paid to government.

13.46 This "accrual-based" approach ensures the best possible alignment between statistics on R\&D expenditures and statistics on R\&D performance and funding. It requires, however, a careful accounting of carried-over tax assets and liabilities. R\&D performed and reported in a given year may be carried forward into the future and eventually never used if, for example, a company ceases to exist.

13.47 A payments or cash-based approach more closely follows the actual flow of money between authorities and tax-paying units, but misses the link with $R \& D$ performance data and the underlying economic and R\&D reality. Hybrid solutions are possible, for example cash-based approaches can be aligned to the 
tax reference year $t$ in which the $R \& D$ was reported rather than the point in time when the tax payments take place (e.g. a number of months into year $t+1$ in the case of annual settlements).

13.48 It is important to note that there is no prevalent approach at present for reporting R\&D tax incentives, with very few countries maintaining a system of records that allows the production of estimates on both an accruals and cash expenditure basis. Ideally, countries should record the following:

1. refundable credits provided to taxpayers or other types of units for $R \& D$ in the reference period (if applicable)

2. forgone tax revenues in the reference period, for R\&D in the same period

3. credits earned but not used in the reference period, e.g. carried forward, valued on a nominal basis

4. credits earned in a previous period used in the reference period, also on a nominal basis.

13.49 The two main indicators for GTARD can be defined on the basis of these components:

- GTARD on an earned or accruals basis=[1]+[2]+[3]

- GTARD on a use or cash basis=[1]+[2]+[4].

13.50 It is recommended to use the accruals approach whenever possible, but cash-based estimates are also acceptable as long as they are consistently applied over time. In some countries, tax beneficiaries can decide when they declare (i.e. file for) tax credits/allowances, which may not be in the reference period during which the $R \& D$ expenditure actually took place. Additionally, some countries allow beneficiaries to carry forward declared, unused credits/ allowances, e.g. as postponed declarations of eligible R\&D. In both circumstances there is the potential for double counting. In compiling GTARD indicators, care should be exercised to ensure that there is no double counting in reported totals.

\section{Types of data}

13.51 There are different possible data sources that can inform compilers how much tax relief governments provided for R\&D. These potential choices are assessed against the objective of providing a comprehensive measure of this type of support. One data source is the recipients of the R\&D tax relief; statistics about them might be obtained from surveys of R\&D performers (i.e. performer-based approach). Another data source is the provider of the R\&D tax relief; statistics about them might be obtained from (verified/approved) tax claim filings (similar to a funder-based approach). The two sources may differ for a variety of reasons.

\section{Surveys of R\&D performers}

13.52 R\&D performer surveys are focused on the identification of $R \& D$ performance and its respective "sources of funds". From this perspective, many 
forms of GTARD do not qualify as government funding, because it is not possible for the respondent to align its own reporting of R\&D performance to the tax relief. This can occur when the performer is uncertain about the level of relief to be received, which may depend on its profits at the end of the tax year. The link between relief and R\&D is therefore in most cases indirect. The relief ultimately received may be used by recipients for other purposes, and may not be realised for years if carried over.

13.53 Eligible $R \& D$ expenditures contribute to the base for relief calculation but are not necessarily the object of funding. Despite the existence of cases where a direct link with intramural performance may apply, it cannot be generally recommended to ask an R\&D performing unit for the tax incentive component of the external sources of funds received for $R \& D$, partly because the tax support can also be for R\&D costs incurred by third parties on the firm's behalf.

13.54 Subject to successful testing, surveys may instead inquire about:

- the extent of eligible intramural R\&D and extramural funding by the unit that have been or will be used to claim R\&D tax relief

- how the unit's tax liabilities (assets) were reduced (increased) as a result of its R\&D activities in the reference year, and changes in the book value of unused allowances and credits.

13.55 For the reasons stated, it is recommended that statistics of GTARD expenditures be compiled on a source basis rather than a performer basis. Surveys of R\&D performers are not recommended for the purposes of reporting GTARD but can provide a second-best solution when actual administrative records cannot be accessed or are too unreliable.

\section{Detailed tax records}

13.56 Tax relief claims processed and subsequently analysed by tax authorities are the major source of information on the extent of tax relief for R\&D. In many countries, the forms required have several elements in common with R\&D surveys, and use their own (often very detailed) taxonomies for different types of expenditures. These data can provide the basis for simple calculations of the value of tax relief for R\&D. Estimates can be based on the entire population of claims or on a representative sample.

13.57 Tax records may however only be available in some cases with a time lag that may also exceed that of traditional R\&D surveys. For example, claims may become available only after tax inspectors have finished working with them. It has become increasingly common among countries providing tax relief for $R \& D$ to provide statistical releases on the number of tax support beneficiaries and on the costs associated with the schemes.

13.58 It is therefore recommended to use tax records for final estimates of GTARD expenditures. 


\section{Budgetary information records}

13.59 Budget records appear to be most appropriate for the purposes of estimating forecasts and now-casting the "impact" of tax relief on the government's budgetary position. In many countries this information is available - although often not published - as a separately identifiable category. Budget publications may include ad hoc analyses that report on the expected implications of modifications in the design of $R \& D$ tax incentive schemes, based on analytical and simulation approaches. Whenever available, these records are recommended only for the purpose of providing preliminary, timely statistics.

\section{Calendar and fiscal years}

13.60 National authorities whose fiscal years do not correspond to the calendar year should provide data, where possible, on a calendar year basis so as to permit maximum comparability with the data of other countries.

\subsection{Priority breakdowns for GTARD statistics}

\section{By beneficiary sector}

13.61 It is recommended that statistics on GTARD expenditure are broken down according to the institutional classification of beneficiary taxpayers, using the main sector classifications in this manual (Business enterprise, Government, Higher education, Private non-profit and Rest of the world). In practice, it may suffice to show the breakdown between the Business enterprise sector and other sectors.

13.62 Among beneficiaries, and in particular within the Business enterprise sector, it is useful to present GTARD statistics by industry/economic activity so that tax relief support can be compared with the allocation of governmentfinanced GERD and BERD based on R\&D survey data. Because the tax statistics may not be fully mapped to business registers, special care should be taken to ensure that the reporting of the activities of head offices does not supress information about the main economic activity of the actual enterprises.

\section{By level of government}

13.63 For comparability purposes, it is proposed that countries report GTARD separately for:

- central (or federal) government (and its social security funds)

- regional (or state) government (and its social security funds).

\section{By type of tax relief}

13.64 Whenever possible, GTARD statistics (whether compiled on an earned basis or on a use basis) should include separate information on the constituent elements (identified in Section 13.4) that underpin the indicator that countries can feasibly report. 


\section{By firm size}

13.65 Within the Business enterprise sector, it is recommended that the following breakdown is used, notwithstanding the national definition of firm size for R\&D tax relief purposes:

- small-sized firms (less than 50 persons employed)

- medium-sized firms (between 50 and 249 employees)

- large-sized firms (250 or more persons employed).

13.66 It is important to note that country-specific GTARD provisions may vary by firm size, and that the categories may differ from standard size group classifications. It is also possible that size eligibility provisions specify different rules on whether, for the purpose of GTARD, an affiliate represents a different enterprise or not. The existence of such provisions may influence the reported distribution of GTARD expenditures by size group.

\section{Presentation of GTARD alongside other R\&D indicators}

13.67 Statistics on government expenditures on tax relief for R\&D may be presented alongside two other types of $R \& D$ indicators in order to give a more complete picture of government support:

- GBARD. Both measures represent source-based estimates of overall government financial support for R\&D. Data compilers should be careful to remove any component of tax support included in GBARD statistics, based on the recommendations made in Chapter 12.

- BERD funded by government. This type of measure can in principle be presented alongside the component of GTARD expenditures in order to illustrate in a more comprehensive way the extent of government financial support for business enterprises. It should be noted that this approach combines funder-based (GTARD) and performer-based statistics, and there may be inconsistencies as a result. For example, some GTARD expenditure may support R\&D outsourced to domestic universities or government institutions or to institutions resident abroad.

\section{References}

EC, IMF, OECD, UN and the World Bank (2009), System of National Accounts, United Nations, New York. https://unstats.un.org/unsd/nationalaccount/docs/sna2008.pdf.

International Monetary Fund (2014), Government Finance Statistics (GFS) Manual, Prepublication Draft, IMF, Washington, DC. www.imf.org/external/np/sta/gfsm/.

OECD (2014), "The OECD classification of taxes and Interpretative Guide", in OECD, Revenue Statistics 2014, OECD Publishing, Paris. DOI: $h$ ttp://dx.doi.org/10.1787/rev_stats-2014-8-en-fr.

OECD (2010), Tax expenditures in OECD countries, OECD Publishing, Paris. DOI: http://dx.doi. org/10.1787/9789264076907-en. 


\section{ANNEX 1 \\ Brief History and Origins of the Present Manual}

This annex provides a summary account of the six previous editions up to the current version of the Frascati Manual. It also acknowledges the contributions of the key individuals who helped make this a globally adopted standard. Those readers interested in consulting the original documents can find those on the manual's website (http://oe.cd/frascati).

\section{Origins}

Encouraged by the rapid growth of the amount of national resources devoted to research and experimental development (R\&D), most OECD Member countries began to collect statistical data in this field around 1960. In doing so, they followed the pioneering efforts of a small number of countries, including the United States, Japan, Canada, the United Kingdom, the Netherlands and France. However, they encountered theoretical difficulties when starting R\&D surveys, and differences in scope, methods and concepts made international comparisons difficult. The need for some attempt at standardisation of the kind undertaken for economic statistics was increasingly felt.

The OECD's interest in this question dates back to the Organisation for European Economic Co-operation (OEEC). In 1957, the Committee for Applied Research of the European Productivity Agency of the OEEC began to convene meetings of experts from member countries to discuss methodological problems. As a result, an Ad hoc Group of Experts was set up, under the auspices of the Committee for Applied Research, to study surveys of research and development expenditure. The Technical Secretary of the Group, Dr J. C. Gerritsen, prepared two detailed studies on the definitions and methods employed to measure R\&D in the government sector of the United Kingdom and France and later of the United States and Canada. Other members of the Group circulated papers describing the methods and results of surveys in their own countries. 


\section{First edition}

When the OECD Directorate for Scientific Affairs took over the work of the European Productivity Agency in 1961, the time was ripe for specific proposals for standardisation. At a meeting in February 1962, the Ad hoc Group decided to convene a conference to study the technical problems of measuring R\&D. In preparation, the Directorate for Scientific Affairs appointed a consultant, Mr C. Freeman, to prepare a draft document; the document was circulated to Member countries in the autumn of 1962 and revised in the light of their comments. The "Proposed Standard Practice for Surveys of Research and Development" (OECD, 1963) was discussed, revised and accepted by experts from the OECD Member countries at the conference, which was held in Frascati, Italy, in June 1963.

Later in 1963, the OECD Directorate for Scientific Affairs invited the United Kingdom's National Institute for Economic and Social Research to undertake an experimental comparison of research efforts in five western European countries (Belgium, France, Germany, the Netherlands and the United Kingdom), the United States and the USSR. While the study (Freeman and Young, 1965) was based on statistics from surveys undertaken before international standards had been decided, it also tested the first draft definitions. It concluded that the available statistical information left a great deal to be desired. The main improvements suggested were:

- a more rigorous conceptual separation of research and experimental development and "related scientific activities"

- careful studies in the higher education sector to estimate the proportion of time devoted to research by teaching staff and postgraduate ( $\mathrm{PhD}$ level) students

- a more detailed breakdown of R\&D manpower and expenditure data to permit, inter alia, a more exact calculation of research exchange rates

- a more systematic measurement of expenditure flows between R\&D sectors

- more data on flows of technological payments and on the international migration of scientific personnel.

In 1964, following the acceptance of the Frascati Manual by Member countries, the OECD launched the International Statistical Year (ISY) on Research and Experimental Development. Member countries returned data for 1963 or 1964. Seventeen countries took part, many of them conducting special surveys and enquiries for the first time (OECD, 1968).

\section{Second edition}

Following the publication of the Statistical Year findings, the OECD Committee for Science Policy requested the OECD Secretariat to prepare a revision of the Frascati Manual in the light of the experience gained. An outline of 
suggestions was circulated to Member countries in March 1968. A draft revision, incorporating most of these suggestions, was examined at the meeting of national experts held in Frascati in December 1968. For this revision, particular attention was paid to making the manual conform, as far as possible, to existing United Nations' international standards such as the System of National Accounts (SNA) (United Nations, 1968) and the International Standard Industrial Classification (ISIC). A revised draft was examined by a small group of experts in July 1969, and a revised version of the manual was published in September 1970 (OECD, 1970).

\section{Third edition}

The second revision of the manual was influenced by two series of events. First, by 1973, Member countries had participated in four ISY surveys, and data accuracy and comparability had benefited greatly from this continued experience. National survey techniques had also greatly improved. Second, in 1972 the OECD Committee for Scientific and Technological Policy (CSTP) set up the first Ad hoc Review Group on R\&D Statistics under the chairmanship of Mr Silver (United Kingdom) to advise it and the Secretariat on how to make optimal use, over the short term, of the restricted resources available for R\&D statistics at the OECD while taking account of Member countries' priorities. Member countries were asked to draw up an inventory of their needs, and nearly all responded. In addition to giving absolute priority to a continuation of the ISY surveys, they made a number of recommendations touching on methodology, notably concerning the need for closer contacts between the OECD and other international organisations.

As a result, the third edition of the Frascati Manual went more deeply into some subjects and addressed new ones. The scope of the manual was expanded to cover research in the social sciences and humanities, and greater stress was placed on "functional" classifications, notably the distribution of R\&D by "objectives". A draft was discussed at a meeting of experts held at the OECD in December 1973, and the final text was adopted in December 1974 (OECD, 1976).

\section{Fourth edition}

For this edition, national experts recommended undertaking only an intermediate revision exercise, with no significant changes to be made in key concepts and classifications. The main stress was to be placed on improving drafting and layout. However, a number of revisions were in fact made to reflect the recommendations of the second Ad hoc Review Group on R\&D Statistics, which met in 1976 under the chairmanship of Mr J. Mullin (Canada), the experience gained by the OECD Secretariat from its international surveys, and analytical reports and suggestions from national experts on R\&D statistics. Revision proposals were presented at the annual meeting of national experts in December 1978. The Ad hoc Expert Group met at the OECD Secretariat in July 1979 for more detailed discussions of a draft prepared by a consultant. A 
revised version incorporating the Group's and the Secretariat's suggestions was discussed in December 1979, and the text was finally adopted in autumn 1980 (OECD, 1981).

The Higher education sector does not appear in the System of National Accounts (SNA) adopted by the United Nations and the OECD. The OECD and UNESCO, however, introduced the sector early in their collection of R\&D statistics because of policy makers' interest in the role of universities and other third-level colleges and institutions in national research efforts. Nonetheless, the problems associated with the collection of accurate data for this sector are significant. They were discussed at the seminar on S\&T indicators for this sector held at the OECD in June 1985. The experts felt that, while the manual gave general guidance, it sometimes gave insufficient practical advice. Therefore, at their annual meeting in December 1985, the Group of National Experts on Science and Technology Indicators (NESTI) agreed to prepare a supplement to the Frascati Manual to address these problems and to make recommendations on improving future survey practice. A first draft was discussed in December 1986, and the amended text was then adopted by NESTI and, subject to some final adjustments, it was recommended for derestriction in December 1987 (OECD, 1989).

\section{Fifth edition}

By the late 1980s, it was clear that the Frascati Manual guidelines needed to be revised to address changes in policy priorities and to obtain the data needed to inform the policy-making process. Many issues were involved, notably developments in the S\&T system and our understanding of it. Some of these issues emerged in the context of the OECD's Technology-Economy Programme - TEP (e.g. internationalisation, software, transfer sciences, etc.). Others concerned data on environmental R\&D, analytical needs for R\&D data that can be integrated with other economic and industrial series, and the revisions of the international standards and classifications applied to R\&D statistics in the manual.

As a result, an expert conference took place in Rome in October 1991 to discuss proposals for revisions to the Frascati Manual, hosted by the Italian Ministry for Universities and Scientific Research. For the first time, experts from the Eastern European countries attended. Following the conference, a draft revised version of the manual, incorporating much of the text of the supplement on higher education, was formally discussed by NESTI at its April 1992 meeting. After further revision by a small editorial group in light of the recommendations made there, the draft was adopted early in 1993 (OECD, 1994).

\section{Sixth edition}

The rationale for undertaking a fifth revision of the Frascati Manual (OECD, 2002) included the need to update various classifications together with an increasing need for data on R\&D in the services sector, on the globalisation of 
$R \& D$ and on human resources for $R \& D$. Various benchmarking projects carried out at the time also increased the need for comparable data. NESTI took the decision to revise the Frascati Manual at its 1999 meeting, and various topics for revision were discussed at a special meeting in March 2000. At the meeting in 2000, 19 topics were identified for further investigation. For each of these, a small group was established, with a lead country or the OECD Secretariat in charge of the work. The groups' reports were discussed at a meeting hosted by the Italian authorities in Rome in May 2001. At the subsequent NESTI meeting in Rome, decisions were taken on the substantial revisions to be made. Proposals for changes in wording were discussed at a meeting in October 2001. The revised manual was adopted in late 2002. The sixth edition of the manual was published in both paper and electronic versions.

In this edition of the manual, an explicit effort was made to strengthen various methodological recommendations. As in the previous revisions, recommendations in the System of National Accounts (SNA) were followed as far as possible and feasible for the purposes of R\&D surveys while continuing to take steps towards bringing R\&D statistics closer to the SNA. These efforts were subsequently justified by the decision adopted in the 2008 SNA to adopt the Frascati definition of R\&D and treat these investments as capital formation (EC et al., 2009).

The manual incorporated new sections on R\&D in software, the social sciences and services, the SNA, globalisation and co-operation on R\&D, as well as detailed examples on types of $R \& D$. The guidance on $R \& D$ personnel was substantially revised, including new proposals to report data by gender and age. This edition also provided detailed recommendations on the reporting of sources of funds and of extramural expenditure. A number of recommendations adopted by Eurostat since the previous revision of the manual were integrated, and the NABS classification was adopted as the basic classification by socio-economic objective. New annexes were introduced in the sixth edition on R\&D in some specific fields of interest, such as ICT, health and biotechnology. One annex containing guidelines on the regionalisation of $R \& D$ variables was added.

\section{Key contributors to previous editions}

All the editions of the manual have been prepared in co-operation between experts from Member countries and international organisations, notably UNESCO, EU and Nordforsk/the Nordic Industrial Fund, and the OECD Secretariat, especially Ms A. Young and Mr Y. Fabian (for the first four editions). Particular debts of gratitude are due to the National Science Foundation, which pioneered the systematic measurement of R\&D.

Among those who must be mentioned in connection with the first edition of the manual are Dr J. Perlman, Professor C. Freeman and the French Délégation Générale à la Recherche Scientifique et Technique (DGRST). 
Mr H. E. Bishop chaired the 1968 Frascati meeting, and Mr H. Stead (Statistics Canada), Mr P. Slors (Netherlands Central Bureau of Statistics) and Dr D. Murphy (Irish National Science Council) made major contributions to the second edition.

Among those who helped to prepare the third version, thanks are due to Mr K. Sanow (National Science Foundation), Mr J. Mitchell (Office of Fair Trading, United Kingdom) and Mr K. Perry (United Kingdom Central Statistical Office), as well as to Mrs K. Arnow (National Institutes of Health, United States), Chairperson of the 1973 meeting of experts, and to Mr T. Berglund (Swedish Central Statistical Office), Mr J. Sevin (DGRST) and Dr F. Snapper (Netherlands Ministry of Education and Science), who chaired discussions on special topics.

The fourth edition owed a great deal to the work of Mr H. Stead (Statistics Canada). Chairing the various expert meetings involved were Mr G. Dean (Central Statistical Office, United Kingdom) in 1978 and Mr C. Falk (National Science Foundation, United States) in 1979. The Higher Education Supplement was prepared by Ms A. FitzGerald (EOLAS - Irish Science and Technology Agency, Ireland). The section on time-budget studies drew heavily on work by Mr M. Åkerblom (Central Statistical Office of Finland). The 1985 Conference on S\&T Indicators for the Higher Education Sector was chaired by Mr T. Berglund (Statistics Sweden).

The fifth edition was largely prepared by Ms A. FitzGerald (EOLAS) on the basis of work by a large number of national experts. Particular thanks are due to Mr T. Berglund (Statistics Sweden), Mr J. Bonfim (Junta Nacional de Investigaçao Cientifica e Tecnologica, Portugal), Ms M. Haworth (Department of Trade and Industry, United Kingdom), Mr A. Holbrook (Industry, Science and Technology Canada, Canada), Mr J.-F. Minder (Ministère de la Recherche et de la Technologie, France), Prof. F. Niwa (National Institute of Science and Technology Policy, Japan), Dr E. Rost (Bundesministerium für Forschung und Technologie, Germany), Mr P. Turnbull (Central Statistical Office, United Kingdom) and Mrs K. Wille-Maus (Norges Allmennvitenskaplige Forskningrad, Norway). Mr G. Sirilli (Consiglio nazionale delle ricerche, Italy) was Chairman of the Group of National Experts on Science and Technology Indicators during this period and also organised the conference held in Rome.

The sixth edition was largely prepared by Mr M. Åkerblom (Statistics Finland; OECD Secretariat for the drafting phase) on the basis of work on specific topics by a large number of national experts. Particular thanks are due to Mr D. Byars (Australian Bureau of Statistics); Ms D. Francoz (Ministère de la Recherche et de la Technologie, France); Mr C. Grenzmann (Stifterverband, Germany); Mr J. Jankowski (National Science Foundation, United States); Ms J. Morgan (ONS, United Kingdom); Mr B. Nemes (Statistics Canada); Mr A. Sundström (Statistics Sweden); Mr H. Tomizawa (NISTEP, Japan); and Ms A. Young (consultant to Statistics Canada). Mr G. Sirilli (Consiglio nazionale delle ricerche, Italy) was 
NESTI Chairman during this period and also organised the conference held in Rome. The manual's sixth edition was completed under the stewardship of Mr F. Gault (Statistics Canada) as Chair of NESTI.

\section{References}

EC, IMF, OECD, UN and the World Bank (2009), System of National Accounts, United Nations, New York. https://unstats.un.org/unsd/nationalaccount/docs/sna2008.pdf.

Freeman, C. and A. Young (1965), The Research and Development Effort in Western Europe, North America and the Soviet Union: An Experimental International Comparison of Research Expenditures and Manpower in 1962, OECD, Paris.

OECD (2002), Frascati Manual 2002: Proposed Standard Practice for Surveys on Research and Experimental Development, The Measurement of Scientific and Technological Activities, OECD Publishing, Paris. DOI: $h t t p: / / d x . d o i . o r g / 10.1787 / 9789264199040-e n$.

OECD (1994), The Measurement of Scientific and Technical Activities: Standard Practice for Surveys of Research and Experimental Development - Frascati Manual 1993, The Measurement of Scientific and Technological Activities, OECD Publishing, Paris. DOI: http://dx.doi. org/10.1787/9789264063525-en.

OECD (1989), R\&D Statistics and Output Measurement in the Higher Education Sector: "Frascati Manual" Supplement, The Measurement of Scientific and Technological Activities Series, Paris.

OECD (1981), Proposed Standard Practice for Surveys of Research and Experimental Development: "Frascati Manual 1980", The Measurement of Scientific and Technical Activities Series, Paris.

OECD (1976), Proposed Standard Practice for Surveys of Research and Experimental Development: "Frascati Manual", The Measurement of Scientific and Technical Activities Series, Paris.

OECD (1970), "Proposed Standard Practice for Surveys of Research and Experimental Development", DAS/SPR/70.40, Directorate for Scientific Affairs, Paris.

OECD (1968), Statistical Tables and Notes ("International Statistical Year for Research and Development: A Study of Resources Devoted to R\&D in OECD Member countries in 1963/64"), Vol. 2, Paris.

OECD (1963), "Proposed Standard Practice for Surveys of Research and Development", Directorate for Scientific Affairs, DAS/PD/62.47, Paris.

United Nations (1968), A System of National Accounts, Studies in Methods Series F, No. 2, Rev. 3, New York. 



\section{ANNEX 2 \\ Glossary of terms}

Accounting on an accruals basis recognises a transaction when the activity (decision) generating revenue or consuming resources takes place, regardless of when the associated cash is received or paid. See also accounting on a cash basis.

Applied research is original investigation undertaken in order to acquire new knowledge. It is, however, directed primarily towards a specific, practical aim or objective.

Appropriations are policy bills that provide / set aside money for specific government departments, agencies, programmes and/or functions. Appropriations provide legal authority to enter into obligations that will result in outlays. See also obligations and outlays.

Authorisations are policy bills that establish, continue or modify government programmes and are often accompanied by spending ceilings or policy guidance for subsequent appropriations. However, an authorised funding level has no necessary link with an appropriated funding level. See also appropriations.

Basic research is experimental or theoretical work undertaken primarily to acquire new knowledge of the underlying foundations of phenomena and observable facts, without any particular application or use in view.

A branch campus abroad (BCA) is defined as a tertiary educational institution that is owned, at least in part, by a local higher education institution (i.e. resident inside the compiling country) but is located in the Rest of the world (resident outside the compiling country); operates in the name of the local higher education institution; engages in at least some face-to-face teaching; and provides access to an entire academic programme that leads to a credential awarded by the local higher education institution.

Business enterprise expenditure on R\&D (BERD) represents the component of GERD incurred by units belonging to the Business enterprise sector. It is the measure of intramural R\&D expenditures within the Business enterprise sector during a specific reference period. See also Gross domestic expenditure on $R \& D$ and intramural $R \& D$ expenditures. 
The Business enterprise sector comprises:

- All resident corporations, including not only legally incorporated enterprises, regardless of the residence of their shareholders. This group includes all other types of quasi-corporations, i.e. units capable of generating a profit or other financial gain for their owners, recognised by law as separate legal entities from their owners, and set up for purposes of engaging in market production at prices that are economically significant.

- The unincorporated branches of non-resident enterprises are deemed to be resident because they are engaged in production on the economic territory on a long-term basis.

- All resident non-profit institutions (NPIs) that are market producers of goods or services or serve business.

This sector comprises both private and public enterprises.

Capital R\&D expenditures are the annual gross amount paid for the acquisition of fixed assets that are used repeatedly or continuously in the performance of R\&D for more than one year. They should be reported in full for the period when they took place, whether acquired or developed in house, and should not be registered as an element of depreciation.

The most relevant types of assets used for R\&D for which capital R\&D expenditures should be compiled are:

- land and buildings

- machinery and equipment

- capitalised computer software

- other intellectual property products.

Capitalised computer software consists of computer software that is used in the performance of R\&D for more than one year. It includes long-term licences or the acquisition of separately identifiable computer software, including programme descriptions and supporting materials for both systems and applications software. The production costs (e.g. labour and materials) of internally produced software should be reported. Software from external vendors may be obtained through the outright purchase of rights or licences to use. Software used or licensed for one year or less should be reported under current expenditures. See also software R\&D.

Carry over provisions (tax relief): a process by which the deductions or credits of one taxable year that cannot be used to reduce tax liability in that year are applied against a tax liability in subsequent years (carryforward) or previous years (carryback).

Accounting on a cash basis recognises a transaction when the cash is received or when cash is paid out. See also accounting on an accrual basis. 
Central (or federal) government is generally composed of a central group of departments or ministries that make up a single institutional unit - this unit is often referred to as the national government and the unit covered by the main budget account - plus, in many countries, other institutional units. The departments may be responsible for considerable amounts of $R \& D$ expenditure (for intramural or extramural R\&D) within the framework of the government's overall budget, but often they are not separate institutional units capable of owning assets, incurring liabilities, engaging in transactions, etc., independently of central government as a whole. Their revenues as well as expenses and expenditures are normally regulated and controlled by a Ministry of Finance or its functional equivalent by means of a general budget approved by the legislature.

Chain linking consists in joining together two time series that overlap in one period by rescaling one of them to make its value equal to that of the other in the same period, thus combining them into a single time series. More complex methods may be used to link together time series that overlap by more than one period.

The Classification of Functions of Government (COFOG) is a generic classification of the functions, or socioeconomic objectives, that general government units aim to achieve through various kinds of expenditure. COFOG provides a classification system for government entities and financial outlays by functions of general interest. The level-one headings in COFOG have significant similarities with classifications of socioeconomic objectives used for R\&D. The use of this classification for government institutions in the context of $R \& D$ statistics cannot be actively recommended by the Frascati Manual, because the categories are not optimised for the purpose of describing R\&D expenditures. See also socio-economic objectives.

Controlled affiliates abroad (CAA) are the majority-owned affiliates located abroad of a parent company resident in the compiling country. See also majorityownership and parent company of a multinational enterprise (MNE).

Corporations comprise all entities that are capable of generating a profit or other financial gain for their owners, that are recognised by law as separate legal entities from their owners who enjoy limited liability, and that are set up for purposes of engaging in market production. The term covers cooperatives, limited liability partnerships and quasi-corporations. For some practical purposes, this category can be extended to comprise households or individuals formally engaged in market production where the separation of liability is difficult to establish. Overall, this group should essentially match the units identified as Business enterprises.

Current R\&D expenditures are composed of labour costs and other current costs (including for external R\&D personnel) used in R\&D. Services and items (including equipment) used and consumed within one year are 
current expenditures. Annual fees or rents for the use of fixed assets should be included in current expenditures.

Doctoral students attend "tertiary programmes which lead to the award of an advanced research qualification [and which] are therefore devoted to advanced study and original research and are not based on course work only". Such students are usually required to submit a thesis or dissertation of publishable quality, i.e. the product of original research that represents a significant contribution to knowledge. See also International Standard Classification of Education.

An economic activity or industry consists of a group of establishments engaged in the same, or similar, kinds of activity. The International Standard Industrial Classification (ISIC) is the reference classification for economic activities. See also International Standard Industrial Classification (ISIC).

Economically significant prices are prices that have a significant effect on the amounts that producers are willing to supply and on the amounts purchasers wish to buy. These prices normally result when (a) the producer has an incentive to adjust supply with the goal of either making a profit in the long run or, at a minimum, covering capital and other costs and (b) consumers have the freedom to purchase or not purchase, and make the choice on the basis of the prices charged. See System of National Accounts.

Editing of collected data is performed to identify possible errors in the data and either to validate a record or variable, or to correct for errors and inconsistencies in the collected data.

Employees include all persons who work in or for the statistical unit, who have a contract of employment with the unit and who receive compensation in cash or in kind at regular intervals of time. Employees engaged in activity ancillary to the main activity of the unit are also included, as well as the following groups: persons on short-term leave (sick leave, annual leave or vacation); persons on special paid leave (educational or training leave, maternity or parental leave); persons on strike; and part-time workers, seasonal workers and apprentices when on the payroll. Employees also include persons working physically outside the statistical unit's premises, when paid by and under the control of the unit (outworkers); for example, outside service engineers and repair and maintenance personnel are employees.

\section{Employment - See persons employed.}

An enterprise is the view of any institutional unit - not necessarily within what the Frascati Manual defines as the Business enterprise sector - as a producer of goods and services (See SNA). The term enterprise may refer to a corporation, a quasi-corporation, a non-profit institution or an unincorporated enterprise. An enterprise is an economic transactor with autonomy in respect of financial and investment decision-making, as well as authority and responsibility for allocating resources for the production of goods and services. It may be engaged in one or more economic activities at one or more locations. An enterprise may be a sole legal unit. 
An enterprise group is a set of enterprises controlled by the group head. The group head is a parent legal unit that is not controlled either directly or indirectly by any other legal unit. It can have more than one decision-making centre, especially for the policy on production, sales and profits, or it may centralise certain aspects of financial management and taxation. It constitutes an economic entity that is empowered to make choices, particularly concerning the units that it comprises. The enterprise group as a unit is particularly useful for financial analyses and for studying company strategies; however, it can be too varied in nature and unstable to be adopted as a unit for statistical surveys and analysis.

An establishment is an enterprise, or part of an enterprise, that is situated in a single location and in which only a single productive activity is carried out or in which the principal productive activity accounts for most of the value added. Establishments are sometimes referred to as local kind-of activity units (local KAUs). See also enterprise.

Estimation is concerned with inference about the numerical value of unknown population values from incomplete data such as a sample.

Exchange funds for R\&D are funding flows from one statistical unit to another statistical unit in return for the performance of R\&D and the delivery of relevant R\&D outcomes. The unit funding the work incurs a delivery risk associated with the uncertainty of the project. Examples of exchange funds activities include R\&D purchases (sales from the perspective of the performer), R\&D outsourcing and contributions in the context of collaborative R\&D agreements.

Experimental development is systematic work, drawing on knowledge gained from research and practical experience and producing additional knowledge, which is directed to producing new products or processes or to improving existing products or processes.

External R\&D funds are the amount of money spent on R\&D that originate outside the control of a reporting unit.

External R\&D personnel (or contributors) are independent (self-employed) or dependent (employee) workers fully integrated into a statistical unit's R\&D projects without formally being persons employed by the same R\&D-performing statistical unit.

In this Manual extramural R\&D is any $R \& D$ performed outside of the statistical unit about which information is being reported; its "funds for extramural R\&D" should include only internal funds (not from external sources) provided to an outside unit for R\&D performance including both where there is an expected compensatory delivery of R\&D (exchange or purchase) and where no compensatory delivery is expected (transfer or grant). It may also be noted that such funds for extramural R\&D often will include payments for costs other than for R\&D, such as cost elements covering depreciation costs, performer profit, delivery charges, etc. 
Fellow enterprises abroad are identified from the point of view of a foreign-controlled affiliate resident in the compiling economy. The term refers to enterprises located outside the compiling country that are under the control or influence of the same foreign parent company as the foreign-controlled affiliate. For the purposes of the Frascati Manual, fellow enterprises abroad are of interest as sources or destinations of R\&D funds involving foreign-controlled affiliates.

The OECD fields of research and development (FORD) classification has been developed in the framework of the Frascati Manual and is used to classify R\&D units and resources by fields of enquiry, namely, broad knowledge domains based primarily on the content of the R\&D subject matter.

Foreign-controlled affiliates (FCA) are the fully consolidated enterprise group within the compiling country that are majority-owned members of foreign MNEs (thus majority-owned by their foreign parent companies. Activities of FCAs are a consequence of inward FDI, whereas activities of CAAs relate to outward FDI. See also majority-ownership, multinational enterprise, parent company and controlled affiliate abroad.

Foreign direct investment (FDI) reflects the objective of obtaining a lasting interest by a resident enterprise in one economy (an MNE parent or "direct investor") in an enterprise resident in another economy (a foreign affiliate or "direct investment enterprise"). For official statistical purposes, a lasting interest is deemed to exist by direct or indirect ownership of $10 \%$ or more of the ordinary shares or voting power of an incorporated enterprise, or the equivalent of an unincorporated enterprise. The $10 \%$ voting power criterion also establishes the existence of a direct investment relationship between an affiliate and its MNE parent.

Full-time equivalent (FTE) of R\&D personnel is defined as the ratio of working hours actually spent on R\&D during a specific reference period (usually a calendar year) divided by the total number of hours conventionally worked in the same period by an individual or by a group.

Public general university funds (GUF) are defined as the R\&D funding share coming from the general grant universities receive from the central government (federal) ministry of education or the corresponding provincial (state) or local (municipal) authorities in support of their overall research/teaching activities.

In broad terms, globalisation refers to the international integration of financing, factor supply, R\&D, production, and trade of goods and services.

Government budget allocations for R\&D (GBARD) encompass all spending allocations met from sources of government revenue foreseen within the budget, such as taxation. Spending allocations by extra-budgetary government entities are only within the scope to the extent that their funds are allocated through the budgetary process. Likewise, R\&D financing by public corporations is outside the scope of GBARD statistics, as it is based on funds raised within the market 
and outside the budgetary process. Only in the exceptional case of budgetary provisions for R\&D to be carried out or distributed from public corporations should this be counted as part of GBARD. See also Socio-economic (SEO) objectives classification.

Government control of NPIs is typically determined by the use of the following five indicators of control:

1. The ability to dictate the appointment of officers or management boards.

2. The ability to dictate other provisions, allowing the government to determine significant aspects of the general policy or programme of the NPI, such as the right to remove key personnel or to veto proposed appointments, to require prior approval of budgets or financial arrangements by the government, or to prevent the NPI from changing its constitution or dissolving itself.

3. The presence of contractual agreements, giving rights to impose conditions, such as those cited above.

4. The degree and type of financing by government, to the extent that this may prevent the NPI from determining its own policy or programme.

5. The existence of risk exposure, if a government openly allows itself to be exposed to all, or a large proportion of, the financial risks associated with an NPI's activities.

Government expenditure on R\&D (GOVERD) represents the component of GERD incurred by units belonging to the Government sector. It is the measure of expenditures on intramural $R \& D$ within the Government sector during a specific reference period. See also Gross domestic expenditure on $R \& D$ (GERD) and intramural $R \& D$ expenditures.

The Government sector consists of the following groups of resident institutional units:

- all units of central (federal), regional (state) or local (municipal) government, including social security funds, except those units that provide higher education services or fit the description of higher education institutions provided in this manual.

- all non-market NPIs that are controlled by government units that are not part of the Higher education sector.

The sector does not include public corporations, even when all the equity of such corporations is owned by government units. Public enterprises are included in the Business enterprise sector.

Government tax relief for R\&D expenditures (GTARD). This concept describes tax relief provisions that apply to taxpayers strictly as a result of their engagement in $R \& D$ performance and/or funding activities, relative to a normal or baseline tax structure. The concept of GTARD applies to the statistical measurement of the cost of such R\&D-specific provisions (GTARD indicator) that is proposed in this manual. 
Government units are unique kinds of legal entities established by political processes that have legislative, judicial or executive authority over other institutional units within a given area. See SNA. These units are of special relevance for the analysis of R\&D budgets and tax incentives.

Gross domestic expenditure on R\&D (GERD) is total intramural expenditure on R\&D performed in the national territory during a specific reference period.

Gross national expenditure on R\&D (GNERD) comprises total expenditure on $R \& D$ financed by a country's institutions regardless of where the $R \& D$ is performed. As such, it includes R\&D performed in the "rest of the world" that is financed by national institutions or residents; it excludes R\&D performed within a country that is funded from institutions outside of the national territory (that is, from institutions that are part of the "rest of the world"). GNERD is constructed by adding the domestically financed intramural expenditures of each performing sector plus the R\&D performed in the "rest of the world" that is financed by domestic funding sectors.

The headcount (HC) of R\&D personnel is defined as the total number of individuals contributing to intramural $R \& D$, at the level of a statistical unit or at an aggregate level, during a specific reference period (usually a calendar year).

Higher education expenditure on R\&D (HERD) represents the component of GERD incurred by units belonging to the Higher education sector. It is the measure of intramural R\&D expenditures within the Higher education sector during a specific period. See also Gross domestic expenditure are R\&D (GERD) and intramural $R \& D$ expenditures.

The Higher education sector comprises all universities, colleges of technology and other institutions providing formal tertiary education programmes, whatever their source of finance or legal status, and all research institutes, centres, experimental stations and clinics that have their R\&D activities under the direct control of, or are administered by, tertiary education institutions.

For inward investment, the immediate parent company of a FCA is the first foreign investor outside the compiling country that exercises control over the foreign affiliate. See also parent company, foreign-controlled affiliate and investor of ultimate control.

Imputation is a procedure for entering a value for a specific data item where the response is missing or unusable.

Industry - see economic activity.

An institutional unit is a national accounting concept and is defined in the System of National Accounts as "an economic entity that is capable, in its own right, of owning assets, incurring liabilities, and engaging in economic activities and transactions with other entities". This concept can be applied to the measurement of $R \& D$ activities and $R \& D$-related flows. In the $R \& D$ case, institutional units have to be capable of decision-making in respect of the 
conduct of $R \& D$, from the allocation of financial resources for internal or external use to the management of $R \& D$ projects. These are weaker requirements than those used to define an institutional unit in the National Accounts, but they serve for the purposes of this manual.

Internal R\&D funds are the amount of money spent on R\&D that originate within the control of and are used for $R \& D$ at the discretion of a reporting statistical unit. Internal $R \& D$ funds do not include $R \& D$ funds received from other statistical units explicitly for intramural R\&D.

Internal R\&D personnel are persons employed by the statistical unit who contribute to the unit's intramural R\&D activities. See persons employed.

International organisations have as members either national states or other international organisations whose members are national states. They are established by formal political agreements between their members that have the status of international treaties; their existence is recognised by law in their member countries, and they are not subject to the laws or regulations of the country, or countries, in which they are located. For example, they cannot be compelled by national authorities to provide statistical information on their R\&D performance or funding activities. For the purposes of the SNA and also for R\&D statistics, international organisations are treated as units that are resident abroad (part of Rest of the world), regardless of the physical location of their premises or operations.

The International Standard Classification of Education (ISCED) is the reference classification for organising education programmes and related qualifications by education levels and fields. ISCED is designed to serve as a framework to classify educational activities as defined in programmes and the resulting qualifications into internationally agreed categories. The basic concepts and definitions of ISCED are therefore intended to be internationally valid and comprehensive of the full range of education systems. ISCED classifies education programmes by their content using two main cross-classification variables: levels of education and fields of education. The ISCED version of 2011 introduces a related classification of educational attainment levels based on recognised educational qualifications.

The International Standard Classification of Occupations (ISCO) is used to classify jobs. For the purpose of ISCO, a job is defined as a set of tasks and duties performed, or meant to be performed, by one person, including for an employer or in self-employment. An occupation is defined as a set of jobs whose main tasks and duties are characterised by a high degree of similarity. A person may be associated with an occupation through the main job currently held, a second job or a job previously held. Jobs are classified by occupation with respect to the type of work performed, or to be performed. The basic criteria used to define the system of major, sub-major, minor and unit groups are the "skill level" and "skill specialisation" required to perform the tasks and duties of the occupations competently. 
The International Standard Industrial Classification of All Economic Activities (ISIC) consists of a coherent and consistent classification structure of economic activities based on a set of internationally agreed concepts, definitions, principles and classification rules. It provides a comprehensive framework within which economic data can be collected and reported in a format that is designed for purposes of economic analysis, decision-taking and policy-making. The classification structure represents a standard format to organise detailed information about the state of an economy according to economic principles and perceptions. The scope of ISIC in general covers productive activities, i.e. economic activities within the production boundary of the System of National Accounts (SNA). A few exceptions have been made to allow for the classification of activities beyond the production boundary but which are of importance for various other types of statistics. These economic activities are subdivided in a hierarchical, four-level structure of mutually exclusive categories, facilitating data collection, presentation and analysis at detailed levels of the economy in an internationally comparable, standardised way. See also economic activity.

Intramural R\&D expenditures are all current expenditures plus gross fixed capital expenditures for R\&D performed within a statistical unit during a specific reference period, whatever the source of funds. Intramural $R \& D$ expenditure is synonymous with the performance of $R \& D$ within a statistical unit. The aggregation of intramural R\&D for all units within a sector is synonymous with the performance of $R \& D$ within a sector of the economy; the summation of intramural $R \& D$ for all sectors is synonymous with the performance of $R \& D$ for the entire economy (GERD).

The investor of ultimate control of a FCA (also called "ultimate controlling institutional unit") is the head of a chain of companies or affiliates that controls all the enterprises in the chain without itself being controlled by any other company. See also foreign controlled affiliate and immediate parent company.

A joint venture involves the establishment of a corporation, partnership or other institutional unit in which each party legally has joint control over the activities of the unit. The units operate in the same way as other units except that a legal arrangement between the parties establishes joint control over the unit. As an institutional unit, the joint venture may enter into contracts in its own name and raise finance for its own purposes. If $R \& D$ joint ventures are stand-alone units, they should also be classified on the basis of the units they predominantly serve, taking whenever possible into account the established practice of the System of National Accounts.

A kind-of-activity unit (KAU) is an enterprise, or a part of an enterprise, that engages in only one kind of productive activity or in which the principal productive activity accounts for most of the value added. Each enterprise must, by definition, consist of one or more kind-of-activity units. 
Land and buildings include land acquired for R\&D use (e.g. testing grounds, sites for laboratories and pilot plants) and buildings constructed or purchased for R\&D use, including major improvements, modifications and repairs. Since buildings are produced assets and land is a non-produced asset in National Accounts, R\&D expenditures for land and for buildings should be separately identified.

Labour costs, or compensation of employed personnel, comprise annual wages and salaries and all associated costs or fringe benefits, such as bonus payments, stock options, holiday pay, contributions to pension funds. In this manual, the concept of labour costs also includes other social security payments and payroll taxes.

Leased employees are included in external R\&D personnel. Leased employment entails the provision for a fee of human resources for client businesses. Leased employees are on the payroll of an employment (or staffing) agency rather than the payroll of the statistical unit paying the fee. This provision of human resources is typically conducted on a short-term basis.

A local unit is an enterprise, or a part of an enterprise, that engages in productive activity at or from one location.

The local (or municipal) government subsector consists of local governments that are separate institutional units in addition to agencies and nonmarket NPIs that are controlled by local governments. In principle, local government units are institutional units whose fiscal, legislative and executive authority extends over the smallest geographical areas distinguished for administrative and political purposes. The scope of their authority is generally much less than that of central government or state governments.

Machinery and equipment cover major (i.e. capitalised) machinery and equipment acquired for use in the performance of R\&D. For the purpose of measuring R\&D for National Accounts, expenditures on machinery and equipment should be identified by more detailed breakdowns, including "information and communications equipment" and "transportation equipment".

Majority-ownership or control refers to ownership of more than $50 \%$ of the ordinary shares or voting power of an incorporated enterprise or the equivalent of an unincorporated enterprise. Examples of majority-owned or controlled affiliates include subsidiaries (incorporated enterprises) and branches (unincorporated enterprises).

Master's students may in some cases be counted as researchers; in particular, this would include students following an ISCED level 7 research master's programme "...leading to the award of research qualifications that are designed explicitly to train participants in conducting original research but are below the level of a doctoral degree". However, it is important that only Master's students receiving payment for their $R \& D$ activity are included in $R \& D$ personnel totals. 
A multinational enterprise (MNE) refers to a parent company resident in the country and its majority-owned affiliates located abroad, which are labelled controlled affiliates abroad (CAA). MNEs are also referred to as global enterprise groups. See also parent company, majority-ownership and controlled affiliates abroad.

NABS classification - see Socio-economic objectives classification.

Non-profit institutions (NPIs) are legal or social entities, created for the purpose of producing goods and services, whose status does not permit them to be a source of income, profit or other financial gain for the units that establish, control or finance them. They can be engaged in market or non-market production.

Non-profit institutions serving households (NPISHs) consist of non-market NPIs that are not controlled by government. They provide goods and services to households free or at prices that are not economically significant. Most of these goods and services represent individual consumption, but it is possible for NPISHs to provide collective services.

Obligations represent the monetary amounts for orders placed, contracts awarded, services received and similar transactions during a given period, regardless of when the funds were appropriated and when the future payment of money is required.

Oriented basic research is basic research carried out with the expectation that it will produce a broad base of knowledge likely to form the basis of the solution to recognised or expected current or future problems or possibilities.

Other current costs comprise non-capital purchases of materials, supplies, equipment and services to support R\&D performed by the statistical unit in the reference year. Examples are water and fuel (including gas and electricity); books, journals, reference materials, subscriptions to libraries, scientific societies, etc.; imputed or actual costs of small prototypes or models made outside the statistical unit; and materials for laboratories (e.g. chemicals, animals, etc.). Other current costs include royalties or licences for the use of patents and other intellectual property rights, the lease of capital goods (machinery and equipment, etc.) and the rental of buildings to support R\&D performed by the statistical unit in the reference year.

Other supporting staff include skilled and unskilled craftsmen, and administrative, secretarial and clerical staff participating in R\&D projects or directly associated with such projects.

Other intellectual property products (in capital R\&D expenditures) include purchased patents, long-term licences or other intangible assets used in $R \& D$, and which are in use for more than one year. Other intangibles that can be reported in a unit's internal financial accounts, such as marketing assets or goodwill, should not be included. See System of National Accounts. 
Outlays (used interchangeably with expenditures in terms of spending) represent the amounts for checks issued and cash payments made during a given period, regardless of when the funds were appropriated or obligated (when referring to government funds).

Survey paradata refer to information related to the survey process. Examples of paradata may include whether or not the unit is in the sample; a response follow-up history; and the mode of collection. Use of paradata after a survey cycle may assist in improving the survey instrument in future iterations.

Parent companies of MNEs are measured as the fully consolidated enterprise group within the compiling country and include all units resident in the compiling country that are majority-owned by the company. See also multinational enterprise, enterprise group, residence and majority-ownership.

Performers of R\&D consist of statistical units that undertake (i.e. perform) $R \& D$ in each of the main sectors covered in this manual: Business enterprise, Government, Higher education and Private non-profit. See Statistical Unit.

Persons employed include both employees and unpaid family workers and working proprietors (i.e. active business partners). Silent or inactive partners whose principal activity is conducted outside of the statistical unit should be excluded. See also internal R\&D personnel.

Private affiliation status - see Public affiliation status.

Private non-profit expenditure on R\&D (PNPERD) represents the component of GERD incurred by units belonging to the Private non-profit sector. It is the measure of intramural R\&D expenditures within the Private non-profit sector during a specific reference period. See also Gross domestic expenditure on $R \& D$ (GERD) and intramural R\&D expenditures.

The Private non-profit (PNP) sector comprises:

- all non-profit institutions serving households (NPISH), as defined in the SNA 2008, except those classified as part of the Higher education sector

- for completeness of presentation, households and private individuals engaged or not engaged in market activities, as explained in this manual.

A "Professor emeritus" is a retired professor who continues to research and collaborate in the academic activities of his/her former employer - usually a university - without receiving any compensation (although he/she may receive some logistical support for their activities).

A prototype is an original model constructed to include all the technical characteristics and performances of the new product.

Public or private sector affiliation status. The public or private status of an institutional unit should be determined by whether or not the unit is controlled by government. Units tagged as private (or public) in all sectors can be grouped together for the presentation of statistics that meet user requirements. 
Purchasers' prices are the amounts paid by the purchasers, excluding the deductible part of value-added taxes (VAT) and similar taxes. Purchasers' prices reflect the actual costs to the users. This means that the valuation of current and capital expenditures on goods and services for R\&D is the total price paid by the reporting unit, including any taxes on products, which act to increase the price paid, and the price-reducing effect of any subsidies on the products purchased.

Pure basic research is basic research carried out for the advancement of knowledge, without seeking long-term economic or social benefits or making any effort to apply the results to practical problems or to transfer the results to sectors responsible for their application.

A quasi-corporation is either an unincorporated enterprise owned by a resident institutional unit that has sufficient information to compile a complete set of accounts and is operated as if it were a separate corporation and whose de facto relationship to its owner is that of a corporation to its shareholders, or an unincorporated enterprise owned by a non-resident institutional unit that is deemed to be a resident institutional unit because it engages in a significant amount of production in the economic territory over a long or indefinite period of time.

R\&D coefficients are a tool for calculating / estimating the shares of personnel and expenditure data attributable to R\&D. They are especially used for distributing total resources among research, teaching and other activities (including administration) in the Higher education sector. They can be used for the total expenditure or for parts of it, like public general university funds (GUF) or for personnel only.

R\&D personnel are classified according to their R\&D function, which may be researcher, technician or other support staff.

R\&D personnel in a statistical unit include all persons engaged directly in $R \& D$, whether employed by the statistical unit or external contributors fully integrated into the statistical unit's R\&D activities, as well as those providing direct services for the R\&D activities (such as R\&D managers, administrators, technicians and clerical staff). See also internal $R \& D$ personnel and external $R \& D$ personnel.

Refundable/payable tax credit. Tax credits can be payable, in the sense that any amount of the credit that exceeds the tax liability is paid to the beneficiary. See also tax credit.

The reporting unit is the unit from which data are reported. This corresponds to the unit that would receive a questionnaire or interview. In the case of administrative data, it would correspond to the unit that is represented by the individual record.

Research and experimental development (R\&D) comprise creative and systematic work undertaken in order to increase the stock of knowledge including knowledge of humankind, culture and society - and to devise new applications of available knowledge. 
Researchers are professionals engaged in the conception or creation of new knowledge. They conduct research and improve or develop concepts, theories, models, techniques instrumentation, software or operational methods.

The residence of an institutional unit is the economic territory with which it has the strongest connection, in other words, its centre of predominant economic interest. The economic territory includes the land area, airspace and territorial waters, including jurisdiction over fishing rights and rights to fuels or minerals. In a maritime territory, the economic territory includes islands that belong to the territory. The economic territory also includes territorial enclaves in the Rest of the world. These are clearly demarcated land areas (such as embassies, consulates, military bases and scientific stations) located in other territories and used by governments that own or rent them for diplomatic, military, scientific or other purposes with the formal agreement of the governments of the territories where the land areas are physically located.

The Rest of the world includes:

- all institutions and individuals without a location, place of production or premises within the economic territory on which or from which the unit engages and intends to continue engaging, either indefinitely or over a finite but long period of time, in economic activities and transactions on a significant scale

- all international organisations and supranational entities, defined further below, including facilities and operations within the country's borders.

For statistical purpose, scientific and technological activities (STA) can be defined as all systematic activities which are closely concerned with the generation, advancement, dissemination and application of scientific and technical knowledge in all fields of science and technology, that is, the natural sciences, engineering and technology, the medical and agricultural sciences (NS), as well as the social sciences and humanities (SSH). The activities that should be covered in the statistical practice may be divided into three broad groups: research and experimental development; S\&T education and training at broadly the third level; and scientific and technological services.

Self-employed persons are persons who are the sole or joint owners of the unincorporated enterprises in which they work, excluding those unincorporated enterprises that are classified as quasi-corporations. In the Frascati Manual, self-employed consultants or contractors undertaking R\&D projects for another unit at an economically significant price are included in the Business enterprise sector.

A socio-economic objectives (SEO) classification is used to distribute GBARD. The criteria for classification should be the purpose of the R\&D programme or project, i.e. its primary objective. The allocation of R\&D budgets to socio-economic objectives should be at the level that most accurately reflects the funder's objective(s). The recommended distribution list is based on the 
European Union classification adopted by Eurostat for the Nomenclature for the Analysis and Comparison of Scientific Programmes and Budgets (NABS) at the one-digit level. See also Government budget allocations for R\&D (GBARD).

A software development project is classified as R\&D if its completion is dependent on a scientific and/or technological advance, and the aim of the project is the systematic resolution of a scientific and/or technological uncertainty. In addition to the software that is part of an overall R\&D project, the R\&D associated with software as an end product or software embedded in an end product could also be classified as R\&D when the R\&D criteria apply. Software development is an integral part of many projects that in themselves have no element of R\&D. The software development component of such projects, however, may be classified as $R \& D$ if it leads to an advance in the area of computer software. An upgrade, addition or change to an existing program or system may be classified as R\&D if it embodies scientific and/or technological advances that result in an increase in the stock of knowledge. Software-related activities of a routine nature are not to be considered R\&D. See also capitalised computer software.

The source of R\&D funds is the unit that provides the funds for $R \& D$ performance. Sources may be internal or external to the reporting unit. In surveys and data presentation, external sources are grouped by main sector and relevant subsectors. In broad terms, there are five main sources for R\&D funding: Business enterprise, Government, Higher education, Private non-profit and the Rest of the world.

The state (or regional) government subsector consists of regional or state governments that are separate institutional units in addition to agencies and nonmarket NPIs that are controlled by regional (state) governments. This subsector exercises some of the functions of government at a level below that of central/ federal government and above that of the governmental institutional units existing at a local level. They are institutional units whose fiscal, legislative and executive authority extends only over the individual "states" into which the country as a whole may be divided. Such "states" may be described by different terms in different countries, i.e. by reference to terms such as "regions" or "provinces".

A statistical unit is an entity about which information is sought and for which statistics are ultimately compiled. It is the unit at the basis of statistical aggregates and to which tabulated data refer.

A supranational authority is an international organisation that has been endowed with the authority to raise taxes or other compulsory transfers within the territories of the countries that are members of the authority. Despite the fact that supranational authorities fulfil some of the functions of government within each member country, they are always considered non-resident institutional units.

The System of National Accounts (SNA) is the internationally agreed standard set of recommendations on how to compile measures of economic activity in accordance with strict accounting conventions based on economic principles. 
Tax allowance. Tax allowances, exemptions and deductions are subtracted from the tax base before the tax liability is computed - it reduces the taxable amount before assessing the tax. See also tax exemptions.

A tax credit is an amount subtracted directly from the tax liability due by the beneficiary household or corporation after the liability has been computed.

Tax exemptions. Exemptions are amounts excluded from the tax base.

Tax expenditures are provisions of tax law, regulation or practices that reduce or postpone revenue collected by government from a group of taxpayers relative to a benchmark or "normal" tax structure. Tax expenditures are sometimes described as synonymous with tax reliefs, tax subsidies and tax aid. In this manual, the term "tax expenditure" is used to describe the measure of the cost to government of related tax relief provisions.

Technicians and equivalent staff are persons whose main tasks require technical knowledge and experience in one or more fields of engineering, the physical and life sciences, or the social sciences, humanities and the arts. They participate in R\&D by performing scientific and technical tasks involving the application of concepts, operational methods and the use of research equipment, normally under the supervision of researchers.

Tertiary education includes what is commonly understood as academic education but also includes advanced vocational or professional education. It comprises ISCED levels 5, 6, 7 and 8, which are labelled as short-cycle tertiary education, Bachelor's or equivalent level, Master's or equivalent level, and doctoral or equivalent level, respectively.

A time-use survey is a statistical survey that aims to report data on how people spend their time. Guidelines on time-use surveys are given in the Frascati Manual to help in deriving the necessary information for estimating the R\&D component of full-time equivalents (FTEs) and expenditures in the Higher education sector, if the necessary coefficients cannot be derived from administrative data or other survey data.

Transactions are voluntary exchanges or transfers where there is a change in economic ownership (who bears the risk and is entitled to benefits) in the provision of goods or services. Flows of goods, services and income are recorded in the current account of the balance of payments. See System of National Accounts.

Transfer R\&D funds are funding flows from one statistical unit to another statistical unit to perform $R \& D$ that does not require any good or service in return and where the funder is not entitled to any significant rights on the outcome of the R\&D it has funded. The unit that provides transfer funds for R\&D may impose some conditions on the performer, such as periodic reporting, compliance with the activity or project description as agreed in the terms of the agreement, or even public dissemination of research outcomes. Examples of transfer funds include grants, debt forgiveness, philanthropy, crowd-funding and personal transfers such as gifts and GUF (by convention for international comparisons). 
To be included as R\&D transfer funds, the funds should be intended by the originating source to be used for R\&D. Normally, the R\&D performer will retain most rights to the outcomes of the $R \& D$, which explains the transfer nature of this R\&D funding transaction.

Types of costs of R\&D include individual current and capital cost categories for intramural R\&D. Types of current costs include labour costs for internal R\&D personnel and other current costs (for external R\&D personnel, purchases of services, purchases of materials, and other costs not elsewhere classified. Types of capital costs include land and buildings, machinery and equipment, capitalised computer software and other intellectual property products.

Three types of R\&D are considered and defined in the Frascati Manual: basic research, applied research and experimental development. See the relevant definitions in this glossary of terms.

A value-added type tax (VAT) is a tax on goods or services that is collected in stages by enterprises but which is ultimately charged in full to the final purchasers. In line with the SNA and for international comparison purposes, a net system of recording VAT should be followed. Under the net system, VAT is recorded as being payable by purchasers, not sellers, and only by those purchasers who are not able to deduct it. Countries should make every effort to exclude deductible VAT from expenditure figures for all R\&D performing sectors. It is recommended that figures forwarded for international comparison should exclude deductible VAT from intramural R\&D totals.

In the context of this manual, volunteers are the part of external R\&D personnel who are unpaid workers providing a statistical unit with a defined R\&D contribution. 


\section{Index}

\section{Notes:}

Locators refer to paragraph numbers. 1.0, 2.0 etc. refer to the unnumbered chapter introductions. In addition, the following abbrevations are used: B - Box, e.g. B3.2 is Box 3.2; F: Figure; T: Table; A1: Annex 1; g: glossary of terms (Annex 2).

\section{A}

academies of science, national, 8.16, 8.18, 9.24 accounting see financial accounting accrual-based approach, 8.92, 13.45-13.46, $g$

acquired R\&D, 4.60-4.61

see also sales and purchases of R\&D

activities of multinational enterprises (AMNE), 11.33

see also multinational enterprises activity, definition in R\&D, 2.12

administrative data see under data

aerospace industry, 2.35-2.36, 2.47

affiliated enterprises, 11.11-11.15, 11.17, 11.22, 11.27-11.28

affiliation status, 3.39-3.41, $\mathrm{g}$

cross-sector linkages, 11.67

in the non-business sector, 11.48

unaffiliated units, 11.22

age breakdown, see under personnel agricultural sciences and forestry as socio-economic objective of R\&D, 12.63

examples, 2.40

applied research

by business enterprises, 7.47

definition and criteria, 1.35, 2.9, 2.29-2.31, $g$ industry orientation of, 7.56

see also research and (experimental) development $(R \& D)$

appraisals and evaluations, treatment of, $2.119,10.18$

appropriations, $g$, see also GBAORD

archaeological research, 2.40

arts $\mathrm{T} 2.2$,

examples, 2.41

artistic expression vs research, 2.67

research for the arts, 2.64, 2.65

research on the arts, $2.17,2.64,2.66$

B

balance of payments, 11.5, B11.1

cross-border transfers in, 11.39

basic research

by business enterprises, 7.47

definition and criteria, 1.35, 2.9, $2.25-2.28, g$

industry orientation of, 7.56

oriented vs pure, $2.28,7.47, \mathrm{~g}$

uncertainty in, 2.18

see also research and (experimental) development (R\&D), science and technology

benchmarks, for tax expenditures, 13.40-13.43 
BERD see Business enterprise expenditure on $R \& D$

biotechnology, 1.81, 7.66-7.67, 8.48, T2.2

branch campuses abroad (BCA), 9.81-9.86. 11.54-11.56, g

budget-based data, 1.74-1.75, 8.82-8.83, 12.39-12.40,12.45-12.49

budget(ing)

as essential for R\&D, 2.19

for surveys, 6.25, 9.107

reporting, choice of year, 6.52

seven broad stages in government, 12.41-12.43

see also government budgets for R\&D

Business enterprise expenditure on $R \& D$ (BERD), 1.56, 11.8, 11.26, 13.67

definition, $7.35, \mathrm{~g}$

functional distributions, 7.35-7.68

reporting on data, 7.107

Business enterprises (as R\&D sector), 1.53-1.56, 3.51-3.59, 7.0-7.108

borderline cases, 3.55-3.59, 8.17-8.18

classification see classification

concentration of R\&D in few entities, 6.1, 6.18

definition, 1.54, 3.43, 7.2-7.8, g

funding from sector, 7.37-7.41

inventory of likely R\&D performers, 7.75-7.76

main characteristics, 3.51-3.52

potential under- and over-reporting, 7.98-7.103

sources of internal funding, 4.91

statistical units in sector, 3.53-3.54, 7.10-7.11, 7.15-7.29

surveys of, 6.18-6.25, 7.70-7.93 (see also surveys)

business registers, 7.71-7.74, 7.84

\section{C}

cash basis (for accounting), 12.43, $\mathrm{g}$

census, 7.78-7.80, 7.85, 8.68, 9.126 see also surveys

Central Product Classification (CPC), 7.57

chain linking (for breaks in series), 6.91, $\mathrm{g}$

classification

activity of, 3.27-3.30

by affiliation status, 3.39-3.41, 7.21

for distribution of funding, 4.133

by field of R\&D, T2.2, 3.44-3.46 (see also FORD (Fields of Research and Development) classification)

for Frascati vs SNA purposes, 6.21

by functions of government, 8.25 by geography, 3.47, 7.29

by industry orientation, 7.51-7.61, T7.2

by legal status, 3.42-3.43, 7.22

by main economic activity, 3.31-3.34, 7.16-7.20, 7.48-7.50, T7.2, 7.60, 8.24

of personnel by function, 5.33

by public or private status, 3.35-3.38, 7.21, 9.28-9.31

record-keeping practices, $3.48-3.49$, T3.2

revision and updating of, 3.27-3.29

by size of enterprise, 7.23-7.28

systems see COFOG, COPNI, CPC, FORD, ISCED, ISIS

technology readiness level (TRL), 2.99, 8.30-8.31

Classification of Functions of Government (COFOG), 8.25, 8.52, 8.66, 12.72, g

Classification of the Purposes of Non-profit Institutions Serving Households (COPNI), 10.13, 10.32

coefficients, R\&D, 9.60-9.61, 9.120-9.124, 9.135-9.136, 12.13, 12.48, g

COFOG, 8.25, 8.52, 8.66, 12.72, $g$

collaborations see joint ventures, partnerships

communication

of new knowledge, 2.20, 2.22, 2.26, 2.85

and open science, 2.93

and publication not part of R\&D, 2.91, 2.93

research into media, 12.65-12.66

of statistics, background information required, 7.107

see also conferences

computing see information and communication technology

conferences, attending/presenting at, 2.85, 9.46

confidentiality issues, $1.53,3.17,6.1,6.47,6.62$, 6.92

and government defence spending, 8.51 consultants, 4.26, 4.63, 5.16, 5.20, T5.2, 7.5, $7.33,8.55,10.4,10.34$

contracts for research, 4.142, 7.42, 9.74, $12.20-12.21,12.24-12.25,12.73$

contract research, 4.67

preparing and monitoring, 4.30

terms of, 4.114-4.115

timescale of, 4.152

vs grants, 7.42

see also funding and procurement control

of affiliates, 3.40, 11.14-11.15, 11.17

controlled affiliates abroad (CAA), 11.14-11.15, 11.27-11.28, 11.30, 11.32, g

of higher education by government, 8.20 , 9.10 
linkages in the global non-business sector, 11.48

or majority ownership, $g$

of NPIs, B8.1, 10.4-10.5, 10.9, 10.42, g

COPNI, 10.13, 10.32

corporations

company reports, 7.75, 7.94

definition, $3.42, g$

public, 3.61

and quasi-corporations, 3.51, 7.2, g

as SNA sector, T3.1, 3.43

see also enterprises, multinational

CPC, 7.57

enterprises

creativity

as core criterion for $R \& D, 2.7,2.17$

and design, 2.62

culture, recreation, religion and mass media, as socio-economic objective of $R \& D$, $12.65-12.66$

D

data

administrative, 6.3, 6.5, 6.30, 6.53-6.56, $6.77,6.82,7.99,8.66,9.95-9.96,9.103-$ 9.104, 9.113-9.118, 9.121

cash and accrual bases, 8.92

collection/acquisition methods, 1.84, 2.97

collection approach, 4.6, 6.4, 7.48-7.61

collection challenges, 7.1, 8.91-8.92

collection and documentation, generalpurpose, 2.90-2.91

collection excluded from R\&D, 2.50, 2.89-2.90

collection methodology, design of, 6.476.52, 6.62-6.70, 7.85-7.93, 8.68-8.70, 9.93-9.118 (see also surveys)

collection and reporting for personnel data, 5.62-5,74, B5.1, T5.3

collection, sectoring and, 3.14

consistency issues, 1.6, 1.12, 3.70, 4.27, $4.103,5.26,5.48,5.59,5.63, \mathrm{~T} 5.3,6.49$, 6.56. $6.59,6.74,7.32,7.48$

cross-tabulations of, 7.61

disaggregated, publication of, 8.74

editing, 6.49, 6.68, 6.72-6.73, 7.92, 9.116, $g$

estimation of, 5.65-5.74, 6.80-6.84, 7.90-7.93, 8.71-8.74, 9.119, 12.49, 13.37-13.39, $\mathrm{g}$

grossing up, 7.93

imputation, 6.536.74-6.78, 7.92, 9.116, $g$

integration, 6.71

measures of collection quality, 7.89, B7.1 metadata, $1.84,6.79,7.60,7.108,9.122$

paradata, 6.63, 6.70, $\mathrm{g}$

projects involving large quantities of, 2.93

quality see under quality

reconciliation (of different sources), 8.90

review and comparison, 7.31-7.34

revisions, 12.49

security see confidentiality issues

sources, 1.52, 3.15, 6.3-6.5, 6.23, 6.39, 7.101, 8.68, 9.114-9.115, 11.7 (for GBARD, 12.39-12.49; for tax relief calculations, 13.51-13.60) (see also administrative data, surveys)

validation, 6.55, 6.85-6.89, 7.92, 12.49

debt forgiveness, 12.32

defence, 2.35-2.36, 2.47, 2.53, 4.151, 4.161, 7.37, $8.51,12.50,12.58$,

as socio-economic objective of R\&D, 12.71

deflators, for R\&D, 1.81

definitions

and concepts for identifying R\&D, 2.1-2.122

in the manual, role of, 1.1-1.4

in national legislation, 1.22

need for stability, 1.12

revision and clarification of, 1.5-1.6

see also 'definition' under individual terms demonstration

definition, B12.1

technology demonstration, 2.101

user vs technical, 2.100

depreciation and amortisation, 4.38-4.39, $4.73,112.15$

design

concept of, 2.62

as part of $R \& D, 2.50,2.62-2.63$

of surveys see under surveys

developing countries, 1.28

doctoral students, $g$

classification of, 1.47, 2.76-2.77, 5.22, T5.2, $5.25,5.39,8.61,9.34, \mathrm{~T} 9.2,9.90,10.38$

costs of, 4.28

treatment of, 5.27-5.31

wages and salaries, 4.20

\section{E}

Earth, exploration and exploitation, as socioeconomic objective of R\&D, 12.56

economic

activity, classification by, 3.31-3.34, 7.16-7.20, 7.48-7.50, T7.2, 7.60, 8.24, g

development, R\&D and, 1.2, 3.15

sectors, 3.19, B3.2

territory, 3.21-3.22 
economics, R\&D in, 2.41

education (and training)

as socio-economic objective of R\&D, 12.64

personal (academic staff), 9.44-9.46

research on topic, 2.41

statistics, 9.138

treatment as R\&D, 2.75-2.78

see also higher education, tertiary education

employees

definition of, T5.1, 5.12-5.13, g

enterprises with none, 7.27

leased, 5.16, T5.1, 5.26, g

vs persons employed, $g$

see also individuals

employment status, analysis by, 5.78

energy, 2.27

as socio-economic objective of R\&D, 12.60, B12.1

engineering, T.2.2

enterprise groups, 3.11, 3.12, B3.1, 4.32, 4.99, $6.15,7.9,7.14,11.13, \mathrm{~g}$

affiliates of, 11.11-11.15

R\&D transfers within, 7.69

enterprises, 3.11, 3.12, 3.54, 3.63, 4.135-4.137, B3.1

classification of see classification

definition, $g$

fellow enterprises abroad, 11.16, $g$

and legal entities, 6.16

multinational see multinational enterprises

non-multinational, 11.18

private and public, 7.3

see also corporations, non-profit institutions

environment, as socio-economic objective of R\&D, 12.57

establishments, 311, 3.12, B3.1, $\mathrm{g}$

estimation see under data

European Union

data on "National public funding to transnationally coordinated R\&D", 12.73

funding, 4.143

treatment in statistics, 4.159

Eurostat, 1.76, 12.4

exchange funds, $1.42,4.113-4.117,4.120-4.121$

see also under funding

expenditure on R\&D

administration costs, 8.35, 8.60, 12.14

aggregated for MNEs and non-MNEs, F11.2

capital, 4.14, 4.44-4.73, 7.60, 8.29, 9.60$9.61,12.15,13.25,13.43, g$

in company accounts vs Frascati standards, 7.94-7.95 current, 4.14, 4.15-4.43, 5.5, 5.45, 8.60, $9.58-9.59,12.15,13.25, \mathrm{~g}$

current vs capital, $4.54-4.55$

data quality issues, 7.31

date to which to assign, $12.40,12.42-12.44$

definitions, 4.4, $g$

double-counting/undercounting see under measurement

extramural see extramural R\&D

incurred abroad, 11.69-11.70

intramural see intramural R\&D

intramural vs extramural, 1.40, 1.42, 4.4, $4.6,4.60-4.61, \mathrm{~T} 8.3,9.78$

measurement of, 1.40-1.43, 4.0-4.165, 5.5 (see also measurement)

on monitoring and evaluation, 12.14

valuation principle, 4.40

see also budget(ing), funding, reporting of statistics

experimental development

by business enterprises, 7.47

definition and criteria, 1.13, 1.35, 2.9, 2.34-2.36, $\mathrm{g}$

external contributors/R\&D personnel see consultants under human resources

external funds, 1.42, 4.81-4.82, T4.2, 4.87, 4.95-4.99, 4.109, 4.124, 4.137, 4.140, 9.64-9.65, 9.74, 10.23, 10.28, $g$

sources of, 9.62-9.63, 9.65, 9.74

see also funding

extramural R\&D, 4.12, $g$

differentiated from intramural, 7.96-7.97

differing perspectives on, 4.135

distribution by providers and recipients of funds, 4.133-4.134

expenditure, 1.40, 1.42, 4.64, 9.78

functional distributions in the Business

enterprise sector, 7.69-7.108

government funding of, 8.54-8.58

measurement of funds, 4.118-4.129, 10.33

tax relief for, 13.23-13.24

\section{F}

feasibility studies, 2.114

feedback

loops, 2.49

on R\&D, 2.36, 2.50, 2.58, 2.60

Fields of Research and Development see FORD

financial accounting

approaches to tax relief, 13.44-13.50

data and standards, 1.25, 4.27, 4.32, 7.94-7.95, B11.1

guidance on, 1.1

financial services, 2.87 
fixed assets, 4.47

see also expenditure, capital

FORD (Fields of Research and Development) classification, 2.42-2.45, 3.44-3.46, 6.13, 9.98-9.100, 12.69-12.70, g

distribution of BERD by, 7.62

distribution of GOVERD by, 8.46-8.47

distribution of PNPERD by, 10.30

level of enquiry for classification, 9.118

six major fields, 9.98

web address for, 8.47

foreign affiliate statistics (FATS), 11.33

foreign-controlled affiliates (FCA), 11.15, 11.17, $g$

foreign direct investment (FDI), 1.69, 11.2, $11.11,11.29, \mathrm{~g}$

OECD Benchmark Definition of FDI, 11.2, B11.1

foreign owned branch campus (FBC), 9.82, 9.84, 11.55-11.56

see also branch campuses abroad

Frascati family of manuals, 1.4, 1.18-1.21

Frascati Manual

annexes, 1.80, 1.81, 2.45

brief history, A1

contributors to, A1

earlier revisions of, 1.3, 1.34, 1.81, A1

general overview, $1.30-1.82$

initial meeting for, 1.3

objectives and background, 1.1-1.4, 1.8-1.11

online version, 1.27, 1.80-1.82, 2.45, 11.7, $11.35,12.19,12.72,13.4$

related documents, 1.4, 1.18-1.21

revision process, outcomes of, 1.86

revisions for this edition, 1.5-1.6, 1.81, $11.1,12.3$

role as a standard, 1.0

full-time equivalent (FTE) as measurement unit, 5.46-5.48

consistency with headcount measure, $5.57,5.59$

definition and treatment, 5.49-5.57, 9

estimation of, 5.65-5.73

functional distribution approach, 3.8-3.9

funding

activities abroad of government, $11.52-11.53$

activities abroad of private non-profit sector, 11.57-11.58

affiliated vs unaffiliated sources, 11.22

breakdown of modes for GBARD, 12.73-12.74

cash and accrual bases, 8.92, 13.45-13.46, $g$ classification for distribution of external funding, 4.133-4.134

competitive basis, 8.89, 12.73

and control by government, 8.15

cross-border, 11.6

crowdfunding, 4.111, 10.25, 10.44-10.46

destination of funds, 12.73

determining sources, 1.10

distribution of BERD by sources of funds, 7.36-7.46, T7.1

distribution of GOVERD by sources of funds, 8.42-8.44, T8.2

distribution of HERD by sources of funds, 9.622-9.77

distribution of PNPERD by sources of funds, 10.24-10.28

double-counting/undercounting see under measurement

exchange and transfer funds, $1.42,4.4$, $4.77,4.109-4.117,7.42,8.44, \mathrm{~T} 8.2,8.78$, $8.88,11.23,11.53, g$

external see external funds

five main sources, 4.104

flows, treatment of, 1.59, 4.74-4.144, F4.1, 7.96-7.97, 8.56, T8.3, 9.78, 10.22-10.23

general university see general university funds

from government see government budgets for R\&D

higher education funding, 9.20, 9.62-9.63, 9.65, 9.74 (see also research grants and scholarships)

intermediaries and original sources, 7.44, $8.57,8.90,10.23,12.17$

internal see internal funds

loans see loans

measurement and sources of funds, 4.0, 4.74-4.165, 9.62-9.77.

10.26-10.28 (see also measurement)

within multinationals, 4.32

non-domestic, 1.68-1.72

by non-performing units, 4.128-4.129

philanthropic, 3.78, 4.97, 4.111, 9.15, 10.25, 10.43-10.46

source, definition, $g$

source details to be collected, 4.104-4.108, T4.3

sources within and outside compiling country, F11.2

to or from other countries in HE, 9.80-

9.87, 11.54-11.56

treatment of financing activities, 2.121

for university hospitals, 9.15

vs performing see performer vs funding approaches

see also expenditure on R\&D 
G

GBAORD, 12.3

GBARD see Government Budget Allocations for R\&D

gender

disaggregation of data, 5.76

issues, $R \& D$ on, 12.67

neutral language, 1.12

General advancement of knowledge, as socio-economic objective of $R \& D$, $12.69-12.70$

General government (as SNA sector), T3.1, 3.43

general university funds (GUF), 1.62, 4.98, 4.106, 4.111, 8.82, 8.89, 9.62-9.64, 9.75-9.77, 9.93, 12.27-12.28, 12.69, $12.77, \mathrm{~g}$

calculation of, 9.135-9.137, 12.48, 12.77

separation from other funding sources, 9.68-9.72

geographic

location of BERD, 7.64

location of statistical units, 3.47, 6.10, 7.29, 7.64

location of GOVERD, 8.53

origin of personnel, 5.85

geography, R\&D in, 2.41

geology/geological research, 2.96-2.98

GERD see gross domestic expenditure on R\&D

GFS (Government Finance Statistics) Manual 2014, 1.10

globalisation

definition, 1.69, 11.2, g

government issues, 11.44, 11.52-11.53

Guide to Measuring Global Production, B11.1, 11.42

Impact of Globalisation on National Accounts, B11.1

indicators of, 11.2

OECD Handbook on Economic Globalisation Indicators, 11.2, B11.1

outside business sector, 11.44-11.70

related international statistical manuals, B11.1

of $R \& D, 1.0,1.68-1.72,9.79,11.0-11.70$

statistics on R\&D, 11.29-11.33

of value chains, 1.6

see also multinational enterprises

GNERD, 1.68, 4.165, T4.5, $g$

goals see objectives

GOVERD see Government expenditure on R\&D

Government (as R\&D sector), 1.57-1.59, $3.60-3.66,8.0-8.93$

borderline cases, 3.64-3.66, 8.17-8.23

classification of units, $8.24-8.25$ definition and scope, 1.57, 3.43, 8.2-8.25, $\mathrm{g}$

at devolved levels, 8.67

and globalisation issues, 11.44, $11.52-11.53$

identification of R\&D, 8.26-8.32

involvement with R\&D abroad, 11.52-11.53

main characteristics, 3.60-3.61

measuring expenditure and personnel, $8.36-8.70$

personnel in, 8.59-8.62

sector, components and boundaries, T8.1

statistical units in, 3.62-3.63

surveys of, 6.26-6.31

vs public sector, $7.3,8.4,8.17$

government

agencies/extra-budgetary units, 8.7, 12.8-12.9

budgetary central government, 12.6

central/federal, 8.6, T8.1, 13.34, g

functions, classification for GBARD, 12.72 (see also Classification of Functions of Government)

local/municipal, 6.31, 8.10, T8.1, 12.5, 13.36

regional/state, 8.9, T8.1, 13.35, $g$

subsectors imposing taxes, 13.34-13.36, 13.63

tax relief see under tax

units, 3.42, 8.3, 8.11-8.13, g

Government Budget Allocations for R\&D (GBARD), 1.75, 1.79, 4.153, 8.49, 8.83, 12.0-12.79, 13.67, $g$

differences from GERD data, 12.76-12.77

distinguished from GOVERD, 12.15

and GTARD, 13.3

reporting and indicators, 12.78-12.79, $\mathrm{T} 12.2$

scope of, 12.5-12.38

support mechanisms and their treatment, $12.20-12.38$

use of data, 12.75-12.79

government budget appropriations or outlays for R\&D (GBAORD), 12.3

government budgets for $R \& D, 1.10,1.57$, 1.73-1.76, 7.42-7.45, 8.1, 8.83-8.93, $12.0-12.79$

central/federal vs provincial/state, 4.107 , 7.43

contracts vs grants, 7.42

measurement of, 8.75-8.93, 12.0-12.79

registers of grants, 7.75

reporting distribution of funds, 4.1384.140

for R\&D performed abroad, 8.87

use of records for tax relief information, 13.59 
Government Expenditure on R\&D (GOVERD), $1.59,8.36-8.58$

definition, $8.36, \mathrm{~g}$

distinguished from GBARD, 12.16

functional distributions, 8.38-8.53

vs government funding of extramural

R\&D performance, $8.54-8.58$

Government Tax Relief for R\&D (GTARD), 1.78, 13.2-13.67, $g$

presentation of statistics, 13.67

priority breakdowns, 13.61-13.66

scope and definitions, 13.5-13.13

scope of statistics, 13.14-13.36

grants and scholarships, 4.28, 4.90, 4.97, 4.111, $4.143,4.149,8.35,9.74,12.26-12.28$, 12.73

administration costs, 4.30

to business enterprises, $7.42,7.75$

to government institutions, 12.20

to higher education institutes, 9.62

statistical treatment of holders, 5.22, T5.2, $5.25,5.29,5.31,8.81$

see also funding

gross domestic expenditure on R\&D (GERD), $1.43,1.68,4.0,4.7-4.9,4.156-4.164,8.76$

defence vs civil, 4.161

definition, 4.8, $\mathrm{g}$

difference from SNA totals, 4.157, B4.1

differences from GBARD data, 12.76-12.77

GERD/GDP ratio, 4.0, 4.162

presentation of, 4.158, T4.4

regional breakdown, 4.163

gross national expenditure on R\&D (GNERD), 1.68, 4.165, T4.5, $g$

GTARD, 1.78, 13.2-13.67, $\mathrm{g}$

GUF see general university funds

\section{$\mathrm{H}$}

headcount as measurement unit, 5.46-5.48, $\mathrm{g}$ consistency with FTE measure, 5.57, 5.59 definition and treatment, 5.58-5.61 estimation of, 5.74

health

as socio-economic objective of R\&D, 12.68 and classification of units, 3.34, 3.72, 8.34 classification of hospitals, 8.22 clinical trials, 2.61, 4.143, 7.75, 8.34, 9.15, $9.49,9.109,10.19$

examples from, 2.21, 2.109, 9.48

funding for research, 4.97

research in hospitals, 6.35-6.36

R\&D related to, $1.81,10.19,12.62$

specialised health care, 2.115, 9.47-9.49 university hospitals, $1.63,6.36,8.22,9.13-$ 9.17, 9.26, 9.32, 9.47-9.49, 9.109-9.112

Higher education (as R\&D sector), 1.60-1.64, 3.67-3.74, 9.0-9.138

borderline between research and teaching, 9.33-9.46

borderline cases, 3.71-3.74, 8.19-8.23, 9.18-9.31

classification of institutions, 1.38, 3.24, T3.1, 3.36, 3.55

definition, 1.61, 9.3-9.4, 9.6-9.7, $g$

funding institutions, 9.20

linkages with Rest of the world, 9.79-9.87, $11.44,11.54-11.56$

main characteristics, 3.67-3.69

measuring expenditure and personnel, 9.52-9.92

methodology for measurement, 9.93-9.137

private institutions, 9.9-9.10, 9.28-9.31, T1

public institutions, 9.9-9.10, 9.28-9.31, T1

statistical units in sector, 3.70

surveys of, 6.32-6.38

vs tertiary education, $3.68,9.12$

higher education

branch campuses abroad, 9.81-9.86

foreign students in, 9.87

Higher education Expenditure on R\&D (HERD), 1.64, 9.53-9.77, 9.83-9.84, 9.136

data compared with GUF and GBARD, 12.77

definition, 9.53, $\mathrm{g}$

by source of funds, 9.62-9.77

reporting distribution of funds, 4.141

sources of external funding, 9.62-9.63, 9.65, 9.74 (see also research grants and scholarships)

sources of internal funding, 4.92, 9.62-9.73 (see also general university funds)

history, R\&D in, 2.40, 2.41

hospitals see under health

households

classification of, 3.42, 7.5, 10.2, 10.14

as Frascati/SNA sector, T3.1, 3.43

as funding sources, 10.27

recommended not to be surveyed, 10.14, 10.27

treated as R\&D units, 3.6, 3.25, 3.75, 3.77

types of contribution to R\&D, 3.78

unpaid members of, 5.13

humanities

$\mathrm{R} \& \mathrm{D}$ in, $2.104-2.107$

see also individual subjects by name 


\section{I}

identification codes, 7.15

immediate host country, 11.30

immediate investing country, 11.29

implementation of recommendations, 1.83-1.86

individuals

classification of, 10.8

as funding sources, 10.27, 10.43-10.46

as inventors/researchers, 3.83, 7.6, 10.8

multiple employment/affiliation of, 5.20 , $8.21,11.68$

not measured as R\&D performers, 10.27

roles of, 3.77-3.78

taxation of, 13.29-13.30

types of contribution to $R \& D, 3.78$

see also headcount, personnel

industrial activity, classification by, 3.31-3.34, 7.16-7.20, 7.48-7.50

industrial production and technology, as socio-economic objective of $R \& D$, 12.61

industry orientation of R\&D, 7.51-7.60

definition, 7.54

informal sector, 3.85

information and communication technology (ICT)

R\&D related to, $1.81,2.40,2.41,7.66,8.48$, 12.59

software see software

infrastructure

for $R \& D$ see research facilities

$\mathrm{R} \& \mathrm{D}$ concerned with, 12.59

scientific, 8.28

innovation

activities, 2.46

borderline with R\&D, T2.3

definition, 2.46

measurement of, 2.46

processes, identifying R\&D in, 2.48-2.61

vs $R \& D, 7.84$

institutional approach to R\&D statistics, T2.1, 3.7-3.9

institutional units, 3.4-3.12, 6.6-6.7, 6.14-6.16

classification decisions, F3.1, 3.31-3.49 (see also sectors, institutional for R\&D)

control of, 3.40, 3.64, 3.80

definition, $3.5,6.8, \mathrm{~g}$

residence of, 3.21

see also statistical units

insurance

examples of $R \& D$ in, 2.87

intangible assets, 4.53

see also intellectual property

intellectual property, 1.6, 1.23 enterprise approaches to, 7.51-7.52

and international trade in R\&D services, 11.6

mineral exploration and, 2.95

OECD Handbook on Deriving Capital

Measures of Intellectual Property

Products, 1.6, 1.23, 2.74, 11.6, B11.1

protection, 2.20, 2.22, 2.31

royalties and licences, $4.23,4.53,4.126$,

$7.57,8.18,11.36$

secrecy and, 2.20 (see also confidentiality)

tax regimes for, 13.28

transfers within MNEs, 11.43

internal funds, $1.42,4.4,4.32,6.61,4.78$, T4.2, F4.1, 4.87, 4.90-4.94, 4.97, 4.101, 4.103. 4.105, 4.117, 4.132, 4.138, 7.37-7.38, $7.40,8.56,9.15,9.62,9.73$

sources, 4.92, 7.38, 9.62-9.73

International Energy Agency (IEA), B12.1

International Monetary Fund (IMF)

Balance of Payments and International Investment Position Manual, B11.1

Government Finance Statistics Manual, 12.4, 12.6

international organisations, 3.87, 3.94, 4.108, 4.159-4.160, 11.53, 11.59-11.66, 12.19, 13.22

definition, 11.59, $\mathrm{g}$

special treatment of, 11.59-11.66

see also supranational authorities

International Standard Classification of Education see ISCED

International Standard Classification of Occupations see ISCO

International Standard Industrial Classification see ISIC

internationalisation see globalisation

intramural R\&D, 4.10-4.73, 9

allocation to domestic sector or Rest of World, 11.68

differentiated from extramural, 7.96-7.97

exclusion from, 4.125

expenditure, definition, 1.40, 1.42, 4.10

government funding for government, $12.20-12.21$

including expenditure incurred abroad, $11.69-11.70$

performed outside national territory, $4.65-4.66$

personnel contributing to, 5.12-5.31

reasons for incomplete and inaccurate reporting, 4.67-4.70

sources of funds, T7.1, 11.45-11.47 (see also under funding)

summary of expenditure categories, T4.1

tax relief for, 13.23-13.24 
investment

R\&D treated as, 1.0, 1.23, 1.41, 2.2, 4.2, B4.1

supporting R\&D, 12.29-12.33

ISCED (International Standard Classification of Education), 1.6, 1.26, 3.67-3.68, 5.34, 5.81-5.82, 9.2-9.3, 9.7, 9.88, $\mathrm{g}$

Fields of Education and Training (ISCED-F), 2.44

levels, 9.37-9.41, 9.91

ISCO (International Standard Classification of Occupations), 5.34, $\mathrm{g}$

ISIC (International Standard Industrial Classification), 1.6, 1.26, 3.33, 7.167.17, 7.48-7.49, 7.57-7.59, 8.24, 9.18, $10.12-10.13,9$

ISIC 72, 7.59, 8.24, 8.47, 11.34

\section{J}

joint ventures, 3.56, 7.1, 7.7-7.8, 10.10, g see also partnerships

\section{K}

"kind-of-activity" units, 3.11, 3.12, B3.1, g

knowledge

acquisition of existing, 2.46

-capturing products, 2.79

new, as focus of R\&D, 2.14-2.16, 2.22, 2.82

preservation, storage and access provision, 8.28

recording of, 2.20

sources, 2.43

traditional, 2.108-2.110

transfer to society, 4.115

see also data, intellectual property

\section{L}

labour costs see under personnel

land and buildings, 4.34-4.35, 4.48-4.50, 4.71, 9.59, $\mathrm{g}$

R\&D concerned with, 12.59

see also research facilities

legal entities, definition, 3.6

legislation

authorising compulsory surveys, 6.2

referring to Frascati Manual, 1.12

libraries and information centres, 2.91, 4.18, 8.28

purchase of libraries, 4.55

linguistics, examples from, 2.41

loans for R\&D, 7.39, 8.79, 12.31-12.32

guarantees for, 12.34

local unit, 3.12, B3.1, $\mathrm{g}$

\section{M}

machinery and equipment, 2.60, 4.47, $4.50-4.51, \mathrm{~T} 4.1,9.60, \mathrm{~g}$

management and reporting of projects, 2.19, $5.37-5.38,5.44$

market

price, 11.6, 11.37, 11.42

research, 2.56

surveys, 2.90 (see also surveys)

value, $4.35,9.59$

master's students, $g$

classification of, 1.47, 5.22, T5.2, 5.25, 8.61, 9.34, 9.91-9.92

costs, $4.20,4.28$

research master's programmes/students, 5.22, 5.30, 9.34, 9. 39, 9.91, g

treatment, 5.27-5.31

measurement

of business R\&D globalisation, 11.4-11.9

double-counting/undercounting issues, $1.59,4.9,4.12,4.21,4.35,4.36,4.46$, $4.58,4.62,4.78,4.82,4.87,4.103,4.119$, 4.122, 4.149, B4.1, 5.26, 5.31, 5.58, 5.60, $6.29,6.45,7.102,8.40,8.41,8.57,8.65$, 8.90, T8.3, 9.16, 9.57, 9.78, 11.68, 12.18, $12.46,13.24$

of expenditure, 1.40-1.43, 4.0-4.165, 5.5, $8.36-8.58$

of funding, 4.0, 4.74-4.165, 9.62-9.77. $10.26-10.28$

of government tax relief for $R \& D$, 13.37-13.67

in the higher education sector, 9.52-9.137 methodologies and procedures, 6.0-6.93

of personnel, 5.0-5.88

in the private non-profit sector, 10.2110.39

of R\&D funding vs services trade statistics, 11.38

units for human resources, 1.49, 5.46-5.61 metadata, 1.84, 6.79

methodologies and procedures, 1.50-1.52, $6.0-6.93,7.77-7.93$

micro-data

analysis, 3.48, 4.3, 6.1, 6.21, 6.74, 7.15

co-ordinated analysis of, 1.84

mineral exploration and evaluation, 2.95-2.98

mission or subject- oriented institutes, 9.21

multinational enterprises (MNEs), $g$

classifications for statistics, 11.29-11.33

international R\&D funding involving, $11.20-11.23$

measurement and reporting of $R \& D$, $11.5-11.9,11.22-11.33$

misreporting in, 4.70 
relevant definitions, 11.10-11.19

reported vs actual R\&D flows, T11.1

reports from, 7.95

structures of, 1.53, 7.1, 7.9

transfer payments in, 4.32

see also corporations, enterprises

music, examples of R\&D, 2.41, 2.65

\section{$\mathbf{N}$}

NABS (Nomenclature for the Analysis and Comparison of Scientific Programmes and Budgets), 1.76, 8.50, 10.31, 12.4, 12.54

classification, T12.1

NACE (Statistical Classification of Economic Activities in the European Community), 7.17

NAICS (North American Industry Classification System), 7.17

nanotechnology, 2.40, 7.66-7.67, 8.48

natural sciences, 2.40

see also science and technology

NESTI see under OECD

Nomenclature for the Analysis and

Comparison of Scientific Programmes and Budgets see NABS

non-governmental organisations (NGOs), 11.62-11.64

non-profit institutions (NPIs), 1.54, 1.65-1.67, B3.2

classification, 3.58, 7.2, 7.4, 8.14-8.16, 10.1

controlled by/serving businesses, 3.81

controlled by/serving government, 8.3, 8.8, T8.1, B8.1, $g$ definition, 3.42, $\mathrm{g}$ dual performance/funding role, 10.22 treatment of different types, T10.1

without separate identity/unincorporated, 10.6-10.7

see also Private non-profit sector (PNP) non-profit institutions serving households (NPISH), 1.66, B3.2, 3.25, T3.1, 3.43, $3.75,10.2,10.14$

novelty, as core criterion for $R \& D, 2.7$, 2.14-2.16, 2.22

objectives and goals of basic research, 2.27 of the Frascati Manual, 1.1-1.4 of the Manual revision, 1.5-1.7 primary and secondary, 12.50-12.53, 12.55

of $R \& D, 2.22, T 2.1$

socio-economic see under socio-economic obligations (budget), 12.49, $\mathrm{g}$

OECD

engagement with non-member countries, 1.6

FORD classification see Fields of Research and Development

NESTI (Working Party of National Experts on Science and Technology Indicators), 1.82, 1.84, A1

reporting data to, $1.29,12.54$

standard definitions, 13.2

working with other institutions, 1.85

off-shoring, 116

organisation

of R\&D activities, 1.6, 5.8

see also corporation, enterprise

Oslo Manual, 1.18, 2.46, 7.84

outputs from R\&D, 1.16-1.17, 2.93, 3.15, 3.45, 7.54, B11.1, 12.26

outsourcing, 4.116, 4.144

see also consultants, contracts, subcontracting

"own reading", 9.45

\section{$\mathbf{P}$}

parent companies, 11.19, F11.1, g

immediate parent company, 11.17, 11.29, g

partnerships, 3.57, 4.117, 8.23, 8.34, 8.42, 10.10

international, 8.87

patents

OECD Patent Statistics Manual, 1.18

"patent boxes", 13.14, 13.28

testing services giving rise to, B11.1

work on, 2.47, 2.50, 7.75, 11.35

see also intellectual property

performer vs funding approaches, 1.10 1.24, 4.6, 4.79-4.88, T4.2, 4.145-4.155, 8.76-8.82, 10.43, 10.47, 12.1-12.2, 12.39, $12.76-12.77$

difficulty in separating performers and funders, 4.78

personnel

age breakdown, 5.79-5.80

analysis by characteristics, $5.75-5.85$

analysis by qualifications, $5.81-5.83$

average, total and specific-date counts, $5.57,5.58$

categories crosswalk, 5.25

categories in higher education, 9.88-9.92 
classification of personnel by function, $5.32-5.45,8.62$

coverage and treatment, 5.6-5.45, T5.2

definition of R\&D personnel, 1.15,

1.44-1.49, 2.22, 4.18, 5.2-5.4, T5.1, 5.18, $5.32, \mathrm{~g}$

employees see employees

external personnel, 1.15, 1.46, 3.84, 4.26, 5.9, 5.15-5.24, T5.2, 5.25, 7.33, 8.61, $g$ (see also consultants)

in government, 8.59-8.62

identified by function, 1.48, 5.2-5.4, 5.77, $\mathrm{g}$

independent workers, 10.35

individuals see individuals

internal personnel, 1.6, 1.15, 1.46-1.47, 5.9

labour costs, 4.16-4.22, 4.62-4.64, 5.11, $5.25,8.39,9.56-9.57, g$

leased employees, 5.16, T5.1, 5.26, g

measurement, 5.0-5.88, 7.32-7.34, 8.70, 10.34-10.39 (see also under measurement)

mobility of, 11.9, 11.49

multiple employment/affiliation of same individual, 5.20, 8.21, 11.68

not currently working, 5.12

permanent vs temporary, 5.78

personnel flows, 5.86

recommended analysis, 5.87-5.88, T5.4.a-e

in Rest of the World, 11.49-11.51

self-employed, 3.82, 4.19, 4.26, 4.63, 5.16, $5.20, \mathrm{~T} 5.2,5.25,7.5,7.33,10.4,10.34$, 13.29

students as, see doctoral students, master's students

supporting/administrative staff, 4.18-4.19, 5.4-5.7, 5.11, 5-43-5.45

see also researchers, technicians

philosophy, R\&D in, 2.106

pilot plants, 2.51-2.52, 2.54

planning

as essential for R\&D, 2.19

town and country, 12.59

PNP see Private non-profit sector

PNPERD see Private non-profit Expenditure on $R \& D$

policy making

on emerging markets, 9.79

Frascati Manual and, 1.1-1.2

objectives see objectives

R\&D contribution to, 2.41

research to support, 2.118

statistics to support, 1.40, 1.51, 7.0, 7.1

policy-related studies, 2.116-2.118, 8.32 political and social systems, structures and processes, as socio-economic objective of R\&D, 12.67-12.68

see also government

pollution, 12.57, 12.59, 12.63, 12.68

pre-production development, 2.35-2.36, 2.50, 7.47

prices

below average, 3.58

economically significant, B3.2, 7.2, 7.3, 7.5, 10.3-10.4, 9

market, 11.6, 11.37

purchasers', 4.40, 9

sales, 4.131, 4.150

transfer, 11.42-11.43

Private non-profit Expenditure on $R \& D$ (PNPERD), 1.67, 10.21-10.32

definition, 10.21, $\mathrm{g}$

recommended functional distributions of funding, 10.24-10.32

Private non-profit sector (PNP), 1.65, 3.42, $3.75-3.86,10.0-10.47$

borderline cases, 3.80-3.86, 10.9-10.11

definition, 1.66, 3.25, 3.43, 10.2-10.3, g

and globalisation issues, 11.44, 11.5711.58

identification of R\&D in sector, 10.16-10.20

main characteristics, 3.75-3.78

recommended institutional

classifications, $10.12-10.15$

residual nature, 10.4-10.8

statistical units, 3.79

surveys of, 6.39-6.40, 10.40-10.47

volunteers in, see under volunteers

private sector, defining for classification, 3.35-3.38, see also public sector

problem solving as R\&D, 2.17, 2.38

process(es)

definition of, 2.10

development, 2.47

experimental development and, 2.32-2.36

procurement of R\&D, 4.114, 4.120, 4.126, 7.43, 8.88, T8.3, 11.53, 12.24

see also contracts, sales and purchases

product(s)

definition of, 2.10

development, 2.34, 2.62, 7.47

experimental development and, 2.32-2.36

professors emeritus, 5.23, T5.2, 5.25, g

profits, treatment of, 4.91, 4.93, 4.131, 4.150, $7.38,8.17,11.63,12.25,12.77,13.6-13.7$

programmatic evaluations, 2.119

project

basis for funding, 8.89 
definition in R\&D, 2.12

hosting of, 8.37

large scale, treatment of, 2.53-2.54, 2.74, 2.89

R\&D in government units, 8.27

questions for identifying R\&D, T2.1

vs programme, 2.30

prototyping, 2.18, 2.21, 2.47, 2.49-2.50, 2.54, $4.23,9$

public sector, 3.35-3.38

and business enterprises, 7.3

differences with government sector, T8.1

publication see communication

Q

qualifications, analysis of personnel by, 5.81-5.83

see also ISCED

quality

assurance, 1.84, 3.49, 6.69

control of business R\&D responses and totals, 7.94-7.108

of data, $6.23,6.56,6.92,6.93,7.31-7.32$

measures for survey responses, 7.89, B7.1

questionnaires, 1.84, 6.4, 6.49-6.51, 7.14, 9.110, 9.112

design considerations, 6.57-6.61, 6.92, 7.82-7.84

electronic, 7.83, 9.112

two-stage process, $7.76,7.80$

see also surveys

\section{$\mathbf{R}$}

regionalisation of $\mathrm{R} \& \mathrm{D}$ statistics, 1.81 , 4.163-4.164,

see also geographical location of statistical units

religious studies, $R \& D$ in, 2.106

rent see under research facilities

reporting

individuals, 6.50, 9.127-9.128

units, 3.12, 3.70, 6.13, 6.14, 6.20, 6.66, 7.12-7.14, 7.29, 8.64, 9.108, 9.127, $11.70, \mathrm{~g}$

reporting of statistics, 3.16-3.18

based on funders, 4.79, 4.145-4.155

based on performers, 4.9, 4.79, 4.79, $4.145-4.155$

errors in, 4.145-4.155

on R\&D tax relief, 13.40-13.43 to OECD and other international organisations, 1.29, 6.90-6.92

see also under communication, funding, surveys

reproducibility, as core criterion for R\&D, 2.7, $2.20,2.22$

research institutes

buildings for see research facilities

classification of, 7.2-7.4, 9.18-9.31

global groupings of, 11.48

government-controlled, 8.7, 8.63

higher education controlled, 9.6

industry-controlled, 3.81

linked to universities, 9.22-9.23

mission or subject orientation, 9.21

revenue generated by, 8.18

and international organisations, 11.66

sources of internal funding, 4.91

surveys of, 8.69

research councils, 8.90, 9.24, 9.62, 9.65

research and (experimental) development (R\&D)

activities and projects, 2.12

activities excluded, 2.15

common features, 2.6

core criteria for, 1.14, 1.33, 2.6-2.8, 2.13-2.22, T2.1

databases and indicators, 1.84

definitions, 1.0, 1.2, 1.5-1.6, 1.12-1.15, 1.22, 1.25, 1.32-1.36, 2.5-2.11, 4.151, B11.1, $g$ definitions for tax purposes, 13.15-13.16

distinguished from related activities, 1.63 examples of boundaries and exclusions, 2.46-2.110

four main sectors, 1.38, 3.0

impact of, 1.2

industry orientation of, 7.51-7.60

institutional approach to classifying, T2.1

with negative results, 2.20

occasional vs continuous, 6.18-6.19, $6.31,7.1$

organisational changes in, 1.6

originals vs other services, 11.34

performers, directories of, 7.75-7.76

performing vs funding see performer vs

funding approaches

pricing issues, 11.42-11.43

role in economic development, 3.15

services, paying for, 12.24-12.25

social and political dialogue on, 1.87

in social sciences, humanities and

arts, 2.3

support activities, 2.122 
three types of activity, 1.35, 2.9

(definitions and criteria, 2.23-2.41;

differentiating between, 2.37-2.40;

distribution of BERD by type, 7.47;

distribution of GOVERD by type, 8.45; order of, 2.11) (see also applied research, basic research, experimental development)

treatment as investment, 1.0, 1.23, 1.41, 2.2, 4.2, B4.1

research, development and demonstration (RD\&D), B12.1

research facilities (buildings)

charging basis, 12.22

government owned, handling of, $4.36-4.37,8.41,8.79$

rent, operations and maintenance, 4.23 , $4.29,4.34-4.37,8.41,9.59$

research parks, 9.25

treatment in GBARD, 12.22-12.23

under joint management, 6.37

see also research associations/institutes

research institutions see research associations/institutes

researchers

affiliated to universities, 9.24, 11.68

categories in HE sector, 9.90

definition, functions, treatment, 5.35-5.39, $7.34,9$

see also human resources

residence of institutional units, 3.21 , 3.90-3.92, 10.11, 11.70, g

Rest of the World (as R\&D sector), 1.68, 3.21, 3.87-3.96, 11.1

borderline cases, 3.90-3.96

definition, 11.1, 11.19, 11.45, $\mathrm{g}$

funding from, 7.41, 7.46

government R\&D funding to, 11.53 , 12.19

higher education links with, 9.79-9.87

international and supranational organisations in, 11.59-11.66

main characteristics, 3.87-3.88

sources of funds, 11.45-11.57

see also globalisation

reverse engineering, 2.15

risk management, $2.41,2.87,7.42, \mathrm{~B} 8.1,12.29$

\section{S}

salaries of R\&D personnel, 5.78 , see also personnel

sale of capital assets, 4.58-4.59 sales and purchases of $R \& D, 4.113$,

4.130-4.132, 8.18, 11.34-11.38,

$12.24-12.25$

pricing issues, $4.131,4.150$

see also contracts, funding

sampling

of non-responding units, 6.69

plan, 6.41-6.46

units, 6.20, 6.27, 6.34, 6.40

science and technology

definition of scientific and technological activities, $g$

distinguished from $R \& D, 2.88-2.89,2.93$, 8.28

government services, 8.28

information services, 2.112

management of activities, 2.99-2.101

scientific advisers, $2.120,8.33$

scientific infrastructure, 8.28

see also research facilities

sectors, institutional for R\&D, 1.38, 3.0-3.96

classification of units see classification

decision tree for allocating units to, F3.1

reasons for sectoring, 3.13-3.18

sectors and borderlines, F3.2

SNA classification, B3.2, T3.1

see also Business enterprises, Higher education, Government R\&D, Private non-profit sector, Rest of the World

seniority of personnel, 5.84

services

definition of services, 2.79

R\&D in, 2.79-2.87

R\&D services, trade in, 11.33-11.43

size of enterprises

basis for determining, 7.23, 7.25

recommended groupings, 7.27-7.28

and R\&D tax relief, 13.65-13.66

small and medium-sized enterprises (SMEs), $2.21,2.34,7.24-7.28,7.99$

micro-enterprises, 7.70, 7.81

SNA see System of National Accounts

social sciences

data collection for, 2.90

R\&D in, 2.103

social security contributions, $4.21,9.57,13.30$

social services, R\&D into, 2.87, 12.67

socio-economic

consultancy, 10.18

objectives of R\&D, 7.63, 8.49-8.51, 10.31, 12.2 (classification, T12.1, g; description of, 12.56-12.71; distribution of GBARD by, 12.50-12.71) 
software

capitalised, 4.52, g

handling of development by OECD and SNA, 2.74, 4.157, B4.1

R\&D in, $1.24,2.40,2.68-2.74,7.66, g$

used in R\&D, 2.69, 4.25

space

exploration, 2.94,

exploration and exploitation, as socioeconomic objective of R\&D, 12.58

spending see expenditure

spin-off enterprises, 9.27, 12.52

standards/standardisation, 1.86, 2.113, 2.92, $2.113,5.34$

Frascati Manual as, 1.0-1.29

standards testing, 2.92, 2.113

see also individual standards by name

statistical units, 1.45-1.46, 3.1, 3.7, 3.9-3.11, 6.9-6.12, 7.10-7.11, 7.15-7.29

attributes, 6.10, 7.11

classified into sectors, 3.13 (see also classification)

definition, 3.10, $\mathrm{g}$

frame/register structure for, T3.2

in the government sector, 8.63-8.67, 12.7

in the higher education sector, 9.97-9.102

institutional classifications, 7.15-7.29

observation and analytical units, 3.10

in the private non-profit sector, 10.41

types and levels, B3.1, 3.11, 3.12

see also institutional units

statistics

atypical features of R\&D, 1.6

classification see classification

comparability of, 1.1, 1.6, 1.9, $1.25-1.27,1.50,1.83,2.89,3.15-3.16$, $3.20-3.26,4.72,4.157,7.84,9.9,9.138$, 11.24

framework for Higher education sector, F9.1

global, 3.95

institutional approach to, T2.1, 3.7-3.9

new methods, 2.90

sources, relating different, 3.15

statistical infrastructure, 6.2

purpose of the Frascati Manual,1.3

use and users, 1.22, 1.37

see also data, measurement of R\&D, methodologies and procedures, reporting, surveys

students see doctoral students, masters' students

subcontracting, 4.123-4.124, 4.143, 7.97, 9.78, 12.17, 13.18 see also consultants, contracts, off-shoring supervision of researchers and students,

$$
2.76-2.77,9.39,9.42-9.43
$$

support(ing)

activities/services, 2.122, 4-23.4-24, $4.29-4.31,5.4-5.5,5.45,8.6$

staff, 4.18-4.19, 4.26-4.27, 5.4-5.7, 5.11, 5-43-5.45 (see also under human resources)

supranational authorities, 3.87, 3.93, 4.108, $11.59-60,9$

as source of funds, 8.42

surveys, statistical, 6.5

briefing of respondents, 7.88

combined purpose, $7.84,9.107,11.25$

design, 6.41-6.71, 7.25, 7.70-7.76, $10.40-10.42$

in different sectors, 6.18-6.40

of government units, 8.84-8.93

of higher education sector, 9.95-9.96, F9.1, 9.102-9.112

to identify business R\&D performers, 7.70 , 7.71

of individuals, 3.77

on international trade in services, 11.36

methodology, 6.72-6.89, 7.77-7.93

of multinational enterprises, 11.22 , 11.25-11.28, 11.33

of non-business global R\&D, 11.47, $11.49-11.51$

of PNP sector, 6.39-6.40, 10.40-10.47

response rates, 6.69, 6.86, 7.85

of tax relief recipients, 13.51-13.55

of trade in services, 11.38-11.39

time-use, 9.95, 9.116, 9.125-9.137, g

training of respondents, 8.69

see also under data, reporting

System of National Accounts (SNA), 1.6, 1.23-1.24, 2.0, 10.27, B11.1, 12.4, A1, g

approach to institutional units and sectors, 3.3

capital stock of R\&D, 6.1

changes in 2008 revision, 1.41, 2.2, 4.2

classification criteria, 1.37-1.38, B3.2, 3.43

differences from GERD calculations, 4.157

treatment of government, 8.0, 8.2-8.4, T8.1, 8.14

treatment of higher education sector, 1.60 , 3.0, 3.24, 9.8-9.9

treatment of R\&D as investment, 1.0, 1.23, $1.41,2.2,4.2, \mathrm{~B} 4.1$

treatment of services, 2.79 
treatment of software, 2.74, 4.157

use of R\&D statistics, 3.15

vs Frascati treatment of capital investment

systematicity, as core criterion for R\&D, 2.7, 2.19

\section{T}

target-setting, 1.9

tax

allowances, 13.6, 13.9, $\mathrm{g}$

benefits to philanthropic funders, 10.43

capital gains, 13.28

corporate, 13.27, 13.29

credits, 13.7-13.9, $\mathrm{g}$

employment subsidy, 13.12

exemptions for international organisations, 13.22

expenditures, $g$

on goods and services, 8.39, 13.33

incentives for/relief on R\&D, 1.0, 1.6,

1.77-1.79, 4.22, 4.100-4.103, 7.38, 7.45, $8.79,12.35-12.37,12.79$ (definition and scope, 13.5-13.9; measurement of, 13.0-13.67) (see also Government Tax Relief for R\&D (GTARD))

instruments, 13.26

"normal" structure, 13.10-13.11

payroll, 13.31

property taxes, 13.32

records, $13.56-13.58$

registers of relief claimants, 7.75, 7.87, 7.101

treatment of deductible, 4.41-4.43

treatment of individuals, 13.20, 13.29

value-added, 8.39, 13.33, $\mathrm{g}$

technicians: definition, functions, treatment, 5.40-5.42

technology

areas, distribution of BERD by, 7.65-7.68

areas, distribution of GOVERD by, 8.48

demonstration, 2.101

and industrial production, R\&D on, 12.61

readiness level (TRL), 2.99, 8.30-8.31

transfer, 8.28

see also information and communication technology, science and technology

territory, economic, 3.21-3.22, 3.92

tertiary education, 3.68, 9.12, 9.29, $\mathrm{g}$

see also higher education testing

by government sector, 8.28 of questionnaires, 6.60

as R\&D process, 2.16, 2.50, 2.92, 4.67

standards testing, 2.92, 2.113

timescale/time issues

for availability of figures to report, 12.48 , 12.78

calendar vs fiscal year, 13.60

carry-over provisions, $13.8, \mathrm{~g}$

and cost allocation for long programmes, $4.152,12.44$

for handling tax relief, 13.44-13.50, 13.57

for measuring international R\&D services, 11.6

for R\&D, 2.30, 2.37

tooling up, 2.59-2.60

trade

in R\&D services, international, 1.71,

11.4-11.6, B11.1, 11.34-11.43

statistics, guidance on, 1.1

traditional knowledge, 2.108-2.110

training, research-related, 9.44-9.45

transactions, $g$

transfer(s)

cross-border, 11.40-11.41

funds, 1.42, 4.111-4.112, 4.120, 4.133, g

(see also under funding)

in-kind donations, 4.112

in-kind transfers, 11.39, 11.41

prices, 11.42-11.43

of R\&D, 1.42, 4.4, 4.77, 4.109-4.117, 7.42, $8.44, \mathrm{~T} 8.2,8.78,8.88,11.23,11.39-11-41$

transferability, as core criterion for R\&D, 2.7, $2.20,2.22$

transport, telecommunications and other infrastructures,

as socio-economic objective of $R \& D$, 12.59

trials/trialling, 2.50, 2.55-2.56

clinical see under health

trouble-shooting, 2.50, 2.57

U

ultimate investing country, 11.29 university(ies) see under higher education university hospitals see under health uncertainty, as core criterion for $R \& D, 2.7$, $2.18,2.22$

United Nations

classification systems see ISCED, ISIC

Manual on Statistics of International Trade in Services, B11.1 
National Quality Assurance Frameworks, 7.105

Provisional Guidelines on Standard International Age Classifications, 5.79

units

relationship between, 6.14-6.17

updating lists of, 6.28

see also enterprise, establishment, government units, institutional units, kind-of-activity units, local units, reporting units, sampling units, statistical units

UNESCO

definitions of scientific and technological activities, 2.89
Recommendation concerning the International Standardization of Statistics on Science and Technology, 2.44

UOE Manual, 9.2, 9.138

V

valuation

of international trade in services, 11.37

at purchasers' prices, 4.40

value chains, global, 11.8

volunteers, T5.1, 5.24, T5.2, 5.25, 5.54, 10.36-10.37, $g$

W

work, organisation of, research into, 12.67 working hours, 9.134 


\section{ORGANISATION FOR ECONOMIC CO-OPERATION AND DEVELOPMENT}

The OECD is a unique forum where governments work together to address the economic, social and environmental challenges of globalisation. The OECD is also at the forefront of efforts to understand and to help governments respond to new developments and concerns, such as corporate governance, the information economy and the challenges of an ageing population. The Organisation provides a setting where governments can compare policy experiences, seek answers to common problems, identify good practice and work to co-ordinate domestic and international policies.

The OECD member countries are: Australia, Austria, Belgium, Canada, Chile, the Czech Republic, Denmark, Estonia, Finland, France, Germany, Greece, Hungary, Iceland, Ireland, Israel, Italy, Japan, Korea, Luxembourg, Mexico, the Netherlands, New Zealand, Norway, Poland, Portugal, the Slovak Republic, Slovenia, Spain, Sweden, Switzerland, Turkey, the United Kingdom and the United States. The European Union takes part in the work of the OECD.

OECD Publishing disseminates widely the results of the Organisation's statistics gathering and research on economic, social and environmental issues, as well as the conventions, guidelines and standards agreed by its members. 
The Measurement of Scientific, Technological and Innovation Activities

Frascati Manual 2015

\section{GUIDELINES FOR COLLECTING AND REPORTING DATA ON RESEARCH AND EXPERIMENTAL DEVELOPMENT}

\section{Contents}

Chapter 1. Introduction to R\&D statistics and the Frascati Manual

Part I. Defining and measuring R\&D: General guidance

Chapter 2. Concepts and definitions for identifying R\&D

Chapter 3. Institutional sectors and classifications for R\&D statistics

Chapter 4. Measurement of R\&D expenditures: Performance and sources of funds

Chapter 5. Measurement of R\&D personnel: Persons employed and external contributors Chapter 6. Measuring R\&D: Methodologies and procedures

Part II. Measuring R\&D: Sector-specific guidance

Chapter 7. Business enterprise R\&D

Chapter 8. Government R\&D

Chapter 9. Higher education R\&D

Chapter 10. Private non-profit R\&D

Chapter 11. Measurement of R\&D globalisation

Part III. Measuring government support for R\&D

Chapter 12. Government budget allocations for R\&D

Chapter 13. Measurement of government tax relief for R\&D

Consult this publication on line at $\boldsymbol{h t t p : / / d x . d o i . o r g / 1 0 . 1 7 8 7 / 9 7 8 9 2 6 4 2 3 9 0 1 2 - e n . ~}$

This work is published on the OECD iLibrary, which gathers all OECD books, periodicals and statistical databases.

Visit www.oecd-ilibrary.org for more information.

OECDpublishing www.oecd.org/publishing
ISBN 978-92-64-23880-0

$922015001 \mathrm{P}$

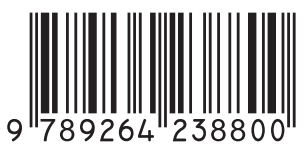

